
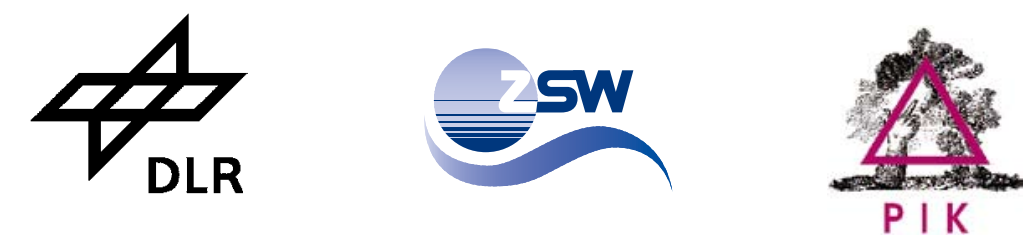

\title{
RECCS
}

\section{Ecological, Economic and Structural Comparison of Renewable Energy Technologies (RE) with Carbon Capture and Storage (CCS) - An Integrated Approach}
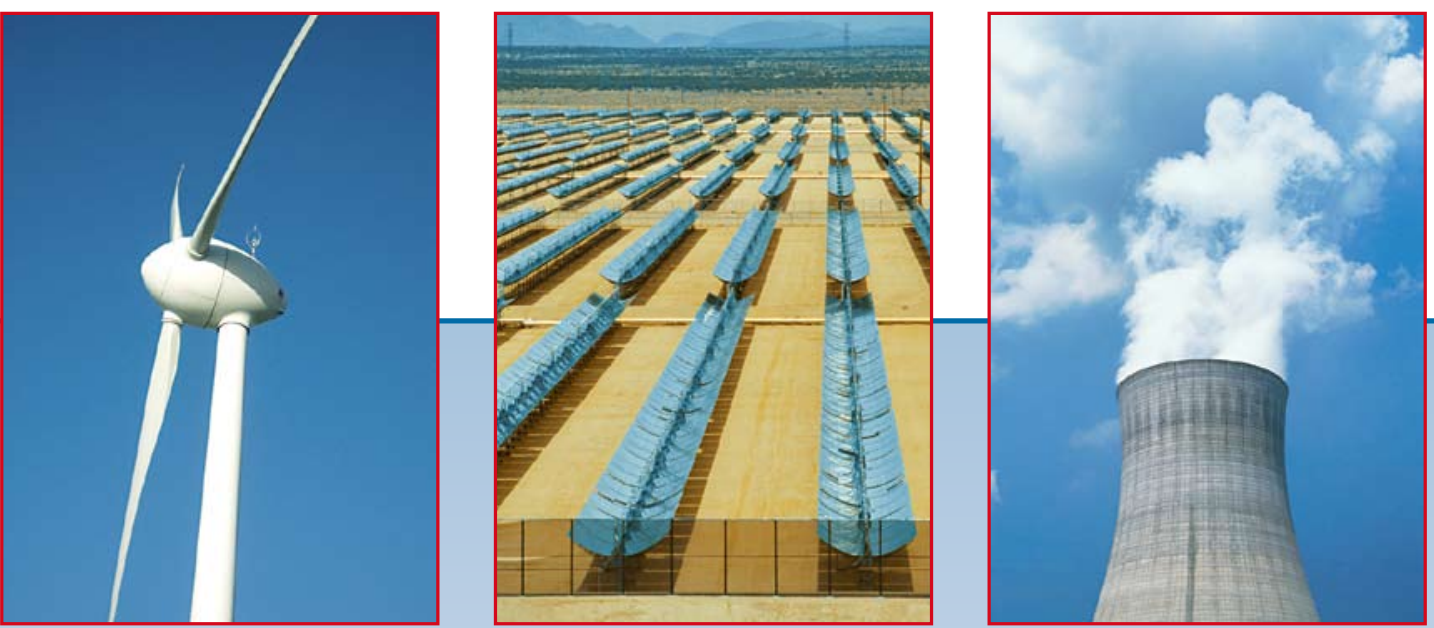


\section{IMPRINT}

\section{Publisher:}

Federal Ministry for the Environment, Nature Conservation and Nuclear Safety (BMU)

\section{Content:}

Wuppertal Institute for Climate, Environment and Energy (WI)

Dr.-Ing. Manfred Fischedick (co-ordinator)

Dipl. Umweltwiss. Andrea Esken

Soz.-Wiss. Andreas Pastowski

Dipl.-Ing. Dietmar Schüwer

Dr. Nikolaus Supersberger

German Aerospace Center (DLR)

Institute of Technical Thermodynamics

Dr. Joachim Nitsch

Dr. Peter Viebahn

Centre for Solar Energy and Hydrogen Research (ZSW)

Dr. Andreas Bandi

Dr. Ulrich Zuberbühler

Potsdam Institute for Climate Impact Research (PIK)

Dr. Ottmar Edenhofer

Layout: VisLab, Wuppertal Institute

Print: Offset Company, Wuppertal

Date: April 2008

Download: www.bmu.de www.wupperinst.org/en/ccs

Print run: 1,000 (long version), 1,500 (short version)

Printed copies are available with the BMU (long version and short version)

Contact:

Dr.-Ing. Manfred Fischedick

Wuppertal Institute for Climate, Environment and Energy

P. O. Box 100480

D-42004 Wuppertal

Tel: $+49-202-2492-121$

Fax: +49-202-2492-198

E-mail: manfred.fischedick@wupperinst.org 


\section{RECCS}

Ecological, Economic and Structural Comparison of Renewable Energy Technologies (RE) with Carbon Capture and Storage (CCS) An Integrated Approach

Wuppertal Institute for Climate, Environment and Energy

German Aerospace Center, Institute of Technical Thermodynamics Centre for Solar Energy and Hydrogen Research

Potsdam Institute for Climate Impact Research 
This publication is based on the German research project

"Ökologische Einordnung und strukturell-ökonomischer Vergleich regenerativer

Energietechnologien mit anderen Optionen zum Klimaschutz, speziell der Rückhaltung und Speicherung von Kohlendioxid bei der Nutzung fossiler Primärenergien“

on behalf of the Federal Ministry for the Environment, Nature Conservation and Nuclear Safety (BMU).

(c) Wuppertal Institute for Climate, Environment and Energy

Design and Layout: VisLab Wuppertal Institute

Print: Offset Company, Wuppertal

$100 \%$ recycling paper ÖkoArt matt 


\title{
Structure
}

\author{
Summary of Theses
}

\section{Summary}

I Introduction and Background

1 Status Quo and the Aims of the Study

2 Terminology

3 Driving Forces: The Attitudes of Relevant Groups to $\mathrm{CO}_{2}$ Capture and Storage

\section{Technologies and Process Chains}

4 An Overview of CCS Processes

$5 \mathrm{CO}_{2}$ Capture Methods for Power Plant and Hydrogen Production

$6 \mathrm{CO}_{2}$ Transport

$7 \quad \mathrm{CO}_{2}$ Storage

8 Central Aspects of $\mathrm{CO}_{2}$ Transport Infrastructure

\section{Comparative Analysis and Assessment}

9 Criteria for a Comparative Assessment of CCS

10 Life Cycle Assessments for Selected CCS-Processes

11 Other Ecological Assessment Criteria for CCS

12 Development of Electricity and Hydrogen Generation Costs with CCS

13 Other Energy Sector Criteria

IV Systems Analysis: A National Perspective

14 Systems Analysis of CCS Scenarios

\section{Global Aspects}

15 CCS in the International Context

\section{Appendix}

\section{References}




\section{Table of Contents}

Background and Introduction

Driving Forces and the Attitudes of Relevant Groups towards

Carbon Capture and Storage

$\mathrm{CO}_{2}$ Capture Methods

$\mathrm{CO}_{2}$ Transport Methods

$\mathrm{CO}_{2}$ Storage Methods and Capacity

Criteria for a Systematic Assessment of CCS

Comparative Life Cycle Assessments $\quad 27$

Other Ecological Assessment Factors for CCS 30

Economic Comparison of CCS and Renewables 30

The Role of CCS in Industrialised Countries - the Example of the

German Energy Supply System

Requirements for Successful International Implementation of CCS

Chapter 1

Status Quo and the Aims of the Study

Chapter 2

Terminology

Chapter 3

Driving Forces: The Attitudes of Relevant Groups to $\mathrm{CO}_{2}$ Capture and Storage

3.1 International and German NGOs

3.2 Industrial Associations and Companies $\quad 42$

3.3 German Political Parties $\quad 42$

3.4 German Ministries and Expert Committees 43

3.4.1 The Federal Ministry of Economics and Technology (BMWi) 43

3.4.2 The Ministry for the Environment, Nature Conversation and Nuclear Safety (BMU) and the Federal Environment Agency (UBA) 43

3.4.3 The Council for Sustainable Development (RNE) 43

3.4.4 Advisory Council on Global Change (WBGU) 43

3.4.5 Advisory Council on the Environment (SRU) 44

3.4.6 Office for the Assessment of the Impact of Technology of the German Bundestag (TAB) 44

Chapter 4

An Overview of CCS Processes

Chapter 5

$\mathrm{CO}_{2}$ Capture Methods for Power Plant and Hydrogen Production 50

$\begin{array}{lll}5.1 & \text { Developments in Power Station Concepts with } \mathrm{CO}_{2} \text { Capture } & 50\end{array}$

5.1.1 Short- to Medium-Term Options $\quad 50$

5.1.2 Long-term Options $\quad 55$

5.1.3 Possibilities and Limits of Retrofitting $\mathrm{CO}_{2}$ Capture at Power Stations 59

5.2 Concepts for Moving towards Large-Scale Production of $\mathrm{H}_{2} \quad 58$

5.2.1 Large-scale $\mathrm{H}_{2}$ Production Today (Steam Reforming of Natural Gas) 58

5.2.2 Possibilities for $\mathrm{CO}_{2}$ Capture and Expense Involved (in $\mathrm{H}_{2}$ Generation) 58 
5.2.3 Hydrogen Production by Gasification of Solids 58

5.2.4 $\mathrm{CO}_{2}$-free Concepts for Generating $\mathrm{H}_{2} \quad 59$

5.3 Learning Curves and Possible Cost Degressions 59

5.4 Relevant Applications for Energy Systems, Case Study Germany 60

Chapter 6

$\mathrm{CO}_{2}$ Transport $\quad 61$

6.1 Physical State for Transport and Energy Required for Compression and Transport $\quad 63$

$\begin{array}{lll}6.2 & \text { Transport Options } & 65\end{array}$

$\begin{array}{lll}6.2 .1 & 65\end{array}$

$\begin{array}{lll}\text { 6.2.2 Transport by Ship } & 67\end{array}$

6.2.3 Transport by Rail and Road Tanker 68

$\begin{array}{lll}6.3 & \text { Transport Costs } & 68\end{array}$

\section{Chapter 7}

$\begin{array}{ll}\mathrm{CO}_{2} \text { Storage } & 71\end{array}$

\begin{tabular}{lll}
\hline $7.1 \quad$ Overview of Methods & 71
\end{tabular}

7.1.1 Marine Storage $\quad 71$

$\begin{array}{lll}7.1 .2 & \text { Geological Storage } & 71\end{array}$

$\begin{array}{lll}7.1 .3 & \text { Other storage options } & 72\end{array}$

7.2 Relevant Global Storage Options and their Potential 73

7.3 Assessment of the Storage Options in Germany as an Example of an
Industrialised Country

\section{Chapter 8}

Central Aspects of $\mathrm{CO}_{2}$ Transport Infrastructure $\quad 78$

\begin{tabular}{lll}
\hline 8.1 & Interdependency between Energy Use and Freight Transport & 78
\end{tabular}

8.2 Determinants of Additional Freight Transport with CCS 80

$\begin{array}{lll}8.3 & \text { Technical Aspects of Bulk Transport Capacity } & 81\end{array}$

8.4 Networkability of Modes of Transport $\quad 83$

8.5 Conclusions $\quad 83$

8.6 Case Study: Transport Options for a 700 MW Coal-fired Power Station $\quad 86$

Chapter 9

Criteria for a Comparative Assessment of CCS $\quad 88$

\section{Chapter 10}

Life Cycle Assessments for Selected CCS-Processes $\quad 93$

\begin{tabular}{lll}
\hline 10.1 & Methodology & 93
\end{tabular}

10.1.1 Goals of Life Cycle Assessment 93

10.1.2 The Methodology of Material Flow Networks 93

10.1.3 Scope of LCAs and Underlying Assumptions 95

10.1.4 Data Sources and Quality 98

10.2 Mathematical Methodology - Captured versus Avoided $\mathrm{CO}_{2} \quad 98$

10.3 Plant and Processes for Conventional Electricity Generation with CCS 99

$\begin{array}{llr}\text { 10.3.1 Reference Power Stations } & 99\end{array}$

$\begin{array}{ll}\text { 10.3.2 Supply Chains } & 101\end{array}$

$\begin{array}{ll}10.3 .3 \quad \mathrm{CO}_{2} \text { Capture Methods } & 101\end{array}$

$\begin{array}{lll}\text { 10.3.4 } & \mathrm{CO}_{2} \text { Liquefaction } & 103\end{array}$

$\begin{array}{lll}10.3 .5 & \mathrm{CO}_{2} \text { Transport } & 103\end{array}$

$\begin{array}{lll}10.3 .6 & \mathrm{CO}_{2} \text { Storage } & 104\end{array}$ 
10.4 Plant for Generating Electricity from Renewables $\quad 105$

10.5 Analyses of Individual Electricity Generating Systems 105

$\begin{array}{ll}\text { 10.5.1 Conventional Power Stations } & 105\end{array}$

10.5.2 Power Plant Using Renewables 107

10.6 Comparison of Energy Generation Systems 107

10.6.1 Greenhouse Gases and Cumulative Energy Demand 107

10.6.2 Other Impact Categories 111

10.7 Sensitivity Analyses of Electricity Generating Systems $\quad 113$

10.7.1 Sensitivity Analysis 2: Variation in Capture Rate (Variable Cost) 115

10.7.3 Sensitivity Analysis 3: Variation in Capture Rates (Fixed Cost) 116

10.7.4 Sensitivity Analysis 4: Variation in Methane Emissions

$\begin{array}{ll}\text { During Coal Mining } & 117\end{array}$

10.8 Conclusions for Electricity Generation 118

10.9 Plant and Processes for Conventional Hydrogen Production with CCS 119

$\begin{array}{lll}10.9 .1 & \text { Reference Plant } & 119\end{array}$

$\begin{array}{ll}10.9 .2 & \text { Supply Chains } \\ 10.9 .3 & 120\end{array}$

$\begin{array}{ll}10.9 .3 \mathrm{CO}_{2} \text { Capture } & 120\end{array}$

$\begin{array}{ll}10.9 .4 \mathrm{CO}_{2} \text { Liquefaction } & 122\end{array}$

10.9.5 $\mathrm{CO}_{2}$ Transport Scenarios $\quad 122$

$\begin{array}{lll}10.9 .6 & \mathrm{CO}_{2} \text { Storage } & 123\end{array}$

10.10 Plant for Producing Hydrogen Using Renewables $\quad 123$

$\begin{array}{ll}\text { 10.10.1 Reference Plant } & 123\end{array}$

10.10.2 Supply Chains 123

10.11 Individual Analyses of Hydrogen Production Systems $\quad 123$

$\begin{array}{lr}10.11 .1 \text { Conventional Plant } & 123\end{array}$

10.11.2 Plant Using Renewables $\quad 125$

10.12 Comparison of Hydrogen Production Systems 125

10.12.1 Greenhouse Gases and Cumulative Energy Demand 125

$\begin{array}{ll}\text { 10.12.2 Other Impact Categories } & 125\end{array}$

10.13 Conclusions for Hydrogen Production 126

Chapter 11

$\begin{array}{ll}\text { Other Ecological Assessment Criteria for CCS } & 127\end{array}$

\begin{tabular}{lll}
\hline 11.1 & $\mathrm{CO}_{2}$ Capture & 127
\end{tabular}

$\begin{array}{lll}11.2 & \mathrm{CO}_{2} \text { Transport } & 127\end{array}$

$\begin{array}{lll}11.3 & \text { Storing } \mathrm{CO}_{2} & 128\end{array}$

11-4 A Comparison of Strategies $\quad 130$

Chapter 12

Development of Electricity and Hydrogen Generation Costs with CCS

12.1 Future Electricity Generation Costs Taking Account of Technological Developments, Fuel Price Rises and Cost of $\mathrm{CO}_{2}$ Emission Certificates $\quad 135$

12.1.1 Price Trends for Fuel and $\mathrm{CO}_{2}$ Emission Certificates 135

12.1.2 Data Used for Cost Calculations and Electricity Costs in $2020 \quad 138$

12.1.3 Electricity Generation Costs with Changing Technology

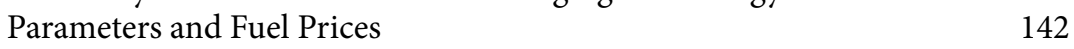

12.1.4 Including the Costs of Transporting and Storing $\mathrm{CO}_{2} \quad 144$

12.1.5 Cost Comparison with Plant Using Renewables 146

12.2 Costs of Hydrogen Production from Fossil Resources with $\mathrm{CO}_{2}$ Capture 148

12.2.1 Hydrogen Production with $\mathrm{CO}_{2}$ Capture 148

12.2.2 Accounting for the Costs of Transport and Storage of $\mathrm{CO}_{2} \quad 152$

12.2.3 Cost Comparison with Hydrogen from Renewables 152 


\section{Chapter 13}

Other Energy Sector Criteria $\quad 155$

\begin{tabular}{lll}
\hline 13.1 & Social Acceptance & 155
\end{tabular}

13.2 Transferability of Technology to Developing Countries 155

13.3 Technology Leadership and Export Opportunities 156

13.4 Import Dependency 156

13.5 Security Policy Implications 156

13.6 Vulnerability and Complexity of the System 157

$\begin{array}{lll}13.7 & \text { Conflicting Alternative Uses } & 158\end{array}$

Chapter 14

Systems Analysis of CCS Scenarios 159

\begin{tabular}{lll}
\hline 14.1 & CCS in the Energy Economy & 159
\end{tabular}

14.1.1 General Factors Affecting CCS 159

14.1.2 Power Station Retrofitting 160

14.1.3 Compatibility of CCS with Other Climate Protection Measures 163

14.2 Scenario Analyses: Assessment of the Strategic Importance of CCS 165

14.2.1 Storylines for Political Relevant CCS Scenarios 165

14.2.2 Definitions and Parameters for the Scenarios 166

14.2.3 Scenarios for Developing CCS Technologies in the Electricity Sector $\quad 170$

14.2.4 Scenarios for Developing CCS Technologies in the Hydrogen Sector 174

14.3 Conclusions of the Scenario Analysis for Germany 175

$\begin{array}{lll}14.4 & \text { Applicability of Results to Other Countries } & 179\end{array}$

Chapter 15

CCS in the International Context $\quad 181$

15.1 The Significance of CCS as a Climate Protection Option 181

15.2 CCS in a Portfolio of Climate Protection Strategies: Analysis of Uncertainty Factors $\quad 183$

15.2.1 The Cost Reduction Potentials of CCS and Renewables and the Discount Rate $\quad 183$

15.2.2 The Costs of Exploration and Extraction of Fossil Fuels 185

$\begin{array}{ll}\text { 15.2.3 Timeframes of CCS Availability } & 187\end{array}$

15.3 Requirements for an Institutional Framework for CCS 188

15.3.1 The Basis for an Institutional Framework: "Cap and Trade" $\begin{array}{lr}\text { versus Technology Protocol } & 189 \\ & 189\end{array}$

$\begin{array}{ll}\text { 15.3.2 Critical Legal Aspects } & 189\end{array}$

15.3.3 Statutory Regulations in Selected States and the EU 190

15.3.4 CCS in the Kyoto Protocol 191

$\begin{array}{ll}\text { 15.3.5 Carbon Sequestration Bonds: A Proposal for Regulating } & 192 \\ & \text { Responsibility for } \mathrm{CO}_{2} \text { Storage }\end{array}$

15.3.6 The Role of Pilot Projects: Levelling the Playing Field 193

15.3.7 CCS in the Kyoto Architecture after 2012: A Possible Strategy
for the EU

\begin{tabular}{ll} 
Appendix & 199 \\
\hline
\end{tabular}

\begin{tabular}{ll}
\hline Contents & 197
\end{tabular}

$\begin{array}{lll}\text { A.1 Physical Properties of } \mathrm{CO}_{2} & 199\end{array}$

A.2 $\mathrm{CO}_{2}$ Capture Methods (to Chapter 5) 199

A.2.1 Chemical/Physical Absorption $\quad 200$

$\begin{array}{ll}\text { A.2.2 Adsorption on Solids } & 201\end{array}$

$\begin{array}{ll}\text { A.2.3 Cryogenic Distillation } & 201\end{array}$

$\begin{array}{ll}\text { A.2.4 Membrane Method } & 202\end{array}$ 
$\begin{array}{lll}\text { A.2.5 High-temperature Methods } & 202\end{array}$

A.2.6 Conclusions 203

A.3 Worldwide Overview of CCS rojects (to Chapter 7) 203

A.3.1 Projects within the EU 206

$\begin{array}{ll}\text { A.3.2 International Activities and Political Strategies } & 210\end{array}$

A.3.3 CCS Projects in Germany 213

A.4 Central Issues for Planning a $\mathrm{CO}_{2}$ Transport Infrastructure (to Chapter 8) 214

A.5 Data Used for Analysing Mass Flows of Fuel and $\mathrm{CO}_{2}$ (to Chapter 10) 214

\begin{tabular}{ll} 
References & 217 \\
\hline
\end{tabular}

\section{Tables}

Table 1: Characteristics and suitability of different modes of transport for $\mathrm{CO}_{2}$ transport

Table 2: $\quad$ Assessment of geological storage options in Germany using selected criteria 27

Table 2-1: Terms relating to carbon capture and storage 38

Table 5-1: Development status of $\mathrm{CO}_{2}$ capture methods $\quad 54$

Table 5-2: Learning rates for capital and running costs for power station $\begin{array}{ll}\text { technologies, after Rubin et al. (2006) } & 60\end{array}$

Table 6-1: Costs of temporary storage facilities (steel tanks and rock shelters) 66

Table 6-2: Transport costs for different 'cost windows', after ECOFYS (2004) 67

Table 6-3: Costs for $\mathrm{CO}_{2}$ capture, transport and storage in $€ /$ tonne (GESTCO 2004) 68

$\begin{array}{lll}\text { Table 7-1: } & \text { Global } \mathrm{CO}_{2} \text { storage options and capacities } & 73\end{array}$

Table 7-2: $\quad$ Overview of estimates of global $\mathrm{CO}_{2}$ storage capacity $\quad 75$

Table 7-3: $\quad$ European $\mathrm{CO}_{2}$ storage options and capacities 76

Table 7-4: Assessment of geological storage options in Germany using selected criteria

Table 8-1: Relevant factors for transport cost for CCS

Table 8-2: Additional annual transport required by CCS in electricity or hydrogen production

Table 8-3: Transport capacities of different modes of transport

Table 8-4: $\quad$ Estimate of annual one way loaded vehicle journeys required for CCS for a $700 \mathrm{MW}$ IGCC power station

Table 9-1: Assessment criteria for various $\mathrm{CO}_{2}$ avoidance options 90

Table 10-1: Selected systems configurations for electricity generation 95

Table 10-2: Selected system configurations for hydrogen production 96

Table 10-3: Impact categories and assessment parameters considered in this study $\quad 97$

Table 10-4: Data sources of processes under consideration 98

Table 10-5: Basic data for fossil-fired reference power stations without and with $\mathrm{CO}_{2}$ capture

Table 10-6: Sources for the LCA modules for the fossil-fired reference power stations 100

Table 10-7: Sources for LCA modules for fossil fuel supply chains $\quad 101$

Table 10-8: Modelled residual efficiency of the steam turbine process 102 
Table 10-9: Consumption and emissions data used for modelling the MEA capture process

Table 10-10: $\mathrm{CO}_{2}$ transport scenarios for power stations $\quad 103$

Table 10-11: Long-distance natural gas pipeline modules in the ecoinvent database 104

Table 10-12: Reference power plant using renewables $\quad 105$

Table 10-13: Sensitivity analyses (electricity generation) 113

Table 10-14: Methane emissions of the primary energy supply chains 117

Table 10-15: Basic data for hydrogen production from fossil fuels without and with $\mathrm{CO}_{2}$ capture

Table 10-16: Sources for the LCA modules for hydrogen production from fossil fuels

Table 10-17: Sources of the LCA modules for the fossil fuel supply chains

Table 10-18: $\mathrm{CO}_{2}$ transport scenarios for hydrogen technologies

Table 10-19: Sources of the LCA modules for production of hydrogen using renewables

Table 10-20: Reference power plant for renewables

Table 11-1: Overall assessment of various climate protection options

Table 12-1: $\quad$ Fuel prices for power stations in two price scenarios without and with $\mathrm{CO}_{2}$ penalty in $\mathrm{ct}_{€ 2000} / \mathrm{kWh}_{\mathrm{th}}$ and in $€_{2000} / \mathrm{GJ}$

Table 12-2: Data used for calculating electricity generation costs of fossil-fuelled power stations

Table 12-3: Data for fossil-fuelled power stations in 2020 and their electricity generation costs on the basis of the same data

Table 12-4: Data for fossil-fuelled power stations in 2020 and their electricity generation costs on the basis of the same data

Table 12-5: $\quad$ Difference in data of power stations with and without $\mathrm{CO}_{2}$ capture

Table 12-6: Comparison of 'market-ready' CCS power stations (2020) with 'mature' CCS power stations (2040) and their reference power stations without CCS

Table 12-7: Electricity generation costs $\left(\mathrm{ct}_{€ 2000} / \mathrm{kWh}_{\mathrm{el}}\right)$ of new CCS power stations at the time of starting operation including transport and storage for three price scenarios and the resulting additional costs compared with the same power station type without $\mathrm{CO}_{2}$ capture

Table 12-8: $\quad \mathrm{CO}_{2}$ avoidance costs of CCS power stations in $€_{2000} / \mathrm{t} \mathrm{CO}_{2}$ for different fuel price scenarios and times of starting operation

Table 12-9: Development of the electricity costs of new renewable energy plant according to the NaturschutzPlus-new scenario (BMU 2005) with comparable economic data

Table 12-10: Data for calculating the cost of generating hydrogen from fossil fuels

Table 12-11: Data for hydrogen production

Table 12-12: Data for hydrogen generation plant using fossil feedstock in 2020 and their generation costs on the basis of the DLR data

Table 12-13: Difference in data of hydrogen generation plant with and without $\mathrm{CO}_{2}$ capture (without transport and final storage of $\mathrm{CO}_{2}$ )

Table 12-14: Hydrogen costs of reference plant (start-up 2020) in relation to fuel price; plant without $\mathrm{CO}_{2}$ capture

Table 12-15: Hydrogen costs of reference plant (start-up 2020) in relation to fuel price; plant with $\mathrm{CO}_{2}$ capture, without transport and final storage 
Table 12-16: Hydrogen costs of reference plant (start-up 2020) in relation to fuel price; plant with $\mathrm{CO}_{2}$ capture, with transport and final storage

Table 14-1: Interaction matrix for CCS and other relevant climate protection strategies

Table 14-2: Demographic and economic data for the scenarios

Table 14-3: Primary and final energy consumption and gross electricity generation in the three scenarios, itemised by energy source

Table 14-4: Effects of applying CCS in electricity generation in the CCSMAX and BRIDGE scenarios in 2050

Table 14-5: Application of CCS in hydrogen production in the CCSMAX and BRIDGE scenarios in 2030, 2040 and 2050

Table 14-6: $\quad \mathrm{CO}_{2}$ emissions in the scenarios with and without CCS technologies, captured $\mathrm{CO}_{2}$ quantities and resulting additional primary energy demand

\section{Figures}

Fig. 1: Measures and goals for $\mathrm{CO}_{2}$ reduction in the power generation sector

Fig. 2: Methods of $\mathrm{CO}_{2}$ capture at the power station

Fig. 3: $\quad \mathrm{CO}_{2}$ storage projects operating worldwide Source: IEA database

Fig. 4: $\quad$ LCAs of CCS plant in comparison with selected renewables (here: greenhouse gases)

Fig. 5: Comparison of greenhouse gas emissions from CCS power stations with selected plant from the fields of renewables and advanced fossil-fuelled CHP technologies

Fig. 6: Comparison of other impact categories for lignite-fired steam power station without and with CCS (post-combustion)

Fig. 7: Development of electricity generation costs (for new plant) for renewables, conventional gas- and coal-fired power stations and CCS

Fig. 8: $\quad$ Primary energy structure today and in the scenarios for 2050

Fig. 3-1: Emissions reduction requirements compared with the trend in stabilising $\mathrm{CO}_{2}$ emissions in the United States (DoE 2003)

Fig. 3-2: Factors promoting $\mathrm{CO}_{2}$ capture and storage world-wide

Fig. 4-1: The different types of fuel, oxidant and technology involved in power generation technology

Fig. 4-2: Physical, chemical and membrane methods for $\mathrm{CO}_{2}$ separation

Fig. 4-3: The process chain from $\mathrm{CO}_{2}$ separation to storage

Fig. 5-1: Measures and goals for $\mathrm{CO}_{2}$ reduction in the power generation sector

Fig. 5-2: Flue gas decarbonisation by amine scrubbing

Fig. 5-3: Pulverised-coal-fired power station with $\mathrm{CO}_{2}$ scrubbing

Fig. 5-4: IGCC power station with $\mathrm{CO}$ shift and $\mathrm{CO}_{2}$ capture (Rectisol scrubbing) 50

Fig. 5-5: $\quad \mathrm{CO}$ shift reactor for converting $\mathrm{CO}$ and $\mathrm{H}_{2} \mathrm{O}$ into $\mathrm{H}_{2}$ and $\mathrm{CO}_{2}$

Fig. 5-6: NGCC power station with membrane separation of $\mathrm{H}_{2}$ and afterburning of the retentate

Fig. 5-7: Physical scrubbing 
Fig. 5-8: $\quad \mathrm{CO}_{2}$ enrichment using membrane technology 52

Fig. 5-9: The oxyfuel process (combustion in pure oxygen) 53

Fig. 5-10: $\mathrm{CO}_{2}$ capture in an SOFC fuel cell with WGSMR afterburner 54

Fig. 5-11: The ZECA process (Lackner 2001) 55

Fig. 5-12: The AZEP process (Göttlicher 2003) 55

Fig. 5-13: Chemical looping combustion: basic processes (left) and material
flows (right)

Fig. 5-14: $\mathrm{CO}_{2}$ capture in an SOFC fuel cell with gas turbine and afterburner $\quad 56$

$\begin{array}{ll}\text { Fig. 5-15: Hydrogen production from natural gas by steam reforming and } & \\ & \mathrm{CO}_{2} \text { capture (MEA scrubbing) }\end{array}$

$\begin{array}{ll}\text { Fig. 5-16: Simplified process flow chart for gasification of carbonaceous slurries } & \\ & \text { for } \mathrm{H}_{2} \text { production (Ullmann's 2002) }\end{array}$

Fig. 6-1: Specific direct and indirect energy consumption for producing and transporting dry ice $\left(\right.$ solid $\left.\mathrm{CO}_{2}\right)$ and pipeline transport of liquid and gaseous $\mathrm{CO}_{2}$

Fig. 6-2: $\quad$ Breakdown of compression costs (ECOFYS 2004) 62

Fig. 6-3: Compression costs as a function of compressor throughput and load factor (ECOFYS 2004) 63

Fig. 6-4: Cost and capacity ranges for various $\mathrm{CO}_{2}$ transport alternatives 66

Fig. 6-5: $\quad$ Accumulated costs for transport scenarios I to VI $\quad 67$

Fig. 6-6: Evaluation of transport costs from seventeen European case studies in the GESTCO project

Fig. 6-7: $\quad$ Mean costs for capture, compression, transport and storage (GESTCO project)

Fig. 6-8: Distribution of CCS costs for capture, compression, transport and storage in the GESTCO project Analysis of 17 European case studies

Fig. 6-9: Span of $\mathrm{CO}_{2}$ transport costs for a $250-\mathrm{km}$ onshore or offshore pipeline as a function of capacity. Source: IPCC (2005)

Fig. 7-1: Various conceivable options for storing $\mathrm{CO}_{2}$

Fig. 7-2: Breakdown of 'low', 'best' and 'high' estimates of global $\mathrm{CO}_{2}$ storage potential (data from ECOFYS 2004)

Fig. 8-1: $\quad$ Example of a possible $\mathrm{CO}_{2}$ transport scenario in Germany 79

Fig. 8-2: The elements of a $\mathrm{CO}_{2}$ transport systemSource: Schlattmann (2006) 80

Fig. 8-3: Distribution of potential $\mathrm{CO}_{2}$ storage formations 84

Fig. 8-4: $\quad \mathrm{CO}_{2}$ sources (power stations) and sinks (aquifers and natural gas storage facilities) in Germany and the existing gas pipeline network

Fig. 9-1: Different development options for electricity generation considered by the Enquete Commssion "Sustainable Energy Supply" of the Germany Bundestag

Fig. 9-2: Climate protection options and their availability timeframes 89

Fig. 10-1: Model of a 'low- $\mathrm{CO}_{2}$ ' coal-fired power station as modelled in Umberto ${ }^{\circ} \quad 94$

Fig. 10-2: Second-level subnet of T1: Coal-fired power plant with CCS from Fig 10-1 94

Fig. 10-3: Third-level subnet T2 $\left(\mathrm{CO}_{2}\right.$ capture $) \quad 95$

Fig. 10-4: Assessment steps for the electricity generation configurations 96

Fig. 10-5: Assessment steps for hydrogen production configurations 97

Fig. 10-6: Methodology for calculating captured and avoided $\mathrm{CO}_{2}$ for the example of a coal-fired power station with and without CCS 
Fig. 10-7: Comparison of $\mathrm{CO}_{2}$ emissions, total greenhouse gases and cumulative energy demand for the coal-fired power station without and with CCS

Fig. 10-8: Comparison of the shares of power plant and high-voltage DC transmission for emissions and cumulative energy demand

Fig. 10-9: Comparison of $\mathrm{CO}_{2}$ emissions from fossil-fuelled reference power stations without and with CCS

Fig. 10-10: Comparison of $\mathrm{CO}_{2}$ emissions from CCS power stations with selected plant from the fields of renewables and advanced fossil-fuelled CHP technologies

Fig. 10-11: Comparison of greenhouse gas emissions from fossil-fuelled reference power stations without and with CCS

Fig. 10-13: Comparison of cumulative energy demand for reference power plant using fossil fuels and renewables without and with CCS

Fig. 10-12: Comparison of greenhouse gas emissions from CCS power stations with selected plant from the fields of renewables and advanced fossil-fuelled CHP technologies

Fig. 10-14: Comparison of absolute $\mathrm{CO}_{2}$ emissions, total greenhouse gases and cumulative energy demand for reference power plant using fossil fuels and renewables without and with CCS

Fig. 10-15: Comparison of relative $\mathrm{CO}_{2}$ emissions, total greenhouse gases and cumulative energy demand for reference power plant using fossil fuels and renewables without and with CCS

Fig. 10-16: Comparison of other impact categories for coal-fired steam power station without and with CCS (post-combustion)

Fig. 10-17: Comparison of other impact categories for the lignite-fired power station without and with CCS (post-combustion)

Fig. 10-18: Comparison of impact categories photooxidant formation, acidification and eutrophication in relative form for reference power plant using fossil fuels and renewables without and with CCS

Fig. 10-19: Stored quantity and leakage over the first 100 years with a leakage rate of $1 \% / a$, for the example of a coal-fired power station

Fig. 10-20: Stored quantity and leakage over the first 100 years with a leakage rate of $0.01 \% / a$, for the example of a coal-fired power station

Fig. 10-21: Sink content over the first 1,000 years with leakage rates of $1 \%$ to $0.0001 \% / a$, for the example of a coal-fired power station

Fig. 10-22: $\mathrm{CO}_{2}$ emissions for the coal-fired power station with different $\mathrm{CO}_{2}$ leakage rates, divided into medium-term and long-term emissions

Fig. 10-23: $\mathrm{CO}_{2}$ emissions, total greenhouse gases and cumulative energy demand for the coal-fired power station with various $\mathrm{CO}_{2}$ capture rates

Fig. 10-24: $\mathrm{CO}_{2}$ emissions, total greenhouse gases and cumulative energy demand for the coal-fired power station with various $\mathrm{CO}_{2}$ capture rates and fixed capture costs

Fig. 10-25: Comparison of total greenhouse gases at various levels of methane emissions in the coal supply chain for the fossil-fuelled reference power stations

Fig. 10-26: Classical steam reforming plus $\mathrm{CO}_{2}$ capture using chemical scrubbing

Fig. 10-27: Comparison of $\mathrm{CO}_{2}$ emissions, total greenhouse gases and cumulative energy demand for coal gasification by IGCC without and with CCS

Fig. 10-28: Comparison of $\mathrm{CO}_{2}$ emissions, total greenhouse gases and cumulative energy demand for natural gas steam reforming without and with CCS 
Fig. 10-29: Comparison of absolute $\mathrm{CO}_{2}$ emissions, total greenhouse gases and cumulative energy demand for hydrogen production using fossil fuels and renewables

Fig. 10-30: Comparison of impact categories photooxidant formation, acidification and eutrophication for hydrogen production using fossil fuels and renewables

Fig. 11-1: $\mathrm{CO}_{2}$ injection wells and possible leakages

Fig. 12-1: Real $\left(\$_{2000}\right)$ and nominal oil price since 1970; energy price scenarios (EWI 2005 and DLR 2005) in real prices until 2050 and (for comparison) the EWI 2006 scenario until 2030

Fig. 12-2: Fuel prices at power station (in $\$_{2000} / \mathrm{GJ}$ ) for natural gas, coal and lignite for price scenarios DLR 2005 (solid lines) and EWI 2005 (broken lines) without (left) and with (right) $\mathrm{CO}_{2}$ penalty

Fig. 12-3: Electricity costs of new coal-fired power stations at the respective start-up time in relation to technological improvements, fuel prices and $\mathrm{CO}_{2}$ penalties

Fig. 12-4: Electricity costs of new gas-fired combined cycle and coal-fired power stations at the respective start-up time in relation to technological improvements, fuel prices and $\mathrm{CO}_{2}$ penalties

Fig. 12-5: Comparison of $\mathrm{CO}_{2}$ avoidance costs of CCS power stations

Fig. 12-6: Development of electricity generation costs (for new plant) for renewables, conventional gas- and coal-fired power stations and CCS power stations

Fig. 12-7: Hydrogen generation costs in relation to prices for natural gas and coal (three price variants through to 2050) for plant without $\mathrm{CO}_{2}$ capture

Fig. 12-8: Cost of reference electrolysis and approximate hydrogen costs given use of wind-generated electricity $(3,500-4,500 \mathrm{~h} / \mathrm{a})$, solar thermal power stations

Fig. 12-9: Cost comparison of hydrogen production from low- $\mathrm{CO}_{2}$ plant using natural gas and coal $(8,000 \mathrm{~h} / \mathrm{a})$ with electrolytic hydrogen from wind power and hydropower

Fig. 13-1: Germany's natural gas suppliers (Source: Ruhrgas 2005)

Fig. 13-2: Required reserve capacity as a function of unit output $\mathrm{P}_{\mathrm{i}}$ (assuming identically sized units) for $100 \mathrm{GW}$ generating capacity

Fig. 14-1: The main factors influencing future $\mathrm{CO}_{2}$ capture and storage

Fig. 14-2: Relationship between possible storage demand and available capacity

Fig. 14-3: Static ranges of storage capacity for different power generation scenarios

Fig. 14-4: Emissions from existing and planned power stations in relation to two emissions reduction trajectories in Germany

Fig. 14-5: Primary energy trends in the three scenarios showing the shares of nuclear and renewables

Fig. 14-6: Remaining output of power stations built before 2001 in Germany, itemised by typ

Fig. 14-7: Installed output in the CCSMAX scenario: old power stations, new renewable energy plant and new fossil-fuelled power stations with and without CCS

Fig. 14-8: Installed output in the BRIDGE scenario: old power stations, new renewable energy plant and new fossil-fuelled power stations with and without CCS

Fig. 14-9: Installed output in the NATP scenario: old power stations, new renewable energy plant and new fossil-fuelled power stations without CCS 
Fig. 14-10: Structure of gross electricity generation of CCSMAX scenario $\mathrm{RE}=$ renewable energies

Fig. 14-11: Gross electricity generation in the NATP scenario

Fig. 14-12: Gross electricity generation in the BRIDGE scenario

Fig. 14-13: $\mathrm{CO}_{2}$ emissions from electricity generation in the scenarios

Fig. 14-14: Primary energy structures in 2000 and 2005 and in the scenarios for 2050, showing the amounts of coal required for production of CCS hydrogen

Fig. 14-15: Primary energy sources in the CCSMAX and NATP scenarios

Fig. 14-16: Energy-related $\mathrm{CO}_{2}$ emissions in the CCSMAX, BRIDGE and NATP scenarios until 2050

Fig. 15-1: Cumulative quantity of anthropogenic $\mathrm{CO}_{2}$ emissions and $\mathrm{CO}_{2}$ captured through CCS in relation to the stabilisation level of atmospheric $\mathrm{CO}_{2}$ concentration

Fig. 15-2: Discounted economic costs in percent of global GDP, taking technological progress into account, in various models that account endogenously for technological learning effects

Fig. 15-3: Optimum cumulative amount of sequestrated carbon between 2000 and 2100 in relation to learning rate and the initial investment costs of renewables

Fig. 15-4: Optimum cumulative amount of sequestrated carbon between 2000 and 2100 in relation to learning rate and floor costs

Fig. 15-5: Optimum cumulative amount of sequestrated carbon between 2000 and 2100 in relation to leakage rate and the energy penalty on the optimum amount of sequestrated $\mathrm{CO}_{2}$

Fig. 15-6: Rogner curve, showing in a simplified form the marginal costs of resource extraction in relation to cumulative resource extraction

Fig. 15-7: Cost of climate protection as percentage loss of global GDP in relation to the resource base $\left(\chi_{3}\right)$ and the parameter characterising the development of extraction costs $\left(\chi_{4}\right)$

Fig. 15-8: Marginal costs of resource extraction in relation to cumulative resource extraction for the scenarios described in the text

Fig. 15-9: Optimum cumulative quantity of sequestered carbon between 2000 and 2100 in relation to the resource base $\left(\chi_{3}\right)$ and the parameter characterising the development of extraction costs $\left(\chi_{4}\right)$

Fig. 15-10: Optimum cumulative quantity of sequestered carbon between 2000 and 2100 in relation to the time when the technology becomes available

Fig. 15-11: Discounted consumption losses in percent caused by cost of climate protection, in relation to the time when the technology becomes available

Fig. 15-12: $\mathrm{CO}_{2}$ emissions paths with different availability dates of CCS 


\title{
Summary of Theses
}

\author{
Driving Forces and the Attitude of Relevant Groups Towards $\mathrm{CO}_{2}$ Capture and Storage
}

- Climate protection is the most important reason for developing $\mathrm{CO}_{2}$ capture and storage. In particular sectors of the economy other economic incentives to capture $\mathrm{CO}_{2}$ already exist today (e.g. enhanced oil recovery).

- Attitudes towards the technology are not uniform in different groups of society. CCS is often described as a possible bridge to the era of renewable energy.

- Environmental organisations prioritise the further expansion of renewables and the full exploitation of energy-saving potentials. All environmental organisations reject the idea of storing $\mathrm{CO}_{2}$ in the oceans. Adequate proof of long-term stability is demanded for all storage options.

\section{$\mathrm{CO}_{2}$ Capture Methods}

- Today there are three technology options for $\mathrm{CO}_{2}$ capture in the short to medium term. Capturing $\mathrm{CO}_{2}$ from the flue gases of conventional power stations (post-combustion capture) leads to a significant increase in electricity generating costs, causes a considerable increase in fuel consumption and substantially reduces power station efficiency. In principle the technology is already available today, although it has yet to be demonstrated at the scale of commercial power plant.

- Capturing $\mathrm{CO}_{2}$ before combustion (pre-combustion capture) in coal- or gas-fired power stations with integrated gasification (IGCC and natural gas combined cycle) is from today's perspective a more advantageous process than capturing $\mathrm{CO}_{2}$ from flue gas. Implementing this $\mathrm{CO}_{2}$ capture method would require considerable improvement and development, especially with regard to scaling it up to conventional power plant dimensions.

- The oxyfuel process involves burning fuel in pure oxygen and currently offers the best prospects for $\mathrm{CO}_{2}$ capture in terms of the achievable overall efficiency of the process and possibly also the resulting costs, because the components involved are largely based on conventional power station technology. A precise evaluation is not yet possible, because the process is only at the beginning of the demonstration phase.

- Considerable additional costs must be factored in for capture at the power station, according to current estimates between $€ 35 / \mathrm{t}$ and $€ 50 / \mathrm{t} \mathrm{CO}_{2}$. Through research and demonstration projects and other technological improvements it is aimed to reduce the costs to less than $€ 20 / \mathrm{t} \mathrm{CO}_{2}$.

- As well as planning new builds with integrated $\mathrm{CO}_{2}$ capture it is in principle also possible to retrofit. Because of the strong increase in energy consumed internally, this only makes sense in power stations which start off with a sufficiently high level of efficiency. In terms of technology, flue gas scrubbing is the primary option for retrofitting from today's perspective. When power stations are planned today, the option of designing them to be 'capture ready' (prepared for retrofitting $\mathrm{CO}_{2}$ capture) should be considered. 


\section{Methods for $\mathrm{CO}_{2}$ Transport}

- Energy efficiency, economic and ecological considerations mean that pipelines (onshore, possibly offshore too) and large tanker ships are the only relevant transport options for large-scale implementation of CCS.

- The decisive parameters for the source/sink relationship are in particular transport distance and capacity, but coordinating the timing of planning, approval and construction of power stations, pipelines and $\mathrm{CO}_{2}$ sinks is also relevant. The high investment costs involved in establishing a $\mathrm{CO}_{2}$ infrastructure necessitate forward-looking planning and coordination between the different parties involved.

- Both gas conditioning (liquefying $\mathrm{CO}_{2}$ by compression, which reduces power station efficiency by up to 3.5 percentage points) and subsequent $\mathrm{CO}_{2}$ transport themselves require a more than negligible additional amount of energy, which in turn causes additional $\mathrm{CO}_{2}$ emissions (and other greenhouse gases and pollution).

- The range of cost estimates for $\mathrm{CO}_{2}$ is - depending on transport distance and capacity approx. $€ 1 / \mathrm{t}$ to $€ 10 / \mathrm{t}$ (for pipeline or ship transport) and represents about $10 \%$ of the total costs of the CCS process (capture, compression, transport, storage).

- In relation to the other infrastructure costs (electricity transmission, fuel logistics) the cost of $\mathrm{CO}_{2}$ transport is likely to be a secondary factor when selecting power station sites. Also, existing power station sites are often likely to be retained for reasons of public acceptance.

- Transport of fuel (oil, oil products, coal) already represents a large proportion of total freight transport in industrialised countries. Introducing CCS on a large scale would considerably increase transport volumes - to supply additional coal and remove $\mathrm{CO}_{2}$. There would also be a risk of pipeline or shipping accidents, although the risk per ship or kilometre of pipeline is relatively small.

\section{$\mathrm{CO}_{2}$ Storage: Methods and Capacity}

- For various reasons the storage possibilities for $\mathrm{CO}_{2}$ are limited, both globally and nationally. Owing to the many uncertainties involved, current estimates of actual storage potential vary enormously. Global estimates show that although the potential is certainly considerable, in the long term it will certainly not be possible to solve the climate problem through $\mathrm{CO}_{2}$ storage alone.

- Ecological, economic and capacity considerations mean that the only option e. g. for Germany is geological storage in empty gas fields and deep aquifers. Taking into consideration only the country's major point sources and factoring in an average increase in energy use for CCS of $30 \%$, the static range in Germany is between thirty and sixty years.

- Guaranteeing very low leakage rates is essential for the acceptance of underground storage. Corresponding evidence will have to be provided in a comprehensible form.

- Little is yet known about the behaviour of $\mathrm{CO}_{2}$ in underground reservoirs. Research projects already under way should greatly improve knowledge of drilling and injection methods, distribution of gases in reservoirs and monitoring methods. 


\section{Comparative Life Cycle Assessments}

- From a holistic perspective the terms zero-carbon, zero-emissions and $\mathrm{CO}_{2}$-free are misleading regarding fossil fuelled electricity generation and hydrogen production. When the supply chain is taken into consideration and the usual assumptions are made about $\mathrm{CO}_{2}$ capture rates at the power station ( $88 \%$ for post-combustion and pre-combustion) the potential for net $\mathrm{CO}_{2}$ reduction is found to be between $72 \%$ and $78 \%$. If the full range of greenhouse gases is included, the reduction compared with a power station without CCS falls to a range of $67 \%$ to $78 \%$. Higher $\mathrm{CO}_{2}$ capture rates of up to $99.5 \%$ (achievable with the oxyfuel process) allow in a coal-fired power station a net $\mathrm{CO}_{2}$ reduction of $90 \%$ and a net greenhouse gas reduction of $78 \%$.

- In this context it is more correct to speak of low- $\mathrm{CO}_{2}$ or low-carbon electricity generation. The $\mathrm{CO}_{2}$ emissions from the 'best' fossil-fuelled power station from the climate protection perspective (natural gas combined cycle, NGCC) are 'only' $50 \%$ higher than those from the 'worst' CCS power station (coal-fired thermal power station with post-combustion capture).

- The increased fuel consumption involved in $\mathrm{CO}_{2}$ capture and storage always leads to a proportional worsening of the outcome in the other impact categories. There are, however, exceptions: with post-combustion capture other emissions are reduced through reaction with the solvent - acidification falls by $10 \%$ and PM10 equivalents (particulate matter) increase by only about $2 \%$. On the other hand, eutrophication increases by $36 \%$ and summer smog by $94 \%$, and demand for cooling water increases by up to $50 \%$ (post-combustion).

- In comparison with CCS power stations, comparable large-scale renewable energy systems (e.g. solar thermal power stations, offshore wind farms) fare considerably better in all impact categories across all stages of the process. Innovative fossil-fuelled power station solutions like natural gas combined cycle (NGCC) including heat extraction and combined heat and power plant units (CHP) available today are comparably environmentally friendly as CCS plant are expected to be in 2020 .

\section{Other Ecological Assessment Factors for CCS}

- As well as direct and indirect effects on the appearance of the landscape (e.g. caused by increased fuel consumption) and the negative consequences of increased transport volumes (of $\mathrm{CO}_{2}$ and additional fuel), the greatest other ecological impact would be the potential unplanned release of stored $\mathrm{CO}_{2}$ and the direct influence of the stored $\mathrm{CO}_{2}$ on the immediate vicinity of the sink over the course of time.

- The different $\mathrm{CO}_{2}$ storage options differ from one another - sometimes considerably - in terms of ecological and safety considerations. Geological sinks (e.g. saline aquifers) are considered to have comparatively high long-term stability, but there is still great uncertainty concerning the underground movement of $\mathrm{CO}_{2}$ and the resulting consequences.

- Regarding $\mathrm{CO}_{2}$ storage in oceans its impact on marine ecosystems is still largely unresearched, but the expectable risks are so great that most countries rule out even conducting further research into this storage option.

\section{Economic Comparison of CCS and Renewable Energy Technologies}

- In terms of electricity generation costs, a general structural difference must be noted when comparing CCS and renewables. Large or very large cost degression and learning effects are still to be expected in both fields, but in the case of CCS these will be counteracted by further rises in fuel prices. This effect is particularly strong in the case of gasfired CCS power stations. 
- It can be assumed that electricity from renewable energies will become economically competitive to fossil-fuel based electricity earlier with the introduction of CCS. By 2020 - the earliest point at which CCS technologies are likely to be commercially viable - a whole range of renewable energy technologies is likely to be able to supply electricity at cost conditions comparable to or better than fossil-fuelled power stations. In the longer term, renewables can be expected to have considerable cost advantages due to their independence from fuel price fluctuations.

- The relative profitability of CCS and renewables is currently still subject to many uncertainty factors. The aforementioned predictions for renewables are based on assumptions of dynamic market development on a global scale, allowing very substantial cost degression effects to be exploited through mass production and learning curve effects.

- When it comes to hydrogen, production using renewables cannot be expected to become competitive with production using fossil fuels (including CCS) in the foreseeable future. Whether or not this is the case, hydrogen is unlikely to become an important factor in the energy economy for several decades due to its generally high costs and the considerable infrastructure challenges associated with its introduction. But in principle this option represents an interesting strategic element for the transport sector - today still largely dependent on oil - and could potentially supplement biofuels as a diversifying element.

\section{The Role of CCS in Industrialised Countries: the Example of the German Energy Supply System}

- The energy systems of industrialised countries are characterised by a number of shared features. Firstly, there is great potential for energy efficiency measures, on both the supply and demand sides. Secondly, the growth in energy consumption, and consequently in energy-related greenhouse gas emissions, is in general much slower than in developing countries. The special case for Germany is that it faces the complex challenge of having to replace a large proportion of its power station capacity within the coming fifteen years. The following theses are formulated for Germany, but are also applicable to other industrialised countries:

- As the main element of a climate protection strategy (the CCSMAX scenario) CCS runs into structural and capacity limits. The earliest date when CCS technologies are expected to be ready for implementation is 2020 , which is too late for the first wave of the necessary power station replacements, which has just begun. It would necessitate extremely rapid growth rates for CCS plant between 2020 and 2050 and speedy establishment of a hydrogen infrastructure.

- If a vigorous political course of promoting renewables and efficiency improvements is pursued over the next ten to fifteen years, the realisation of energy-saving potential and the successive expansion of renewables would be able to make a more rapid contribution to climate protection than CCS. Increasing energy productivity makes sense in purely economic terms, too. Both strategy elements are also associated with strong innovative stimuli for taking a share of growing global markets. Considerable increases in efficiency and the further expansion of renewables are absolute preconditions for effective climate protection. If a sustained high rate of implementation is maintained, as described in the NaturschutzPlus (NATP) scenario, the use of CCS technologies is not absolutely necessary for meeting even ambitious climate protection targets. The strategy outlined in NATP is the best for the economy as a whole in the medium to long term, and should therefore be an aim of energy policy. 
- The period until 2020 should be used to thoroughly explore the development and costcutting potentials of CCS technologies and to demonstrate the technological feasibility. If that process proves successful, CCS would offer the possibility, as described in the BRIDGE scenario, of switching to a climate-friendly path even if it has not proved possible to sustain the ambitious pace of implementation of efficiency potentials and renewables over time. In view of the real interests involved in the field of energy, especially in the global context (where energy saving efforts are counteracted by substantial growth trends), this constellation may well become reality.

- The successive introduction of CCS after 2020 (presuming the availability of suitable sinks with long-term stability) can act as an ancillary element helping to make it easier to maintain the sustained efforts that will be required to further improve efficiency and expand renewables. In this situation CCS can attain significant importance in fulfilling a bridging function to the establishment of a renewable energy economy. Consequently, it would appear that further development efforts for CCS are necessary and in the international context of climate protection indeed unavoidable. But this must not occur at the expense of R\&D efforts in the field of efficiency and renewables.

- Overall it must be ensured that measures for establishing a CCS infrastructure are compatible with the further expansion of renewables and that permanent structural commitments and use conflicts (for example with geothermal energy or decentralised CHP) are avoided.

- If CCS is included as a climate protection element, upcoming power station planning processes must already begin considering the possibility of future implementation of CCS. The idea of designing new builds 'capture ready' is central here, and is reinforced by discussions at the EU level about possibly making 'capture ready' status obligatory for all new power stations in the medium term.

\section{CCS in the International Context}

- Above all at the global level CCS could, from today's perspective, make a noticeable contribution to meeting ambitious climate protection goals alongside renewables and energy efficiency. Under plausible assumptions CCS could also help to reduce the economic costs of climate protection if today's expectations about its technological development (especially the cost-cutting possibilities) prove to be realistic. Including CCS in an integrated overall concept seems to be one option to stabilise the $\mathrm{CO}_{2}$ concentration in the atmosphere at $450 \mathrm{ppm}$ with an acceptable level of loss of economic growth. This applies in particular if the alternative investment required in measures to adapt to the looming climate change is taken into account.

- Internationally too, CCS can fulfil a 'bridging function' to an emission-free energy system, but only if the technologies are available in time for large-scale implementation and the costs of fossil fuels do not rise too steeply.

- The large-scale introduction of CCS presupposes that an institutional framework will be established (preferably at the international level) to sensibly regulate responsibility for the risks stemming from CCS (giving consideration to the precautionary and polluter pays principles) and offer involved parties an incentive to guarantee the safety of storage.

- Plausible proposals already exist for the shape of such an institutional framework (e.g. carbon sequestration bonds), that could be integrated in the existing climate protection regime and via market mechanisms involve the public in decisions about the use of CCS. 
- Further research - and also political decisions - are required concerning the development and discussion of the institutional framework, especially integration in the mechanisms of the UN Framework Convention on Climate Change, the development of liability mechanisms and the implementation of legal provisions to restrict local risks associated with CCS.

- In upcoming climate protection negotiations CCS could improve the chances of persuading more states (e.g. United States, China) to undertake firm obligations on emissions, because it would allow them to retain their familiar structures and their domestic primary energy base.

- Ultimately, for reasons of capacity (limited storage potential and finite fossil energy resources), CCS cannot obviate the global need for further expansion of renewables and a considerable increase in energy efficiency. But under particular conditions CCS can help in meeting ambitious climate protection targets while at the same time extending the time available for the necessary restructuring of the energy system. 


\section{Summary}

\section{Background and Introduction}

In recent years the discussion about carbon capture and storage (CCS) has moved steadily up the agenda in many countries as well as globally in the context of meeting climate protection targets - even more so as oil and gas prices have risen sharply and the increasingly urgent debate over security of energy supplies has swung towards greater use of coal.

Carbon capture and storage technologies are not fundamentally new. Some of them are already used on an industrial scale and finds commercial application in oil extraction (enhanced oil recovery to increase the extraction rate of oil fields) or for conditioning natural gas (separating off the accompanying $\mathrm{CO}_{2}$ ). However, for the much larger volumes that would generally be involved in application in power stations or for centralised hydrogen production numerous questions still remain unanswered. That also applies to the field of transport, to the possible configurations of a $\mathrm{CO}_{2}$ infrastructure and to storage. Demonstration projects (e.g. in Germany: $30 \mathrm{MW}_{\text {th }}$ pilot plant using the oxyfuel process, planned start of operation 2008) and the first semi-commercial test facilities (the German company RWE Power AG plans to construct a coal-fired power station with integrated gasification, $\mathrm{CO}_{2}$ capture and storage with a net output of $360 \mathrm{MW}_{\mathrm{el}}$ by 2014) aim to achieve significant progress in developing the technologies at the scale required for power stations.

Studies so far conducted in this field have concentrated largely on the technical feasibility of carbon capture and storage. There has not yet been a detailed investigation of the ecological, economic and social impact across all stages of the process (e.g. energy balance, cumulative energy demand, environmental impact, resource consumption, risks and costs) of the kind that is today a matter of course for other new energy technologies, in particular renewable enery technologies. Only after such a study has been completed will it be possible to decide how environmentally beneficial the CCS option really is, what its benefits and drawbacks are compared to renewables and what contribution it can make to a sustainable economic structure. Including carbon capture and storage in the fossil fuel cycle makes it possible for the first time to conduct a comparison with renewables on equal terms (with respect to climate policy). Such a comparison, made on the basis of a comprehensive set of criteria, is the main object of the present study, answering the following questions:
- What are the conceivable paths for carbon capture and storage (technologies, infrastructures) and how do they fit on the time axis (development periods)?

- How do the LCAs of these processes look, and how does low- $\mathrm{CO}_{2}$ fossil electricity generation compare with $\mathrm{CO}_{2}$-free options (especially renewables) in this respect?

- What role can carbon capture and storage play for climate protection in comparison with other relevant options, and when (systematic comparison on the basis of significant criteria such as cost, window of opportunity, ecological restrictions, etc.)?

- What role can carbon capture and storage play at the national and international levels as a possible bridge to a renewable energy system?

\section{Driving Forces and the Attitudes of Relevant Groups towards Carbon Capture and Storage}

Several different motivations are central to the development of technologies for capturing, transporting and storing $\mathrm{CO}_{2}$. Alongside climate protection as the overriding motivation, questions of security of supply, technological aspects, and in some cases also very real commercial considerations (e.g. measures in the field of enhanced oil recovery in countries with a $\mathrm{CO}_{2}$ tax such as Norway) play a decisive role. Technology that can generate progress in international climate protection negotiations is of particular importance. Among the supporters of CCS are - above all - those states that have so far adopted a rejectionist or wait-and-see stance in the international climate protection process, such as the United States. The United States has also made CCS a central priority of the Asian Pacific Partnership (APP), a more technology-oriented climate protection agreement that represents a counterpole to the Kyoto Protocol.

Not least for these reasons, carbon capture and storage has become the subject of a broad range of networks at the international level, such as the Carbon Sequestration Leadership Forum (CSLF), which was initiated by the United States in 2003. 
The attitudes of actors in society towards CCS differ rather widely. Across the world environmental and nature conservation NGOs (non-governmental organisations) - with very few exceptions - agree on the following points and demands concerning CCS:

- $\mathrm{CO}_{2}$ must not be stored in ecosystems (namely, oceans),

- Long-term stability of storage systems must be demonstrably proven and guaranteed,

- Development of CCS must not be at the expense of R\&D funding for renewables, and

- Renewable energy sources and more rational use of energy are preferable to $\mathrm{CO}_{2}$ storage, and their implementation should be stepped up.

That is as far as the consensus extends internationally. German NGOs, for example, are generally at the more sceptical end of the international spectrum in their attitudes to $\mathrm{CO}_{2}$ storage.

Political parties, too, differ in their positions on the technology. In Germany, for example, they range from the expectation that low- $\mathrm{CO}_{2}$ fossil-fuelled power stations will represent 'an important pillar' of energy policy (the conservative CDU) to the call for a coordinated research campaign (the social democratic SPD) or clear rejection (the left-wing Die Linke).

The positions of the different German ministries and expert committees can be summarised as follows: The Federal Ministry of Economics (BMWi) is supporting carbon capture and storage through the COORETEC research programme. This wide-ranging research programme is designed to allow the process of replacing and expanding capacity in the fossil-fuelled power sector that will begin around 2010 to be conducted at a high technological standard. The Federal Ministry for the Environment, Nature Conservation and Nuclear Safety (BMU) and the Federal Environment Agency (UBA) believe that there are still many unanswered questions to be resolved before CCS can be regarded as a safe long-term option that is acceptable in social, ecological and economic terms. In a comprehensive investigation the UBA has examined carbon capture and storage in terms of sustainability criteria, and has come to the conclusion that CCS is a set of non-sustainable technologies that can at best represent a transitional solution.

In its position paper the Council for Sustainable Development calls carbon capture and storage a potentially important bridge 'to the era of renewable energy supplies'. To this end, it believes, $\mathrm{CO}_{2}$ capture technologies should be integrated in highly efficient power stations, but only from the point of view of economic efficiency. The German government's Advisory Council on Global Change (WBGU) has taken a firm stance in favour of storing carbon dioxide, referring in this connection to an 'end-of-pipe technology' that can make a contribu- tion to climate protection for a limited period of time. It rejects the storage options in ocean waters (ecological reservations and missing long-term effect), biomass (lack of potential for expansion) and saline aquifers (no guarantee of safety and long-term storage). Exhausted oil and gas fields could be used temporarily, but only if a sufficient retention period can be guaranteed. In terms of storage period, the WBGU has called for secure sequestration for at least 10,000 years. The WBGU believes storage under the seabed to be permissible only under certain conditions. The Advisory Council on the Environment (SRU) believes that carbon capture and storage may be too expensive in comparison with other $\mathrm{CO}_{2}$ avoidance options, and that the technologies may also come too late for the upcoming expansion and replacement of power station capacity.

Industrial Associations are definitely positive about CCS as a long-term option, but often prioritise improving the efficiency of the power station process as a contribution to climate protection. Capture of $\mathrm{CO}_{2}$, as previously mentioned, already offers opportunities for the oil and gas industry today.

\section{$\mathrm{CO}_{2}$ Capture Methods}

This investigation of carbon capture and storage in the use of fossil fuels has restricted itself to the field of electricity generation in power stations and the potential future production of hydrogen by means of coal gasification - in other words to plants emitting particularly large amounts of $\mathrm{CO}_{2}$ centrally (point sources). In terms of reducing $\mathrm{CO}_{2}$ emitted through the use of fossil fuels, efficiency-improving technologies have previously been the main focus of attention. Applying these technologies quickly over the past decades has achieved a continuous increase in power station efficiency (despite stricter environmental regulations that have in some cases led to increased fuel requirement). The efficiency levels achievable today are $43 \%$ for lignite-fired power stations and $46 \%$ for coal-fired power stations, while for gas-fired power stations $58 \%$ efficiency is now possible. For reasons of thermodynamics and materials technology this trend cannot continue forever. So a further significant reduction in $\mathrm{CO}_{2}$ emissions from fossil electricity generation will require the application of $\mathrm{CO}_{2}$ capture techniques (which are largely already known today) or a move to innovative new power station technologies that include $\mathrm{CO}_{2}$ capture (e.g. chemical looping combustion).

$\mathrm{CO}_{2}$ capture technologies are more likely to become available in the medium term (large-scale application is unlikely to occur before 2020) while the development of new, innovative power station concepts should be regarded more as a long-term option (see Fig. 1). Disadvantageous for $\mathrm{CO}_{2}$ capture is the high energy requirement for the capture process itself, which leads to significant reductions in efficiency (in some cases 10 percentage points and more) and significantly reduces 


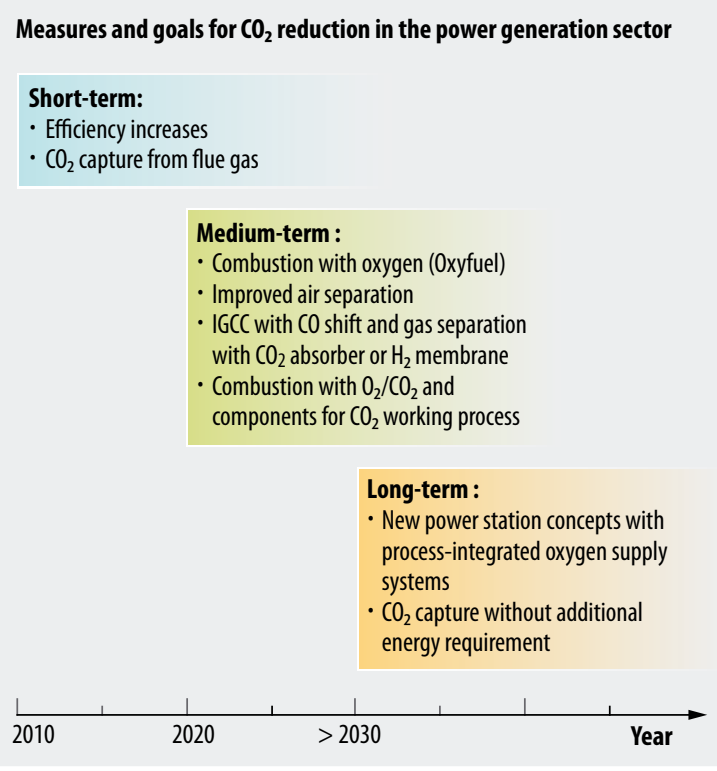

Fig. 1: Measures and goals for $\mathrm{CO}_{2}$ reduction in the power generation sector

the levels of efficiency achieved today (roughly to the level of twenty or thirty years ago). This means that $\mathrm{CO}_{2}$ capture would lead to a significant increase in electricity generating costs and cause a considerable increase in fuel consumption, the logistics of which must also be taken into account. For power stations constructed around 2020, estimates of the cost of $\mathrm{CO}_{2}$ capture at the power station (which dominates the additional costs of carbon capture and storage) currently vary between $€ 30$ and $€ 60 / t \mathrm{CO}_{2}$. Various research, demonstration and pilot projects aim to significantly reduce these costs, with the goal of bringing the overall cost of the whole CCS process (including transport and storage) down below $€ 20 / \mathrm{t} \mathrm{CO}_{2}$.

From today's (technology) perspective there are three relevant options for $\mathrm{CO}_{2}$ capture in the short to medium term (see Fig. 2). Flue gas scrubbing will probably be an adequate option for retrofitting, especially if it turns out to be possible to reduce the energy required still further through new scrubbing agents. Implementing integrated coal gasification (IGCC) would require much greater availability, which is not yet adequate for the power station scale. The crucial point for the oxyfuel process will be to collect experience and successfully put the lessons learned into practice (e.g. through the demonstration project at Schwarze Pumpe in Germany, launched in 2006 by Vattenfall).

The method of capturing $\mathrm{CO}_{2}$ from flue gases in conventional power stations (post-combustion capture) is basically available today, but has not yet been demonstrated on a commercial power station scale. In the longer term this technology is unlikely to become widely established unless its energy consumption can be reduced significantly.
Pre-combustion capture of $\mathrm{CO}_{2}$ in coal- or gas-fired power stations with integrated gasification combined cycle (IGCC and natural gas combined cycle, NGCC) is from today's perspective a better method than flue gas capture of $\mathrm{CO}_{2}$. Apart from its higher efficiency levels, the prime advantage of this technology lies in its flexibility both in terms of fuel (coal, biomass, substitute fuels) and in terms of product (electricity, hydrogen, synthetic gas and liquid fuel). The next step here is large-scale technical demonstration. The IGCC technology itself - without $\mathrm{CO}_{2}$ capture - has already been tested in several plants (e.g. Buggenum in the Netherlands and Puertollano in Spain). Before $\mathrm{CO}_{2}$ capture is implemented there will be a need for improvement and development of individual components (e.g. hydrogen turbines). In Germany RWE Power intends to take the first step towards implementing this technology by building a full-scale IGCC power station with $\mathrm{CO}_{2}$ capture (output (450 $\mathrm{MW}_{\text {gross }} / 360 \mathrm{MW}_{\text {net }}$ ) by 2014.

The oxyfuel process (combustion in pure oxygen) currently offers the best prospects for $\mathrm{CO}_{2}$ capture in terms of achievable overall efficiency of the process (and also the resulting costs), because it is largely based on conventional power station components and technology. It is not yet possible to provide a precise assessment because the process is still at the beginning of the demonstration phase. At Schwarze Pumpe in eastern Germany Vattenfall Europe is building the world's first pilot plant for lignite combustion using the oxyfuel process. The Vattenfall pilot plant, which has an output of $30 \mathrm{MW}$ (thermal), will be used for research and development purposes with the aim of developing the new technology to the point where it is commercially viable. It is scheduled to begin operation in 2008 after a construction phase lasting about three years. Initially the $\mathrm{CO}_{2}$ will not be stored, but corresponding concepts (e.g. transport options) are being investigated.

Whether $\mathrm{CO}_{2}$ capture technologies become relevant for power station replacement will depend on political and economic circumstances. The lack of incentives for retrofitting existing power stations with $\mathrm{CO}_{2}$ capture has meant that this option has not been relevant to date. In order to be prepared for future developments it might make sense to build new power stations 'capture ready' (prepared for retrofitting with $\mathrm{CO}_{2}$ capture). That discussion is already under way.

The space required for the additional components can place restrictions on the implementation of $\mathrm{CO}_{2}$ capture and storage. Connection to suitable storage and transport infrastructures is also a significant location factor. 


\section{$\mathrm{CO}_{2}$ capture processes}

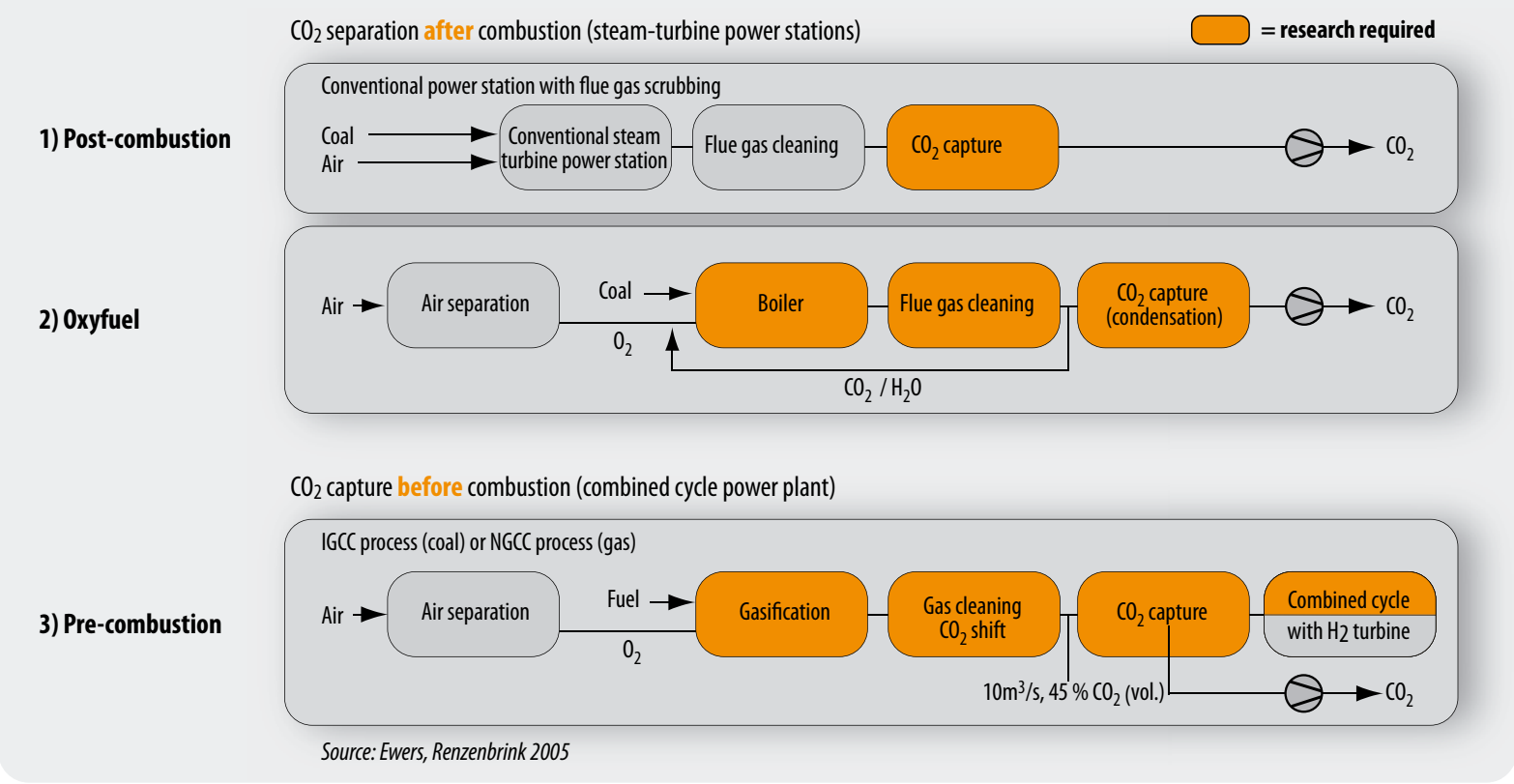

Fig. 2: Methods of $\mathrm{CO}_{2}$ capture at the power station

\section{$\mathrm{CO}_{2}$ Transport Methods}

Because of the considerable transport volumes that occur with CCS, the main issue when analysing locations for sources and sinks is to reduce transport distances and costs to a minimum. Case studies show that the specific transport costs can vary very considerably from case to case. Even if the cost of transport appears small in comparison with the cost of $\mathrm{CO}_{2}$ capture at the power station, the aspect of cost efficiency of CCS-related transport will have to be included when selecting locations for new sources.

Alongside transport distance, the question of the general accessibility of the various transport infrastructures that are suitable for CCS is an initial parameter for location analysis. Wherever it is possible to use existing bulk-capable means of transport and transshipment facilities there will be potential for reducing transport costs.

From the energy efficiency, economic and ecological perspectives the only relevant options for large-scale $\mathrm{CO}_{2}$ transport are pipelines (onshore and possibly offshore) and large tanker ships (depending on the location conditions barges or seagoing vessels for offshore storage). The advantage of the pipeline is that it can transport very large quantities of $\mathrm{CO}_{2}$ without interruption at relatively acceptable environmental and financial cost. But constructing a $\mathrm{CO}_{2}$ pipeline infrastructure would be a time-consuming process and would tie up considerable capital; this would only appear reasonable for long-term usage ( $>20$ to 30 years). Ships, on the other hand, are more flexible and more quickly available, but require intermediate storage facilities and loading/unloading infrastructure. With inland waterways the restrictions on availability during periods of low water levels must be taken into consideration. Transporting $\mathrm{CO}_{2}$ by road and rail tanker is an option only for small quantities and will therefore probably only be relevant for the demonstration and launch phase (see Table 1).

The high investment costs involved make it especially important to coordinate the timing of planning, approval and construction of power stations, pipelines and $\mathrm{CO}_{2}$ sinks. So establishing a $\mathrm{CO}_{2}$ infrastructure necessitates forward-looking planning and coordination between the different parties involved.

Unlike the case of pipeline transport, there has so far been practically no experience in transporting $\mathrm{CO}_{2}$ by ship. However, because $\mathrm{CO}_{2}$ has similar physical properties to LPG (liquefied petroleum gas), experience with LPG transport is partially applicable to $\mathrm{CO}_{2}$ transport.

Both the aforementioned transport options require gas conditioning in order to transport the $\mathrm{CO}_{2}$ in the densest possible form (liquid or supercritical). Pipelines require conditioning to high pressure (approx. 80 to $120 \mathrm{bar}$ ), while tankers require very low temperatures at ambient pressure (low-temperature tankers) or temperatures below normal combined with pressure above normal (hybrid tankers). 


\begin{tabular}{|l|c|l|l|l|l|}
\hline $\begin{array}{l}\text { Mode of } \\
\text { transport }\end{array}$ & $\begin{array}{l}\text { Capacity } \\
\text { in Mt/a }\end{array}$ & Availability & $\begin{array}{c}\text { Cost in } \mathbf{\epsilon} / \mathbf{t} \\
\mathbf{2} 250 \mathbf{k m})\end{array}$ & $\begin{array}{l}\text { Infrastructure } \\
\text { already exists at } \\
\text { source/sink? }\end{array}$ & \multicolumn{1}{|c|}{ Comments } \\
\hline $\begin{array}{l}\text { Seagoing } \\
\text { tanker }\end{array}$ & $<50$ & Always & $<1$ & Almost never & $\begin{array}{l}\text { Generally requires } \\
\text { multi-mode transport }\end{array}$ \\
\hline $\begin{array}{l}\text { Inland } \\
\text { waterways }\end{array}$ & $<10$ & $\begin{array}{l}\text { Seasonally } \\
\text { restricted (water } \\
\text { levels) }\end{array}$ & approx.1 & Sometimes & $\begin{array}{l}\text { Barges not seagoing, } \\
\text { time restrictions }\end{array}$ \\
\hline Pipeline & $<100$ & Always & $\begin{array}{l}\text { approx. 1.5 } \\
\text { (function of } \\
\text { diameter) }\end{array}$ & $\begin{array}{l}\text { Will almost } \\
\text { always have to be } \\
\text { constructed from } \\
\text { scratch (largely } \\
\text { investment) }\end{array}$ & $\begin{array}{l}\text { 25 year operating } \\
\text { period, higher costs in } \\
\text { built-up areas }\end{array}$ \\
\hline Rail & $<1.2$ & Always & approx.5 & Generally & Noise \\
\hline Road & $<0.5 \mathrm{Mt} / \mathrm{a}$ & $\begin{array}{l}\text { Restricted in win- } \\
\text { ter, congestion }\end{array}$ & approx. 25 & Always & $\begin{array}{l}\text { Cost, noise and } \\
\text { emissions, acceptance, } \\
\text { time restrictions }\end{array}$ \\
\hline
\end{tabular}

Table 1:

Characteristics and suitability of different modes of transport for $\mathrm{CO}_{2}$ transport
Both gas conditioning and $\mathrm{CO}_{2}$ transport require quite a lot of energy, normally electricity for compression and/ or cooling. According to current knowledge the energy required for $\mathrm{CO}_{2}$ compression is equivalent to an efficiency loss at the power station of about 2 percentage points (for gas-fired power stations) to 3.5 percentage points (for coal-fired power stations). This additional energy requirement causes additional $\mathrm{CO}_{2}$ emissions. Estimates of additional (energy-related) $\mathrm{CO}_{2}$ emissions associated with $\mathrm{CO}_{2}$ transport vary greatly, especially in relation to transport distance and capacity. Here additional (energy-related) emissions of $1 \%$ to $4 \%$ per 1,000 $\mathrm{km}$ are expected for ship transport and $1 \%$ to $2 \%$ per $1,000 \mathrm{~km}$ for pipeline transport.

The range of average cost estimates for $\mathrm{CO}_{2}$ transport by pipeline or ship is between about $€ 1$ and $€ 10 / t$ (depending on mode of transport, distance and capacity) and represents about a $10 \%$ share of the overall costs of the CCS process (comprising capture, compression, transport and storage). In relation to the other infrastructure costs (electricity transmission, fuel logistics) the cost of $\mathrm{CO}_{2}$ transport is likely to be a secondary factor when selecting power station sites. Also, existing power station sites are often likely to be retained for reasons of public acceptance.

Already today, fuel (oil, oil products, coal) represents a large share of goods transport. Introducing CCS on a large scale would increase freight volumes considerably, through the supply of additional coal to power stations and the removal of $\mathrm{CO}_{2}$.

Safety statistics for existing $\mathrm{CO}_{2}$ pipelines (in particular in the United States) show a smaller leakage risk than for pipelines carrying natural gas or hazardous substances; nonetheless, routes should avoid densely populated areas where possible for reasons of safety.
In populated areas safety measures against leakage and overpressure are required. Although the relative risk associated with ship transport is also predictable, large-scale introduction of $\mathrm{CO}_{2}$ tankers for CCS would increase the absolute risk of shipping collisions and tanker accidents.

\section{$\mathrm{CO}_{2}$ Storage Methods and Capacity}

There are various different ways to withdraw $\mathrm{CO}_{2}$ from the atmosphere. A distinction must be made between utilisation for technical and chemical purposes (e.g. producing carbonic acid, dry ice and feedstock for polymer chemistry), storage in geological formations (e.g. saline aquifers), sequestering $\mathrm{CO}_{2}$ in the marine environment either directly (e.g. depositing it in the ocean depths) or indirectly (e.g. algae formation) and withdrawing $\mathrm{CO}_{2}$ from the atmosphere by intentionally growing biomass (e.g. forestation). A mineralisation process for binding $\mathrm{CO}_{2}$ to silicates is also under discussion (especially in the United States) but it is still in the early stages of development and is associated with very high energy requirement and very large amounts of material to be disposed of. Fig. 3 shows an overview of storage projects currently under way across the world.

For various reasons the storage possibilities for $\mathrm{CO}_{2}$ are restricted at both the national and global levels. The many uncertainty factors lead to a very wide range of estimates about the extent of existing capacity, and the same applies to the question of the fundamental suitability of the various storage options, where ultimately a case-by-case analysis will be required to obtain practically relevant results. 


\section{$\mathrm{CO}_{2}$ storage projects operating worldwide}

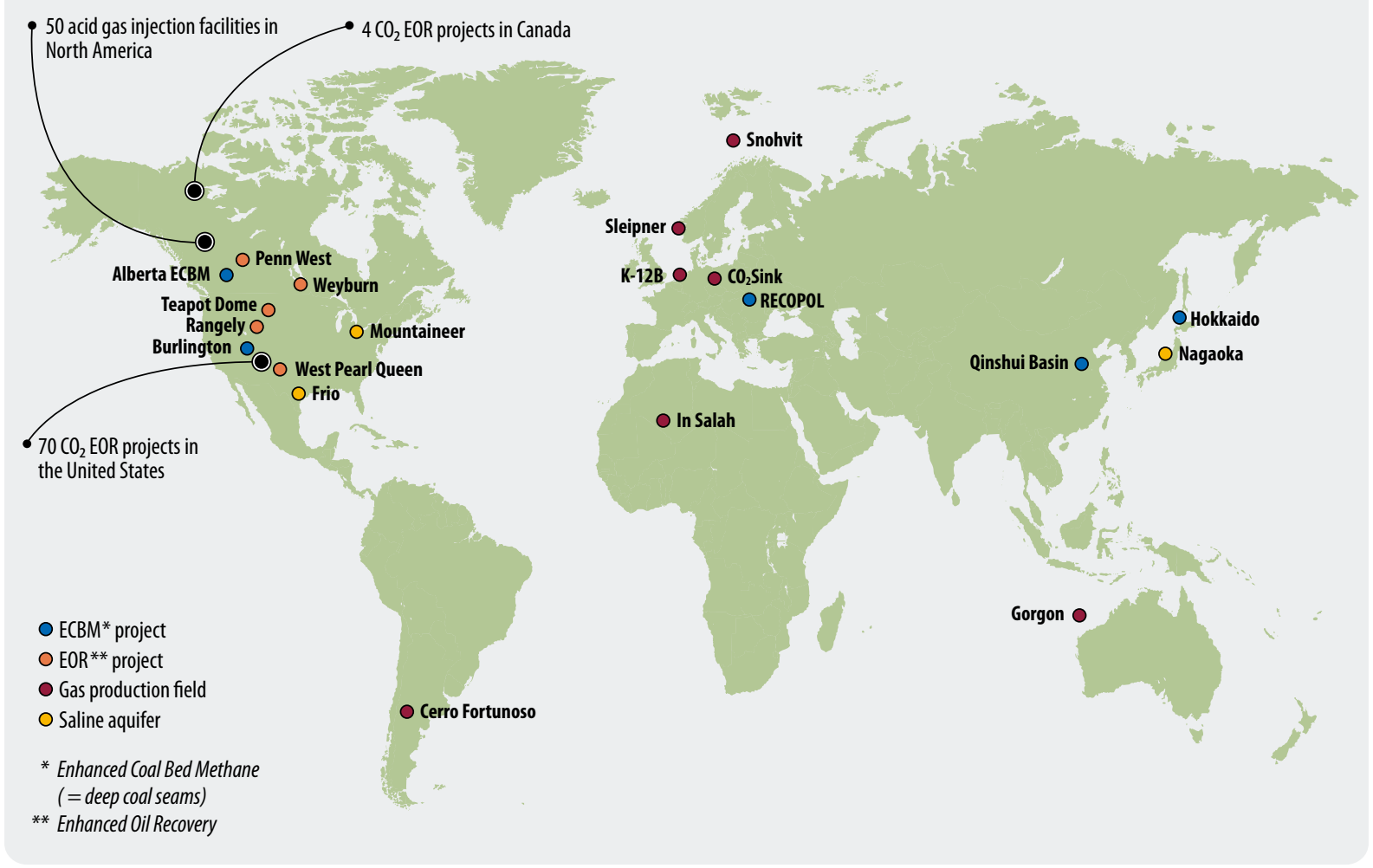

Fig. 3: $\mathrm{CO}_{2}$ storage projects operating worldwide (IEA database)

Estimates made in 2004 put global storage potential in the range between 476 and $5,880 \mathrm{Gt} \mathrm{CO}_{2}$ (with a probable potential of $1,660 \mathrm{Gt} \mathrm{CO}_{2}$ ). By comparison, global $\mathrm{CO}_{2}$ emissions in 2005 were $27.3 \mathrm{Gt} \mathrm{CO}_{2}$. This shows that the potential of CCS is certainly considerable but that regardless of other factors, the limited storage capacity alone means that it will not be possible to achieve a lasting solution to the climate problem through CCS. Table 2 shows the storage capacity and a selection of assessment criteria, for the example of Germany.

According to current information the theoretical storage potential in Germany is between 19 and $48 \mathrm{Gt} \mathrm{CO}_{2}$. The largest and - in view of the numerous as yet unresolved issues affecting storage in deep coal seams (e.g. concerning permeability) - most important share relates to deep saline aquifers, supplemented by the more limited possibilities for storage in depleted gas fields. A calculation focusing on these two storage options and taking into account an average extra energy requirement for CCS of $30 \%$ comes up with a static range of between thirty and sixty years for $\mathrm{CO}_{2}$ point emission sources in Germany (2005: 393 Mt/a). ${ }^{1}$

In principle the storage of $\mathrm{CO}_{2}$ in geological structures can draw on many methods and technological proc-

1 Taken together these two storage options have a potential of 14.3 to $30.5 \mathrm{Gt} \mathrm{CO}_{2}$. esses currently in use in the oil and gas industry and in the disposal of liquid wastes. However, drilling and injection methods, computer simulations of the distribution of gas in reservoirs and monitoring methods will have to be adapted to the special requirements of $\mathrm{CO}_{2}$ storage. Here there is still a great need for research and development. In Germany the EU-funded CO2SINK project will significantly increase knowledge about the behaviour and controllability of $\mathrm{CO}_{2}$ in underground reservoirs.

\section{Criteria for a Systematic Assessment of CCS}

A systematic comparison of various CCS technologies with other technology options such as energy efficiency and renewables requires a comprehensive catalogue of criteria. The criteria used here can be categorised as follows:

\section{Ecological criteria}

- Environmental impact as per life cycle assessment (LCA)

- Energetic efficiency

- Other ecological impacts, ecological restrictions, consequences and risks (direct and indirect) 


\begin{tabular}{|c|c|c|c|c|c|c|}
\hline Option & Capacity [Gt] & $\begin{array}{l}\text { Long-term } \\
\text { stability }\end{array}$ & Costs* & $\begin{array}{l}\text { Available } \\
\text { technologies }\end{array}$ & $\begin{array}{l}\text { Utilisation } \\
\text { conflicts }\end{array}$ & General risks \\
\hline Depleted gas fields & $\underset{2.3-2.5^{* *}}{+}$ & + & + & $+(+)$ & - & + \\
\hline Deep saline aquifers & $\begin{array}{c}++ \\
12-28^{* *}\end{array}$ & + & -- & + & - & $(+)$ \\
\hline Deep coal seams & $\begin{array}{c}+(+) \\
3.7-16.7\end{array}$ & + & -- & - & - & - \\
\hline Depleted oil fields & $\begin{array}{l}-- \\
0,11\end{array}$ & + & ++ & ++ & - & + \\
\hline Salt caverns & $\begin{array}{l}-- \\
0.04\end{array}$ & -- & k. A. & + & -- & -- \\
\hline Disused coal mines & $\begin{array}{c}+ \\
0.78\end{array}$ & -- & -- & -- & -- & - \\
\hline \multicolumn{7}{|c|}{$\begin{array}{l}\text { * Cost estimate contains only storage costs without capture, compression or transport (after ECOFYS 2004, BGR, authors' additions) } \\
\text { ** Figures after May et al (2006a) }\end{array}$} \\
\hline $\begin{array}{l}\text { Criteria: } \\
-- \text { Negative or very pr } \\
-\quad \text { Fundamental diffic } \\
+\quad \text { Good, or few obsta } \\
++ \text { Very good }\end{array}$ & $\begin{array}{l}\text { atic } \\
\text { till exist, but may }\end{array}$ & solvable & & & & \\
\hline \multicolumn{7}{|c|}{ () Parentheses indicate uncertainties or places where each individual case will have to be assessed } \\
\hline
\end{tabular}

Table 2:

Assessment of geological storage options in Germany using selected criteria

\section{Economic criteria}

- Generation costs and $\mathrm{CO}_{2}$ avoidance costs (specific investment costs, resulting electricity and hydrogen production costs)

\section{Other criteria}

- Timeframe for application (possible time of implementation) and market readiness and/or R\&D still required

- Compatibility with power plant replacement needs

- Acceptance

- Compatibility with existing structure and possible future development trajectories

- (Technological) stimuli for global climate protection

- Industrial policy opportunities

- Transferability to developing countries (not applicable for Germany)

- Compatibility with other climate protection strategies (decentralised options)

- Impact on import dependency

- Security policy implications

\section{Comparative Life Cycle Assessments}

For the ecological evaluation of selected system configurations (process chains from natural gas and coal to low- $\mathrm{CO}_{2}$ electricity and hydrogen) the life cycle assessment method (LCA) defined by ISO $14.040 \mathrm{ff}$ was used. This integrative approach analyses the material and energy flows required to produce a kilowatt-hour of electricity or hydrogen and calculates their environmental impact.

For electricity generation the environmental impact of the following fossil fuel conversion paths were investigated: post-combustion (with coal- and lignite-fired thermal power plant and natural gas CC), pre-combustion (coal-fired IGCC) and oxyfuel (with coal). The Ruhr region (a densely populated industrial region in western Germany) was selected as the location of the power stations and an empty gas field $300 \mathrm{~km}$ away in northern Germany as the sink. For purposes of comparison with renewable energy paths, electricity generated by solar thermal power stations (in Algeria) and by wind power (in the German North Sea) was also modelled. In order to have the same reference location as with the fossilfuelled options, the electricity was assumed to be transported to the Ruhr region using high-voltage DC lines. The following central conclusions can be drawn: 


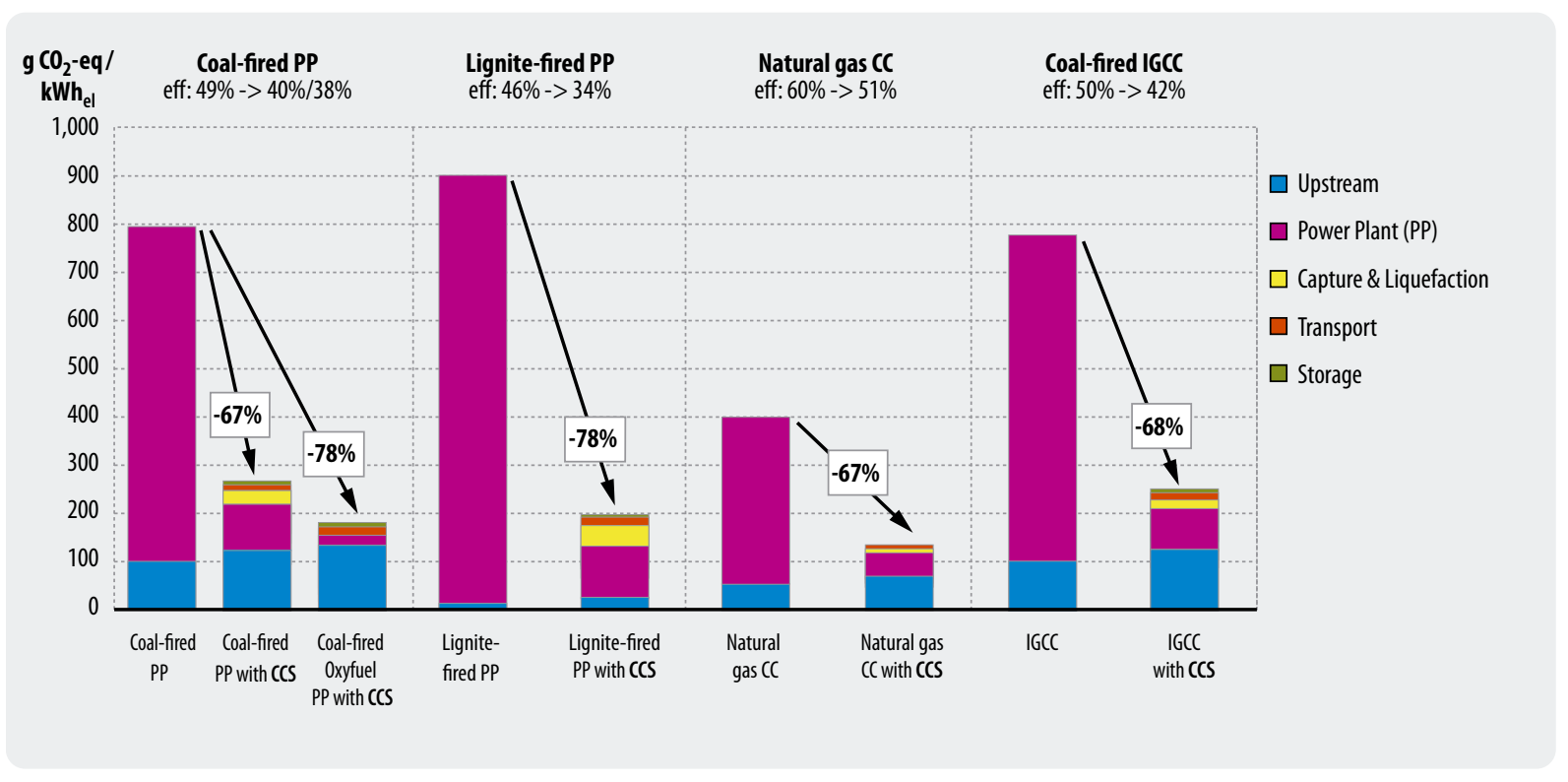

Fig. 4: LCAs of CCS plant in comparison with selected renewables (here: greenhouse gases)

The high rates of $\mathrm{CO}_{2}$ reduction generally cited in the CCS discussion (capture rates of $88 \%$ and more) relates only to $\mathrm{CO}_{2}$ emissions directly in power station operation. If we take a holistic approach, $5 \%$ of the $\mathrm{CO}_{2}$ emissions already occur in the supply chain both with coal-fired thermal power stations and with natural gas CC. Reduced efficiency also causes higher consumption of primary energy and thus a 'larger' coal or natural gas supply chain. Taken together, these factors mean that with a capture rate of $88 \%$ actual $\mathrm{CO}_{2}$ emissions can not be reduced by $88 \%$, but only by $72-78 \%$. In view of this fact it is unjustified to speak of ' $\mathrm{CO}_{2}$-free' or 'zerocarbon' power stations. Even if the capture rate at the power station can be increased still further in future, the designation 'low- $\mathrm{CO}_{2}$ ' is more pertinent. ${ }^{2}$

The discussion to date has also neglected to consider that greenhouse gas emissions as a whole - and not only $\mathrm{CO}_{2}$ emissions - have to be reduced. The Kyoto Protocol requires Germany, for example, to reduce a total of six greenhouse gases (and not just $\mathrm{CO}_{2}$ ) by $21 \%$ by 2012. If the effects of $\mathrm{CO}_{2}$ capture on greenhouse gas emissions are calculated, it is found that the potential reduction is less than proportional. For example, with a $\mathrm{CO}_{2}$ capture rate of $88 \%$ (at the power plant) greenhouse gases as a whole can only be reduced by $67-78 \%$ (see Fig. 4). ${ }^{3}$ The reasons for this are again the considerably increased primary energy consumption and the methane emissions associated with fuel extraction and transport, which can be relatively high depending on the fuel and its source. Under the given assumpti-

2 For example, future capture rates of up to $99.5 \%$ are expected through the oxyfuel process. For a coal-fired power station this would result in a net $\mathrm{CO}_{2}$ reduction of $90 \%$.

3 Even with the oxyfuel method the net greenhouse gas reduction for a coal-fired power station would not be greater than $78 \%$ (despite the higher capture rate of $99.5 \%$ ). ons these have a disproportionately large impact on the greenhouse effect. Improvements in the supply chain (e.g. collecting and using mine gas) could strongly improve the results. From a holistic perspective this lessens the reduction achievable through CCS power stations. With $396 \mathrm{~g} \mathrm{CO}_{2}$ equivalent per kWh the 'best' power station (in climate terms) without CCS (natural gas CC) has only $51 \%$ more greenhouse gas emissions than the 'worst' power station with CCS (coal-fired thermal power station with $262 \mathrm{~g} \mathrm{CO}_{2}$ equivalent per $\mathrm{kWh}$ ). Of all the fossil-fuelled power stations considered, oxyfuel produced the best greenhouse gas results under the given assumptions. Physical capture of almost $100 \%$ of the $\mathrm{CO}_{2}$ allows net rates of reduction of $90 \%$ for $\mathrm{CO}_{2}$ emissions and $78 \%$ for greenhouse gas emissions.

Fig. 5 shows this in comparison with selected technologies from the field of renewables, whose impact by contrast are very small (resulting from manufacturing of the plant).

Overall, $\mathrm{CO}_{2}$ capture requires additional energy consumption of 20 to $44 \%$, depending on the process. The higher energy consumption is felt directly and proportionately in various impact categories in the LCA. This applies, for example, to photo-oxidant formation, eutrophication, acidification of soil and water, and particle emissions (PM10). On the other hand, individual emissions such as $\mathrm{SO}_{2}, \mathrm{NO}_{2}$ or dust are reduced through reactions with the solvent, which in overall terms causes a reduction or at least a reduced increase in individual impact categories. Fig. 6 shows this effect for the example of the modelled lignite-fired power station (post-combustion).

The $44 \%$ increased energy consumption initially causes a proportional increase in all impact categories. But overall the aforementioned influences cause a reduction 


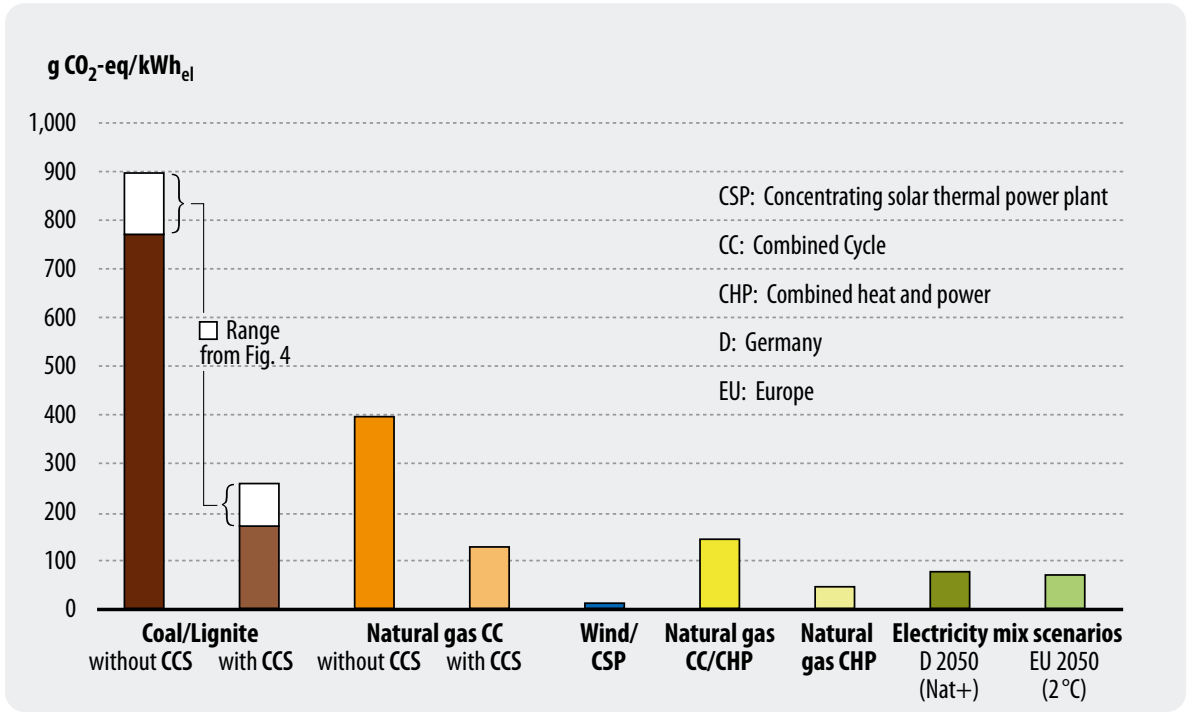

Fig. 5:

Comparison of greenhouse gas emissions from CCS power stations with selected plant from the fields of renewables and advanced fossil-fuelled CHP technologies

of $3 \%$ in the acidification category, and PM10 equivalents rise by only approx. $24 \%$; on the other hand eutrophication rises by $40 \%$ and photo-oxidant formation by $524 \%$.

A comparative analysis, however, showed the investigated renewable energy options to have considerably better values than the fossil-fuelled power stations with $\mathrm{CO}_{2}$ capture. Even when electricity transmission is included, the $\mathrm{CO}_{2}$ emissions, greenhouse gases (see Fig. 4) and cumulative energy demand of solar thermal electricity and electricity from wind power is just 2 to $3 \%$ of the corresponding figures for fossil-fuelled CCS plant.

For hydrogen production the environmental impact of steam reforming of natural gas and coal gasification were investigated. The Ruhr region was again selected as the location. Renewable hydrogen production was modelled as electrolysis using electricity from solar thermal power stations in Algeria and offshore wind farms in the North Sea (as modelled for electricity generation). The location for electrolysis was the Ruhr region; again high-voltage DC lines were used for transmission. The following central conclusions can be drawn:

As with the case of power stations, we cannot speak of ' $\mathrm{CO}_{2}$-free' production of hydrogen. It would be more pertinent to use the term 'low- $\mathrm{CO}_{2}$ ' hydrogen. When the supply chain is taken into account, even with a capture rate of $88 \%$ (coal gasification) it would only be possible to reduce $\mathrm{CO}_{2}$ emissions by $81 \%$.

With natural gas steam reforming, reduction rates of only $39 / 52 \%$ ( $\mathrm{CO}_{2}$ emissions, depending on different

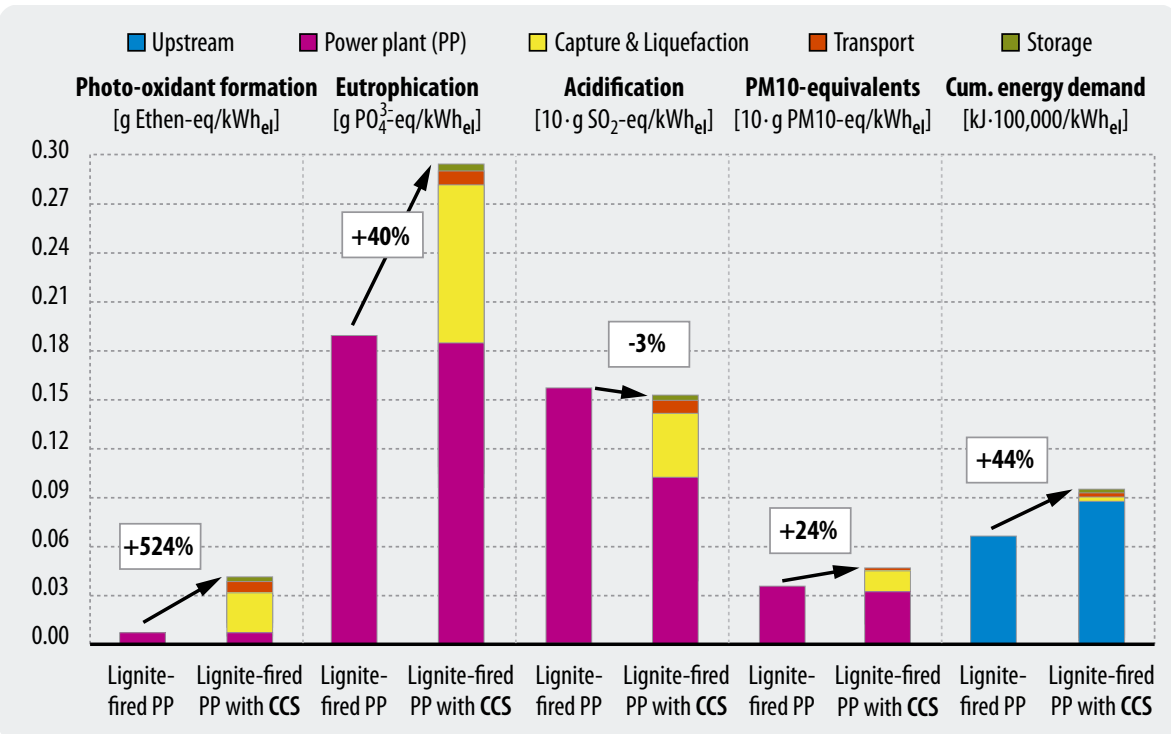

Fig. 6:

Comparison of other impact categories for lignite-fired steam power station without and with CCS (postcombustion) 
reforming technologies) and 36/49\% (greenhouse gas emissions) are possible from today's perspective, if it is assumed that only the $\mathrm{CO}_{2}$ emissions from the synthesis gas can be captured at reasonable cost, and not those that occur beforehand when natural gas is burned to produce process heat.

\section{Other Ecological Assessment Factors for CCS}

The systematic approach of the LCA does not cover every ecological criterion. As well as direct and indirect influences on the landscape (e.g. through increased fuel usage) and the negative consequences of increased transport volume through the construction of a $\mathrm{CO}_{2}$ infrastructure, the greatest impact would result from the possibility of unplanned release of stored $\mathrm{CO}_{2}$ and the direct influence of the stored $\mathrm{CO}_{2}$ on the surroundings of the sink over the course of time.

The various storage options differ - in some cases considerably - in terms of ecological and safety aspects. The risk of leakage is present in all geological storage options. Whereas storage in exhausted oil and gas fields and use in oil production (enhanced oil recovery, EOR) appear relatively safe for the population and the environment, injecting $\mathrm{CO}_{2}$ into disused coal seams could pose considerably greater risks. Saline aquifers are regarded as relatively stable long-term sinks, although there is still a great need for research into the underground movement of $\mathrm{CO}_{2}$ (mechanisms of dissemination and activity). Such aquifers have so far generally only been explored in the vicinity of hydrocarbon deposits so there is a shortage of comprehensive data and assessments of their petrophysical properties. The introduction of $\mathrm{CO}_{2}$ leads to acidification of the water in the aquifer. Through its corrosive properties the acidic water could cause changes to the surrounding strata (especially carbonates) and to unprotected borehole seals.

The use of deep (currently uneconomic) coal seams bears the ecological risk of the extracted methane escaping (methane is a considerably more potent greenhouse gas than $\mathrm{CO}_{2}$, by a factor of 21 ).

Marine storage options are associated with very great uncertainties and risks. Direct cause and effect relationships have so far only been demonstrated in certain cases. Acidification of seawater shifts the carbonate equilibrium: the shells of calcifying organisms become thinner and can even dissolve, interrupting food chains or at least altering them with inestimable consequences. $\mathrm{CO}_{2}$ lakes on the ocean floor affect more than the local ecosystems. Many aspects of the behaviour of the ocean floor - submarine slides, undersea quakes, etc. - may be understood, but they remain unpredictable. Fundamentally it must be noted that storage in the oceans would not lead to permanent sequestration of the $\mathrm{CO}_{2}$. Dissolving $\mathrm{CO}_{2}$ in the ocean depths leads to delayed re-emission into the atmos- phere after a few hundred years at the latest, when oceanic circulation brings the water masses into contact with the atmosphere again. In view of the unclarified consequences of marine storage options they are categorically rejected by the environmental organisations and are being pursued in any form in only a very few countries (in particular Japan).

Fixing $\mathrm{CO}_{2}$ in biomass by planting forests and growing monocultures brings with it multifarious ecological problems. It must also be emphasised that this form of storage is only a temporary one, with delayed release. When a period of several generations is considered, the reduction effect is nil. Additionally, monocultures displace other species and alter biotopes.

The construction and operation of renewable energy technologies - e.g. constructing wind farms, hydroelectric dams and solar thermal power stations - can in certain cases be associated with considerable ecological consequences and disfiguration of the landscape. Within a social and energy system guided by sustainability principles, decisions would have to be made about which interventions are acceptable for the population and the natural environment and which should be avoided. Whereas the impact of using renewables is largely known and understood, decision-making with respect to CCS is from today's perspective still hampered by numerous uncertainties and open questions.

\section{Economic Comparison of CCS and Renewables}

If the capture and storage of $\mathrm{CO}_{2}$ emissions from fossil-fuelled power stations can be demonstrated successfully, electricity generating costs (at power station) of between 6.5 and $7 \mathrm{ct} / \mathrm{kWh}$ can be expected on the basis of CCS power stations commercially available in 2020 (interest rate $10 \% / a)$. In view of the fuel price rises expected in the longer term, a further rise in costs to between $7 \mathrm{ct} / \mathrm{kWh}$ (coal) and $8 \mathrm{ct} / \mathrm{kWh}$ (natural gas) is probable by 2040 . In coal-fired power stations the fuel price effects could potentially be largely balanced out by further technical progress. Our calculations put $\mathrm{CO}_{2}$ avoidance costs at between $€ 35$ and $€ 50 / \mathrm{t} \mathrm{CO}_{2}$ in 2020 , when the same power station without CCS is taken as the reference for comparison. Here coal-fired power stations are towards the bottom end of the range, gas-fired towards the top. This is less than the cost range assumed today and assumes that significant learning processes will already have occurred by then, but is still significantly higher than the costs of about $€ 20 / \mathrm{t} \mathrm{CO}_{2}$ that the energy business is aiming at for the process as a whole.

Renewables, which - on the basis of a representative mix - today still involve electricity generating costs of approx. 13 to $14 \mathrm{ct} / \mathrm{kWh}$ (again assuming interest rate $10 \% / a)$ can also achieve that level of costs by 2020 if their market introduction continues at a similar pace to now. With a continuing global increase in market penetration and learning effects significant cost degres- 


\section{Electricity generating costs in ct/kWh}

DLR 2005 price forecast with $\mathrm{CO}_{2}$ penalty; interest rate $10 \% /$ a

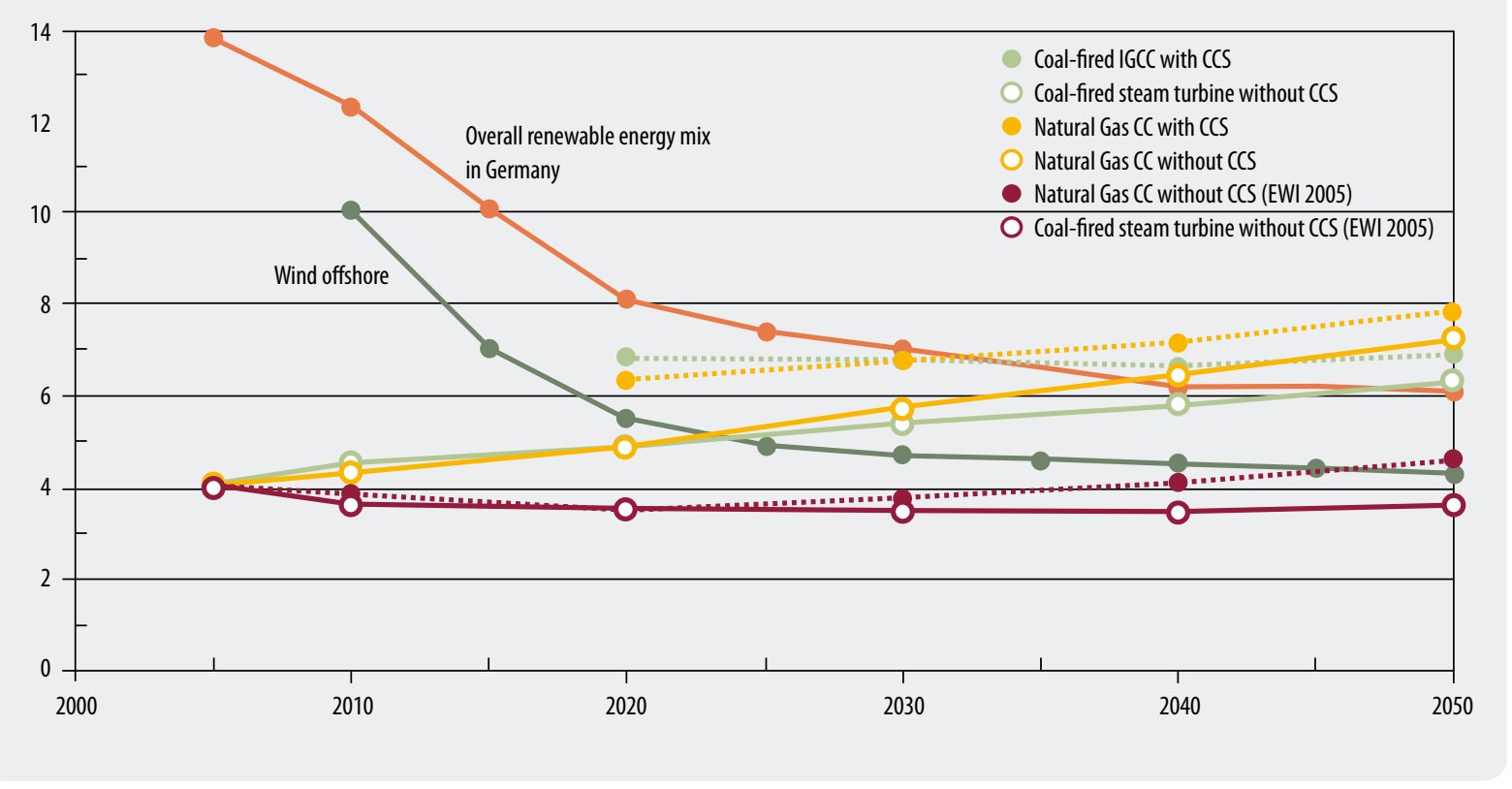

Fig. 7: Development of electricity generation costs (for new plant) for renewables, conventional gas- and coal-fired power stations and CCS power stations. Fuel prices after "DLR 2005" and for conventional power stations without CCS after EWI 2005 given for comparison

sions can still be expected for renewables in future, so that by 2050 the level of costs for generating electricity from renewables in the characteristic mix under consideration could fall to $6 \mathrm{ct} / \mathrm{kWh}$. Individual technologies could achieve electricity costs of approx. $4 \mathrm{ct} / \mathrm{kWh}$ if a continuing expansion of global markets allows the learning curve to continue to be exploited (see Fig. 7).

If the pace of expansion of renewables in the electricity sector remains fast - as in the various scenarios that describe a switch to a climate-friendly energy supply based on a combination of stepping up the expansion of renewables and energy efficiency (e.g. the Naturschutzplus scenario) - at the time when the first CCS power stations might be coming on stream some technologies (e.g. wind offshore) could already be offering cheaper electricity generation costs and further increase that advantage over the course of time. Here significant cost-reduction effects come through the global market effects, so even if renewables in Germany were to grow less dynamically, cost parity between CCS and individual renewables can be expected. Only if fuel price rises were to be very small or cost reductions in the CCS process were to surpass the foreseeable effects would the situation be more favourable for CCS plant. This would not negate the general effect, but would push back the point on the time axis where renewables become relatively competitive.

Under the given assumptions there is neither a compelling economic reason to give CCS technologies preference over a further expansion of renewables for elec- tricity generation. Nor, though, do they represent a prohibitively expensive option and if successfully commercialised under suitable conditions (inexpensive, stable long-term storage options, good infrastructure, cheap coal) could become part of the future electricity generating regime in some world regions.

In an economic comparison of low- $\mathrm{CO}_{2}$ and largely $\mathrm{CO}_{2}$-free options for hydrogen production (CCS versus renewables) the fossil option comes off best. By 2020 hydrogen from coal gasification with $\mathrm{CO}_{2}$ capture will cost approx. €12.50/GJ (4.50 ct/kWh, upper heating value, at plant), or about twice the cost of today's hydrogen from natural gas reforming. Further fuel price rises until 2050 increase the cost to about $€ 14 / \mathrm{GJ}$ (5.04 ct/ $\mathrm{kWh}$ ). Only electrolytic hydrogen via electricity from cheap hydropower can compete with this, but the available capacity is small. Only in the longer term costs of around $€ 16-18 / G J$ for electrolytic hydrogen from wind or solar electricity can be expected; around 2020 the cost will probably be about $€ 19-20 / G J$. In the medium term the cost of generating hydrogen will always be at least double the cost of natural gas. So for economic reasons hydrogen will not be implemented as a fuel before 2030. Regardless of the way it is produced, it will probably be several decades before hydrogen becomes important in the energy sector in relevant quantities because of the considerable infrastructure challenges associated with its introduction. 


\section{The Role of CCS in Industrialised Countries - the Example of the German Energy Supply System}

In this study three different scenarios were developed for the future energy supply in Germany (as a representative industrialised country) in order to analyse the role of CCS in the energy sector in comparison to renewables. In all three scenarios energy-related $\mathrm{CO}_{2}$ emissions were reduced to 240 million t/a by 2050 , which corresponds to a reduction of about $75 \%$ compared with 1990. The scenarios are based on the following assumptions:

- CCSMAX: CCS as the main element of a climate protection strategy with 'maximum' use of CCS technologies within the framework of a development that otherwise largely follows current trends for energy consumption and expansion of renewables (relatively small mobilisation of efficiency potentials, limited implementation of the expansion potentials of renewables).

- NATP: Concentration on across-the-board exploitation of energy saving potentials and vigorous expansion of renewable energy technologies, as described in the 'NaturschutzPlus' scenarios prepared for the Federal Environment Ministry (after BMU 2004 and BMU 2005). In this scenario CCS is not required.

- BRIDGE: CCS as a bridge to further expansion of renewables while at the same time increasing energy efficiency and expanding renewables more strongly than in the reference case but less than in NATP. In this scenario the two strategy elements are insufficient to achieve the climate target unaided, so the use of CCS is required.

Various key findings can be drawn from the scenario analyses. Emission-reducing measures in the field of electricity generation alone will simply not be enough to meet the climate protection target. Similarly comprehensive measures in the heating and vehicle fuel sectors are also required. As well as expanding renewables, the exploitation of efficiency potential will have to make a very considerable contribution. If greater use is made of fossil resources, the alternative of generating hydrogen by gasifying coal with carbon capture and storage is always an option.

As the main element of a climate protection strategy CCS runs into structural and capacity limits (CCSMAX scenario). The earliest date when CCS technologies are expected to be ready for implementation is 2020, which is too late for the first wave of the power station replacement needs, which has just begun. This scenario would necessitate extremely rapid growth rates for CCS plant between 2020 and 2050 and speedy establishment of a hydrogen infrastructure. With 5,900 PJ/a the demand for coal in CCSMAX rises to three times today's level. By 2050 hydrogen would be the dominant form of energy, supplying $47 \%$ of final demand. The amount of
$\mathrm{CO}_{2}$ to be captured and stored in 2050 would amount to about 600 million t $\mathrm{CO}_{2} / \mathrm{a}$ (Fig. 8). At that level the storage capacity available in Germany would last for just one or two decades. Cost advantages for energy produced using CCS are either non-existent (for electricity) or marginal (for hydrogen) so there is no decisive economic incentive for such a prominent preference for CCS. The high level of funding already required today in the form of R\&D and demonstration plant for such a strong expansion of CCS technologies would probably demand a major turn away from support for efficiency strategies and strategies for expanding renewables. A great challenge in view of the very many questions that are still open is that the lead times involved mean that it would be necessary relatively quickly to achieve a very high level of certainty about the ecological impact and long-term stability of the potential $\mathrm{CO}_{2}$ sinks.

A climate protection strategy following the NATP scenario, which manages without CCS, would not yet develop of its own accord. As well as maintaining the current dynamic rate of expansion of renewables in the electricity sector and extending their use to the heat sector on a significant scale, considerable additional support measures to encourage much greater efficiency in use and conversion of energy would be required if the 2050 climate protection target is to be met on time by this strategy. Expanding renewables and increasing efficiency are measures that take effect relatively quickly, so as long as the necessary support measures impact fast, they allow the restructuring process to run more harmoniously than in the CCSMAX case described above. Major conversion of energy infrastructures would be required, but this could be realised in stages. A strategy concentrating especially on energy productivity also makes sense in broader economic terms because many of the efficiency measures represent the most economic option for climate protection regardless of what measures are taken on the supply side. If external costs were included the overall economic situation would be even more favourable. To that extent this scenario represents an 'ideal strategy' but one which demands that very effective energy policy decisions be taken quickly, especially a clear rationalisation and expansion of energy efficiency policy. In the longer term this scenario necessitates considerable structural changes, increasing the network and system integration of renewables on the electricity side, integrating energy import structures (e.g. electricity from solar thermal power plant in North Africa) and greatly expanding district heating systems.

To pursue both strategies 'at full steam' until 2020 (efficiency and expansion of renewables following NATP until 2020; CCS development as in CCSMAX), but then to largely drop one of the options would not seem to be a sensible way to proceed. Consequently, the third scenario discusses the extent to which the two strategies could be combined compatibly in a forward-looking strategy.

In a development corresponding with the BRIDGE scenario the timeframe for introducing CCS technologies and a hydrogen infrastructure is more relaxed than in CCSMAX because until 2030 the contribution 


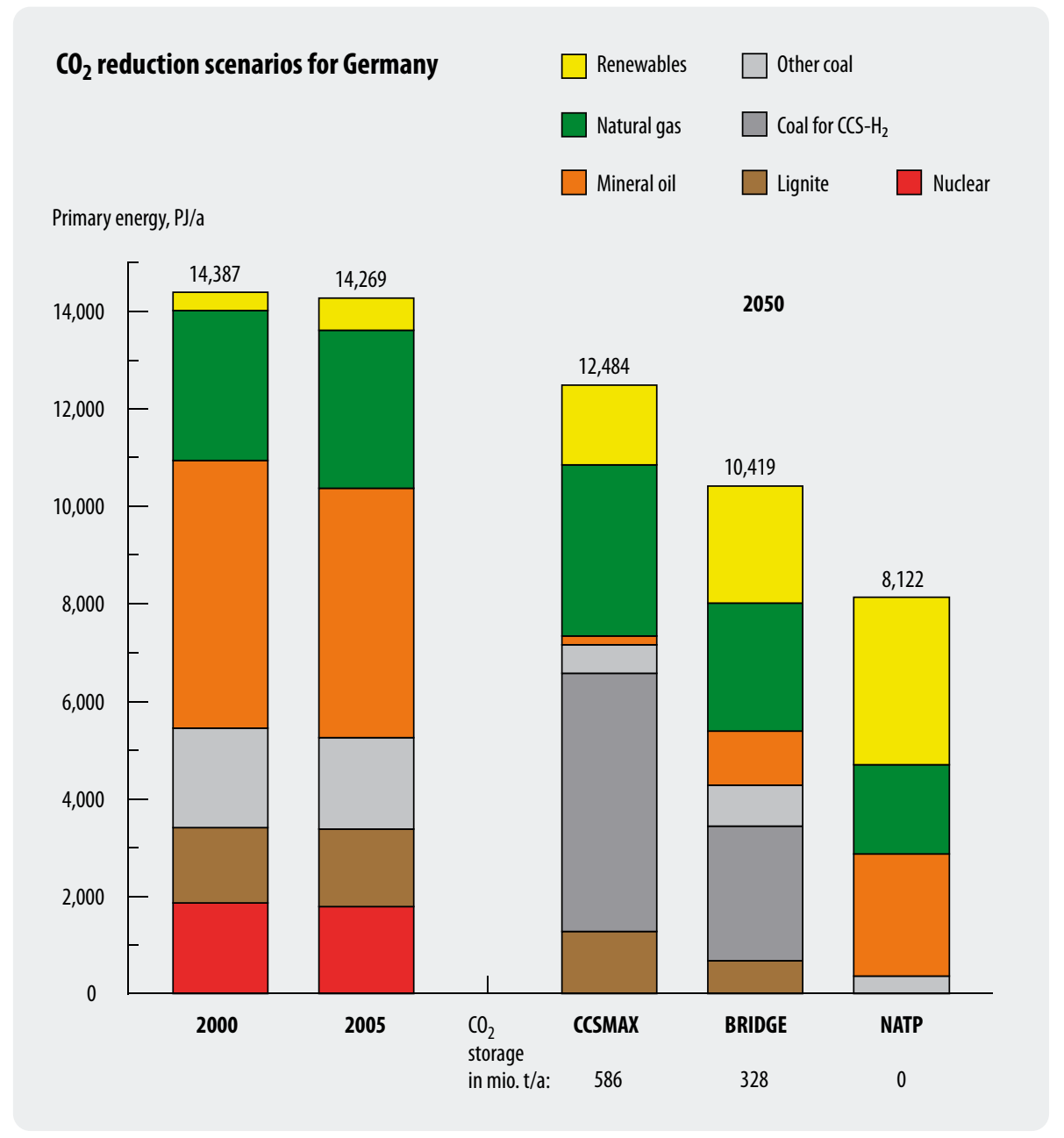

Fig. 8:

Primary energy

structure today and in

the scenarios for 2050 required from this option can remain relatively small. In the event that CCS technologies turn out to be a sensible and ecologically sustainable energy option, even the level of expansion required by 2050 does not encounter any fundamental barriers concerning required plant capacity, infrastructure modifications or sink capacity. In this case about 330 million $\mathrm{t} \mathrm{CO}_{2}$ /a would have to be captured and stored in 2050. For this, however, fossil-fuelled power stations built before 2020 must also be suitable for retrofitting with CCS, if the electricity sector is to make a substantial contribution to reducing $\mathrm{CO}_{2}$. This should be taken into account in current ongoing power station planning, and where possible plant should be designed to be 'capture ready'.

An energy policy following the BRIDGE strategy will definitely demand a general intensification of energy policy in all the listed fields if long-term climate protection goals are seriously to be achieved. So including 'CCS technologies' as an additional climate protection option should not serve as an excuse for neglecting the strategy elements of 'energy efficiency' and 'renewables' as the process intensifies. Instead these should be mobilised by 2020 at least to the extent that they can continue to 'take off' thereafter if CCS technologies should turn out to be unworkable on the desired scale in the energy sector. At the same time, this timeframe offers the opportunity to explore the development and cost potentials of CCS technologies thoroughly and without massive pressure of time. But the successive introduction of CCS could help as an ancillary element to make it easier to maintain the sustained impetus for further efficiency increases and a greater expansion of renewables than would possibly be the case with the significantly higher hurdles in the NATP scenario. This could identify ways to soften resistance and to offset obstacles that remain insurmountable despite massive support and energy policy intervention. In view of the real constellations of interests and different evaluations of technology options in the field of energy, especially in the global context, a development following the BRIDGE scenario can be regarded as a 'pragmatic' strategy.

A cost comparison of renewables and CCS technologies for electricity and hydrogen production shows no economic advantages for the CCS option at the point of its possible introduction around 2020. The latter would then require $\mathrm{CO}_{2}$ prices between $€ 40$ and $€ 50 / \mathrm{t} \mathrm{CO}_{2}$ if it is to be attractive to private investors in place of conventional electricity generation from fossil fuels. Even after 2020 renewable energy technologies will probably continue to have exploitable cost degression potentials, 
whereas the cost of generating electricity from coal with CCS will probably remain roughly constant, assuming a corresponding degree of technical development. If we factor in the external costs, we find further advantages for the development path building on renewables and energy efficiency. From today's perspective, the relative profitability of CCS and renewables is associated with diverse imponderables. The above assessments for renewables work on an assumption of dynamic global market developments allowing very considerable cost degression potentials to be exploited via mass production and learning curve effects.

One obstacle to a comprehensive CCS strategy could also be that a strategy building largely on CCS would require the earlier introduction of $\left(\right.$ low- $\left.\mathrm{CO}_{2}\right)$ hydrogen on a broad scale, which is associated with great infrastructure challenges, whereas a strategy orientated on NATP would not require this on an appreciable scale until the middle of the century.

From the aforementioned aspects it follows that a rigorous strategy based on the NATP scenario could also represent the more favourable option in broader economic terms in the medium to long term and should thus be the aim of energy policy. At the same time, it would be recommendable to continue to subject the CCS option to thorough scrutiny and in particular a realistic practical demonstration, in order to possess after a decade more precise knowledge of the potential and limits of this set of technologies. If it then turned out that in terms of efficiency and expanding renewables the restructuring of the global energy supply can 'only' proceed at the intensity described in BRIDGE, then CCS would be available as an additional climate protection option.

\section{Requirements for Successful International Implementation of CCS}

The concluding part of the study broadens the perspective to examine whether CCS is necessary from a global perspective in order to meet ambitious climate protection targets and how an institutional framework can be established to sensibly regulate the risks of CCS.

The role of CCS in the context of other technology options - i.e. in particular the expansion of renewables - was analysed by means of an economic scenario analysis. Models to maximise global social welfare for a given limitation of the atmospheric $\mathrm{CO}_{2}$ concentration were chosen by simulating the progress over time of implementation of the three named options (and in the process including the technological learning effects). Central uncertainty factors that have a strong influence on the implementation of CCS and on the costs of climate protection were identified and interpreted by means of sensitivity analyses:
- Learning rates for CCS and renewables influence the cost reduction curve of the technologies and thus their application. The quicker the cost-cutting potential of renewables is realised and the slower that of CCS takes effect, the less CCS will be used. However, in both fields of technology as yet unforeseeable development leaps and costs that cannot be reduced through learning effects (e.g. for fuels) could have a strong influence on their respective future market shares.

- Leakage rates (quantifying the slow escape of $\mathrm{CO}_{2}$ from storage formations) must be well below $0.1 \%$ per year if CCS is to be used efficiently at all.

- The discount rate determines the weighting of consumption over the course of the planning period. If a high discount rate is chosen - giving welfare in the present a higher weight and consequently resulting in less being invested in renewables - CCS gains and greater use of renewables is shifted back to a later date. This occurs above all when realising learning rates in renewables requires high initial investment compared with CCS.

- The rising cost of exploration and extraction associated with possible shortages of fossil resources has a strong effect on the role of CCS. Because of the attractiveness of fossil fuels, if their costs of do not rise until relatively late, CCS will be used extensively in order to meet the set climate protection target at all. But under 'peak oil' scenarios, which predict rapidly rising costs due to depletion of oil reserves, the substitution of various fossil fuels could occur considerably earlier, which would reduce the demand for CCS. However, the timeframe and interrelationships of these effects are not yet fully understood.

- The use of CCS is worthwhile even if the time when CCS technologies become available for largescale application is delayed by several decades. But if CCS were not available until 2050 the amount of $\mathrm{CO}_{2}$ stored to meet climate protection targets would be reduced considerably because it would then be more worthwhile to step up implementation of renewables from the outset.

The outcome of the economic scenario analysis is that at the global level CCS can make a tangible contribution to meeting ambitious climate protection targets. CCS can fulfil a 'bridging function' of avoiding emissions on a scale that renewables and efficiency improvements cannot achieve on their own, and in that context the two technology options can complement one another. There can be no doubt, however, that in the long term a sustainable reduction of climate change is achievable in the energy sector only through renewables and high energy efficiency. 
Overall, according to the calculations, keeping the atmospheric concentration of $\mathrm{CO}_{2}$ below 450 ppm over the course of the twenty-first century could be achieved with a relative loss of $0.6 \%$ of global GDP compared with the business-as-usual trajectory, in the process of which a total of approx. $456 \mathrm{GtC}$ (or 1,672 $\mathrm{Gt} \mathrm{CO}_{2}$ ) would have to be captured and stored. These results should be understood as plausible mid-range figures assuming a leakage rate of $0.05 \%$ per year and a learning rate for renewables of $15 \%$. The precise figure for cumulative storage and the cost reduction will depend on the development of the investigated uncertainty factors. The model calculations show that with a combination of both measures (renewables plus increased efficiency and CCS) it would be possible to achieve ambitious global climate protection targets at a relatively small loss of economic growth. The calculated growth losses are relativised still further if the necessary investments in measures for adapting to climate change are factored in.

Large-scale introduction of CCS presumes the implementation of an institutional framework that sensibly regulates the risks of CCS and offers incentives to use the safest possible storage options.

Many details of the national and international legal situation have yet to be clarified, and special frameworks for CCS have yet to be developed. In view of the long-term nature of $\mathrm{CO}_{2}$ storage, the principles of environmental law require legislators to ensure there are suitable rules for dealing with future risks and to strike a suitable balance between business liability for harm caused and the ultimate responsibility of the state. Monitoring sinks and defining an appropriate leakage rate are particularly important here. Because of the transfrontier effects of CCS, international agreements are imperative.

As the economic analysis showed, it makes sense to embed CCS in international climate protection agreements. However, CCS is not yet included in the mechanisms of the UN Framework Convention on Climate Change. Guidelines for accounting for the emissions saved through CCS (and those that may be released again) have not yet been implemented. That would be an important precondition for being able to include CCS in the flexible mechanisms of the Framework Convention on Climate Change. With regard to the debate between the two fundamental approaches to climate protection agreements (cap and trade system and technology protocol) CCS, with its technological challenges that are yet to be mastered, could serve to illustrate that both approaches are possible and useful.

Regulating responsibility for risks from CCS could be achieved through tradable carbon sequestration bonds, which the operator of a CCS project would be obliged to purchase and which would be depreciated proportionately if leakage occurs. The bond system offers incentives for efficient limitation of harm caused by $\mathrm{CO}_{2}$ leakage and involves the financial markets and through them the public (via investment decisions for safe CCS projects) in the control of risks. State revenues through devaluation of bonds could be used to promote renewables, thus balancing out the delay in their development resulting from the use of an unsafe storage option. 


\section{Chapter 1}

\section{Status Quo and the Aims of the Study}

Long-term scenarios on the development of energy systems show that the transition to a climate-friendly energy supply will in some way rule out coal. However, coal is the fossil fuel with the largest global reserves distributed over many regions of the world - and is subject to fewer geopolitical risks than oil and gas.

This raises the question of how the use of coal could be made more climate-friendly. Alongside improvements in the efficiency of the various ways coal is used (primarily by increasing the conversion efficiency of power stations and expanding the use of combined heat and power) the technology option of carbon capture and storage (CCS) could also make a contribution. Its introduction could make it possible to produce 'low- $\mathrm{CO}_{2}$ ' energy based on coal. The important fields in this context are electricity generation, and even more so the production of hydrogen as a universal storable fuel. The same also applies in principle to natural gas and oil, although from the climate perspective natural gas is a less critical issue owing to its lower carbon intensity.

There are still many unanswered questions today concerning the possibilities of capturing $\mathrm{CO}_{2}$ and especially storing it safely for a very long time. These questions include not only how much safe, long-term storage capacity there actually is for $\mathrm{CO}_{2}$ (and its regional distribution), but also what costs and ecological risks are involved. If CCS can be successfully introduced as a new technology option at reasonable cost and with acceptable ecological impacts, it could make a major contribution to providing a more secure and climate-friendly supply of energy.

Previous studies in this field have tended to concentrate on the general technical feasibility of the concept. There has not yet been a detailed examination of the ecological, economic and social impacts along the whole process chain (e.g. energy balance, cumulative energy demand, environmental impact, use of resources, risks, costs) of the kind that is a matter of course today for other new technologies, especially renewables. Only after such scrutiny will it be possible to decide how environmentally beneficial this technology option really is, what advantages and disadvantages it has compared with renewables and what contribution it can make to a sustainable economic structure. That is the focus of the present study.

This project is particularly relevant in view of recent political initiatives on international level for using the so-called 'clean coal' option, extensive research activities globally and the publication of the German Environ- ment Agency's assessment of CCS from the sustainability perspective in mid-2006.

More and more scientists, politicians, and NGOs are calling for investigation and consideration of 'clean coal' technology. The energy sector itself is planning to open various small CCS demonstration plant in 2008 and the following years mainly in Europe and USA.

The findings so far show that introducing carbon capture and storage only makes sense if done on a large scale. Given the great volume of investment required and the implications for other options for reducing greenhouse gases, the decision about whether CCS should be made a central pillar of energy policy will have to be thoroughly considered on a solid scientific basis. It is already recognised today that new technologies will have to satisfy numerous technological, structural, economic, ecological and social criteria before they can be regarded as viable options for a sustainable future energy supply. So they will be subjected to a rigorous selection process before their suitability as future key technologies is accepted. As well as detailed investigation of the potential, the achievable future costs, the implications for industrial policy and social impact of a technology, differentiated life cycle assessments (LCAs) of the whole system represent a suitable instrument for assessing the practicability of new technologies against various sustainability criteria. Very detailed LCAs are already available for the various technologies based on renewables, which represent one of the main other options for avoiding greenhouse gases. Suitable data for making a solid assessment of capability and environmental and system impact are also already available for numerous technologies in the field of efficiency (e.g. modern combined heat and power).

The goal of this project is consequently to weigh up the range of technologies for carbon capture and storage currently under discussion in terms of their fundamental suitability for a future energy supply. We outline several reference systems and realistic system configurations for supplying electricity and hydrogen together with all the relevant data required to properly appraise and assess the options in the scope of an overall concept for a future sustainable energy supply. These make it possible to identify the fundamental potential of the proposed technologies, the technological advancements still required and the environmental impact. A systematic comparison with other options for a climatefriendly energy supply - especially the use of renew 
ables - concludes the study. This is the context in which the discussion about the possible role of the CCS option in longer-term energy supply scenarios must be conducted, in which the timeframe of future development steps (establishing an infrastructure) must be considered and in which fundamental energy policy decisions must be addressed. This investigation supplies a sophisticated set of data for placing the carbon capture and storage option in the energy and especially the climate policy context. As such it can make an important contribution to energy policy decisions currently on the agenda.

The principle research questions can be summarised as follows:

- What are the conceivable routes for CCS (technologies, infrastructures, development timetables)?

- What does the overall life cycle assessment of these processes look like, and how does low- $\mathrm{CO}_{2}$ fossilbased electricity compare with $\mathrm{CO}_{2}$-free options, especially renewables (comparison on an equal footing)?

- What role can CCS play for climate protection in comparison with other relevant options, and when (systematic comparison on the basis of significant criteria such as cost, timeframe, ecological restrictions, etc.)?

- What role can CCS play as a possible bridge to a renewable energy system?

The report has five parts:

Part one (introduction and background) examines the driving forces behind CCS and the attitudes of relevant actors.

Part two takes a closer look at technological developments in the field of $\mathrm{CO}_{2}$ capture (in electricity generation and hydrogen production) and at the individual steps involved in $\mathrm{CO}_{2}$ capture, transport and storage.

The third part presents a comparative assessment of CCS and other relevant climate protection technologies on the basis of a comprehensive set of criteria. The life cycle assessment method (LCA) is used to conduct a thorough comparison of the ecological performance of CCS in comparison with continued expansion of renewables. The economic parameters are also examined in greater depth. Additional criteria are used to differentiate and expand the comparison with renewables.

Part four examines the significance of CCS for national energy sectors, including thorough system and scenario analyses. The significance of CCS and renewables for energy and climate policy are compared. The Germany energy system was chosen as an example.
Finally, part five turns to a more global perspective on CCS, showing the requirements and preconditions that have to be met for international implementation of this technology option. 


\section{Chapter 2}

\section{Terminology}

Before proceeding to the body of the report, it would seem appropriate to examine the definitions of the fundamental concepts involved in carbon capture and storage.

In the literature on 'carbon capture and storage' we find divergent terminology being used. ${ }^{1}$ The issue itself is often subsumed under the term 'low-emission/carbonfree (coal) power stations' or the catchword 'clean coal.' The following table presents a selection of the terms commonly found in the literature. The first column lists the umbrella terms for the whole process from $\mathrm{CO}_{2}$ separation through conversion and transport to storage, while the second and third columns respectively list synonyms for the individual processes of $\mathrm{CO}_{2}$ capture and $\mathrm{CO}_{2}$ storage.

Table 2-1: Terms relating to carbon capture and storage

\begin{tabular}{|l|l|l|}
\hline $\begin{array}{l}\text { Carbon capture and } \\
\text { storage }(\mathrm{CCS})\end{array}$ & $\mathrm{CO}_{2}$ capture & $\mathrm{CO}_{2}$ Storage \\
\hline $\mathrm{CO}_{2}$ sequestration & Separation & Disposal \\
\hline Carbon management & & Discharge \\
\hline & & Injection \\
\hline & & Insertion \\
\hline & & Dumping \\
\hline & & Removal \\
\hline
\end{tabular}

1 'Sequestration', for example, is normally taken to mean the whole process from separation through transport to storage. However, some authors use the term to refer only to $\mathrm{CO}_{2}$ separation at the power station, while others use it exclusively to designate storage, for example in a geological formation.

2 The terms 'emission-free, ' $\mathrm{CO}_{2}$-free' and 'clean' are misleading, because with today's technology it is only possible to reduce $\mathrm{CO}_{2}$ at the power station by about 80 to max. $95 \%$ compared with conventional power stations. Additionally, depending on the technology, other pollutants $\left(\mathrm{SO}_{2}, \mathrm{NO}_{\mathrm{x}}\right.$, dust, etc.) may still be emitted (indeed, owing to the increased energy requirement possibly even in increased quantities).
It should be noted that the terms are applied with varying precision. For example 'storage' strictly speaking means to 'keep for the purpose of later retrieval'. This applies to the $\mathrm{CO}_{2}$ issue only if 'storage' is indeed intended as a temporary solution (which, depending on the storage technology and the order of magnitude of the associated leakage rate, it may well be).

Certain of the terms listed in the ' $\mathrm{CO}_{2}$ storage' column relate only to particular sinks. For example, 'dumping' refers to storing $\mathrm{CO}_{2}$ in the sea.

It should also be noted that some of the terms are positively or negatively loaded. For example, the term 'storage' sounds rather positive, 'insertion' is more neutral, while the term 'dumping' may have more negative connotations, in particular due to its association with the controversy over dumping of radioactive waste at sea. Richter (2003) uses this phenomenon to classify the users of the different terms into supporters and opponents of ' $\mathrm{CO}_{2}$ sequestration'.

In this report we primarily use the terms set in bold in the above table: 'carbon capture and storage' ('CCS'), 'capture' and 'storage'. 


\section{Chapter 3 \\ Driving Forces: The Attitudes of Relevant Groups to $\mathrm{CO}_{2}$ Capture and Storage}

The development of technologies for the capture, transport and storage of $\mathrm{CO}_{2}$ is being promoted from various actors and driving forces. These include:

Global driving forces for climate protection: The necessity of reducing emissions of greenhouse gases, in particular CO2, has given a clear boost to CCS at the global level. This applies especially to those who doubt that long-term climate protection goals can be achieved at all or achieved quickly enough solely by expanding sources of renewable energy and significantly improving energy efficiency. In their view, as long as it gains sufficient acceptance by various actors, including the consumer, CCS could provide considerably more leeway for action and reduce the pressure for developing renewable energy and energy efficiency. For this reason some actors speak of CCS having a 'joker function'. Its advocates even include some states that have tended in the past to take a negative attitude to the international climate protection process. Here the United States in particular should be mentioned as a major promoter of CCS. A roadmap produced by the US Department of the Environment (DoE) envisages the first pilot and demonstration facilities being completed in 2018 (DoE 2003). In the few climate protection scenarios produced by the United States CCS is assigned a dominant role. Experts at the DoE believe that stabilising emissions at the present level will only be possible if the overwhelming share of emissions reductions is achieved via $\mathrm{CO}_{2}$ capture and storage (Fig. 3-1).

This 'enthusiasm' can be explained by the fear in the United States that the increased use of renewables and an increase in energy efficiency will place an unacceptable burden on the economy and will excessively limit the 'freedom' to use energy. In addition the strong lobbies of the oil and coal industries play a significant role in shaping US government policy on this issue. The United States has also made advancing CCS a major task of the Asia-Pacific Partnership.

But in other countries, too, CCS enjoys a strong measure of support in the context of climate protection. Examples include Japan, the Netherlands and Germany. In Germany, Vattenfall Europe has become the first energy supply company to begin building a low$\mathrm{CO}_{2}$ oxyfuel-based demonstration power station (30 MWth in the first phase of the project), and the Federal Ministry of Economics and Technology has launched a major research and development program in this field called COORETEC.

National energy security: The obligation to protect the climate in some respects clashes with requirements for

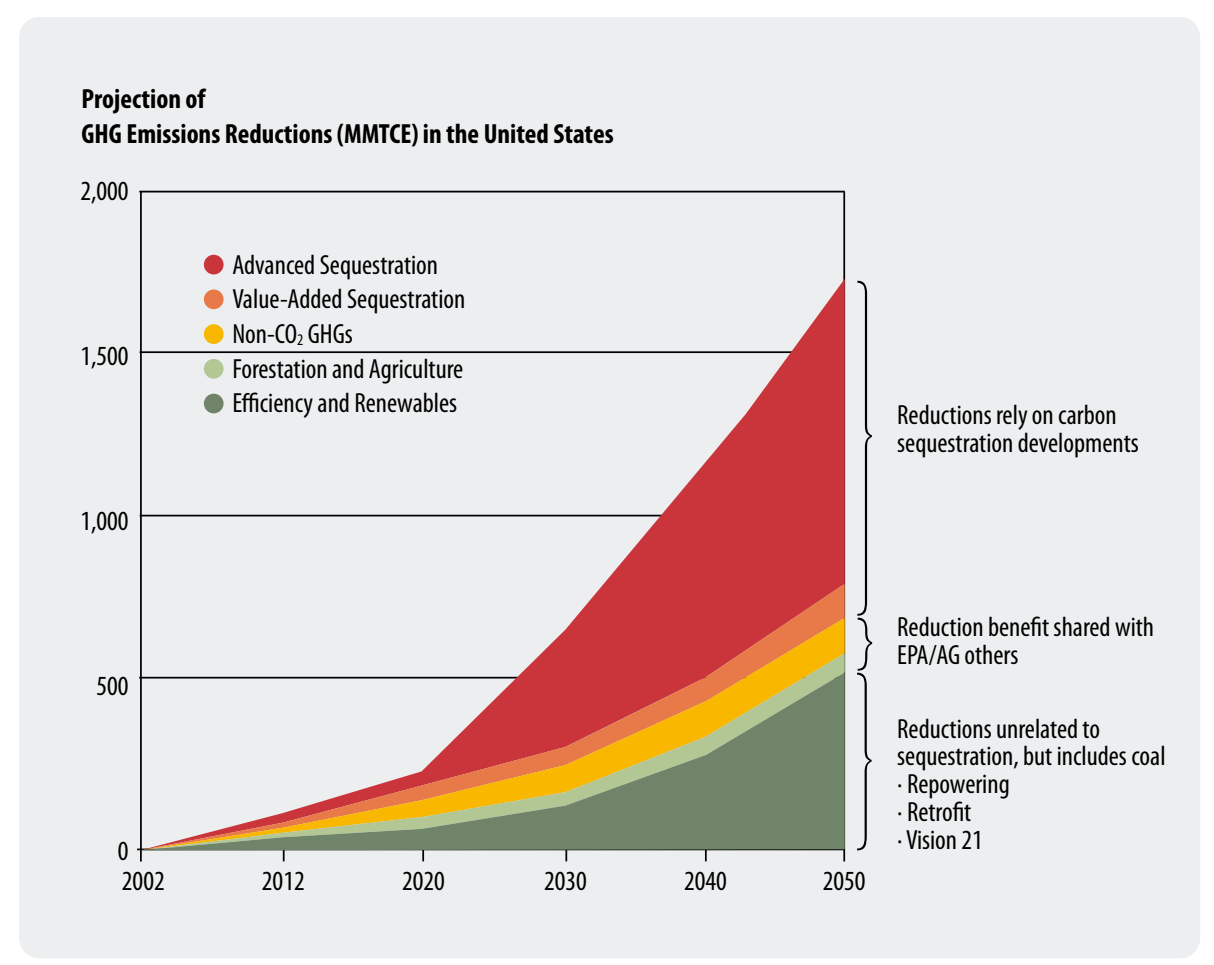

Fig. 3-1:

Emissions reduction requirements compared with the trend in stabilising $\mathrm{CO}_{2}$ emissions in the United States (DoE 2003) 
states and communities of states to maintain or improve their energy security (see the European Union green papers on Security of Supply and Energy Security [EU $2006,2001])$. For many countries a baseline contribution from fossil fuels (mainly coal) is essential, since they have their own reserves of these. In order to attain climate protection goals nonetheless, the argument goes, it is imperative to engage in $\mathrm{CO}_{2}$ capture and storage while maintaining or even increasing the proportion of fossil fuels.

Many states, particularly India and China, are currently experiencing strong economic growth. In order to maintain their energy supply they believe it is essential to increase exploitation of domestic coal reserves, since other sources of energy cannot be tapped as easily, as quickly or as cheaply. Even if these countries have yet to enter into any quantitative climate protection obligations, the protection of the global climate plays an increasingly important role for them.

Technological innovation and export opportunities: Technological advancements have facilitated some aspects of capturing $\mathrm{CO}_{2}$ in the power station process. This applies, for example, to coal-fired power stations with integrated coal gasification (integrated gasification combined cycle: IGCC), where the $\mathrm{CO}_{2}$ produced during gasification can be separated from the resulting synthesis gas fairly easily prior to the combustion process. Subsequent storage of the $\mathrm{CO}_{2}$ is then seen as a logical extension of the process for the purpose of climate protection. Here capturing $\mathrm{CO}_{2}$ is seen not as the direct purpose of the new process - as it is for example when sulphur dioxide or nitrogen oxide is separated during flue gas cleaning - but rather as a side-effect.
Another, comparable issue is compatibility with a coalbased hydrogen economy (polygeneration of electricity, heat, synthesis gases and hydrogen). There is currently a fair degree of optimism about the future use of hydrogen as a fuel. Coal gasification represents one possibility for production of $\mathrm{H}_{2}$. The rise in the prices of oil and gas is causing this approach to receive an increasing amount of attention. The same applies to the process of liquefying coal to provide fuel, known as coal-to-liquid (CTL). To make these processes compatible with protecting the climate, safe storage of the by-product $\mathrm{CO}_{2}$ is necessary.

Plant engineering: Many power engineering businesses and component suppliers see the large-scale introduction of $\mathrm{CO}_{2}$ capture processes as providing major economic opportunities not only to sell the additional components required to build new fossil-fuelled power stations but also generally to preserve the market for large-scale power stations. The large proportion of hightech components required for coal power station processes involving $\mathrm{CO}_{2}$ capture also means that exports of these technologies achieve correspondingly high added value. The building of a transport infrastructure for $\mathrm{CO}_{2}$ would also open up new areas of business for suppliers in the pipeline construction sector.

Economic incentives: Several states such as Denmark and Norway have introduced a $\mathrm{CO}_{2}$ tax. The economic incentives that this tax provides for avoiding $\mathrm{CO}_{2}$ emissions were the main reason why the Norwegian oil company Statoil decided to launch what is to date the world's largest $\mathrm{CO}_{2}$ storage project and to store in a geological formation approx. 1 million tonnes of $\mathrm{CO}_{2}$ produced
Fig. 3-2:

Factors promoting $\mathrm{CO}_{2}$ capture and storage worldwide
Global driving forces: - Climate Protection - Emission Trading

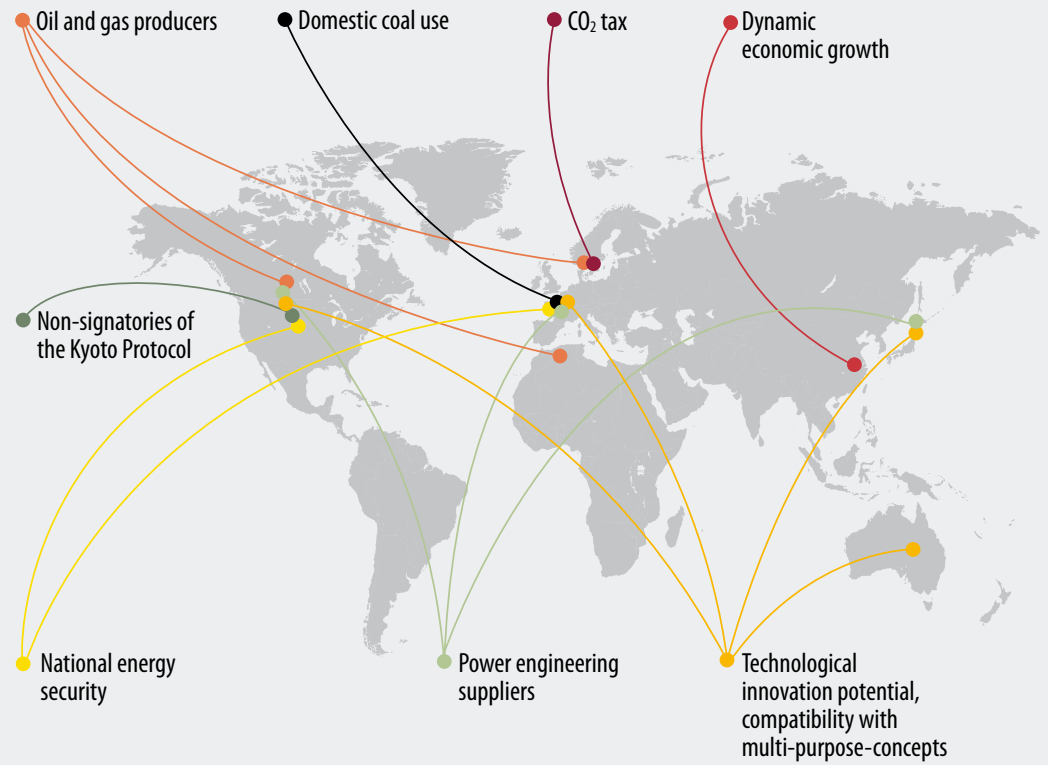


annually as an undesirable by-product in the extraction of natural gas from the Sleipner gas field (Statoil 2004). Oil companies also have an increasing interest in $\mathrm{CO}_{2}$ capture, since in the process of enhanced oil recovery (EOR) $\mathrm{CO}_{2}$ can increase the yield of oil extraction.

The various factors can be assigned differing degrees of importance depending on the region. The above diagram (Fig. 3-2) gives a broad overview of the major factors in various regions of the world.

\subsection{International and German NGOs}

Where non-governmental organisations (NGOs) are concerned, the process of developing positions on CCS has turned out to be very diverse and complex. Overall, NGOs (including those outside Europe) concur on only three points:

- They reject the storage of $\mathrm{CO}_{2}$ in ecosystems - specifically oceans,

- Currently (February 2008) no campaigns against $\mathrm{CO}_{2}$ disposal are planned,

- Renewable energy and more rational use of energy should be given priority over $\mathrm{CO}_{2}$ storage and their implementation should be pushed.

There is no common position that goes beyond these three points. One major reason for this is that the positions of the national NGOs must always take into account the national energy situation (expected energy consumption trends, fuel mix, domestic energy resources, etc.). Another is that the focus of the individual groups and organisations varies considerably. Whereas some focus on climate protection and go into detail on the different solutions proposed, others have a broader range of goals and give more weight to issues such as local ecology and competition with renewables.

The World Wide Fund for Nature (WWF) advocates $\mathrm{CO}_{2}$ storage under certain conditions (WWF 2005, 2004):

- No storage in oceans, open aquifers or lakes,

- International monitoring of storage must be introduced,

- Public funding of research into $\mathrm{CO}_{2}$ storage should have no influence on the level of research funding for renewables,

- Emissions trading: only developed countries with ' $\mathrm{CO}_{2}$ caps' should be allowed to offset 'carbon capture and storage',
- CCS should complement rather than substitute for the expansion of renewables.

Another reason why the WWF takes a positive view of the role of $\mathrm{CO}_{2}$ storage is because it sees it as a stopgap that can be used until other technologies have been developed sufficiently to be able to make a decisive contribution to $\mathrm{CO}_{2}$ reduction.

Greenpeace generally rejects CCS, but in the event that $\mathrm{CO}_{2}$ capture and storage should be introduced Greenpeace believes it should be used as an additional option and not as a substitute for expanding the use of renewables and introducing energy saving measures. In addition a number of 'essential conditions' must be fulfilled (Greenpeace 2004, 2007):

- $\mathrm{CO}_{2}$ storage sites must be leak-proof for several thousand years,

- $\mathrm{CO}_{2}$ should be stored only in disused oil or natural gas fields; no storage in oceans, coal seams or salt domes; storage in saline aquifers only after careful examination of safety aspects, potential utilisation conflicts and environmental impact,

- No use of $\mathrm{CO}_{2}$ for EOR and EGR,

- Drawing up of national, European and international guidelines regulating $\mathrm{CO}_{2}$ storage,

- CCS should not be offset under the Clean Development Mechanism (CDM),

- Emissions trading: still a need to discuss whether $\mathrm{CO}_{2}$ storage should be included,

- Research and development: public research funding should be used exclusively for research into storage facilities (because safety is in the public interest),

- Export of the technology only after safe use in industrialised countries has been proven.

Above and beyond this Greenpeace sees no requirement for CCS in industrialised countries (Greenpeace 2005).

Climate Action Network (CAN) is an umbrella organisation of more than 350 NGOs active in climate protection world-wide. In May 2006 CAN Europe published its position on CCS, much of which corresponds with that of many other NGOs: no disposal of $\mathrm{CO} 2$ in the oceans, priority to be given to renewables and energy efficiency (e.g. in the area of research funding) and authorisation of CCS only after it has been proven that (geological) storage facilities are leak-proof in the long term. CAN also regards the development of a legal framework (operator liability for leaking storage facilities, no burden on public budgets) as an essential prerequisite for the introduction of CCS (CAN 2006). 
Compared with those in other countries, German NGOs tend to take a rather sceptical attitude to the storage of $\mathrm{CO} 2$, but they have no uniform position on the matter. They all agree, however, that top priority must be given to expanding the use of renewables and to more rational energy use. This position stems from the fear that funds for CCS research might be made available at the expense of research in the fields of renewables and energy efficiency.

Specifically, the following reasons or fears have been named:

- CCS constitutes a classic 'end-of-pipe' approach, where problems higher up the process chain (those associated with the supply of fuel) are not only not solved, but tend to be aggravated (e.g. environmental damage caused by open-cast lignite mining) (NABU 2005).

- CCS offers 'no solution to the problem of providing a sustainable supply of energy' because of the large volume of additional energy required, an underestimation of the dangers of 'permanent disposal of $\mathrm{CO}_{2}$ ' and high costs. The use of CCS, it is argued, will prevent a switch of the energy system towards energy efficiency and renewable energies (BUND 2005, 2006; Robin Wood 2006).

- There are still too many open questions regarding the quality and quantity of storage sites. In addition the long periods of time that would have to be bridged until a large-scale system of storage is established make the actual contribution of $\mathrm{CO}_{2}$ storage to a reduction in emissions seem questionable (Germanwatch 2004).

\subsection{Industrial Associations and Companies}

In a statement on capture-ready concepts the European Power Plant Suppliers Association (EPPSA 2006) gives recommendations for the use of CCS technology at power stations: 'Efficiency improvement is the least costly method for direct $\mathrm{CO}_{2}$ reduction and also minimises the capital and operation costs for the $\mathrm{CO}_{2}$ capture equipment by reducing the flue gas $/ \mathrm{CO}_{2}$ volume that the equipment needs to handle ... The authorisation process should allow the plant to run with or without $\mathrm{CO}_{2}$ capture'

Associations representing the interests of the coal industry in various countries fear that a reduction in supplies and market share motivated by environmental and climate protection considerations will have a negative effect on turnover and employment in the coal industry, so these traditional sectors of the energy economy are among the most active promoters of $\mathrm{CO}_{2}$ capture and storage. The coal industries in Poland and
Spain, for instance, are among those in a number of countries that advocate the use of large-scale technology for $\mathrm{CO}_{2}$ storage.

Oil and gas producers see $\mathrm{CO}_{2}$ capture and storage as a promising additional business opportunity in the future. For this reason companies like Shell, BP and Statoil are among the advocates of $\mathrm{CO}_{2}$ capture and storage. Initial practical steps have already been taken; $\mathrm{CO}_{2}$ is already being pumped into oil fields in order to raise the yield of oil. ${ }^{1}$ This is made additionally profitable in some cases, as already explained, by the existing tax on $\mathrm{CO}_{2}$. Thus in this respect $\mathrm{CO}_{2}$ storage generates direct economic profits (Williams 2003). In addition today's oil and gas producers could in future become important suppliers of potential $\mathrm{CO}_{2}$ storage sites in the form of disused oil and gas fields.

To date few German industrial associations have produced position papers stating their position on $\mathrm{CO}_{2}$ storage. Those that have include the German Lignite Industry Association (DEBRIV), which advocates the capture and storage of $\mathrm{CO}_{2}$, as well as the German Coal Mining Association (GVSt) and the Association of German Engineers (VDI). The GVSt and the VDI call for clarification of this 'long-term option', but their main priority is a maximum increase in the efficiency of the power plant process as a contribution to climate protection (RWE Rheinbraun / Vattenfall Europe 2003).

\subsection{German Political Parties}

Germany's political parties take different positions on CCS. The current governing coalition of conservatives (CDU/CSU) and social democrats (SPD) is positive about carbon capture and storage. The CDU sees CCS as a means of reducing carbon dioxide emissions worldwide and therefore advocates further research efforts in this field. Both the CDU and the CSU describe low- $\mathrm{CO}_{2}$ fossil fuel power stations as 'important cornerstones' of their energy policy (Union 2002). The SPD calls for '... a co-ordinated research offensive for low- $\mathrm{CO}_{2}$ or $\mathrm{CO}_{2}$ free power stations $\left(\mathrm{CO}_{2}\right.$ capture)' (SPD 2003). ${ }^{2}$ The liberal party, FDP, sees the capture and storage of carbon dioxide as an option for emissions reduction (FDP 2003). Alliance 90/The Greens believe that CCS is currently too immature a technology to provide any justification for increasing the number of coal-fired power stations in Germany (B90/Grüne 2003). The Left Party, on the other hand, comes to the conclusion that there is no place for 'coal-fired power stations, however "vision-

1 As in the Norwegian Sleipner field, this $\mathrm{CO}_{2}$ often appears as a by-product of oil and natural gas extraction and is injected back into the formation (EOR/EGR, enhanced oil/gas recovery).

2 'eine koordinierte Forschungsoffensive für $\mathrm{CO}_{2}$-arme bzw. $\mathrm{CO}_{2}$ freie Kraftwerke ( $\mathrm{CO}_{2}$-Abscheidung) ...' 
ary" their technology is' in its demand for a complete switchover to a renewable energy system by 2050 (PDS 2004).

\subsection{German Ministries and Expert Committees}

\subsubsection{The Federal Ministry of Economics and Technology (BMWi)}

The Federal Ministry of Economics and Technology is supporting carbon capture and storage with its research program COORETEC. This broad research programme is intended to provide a high-tech basis for meeting the need to replace old fossil-fuelled power stations by new ones. One branch of research in this programme is the long-term development of low- $\mathrm{CO}_{2}$ power plants (misleadingly called 'zero emission power plants') (Rüggeberg 2004).

\subsubsection{The Ministry for the Environment, Nature Conversation and Nuclear Safety (BMU) and the Federal Environment Agency (UBA)}

Despite numerous research efforts, the Federal Ministry of the Environment and the Federal Environment Agency still have many open questions about the long-term safety and social, ecological and economic acceptability of CCS. Specifically there has so far been no systematic examination of CCS as a whole in the form of an ecological evaluation, an analysis of possible interaction with other aspects of the energy economy or a comparison with other measures for the reduction of $\mathrm{CO}_{2}$ emissions - which is the main justification for the current research project. In August 2006 the Federal Environment Agency published a position paper entitled: 'Separation and Storage of $\mathrm{CO}_{2}$ - only an interim solution - possible effects, potential and requirements', which examined the extent to which the introduction of CCS would be compatible with sustainability requirements, particularly in Germany (UBA 2006). In line with the guiding principles for sustainability issued by the Enquete Commission for the 'Protection of People and the Environment' of the thirteenth German Bundestag, the following theses were developed:

1. Climate protection can be achieved using renewables and energy efficiency. The technical capture and storage of $\mathrm{CO}_{2}$, on the other hand, is not sustainable and is therefore at best an interim solution.

2. Capacity for $\mathrm{CO}_{2}$ storage should be the main focus of discussion: in Germany this may be limited to forty years.

3. Technical capture and storage of $\mathrm{CO}_{2}$ involves costs. Assuming ambitious climate protection goals, some projects will probably be economically viable.
4. $\mathrm{CO}_{2}$ storage facilities should not exceed a leakage rate of $0.01 \%$ per year. Dangers to health and environment should be avoided.

5. Storing $\mathrm{CO}_{2}$ in the oceans and the 'artificial mineralisation' of $\mathrm{CO}_{2}$ cannot be considered options.

6. A national and international legal framework must be developed for CCS.

7. The discussion should include environmental issues and questions of equity. Research, state regulation and demonstration projects should not be limited to technical aspects alone.

Altogether the UBA advocates initiating a more farreaching discussion of sustainability issues in order to add a sustainability dimension to a 'discussion that to date has been conducted mainly with a view to technical aspects. The results of the ecological and economic calculations done within the current project offer a preliminary basis for a concept of this kind and should be included in any fundamental discussion of sustainability.

\subsubsection{The Council for Sustainable Development (RNE)}

In a position paper the Council for Sustainable Development calls the capture and disposal of carbon dioxide a possible important bridge 'on the way to the era of renewable energy supplies'. Here it recommends integrating technology for $\mathrm{CO}_{2}$ capture in high-efficiency power stations, only, however, from the point of view of economic efficiency. If this goal is not attainable, fossilfuelled power stations should not be part of a long-term strategy for a sustainable energy supply. While the Council for Sustainable Development advocates research into technology paths of this kind, this must not compete for research funds in a way that might give priority to this end-of-pipe technology over research into renewables and improved energy efficiency. The Council for Sustainable Development lists CCS as a field of research along with research into renewables, energy efficiency and material efficiency (RNE 2004).

\subsubsection{Advisory Council on Global Change (WBGU)}

The Advisory Council on Global Change (WBGU) set up by the German government has taken up a clear position on the storage of carbon dioxide. It refers to CCS as an 'end-of-pipe technology' and states: 'Fossil fuels will continue to be the dominant source of energy in many countries for decades to come ... Therefore the end-of-pipe technology for carbon storage provides ... an option for climate protection'. (WBGU 2003). The criteria for evaluating various options include length of storage, storage safety and environmental impact. WBGU rejects as storage options disposal in the oceans (ecological reservations), terrestrial sinks/biomass 
(lack of potential for expansion) and saline aquifers (no guarantee of safety and long-term storage). With regard to the length of storage the WBGU concludes in its most recent report (WBGU 2006): 'Sequestration ... only represents an acceptable climate protection technology if it can be guaranteed that $\mathrm{CO}_{2}$ will remain in a deposit for at least 10,000 years.'

Disused oil and gas fields could be used for interim storage, but only if the retention period mentioned above could be guaranteed. In the opinion of the WBGU there is a need for further research, above all on the permanent storage issue (WBGU 2003). Under certain conditions storage under the seabed might also be a feasible option. The WBGU recommends regulating $\mathrm{CO}_{2}$ storage under the seabed and proposes a number of instruments for this purpose:

- The formulation of minimum standards,

- Direct volume limitations: in international climate protection agreements stored volumes of $\mathrm{CO}_{2}$ should not be counted in full as avoided $\mathrm{CO}_{2}$ emissions,

- The establishment of liability mechanisms.

In principle the WBGU advocates sequestration under the sea floor, however only for 'a transition period as an additional option to more sustainable emissions avoidance strategies' (WBGU 2006). It further recommends, 'clarifying the question of the compatibility of $\mathrm{CO}_{2}$ storage under the sea floor with the London Convention or the London Protocol ... in such a way that $\mathrm{CO}_{2}$ sequestration in geological formations ... is permissible' (WBGU 2006). At the same time the WBGU calls for such activities to be limited to a certain period of time (several decades), thus underlining its statement that CCS should only constitute an interim solution. The WBGU believes it would be sensible to apply flexible mechanisms to sequestrated $\mathrm{CO}_{2}$ as well, although within the above-mentioned constraints.

\subsubsection{Advisory Council on the Environment (SRU)}

The Environmental Council believes that the capture and storage of carbon dioxide may be too expensive in comparison with other emissions avoidance options. An additional reservation is that even its advocates think that it will not be realisable until after 2020'. This would mean that this technology would come too late for the upcoming renewal and expansion of power station capacity (SRU 2004, 2000). The SRU is keeping track of this issue and continues to see a great need for action with regard to making a comprehensive evaluation of this technology (Hey 2006).

\subsubsection{Office for the Assessment of the Impact of Technology of the German Bundestag (TAB)}

As part of its monitoring of 'the sustainable supply of energy' the TAB has addressed the issue of ' $\mathrm{CO}_{2}$ capture and storage for power stations'. A study surveyed the existing literature on the subject and a workshop of experts was held to identify critical gaps in knowledge and to 'define areas in which a more profound analysis can be undertaken' (TAB 2006). 


\section{Chapter 4}

\section{An Overview of CCS Processes}

Because of the high costs and complex infrastructure involved, $\mathrm{CO}_{2}$ capture and storage is by necessity suited primarily for centralised, large-scale power generation structures. $\mathrm{CO}_{2}$ can in principle be separated from any point source, which means first and foremost from power stations and industrial plants. Electricity generation, which accounts for about one third of global $\mathrm{CO}_{2}$ emissions, represents the largest source. Although $\mathrm{CO}_{2}$ can in principle be filtered out of the atmosphere, this aspect is considered only in passing here. Feasible practical methods for the numerous smaller emissions sources (e.g. motor vehicles) are not as yet available. ${ }^{1}$

That said, it is possible to integrate CCS into decentralised structures at least indirectly, by linking the process to the introduction of the hydrogen energy economy. Hydrogen produced centrally in a process involving $\mathrm{CO}_{2}$ separation (e.g. coal gasification or steam reforming of natural gas) could be distributed (through specially constructed pipeline networks) and used decentrally, for example to generate electricity and heat or in mobile energy consumers. ${ }^{2}$ Although this would involve additional energy losses because it increases the number of steps in the process, the use of pure hydrogen applications would make high efficiency ratios possible, e.g. in fuel cell systems. So alongside the application of CCS in the field of power generation, we should also consider to what extent and in which applications and timeframes it would make sense to introduce a hydrogen energy economy using CCS, and whether this would lead to a sensible energy balance.

The CCS process chain consists of various steps, from $\mathrm{CO}_{2}$ separation, through liquefaction of the separated $\mathrm{CO}_{2}$ and transport, to permanent storage. In order to gain a full and complete picture of the process, the following fundamental aspects have to be differentiated:

- Type of fuel (largely natural gas and coal),

- General type of separation (pre-combustion/postcombustion),

- Type of electricity generation plant (steam turbines (ST) / gas turbines (GT) / natural gas combined cycle (NGCC) / power stations with integrated coal

1 Given that the weight of the $\mathrm{CO}_{2}$ produced by combustion is 3.67 times the weight of the carbon in the fuel, separation in the vehicle itself would be problematic and would automatically impact negatively on the energy balance.

2 It might be possible to use and expand existing infrastructure such as natural gas pipelines. gasification (IGCC) / fuel cells (FC) / combined processes and hybrid versions / new cycles and methods, etc.),

- Type of separation technology (e.g. chemical absorption, physical absorption, membrane separation methods, adsorption on solid surfaces, cryogenic processes),

- Type of transport (e.g. pipeline, inland waterways) and transport state (liquid, solid, gaseous),

- Type of storage (e.g. geological etc.).

Just considering the levels of differentiation in the first step of the process - $\mathrm{CO}_{2}$ separation - by different power generation technologies (Fig. 4-1) and different $\mathrm{CO}_{2}$ separation methods (Fig. 4-2) shows clearly how complex the whole CCS process chain is (Fig. 4-3).

The next figure focuses on the separation and storage options currently under discussion, regardless of their prospects for implementation, the potential obstacles involved and the question of what restrictions they may face (including ecological repercussions).

The individual parts of the material flow diagram are described and discussed in more detail in the following chapters, including an analysis of the efficiencies, emissions and costs involved in $\mathrm{CO}_{2}$ capture and storage. This relevance analysis identifies those options whose chances of implementation are especially high from today's perspective or where a market launch seems most likely. The analysis is based on studies and reports by BMWA (BMWA 2003), ECOFYS (ECOFYS 2004), Germanwatch (Germanwatch 2004), IEA (Gielen 2003, IEA 2003, 2004), IPCC (IPCC 2002, 2005) and WGBU (Ploetz 2003; WGBU 2003), as well as the authors' own experience. 


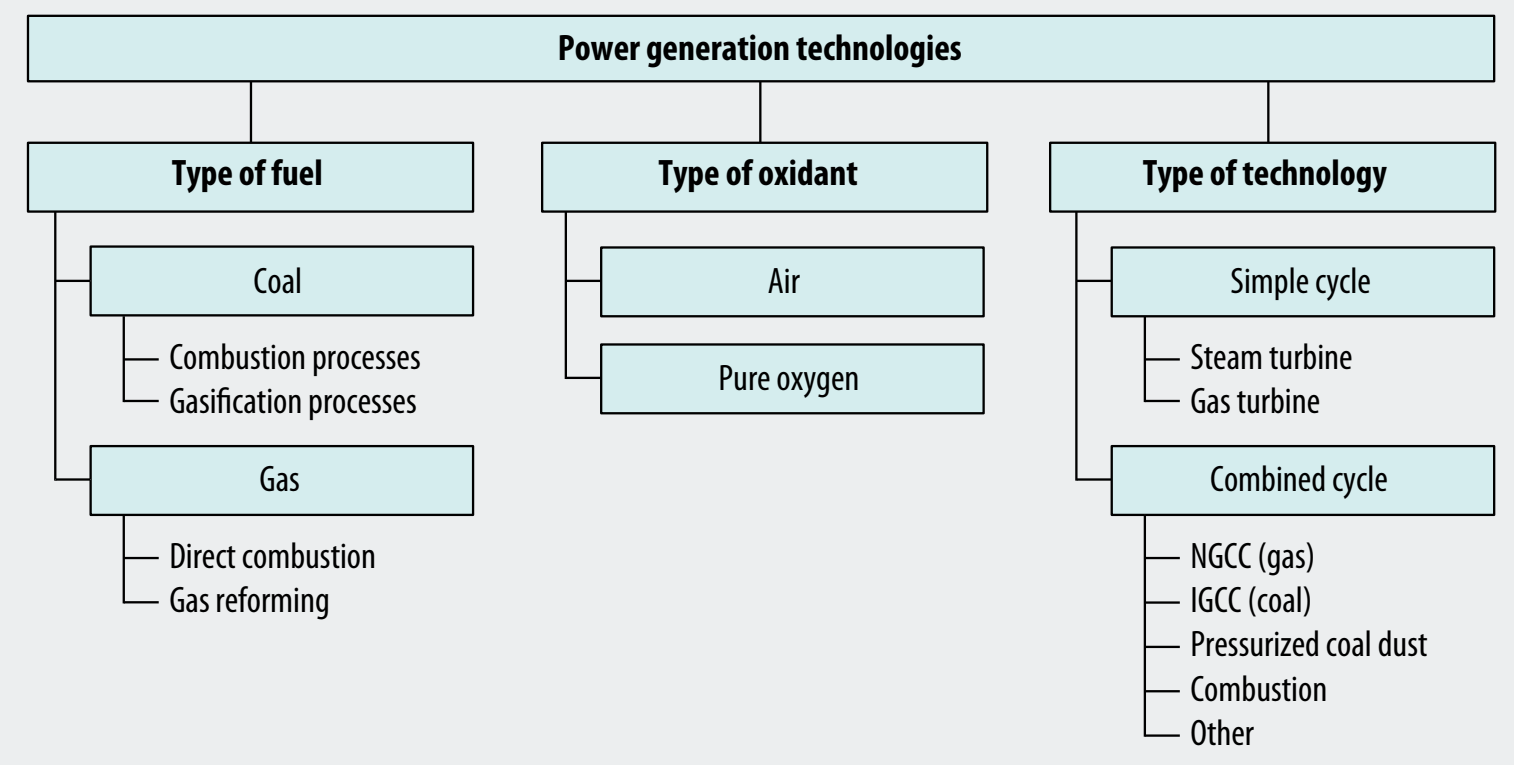

Fig. 4-1: The different types of fuel, oxidant and technology involved in power generation technology

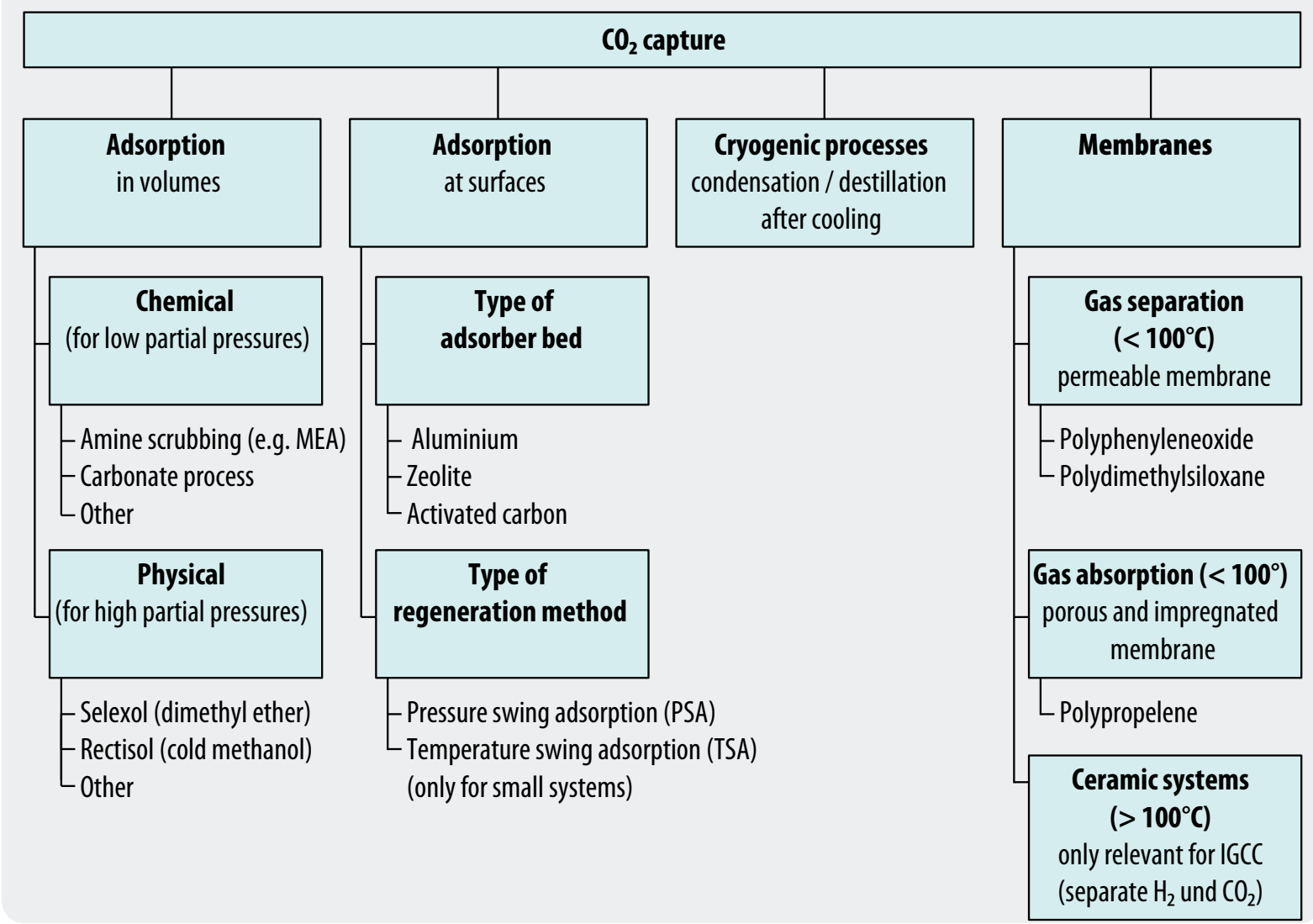

Fig. 4-2: Physical, chemical and membrane methods for $\mathrm{CO}_{2}$ separation (Environmental Scientific Technologie 2002) 


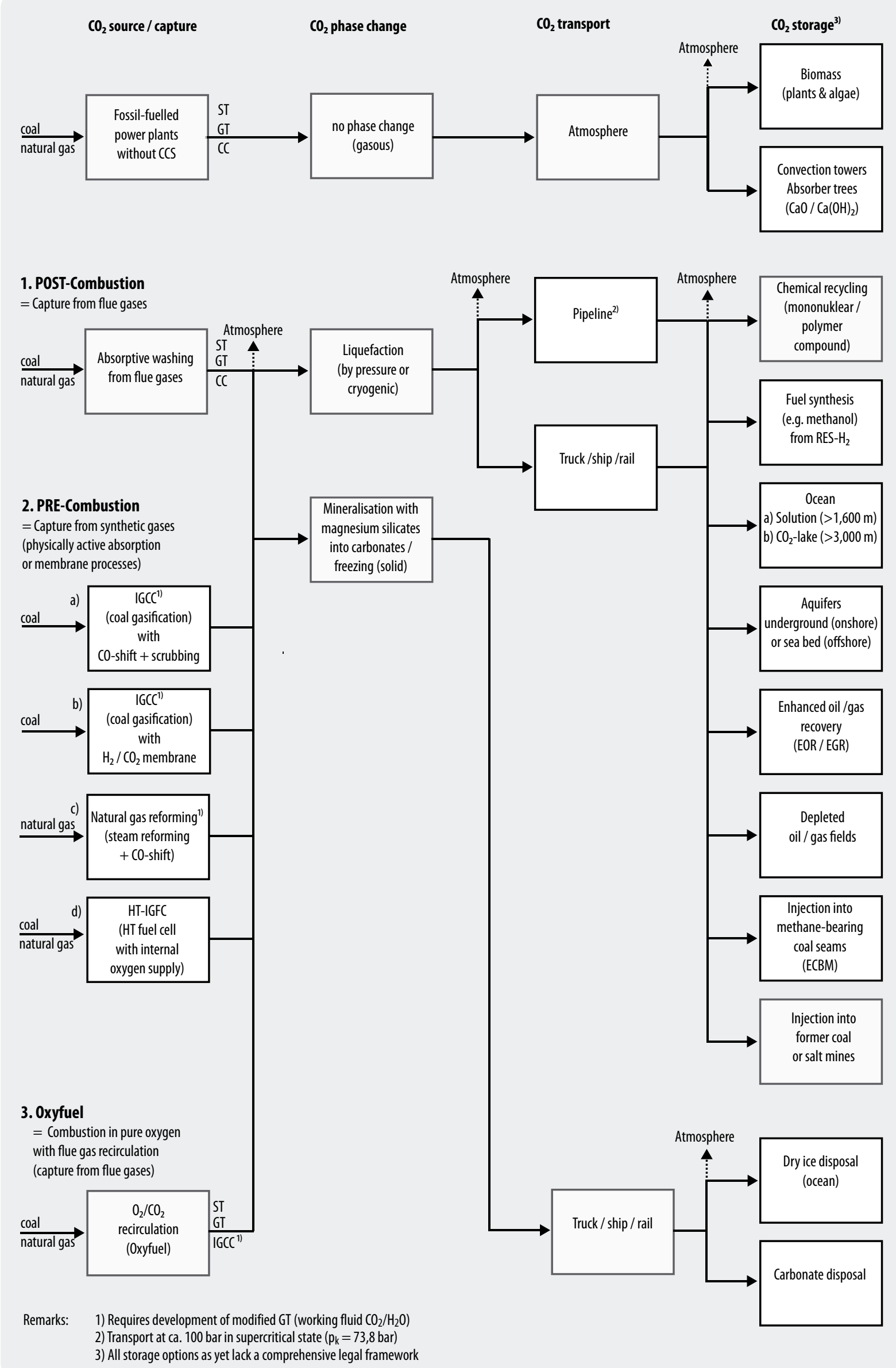

Fig. 4-3: The process chain from $\mathrm{CO}_{2}$ separation to storage 


\section{Chapter 5}

\section{$\mathrm{CO}_{2}$ Capture Methods for Power Plant and Hydrogen Production}

This chapter examines developments in power station concepts with $\mathrm{CO}_{2}$ capture (new builds and retrofit) from the short-, medium- and long-term perspectives, and explains the various concepts and methods for hydrogen production with integrated $\mathrm{CO}_{2}$ capture. The cost reduction potentials (learning curves) for both power generation and $\mathrm{H}_{2}$ production are estimated, and finally the question of which of the considered technologies could be relevant in future is examined.

\subsection{Developments in Power Station Concepts with $\mathrm{CO}_{2}$ Capture}

Fig. 5-1 shows the development status of measures for $\mathrm{CO}_{2}$ capture in the power generation sector and the expected implementation timeframe for new power station concepts. The short- to medium-term options can mostly be assigned to the following fields:

- Post-combustion capture,

- Pre-combustion capture and

- Oxyfuel (combustion in oxygen).

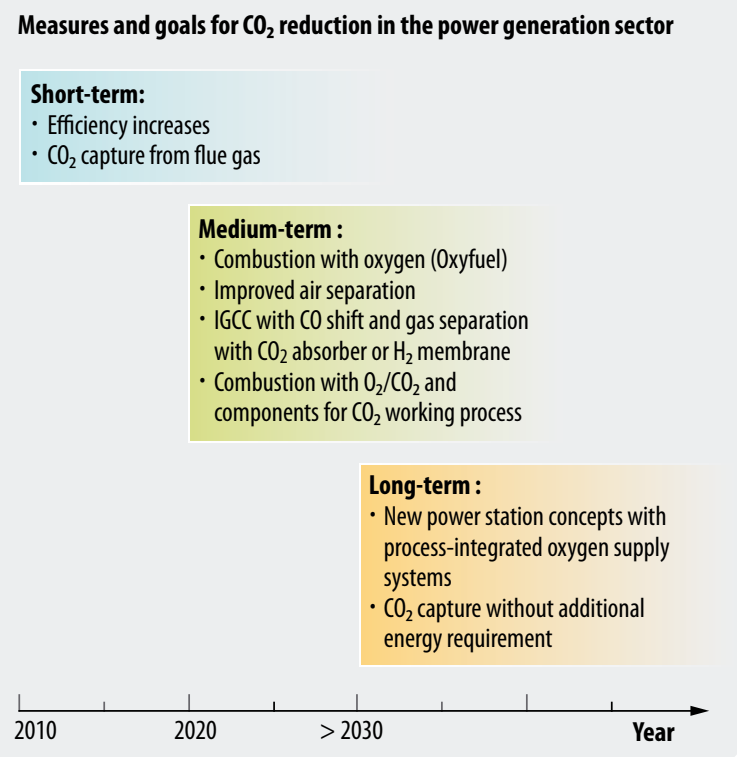

Fig. 5-1: Measures and goals for $\mathrm{CO}_{2}$ reduction in the power generation sector
In the longer term power station concepts involving new combustion processes for energy conversion are under consideration, such as chemical looping combustion (CLC) or high-temperature fuel cells (MCFC and SOFC).

An overview of the main methods is provided below, including an outline of the current status of implementation and the development perspectives.

\subsubsection{Short- to Medium-Term Options}

As already indicated, there are numerous $\mathrm{CO}_{2}$ capture methods, which have all reached different stages of development. The most promising short- and mediumterm options are described below (timeframe 2020 to 2030).

\section{$\mathrm{CO}_{2}$ capture after combustion (flue gas decarbonisation / post-combustion)}

In this method the $\mathrm{CO}_{2}$ is captured from the power station's flue gas. Because the concentration of $\mathrm{CO}_{2}$ in the flue gas is relatively low (3-15\%, fuel-dependent), a large volume of gas has to be treated. The use of large quantities of chemicals and energy increases costs accordingly and reduces overall effectiveness.

The least favourable conditions result from the application of $\mathrm{CO}_{2}$ washers in conventional coal-fired power stations. When coal-fired power stations are retrofitted, efficiency losses of between 8 and 14 percentage points must be expected, with a 10 to $35 \%$ increase in fuel consumption and additional investment costs of 30 to $150 \%$. In gas-fired power stations the situation is a little better (because the specific $\mathrm{CO}_{2}$ emissions are lower compared with coal). The scrubbing fluids used are sensitive to flue gas impurities such as sulphur oxides $\left(\mathrm{SO}_{\mathrm{x}}\right)$, nitrous oxides $\left(\mathrm{NO}_{\mathrm{x}}>10 \mathrm{ppmv}\right)$, dust, oxygen (if $>1.5$ vol. \%), etc., so the flue gas must be cleaned before $\mathrm{CO}_{2}$ capture. Most of the solvents used degrade over time, leading to losses and associated environmental problems. Potential is seen above all in the provision of stable scrubbing fluids with reduced corrosiveness and in the development of corrosion-resistant materials. In the medium term membranes are highly unlikely to play a role in $\mathrm{CO}_{2}$ capture.

Washing processes are de facto the only possibility for retrofitting power stations without intervening in the existing process. Additionally, the separation of $\mathrm{CO}_{2}$ 
Fig. 5-2:

Flue gas decarbonisation by amine scrubbing

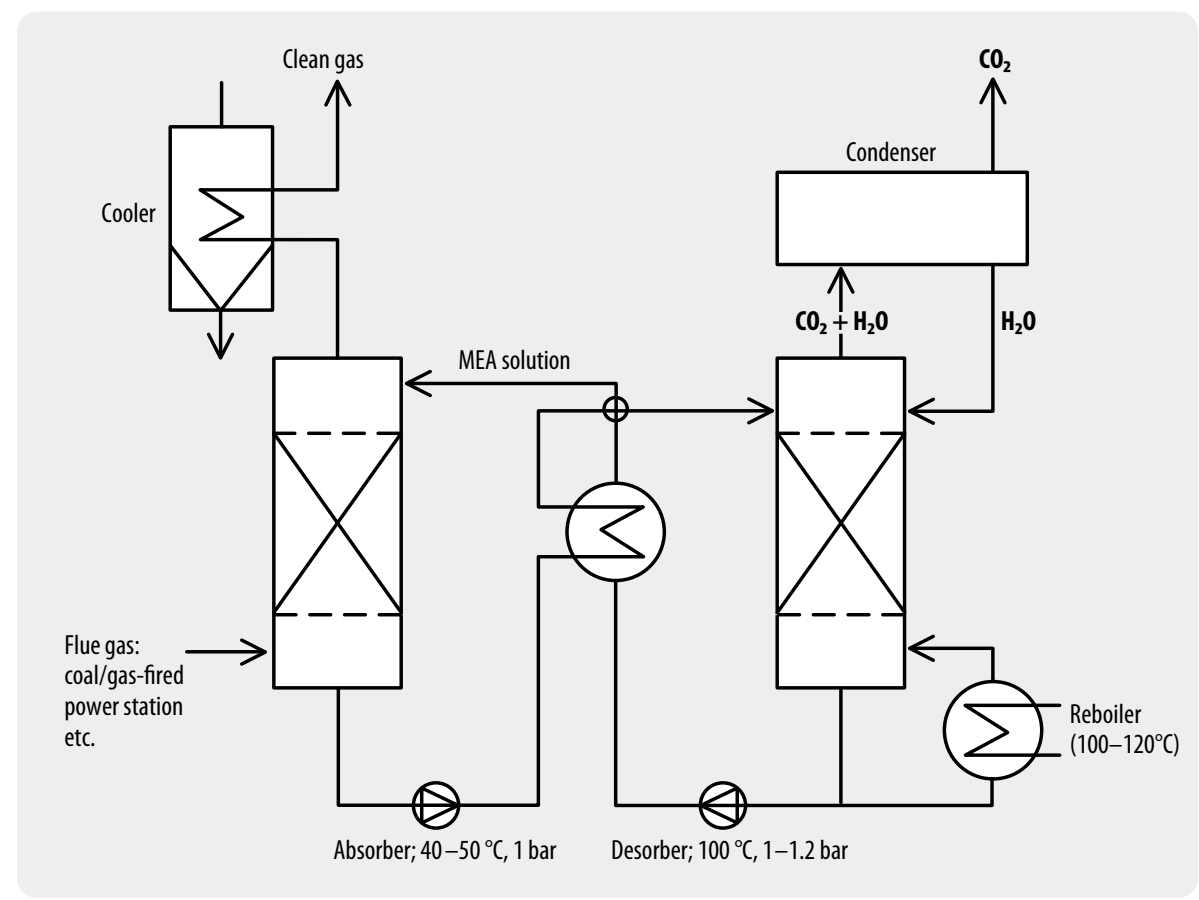

from flue gases is already an established chemical engineering process, albeit not yet on the power station scale.

There are already more than ten different technology lines for capturing $\mathrm{CO}_{2}$ (BMWA 2003). One quickly available process is amine scrubbing, which functions similarly to flue gas scrubbing for desulphurisation. Also under development are membrane technologies (polymer-based, ceramic or metal-based), which are expected to reduce the cost of $\mathrm{CO}_{2}$ capture in the medium to long term.

Amine scrubbing is an available and established process that has similarities to flue gas desulphurisation. Monoethanolamine (MEA, $30 \mathrm{vol}$. \% solution in water) and methyldiethanolamine (MDEA, 40 vol. \% solution in water activated with piperazine) are among the preferred amine solutions. MEA is a relatively strong base which strongly absorbs $\mathrm{CO}_{2}$, so it is used where $\mathrm{CO}_{2}$ concentrations are low or a high capture rate is required. Owing to its strong basicity MEA binds $\mathrm{CO}_{2}$ very strongly, so regenerating the solution requires a great deal of energy. MDEA by contrast is a weaker base with a high capacity. It does not achieve high capture rates and is largely used where $\mathrm{CO}_{2}$ content is high. Amine scrubbing for flue gas decarbonisation can be applied in both coal-fired and gas-fired power stations.

Fig. 5-2 shows a flow chart of a MEA system. Absorption takes place at approx. $40-50^{\circ} \mathrm{C}$ and 1 bar, desorption at $100^{\circ} \mathrm{C}, 1-1.2$ bar. Amine solutions are stable at $100-120^{\circ} \mathrm{C}$. The main components of a typical MEA system are the absorber and desorber columns.
Owing to the corrosiveness of amine solutions the equipment is made largely of high-grade stainless steel (e.g. 14571 or 14301). Where there is no oxygen in the flue gas carbon steel can also be used. Today's plant capacities range from 6 to approx. 1,000 $\mathrm{tCO}_{2} / \mathrm{d}$, but no problems are anticipated in building units with capacities up to 4,500 $\mathrm{tCO}_{2} / \mathrm{d}$ (Chapel 1999). Plant design is largely determined by the volume of flue gas to be treated and the partial pressure of the $\mathrm{CO}_{2}$. A unit for a typical coal-fired power station $(1,000 \mathrm{MW})$ would have to cope with a flue gas volume of approx. 2 million $\mathrm{Nm}^{3} /$ h or about $13,200 \mathrm{tCO}_{2} / \mathrm{d}$, which is larger by a factor of three. Fig. 5-3 shows basic processes in a pulverised-coal-fired power station. The additional steps required for $\mathrm{CO}_{2}$ capture are shaded grey in the figure.

The principles illustrated in Fig. 5-3 apply identically to $\mathrm{CO}_{2}$ capture from flue gas in gas-fired power stations, but the specific quantity of $\mathrm{CO}_{2}$ per $\mathrm{kWh}$ is smaller than in coal-fired power stations, which reduces the additional specific cost of $\mathrm{CO}_{2}$ capture per kWh. ${ }^{1}$ Consequently the negative effects of $\mathrm{CO}_{2}$ capture on electrical efficiency and costs in gas-fired power stations are smaller than in coal-fired power stations.

Where this $\mathrm{CO}_{2}$ capture technology is applied the additional costs and efficiency losses in the power stations are considerable, so widespread application in the future appears rather unlikely (although retrofitting is a possibility) on the one hand. On the other hand, flue gas scrubbing represents the only $\mathrm{CO}_{2}$ capture method that is already ready for application today. The extent to which retrofitting is carried out will depend on numer-

1 In relation to the actual volume of $\mathrm{CO}_{2}$ emissions, however, the picture is reversed, because the cost of the additional equipment stands in relation to a smaller volume flow of $\mathrm{CO}_{2}$. 


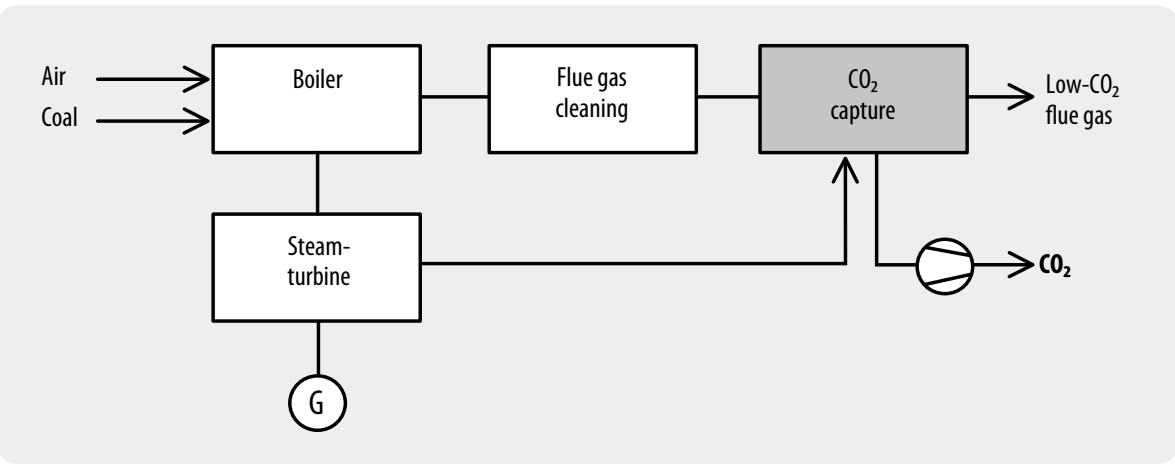

Fig. 5-3:

Pulverised-coal-fired power station with $\mathrm{CO}_{2}$ scrubbing

ous factors, such as the speed at which climate protection regimes are introduced and the associated incentives for $\mathrm{CO}_{2}$ reduction, the cost structure of other climate protection strategies and the development of other $\mathrm{CO}_{2}$ capture methods.

\section{$\mathrm{CO}_{2}$ capture before combustion (fuel gas decarbonisation/pre-combustion)}

Alternatives to flue gas scrubbing are currently attracting increasing attention. In very broad terms, we can speak of a 'hydrogen solution' and an 'oxygen solution'. In the hydrogen process described below $\mathrm{CO}_{2}$ is captured before combustion. By means of gasification and steam reforming, solid coal is first converted into a gas largely made up of $\mathrm{H}_{2}, \mathrm{CO}$ and $\mathrm{CO}_{2}$. This synthesis gas can also be produced directly from natural gas by steam reforming. In a shift reactor steam is used to convert the $\mathrm{CO}$ into $\mathrm{CO}_{2}$ and additional hydrogen. Then the $\mathrm{CO}_{2}$ is captured and a hydrogen-rich gas becomes available for combustion. Gasification and reforming are normally conducted under pressure (30-60 bar), producing a gas with high $\mathrm{CO}_{2}$ partial pressure. This makes it possible to capture the $\mathrm{CO}_{2}$ from the $\mathrm{H}_{2} / \mathrm{CO}_{2}$ mixture using physical scrubbing scrubbing(state of the art), which is considerably less energy-intensive than amine scrubbingscrubbing. In future membrane technology (hydrogen membranes) will also be an option for $\mathrm{CO}_{2}$ capture, bringing with it the advantage of a further reduction of energy consumption. Another important aspect of fuel gas decarbonisation is that the combination of gasification (reforming) with $\mathrm{CO}_{2}$ capture opens the way to a hydrogen economy. The generated hydrogen or synthesis gas can be used not only to generate electricity but also for other applications, for example methanol synthesis (co-production). Coal gasification without $\mathrm{CO}_{2}$ capture is already used in a number of combined cycle power stations (IGCC, integrated gasification combined cycle), where the synthesis gas is burned directly in a gas turbine. With an additional reforming step, the same process can also be

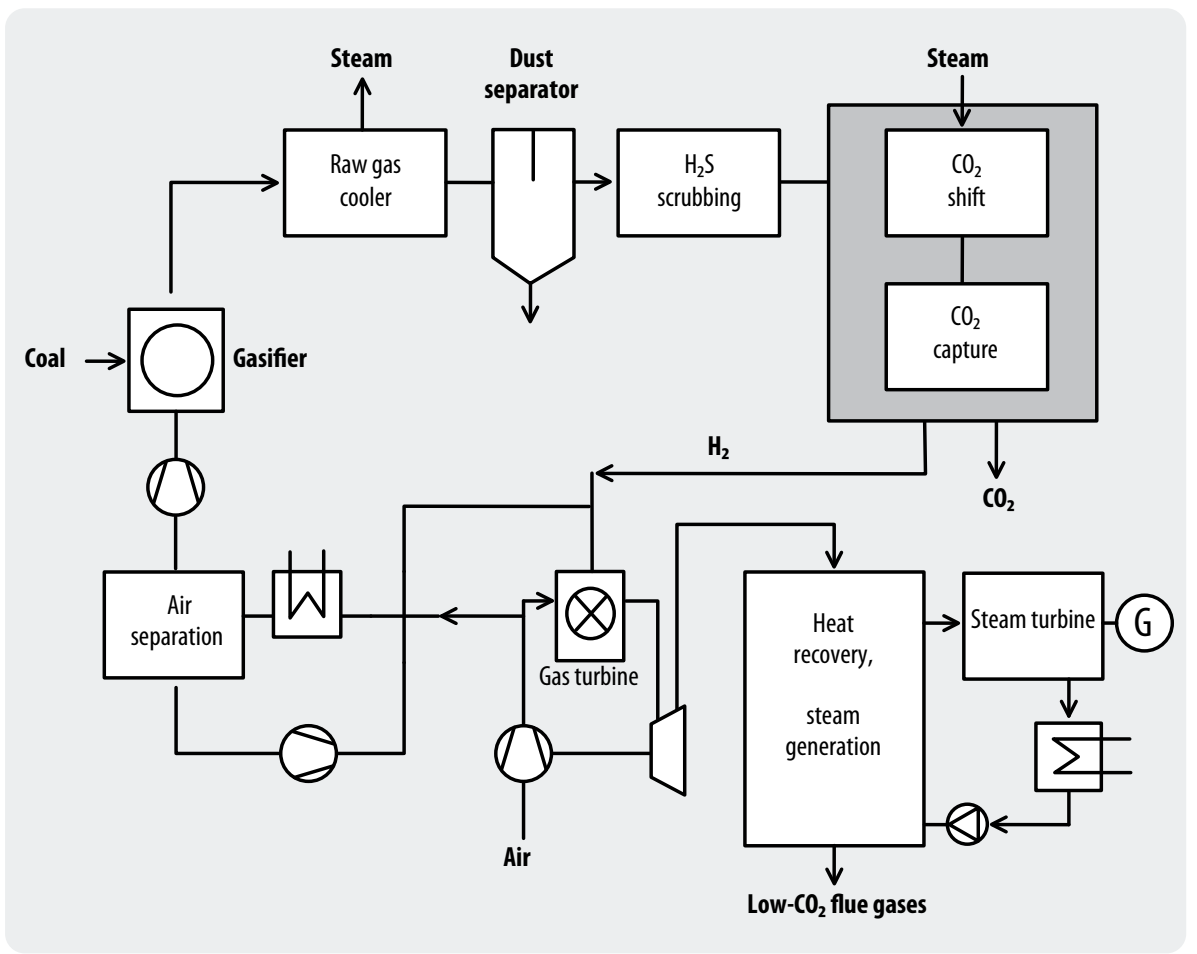

Fig. 5-4:

IGCC power station with $\mathrm{CO}$ shift and $\mathrm{CO}_{2}$ capture (Rectisol scrubbing) 
Fig. 5-5:

$\mathrm{CO}$ shift reactor for converting

$\mathrm{CO}$ and $\mathrm{H}_{2} \mathrm{O}$ into $\mathrm{H}_{2}$ and $\mathrm{CO}_{2}$

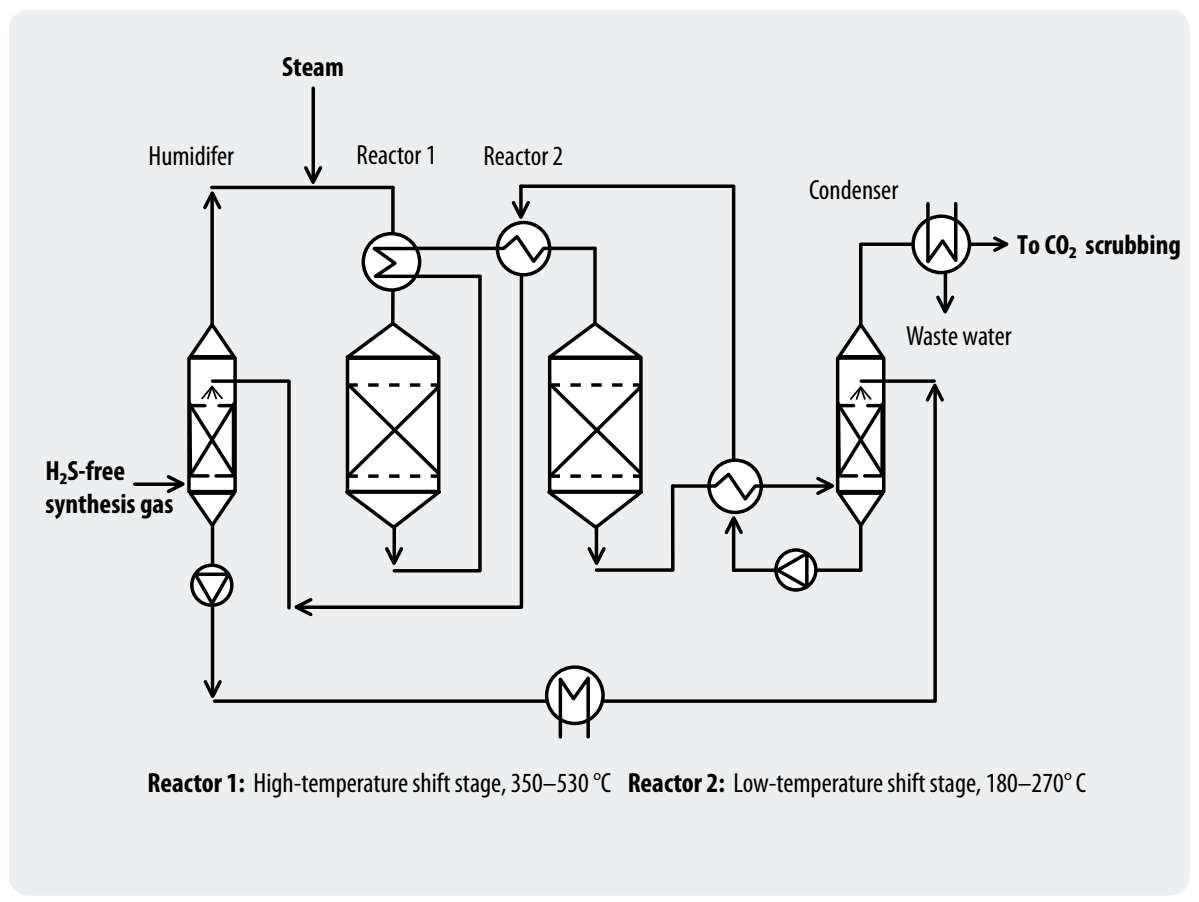

implemented in gas-fired combined cycle power stations (NGCC, natural gas combined cycle). IGCC with oxygen gasification offers a more economical way to achieve $\mathrm{CO}_{2}$ capture than flue gas decarbonisation. The advantages of these pre-combustion processes lie in their clearly lower costs and higher levels of power station efficiency. The disadvantages are found in the lack of availability of IGCC power station technology. There is also a need for additional development work on individual components, such as the hydrogen turbines. As complete processes, IGCC and NGCC with $\mathrm{CO}_{2}$ capture have yet to be demonstrated at the scale of real power stations. Fig. 5-4 shows the operating principles of an IGCC power station with $\mathrm{CO}_{2}$ capture (physical scrubbing with Rectisol), while Fig. 5-5 illustrates the CO shift stage.

The pressurised IGCC process reduces the volume flow of gas to be treated and increases the $\mathrm{CO}_{2}$ partial pressure. Both effects simplify $\mathrm{CO}_{2}$ capture (because physical scrubbing or membrane technology can be used) and avoid the disadvantages of unpressurised capture processes such as amine scrubbing.

As an alternative to $\mathrm{CO}_{2}$ capture, the hydrogen itself can be separated from the $\mathrm{H}_{2} / \mathrm{CO}_{2}$ gas mixture. The difference in size between $\mathrm{H}_{2}$ and $\mathrm{CO}_{2}$ molecules means that membrane methods can be used, which reduces the cost and energy consumption of the separation process. $\mathrm{H}_{2}$ separation by membrane is close to commercial viability. Fig. 5-6 shows the basic processes in an NGCC power station with membrane separation of $\mathrm{H}_{2}$ and afterburning of the retentate with $\mathrm{O}_{2}$. In the illustrated example the conversion of natural gas into $\mathrm{H}_{2}$ is accomplished by means of partial oxidation with a subsequent CO shift reactor and generally comprises a low- temperature stage and a high-temperature stage. This is necessary in order to maximise CO conversion. Provision of oxygen for partial oxidation and afterburning is an important cost item in this concept.

Fig. 5-7 and Fig. 5-8 show the components of a physical scrubbing plant and a membrane separation system $\left(\mathrm{H}_{2}\right.$ membrane). Unlike chemical absorption processes (e.g. amine scrubbing), in physical scrubbing the absorption solution is regenerated by pressure release. The equipment for the membrane method is very simple and compact.

\section{The oxyfuel process}

The technology of combustion in pure oxygen represents another method to simplify $\mathrm{CO}_{2}$ capture in the power station (the 'oxygen solution'). Here fuel is burned in pure oxygen rather than air, producing a much smaller volume of waste gas (owing to the absence of nitrogen). The flue gases contain primarily $\mathrm{CO}_{2}$ (approx. 80 vol. \%) and water vapour. Subsequently condensing out the water vapour allows the flow of $\mathrm{CO}_{2}$ to be transferred to storage facilities without any additional technical complexities. Another advantage is that combustion in pure oxygen produces no nitrous oxides and there is no need for complex denitrification equipment. The large amount of energy required to produce the oxygen is a disadvantage. Before this $\mathrm{CO}_{2}$ sequestration process can be implemented on a large scale significant improvements will be required, especially in the field of $\mathrm{O}_{2}$ generation processes. Intensive research and development work on membrane separation technologies is currently in progress. Combustion in oxygen can in principle be applied in any power station type. 


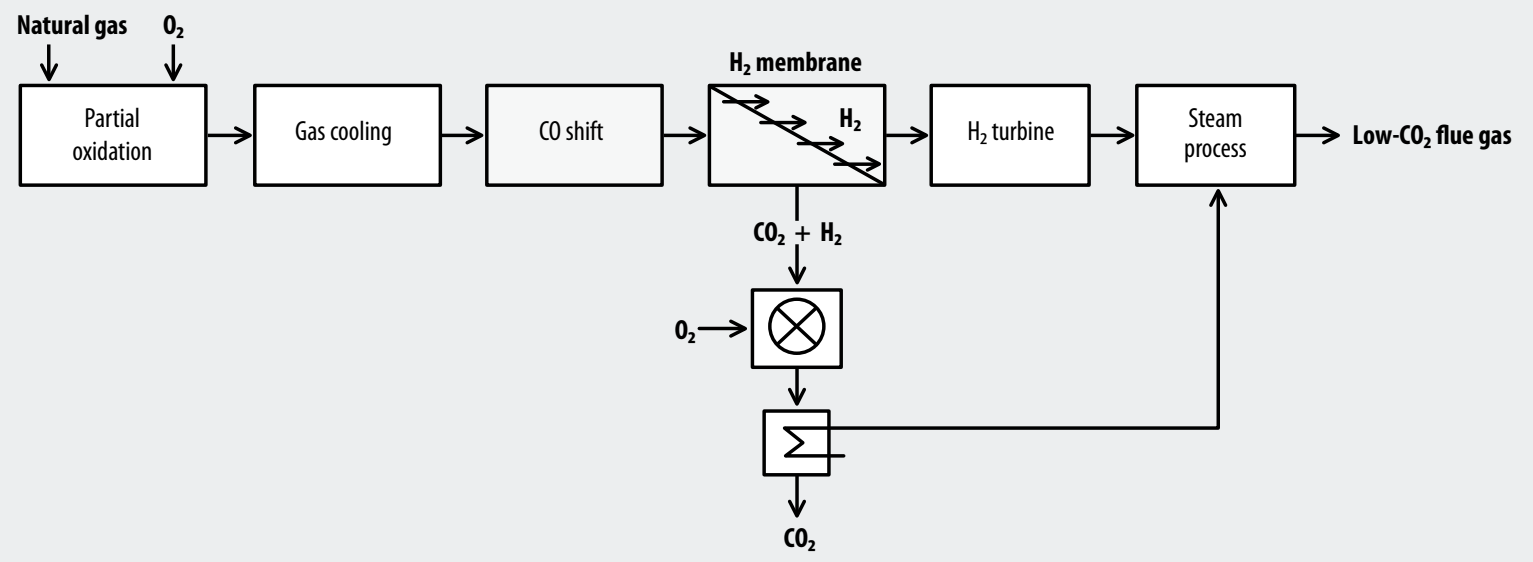

Fig. 5-6: NGCC power station with membrane separation of $\mathrm{H}_{2}$ and afterburning of the retentate

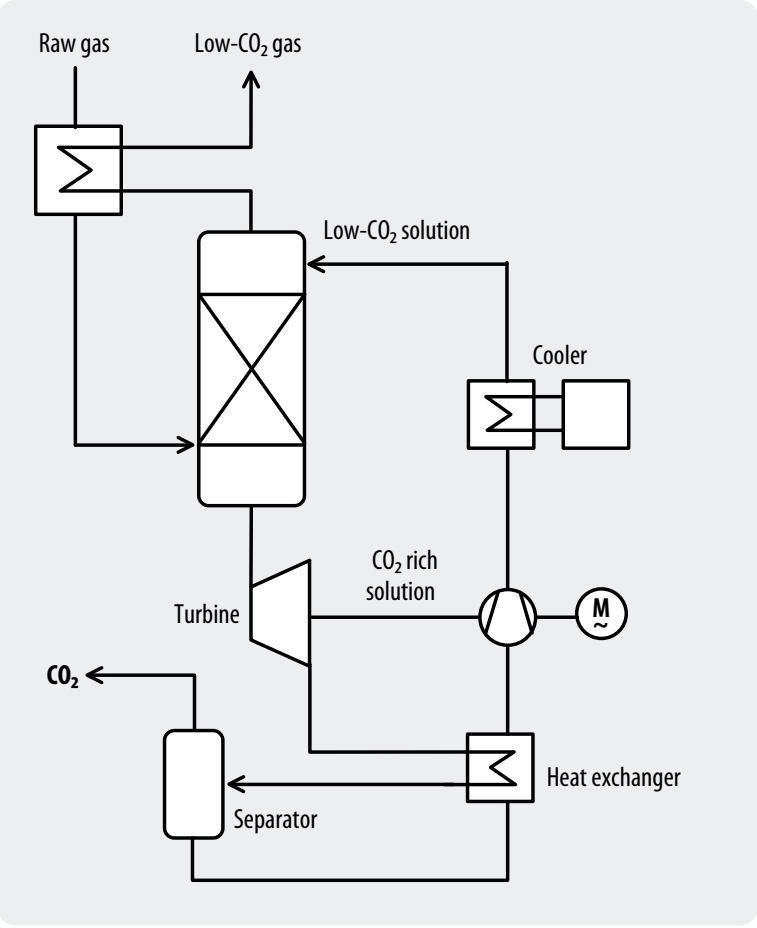

Fig. 5-7: Physical scrubbing

Retrofitting is also possible, although this would be very expensive because both an air separation facility and a flue gas recirculation facility to regulate the combustion chamber temperature would be required.

The process can most simply be implemented in power stations with a steam boiler. Fig. 5-9 shows the operating principles of the oxyfuel process with a steam boiler. After combustion and gas cleaning, actual $\mathrm{CO}_{2}$ capture involves no more than a condenser to remove the water and a compressor to compress the $\mathrm{CO}_{2}$ for transport and storage.

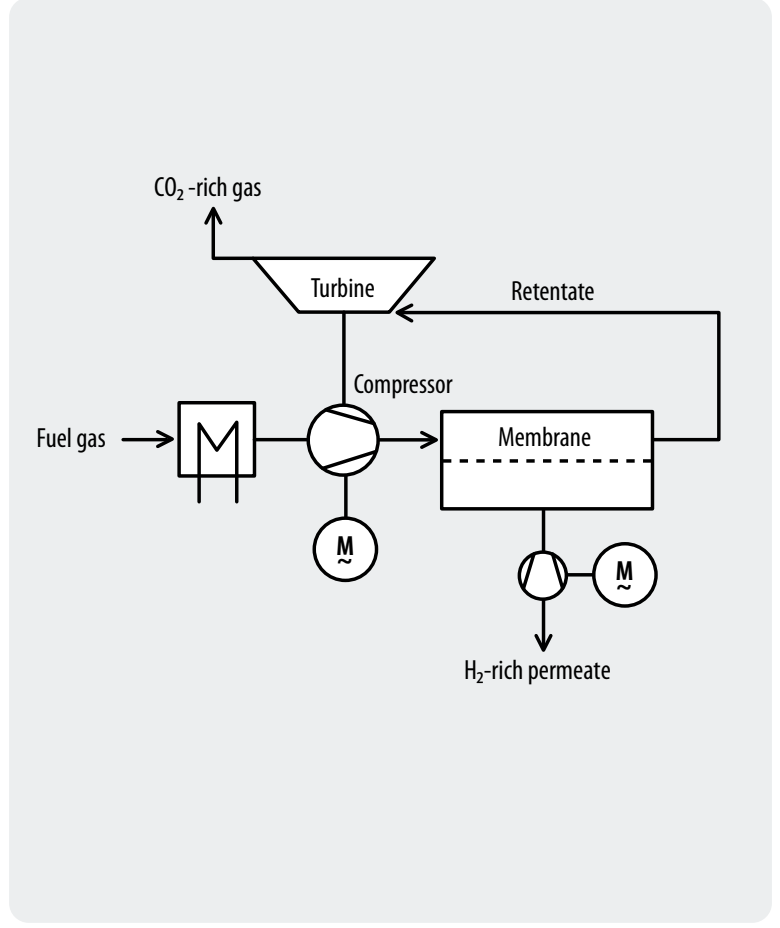

Fig. 5-8: $\mathrm{CO}_{2}$ enrichment using membrane technology

For use with natural gas, further development work will be required not only on the provision of oxygen but also on the turbines to be used. High-temperature membranes for oxygen production represent an optimisation that could drastically reduce the energy required. Such special membranes capable of allowing ions and electrons to pass are not yet technologically viable. Overall, the oxyfuel process has yet to pass through the usual development phases from prototype to pilot plant to demonstration plant and will therefore only be able to achieve commercial viability in the medium to long term. 
Fig. 5-9:

The oxyfuel process

(combustion in pure oxygen)

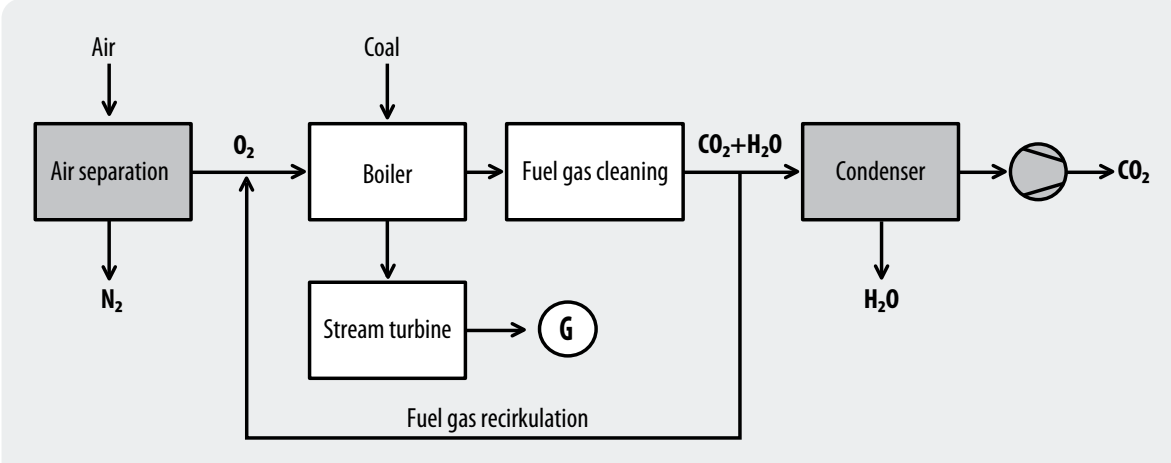

Summary of $\mathrm{CO}_{2}$ capture technologies (short- to medium-term options)

- Separating $\mathrm{CO}_{2}$ out of flue gases (post-combustion) in conventional power stations leads to a significant increase in electricity generation costs, causes considerable additional fuel consumption and substantially reduces power station efficiency (for details see chapters 10 and 12). The technology is available today, but has not yet been demonstrated in power stations on a commercial scale. In the longer term this technology is unlikely to become widely established unless climate protection regulations are tightened up considerably in the near future, in which case it could act as a stopgap while other processes are developed.

- Pre-combustion capture of $\mathrm{CO}_{2}$ in IGCC and NGCC power stations is from today's perspective a more attractive method than flue gas separation of $\mathrm{CO}_{2}$. The next step here is large-scale technical demonstration. The IGCC technology itself without $\mathrm{CO}_{2}$ capture - has already been tested in several plants. Before $\mathrm{CO}_{2}$ capture can be implemented there will be a need for improvement and development of several components (e.g. hydrogen turbines). In Germany RWE Power intends to take the first step towards implementing this technology by building a full-scale IGCC power station with $\mathrm{CO}_{2}$ capture (360 MWel output) by 2014 .

- The oxyfuel process currently offers the best prospects for $\mathrm{CO}_{2}$ capture in terms of achievable overall efficiency of the process as a whole (and also the resulting costs), because it is largely based on conventional power station components and technology. It is not yet possible to provide a precise assessment because the process is still at the beginning of the demonstration phase.

- At Schwarze Pumpe in eastern Germany Vattenfall Europe is building the world's first pilot plant for lignite combustion using the oxyfuel process. The Vattenfall pilot plant, which has an output of $30 \mathrm{MW}$ (thermal), will be used for research and development purposes with the aim of developing the new technology to the point where it is com- mercially viable. It is scheduled to begin operation in 2008 after a construction phase lasting about three years. Initially the $\mathrm{CO}_{2}$ will not be stored, but corresponding concepts (e.g. transport options) are being investigated.

- TOTAL has announced that it will be starting up a pilot project in a combined cycle plant in Lacq in November 2008. Here $\mathrm{CO}_{2}$ will be captured using the oxyfuel process and transported by pipeline to the disused gas field at Rousse (approx. $30 \mathrm{~km}$ from Lacq) where it will be injected through an existing borehole into an aquifer at a depth of 4,500 m.

The processes and methods available for short- to medium-term measures are summarised in Table 5-1 along with assessments of their development status.

\subsubsection{Long-term Options}

Application of the short- to medium-term options for $\mathrm{CO}_{2}$ capture described in Table 5-1 is in all cases associated with a relatively high energy requirement. Innovative separation processes combined with new power station types could minimise energy use and thus make $\mathrm{CO}_{2}$ capture more efficient. The principal options here are power station concepts where high-temperature fuel cells (SOFC, MCFC) are used to generate electricity or new power station concepts that draw the oxygen required for combustion from the reduction of a metal oxide (chemical looping combustion). Both approaches offer the possibility of isolating $\mathrm{CO}_{2}$ from the process without using additional energy. However, the feasibility of most of these technology combinations has yet to be demonstrated.

\section{$\mathrm{CO}_{2}$ capture with fuel cells}

In principle any type of fuel cell can be combined with pre- or post-cell $\mathrm{CO}_{2}$ capture in various configurations. The most interesting is the concept of combining a high-temperature SOFC (solid oxide fuel cell) with a WGSMR afterburner (water gas shift membrane reactor). The residual anode off-gas, still containing 
Table 5-1: Development status of $\mathrm{CO}_{2}$ capture methods

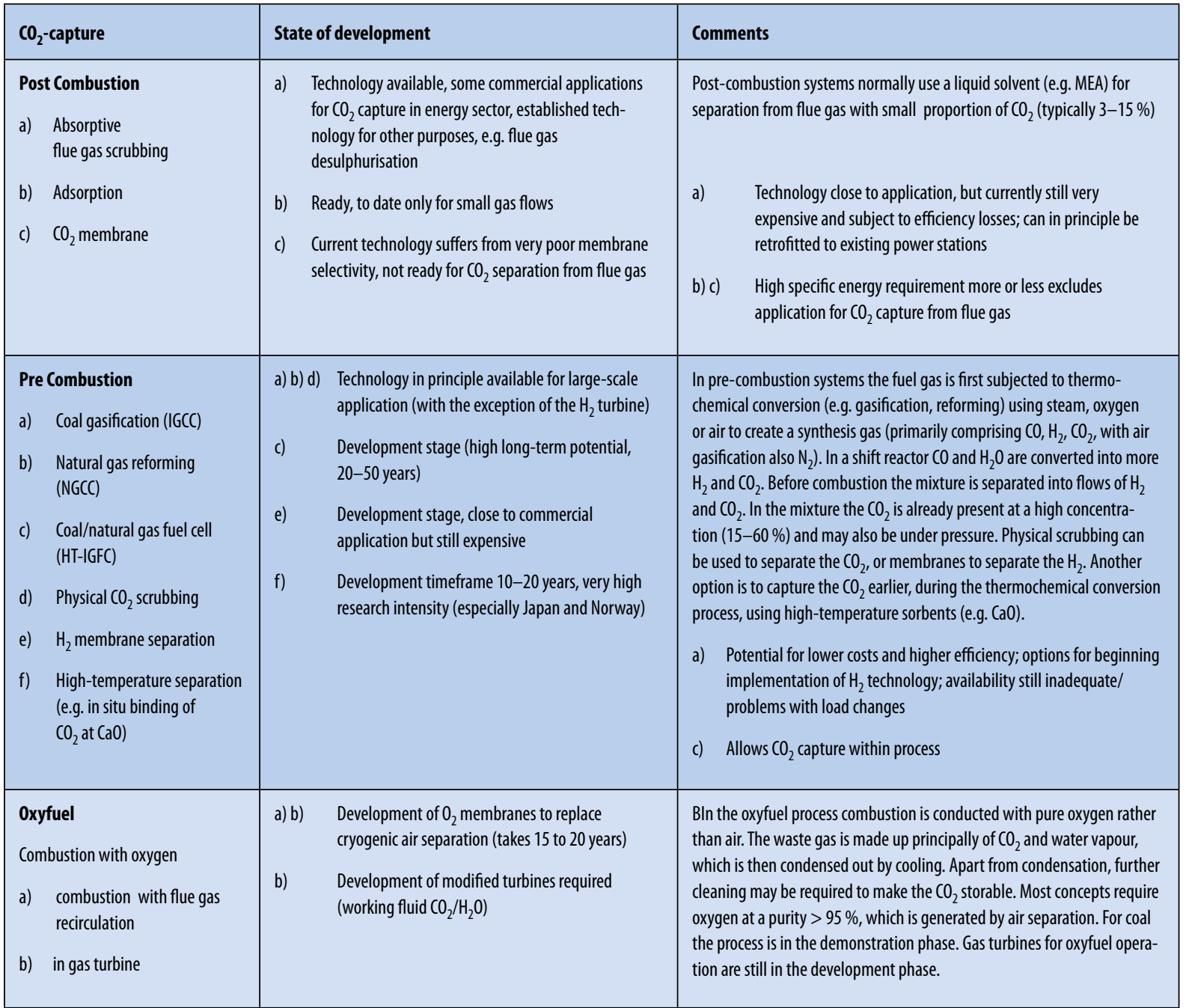

30-35\% unused fuel gas, is passed to a shift reactor with a hydrogen membrane where the hydrogen diffuses through the membrane and is combusted with air in a turbine on the permeate side. After the water has been condensed out of the retentate the $\mathrm{CO}_{2}$ is compressed and transported away. The electrolyte of the SOFC fuel cell also has the function of separating the $\mathrm{O}_{2}$ from the $\mathrm{N}_{2}$. Air is fed to the cathode under pressure. The oxygen ions diffuse from the cathode side of the electrolyte to the anode side, where they react with the fuel $\left(\mathrm{H}_{2}, \mathrm{CO}, \mathrm{CH}_{4}\right)$.
The residual anode off-gas is made up only of $\mathrm{CO}_{2}$ and uncombusted fuel gas. In order to use the energy of the anode off-gas the gas must be passed to an afterburner. This concept is being investigated at ECN in the Netherlands and is illustrated in Fig. 5-10 (Dijkstra 2002). The calculated electrical efficiency of combined cycle power stations with SOFC and $\mathrm{CO}_{2}$ capture is about $60 \%$. However, high-temperature fuel cells for power stations will probably not be available before 2030 .

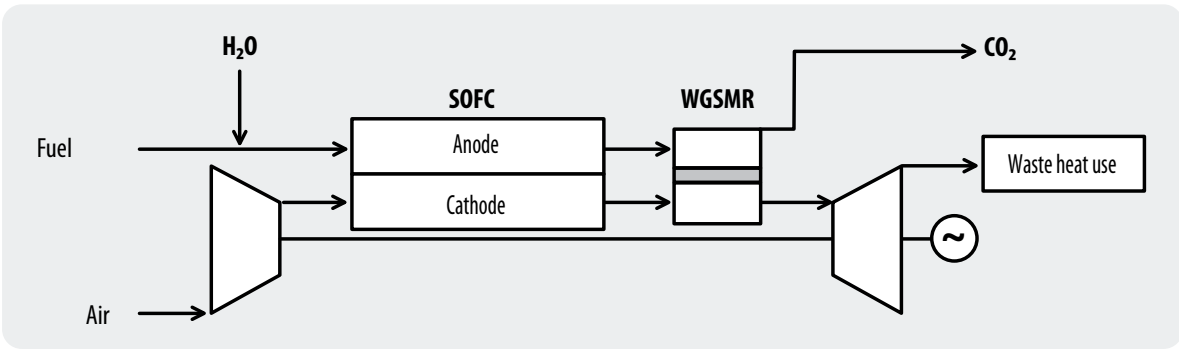

Fig. 5-10:

$\mathrm{CO}_{2}$ capture in an SOFC fuel cell with WGSMR afterburner 
Fig. 5-11:

The ZECA process

(Lackner 2001)

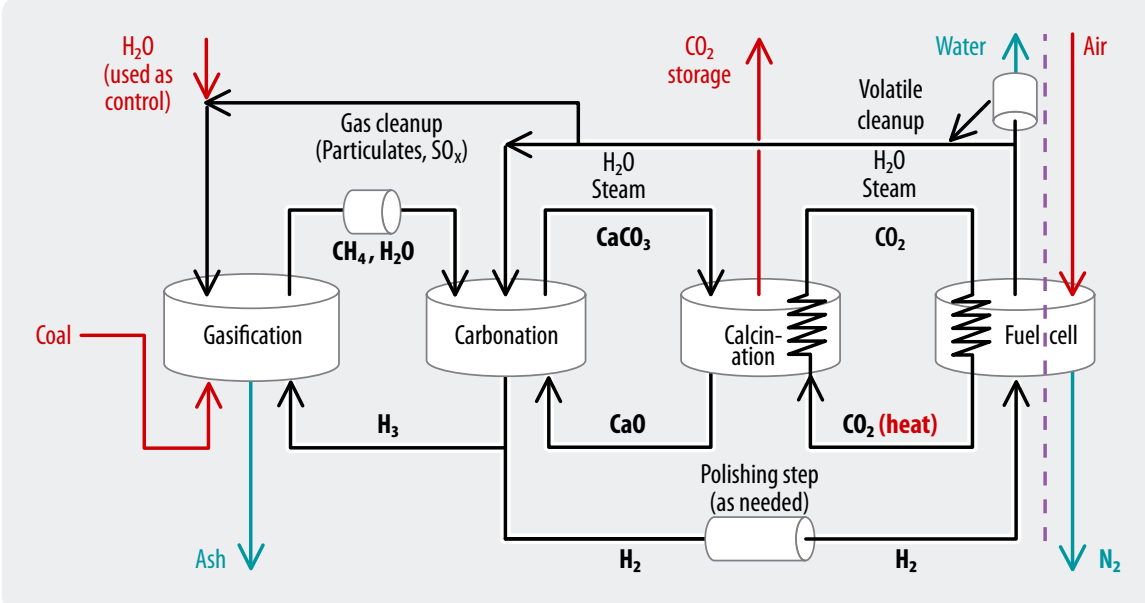

The ZECA process combines high-temperature fuel cell technology with hydrating coal gasification and a calcium oxide/calcium carbonate cycle. In this process (Fig. 5-11) the coal is converted into $\mathrm{CH}_{4}$ through hydrating pressure gasification with $\mathrm{H}_{2}$. In the next step steam in the presence of $\mathrm{CaO}$ converts $\mathrm{CH}_{4}$ into $\mathrm{H}_{2}$ and $\mathrm{CaCO}_{3}$. Half the hydrogen is fed to the hydrogasification process, while the other half is used to generate electricity in an SOFC. The waste heat from the SOFC is used to regenerate the $\mathrm{CaO}$ (through thermal decomposition of $\mathrm{CaCO}_{3}$ into $\mathrm{CaO}$ and $\mathrm{CO}_{2}$ ). Pure $\mathrm{CO}_{2}$ leaves the reactor at 1 bar.

The key component of the process is the SOFC, which operates at a pressure of 30 bar. Fuel cells of this type with the output required for power stations will probably be available in 25-30 years (Lackner 2001). There are also still many unresolved issues, such as how to connect up systems operating at different pressure levels (gasifier 60 bar, calciner 1 bar, SOFC 30 bar). Problems are also still raised by incomplete substance con- version and stability of the sorbents, etc. The electrical efficiency of the system is estimated at $70 \%$, but if today's technologies are used, this concept achieves an efficiency of 'only' $39 \%$. Research on this process is primarily being conducted by the ZECA Corporation in North America (formerly the Zero Emission Coal Alliance), a collaboration of power companies, the coal industry and research institutes.

\section{The AZEP concept}

The AZEP process (Advanced Zero Emission Power Plant) developed as part of an EU project in its 5th Research Framework Programme is based on a power station concept with gas turbine, combustion in oxygen and $\mathrm{CO}_{2}$ retention (Fig. 5-12). The key element in this concept is a reactor with an integrated ceramic high-temperature oxygen membrane. Unlike the oxyfuel process, where oxygen is produced in a separate air separation facility, in the AZEP concept oxygen sepa-

Fig. 5-12: The AZEP process (Göttlicher 2003)

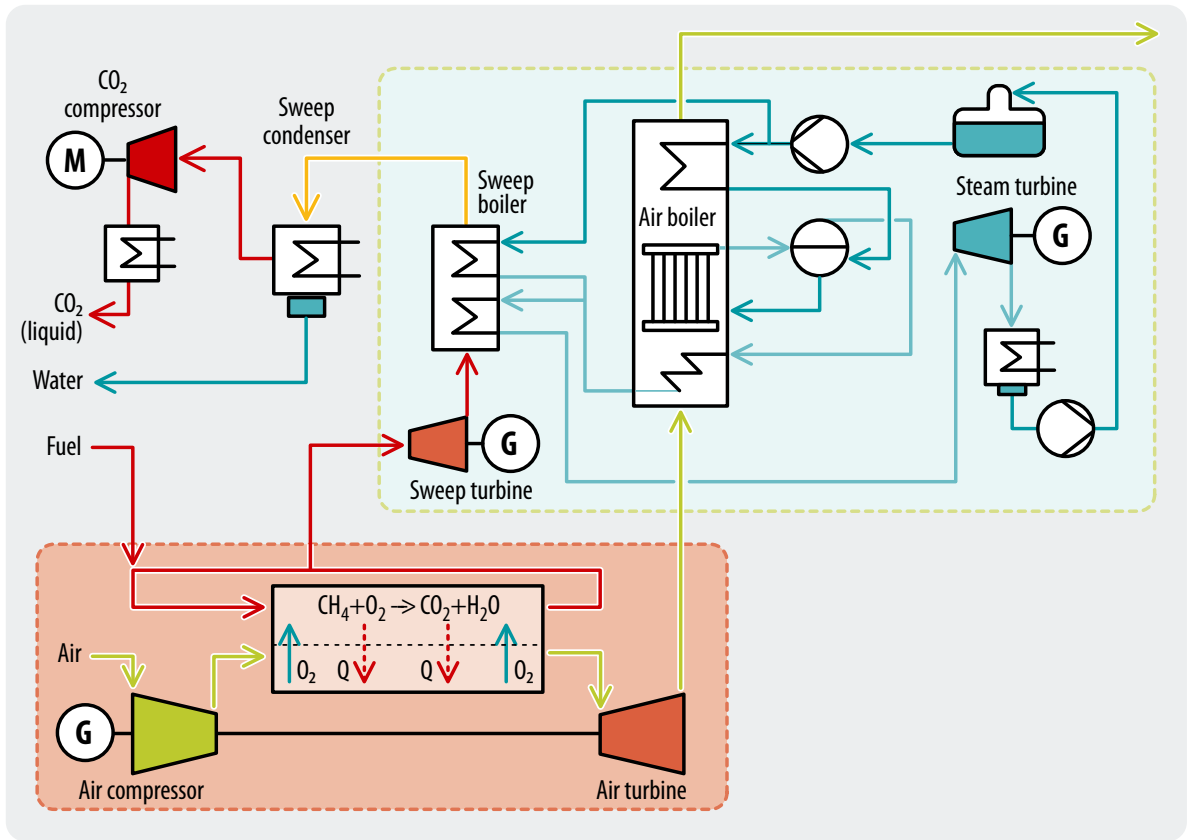




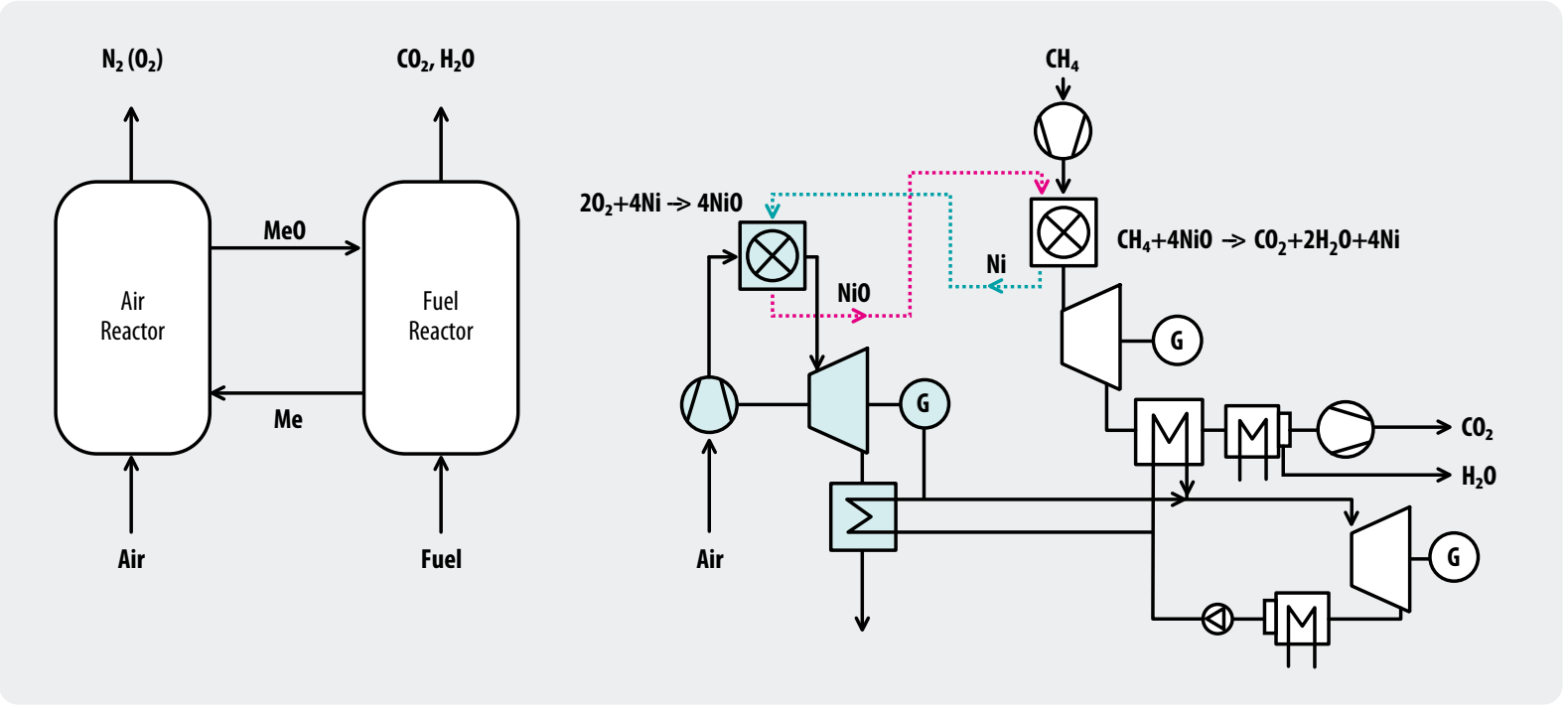

Fig. 5-13: Chemical looping combustion: basic processes (left) and material flows (right)

ration occurs directly in the combustion chamber. The fuel (natural gas) is burnt in oxygen, and the waste gases largely comprise $\mathrm{CO}_{2}$ and water and are fed into a conventional steam process. Then the water is condensed out and separated from the $\mathrm{CO}_{2}$. Calculations show that in the AZEP concept the efficiency loss in the power station is only 2-5\% compared to approx. $10 \%$ for conventional $\mathrm{CO}_{2}$ capture. After the water has been condensed out, the waste gases are made up of concentrated $\mathrm{CO}_{2}$, so there is no need for complex, expensive separation processes.

\section{Chemical Looping Combustion process (CLC)}

In this process a metal oxide is used to oxidise the fuel rather than oxygen. This avoids direct contact between the fuel and the air supplied for combustion. The waste gases produced by combustion are composed largely of $\mathrm{CO}_{2}$ and water, which means that it is easy to separate the $\mathrm{CO}_{2}$ by condensing out the water - in the same way as in the oxyfuel process. Fig. 5-13 shows the flow chart (Lyngfelt 2001). Gaseous materials are suitable as fuel; solids such as coal would have to be gasified first. The system principally comprises two reactors. In the first the carrier metal (e.g. $\mathrm{Fe}, \mathrm{Cu}, \mathrm{Ni}, \mathrm{Co}$, etc.) is oxidised in air. The oxide then passes to the second reactor where it reacts with the gaseous fuel (e.g. natural gas, $\mathrm{H}_{2}$, synthesis gas, etc.) to form $\mathrm{CO}_{2}$ and water.

The crucial issue in the CLC process is to develop an oxygen carrier that can withstand repeated chemical oxidation/reduction cycles and is resistant to physical and chemical degradation. Generally a metal oxide is used as the oxygen carrier.

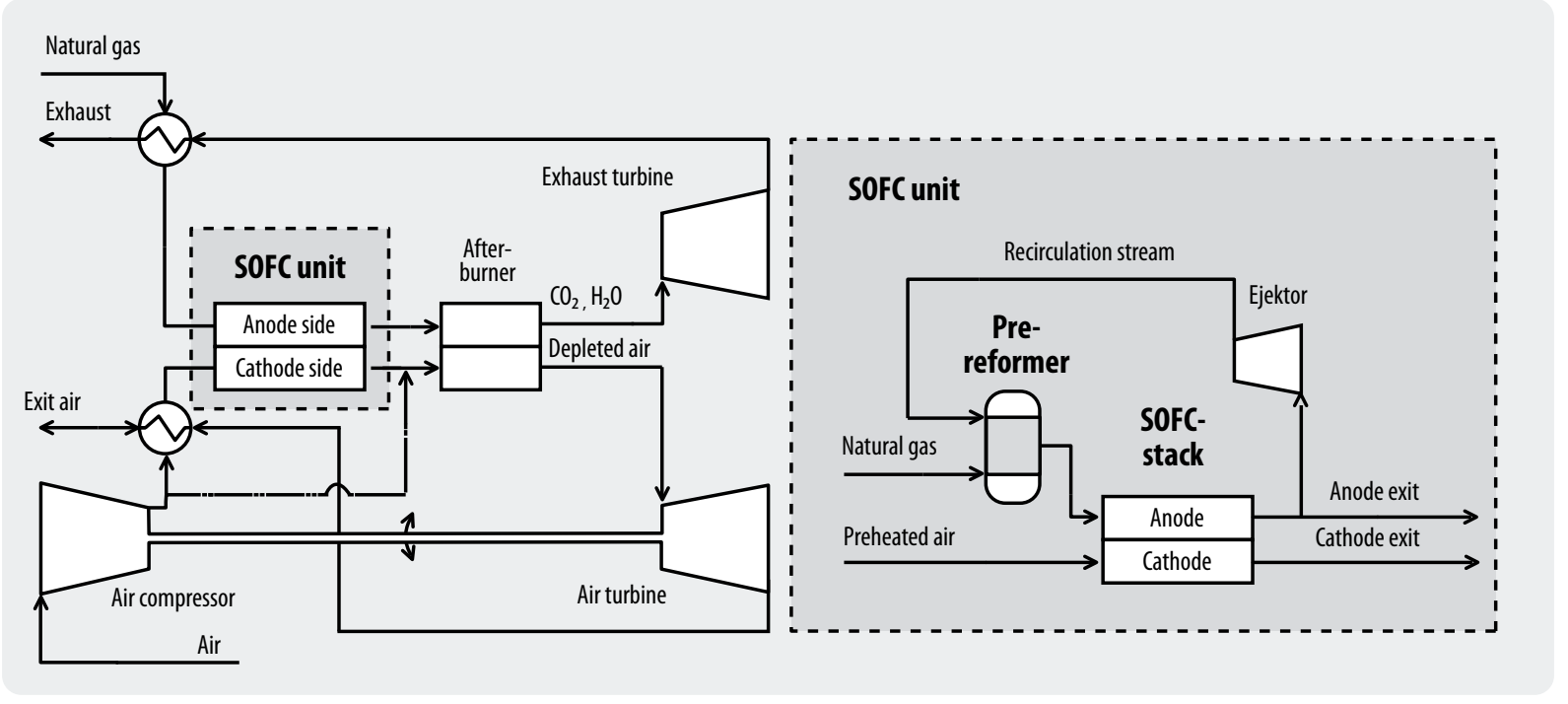

Fig. 5-14: $\mathrm{CO}_{2}$ capture in an SOFC fuel cell with gas turbine and afterburner (Source: Maurstad et al. 2005) 
At Chalmers University in Gothenburg an experimental $10 \mathrm{~kW}$ plant using nickel was operated for 100 hours in 2004 (Greenhouse Issues 2004).

\section{New high-efficiency power station concepts}

One highly efficient concept for generating electricity from natural gas is the combination of a high-temperature fuel cell with a gas turbine (see Fig. 5-14, Maurstad et al. 2005). Operating with integrated $\mathrm{CO}_{2}$ capture this system can theoretically achieve efficiencies of up to $65 \%$ on the basis of the following principles:

With SOFCs the theoretically achievable efficiency is not restricted by the Carnot process, as is the case for example with pure gas turbine and steam turbine processes.

Endothermic reforming (in the high-temperature fuel cell or a pre-reformer) converts thermal energy (waste heat) into chemical energy (fuel).

\subsubsection{Possibilities and Limits of Retrofitting $\mathrm{CO}_{2}$ Capture at Power Stations}

In the next twenty years many fossil fuel-fired power stations in Germany (and in many other countries in Europe and overseas) will come up for replacement. Given the long service life of a power station (approx. forty years) and the necessity of achieving a long-term reduction in $\mathrm{CO}_{2}$ emissions from electricity generation, today's investment decisions should take into account the possibility of later retrofitting with $\mathrm{CO}_{2}$ capture technology. Power stations where the possibility of later retrofitting is taken into account at the planning and construction stages are designated 'capture ready'.

For upcoming generating capacity replacement programmes economic considerations dictate that only modern conventional power station types in the upper output class with blocks of up to $1,000 \mathrm{MW}_{\mathrm{el}}$ and load factors of 25-100\% come into question (Fischedick et al. 2006). Additionally, rising fuel prices are causing $\mathrm{R} \& \mathrm{D}$ efforts to focus on maximising efficiency, which in itself brings about a reduction in specific $\mathrm{CO}_{2}$ emissions $\left(\mathrm{gCO}_{2} / \mathrm{kWh}_{\mathrm{el}}\right)$.

There are two possibilities for retrofitting $\mathrm{CO}_{2}$ capture in existing power stations. One is post-combustion $\mathrm{CO}_{2}$ capture from the flue gas, e.g. by MEA scrubbing; the other involves converting the combustion process to pure oxygen (oxyfuel). Both involve considerable modifications to the power station infrastructure. In the case of MEA scrubbing this means first and foremost the provision of substantial additional space for the flue gas scrubbers and the column for regenerating the scrubbing fluid, as well as the associated storage facilities. In the case of retrofitting as an oxyfuel power station, an air separation facility is required for the necessary oxygen supply, and a conversion of this type involves major rebuilding work in the furnace, for example to allow the recirculation of $\mathrm{CO}_{2}$ from the flue gas, in order to control the temperature of combustion. There are also simpler forms of retrofitting (in the form of pre-combustion technology) if the route of gasification technology is chosen from the outset. Here the initial costs are greater than for conventional power station technology, but the additional cost of retrofitting is less.

Even where the technical and local conditions allow retrofitting at all, retrofitted $\mathrm{CO}_{2}$ capture will always cause a loss in efficiency, which will have to be made up in extra fuel if the electrical output is to remain constant. The consequential increase in electricity generation costs means that $\mathrm{CO}_{2}$ capture is not economical under today's conditions. However, if the overall conditions were to change (e.g. through the introduction of $\mathrm{CO}_{2}$ certificate trading) retrofitting $\mathrm{CO}_{2}$ capture could become an economic proposition within a few years, and it is this that explains the fundamental interest in the retrofitting option. This has already led certain companies to think about ways they can build plant so that it is 'capture ready', in other words to take suitable measures to prepare plant for later retrofitting.

Sekar et al. (2005) examine future regulatory frameworks for $\mathrm{CO}_{2}$ and current investment in the electricity generating sector. In North America they identify two main technologies that are being considered today for new coal-fired power stations: PC (pulverised coal) technology and IGCC (integrated coal gasification combined cycle). They investigate the effects of future costs of $\mathrm{CO}_{2}$ regimes, of retrofitting $\mathrm{CO}_{2}$ capture and of a possible emissions levy. Using the key data (e.g. $\mathrm{CO}_{2}$ tax) they compare the economic viability of the two concepts and determine the point at which it becomes worthwhile, for example, to retrofit $\mathrm{CO}_{2}$ capture.

In the following we examine some of the preconditions for retrofitting existing power stations. Process integration is particularly important in order to minimise the efficiency losses that several studies predict for postcombustion $\mathrm{CO}_{2}$ capture (in the range $>10 \%$ ). Gibbins et al. (2004) propose six rules for retrofitting, and explain them using examples. The aim of their work was to maximise the effectiveness of post-combustion solutions and to identify potential for improvement over and above earlier studies that previously failed to take into consideration optimised process integration.

- One of the most important preconditions for retrofitting $\mathrm{CO}_{2}$ capture at the power station is the considerable additional space requirement, which can act as a limiting factor (initial estimates put the additional space requirement at about 50 to $100 \%)$.

- If power stations are retrofitted with $\mathrm{CO}_{2}$ capture they should demonstrate a good level of efficiency or else the power generation process itself must be modernised. It makes no economic sense to retrofit flue gas $\mathrm{CO}_{2}$ capture in a power station that is operating at an efficiency of $30 \%$. 
- With $\mathrm{CO}_{2}$ capture from flue gas, the expense in terms of equipment and energy increases disproportionately as the $\mathrm{CO}_{2}$ concentration in the flue gas diminishes. This means that partial $\mathrm{CO}_{2}$ capture may be the most economic solution.

\subsection{Concepts for Moving towards Large-Scale Production of $\mathrm{H}_{2}$}

Large-scale generation of hydrogen from fossil fuels can be accomplished by reforming natural gas, partial oxidation of hydrocarbons and gasification of coal. Hydrogen can also be produced as a secondary product via electrolysis of water (e.g. as a by-product of chlorine production). Electrolysis of water can function without using primary fuels and is regarded as a long-term pillar of a renewable hydrogen economy.

\subsubsection{Large-scale $\mathrm{H}_{2}$ Production Today (Steam Reforming of Natural Gas)}

One of the largest producers of hydrogen is the German firm of Linde, which also manufactures $\mathrm{H}_{2}$ synthesis plant in capacities up to $100,000 \mathrm{~m}_{\mathrm{N}}^{3} / \mathrm{h}$ (approx. 300 $\mathrm{MW})$. In the Leuna/Bitterfeld region major customers are supplied via a pipeline network, and the gas is distributed in bottled form through eight hundred dealers across Germany.

In the first step of the steam reforming process natural gas and steam are heated to high temperatures in a reactor to generate hydrogen, carbon monoxide and carbon dioxide. In the second step steam is used to convert the carbon monoxide to carbon dioxide and water (CO shift stage). Finally, the hydrogen is separated from the residual gas using pressure swing adsorption (PSA). As well as $\mathrm{CO}_{2}$, the residual gas also contains up to $60 \%$ combustible elements and is used to heat the reformer.

\subsubsection{Possibilities for $\mathrm{CO}_{2}$ Capture and Expense Involved (in $\mathrm{H}_{\mathbf{2}}$ Generation)}

In large-scale $\mathrm{H}_{2}$ production $\mathrm{CO}_{2}$ can be captured using MEA scrubbing, as outlined in Fig. 5-15 (Vagnetti 2005). In the outlined arrangement the $\mathrm{CO}_{2}$ cannot be captured completely because the residual gas and part of the natural gas are used to heat the reformer, and the waste gas produced there also contains $\mathrm{CO}_{2}$. Vagetti (2005) assumed a $\mathrm{CO}_{2}$ capture rate of $71 \%$. The effort of $\mathrm{CO}_{2}$ capture is comparable with that of amine-based post-combustion systems for capturing $\mathrm{CO}_{2}$ from the flue gases of coal-fired power stations. In order to generate base data for life cycle assessments the above process was modelled using IPSE-Pro process simulation software. Here a $\mathrm{CO}_{2}$ capture rate of $51 \%$ was found, which is lower than that found by Vagnetti (2005).

\subsubsection{Hydrogen Production by Gasification of Solids}

Currently approx. $83 \%$ of total hydrogen production originates from natural gas reforming and approx. $14 \%$ from naphtha reforming in oil refinery processes. Only approx. $3 \%$ is produced through the gasification of heavy hydrocarbon residues (see simplified process flow chart in Fig. 5-16). The process is also fundamentally suited for producing $\mathrm{H}_{2}$ from coal. A pumpable slurry of hydrocarbon residues or coal is gasified with oxygen and steam. Alongside $\mathrm{H}_{2}$ and other components $\left(\mathrm{CO}_{2}\right.$, $\mathrm{H}_{2} \mathrm{~S}, \mathrm{COS}$ ) the raw gas also contains up to approx. $50 \%$ $\mathrm{CO}$, which has to be converted using steam to $\mathrm{H}_{2}$ and $\mathrm{CO}_{2}$ in a shift stage. The main steps of the process are:

- Air separation and oxygen compression

- Entrained-flow gasification (multi-purpose gasification, MPG) quench configuration

- Raw gas for CO conversion

- Desulphurisation

- $\mathrm{H}_{2}$ separation (not illustrated in Fig. 5-16)

The gasification part and the gas conditioning stages of the described process for generating $\mathrm{H}_{2}$ from coal are largely the same as those in an IGCC power station with $\mathrm{CO}_{2}$ capture before combustion in a gas turbine. $\mathrm{H}_{2}$ separation is not shown in the simplified process flow chart. Depending on the quality requirements for the generated hydrogen, the following possibilities are available for separating the $\mathrm{H}_{2}$ :

- For a high degree of purity of $\mathrm{H}_{2}$ separation by pressure swing adsorption (PSA) is an option. The remainder is a mixture of $\mathrm{CO}_{2}$, residual $\mathrm{H}_{2}, \mathrm{CO}$ and residual gases.

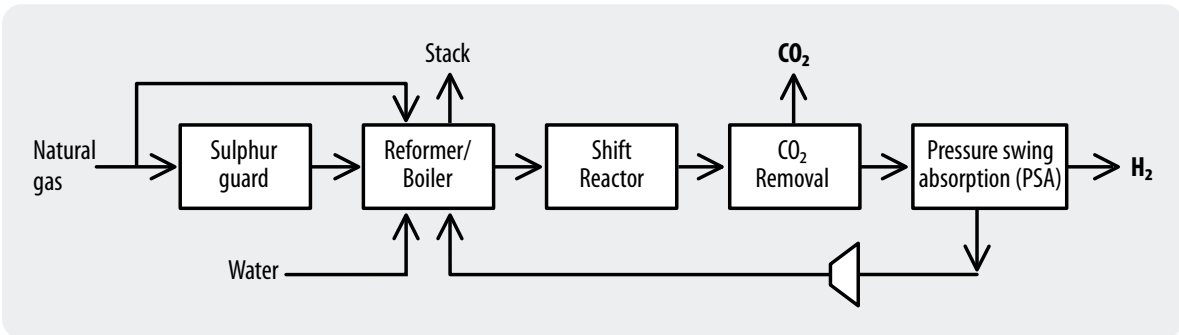

Fig. 5-15:

Hydrogen production from natural gas by steam reforming and $\mathrm{CO}_{2}$ capture (MEA scrubbing) 
Fig. 5-16:

Simplified process flow chart for gasification of carbonaceous slurries for $\mathrm{H}_{2}$ production (Ullmann 2002)

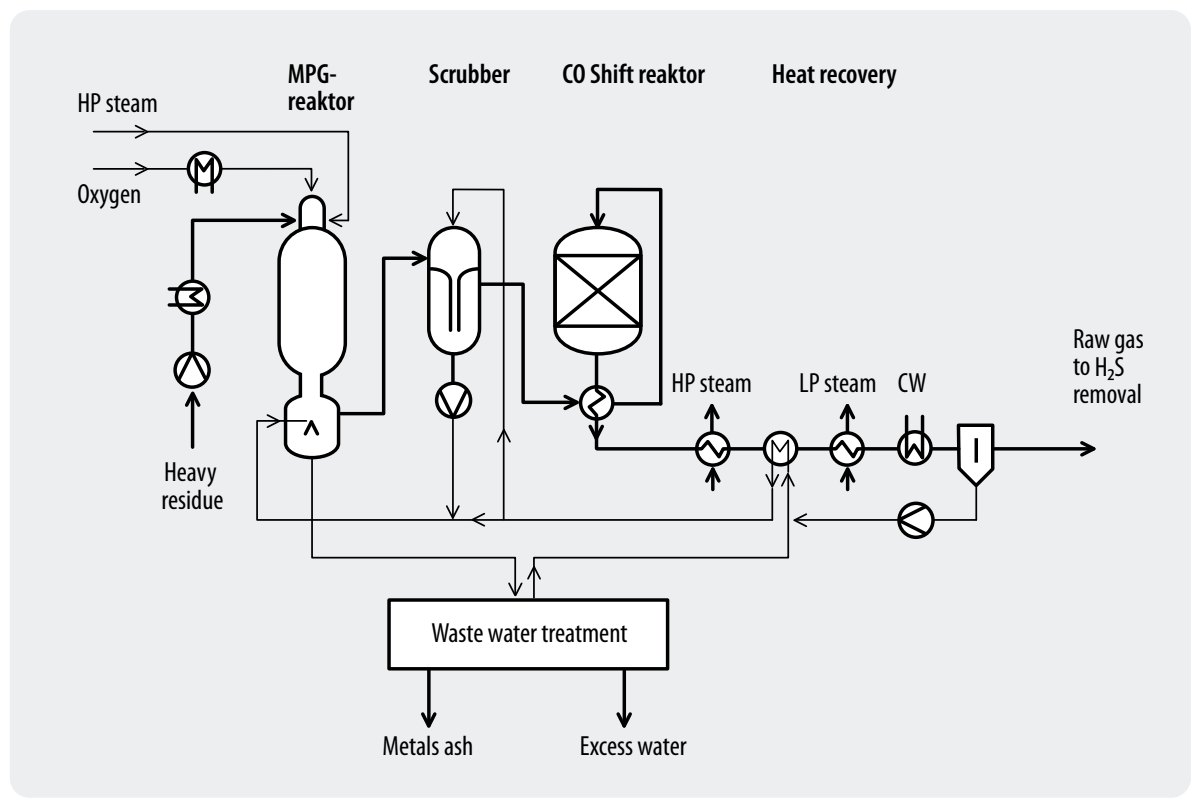

- $\mathrm{CO}_{2}$ can be captured from the product gas in the same way as in the IGCC power station concept (physical scrubbing, e.g. Rectisol). The remaining gas consists largely of hydrogen (but not in the highly pure form), which in an IGCC power station would be burnt in a special $\mathrm{H}_{2}$ gas turbine.

\subsection{4 $\mathrm{CO}_{2}$-free Concepts for Generating $\mathrm{H}_{2}$}

Since the early 1980s Kværner Engineering S.A. of Norway has been working on a process for $\mathrm{CO}_{2}$-free generation of hydrogen that bears the company's name (Kværner Carbon Black and Hydrogen Process). In this process hydrocarbons (natural gas, crude oil) are separated into activated carbon (pure carbon) and hydrogen in a plasma torch at approx. $1600^{\circ} \mathrm{C}$. A pilot plant that has been operating in Canada since 1992 uses 1,000 m ${ }_{\mathrm{N}}^{3} / \mathrm{h}$ natural gas and $2,100 \mathrm{~kW}_{\mathrm{el}}$ electrical energy to generate $1,000 \mathrm{~kW}$ hot steam, about $500 \mathrm{~kg} / \mathrm{h}$ activated carbon and $2,000 \mathrm{~m}_{\mathrm{N}}^{3} / \mathrm{h}$ of hydrogen. Taking into consideration all the useable products, the plant achieves an efficiency of $93 \%$. Approx. $50 \%$ of this is represented by the hydrogen, about $40 \%$ by the activated carbon and $10 \%$ by the hot steam.

\subsection{Learning Curves and Possible Cost Degressions}

Estimates of possible cost degressions for economic goods often use the Boston model, according to which doubling the volume can be expected to result in cost degressions in the range of $10-30 \%$. In principle this model can also be applied to estimate the costs of future technologies for reducing $\mathrm{CO}_{2}$ in the electricity generation sector, as described in detail by Riahi et al. (2006) and applied to estimate the future costs of power station concepts with CCS. Here, the basis of an expected cost reduction is a continuous improvement in the tech- nology with each new generation manufactured, gains in experience to apply technologies more efficiently and rationalisation gains in manufacturing of greater volumes. These effects produce learning curves that describe changing plant costs as a function of cumulative installed capacity. When we consider different scenarios these learning curves allow us to take account of a dynamic cost reduction resulting from an assumed implementation of the technology under consideration.

In order to predict possible future trends concerning power station costs with $\mathrm{CO}_{2}$ capture Rubin et al. (2006) examined the historical cost development of power station components such as flue gas desulphurisation and de-nitrification as well as classical power station components. The learning rates they found for power station engineering components are listed in Table 5-2.

It is interesting to note here that the learning rates achieved for desulphurisation correspond to other power station engineering learning rates, but were only achieved because legal measures forced the installation of the volume of capacity required to cause cost reductions (Riahi et al. 2004). This fact somewhat relativises the applicability to other fields. Another interesting point regarding learning rates for CCS technology is found in an uncertainty analysis prepared by Gielen (2003), who concludes that when comparing scenarios learning effects play only a subsidiary role compared to other uncertainties.

For the CCS-specific components we can draw on comparable learning rates from the field of flue gas cleaning. But for investment costs for conventional power station technology learning curves can be regarded as relatively small (e.g. pulverised-coal-firing). On the one hand, we are dealing here with highly developed technologies and manufacturing processes, on the other the demand for continuing increases in efficiency often also results in increasing manufacturing costs and the 
Table 5-2: Learning rates for capital and running costs for power station technologies, after Rubin et al. (2006)

\begin{tabular}{|l|c|c|}
\hline \multirow{2}{*}{ Technology } & \multicolumn{2}{|c|}{ Learning rate* } \\
\cline { 2 - 3 } & $\begin{array}{c}\text { Capital } \\
\text { costs }\end{array}$ & $\begin{array}{c}\text { Running } \\
\text { costs }\end{array}$ \\
\hline Flue gas desulphurisation & 0.11 & 0.22 \\
\hline $\begin{array}{l}\text { SCR denitrification } \\
\text { (selective catalytic reduction) }\end{array}$ & 0.12 & 0.13 \\
\hline Combined cycle) & 0.10 & 0.06 \\
\hline Coal dust firing & 0.05 & $0.07-0.30$ \\
\hline $\begin{array}{l}\text { LNG production } \\
\text { (liquefied natural gas) }\end{array}$ & 0.14 & 0.12 \\
\hline $\begin{array}{l}\text { Qxygen production } \\
\text { Hydrogen production } \\
\text { (SMR, steam methane reforming) }\end{array}$ & 0.10 & 0.05 \\
\hline
\end{tabular}

* Proportional reduction in costs caused by a doubling of capacity

use of expensive materials. Increasing efficiency with unchanged investment costs can also reduce the costs of electricity generation.

The learning effects discussed here for CCS components and conventional power station components were used when determining the electricity generation costs of CCS power stations and are explained in detail in chapter 12. Taking as the base line reference technologies defined as 'commercially viable' by 2020 , we define there a technology status of 'perfected CCS power stations' for 2040 that will have realised efficiency gains and improved $\mathrm{CO}_{2}$ capture rates and therefore reduced specific investment costs.

\subsection{Relevant Applications for Energy Systems, Case Study Germany}

Our examination of the question of capture and storage of carbon dioxide has been restricted (apart from the examination of hydrogen production) to the field of electricity generation in power stations, because there large quantities of $\mathrm{CO}_{2}$ are emitted centrally. The highest specific $\mathrm{CO}_{2}$ emissions per generated $\mathrm{kWh}_{\mathrm{el}}$ are found with coal-fired power stations (especially lignite), which should not, however, be taken to mean that there is no case for $\mathrm{CO}_{2}$ capture in gas-fired power stations.

In Germany, for example, about half of net electricity output is currently based on coal. The scenarios for future energy supply assume various degrees of reduction in coal's share in Germany's electricity generating capacity. Despite this reduction it is forecast that Ger- many will need to replace approx. $40 \mathrm{GW}_{\mathrm{el}}$ of installed power station capacity by 2030 (Fischedick et al. 2006), which partially - or depending on changed overall conditions (cf. Prognos and EWI 2006) possibly largely will have to be covered by coal-fired power stations. Worldwide it is expected that large numbers of coalfired power stations will be built (mainly in China and India). Even if CCS technology is not applied in replacement German power stations in the next two decades, the technology is relevant for Germany because leading manufacturers and exporters of power station technology are based here.

With regard to reducing $\mathrm{CO}_{2}$ when using fossil fuels, the main interest is on technologies that increase efficiency. In recent decades - due to more stringent environmental regulations (which in some cases have led to increased fuel consumption) - it has been possible to achieve a continuous increase in power station efficiency. For reasons of thermodynamics and material technology this trend cannot continue for ever. So a further significant reduction in $\mathrm{CO}_{2}$ from electricity generation using fossil fuels requires the application of $\mathrm{CO}_{2}$ capture methods that currently cause efficiency losses or new power station concepts. While $\mathrm{CO}_{2}$ capture technologies will be available in the medium term, the development of new power station concepts should be regarded rather as a long-term matter.

From today's perspective we cannot say which of the $\mathrm{CO}_{2}$ capture processes that will in principle become available in the short to medium term will have the best chances of implementation. From the technological point of view, all three options could become relevant in the future. Flue gas scrubbing will probably be an adequate option for retrofitting, especially if it turns out to be possible to reduce the energy required still further through new scrubbing agents. IGCC technology is not yet ready for implementation in the electricity generating process, but there is significant room for improvement. For the oxyfuel process it will depend on whether the demonstration projects that have recently been initiated manage to collect worthwhile experience and successfully put the lessons learned into practice.

Whether $\mathrm{CO}_{2}$ capture technologies become relevant for power station replacement will depend on political and economic circumstances. Without corresponding incentives retrofitting existing power stations with $\mathrm{CO}_{2}$ capture will not be relevant. In order to be prepared for future developments it might make sense to build new power stations 'capture ready' (prepared for retrofitting with $\mathrm{CO}_{2}$ capture).

With regard to choice of location, above all the space required for the additional components will be a decisive variable. But connection to suitable storage structures could also represent a significant factor (cf. chapter 8 ). Good chances for the introduction of CCS technologies exist for power station locations in connection with a specific demand for $\mathrm{CO}_{2}$, for example for enhanced oil/gas recovery (EOR/EGR). 


\section{Chapter 6 \\ $\mathrm{CO}_{2}$ Transport}

This chapter takes a closer look at the technical and thermodynamic characteristics of $\mathrm{CO}_{2}$ which are relevant for transport and estimating the energy required to transport $\mathrm{CO}_{2}$ in different physical states and by different means (section 6.1). It then goes on to examine the various transport options available for $\mathrm{CO}_{2}$ and their specific advantages and disadvantages (section 6.2). Finally, in section 6.3, we compare specific transport costs for various transport options cited in a number of scientific studies.

\subsection{Physical State for Transport and Energy Required for Compression and Transport}

When $\mathrm{CO}_{2}$ is transported by road, rail or water it is usually under high pressure in a liquid or supercritical state (exception: dry ice). For pipeline transport the $\mathrm{CO}_{2}$ is brought to a supercritical pressure higher than 74 bar at a density of approx. $1,100 \mathrm{~kg} / \mathrm{m}^{3}{ }^{1}$ The advantage of the supercritical state over the liquid state is that stability is greater and problems with cavitation in pumps, com- pressors, etc. are not to be expected..$^{2}$ Gaseous transport is less attractive, because the density - and consequentially the possible throughput - is very much lower.

Transport of solid $\mathrm{CO}_{2}$ (dry ice) is only relevant for dry ice applications and plays no role for $\mathrm{CO}_{2}$ storage, because the production of dry ice is extremely energy-intensive. VGB (2002) cites a direct specific energy requirement of approx. $375 \mathrm{kWh} / \mathrm{t}_{\mathrm{CO} 2}$ for producing dry ice and transporting it two hundred miles, while the same source cites $106 \mathrm{kWh} / \mathrm{t}_{\mathrm{CO} 2}$ for transporting liquid $\mathrm{CO}_{2}$ one hundred kilometres by pipeline (of which $93 \mathrm{kWh} / \mathrm{t}_{\mathrm{CO} 2}$ is required simply for liquefaction) and $26 \mathrm{kWh} / \mathrm{t}_{\mathrm{CO} 2}$ for transport in the gaseous state. In his detailed early CCS study Göttlicher (1999) cites specific energy requirements of $111-113 \mathrm{kWh} / \mathrm{t}$ for compressing $\mathrm{CO}_{2}$ to a pressure of 110 bar (corresponding to an energy requirement of approx. $3.5 \%$ in relation to coal fuel $\mathrm{H}_{\mathrm{i}}$ ), $160 \mathrm{kWh} / \mathrm{t}$ for cryogenic liquefaction $(5.2 \%)$ and $260-420 \mathrm{kWh} / \mathrm{t}$ for dry ice production $(8.4-13.5 \%)$.

Fig. 6-1 shows the direct and indirect energy requirements per tonne of $\mathrm{CO}_{2}$ for dry ice production and

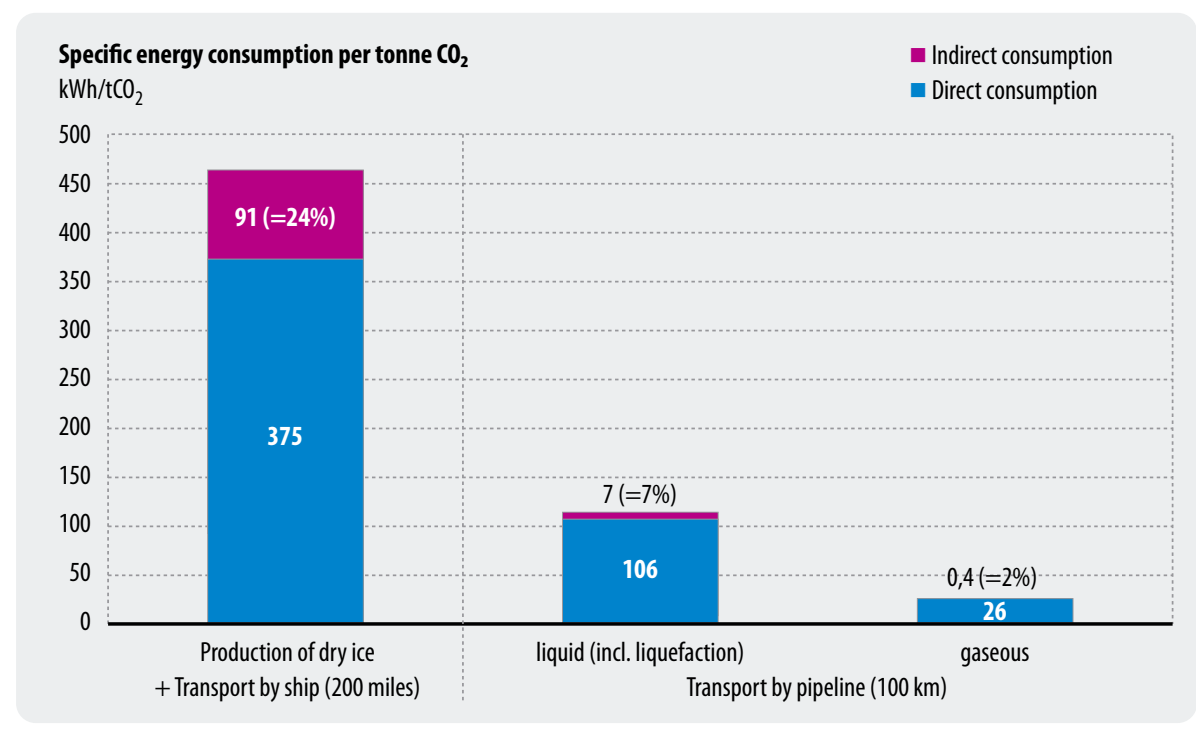

Fig. 6-1:

Specific direct and indirect energy consumption for producing and transporting dry ice $\left(\right.$ solid $\left.\mathrm{CO}_{2}\right)$ and pipeline transport of liquid and gaseous CO, (VGB 2002 (direct energy consumption) and own calculations (indirect energy consumption))

\footnotetext{
1 In thermodynamics, the term 'supercritical' is used to describe a very dense state above the 'critical point', where a clear distinction between the liquid and gaseous states is no longer possible.
}

2 'Cavitation' is the formation of gas bubbles in a liquid caused by local negative pressure. The pressure surges caused by sudden vapourisation and subsequent implosion of gas bubbles can be very harmful to surrounding materials and equipment. 
for pipeline transport in the form of a bar chart, the indirect energy requirements here being understood as the energy required for preceding and subsequent process steps (data for direct consumption from VGB 2002). The chart clearly shows how dry ice production (including two hundred miles of sea transport) involves additional indirect energy consumption amounting to about a quarter of the direct energy requirement, and corresponding additional $\mathrm{CO}_{2}$ emissions. ${ }^{3}$ For pipeline transport the indirect energy consumption and emissions are much lower, at about $7 \%$ (liquid) and $2 \%$ (gaseous). The lower energy requirement for gaseous transport is relativised, however, because the $\mathrm{CO}_{2}$ will probably have to be compressed for subsequent storage.

Ship transport involves higher specific $\mathrm{CO}_{2}$ emissions than offshore pipelines because of the additional energy required by the liquefaction plant and the fuel required by the tankers. The IEA estimates the additional emissions for ship transport to be at least $2.5 \%$ (for a distance of $200 \mathrm{~km}$ ) up to a maximum of $18 \%$ (for a distance of $12,000 \mathrm{~km}$ ). By comparison the specific emissions for pipelines (according to IEA 2004) are only approx. 1 to $2 \%$ per $1,000 \mathrm{~km}$. The authors of the IPCC study (2005) state specific additional emissions of 3 to $4 \%$ per $1,000 \mathrm{~km}$ for ship transport through cargo vaporisation losses and $\mathrm{CO}_{2}$ emissions from the ship's engines, which they believe could be reduced to 1 to $2 \%$ per $1,000 \mathrm{~km}$ by collecting and reliquefying the vaporised $\mathrm{CO}_{2}$. However, they do not give figures for the energy required for cooling and (re)liquefaction.

For transport, $\mathrm{CO}_{2}$ is generally first compressed to 8 to $12 \mathrm{MPa}$ for transport on land and up to $20 \mathrm{MPa}$ for offshore transport (and thus liquefied). Of the studies under consideration here, only the ECOFYS study (2004) itemises the costs for in detail. As an example, the ECOFYS study calculated the costs for the following plant:

$\begin{array}{ll}\text { - Output of } \mathrm{CO}_{2}: & 50 \mathrm{~kg} / \mathrm{s} \\ \text { - Full load hours: } & 7,500 \text { hours/year } \\ \text { - Annuity: } & \begin{array}{l}13 \% \text { (discount rate } 10 \% \\ \text { over an operating period of } \\ \text { fifteen years) }\end{array}\end{array}$

\section{- Electricity price: $\quad 0.04 \mathrm{EUR} / \mathrm{kWh}_{\mathrm{el}}$}

The following pie chart (Fig. 6-2) shows that the electricity consumption alone represents more than half of the cost of compression, followed by depreciation and running costs.

\section{Breakdown of compression costs}

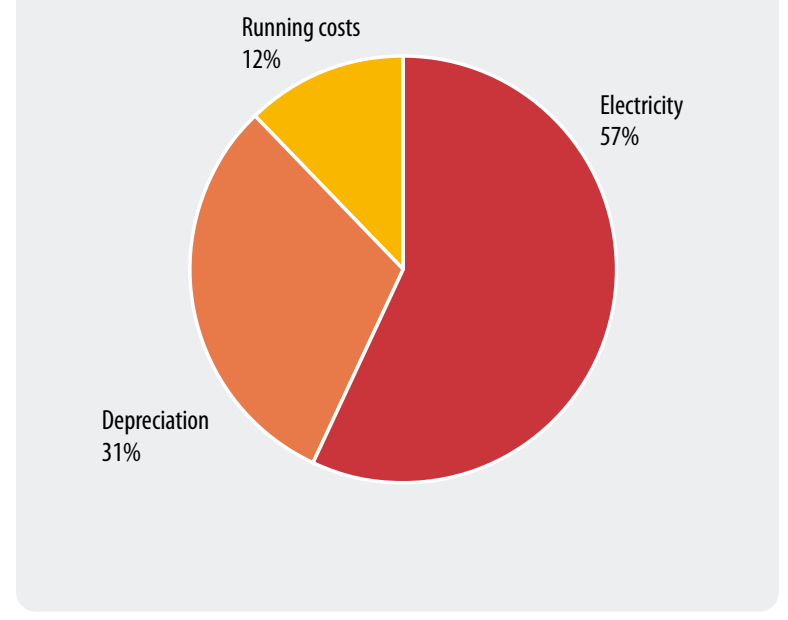

Fig. 6-2: Breakdown of compression costs (ECOFYS 2004)

Fig. 6-3 shows the cost curves in relation to throughput $(\mathrm{kg} / \mathrm{s})$ for different levels of annual utilisation $(100 \%=$ 8,760 hours). Clearly, the cost of compression depends strongly on the flow rate, which means that on the cost side there is a strong incentive to centralise $\mathrm{CO}_{2}$ compression - which is more or less automatically the case where $\mathrm{CO}_{2}$ is captured at the power station.

Gerling (2004), citing figures from the GESTCO Summary Report (2003), gives a range of EUR 3.5 to EUR $26.1 /$ t of captured $\mathrm{CO}_{2}$ for the cost of compression (with a mean of EUR 8.4/t $\mathrm{CO}_{2}$ ).

According to ECOFYS the costs of compression amount to between EUR 6 and EUR 10/t of captured $\mathrm{CO}_{2}$, assuming the compressor output is greater than $100 \mathrm{~kg} / \mathrm{s}$. These figures concur with the findings of the GESTCO project. The electricity required for compression reduces the efficiency of the overall process by a further 2 to 2.7 percentage points for gas-fired power stations and 3 to 4 percentage points for coal-fired ones (Göttlicher 2003a). 
Compression costs (EUR/t $\left.\mathrm{CO}_{2}\right)$

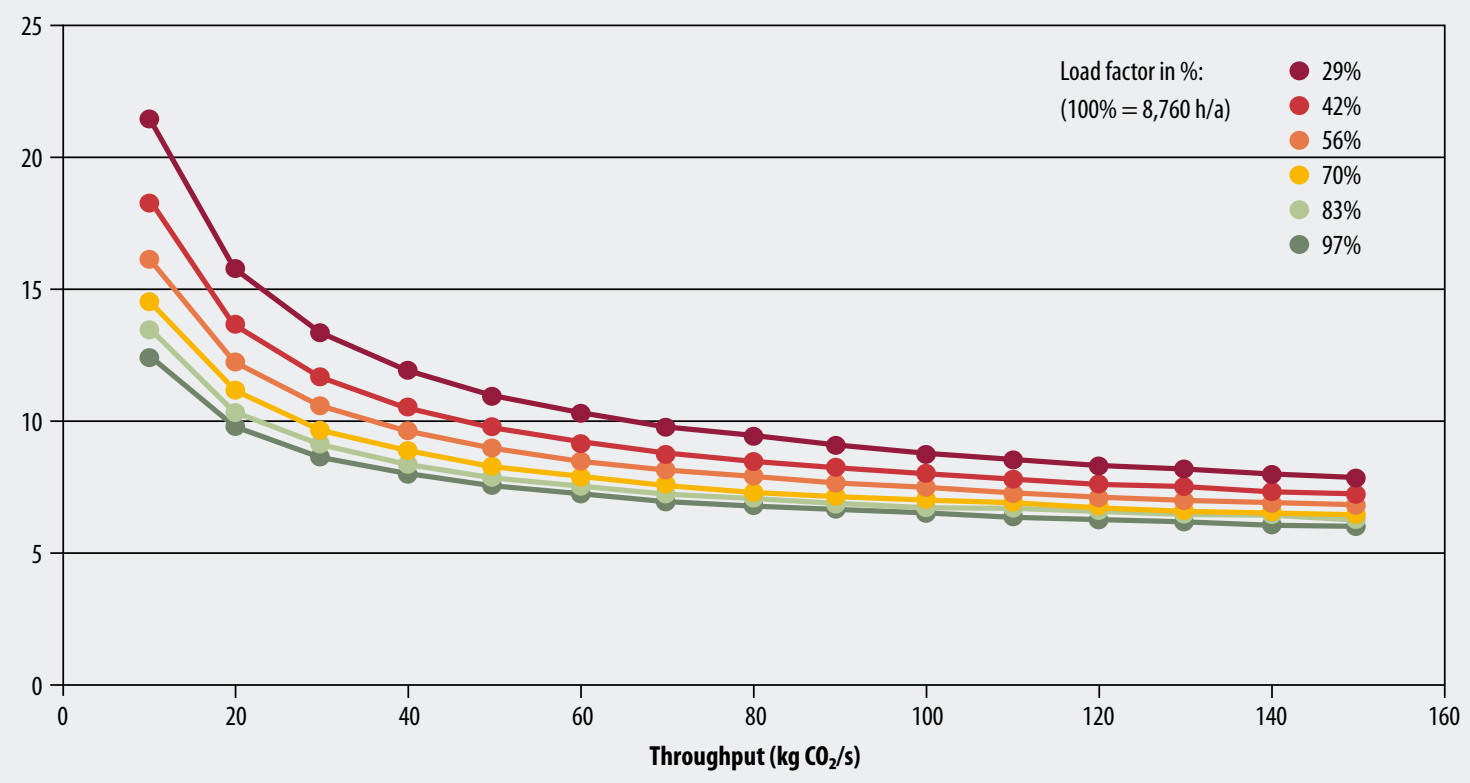

Fig. 6-3: Compression costs as a function of compressor throughput and load factor (ECOFYS 2004)

\subsection{Transport Options}

The following three parameters are crucial when selecting a suitable means of transport for $\mathrm{CO}_{2}$ :

- Transport capacity,

- Distance (from source to sink),

- Sink location (onshore/offshore).

The most important means of transport for handling large quantities of gases in general - and $\mathrm{CO}_{2}$ in particular - is the pipeline. Of all the non-pipeline transport options, the ship is the only one that could sensibly be used. Other $\mathrm{CO}_{2}$ transport options (road tanker, pressurised cylinders, dry ice) are only relevant on a small scale (e.g. for breweries and the food industry in volumes of a few $100,000 \mathrm{t} / \mathrm{a}$ ) or for the introduction phase of a CCS infrastructure. In the following sections we examine the individual transport options in greater detail before moving on - in section 6.3 - to estimate the respective costs involved.

\subsubsection{Pipeline Transport}

\section{Onshore}

On land pipelines represent the only sensible alternative for bulk transport. Inland waterways, rail and road transport are conceivable as alternatives only for a transitional period (while $\mathrm{a}_{2}$ pipeline infrastructure is being built).

\section{Offshore:}

Offshore pipelines are well suited for handling highvolume capacities at low cost, but first the infrastructure must be constructed, which is time-consuming and expensive. Ships, on the other hand, can be used more flexibly and are available more quickly, but they require temporary storage facilities and loading/unloading infrastructure.

Considerable experience has already been gathered in gas pipeline construction and operation both for onshore pipelines (generally laid at depths of at least one metre) and offshore (down to a depth of 2,200 m).

For onshore pipeline transport over greater distances or in hilly terrain compressor stations may be required along the pipeline. If the initial pressure is sufficient and/or transport speed is slow (with large pipe diameter) the resulting smaller pressure losses may make it possible to do without expensive intermediate compressor stations. ${ }^{4}$ The usual transport speed is approx. 1 to $5 \mathrm{~m} / \mathrm{s}$, the usual operating parameters are one hundred to several hundred bar pressure and a maximum temperature of $50^{\circ} \mathrm{C}$.

So pipeline design is a matter of optimising the most important parameters: diameter, wall thickness and pressure loss. The quality (purity) of the $\mathrm{CO}_{2}$ being transported also requires adequate material selection

4 For example the 328-kilometre Weyburn Pipeline in the United States operates without intermediate compressor stations. 
and corrosion protection. For example, for dry $\mathrm{CO}_{2}$ with an $\mathrm{H}_{2} \mathrm{O}$ proportion under 50 ppm simple carbon steel is sufficient. ${ }^{5}$

The main parameters relevant for pipeline design are listed below:

\section{Design parameters}

- Pressure, temperature,

- Diameter, length, wall thickness,

- Impurities / purity of $\mathrm{CO}_{2}{ }^{\circledR}$ corrosion protection requirements,

- Number of compressors and measuring stations

- Terrain and infrastructure: topography, composition of ground, settlements, obstacles (water bodies, roads, pipelines ...), nature reserves,

- Vegetation, geothermal and seismic activity,

- Offshore: restrictions through fishing activities (nets), currents, shipping (anchors).

\section{Safety aspects for $\mathrm{CO}_{2}$ pipelines}

Because $\mathrm{CO}_{2}$ is not combustible there is no risk of explosion - unlike natural gas, for example, which is already transported in large quantities by pipeline. Nonetheless, certain safety precautions must still be taken, because $\mathrm{CO}_{2}$ leads to death by asphyxiation in high concentrations (> 40,000 ppm) - and it is colourless and odourless. ${ }^{6}$ Additionally, $\mathrm{CO}_{2}$ is heavier than air, which means that it would collect at high concentrations in depressions. It may also be necessary to take account of the effects of unwanted impurities. For example, NIOSH puts the toxicity threshold for $\mathrm{H}_{2} \mathrm{~S}$ at 100 ppm. ${ }^{7}$

EOR statistics indicate a smaller leakage risk than for pipelines carrying natural gas or hazardous substances, but safety considerations still dictate that pipelines should be routed away from densely populated areas wherever possible. In populated areas safety measures against leakage and overpressure are required, the latter because if the temperature increases suddenly above the allowable level the $\mathrm{CO}_{2}$ gas may move from the liquid/ supercritical state to the gaseous state, which can cause a sudden and very large increase in pressure.

Pipeline monitoring can be external (outside the pipeline) or internal. Onshore pipelines can be monitored externally on foot or from vehicles, or from the air, while at sea special ships or remotely operated submersibles can be used. Fixed monitoring devices and 'pipeline pigs' (cylindrical automatic cleaning and inspection devices propelled through a pipeline by pressure) are possible methods of internal monitoring.

5 Example for a specification: $\mathrm{CO}_{2}>95 \%{ }_{\mathrm{Mol}}$, no free $\mathrm{H}_{2} \mathrm{O}$, $\mathrm{H}_{2} \mathrm{O}_{\text {vapour }}<50$ ppm, $\mathrm{H}_{2} \mathrm{~S}<1,500$ ppm.

6 For this reason there are proposals to odourise the $\mathrm{CO}_{2}$ gas to make it detectable, as is already done with household natural gas supplies.

7 NIOSH: National Institute for Occupational Safety and Health, USA.
Offshore pipelines are especially vulnerable to damage by ships' anchors and fishing nets. The potential ecological impacts of a marine pipeline leak have not yet been investigated.

The inherent risk of military and/or terrorist attack on pipeline infrastructures is held to be relevant enough to have already made it the subject of various conferences.

Risk studies for onshore natural gas pipelines found a statistical accident frequency of less than 0.02 accidents per 100 kilometres per year for Western Europe in 2002. Larger pipelines $(>500 \mathrm{~mm})$ present an even smaller risk $(<0.005 / 100 \mathrm{~km} /$ year $)$. An analysis of accidents in the United States between 1986 and 2002 (Guijit 2004) found a statistical risk of 0.011 accidents $/ 100 \mathrm{~km} /$ year. When comparing figures it must be remembered that the thresholds and definitions for 'accidents' in the different studies are not necessarily identical. Gale (2002) reports ten accidents between 1990 and 2002 in the onshore $\mathrm{CO}_{2}$ pipelines that already exist in the United States, which corresponds to an accident rate of 0.032 accidents $/ 100 \mathrm{~km} /$ year. $^{8}$ Damage amounting to US $\$ 470,000$ was recorded, but no deaths or injuries. Because $\mathrm{CO}_{2}$ pipelines have to date overwhelmingly been laid in thinly populated regions, it can be expected that the risks associated with accidents will increase when future infrastructure is built in densely populated areas too.

\section{Experience with $\mathrm{CO}_{2}$ pipeline transport}

There is much experience with on- and offshore pipeline transport of large quantities of gas, oil, condensate and water over distances up to more than $1,000 \mathrm{~km}$, with pipelines crossing deserts, mountains, densely populated regions, the Arctic, and oceans (in oceans with pipeline diameter up to $1,400 \mathrm{~mm}$ and at depths down to $2,200 \mathrm{~m}$ ). Worldwide there are seven large onshore high-pressure $\mathrm{CO}_{2}$ pipelines in three countries (five in the United States, most of them in the Permian Basin, one from the United States to Canada and one in Turkey) with a total transport capacity of approx. $50 \mathrm{Mt} / \mathrm{a}$ and a total length of approx. $2,600 \mathrm{~km}$. The oldest is the Canyon Reef Carriers Pipeline, which the American firm Kinder Morgan has been operating since 1972. It supplies $5.2 \mathrm{Mt} \mathrm{CO}_{2}$ annually from a coal gasification plant to consumers $225 \mathrm{~km}$ away. The largest facility, which opened in 1984, is also in the United States, supplying $\mathrm{CO}_{2}$ from a natural source in the McElmo Dome through an $808-\mathrm{km}$ pipeline with an annual capacity of 19.3 Mt. Oil producers who use carbon dioxide to boost production (EOR) pay about US \$9-18/tonne for $\mathrm{CO}_{2}$ supplied to the injection wells. All the main pipelines are made of ordinary carbon steel.

8 For a 500-km pipeline this would correspond to one accident approx. every six years. 
There has not yet been any experience with offshore $\mathrm{CO}_{2}$ pipeline operation, but it is held to be feasible in principle (see also the CENS infrastructure project). ${ }^{9}$ The expense involved is roughly proportional to the product of water depth and pipeline diameter.

\subsubsection{Transport by Ship}

Gas transport by ship is more flexible and more quickly available than pipeline transport, but suffers the drawback that temporary storage and loading/unloading facilities are required. There is also the challenge of competition with other shipping traffic. Additional traffic is also associated with undesirable side effects (e.g. increased risk of collisions at sea, harmful emissions through combustion of heavy fuel oil).

As described above, only transport of $\mathrm{CO}_{2}$ in the liquid state is relevant, for reasons of logistics and energy efficiency. We distinguish three different types of tank structure for this form of transport:

\section{Pressure tank}

$\mathrm{CO}_{2}$ compressed at high pressure at ambient temperature (for small-scale applications)

\section{Low-temperature tank}

Refrigerated $\mathrm{CO}_{2}$ at atmospheric pressure (for bulk transport, this type is already used for LPG and LNG)

\section{Hybrid tank, semi-refrigerated tank} $\mathrm{CO}_{2}$ pressurised and cooled ( adapted to different loading and unloading conditions)

The hybrid type is seen as the most economical version for future large-scale $\mathrm{CO}_{2}$ transport. A design combining temperatures around $-50^{\circ} \mathrm{C}$ and pressure of 6 to 8 bar would be close to the triple point of $\mathrm{CO}_{2}$. A design study has been prepared for a capacity of approx. $20,000 \mathrm{~m}^{3}\left(\approx 22,000 \mathrm{t} \mathrm{CO}_{2}\right)$.

External heating would create carbon dioxide vapour in the tank and increase the pressure so the vapour would have either to be vented into the atmosphere (neither harmful nor dangerous, but worsens the $\mathrm{CO}_{2}$ balance) or - like with LPG tankers - re-liquefied by recooling. The latter is an energy-intensive process and is therefore also associated with $\mathrm{CO}_{2}$ emissions.

Approx. 1 to 2 years must be allowed simply for the construction of tankers.

9 CENS $\left(\mathrm{CO}_{2}\right.$ for EOR in the North Sea) is a joint project operated by the Danish electricity generator Elsam and the American $\mathrm{CO}_{2}$ company Kinder Morgan and coordinated by the Norwegian company $\mathrm{CO}_{2}$-Norway.

\section{Safety aspects of $\mathrm{CO}_{2}$ tankers}

A safety assessment of gas tankers by Lloyds Maritime Information Service for the period from 1978 to 2000 found the following (IPCC 2005):

LPG (number of tankers in 2000: 982):

20 serious accidents $\rightarrow 0.00091$ accidents/ship/year

LNG (number of tankers in 2000: 121):

one serious accident $\rightarrow 0.00037$ accidents/ship/year

Most accidents are inherent to the system or occur due to human error; safety regulations are often ignored. The types of accident include collision, running aground, sinking and fire. The only way to ensure that risk is minimised is to maintain high safety standards of equipment and navigation (including monitoring of the same) and adequate crew training.

The behaviour of $\mathrm{CO}_{2}$ leaking from a ship's tank and spreading on the surface of the sea has not yet been investigated. The possible consequences include local ecological effects on marine organisms and - given high concentrations and unfavourable weather conditions danger to the crew and engine failure through lack of oxygen.

The provisions of the following international conventions will apply to transboundary and marine transport of $\mathrm{CO}_{2}$ :

- UN Law of the Sea Convention,

- London Convention,

- ESPOO Convention (Convention on Environmental Impact Assessment in a Transboundary Context),

- OSPAR Convention (for the Protection of the Marine Environment of the North-East Atlantic),

- Basel Convention on the Control of Transboundary Movements of Hazardous Wastes and their Disposal.

National (and possibly also regional) rules and regulations will also have to be observed (see IEA 2003a). The legal applicability of the different treaties and conventions has not yet been finally clarified; one of the open questions is whether $\mathrm{CO}_{2}$ is to be classified as waste.

\section{Experience with ship transport of $\mathrm{CO}_{2}$}

There has so far been little experience with $\mathrm{CO}_{2}$ transport by ship. In 2004 there were only four small tankers (of the hybrid type) in operation worldwide transporting food-quality $\mathrm{CO}_{2}$ from $\mathrm{CO}_{2}$ point sources in northern Europe (e.g. ammonia plants) to consumers. On the other hand, a great deal of experience has already been gathered with LPG (liquefied petroleum gas, principal components propane and butane) and LNG (liquefied natural gas), with tankers up to $145,000 \mathrm{~m}^{3}$ capacity. LPG in particular has similar physical properties to liquefied $\mathrm{CO}_{2}$, which means that comparable transport conditions prevail. Design studies for larger tankers 
including the necessary peripherals (liquefaction plant, temporary storage facilities) are currently under preparation in Norway and Japan.

\subsubsection{Transport by Rail and Road Tanker}

As already mentioned at the beginning of this chapter, environmental and capacity considerations mean that neither rail transport, nor still less road tankers, will be in a position to make any appreciable contribution to handling very large quantities of $\mathrm{CO}_{2}$. A limited use of these two means of transport might be relevant only for pilot and demonstration projects and possibly as a stopgap while pipeline infrastructure is established.

In technical terms, $\mathrm{CO}_{2}$ transport by road or rail would be accomplished in a cooled pressure tank at approx. 20 bar and $-20^{\circ} \mathrm{C}$ (IPCC 2005). Other sources quote a pressure range of $12-17$ bar and a temperature of -50 to $-70^{\circ} \mathrm{C}$ (Air Liquide 2005). With a permissible gross weight of $40 \mathrm{t}$, an articulated lorry has a capacity of approx. $20 \mathrm{t} \mathrm{CO}_{2}$, while a complete freight train carrying 1,300 to $3,000 \mathrm{t} \mathrm{CO}_{2}$ can transport considerably greater quantities.

\subsection{Transport Costs}

The transport costs can be itemised into investment costs, running costs, and repair and maintenance costs (including spending on health and safety and environmental protection).

In the following we estimate the costs of transport in relation to distance, means of transport (pipeline or ship) and transport capacity. The data originates primarily from four sources (including studies quoted by them): VGB (2004), ECOFYS (2004), GESTCO (2004) and IPCC (2005).

\section{Source 1: VGB (2004)}

With costs of more than $€ 25 / \mathrm{t}_{250} \mathrm{~km}$ for road transport and more than $€ 5 € / t_{250} \mathrm{~km}$ for rail these two options are (very) expensive and therefore suitable only for small-

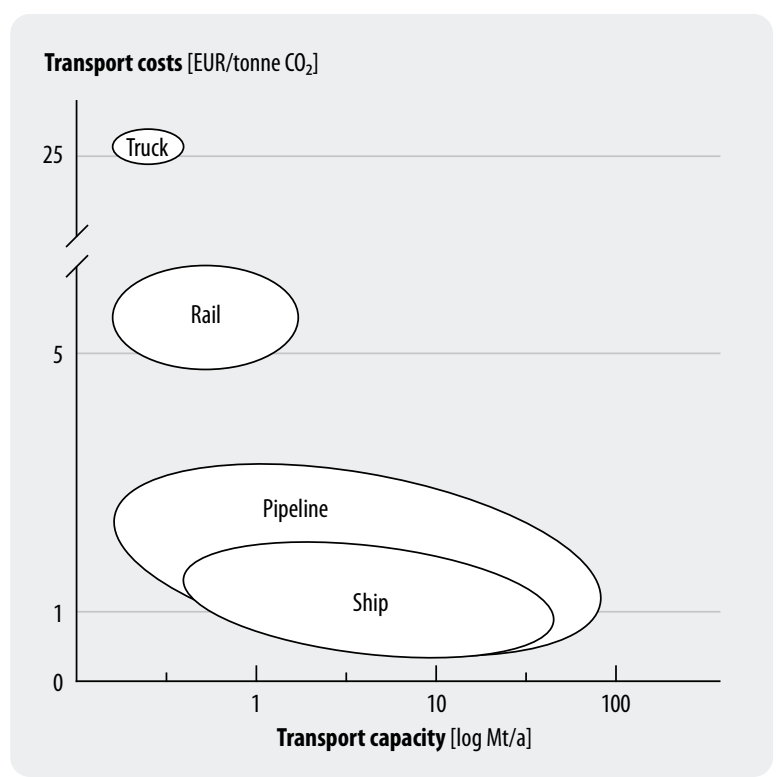

Fig. 6-4: Cost and capacity ranges for various $\mathrm{CO}_{2}$ transport alternatives (250 km distance) (Odenberger and Svensson 2003, in VGB 2004)

scale transport requirements or for a possible CCS start-up phase.

Pipelines $\left(€ 1-3 / t_{250 \mathrm{~km}}\right)$ and ships (approx. $€ 1 / \mathrm{t}_{250 \mathrm{~km}}$ ) are considerably more economical and are suitable for high (and very high) volumes. However, it is first necessary - especially for pipelines - to construct an extremely cost-intensive infrastructure. Hilly terrain adds about $50 \%$ to the cost of pipeline construction, while a supplement of $100 \%$ must be allowed for crossing densely populated areas and nature reserves, and 40 to $70 \%$ for laying offshore pipelines.

The figures listed above for non-pipeline transport options by road, rail or water (cf. Fig. 6-4) do not include the costs of the necessary temporary storage. Two main technologies come into question for storage:

1. Underground storage

suitable for large quantities, cheap, already used for LPG but not yet for $\mathrm{CO}_{2}$

2. Steel tanks suitable for small quantities, expensive, state of the art

Table 6-1: Costs of temporary storage facilities (steel tanks and rock shelters) after Odenberger and Svensson 2003, in VGB 2004

\begin{tabular}{|l|c|c|c|c|c|}
\hline & $\begin{array}{c}\text { Size } \\
\left(\mathbf{m}^{3}\right)\end{array}$ & $\begin{array}{c}\text { Investment cost } \\
\text { (EUR) }\end{array}$ & $\begin{array}{c}\text { Annual charge } \\
\text { (EUR/y) }\end{array}$ & $\begin{array}{c}\text { Throughput } \\
(\mathbf{t} / \mathbf{y})\end{array}$ \\
\hline Steel tanks & 3,000 & $6,500,000$ & 460,000 & $1,000,000$ \\
\hline Rock shelter & 120,000 & $17,000,000$ & $1,200,000$ & $20,000,000$ \\
\hline
\end{tabular}




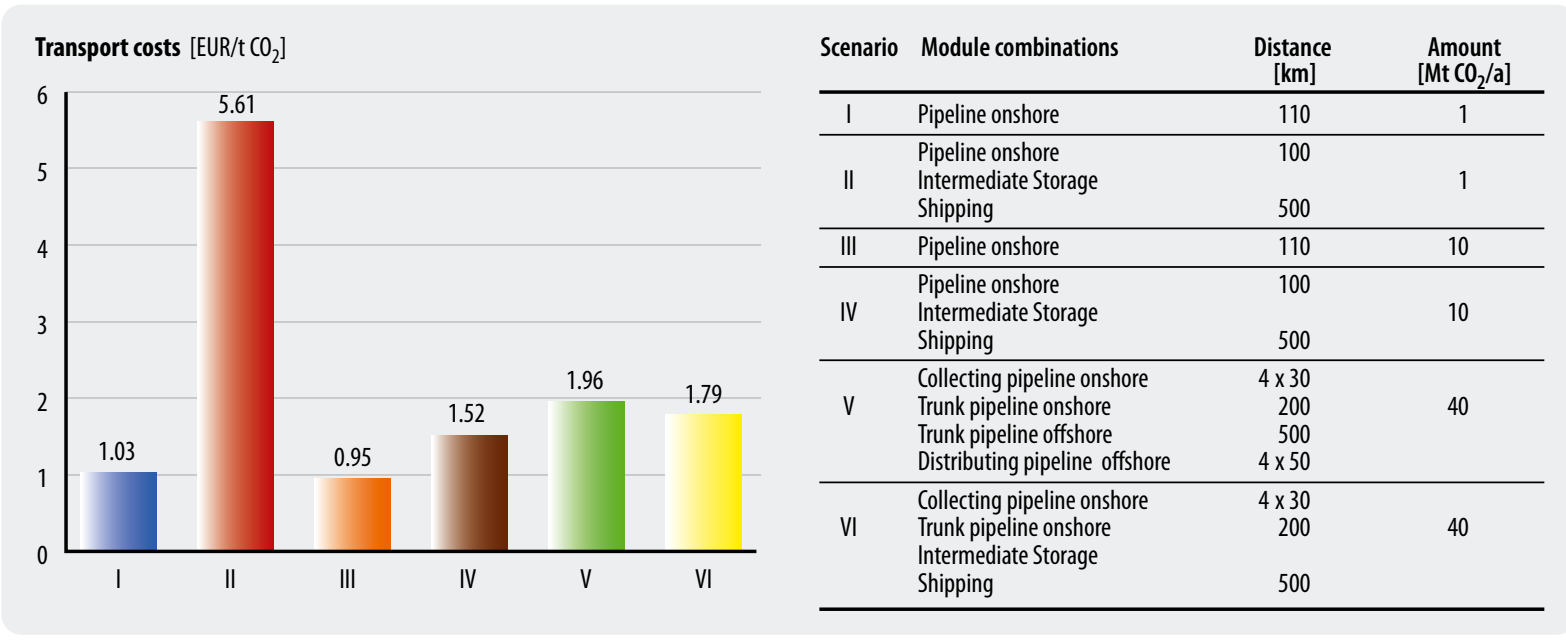

Fig. 6-5: Accumulated costs for transport scenarios I to VI (Odenberger and Svensson (2003) in VGB (2004).

Cost data includes transport, reloading and temporary storage, but not costs of necessary gas conditioning (pressure and temperature) in order to make $\mathrm{CO}_{2}$ transportable/storable.

The estimated costs of temporary storage facilities are listed in Table 6-1.

Fig. 6-5 itemises six different transport scenarios that differ in terms of capacity ( $1 \mathrm{Mt} / \mathrm{a}, 10 \mathrm{Mt} / \mathrm{a}, 40 \mathrm{Mt} / \mathrm{a})$, distance $(30 \mathrm{~km}$ to $500 \mathrm{~km})$, means of transport (pipeline, ship or combination of both) and pipeline type (collecting/trunk/distributing, onshore/offshore). The spectrum of costs is accordingly broad, ranging from $0.95 € / \mathrm{t}$ (scenario 3 for $110 \mathrm{~km}$ and $10 \mathrm{Mt} / \mathrm{a}$ ) to $5.61 € / \mathrm{t}$ (scenario 2 for $600 \mathrm{~km}$ and $1 \mathrm{Mt} / \mathrm{a}$ ).

The capacities selected in the scenarios are those associated with typical power station sizes. For example, in a CCS start-up phase a $200 \mathrm{MW}_{\mathrm{el}}$ pilot plant with $1 \mathrm{Mt}$ annual $\mathrm{CO}_{2}$ emissions would be expected to have transport costs of approx. $€ 1 / \mathrm{t}$ (onshore permanent storage close to the power station location) up to $€ 6 / \mathrm{t}$ (offshore sink). In a fully developed CCS infrastructure (several $1,000 \mathrm{MW}_{\mathrm{el}}$ power stations with 40-300 Mt/a) transport costs could be expected to fall to approx. $€ 2 / \mathrm{t}$ (offshore).

The cost calculations are based on the following assumptions:

- Depreciation over 25 years,

- Interest rate $5 \%$,

- Costs of $\mathrm{CO}_{2}$ liquefaction NOT included in calculation!

- Costs of $\mathrm{CO}_{2}$ intermediate compressor stations along pipeline are included,

- Power station locations selected so as to minimise $\mathrm{CO}_{2}$ transport distances,

- Mature technologies.

\section{Source 2: ECOFYS (2004)}

ECOFYS (2004) defined five 'cost windows' to allow the transport costs to be estimated for different scenarios (and distances), and found costs in relation to distance as shown in Table 6-2.

Taking these cost windows as the starting point, ECOFYS (2004) estimated the transport costs for various regions, distinguishing in each case between storage in aquifers, in onshore and offshore oil and gas fields and in coal seams. For Western Europe transport costs of $€ 3 / \mathrm{t} \mathrm{CO}_{2}$ (aquifers, offshore oil and gas fields, coal seams) to $€ 5 / \mathrm{t}$ $\mathrm{CO}_{2}$ (onshore oil and gas fields) were found (ECOFYS 2004). The study stressed, however, that this represents only a very rough approximation.

In fact the figures appear to have been estimated very optimistically, because elsewhere in the same study costs of $€ 1$ to $6 / \mathrm{t} \mathrm{CO}_{2}$ are given for a distance of 100 $\mathrm{km}$, depending on the capacity and flow rate (ECOFYS 2004).

Table 6-2: Transport costs for different' cost windows', after ECOFYS (2004)

\begin{tabular}{|l|c|c|}
\hline $\begin{array}{c}\text { Distance } \\
\text { Source-sink }\end{array}$ & $\begin{array}{c}\text { Average } \\
\text { distance }(\mathbf{k m})\end{array}$ & $\left.\begin{array}{c}\text { Average cost } \\
(\text { EUR/t C }\end{array}\right)$
\end{tabular}


Table 6-3: Costs for $\mathrm{CO}_{2}$ capture, transport and storage in $€ /$ tonne after GESTCO (2004)

\begin{tabular}{|c|c|c|c|c|c|c|c|c|c|}
\hline & Country & Belgium & \multicolumn{2}{|c|}{ Denmark } & \multicolumn{3}{|c|}{ Germany } & \multicolumn{2}{|c|}{ Greece } \\
\hline & Project & Langerloo & Havnso & Tyra & Greifsw. B.I & Greifsw. B.II & Afeld-Elze & N. Karvali & Komotini \\
\hline & Plant typ & $\mathrm{NGCC}$ & Coal ST & Coal ST & Gas ST & Gas ST & Sugar & $\mathrm{NH}_{3}$ plant & NGCC \\
\hline & Capture process & Post & Post & Post & Pre & Post & Post & $\mathrm{CO}_{2}$ source & Post \\
\hline & Storage method & Coal seam & Aquifer & Oil-/Gas field & Aquifer & Aquifer & Aquifer & Aquifer & Aquifer \\
\hline \multirow{5}{*}{ 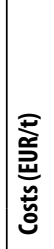 } & Capture & 82.1 & 21.5 & 25.3 & 33.2 & 26.6 & 75.5 & 0.6 & 76.3 \\
\hline & Compression & 12.8 & 7.4 & 7.4 & 4.4 & 6.1 & 15.9 & 7.2 & 13.5 \\
\hline & Transport & 3.5 & 1.4 & 14.8 & 1.1 & 1.1 & 1.1 & 3.4 & 13.0 \\
\hline & Storage & 4.0 & 1.3 & 4.1 & 0.6 & 0.6 & 8.3 & 2.6 & 2.5 \\
\hline & Total & 102.4 & 31.6 & 51.6 & 39.3 & 34.4 & 100.8 & 13.8 & 105.3 \\
\hline
\end{tabular}

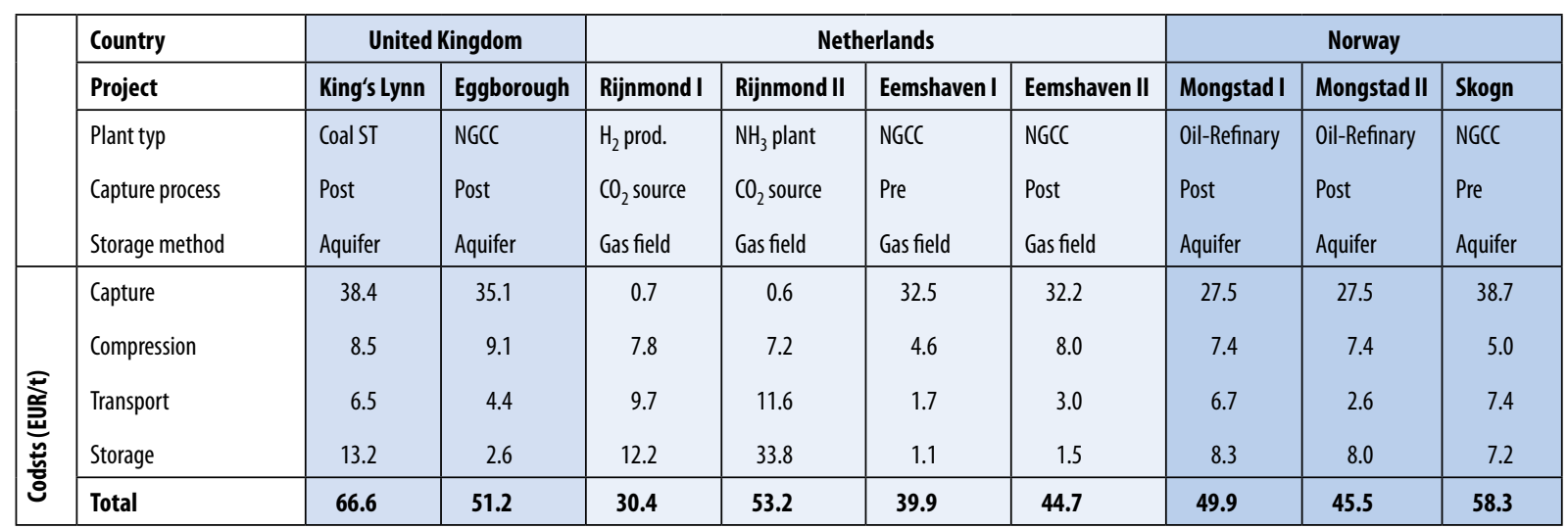

\section{Source 3: GESTCO (2004)}

The GESTCO project (2004) investigated seventeen case studies from seven European countries. In particular, estimates were made for the individual processes of $\mathrm{CO}_{2}$ capture, compression, transport and storage. The analysis covered six different types of plant (NGCC, coal steam turbine (ST), $\mathrm{H}_{2}$ production, natural gas ST, oil refinery, $\mathrm{NH}_{3}$ production) for four different products (electricity 330-3,134 $\mathrm{MW}_{\mathrm{el}}$, oil 9,285 kt/a, $\mathrm{NH}_{3}$ $\left.15.2-138 \mathrm{kt} / \mathrm{a}, \mathrm{H}_{2} 17.6 \mathrm{kt} / \mathrm{a}\right)$ with three different capture processes (post-combustion, pre-combustion, pure $\mathrm{CO}_{2}$ sources) and three different storage options (aquifer, oil/gas field, coal mine) (see Table 6-3).

\section{GESTCO project - Specific costs for $\mathrm{CO}_{2}$ transport}

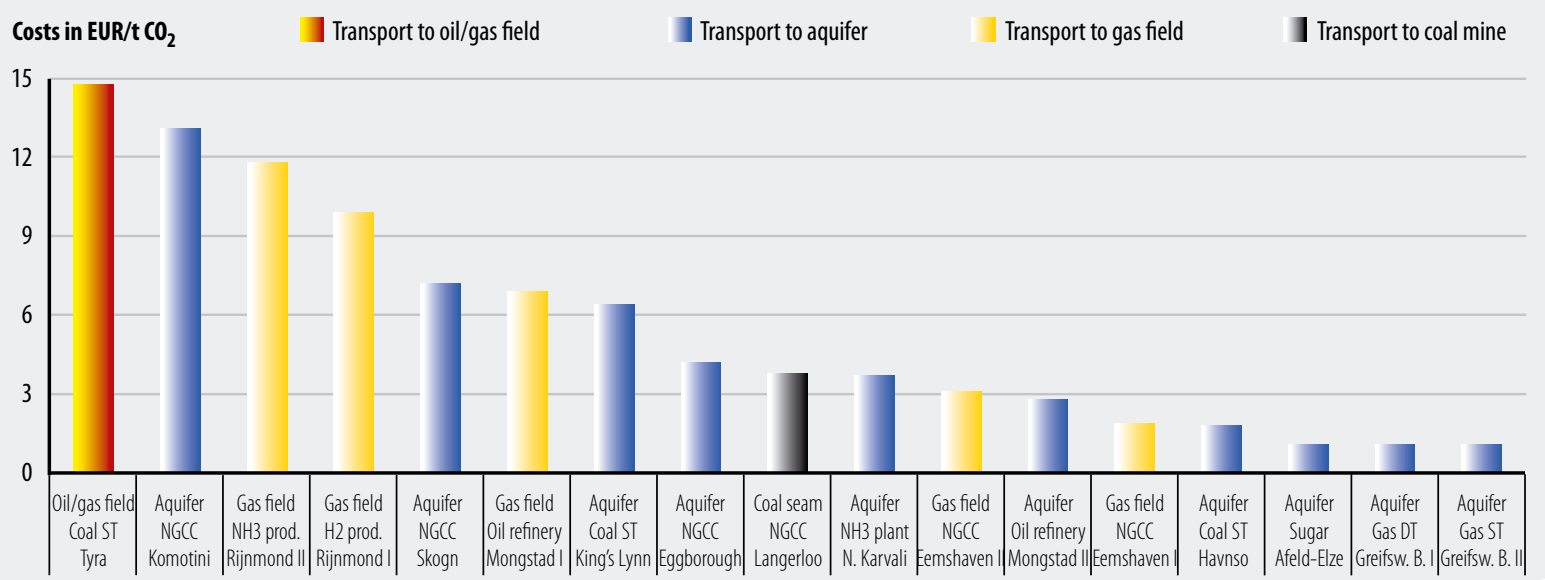

Fig. 6-6: Evaluation of transport costs from seventeen European case studies in the GESTCO project 


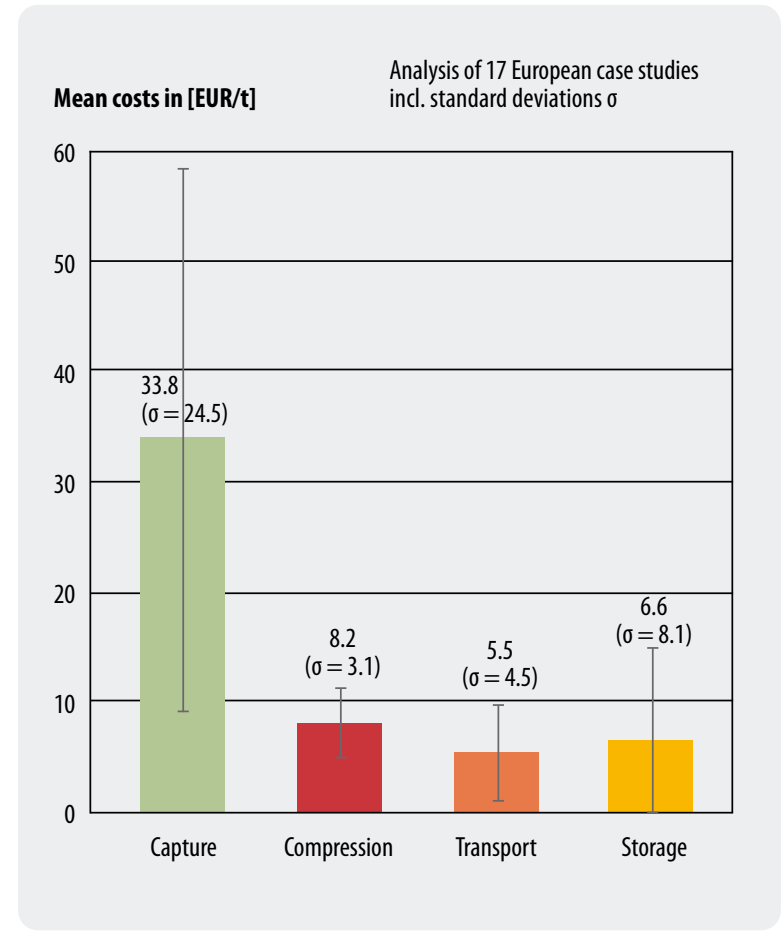

Fig. 6-7: Mean costs for capture, compression, transport and storage (GESTCO project)

Fig. 6-6 shows the resulting transport costs as a bar chart. As can be seen, the variation in transport costs between the best case $(€ 1.10 / \mathrm{t})$ and the worst $(€ 14.80 / \mathrm{t})$ is very large.

Fig. 6-7 shows the mean costs and their spread (standard deviation $\sigma$ ) for the individual steps of the process. The mean value for transport cost is $€ 5.50 / t$ with a large standard deviation of $€ 4.50 / t$ (absolute) or $81 \%$ (relative).

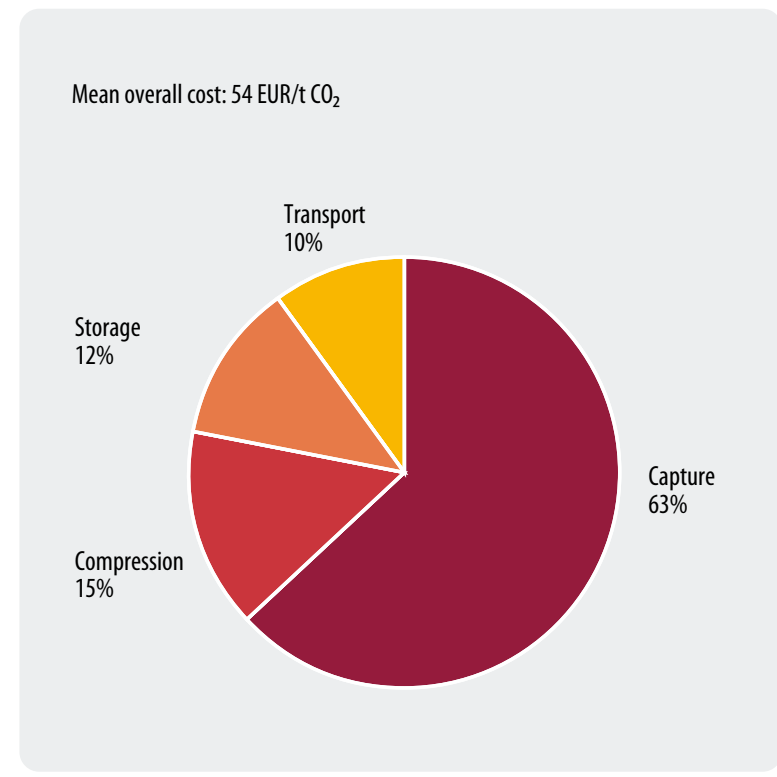

Fig. 6-8: Distribution of CCS costs for capture, compression, transport and storage in the GESTCO project Analysis of 17 European case studies

\section{Transport costs $\left(\mathrm{US} \$ / \mathrm{tCO}_{2} / 250 \mathrm{~km}\right)$}

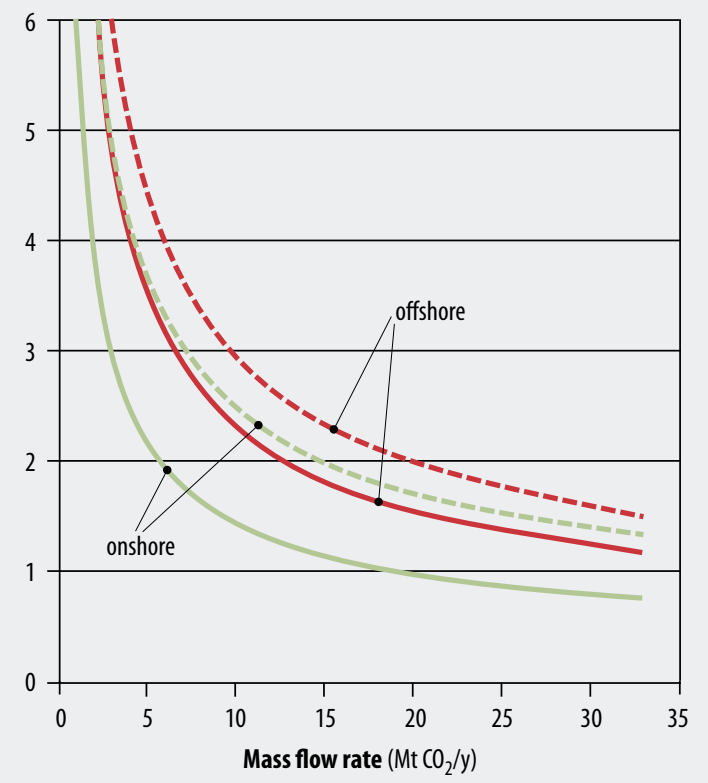

Fig. 6-9: Span of $\mathrm{CO}_{2}$ transport costs for a 250-km onshore or offshore pipeline as a function of capacity (IPCC 2005)

Fig. 6-8 shows a breakdown of the relative costs of the four steps of the overall CCS process. It shows that at $10 \%$ of the mean overall costs of about $€ 54.00 / t$ in the case studies investigated in the GESTCO project, transport had the smallest share.

\section{Source 4: IPCC (2005), Hendriks et al. (2003), Bock (2003), IEA (2002) 10}

The specific investment costs for pipelines with small diameters $(200 \mathrm{~mm})$ are approximately $\$ 0.2$ million $/ \mathrm{km}$ (onshore) to $\$ 0.3 \mathrm{million} / \mathrm{km}$ (offshore) and for larger diameters $(1.00 \mathrm{~m}$ ) approx. $\$ 0.8 \mathrm{million} / \mathrm{km}$ (onshore) to $\$ 1.2 \mathrm{million} / \mathrm{km}$ (offshore) (IEA 2002; Hendriks et al. 2003; Bock 2003). Transport costs for a $250-\mathrm{km}$ small diameter pipeline were estimated at approx. $\$ 5 / \mathrm{t}$ (onshore) and $>\$ 8 / \mathrm{t}$ (offshore) and for a large-diameter pipeline approx. $\$ 1.2 / \mathrm{t}$ (onshore) and $\$ 1.8 / \mathrm{t}$ (offshore). For this distance the IPCC report gives typical pipeline transport costs of \$1-8/t. Fig. 6-9 shows how transport costs depend strongly on the mass flow rate.

The investment costs for the EOR Weyburn Pipeline (length $330 \mathrm{~km}$, diameter 300 to $350 \mathrm{~mm}$, capacity $1.8 \mathrm{Mt} / \mathrm{a}$, pressure $152 \mathrm{bar}$ ), for example, amounted to a total of $\$ 110$ million or $\$ 330,000 / \mathrm{km}$.

For ship transport, as well as the cost of the tanker itself, additional costs for loading/unloading, temporary storage and liquefaction facilities must be calculated.

10 The transport chapter in the IPCC report refers to other sources (in particular IEA, Hendriks et al., Bock) so all four sources are addressed together here. 
Ship transport is only economical for long distances. The break-even distance where the $\mathrm{CO}_{2}$ tanker begins to have an advantage over offshore pipelines lies (assuming an annual volume of $6 \mathrm{Mt}$ ) in the range of approx. 500 to $2,000 \mathrm{~km}$. Other influencing factors that may mitigate for or against offshore pipelines include water depth, seabed stability, existing pipeline routes and fuel costs.

There has not yet been any practical experience with the complete marine transport chain for $\mathrm{CO}_{2}$ in the order of magnitude relevant for CCS, but there are studies that make certain statements about the issues. The Norwegian company Statoil estimates that the costs for a $\mathrm{CO}_{2}$ tanker would be approx. 30 to $50 \%$ above those of a similarly sized LPG tanker (with a semi-refrigerated tank). It should be noted here that owing to the greater density of $\mathrm{CO}_{2}$ (in transportable state approx. $1,100 \mathrm{~kg} / \mathrm{m}^{3}$ compared with just about $500 \mathrm{~kg} / \mathrm{m}^{3}$ for LPG and LNG) a tanker of the same size would be able to transport a greater mass of $\mathrm{CO}_{2}$ than LPG.

The International Energy Agency estimates the costs of a $10 \mathrm{kt}$ tanker $(30 \mathrm{kt} / 50 \mathrm{kt})$ at $\$ 34$ million ( $\$ 60 \mathrm{mil}$ lion $/ \$ 85$ million) and the costs of a liquefaction plant with a capacity of $6.2 \mathrm{Mt} / \mathrm{a}$ at US $\$ 80$ million or US $\$ 30$ million if the carbon dioxide supplied is already at a pressure of 100 bar (IEA 2004). ${ }^{11}$ Statoil estimates a cost of $\$ 50$ to 70 million for a ship with a capacity of 20 to $30 \mathrm{kt}$ and $\$ 35$ to 50 million for a liquefaction plant (1 Mt/a) (IPCC 2005).

For a distance of 7,600 km with a $30 \mathrm{kt}$ tanker the IEA gives specific transport costs of $\$ 35 / \mathrm{t}$ and for a $50 \mathrm{kt}$ tanker $\$ 30 / t$, but there are still great uncertainties concerning possible economies of scale. Further, the actual costs are determined by conditions on the ground. In a study for a marine $\mathrm{CO}_{2}$ transport system with a capacity of $5.5 \mathrm{Mt} / \mathrm{a}$ Statoil estimates costs between $\$ 34 / \mathrm{t}$ (without liquefaction) and $\$ 55 / \mathrm{t}$ (with liquefaction) (IPCC 2005).

11 By way of comparison, the largest liquefaction plant currently in existence has a capacity of $0.35 \mathrm{Mt} / \mathrm{a}$. 


\section{Chapter 7 \\ $\mathrm{CO}_{2}$ Storage}

As well as natural sinks for carbon dioxide, various technical methods could be developed to open up additional $\mathrm{CO}_{2}$ storage capacity (see Fig. 7-1).

\subsection{Overview of Methods}

There are various ways of withdrawing $\mathrm{CO}_{2}$ from the atmosphere. The possible methods are outlined below.

\subsubsection{Marine Storage}

Isolated $\mathrm{CO}_{2}\left(\mathrm{CO}_{2}\right.$ lake $)$

Mathematical models show that if $\mathrm{CO}_{2}$ is brought into the ocean at depths below $3,000 \mathrm{~m}$, the water pressure would cause it to form a lake of liquid $\mathrm{CO}_{2}$ on the seabed with a chlatrate layer separating the carbon dioxide from the seawater above and inhibiting dissolution of the $\mathrm{CO}_{2}$.

\section{Dispersed $\mathrm{CO}_{2}$}

When $\mathrm{CO}_{2}$ is injected into the sea at depths below $500 \mathrm{~m}$, bubbles form and the gas dissolves; models suggest that it would remain trapped below the oceanic thermocline. If carbon dioxide is injected at greater depths (between 500 and 3,000 m) a 'trail of droplets' forms, where the droplets should best be surrounded with hydrates to slow the rate of dissolution.

\section{$\mathrm{CO}_{2}$ in the form of dry ice}

Solid $\mathrm{CO}_{2}$ in the form of a block of dry ice is taken out to sea by ship and allowed to sink to the seabed. However, because this form of $\mathrm{CO}_{2}$ storage is extremely costly and energy-intensive it will not be discussed any further here.

\section{Algae}

Here the ocean is seeded with iron to induce an algae bloom which increases the $\mathrm{CO}_{2}$ take-up by the ocean as an ecological system. An initiated algae bloom would be possible above all in the southern oceans, which are undersupplied with iron compounds. However, trials and experiments conducted to date have not produced the hoped-for success, because no more than $1 \%$ of the bound $\mathrm{CO}_{2}$ sinks to the seabed (Smetacek 2004).

\subsubsection{Geological Storage}

\section{Deep saline aquifers}

Storage in salt-water-bearing porous geological strata requires deep sedimentary basins, which are found all over the world. However, because such structures have to date only been investigated in connection with hydrocarbon deposits, there has not yet been a comprehensive assessment of their extent or of their petrophysical properties such as pore volume (which determines gas saturation), fracturing and deformation processes (impermeability of overlying layers) and their chemical properties. Such data are necessary in order to assess the storage capacity of these geological structures (May et al. 2003).

\section{Depleted oil and gas fields}

In many countries exhausted oil fields offer only restricted capacity compared with gas fields, which promise large overall capacities world-wide. The productivity of oil and gas fields in the final stages of exploitation can be increased by injecting $\mathrm{CO}_{2}$ (EOR/EGR, enhanced oil/gas recovery). This brings economic benefits and at the same time allows $\mathrm{CO}_{2}$ to be stored in the geological structure.

\section{Deep (presently unexploitable) coal seams}

Storing carbon dioxide in deep coal seams where mining is currently not economic for technical reasons while at the same time extracting and using methane (ECBM, enhanced coal bed methane) is currently in the pilot phase. Here $\mathrm{CO}_{2}$ replaces the methane in the coal seam (coal can absorb about twice as much $\mathrm{CO}_{2}$ as $\mathrm{CH}_{4}$ ) and is thus held there. This, however, presupposes that the coal has a suitable permeability, which varies from one type of coal to another and has not yet been investigated under the geological conditions of deep seams.

\section{Closed coal mines}

It is theoretically possible to store $\mathrm{CO}_{2}$ in the branching tunnel systems of coal mines. However, because the workings of different mines often join up and mining 


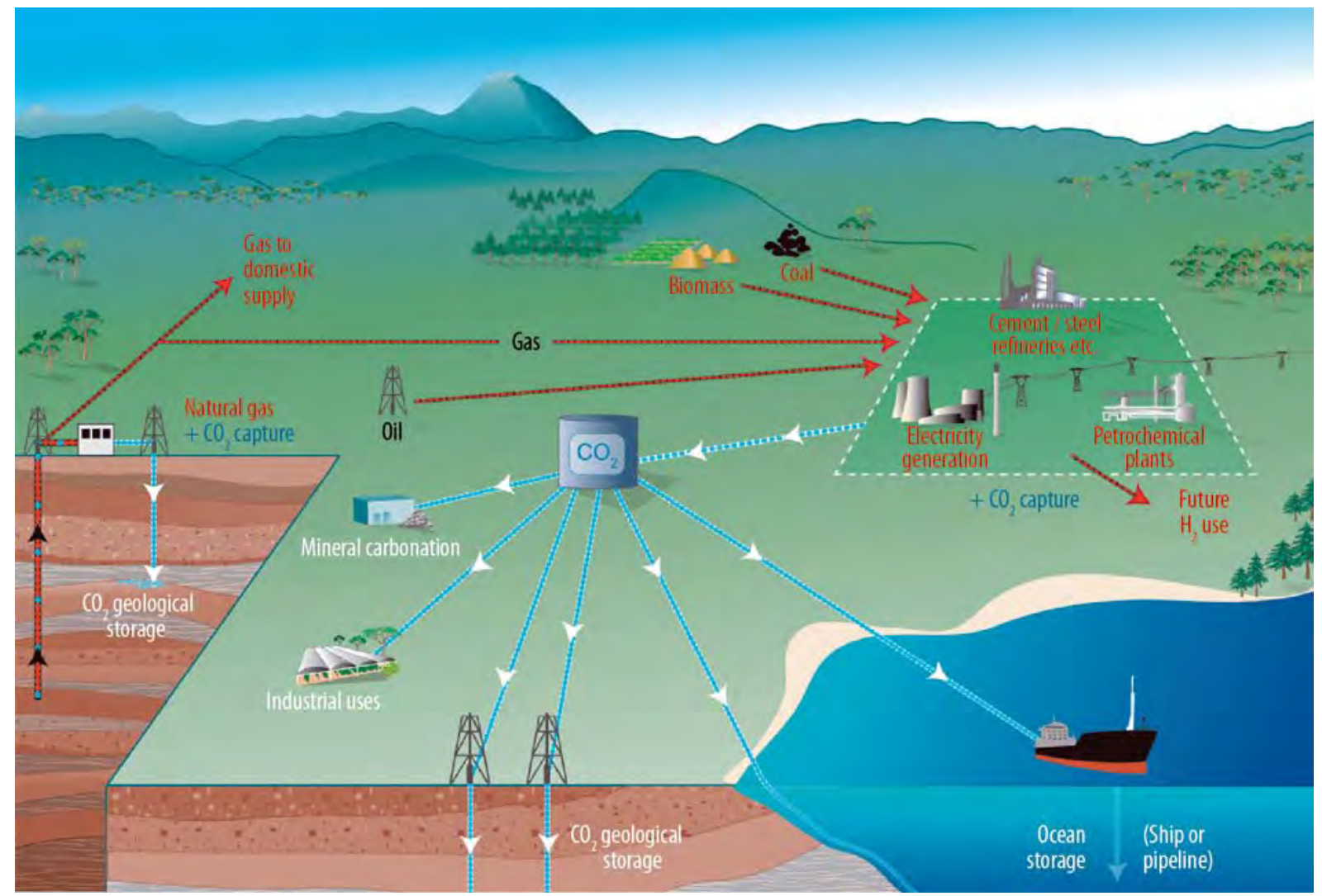

Fig. 7-1: Various conceivable options for storing $\mathrm{CO}_{2}\left(\mathrm{IPCC} 2005\right.$, courtesy of $\mathrm{CO}_{2}(\mathrm{RC})$

continues in other parts of the complex, all the shafts and levels would have to be sealed before they were used for storage. Moreover, such sealing systems have yet to be developed and tested for long-term stability. In Germany some of these tunnel systems lie under heavily populated areas (Ruhr region and North RhineWestphalia) and the covering strata are in some cases relatively thin or strongly fractured.

\section{Salt caverns}

In comparison with other geological options, this alternative offers only very limited capacity and faces competition with other uses (e.g. waste dumping).

\subsubsection{Other storage options}

\section{Biomass}

Where carbon dioxide is fixed in trees, it can be stored temporarily, for example when the timber is used as a construction material. This allows the $\mathrm{CO}_{2}$ to be stored for approx. 100-150 years in the timber construction elements.
Ways of fixing $\mathrm{CO}_{2}$ using algae are also currently being researched. Like terrestrial plants, marine algae and seaweed convert carbon dioxide gas into biomass via photosynthesis using the energy of sunlight. To date power station flue gases contained too many other pollutants such as soot and nitrous oxides, but flue gas scrubbing allows these to be filtered out - with the result that the algae consume the remaining $\mathrm{CO}_{2}$ gas. Biomass produced by algae can be turned into animal fodder, biodiesel or construction materials. Construction materials have the advantage that they allow $\mathrm{CO}_{2}$ to be fixed as a form of organic carbon that will not decompose again quickly. ${ }^{1}$

Similar ideas have also been proposed for greenhouses, which could be heated using combined heat and power (electricity and heat from microturbines). The waste gases are $\mathrm{CO}_{2}$-rich and relatively clean and can also be used to enrich the greenhouse atmosphere with $\mathrm{CO}_{2}$ in order to increase biomass production.

\section{Absorption in minerals}

$\mathrm{CO}_{2}$ can be bound permanently in magnesium silicate (e.g. olivine or serpentine), which is available globally in great quantities, forming magnesium carbonate. The

1 See: http://www.radiobremen.de/magazin/wissenschaft/ stadt-der-wissenschaft/themen/co2.html. 
reaction takes place at high pressure ( 340 bar) and at a high temperature $\left(500^{\circ} \mathrm{C}\right)$ and is decisively influenced by particle size (the smaller the particles the faster the reaction). Per tonne of $\mathrm{CO}_{2}$ the reaction produces $0.66 \mathrm{t}$ quartz and $1.92 \mathrm{t}$ magnesium carbonate, which can be disposed of, for example, in ore mines that produce serpentine as a by-product.

\section{Chemical and technical uses}

Using $\mathrm{CO}_{2}$ in various industrial processes (e.g. as carbonic acid, for freeze-drying, in mononuclear and polymer compounds) in effect represents a way of recycling this 'waste product', although the storage period depends very much on the use to which the product in question is put (Breuer 2001). Estimates by the IPCC (2005) put the entire current global large-scale industrial use of $\mathrm{CO}_{2}$ at approx. $104 \mathrm{Mt} / \mathrm{a}$, which represents less than $0.5 \%$ of current total global anthropogenic emissions. It is thought that rigorous conversion in the chemicals industry - driven particularly by research and development programmes - would make it possible to increase that figure to a maximum of $5 \%$ (Plass 2002).

\section{Fuel synthesis}

Using chemical processes involving hydrogen, $\mathrm{CO}_{2}$ can be converted into liquid fuels such as methanol $\left(\mathrm{CH}_{3} \mathrm{OH}\right)$. This technology is still in the development/ demonstration phase because it would require the supply system to be converted to provide hydrogen gained in environmentally friendly and climate-compatible ways, which means it can only be a medium- to longterm option. Direct use of renewable hydrogen is also considerably more efficient.

Ecological considerations are, of course, of special importance for the practicability of the listed storage methods. They include in particular the global and local risks of $\mathrm{CO}_{2}$ leakages. The ecological restrictions for the respective storage options are listed in chapter 11.

\subsection{Relevant Global Storage Options and their Potential}

Estimates of existing storage potential currently differ enormously. The same applies to the fundamental suitability of the different storage options, where case-bycase examination will be required in order to gain clarity. Table 7-1 provides an overview of currently known $\mathrm{CO}_{2}$ storage possibilities and lists a number of possible restrictions that could exclude possible future use (see also chapter 11).

The geological options of disused salt and coal mines are not taken into consideration by the authors cited in Table 7-1. This appears justified: in the case of salt

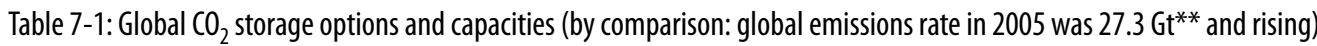

\begin{tabular}{|c|c|c|c|c|c|}
\hline Options & $\begin{array}{l}\text { Capacity } \\
\text { IPCC } \\
\text { Gale (2002) }\end{array}$ & $\begin{array}{l}\text { Capacity } \\
\text { Hendricks + } \\
\text { Turkenburg (1997) }\end{array}$ & $\begin{array}{l}\text { Capacity } \\
\text { Grimston et al. (2001) }\end{array}$ & $\begin{array}{l}\text { Capacity } \\
\text { ECOFYS (2004) }\end{array}$ & Restrictions \\
\hline Geological: & & & & & $\begin{array}{l}\text { Effects of } \mathrm{CO}_{2} \text { on soil organisms unresearched, } \\
\text { possible danger to groundwater through } \\
\text { leakages }\end{array}$ \\
\hline Disused salt mines & n.a. & n.a. & n.a. & n.a. & Conflict with other uses \\
\hline Disused coal mines & n.a. & n.a. & n.a. & n.a. & $\begin{array}{l}\text { Risk of leakage, use conflicts with mine gas } \\
\text { utilisation }\end{array}$ \\
\hline $\begin{array}{l}\text { Deep coal seams } \\
\text { (ECBM) }\end{array}$ & $40 \mathrm{Gt}$ & n.a. & $80-260 \mathrm{Gt}$ & $0-267-1480^{*} \mathrm{Gt}$ & $\begin{array}{l}\text { Future use of deposits excluded, technology } \\
\text { undergoing testing }\end{array}$ \\
\hline Depleted oil fields & $120 \mathrm{Gt}$ (incl. EOR) & n.a. & $\begin{array}{l}\text { (0il and Gas together) } \\
130-500 \mathrm{Gt}\end{array}$ & $\begin{array}{l}22-33-44^{*} \mathrm{Gt} \text { onshore } \\
20-60-107^{*} \mathrm{Gt} \text { offshore }\end{array}$ & Risk of leakage relatively low \\
\hline $\begin{array}{l}\text { Enhanced oil } \\
\text { recovery (EOR) }\end{array}$ & see above & $40-100 \mathrm{Gt}$ & $20-65 \mathrm{Gt}$ & $\begin{array}{l}\text { 9-112-734* Gt onshore } \\
3-37-308^{*} \mathrm{Gt} \text { offshore }\end{array}$ & Future use of deposits excluded \\
\hline Depleted gas fields & $690 \mathrm{Gt}$ & $90-400 \mathrm{Gt}$ & see above & $\begin{array}{l}\text { 4-219-391* Gt onshore } \\
20-20-32^{*} \mathrm{Gt} \text { offshore }\end{array}$ & Risk of leakage \\
\hline $\begin{array}{l}\text { Enhanced gas } \\
\text { recovery (EGR) }\end{array}$ & n.a. & n.a. & n.a. & $\begin{array}{l}\text { 219-391-925* Gt onshore } \\
149-281-778^{*} \mathrm{Gt} \text { offshore }\end{array}$ & Future use of deposits excluded \\
\hline
\end{tabular}




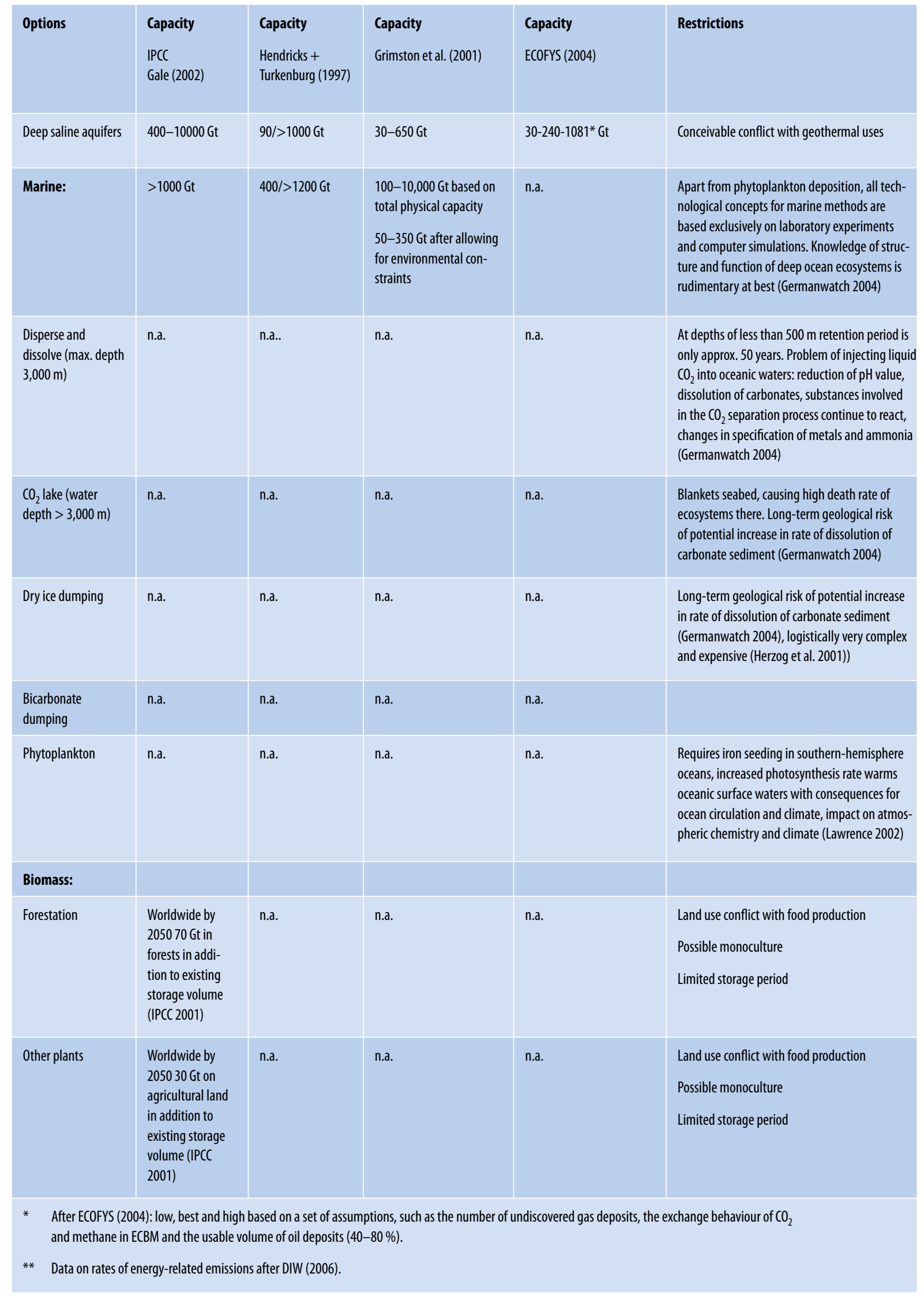


mines given the small potential capacity, in the case of coal mines because of the problematic issue of leakage. Furthermore, it must be pointed out that certain regions - such as South-East Asia and India - are as yet completely unresearched with regard to some of the listed options. Studies of storage capacity have been conducted largely in North America, Europe, Australia and Japan (Germanwatch 2004).

The analysis of potential capacity found great variance in the data for the global capacity of deep coal seams. This is because different types of coal absorb $\mathrm{CO}_{2}$ to very varying extents. In the capacity data for $\mathrm{CO}_{2}$ storage in exploitable oil and gas fields, on the other hand, the different authors give almost identical figures. The particularly large variance in the global capacity figures for saline aquifers stems from the very great uncertainty about their extent and technical potential, as well as specific problems of this storage option (structural complexity, varying thicknesses, varying porosity, saturation) (May et al. 2003).

When it comes to the marine options, usually only general figures are given, without differentiating between the individual technologies and methods. As a result these values also vary greatly from one author to another. Only one of the authors gives any figures at all for storage in the form of biomass.

Table 7-2: Overview of estimates of global $\mathrm{CO}_{2}$ storage capacity, after ECOFYS (2004)

\begin{tabular}{|c|c|c|c|}
\hline \multicolumn{4}{|c|}{ Global $\mathrm{CO}_{2}$ seq. potential [Gt] } \\
\hline Estimate: & Low & Best & High \\
\hline Remaining oil fields onshore & 9 & 112 & 734 \\
\hline Remaining oil fields offshore & 3 & 37 & 308 \\
\hline Depleted oil fields onshore & 22 & 33 & 44 \\
\hline Depleted oil fields offshore & 20 & 60 & 107 \\
\hline Oil fields (total) & 54 & 242 & 1,193 \\
\hline Remaining gas fields onshore & 219 & 391 & 925 \\
\hline Remaining gas sfieldss offshore & 149 & 281 & 778 \\
\hline Depleted NG fields onshore & 4 & 219 & 391 \\
\hline Depleted NG fields offshore & 20 & 20 & 32 \\
\hline Gas fields (total) & 392 & 911 & 2,126 \\
\hline ECBM & 0 & 267 & 1,480 \\
\hline Aquifers & 30 & 240 & 1,081 \\
\hline Total & 476 & 1,660 & 5,880 \\
\hline
\end{tabular}

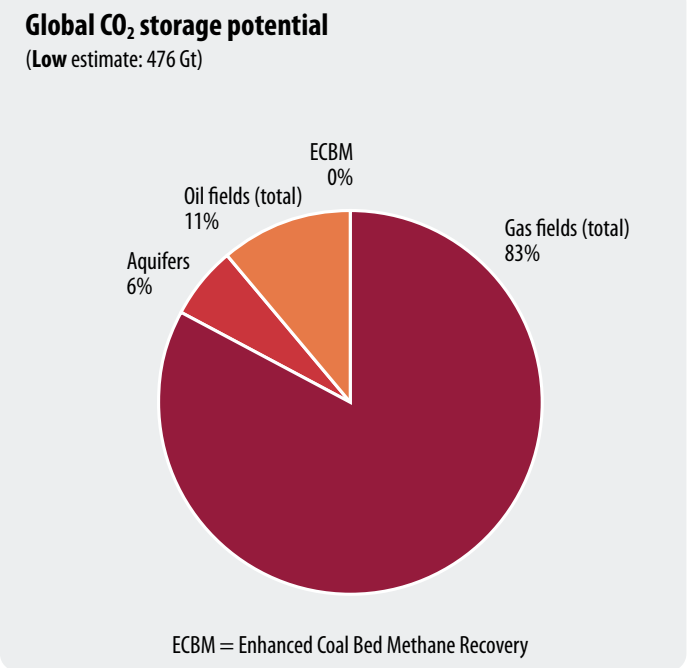

\section{Global $\mathrm{CO}_{2}$ storage potentia \\ (Best estimate: 1,660 Gt)}

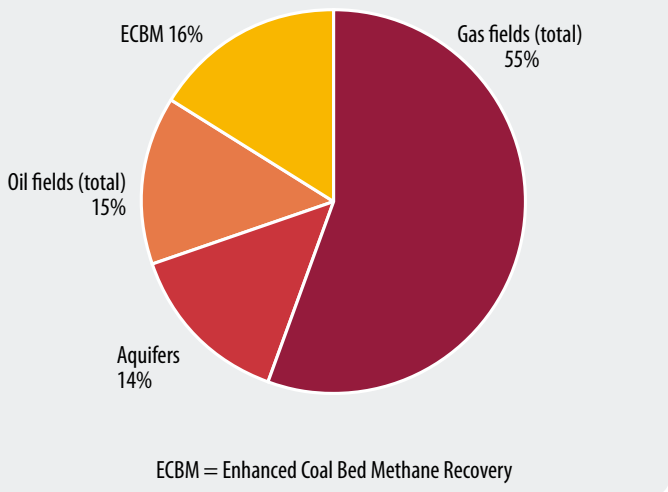

\section{Global $\mathrm{CO}_{2}$ storage potential}

(High estimate: $5,880 \mathrm{Gt}$ )

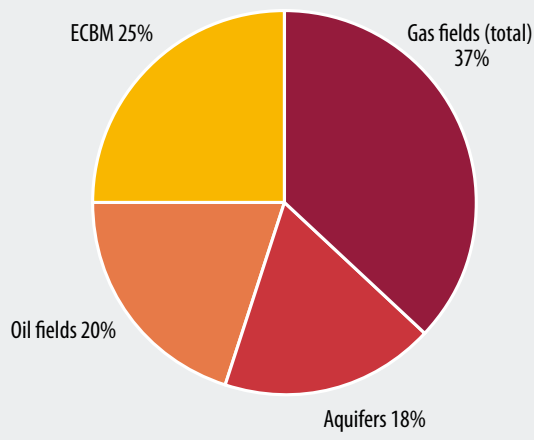

ECBM $=$ Enhanced Coal Bed Methane Recovery

Fig. 7-2: Breakdown of 'low', 'best' and 'high' estimates of global $\mathrm{CO}_{2}$ storage potential (data from ECOFYS 2004) 
Table 7-3: European $\mathrm{CO}_{2}$ storage options and capacities

By comparison: the annual rate of energy-related emissions in Europe (EU15) in 2005 was $3.5 \mathrm{Gt} \mathrm{CO}_{2}$

\begin{tabular}{|c|c|c|c|c|c|c|}
\hline Capacities & $\begin{array}{l}\text { Deep coal seams } \\
\text { (ECBM) }\end{array}$ & $\begin{array}{l}\text { Depleted } \\
\text { oil fields }\end{array}$ & $\begin{array}{l}\text { Enhanced oil } \\
\text { recovery (EOR) }\end{array}$ & $\begin{array}{l}\text { Depleted } \\
\text { Gas fields }\end{array}$ & $\begin{array}{l}\text { Enhanced Gas } \\
\text { recovery (EGR) }\end{array}$ & $\begin{array}{l}\text { Deep saline } \\
\text { aquifers }\end{array}$ \\
\hline & $0-1.7-9.9 \mathrm{Gt}^{*}$ & & & & & $1.3-10.4-36.9 \mathrm{Gt}$ \\
\hline Onshore & & $0.4-0.6-0.8 \mathrm{Gt}$ & $0.1-1.0-6.2 \mathrm{Gt}$ & $0.2-7.6-14.3 \mathrm{Gt}$ & $7.6-14.3-23.5 \mathrm{Gt}$ & \\
\hline Offshore & & $3.4-10.3-18.2 \mathrm{Gt}$ & $0.3-4.0-39.9 \mathrm{Gt}$ & $10.3-10.1-13.3 \mathrm{Gt}$ & $12.9-26.8-111.9 \mathrm{Gt}$ & \\
\hline
\end{tabular}

* After ECOFYS (2004): low, best and high estimates are based on a series of assumptions, such as the number of undiscovered gas deposits, the exchange behaviour of $\mathrm{CO}_{2}$ and methane for ECBM and the utilisable volume of oil deposits (40-80\%)

Taken together, the listed storage capacities are very considerable and represent many times the annual global $\mathrm{CO}_{2}$ emissions generated by energy use, which amount to $27.3 \mathrm{Gt} \mathrm{CO}_{2}$ (as of 2005: DIW 2006). A glance at the summary shown in Table 7-2 (ECOFYS 2004) shows the remaining uncertainties in the estimates. The low and high estimates of total storage capacity differ by as much as a factor of ten. The extent to which the listed options can actually be used to store $\mathrm{CO}_{2}$ will have to be investigated in each individual case anyway.

Table 7-3 provides an overview of potential capacity of geological storage in Europe. The broad range of the capacity figures for deep coal seams results from uncertainty about exchange behaviour and permeability of the different types of coal. ${ }^{2}$ Here there is a great need for research, which has already been initiated in various projects (e.g. RECOPOL, see the Overview of Global CCS Projects. The $\mathrm{CO}_{2}$-EOR method is an option for Europe - and one that may become profitable in view of rising oil prices and trading in $\mathrm{CO}_{2}$ certificates. European gas fields (e.g. in the Netherlands and Norway) also represent an attractive option for $\mathrm{CO}_{2}$ storage with respect to technical and economic aspects and their relatively precisely quantifiable capacity. For deep saline aquifers in Europe (as at the global level) there is a considerable lack of research into quality and volume.

Taking ECOFYS's best estimate as a guide puts the total potential capacity in Europe at about $87 \mathrm{Gt} \mathrm{CO}_{2}$. That is little more than twenty times the current annual emission rate of $4.114 \mathrm{Gt} \mathrm{CO}_{2}$ in the EU25, which means that under these assumptions the application of $\mathrm{CO}_{2}$ capture and storage technology as a central element of climate protection is a rather limited option.

\subsection{Assessment of the Storage Options in Germany as an Example of an Industrialised Country}

Table 7-4 gives volume estimates and quality criteria for the storage options in Germany. The assessment is based on a matrix developed by the Federal Institute for Geosciences and Natural Resources (BGR), to which criteria of cost, technology and general risks have been added.

information the theoretical storage potential in Germany is between 19 and $48 \mathrm{Gt} \mathrm{CO}_{2}$. The largest and - in view of the numerous as yet unresolved issues affecting storage in deep coal seams (e.g. concerning permeability) - most important share relates to deep saline aquifers, supplemented by the more limited possibilities for storage in depleted gas fields. A calculation focusing on these latter two storage options and taking into account an average extra energy requirement of $30 \%$ comes up with a static range of between thirty and sixty years for $\mathrm{CO}_{2}$ point emission sources in Germany (2005: 393 $\mathrm{Mt} / \mathrm{a}){ }^{3}$

In principle the storage of $\mathrm{CO}_{2}$ in geological structures can draw on many methods and technological processes currently in use in the oil and gas industry and in the disposal of liquid wastes. However, drilling and injection methods, computer simulations of the distribution of gas in reservoirs and monitoring methods will have to be adapted to the special requirements of $\mathrm{CO}_{2}$ storage. Here there is still a great need for research and development. In Germany the EU-funded $\mathrm{CO}_{2} \mathrm{SINK}$ project will significantly increase knowledge about the behaviour and controllability of $\mathrm{CO}_{2}$ in underground reservoirs.

2 Deep coal seams cannot currently be mined for technical and economical reasons. However, injecting $\mathrm{CO}_{2}$ might make it possible to extract the methane they contain, while at the same time ensuring that the $\mathrm{CO}_{2}$ remained underground. The theoretical storage capacity of this option is greater than most other possibilities.

3 Taken together these have a potential of 14.3 to $30.5 \mathrm{Gt} \mathrm{CO}_{2}$ 
Table 7-4:

Assessment of geological storage options in Germany using selected criteria

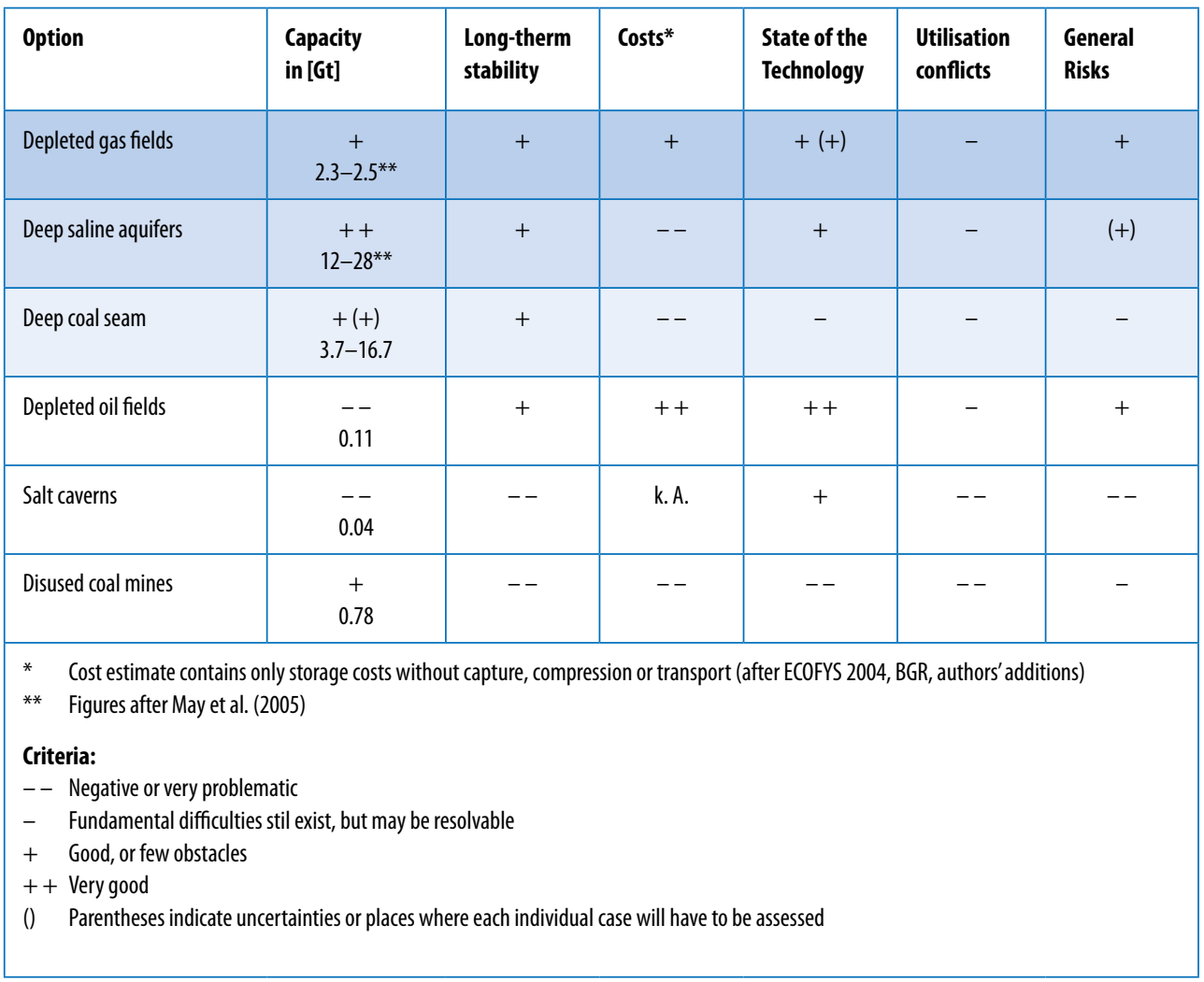




\section{Chapter 8}

\section{Central Aspects of $\mathrm{CO}_{2}$ Transport Infrastructure}

Setting up a transport infrastructure will be a major cost factor in any future CCS regime. Consequently, questions concerning transport infrastructure will play a central role in location decisions for power stations and sinks. This is a classical optimisation problem, which can be resolved by defining one or more of the following target parameters:

- Minimise $\mathrm{CO}_{2}$ transport,

- Minimise electricity transport,

- Minimise fuel transport,

- Minimise transport costs,

- Minimise ecological/social impact.

The following questions are decisive for configuring capture location, transport structure and storage location (see section 8.5):

- Where will future $\mathrm{CO}_{2}$ sinks be? Onshore/offshore? Domestic/abroad?

- When can they be developed?

- When will they be exhausted?

- Where will power stations be located? Close to consumers/fuel/sinks? Centralised/decentralised?

- What will be transported? $\mathrm{CO}_{2}$ /electricity/ $\mathrm{H}_{2} / \mathrm{SNG}$ (synthtic natural gas)?

- Mode of transport? Pipeline/rail/road/ship?

- What kind of infrastructure will be required? Pipelines, compressors, collectors, intermediate storage, ports, ...

Fig. 8-1 shows a possible $\mathrm{CO}_{2}$ transport scenario (for Germany). In this example $\mathrm{CO}_{2}$ is collected from point sources in North Rhine-Westphalia (e.g. large power stations), taken by branch pipelines to a main pipeline, compressed, and taken to onshore sinks in a neighbouring state (from North Rhine Westfalia to Lower Saxony in the example). For offshore storage (not illustrated here) the $\mathrm{CO}_{2}$ would have to be transferred from the pipeline to ships using the corresponding infrastructure (port, loading facility, intermediate storage).

Fig. 8-2 shows the elements of the $\mathrm{CO}_{2}$ transport infrastructure.
An estimate of the spectrum of transport costs for different transport scenarios (i.e. depending on level of development, capacity, distance and means of transport) has already been provided in chapter 6 (see especially figures 6-5 and 6-6).

\subsection{Interdependency between Energy Use and Freight Transport}

Transporting fossil fuels used primarily for energy purposes still represents a high proportion of freight transport. This applies in particular to shipping, but also to bulk transport on land. The high proportion of fossil fuels in international shipping cargoes is surprising given that public discussion of the transport issue is dominated by the internationalisation of production networks and the associated trade in complex industrial products (globalisation). In 2003 industrial manufactured products ('other goods') represented nearly $30 \%$ of the tonne-kilometres transported by ship, while crude oil, oil products and coal still made up a good $53 \%$ - although with a slight downward trend. Gas, crude oil and oil products account for almost $100 \%$ of pipeline transport.

Growth in demand is a significant reason for the increase in pollution through freight transport, so initiatives to decouple demand for freight transport from economic growth have gained at least theoretical and political importance. In the energy sector especially, there is significant potential to reduce freight transport intensity (Pastowski 1997).

On the other hand, capturing and storing the $\mathrm{CO}_{2}$ produced by burning fossil fuels has a tendency to increase freight transport intensity, because the $\mathrm{CO}_{2}$ has to be transported to a sink. Thus, the reduced emissions and resulting climate protection effect obtained through the application of CCS - in the energy sector and elsewhere - would be counterbalanced by the increase in $\mathrm{CO}_{2}$ emissions and other environmental costs associated with additional freight transport. In order to minimise these trade-offs and to cost-optimise the implementation of a CCS system, it is necessary to take a closer look at the consequences in the freight sector. 


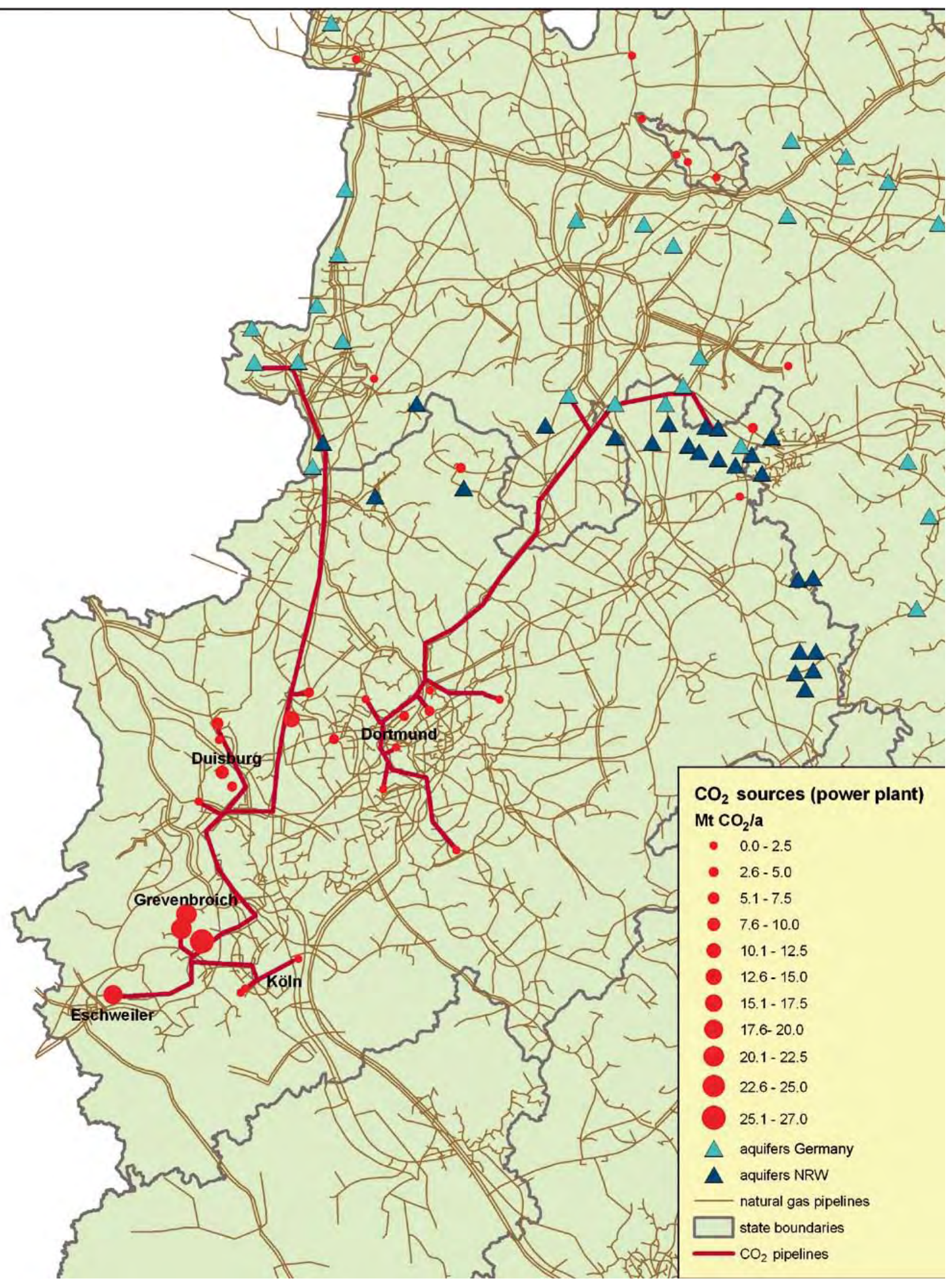

Fig. 8-1: Example of a possible $\mathrm{CO}_{2}$ transport scenario in Germany 


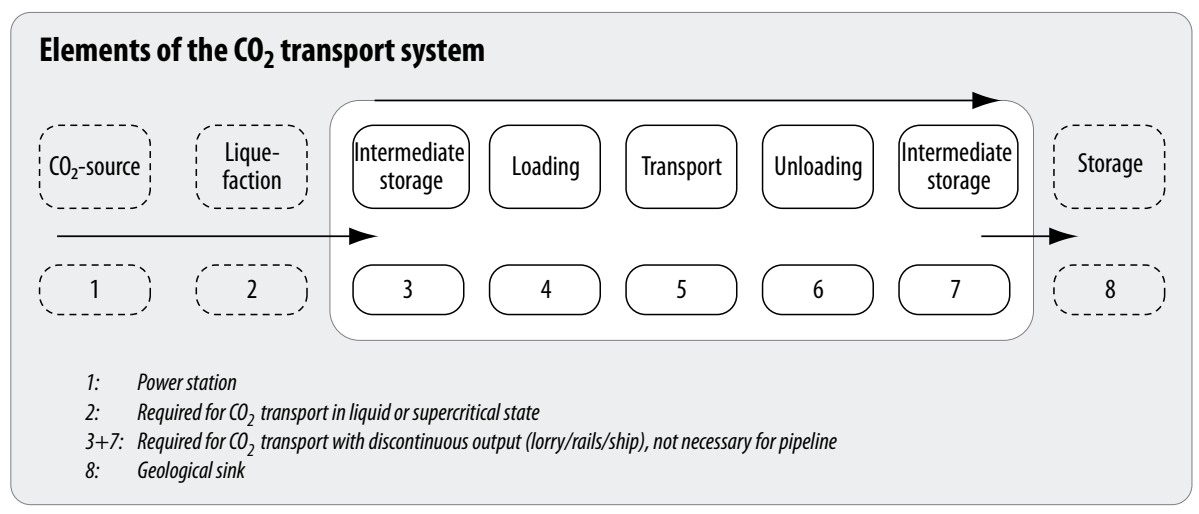

Fig. 8-2:

The elements of a $\mathrm{CO}_{2}$ transport system (Schlattmann 2006)

\subsection{Determinants of Additional Freight Transport with CCS}

The total extra transport required by $\mathrm{CO}_{2}$ capture and storage can be determined through a with/without analysis, where the additional transport required for CCS is examined, and each case is analysed in terms of a series of determinants. The cost of transport is determined by the quantities transported, the distances involved and the means of transport used. Table 8-1 provides an overview of the relevant factors, which are described in more detail below.

\section{Technical capture method}

The relative and absolute quantities to be transported are influenced primarily by the choice of technical process for capture. $\mathrm{CO}_{2}$ capture requires energy, so the fuel consumed by the power station increases to feed the same amount of electricity into the grid. Some capture methods also require additional materials (e.g. amine scrubbing agent), which also have to be transported. Table 8-2 shows the quantities of $\mathrm{CO}_{2}$ and additional fuel that would have to be transported for various types and sizes of power station. In the case of MEA scrubbing, amine is required, some of which is lost or degraded during operation and has to be replaced. However, for a $700 \mathrm{MW}$ power station, the latter represents an annual estimated quantity of 3,000 to 3,500 tonnes, which is negligible compared to the additional fuel requirement and the amount of $\mathrm{CO}_{2}$ to be stored. ${ }^{1}$

\section{Plant size and efficiency}

The quantities of materials are also determined by the size of the plant. Here the efficiency of the respective plant - which may also depend on the size - also plays a role. The quantities of materials and $\mathrm{CO}_{2}$ that have to be transported are known. At the same time, the size and location of the plant also determines the required transport of electricity and other products. The quantities of materials and $\mathrm{CO}_{2}$ are relevant for the choice of means of transport because sufficient transport capacity must always be available in the immediate vicinity of the plant. Otherwise the required capacity will have to be created. As Table 8-2 shows, even just for individual power stations CCS will involve considerable transport requirements.

For reasons of cost, the coal burnt in power stations is largely supplied by barge or rail. In Germany, for example, these two modes of transport together transported 87.4 million tonnes of coal in 2003 (BMVBW 2004). Even just at the level of individual power stations of the types and sizes under consideration, the additional fuel consumption caused by CCS is not negligible (approx. 0.23 to 1.6 million tonnes annually). Even more significant are the quantities of $\mathrm{CO}_{2}$ to be transported, amounting to 3.4 to 5.1 million tonnes/year (for coal-fired power stations). So it must be assumed that if extensive capture and storage of $\mathrm{CO}_{2}$ were implemented, considerable bulk transport capacity would have to be provided at the power station alone.

\section{Location of sources and sinks}

Alongside the additional quantities of material to be transported for CCS, the transport distance between sources and sinks will play a decisive part in determining the total transport cost. At the same time, particular conditions determine the use of particular modes of transport. An existing power station or sink may be far from the nearest waterway, thus allowing water transport only in a multi-modal context, where trans-shipment causes additional costs. It can be assumed that many of the plants that are suitable for CCS will already have rail or waterway links to supply them with materials such as coal. And with new plants these factors can be taken into account in location selection and planning. The choice of sink locations depends largely on their natural distribution. In the case of $\mathrm{CO}_{2}$ storage in gas fields, it would sometimes be possible to make use of existing transport infrastructure.

1 Note, however, that MEA (monoethanolamine) is a corrosive liquid that must be handled as a hazardous substance. 
Table 8-1: Relevant factors for transport cost for CCS

\begin{tabular}{|l|l|l|l|l|l|}
\hline $\begin{array}{l}\text { Technical capture } \\
\text { method }\end{array}$ & Plant size & $\begin{array}{l}\text { Geographical location } \\
\text { of source }\end{array}$ & $\begin{array}{l}\text { Means of } \\
\text { transport }\end{array}$ & $\begin{array}{l}\text { Geographical location } \\
\text { of sink }\end{array}$ & $\begin{array}{l}\text { Technical method } \\
\text { of storage }\end{array}$ \\
\hline $\begin{array}{l}\text { Transport quantity of } \mathrm{CO}_{2}, \\
\text { separating agent, } \\
\text { additional fuel }\end{array}$ & $\begin{array}{l}\text { Capacity and } \\
\text { efficiency }\end{array}$ & $\begin{array}{l}\text { Transport distance } \\
\text { and access }\end{array}$ & $\begin{array}{l}\text { Capacity, } \\
\text { efficiency } \\
\text { and ccosts }\end{array}$ & $\begin{array}{l}\text { Transport distance } \\
\text { and access }\end{array}$ & Accessibility, especially with \\
offshohre storage
\end{tabular}

\section{Availability of means of transport at the locations}

Fundamentally, the use of pipelines, barges, oceangoing ships, freight trains and road tankers to transport $\mathrm{CO}_{2}$ is conceivable. However, some of these are subject to restrictions where very large quantities are involved. Road transport quickly reaches the capacity limits of the road network, and in rail transport too, very large freight volumes can lead at least to local overloading of the network, which can only be avoided by expanding capacity. For many of the potential sources a connection to waterways and/or the railway network will already exist. In these cases the decisive question will simply be whether there is enough spare capacity for the transport required by CCS. Pipeline transport will almost always involve building new pipelines, with a potentially detrimental effect on costs in comparison to other options that make use of existing infrastructure.

\section{Technical method of storage}

The selected technical method of storage is relevant for transport to the extent that it determines the location and influences the maximum transportable volumes. Offshore storage involves special additional com- plications, because here the $\mathrm{CO}_{2}$ can only be supplied by pipeline or ship (ocean-going or coaster). Whereas pipeline transport from source to sink is feasible in principle, ocean-going ships or coasters will in many cases only represent one link in a transport chain where the $\mathrm{CO}_{2}$ has to be transported to the coast/port by pipeline, barge or rail and transferred between the different modes of transport involved.

\subsection{Technical Aspects of Bulk Transport Capacity}

$\mathrm{CO}_{2}$ transport is technically possible with all the available modes of transport. There are, however, relevant differences associated with the physical state of the $\mathrm{CO}_{2}$, the continuous nature of its production at sources such as power stations and the considerable quantities involved.

Because new pipelines generally have to be built specially for the purpose of transporting $\mathrm{CO}_{2}$, they can be dimensioned accordingly. Their capacity should be calculated so as to make intermediate storage unnecessary.

Table 8-2: Additional annual transport required by CCS in electricity or hydrogen production (capture rate: $88 \%$; $99.5 \%$ for oxyfuel and $71 \%$ for natural gas reforming) (Wuppertal Institute's calculations (for details see tables A 3 and A 4 in the Appendix))

\begin{tabular}{|c|c|c|c|c|c|c|}
\hline \multirow{2}{*}{ Power station type } & \multirow{2}{*}{$\begin{array}{c}\text { Net output } \\
{\left[\mathrm{MW}_{\mathrm{el}}\right]}\end{array}$} & \multicolumn{2}{|c|}{ Efficiency [\%] } & \multirow{2}{*}{$\begin{array}{l}\text { Full load hours } \\
\qquad \text { [h/a] }\end{array}$} & Additional fuel & \multirow{2}{*}{$\begin{array}{c}\mathrm{CO}_{2} \text { to store } \\
{[\mathrm{kt} / \mathrm{a}]}\end{array}$} \\
\hline & & without CCS & with CCS & & {$\left[k_{\text {coal }} / \mathrm{a}\right] \quad\left[m_{\text {gas }}^{3} / a\right]$} & \\
\hline Lignite steam turbine & 700 & 46 & 34 & 7,000 & 1,574 & 5,114 \\
\hline $\begin{array}{l}\text { Coal } \\
\text { - steam turbine } \\
\text { - steam turbine (oxyfuel) } \\
\text { - IGCC }\end{array}$ & $\begin{array}{l}700 \\
700 \\
700\end{array}$ & $\begin{array}{l}49 \\
49 \\
50\end{array}$ & $\begin{array}{l}40 \\
38 \\
42\end{array}$ & $\begin{array}{l}7,000 \\
7,000 \\
7,000\end{array}$ & $\begin{array}{l}276 \\
343 \\
229\end{array}$ & $\begin{array}{l}3,570 \\
4,249 \\
3,400\end{array}$ \\
\hline $\begin{array}{l}\text { Natural gas } \\
\text { combined cycle }\end{array}$ & 700 & 60 & 51 & 7,000 & $143,044,811$ & 1,705 \\
\hline $\mathrm{H}_{2}$ : Coal gasification & 560 & 59 & 55 & 8,000 & 68 & 2,374 \\
\hline $\begin{array}{l}\mathrm{H}_{2} \text { : Natural gas } \\
\text { reforming }\end{array}$ & 350 & 74 & 69 & 8,000 & $24,590,628$ & 580 \\
\hline
\end{tabular}


With other modes of transport - ocean-going ships, barges, railway and road - $\mathrm{CO}_{2}$ will generally be transported in pressurised vessels. We should assume that it will be transported in liquefied form (like LPG and LNG) because transport in the gaseous state would require too much transport capacity (volume). The $\mathrm{CO}_{2}$ will be loaded at a temperature and pressure that ensures that the maximum operating pressure of the vessel will not be exceeded before the destination is reached. To prevent heating and to ensure that the operating pressure remains within safety limits during the journey, the pressure vessels will be shaded by sunscreens, and in some cases pressure vessels insulated with polyurethane can be used. To maintain the required temperatures in ships, which travel considerably more slowly, active cooling systems can be used.

In the case of road transport, articulated road tankers are usually used to supply $\mathrm{CO}_{2}$. With a maximum permitted weight of 40 tonnes (in Germany), they can load 20 tonnes of $\mathrm{CO}_{2}$, which is transported at a pressure of 12-17 bar and a temperature between -50 and $-70^{\circ} \mathrm{C}$ (Air Liquide 2005).

The smaller the individual transport vessels, the more difficult it becomes to ensure continuous filling at the source and unloading at the sink. While tanker ships can themselves serve as buffer stores during loading, in the case of rail and road transport in pressurised vessels, the small capacity of each individual vessel means that a large number of vehicles would be required. At the same time, handling is more costly and time-consuming, because each of these vessels has to be filled individually. Today there is a system called the "block train' where all the tank wagons in a train are connected together and can be filled at one go (VTG 2005a) but this technique is available only for transporting unpressurised liquids where the tank can be filled from above. A solution of this kind is not available for tank wagons containing liquefied gases because of the high pressures involved and because the loading/unloading connections have to be underneath. To reduce the time required to fill tanks with liquefied gases, loading facilities that allow several tank wagons to be filled or emptied simultaneously are usually used (Transpetrol 2005).

Table 8-3: Transport capacities of different modes of transport, summarised by the Wuppertal Institute

\begin{tabular}{|l|r|}
\cline { 2 - 2 } \multicolumn{1}{c|}{} & Capacity [t] \\
\hline Pipeline & as required \\
\hline Gas tanker & $10,000-135,000$ \\
\hline Barge & $400-6,000$ \\
\hline Trainload C ${ }_{2}$ & $1,000-3,000$ \\
\hline Trainload coal & $800-1,400$ \\
\hline Road tanker & 20 \\
\hline
\end{tabular}

As well as the size of the individual containers and the number of individual tank wagons that can be joined to form a train, the speed must also be taken into account when considering the time factor in transport capacity. Although a ship possesses an impressive capacity as an individual vehicle, it moves considerably more slowly than a train or lorry, and this reduces its capacity per unit of time. This does not affect the number of vehicle movements required for transport, but it does influence the number of vehicles that actually have to be deployed. Table 8-3 compares the transport capacities of the modes of transport under consideration.

In the case of a pipeline, the dimensions usually correspond to the transport requirements, so a pipeline should always provide the required capacity. However, this is easier to ensure for a single pipeline than for a network, some parts of which will be used simultaneously for different transport connections and quantities, which may also be subject to change over time. In the case of other modes of transport a comparison of capacities is important, because - depending on the quantity of $\mathrm{CO}_{2}$ to be transported - a large number of vehicle movements may be required. These will place a great strain not only on the respective transport network (waterways, rail, road) but also on residents living in the vicinity of the plant and routes in question. This may have a negative impact on practicability and acceptance.

With water-borne transport, inland waterways and in the case of transport to offshore sinks - ocean-going ships come into consideration. Ocean-going ships offer considerable capacity but due to their dimensions their use on inland waterways is restricted or impossible. So ideally ocean-going vessels would be used to transport $\mathrm{CO}_{2}$ to offshore sinks from sources located on appropriately dimensioned waterways - a combination that considerably reduces the possibilities. Another option for using ocean-going ships for maritime storage would be to build pipelines to ports that are capable of handling correspondingly dimensioned ships, or other forms of combined transport.

For transport on inland waterways tanker barges are available with the following dimensions: length 50-135 $\mathrm{m}$, width $6.6-17.0 \mathrm{~m}$, draught $2.2-4.0 \mathrm{~m}$ and capacity 400-6,000 tonnes. Apart from the quantity to be transported, the narrowest point in the respective waterway network will influence the selection. For barges this applies especially to width and draught. Maximum bridge clearance is insignificant for barges, but it does play a role with coasters whose superstructure protrudes higher out of the water.

Gas tankers are the usual means for transporting liquid gas by sea. There are different designs and specifications. A distinction can be made between designs with high pressure and moderately low temperature and less highly pressurised types with very low temperatures (semi-refrigerated versions). An example of the former would be similar to the tankers currently used to trans- 
port liquefied gas at a temperature of $-55^{\circ} \mathrm{C}$ and a pressure of 6 bar. In the latter design liquefied natural gas is transported in a less highly pressurised form (max. 230 mbar) at a temperature of -164 to $-161^{\circ} \mathrm{C}$.

In terms of capacity, a type II liquefied gas carrier (Det Norske Veritas classification) with a length of $145.7 \mathrm{~m}$ and a draught of $9.7 \mathrm{~m}$, for example, provides a cargo capacity of $12,500 \mathrm{~m}^{3}$ (Thyssen-Nordseewerke 2005). The ships made by Thyssen offer capacities from approx. 10,000 to $55,000 \mathrm{~m}^{3}$, which at the temperatures and pressures involved here represent about the same in terms of tonnage. There are also considerably larger units for LNG transport. Alongside today's tankers with a total volume of $125,000-135,000 \mathrm{~m}^{3}$, ships with a capacity of up to $250,000 \mathrm{~m}^{3}$ are planned. However, their deployment will require correspondingly dimensioned ports and an appropriate volume of supply by other modes of transport, except where the $\mathrm{CO}_{2}$ sources are located in the immediate vicinity of the port.

\subsection{Networkability of Modes of Transport}

Another decisive factor for the deployment of the various modes of transport is their networkability: The different densities of the respective transport networks determine whether a given means of transport can offer uninterrupted transport as well as determining the length of the actual route involved. The significance of networkability is smaller in the case of especially high transport costs, because here the transport requirements and costs will have already been given priority consideration in the choice of location. This is already the case for many facilities where CCS is an option, especially for power stations fired with solid fuels. It applies, however, in a special way for $\mathrm{CO}_{2}$, because it almost never has any economic value, and instead its disposal costs money. Networkability has a particular influence on the choice of new locations for $\mathrm{CO}_{2}$ sources, whereas in the case of sinks the choice is limited to a finite number of fundamentally suitable locations, which are better or less well connected by the respective modes of transport.

In most countries roads demonstrate the greatest networkability. Sources and sinks are very likely already connected to the road network. If they are not they can be connected at limited cost. However, transporting large quantities of $\mathrm{CO}_{2}$ would mean placing a great strain on the affected sections of the road network; not only in terms of the number of vehicles, but also in road damage and nuisance to the environment through noise and emissions. Even without taking these factors into consideration, road transport of large quantities of $\mathrm{CO}_{2}$ is unlikely simply because of the relatively high specific costs involved.

The rail network is considerably less dense than the road network, but it is reasonable to assume that many
$\mathrm{CO}_{2}$ sources such as power stations will already possess a railhead. So for $\mathrm{CO}_{2}$ transport by rail it is of primary importance whether the potential sinks have a rail connection or whether this can be created at reasonable cost. With regard to capacity, it should be noted that traffic on the main arteries of the rail network is sometimes already very dense, but freight traffic is generally handled at night, which allows routes and times with capacity problems to be avoided. On the other hand, depending on the location of the route, noise problems in inhabited areas can be exacerbated by night traffic, which can impair the acceptance of such traffic.

The extent of the network of viable navigable waterways differs from country to country, but is limited in many. While some existing $\mathrm{CO}_{2}$ sources (e.g. coal-fired power stations) are often close to or directly beside waterways for supply with fuel and other materials, this applies only to a very limited extent to sinks. Furthermore, the navigability within the network is not homogeneous, but the possibilities differ depending on the type and size of vessel: In the smaller branches of the network of rivers and canals it is often only possible to use smaller types of barge. Because transport by ship can be accomplished relatively inexpensively, much speaks in favour of this mode of transport as long as the location of sources and sinks allows access. There are also advantages in terms of local environmental factors (compared with road or rail transport) because waterways do not normally run directly through densely populated areas and noise remains less significant. Attempts would have to be made to reduce emissions of air pollutants primarily by technical means in the same way as for road vehicles.

Overall we can say that the modes of transport with the best bulk carrying capacity present drawbacks when it comes to networkability and the optimal connection of sources and sinks (in the case of pipelines to date not at all). In particular cases this may necessitate either increased investment to connect to networks or the use of several different modes of transport, at correspondingly increased cost. Of all the modes of transport, pipelines suitable for $\mathrm{CO}_{2}$ currently demonstrate the lowest networkability. So, while transporting large quantities of $\mathrm{CO}_{2}$ by lorry is problematic owing to the lack of bulk carrying capacity and the high cost and environmental impact, a pipeline network for large-scale transport of $\mathrm{CO}_{2}$ between different sources and sinks would have to be created from scratch in a concerted initiative that would require time and corresponding investment.

\subsection{Conclusions}

Here we provide answers (for the case study Germany) to the questions posed at the beginning of this chapter, to the extent that current knowledge allows. 


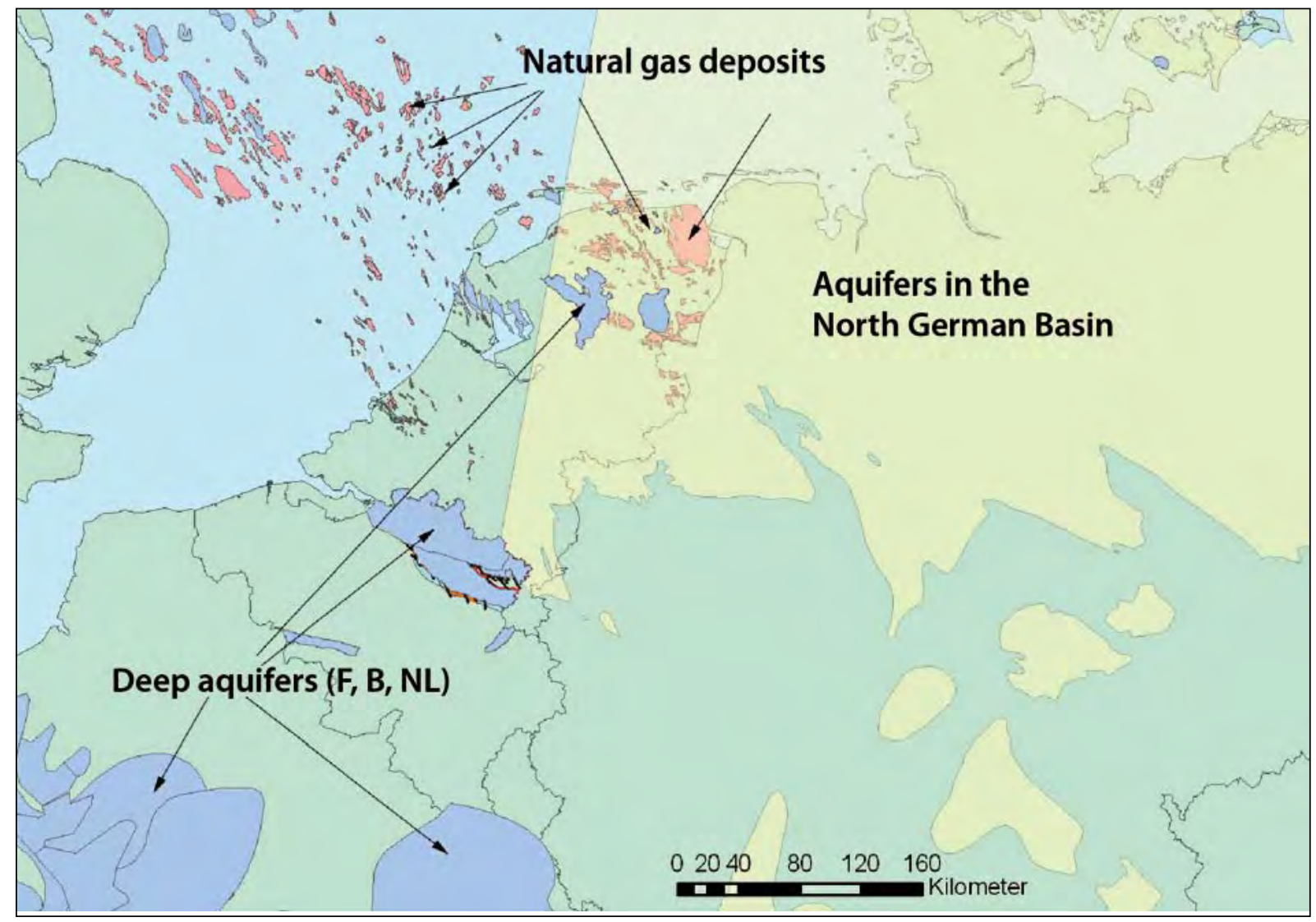

Fig. 8-3: Distribution of potential $\mathrm{CO}_{2}$ storage formations

The beige area designates the general distribution of deep aquifers $\left(>1000 \mathrm{~m}\right.$ ) that would potentially be suitable for $\mathrm{CO}_{2}$ storage. The blue areas designate deep aquifers in France and the Benelux countries. In addition, natural gas deposits are also shown for the Netherlands. After GESTCO (2004)

\section{Where will the future $\mathrm{CO}_{2}$ sinks be?}

The most obvious options for $\mathrm{CO}_{2}$ storage in Germany are exhausted gas fields and saline aquifers, which are located above all in northern Germany: an east-west belt of gas fields approximately $100 \mathrm{~km}$ wide and saline aquifers located largely in the North German Basin. Fig. 8.3 also shows potential sinks in the western neighbouring countries of the Netherlands, Belgium and France. Here future cross-border cooperation on the use of sinks would certainly be conceivable, especially for the state of North Rhine-Westphalia. This is most relevant for the large point sources in the Ruhr region and in the Rhine lignite mining area.

\section{When can future sinks be developed?}

Some gas fields have already been exhausted, and some of these serve as natural gas storage facilities, for example WINGAS's underground gas storage facility at Rehden. This is the biggest gas storage facility in Western Europe, and represents about one fifth of existing natural gas storage capacity in Germany. Other fields will become exhausted during the next ten to twenty years and would then - assuming they are suitable - be able to serve as $\mathrm{CO}_{2}$ sinks.

\section{When will $\mathrm{CO}_{2}$ sinks be full?}

The storage potential of the exhausted natural gas fields and saline aquifers in Germany amounts to between 14 and 30 gigatonnes of $\mathrm{CO}_{2}$ (see also chapter 7.3), which means there would be a range of times until all sinks are completely full. For example, if we take the annual emissions of all German industrial plant and power stations (combustion facilities $>50 \mathrm{MW}$ ) with an emissions rate of 1 megatonne per year, this would amount to a total of $343.4 \mathrm{MtCO}_{2}$ in $2004,{ }^{2}$ and a theoretical storage capacity of 41 to 87 years. However, this estimate neglects the increase in $\mathrm{CO}_{2}$ emissions - approx. $30 \%$ would currently appear realistic - caused by the additional energy required in the CCS process as a whole. Taking these additional $\mathrm{CO}_{2}$ emissions into account would reduce maximum storage capacity to 31 to 67 years. Deep coal seams would be another option, but because it is currently completely unclear whether, when and to what extent it might be possible to use them, they have not been considered here.

2 Source: European Pollutant Emission Register (EPER: www.eper.de) 


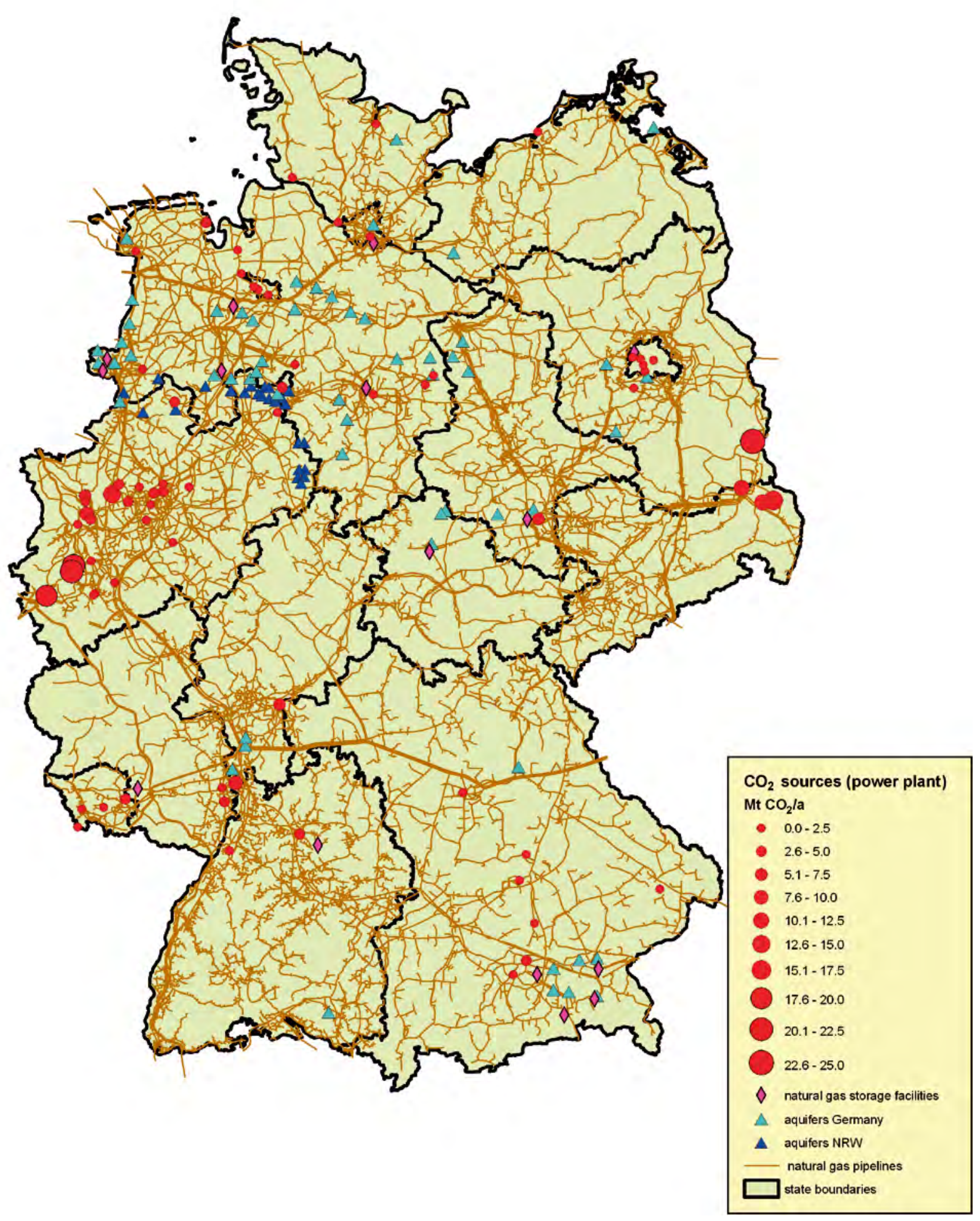

Fig. 8-4: $\mathrm{CO}_{2}$ sources (power stations) and sinks (aquifers and natural gas storage facilities) in Germany and the existing gas pipeline network 


\section{Where will future power stations be located? (Close to consumers/to transport networks/to sinks, centralised/decentralised)?}

Existing power station locations have been selected according to various optimisation parameters. Due to the high transport intensity of the fuel, for example, lignite-fired power stations are located in the lignite-mining areas of the Rhineland and Lausitz regions (identifiable in Fig. 8.4 as the biggest $\mathrm{CO}_{2}$ point sources), because transporting low-calorific lignite over long distances is too expensive. Coal-fired power stations, on the other hand, are built closer to major electricity consumers (big cities and industrial regions, especially in the Ruhr region). They also generally depend on a good inland waterway connection for cost-effective bulk delivery of coal. Medium-sized and small power stations using efficient combined heat and power are located decentrally in the immediate vicinity of heat sinks (housing estates, urban districts, industrial plant). The distance to and location of $\mathrm{CO}_{2}$ sinks comes into play as an additional parameter when selecting the location of future new CCS power stations. It remains to be seen what actual influence this will have on the selection of location, because the other factors outlined above (closeness to fuel and consumers, transport connections) will remain valid. Ultimately, weighing up the economic aspects will lead to a location decision. Questions of acceptance may also play a role and restrict the options for developing new power station locations.

\section{What will be transported $\left(\mathrm{CO}_{2}\right.$, electricity, $\left.\mathrm{H}_{2}\right)$ ?}

This question, too, will be answered primarily in terms of economic aspects. It is directly connected to the locational interrelationship between $\mathrm{CO}_{2}$ source and sink. If the power station location remains close to the fuel (lignite-fired) or relatively close to the consumer (coal-fired), the $\mathrm{CO}_{2}$ will have to be transported to potential sinks. If future power stations were to be built directly at $\mathrm{CO}_{2}$ sinks, the amount of electricity to be transported would increase. If we take a third approach - decarbonisation of fuel at the $\mathrm{CO}_{2}$ storage location (i.e. coal gasification or natural gas reforming to produce $\mathrm{H}_{2}$ ) - this would eliminate or reduce the transport of $\mathrm{CO}_{2}$ and electricity, but at the same time make it necessary to transport $\mathrm{H}_{2}$. In $\mathrm{SNG}$ production the existing natural gas networks could be used for transport and distribution. As in the case of construction of new power stations, the question of acceptance can be of decisive importance when realising new transmission and pipeline infrastructure networks (electricity, $\mathrm{CO}_{2}, \mathrm{H}_{2}, \mathrm{SNG}$ ). Experience in this matter has yet to be gathered.

\section{How will $\mathrm{CO}_{2}$ be transported?}

From the economic, energy-efficiency and ecological perspectives, pipelines and ship transport are the first choices for CCS applications. Rail transport would require capacity to be expanded, and lorry transport would be acceptable only for a transitional period, for example for pilot projects, because of the small unit capacity, the environmental impact and the already crowded road network.

\section{What infrastructure will be required?}

For $\mathrm{CO}_{2}$ transport by pipeline a completely new pipeline network would have to be constructed. In individual cases it might be possible to use existing natural gas pipelines or follow their routes. Depending on the pipeline length and initial pressure, individual compressor stations might be required. For ship transport new large-capacity tankers would have to be designed and the required loading/unloading infrastructure and intermediate storage facilities would have to be built at the port.

\subsection{Case Study: Transport Options for a 700 MW Coal-fired Power Station}

In order to generate estimates of the volume of freight transport demand created by CCS, it makes sense to start by estimating the transport requirments for an example power station. In this way the least promising transport options can be weeded out at the beginning.

The following example in Table 8-4 estimates the vehicle journeys required for CCS (for transporting $\mathrm{CO}_{2}$ and the extra coal required) for a $700 \mathrm{MW}_{\mathrm{el}}$ IGCC power station (7,000 full load hours per year). The assumed annual transport volumes are approx. 3.4 million tonnes $\mathrm{CO}_{2}$ and approx. 230,000 tonnes of additional coal (see Table 8-2). Where applicable, a range of figures is given to represent larger and smaller load capacities within each mode of transport.

The corresponding return journeys must also be taken into account, and these will generally be empty because appropriate loads will seldom be available. So ultimately the number of vehicle journeys will be nearly double. At the same time, the number of vehicle journeys says nothing about the transport distances involved, which will depend on the conditions in each individual case. The same applies to the number of vehicles required for transport, which will depend on the exact type of vehicle, distance, speed and other factors. 
Table 8-4: Estimate of annual one way loaded vehicle journeys required for CCS for a 700 MW IGCC power station (7,000 full load hours per year), authors' own estimates

\begin{tabular}{|l|c|c|c|}
\hline \multirow{2}{*}{$\begin{array}{l}\text { Mode of } \\
\text { Transport }\end{array}$} & Capacity & \multicolumn{2}{|c|}{ Additional journeys per year } \\
& {$[\mathbf{t}]$} & $\mathbf{C O}_{2}$ & Coal \\
\hline Gas tanker & 10,000 & 340 & - \\
& 135,000 & 25 & - \\
\hline Barge & 400 & 8,500 & - \\
& 6,000 & 570 & - \\
\hline Trainload CO 2 & 1,000 & 3,400 & - \\
& 3,000 & 1,130 & - \\
\hline Trainload coal & 800 & - & 289 \\
& 1,400 & - & 164 \\
\hline Road tanker & 20 & 170,000 & - \\
\hline
\end{tabular}

Here it already becomes apparent that road transport is not a plausible option - because of the high cost, but also because of the immense number of vehicle journeys which would cause traffic congestion at the sources and sinks and along the routes in-between. Every day there would be about 930 heavy road tankers arriving at and leaving the sink and the source.

Transport using small barges with 400 t capacity would also lead to considerable congestion problems. Every day about 23 barges of this type would have to be loaded and unloaded. Consequently, such cases can be excluded from further analyses and scenarios. Compared with $\mathrm{CO}_{2}$ transport, moving the additional coal will have less impact, because the quantities involved are smaller and deliveries are already supplied by ship, barge or train. Nonetheless, the additional transport volume involved here is not negligible (for one $700 \mathrm{MW}_{\mathrm{el}}$ power station one additional trainload of coal every day or two).

The volume of amine that would have to be transported for MEA scrubbing is negligible by comparison, although unlike coal and $\mathrm{CO}_{2}$, MEA would have to be transported as a hazardous substance. 


\section{Chapter 9}

\section{Criteria for a Comparative Assessment of CCS}

As part of the study we drew up a catalogue of criteria to allow a systematic comparison of various CCS technologies with other, fundamentally different technology options such as energy efficiency and renewables. The various criteria can be categorised as follows:

- Ecological criteria

- Environmental impact as per life cycle assessment (LCA)

- Energy efficiency

- Other ecological criteria, ecological restrictions, consequences and risks (direct and indirect)

- Ecological impact

- Economic criteria

- Cost
- Industry policy

- Applicability for developing countries

- Compatibility with existing energy infrastructure and possible future development paths

- Compatibility with other climate protection strategies (decentralised options)

- Impact on import dependency

- Security policy implications

In the following chapters some of these aspects are illustrated and examined in greater depth. A comprehensive criteria-based comparison of CCS with the potential renewable alternatives that are to be expected during a comparable development timeframe can be found in Table 9-1.
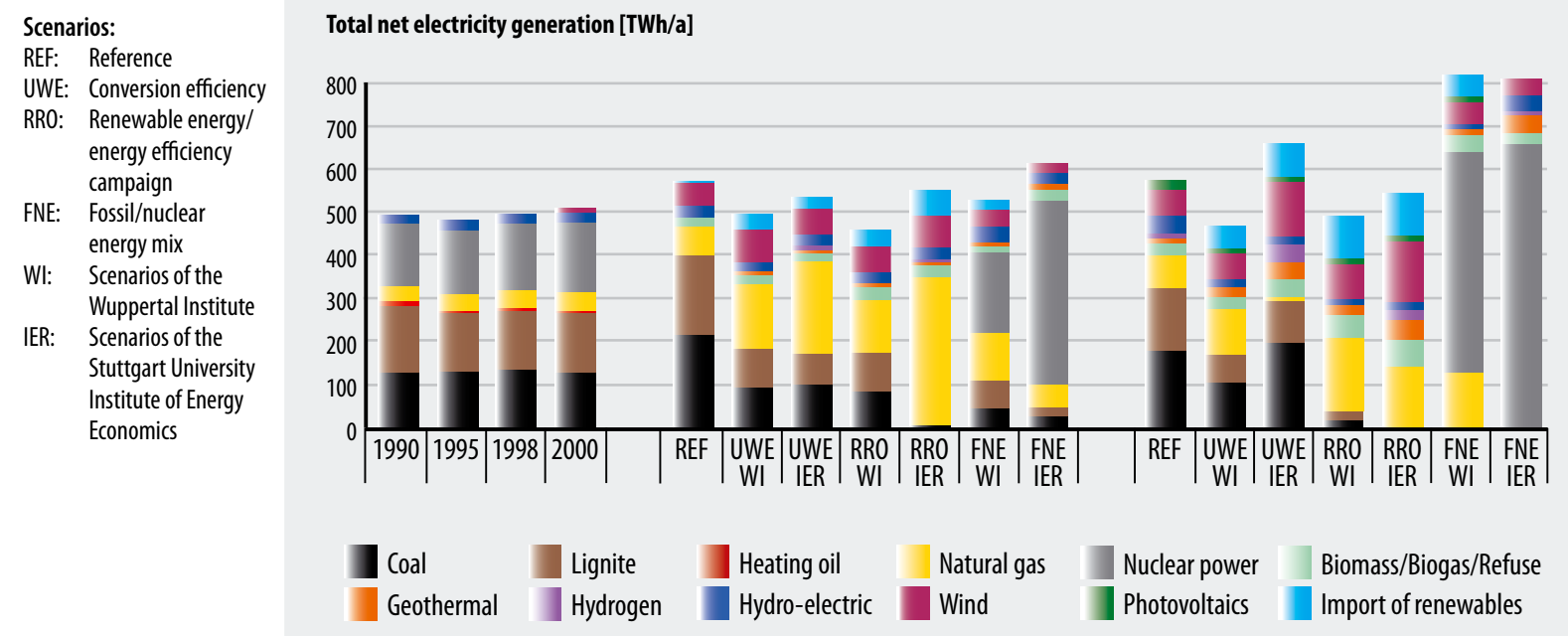

Fig. 9-1: Different development options for electricity generation considered by the Enquete Commssion "Sustainable Energy Supply" of the Germany Bundestag (Enquete 2002) for achieving ambitious climate protection goals in Germany

- Energy policy and other criteria

- Timeframe for application (possible time of implementation) and market readiness and/or $\mathrm{R} \& \mathrm{D}$ still required

- Compatibility with power plant replacement needs

- Acceptance

- (Technological) stimuli for global climate protection
As existing analyses show, large-scale CCS will probably not be technically ready for the power plant sector before 2020. This raises the question of which technologies CCS will actually be competing with, from the energy policy and climate protection perspectives. The Enquete Commission "Sustainable Energy Supply" of the German Bundestag outlined three different routes by which Germany could achieve ambitious climate protection goals by 2050 (see Fig. 9-1): 
Fig. 9-2:

Climate protection options and their availability timeframes

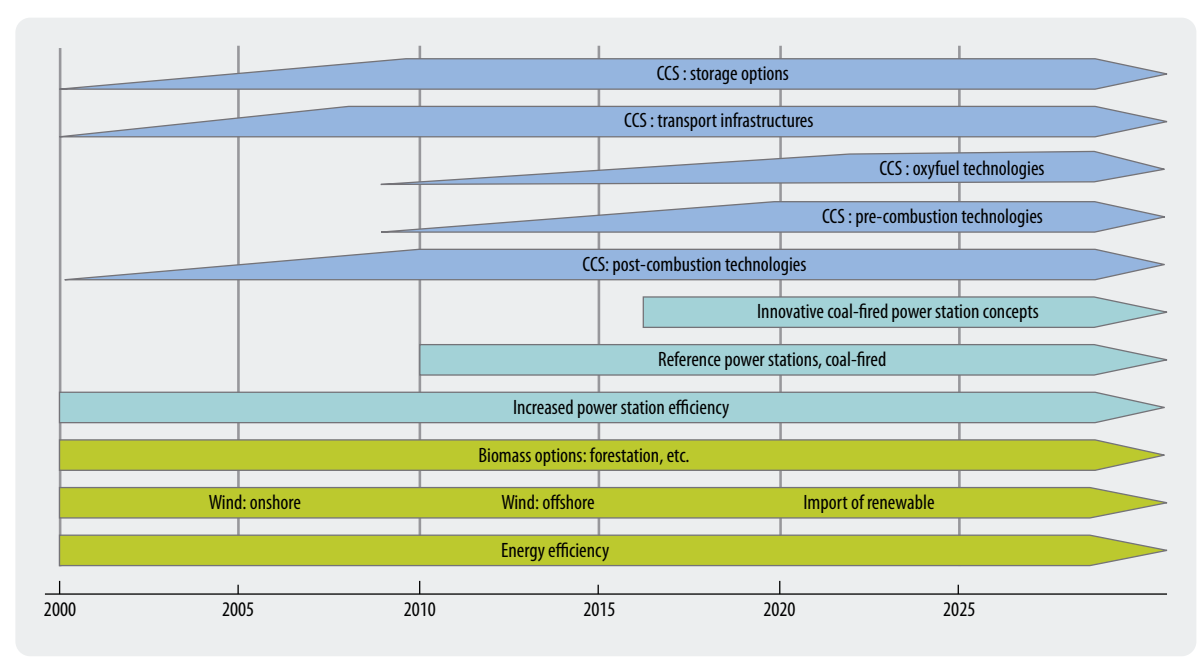

1. Large-scale implementation of $\mathrm{CO}_{2}$ capture and storage, ${ }^{1}$

2. Implementation of a large-scale renewable energy system joining Western Europe and North Africa on the basis of large-scale renewable energy technologies for and the utilisation of decentralised renewable energy options as well as the exploitation of energy efficiency potentials,

3. A renaissance of nuclear power.

These are broadly focused strategies, of which only strategy 2 would achieve the required reduction in greenhouse gases. Scenarios 1 and 3 additionally assume a further expansion of renewables and the use of at least some of the potential for energy saving.

At the moment all fields still contain unresolved issues, which need to be clarified as quickly as possible. Even if the three named strategies can to some extent be combined, it would still appear that an early fundamental decision about the main direction of change in the energy system will be unavoidable, and that the pending power plant replacement needs will have to be handled accordingly. If we also assume that the current policy decision in Germany to phase out nuclear power will hold - which would appear justified in view of nuclear power's continuing lack of public acceptance - this would seems to imply competition primarily between CCS and large-scale generation of electricity from renewables (including imports from abroad).
The following chapters focus on the aforementioned criteria in the context of the following questions:

- When will large-scale technical solutions become available?

- How do the available technologies (development horizon) fit with the timeframe for power plant replacement?

- How will economic competitiveness of CCS with other options develop, how does the relationship change over time (for example as fossil fuel prices rise)?

- What stimuli can be generated by implementation at the international level?

Comparable questions also arise at the global level; these are analysed in greater detail in chapter 15 .

Fig. 9-2 provides an overview of the possible timeframe for the availability of relevant climate protection options. With respect to the according timeframe the figure makes it clear that significant competition will rise above all between CCS and the large-scale development of offshore wind power as well as the introduction of renewable energy import systems (e.g. based on solar thermal power plant). The following chapters therefore concentrate mainly on a comparison with these technologies.
1 For $\mathrm{CO}_{2}$ capture and storage in Germany an annual volume of 202 to 260 million tonnes by 2050 was assumed. The cumulative amount of $\mathrm{CO}_{2}$ to be stored by 2050 would be in the order of 2,020 to 4,500 million tonnes (Enquete 2002). 
Table 9-1: Assessment criteria for various $\mathrm{CO}_{2}$ avoidance options

\begin{tabular}{|c|c|c|c|}
\hline Criterion & CCS & Renewables: wind offshore & $\begin{array}{l}\text { Imported renewables: } \\
\text { solar electricity from North Africa }\end{array}$ \\
\hline Energy efficiency & $\begin{array}{l}\text { Falls in comparison with conventional } \\
\text { electricity generation ( } 20-30 \% \text { loss of } \\
\text { efficiency). }\end{array}$ & & $\begin{array}{l}\text { Transport losses } \\
\text { (approx. } 10 \% \text { over } 3,000 \mathrm{~km} \text { with high } \\
\text { voltage transmission line) }\end{array}$ \\
\hline Costs in $\mathrm{ct}_{\mathrm{EUR}} / \mathrm{kWh}$ & $\begin{array}{l}\text { Depends on technology (approx. } \\
6-8 € c t / k W h \text { in 2020). }\end{array}$ & $\begin{array}{ll}\text { Current: } & 6-10 € c t / k W h \\
\text { Future: } & 4-6 € c t / k W h\end{array}$ & $\begin{array}{ll}\text { Current: } & \text { ca. } 15 € c t / k W h \\
\text { Future: } & 5-10 € c t / k W h\end{array}$ \\
\hline $\begin{array}{l}\text { Environmental impact, } \\
\text { ecological restrictions, } \\
\text { consequences and risks } \\
\text { (direct and indirect) }\end{array}$ & $\begin{array}{l}\text { Intervention in ecosystems through } \\
\text { increased extraction of fuels (especially } \\
\text { coal) and construction of } \mathrm{CO}_{2} \text { pipelines; } \\
\text { increased pollution through increase in } \\
\text { energy and } \mathrm{CO}_{2} \text { transport (ships carrying } \\
\text { coal, } \mathrm{CO}_{2} \text { etc.); environmental impact } \\
\text { of toxic agents (e.g. MEA) in flue gas } \\
\text { scrubbing. }\end{array}$ & $\begin{array}{l}\text { Disruption to benthic ecosystems, possible dis- } \\
\text { orientation of whales through infrasound; anthropo- } \\
\text { centric argumentation: creation of new ecosystems } \\
\text { could have positive effect on fish stocks (hard } \\
\text { substrates offer new habitats for shellfish, etc.; } \\
\text { undisturbed zone in wind farms can serve as breed- } \\
\text { ing grounds for marine organisms; no-fishing zone). } \\
\text { Laying cables involves intervention in benthic fauna. }\end{array}$ & $\begin{array}{l}\text { Plant location: Intervention in desert eco- } \\
\text { systems. } \\
\text { High voltage transmission line: Interven- } \\
\text { tion comparable with other power lines, } \\
\text { primarily affects the appearance of the } \\
\text { landscape. }\end{array}$ \\
\hline $\begin{array}{l}\text { Resource and material } \\
\text { consumption }\end{array}$ & $\begin{array}{l}\text { Depending on the technology: increased } \\
\text { energy consumption, increased use } \\
\text { of materials due to add-on charac- } \\
\text { ter of post-combustion technologies. } \\
\text { Expansion of fossil fuel production has } \\
\text { repercussions for production dynamics } \\
\text { (availability). }\end{array}$ & $\begin{array}{l}\text { Insignificant during operation. } \\
\text { Use of materials for plant construction and grid } \\
\text { connection. }\end{array}$ & $\begin{array}{l}\text { Insignificant during operation. } \\
\text { Use of materials for plant construction and } \\
\text { grid connection. }\end{array}$ \\
\hline $\begin{array}{l}\text { Window of opportunity } \\
\text { (time of possible imple- } \\
\text { mentation) and market- } \\
\text { readiness and/or R\&D } \\
\text { requirements }\end{array}$ & Not before 2020 & $\begin{array}{l}\text { Systems are market-ready and offshore wind farms } \\
\text { already exist; problems may be caused by bottle- } \\
\text { necks in financing and in some cases also by official } \\
\text { approval procedures. } \\
\text { No long-term experience with large offshore } \\
\text { facilities. } \\
\text { Connecting system and grid is a complex matter. }\end{array}$ & $\begin{array}{l}\text { In technological terms systems are } \\
\text { market-ready (solar thermal power } \\
\text { stations). Higher generation costs and } \\
\text { high level of subsidies for fossil fuels in } \\
\text { the targeted countries have to date made } \\
\text { financing difficult (low returns in compari- } \\
\text { son with conventional power station with } \\
\text { conservative estimate of future fuel pro- } \\
\text { curement costs). Planning of high-tension } \\
\text { transmission routes takes several years, } \\
\text { so long-distance electricity transport will } \\
\text { not be available before 2010-2015. Tech- } \\
\text { nology could, however, be implemented } \\
\text { earlier to supply domestic demand in the } \\
\text { states where solar thermal power stations } \\
\text { are built }\end{array}$ \\
\hline $\begin{array}{l}\text { Compatibility with power } \\
\text { station replacement } \\
\text { needs, case study } \\
\text { Germany }\end{array}$ & $\begin{array}{l}\text { Availability will be too late for the first } \\
\text { wave of power station replacements (a } \\
\text { large proportion of Germany's existing } \\
\text { capacity will already have been replaced } \\
\text { by 2020) }\end{array}$ & $\begin{array}{l}\text { Could cover part of replacement demand according } \\
\text { to BMU expansion strategy ( } 25 \text { GW by } 2020-2030)\end{array}$ & $\begin{array}{l}\text { Blf implemented immediately it might be } \\
\text { possible to cover some part of the capacity } \\
\text { replacement need using renewable elec- } \\
\text { tricity imports }\end{array}$ \\
\hline $\begin{array}{l}\text { Potentials and their } \\
\text { geographical distribution }\end{array}$ & $\begin{array}{l}\text { Resource potential depends on: } \\
\text { geological availability } \\
\text { possibility of production within } \\
\text { timeframe } \\
\text { acceptable side-effects (pollu- } \\
\text { tion, etc.) } \\
\text { individual analyses required (cover- } \\
\text { ing supplying country and infra- } \\
\text { structure) } \\
\text { regional differences in availability of } \\
\mathrm{CO}_{2} \text { storage }\end{array}$ & 25,000 MW for Germany & $\begin{array}{l}\text { By European standards unlimited } \\
\text { Area of desert theoretically required to } \\
\text { cover Germany's electricity needs in full: } \\
45 \mathrm{~km}^{2} \\
\text { Theoretical total potential in the Magh- } \\
\text { reb states: many times global electricity } \\
\text { demand }\end{array}$ \\
\hline
\end{tabular}




\begin{tabular}{|c|c|c|c|}
\hline Criterion & CCS & Renewables: wind offshore & $\begin{array}{l}\text { Imported renewables: } \\
\text { solar electricity from North Africa }\end{array}$ \\
\hline Acceptance & $\begin{array}{l}\text { So far unclear, will depend to an extent } \\
\text { on the argumentation strategy }\end{array}$ & $\begin{array}{l}\text { High (even in holiday regions, contrary to the fears } \\
\text { of the tourism branch) }\end{array}$ & $\begin{array}{l}\text { So far unclear but acceptance of renew- } \\
\text { ables is very high; little public knowledge } \\
\text { or discussion of renewable electricity } \\
\text { imports, possible acceptance problems } \\
\text { with construction of high voltage trans- } \\
\text { mission lines }\end{array}$ \\
\hline Feasibility & $\begin{array}{l}\text { At the moment there is still uncer- } \\
\text { tainty about the regulatory framework } \\
\text { (including integration in international } \\
\text { emissions trading) and legal aspects }\end{array}$ & $\begin{array}{l}\text { Some locational and infrastructure issues still } \\
\text { unresolved }\end{array}$ & $\begin{array}{l}\text { Uncertainties concerning sites. } \\
\text { Implementation of solar thermal power } \\
\text { plant began in the } 1980 \text { s ( }>350 \mathrm{MW} \text { in the } \\
\text { United States), further expansions under } \\
\text { way or planned (Spain }>100 \mathrm{MW} \text { under } \\
\text { construction, several solar thermal facili- } \\
\text { ties at planning stage in North Africa) }\end{array}$ \\
\hline a) Technical challenges & $\begin{array}{l}\text { Technically feasible within the afore- } \\
\text { mentioned timeframe }\end{array}$ & $\begin{array}{l}\text { Already being implemented. First reports on tech- } \\
\text { nological aspects available but no long-term studies } \\
\text { yet. Grid connection problematic }\end{array}$ & $\begin{array}{l}\text { Technically realisable in the aforemen- } \\
\text { tioned timeframe. The development of dry } \\
\text { cooling systems will be required later for } \\
\text { opening up further potential (sites without } \\
\text { cooling water supply) }\end{array}$ \\
\hline b) Legal framework & $\begin{array}{l}\text { Legal status of } \mathrm{CO}_{2} \text { not yet properly } \\
\text { clarified: classification of } \mathrm{CO}_{2} \text { as waste } \\
\text { would restrict storage }\end{array}$ & $\begin{array}{l}\text { Approval processes in progress, implementation } \\
\text { under way }\end{array}$ & $\begin{array}{l}\text { Unresolved problems: Power lines cross } \\
\text { numerous countries. Owing to low level of } \\
\text { environmental problems, legal and regula- } \\
\text { tory questions should be of little relevance, } \\
\text { acceptance of grid infrastructure unclear }\end{array}$ \\
\hline c) Other & $\begin{array}{l}\text { Some problems expected with: } \\
\text { lack of space at power stations (no room } \\
\text { to build capture unit) } \\
\mathrm{C}_{2} \text { pipeline routes difficult to find in } \\
\text { highly populated regions }\end{array}$ & $\begin{array}{l}\text { Some conflicts with environmental protection } \\
\text { (cable-laying in nature reserves ). Otherwise com- } \\
\text { patible with regulatory framework (permits already } \\
\text { granted). }\end{array}$ & \\
\hline $\begin{array}{l}\text { (Technological) Stimuli } \\
\text { for global climate } \\
\text { protection }\end{array}$ & Present & $\begin{array}{l}\text { Great potential for widespread use in developing } \\
\text { countries. Plant maintenance may be complex }\end{array}$ & $\begin{array}{l}\text { Large-scale introduction e.g. of solar ther- } \\
\text { mal power opens up opportunities for } \\
\text { initiating a renewable } \mathrm{H}_{2} \text { economy. Other } \\
\text { stimuli through combination with seawater } \\
\text { desalination or other use of waste heat } \\
\text { (e.g. solar cooling and solar process heat) }\end{array}$ \\
\hline $\begin{array}{l}\text { Industry policy } \\
\text { opportunities }\end{array}$ & $\begin{array}{l}\text { Technology manufacture will probably } \\
\text { remain restricted to big corporations } \\
\text { (Siemens, Linde, Alstom, etc.) }\end{array}$ & $\begin{array}{l}\text { Strong medium-sized companies have grown up; } \\
\text { increasing trend to concentration in market }\end{array}$ & $\begin{array}{l}\text { With solar thermal power stations Spanish, } \\
\text { US- and German companies are among } \\
\text { the leaders }\end{array}$ \\
\hline $\begin{array}{l}\text { Transferability to } \\
\text { developing countries }\end{array}$ & $\begin{array}{l}\text { Possible but questionable whether tech- } \\
\text { nologies are robust enough to function } \\
\text { properly in developing countries (where } \\
\text { engineers may be less highly trained, } \\
\text { etc.) }\end{array}$ & $\begin{array}{l}\text { Integration of developing countries as export mar- } \\
\text { kets would offer great opportunities for co-operation } \\
\text { between developing and industrialised countries }\end{array}$ & $\begin{array}{l}\text { Integration of developing countries as } \\
\text { export markets would offer great opportu- } \\
\text { nities for co-operation between developing } \\
\text { and industrialised countries. Technolo- } \\
\text { gies are comparable with conventional } \\
\text { power stations (plus collector fields, whose } \\
\text { operation and servicing are relatively } \\
\text { simple). Very high potential for application } \\
\text { in developing countries especially in com- } \\
\text { bination with use of waste heat for sea- } \\
\text { water desalination. }\end{array}$ \\
\hline $\begin{array}{l}\text { Compatibility with exist- } \\
\text { ing infrastructure (e.g. } \\
\text { load cycle response) and } \\
\text { with possible future } \\
\text { developments }\end{array}$ & $\begin{array}{l}\text { Despite growing experience and } \\
\text { increasing plant reliability, CCS tech- } \\
\text { nologies will curtail the flexibility of the } \\
\text { electricity supply system (counteracting } \\
\text { the increase in flexibility brought about } \\
\text { by integrating renewable electricity). } \\
\text { IGCC using storable gases could } \\
\text { represent an exceptio }\end{array}$ & $\begin{array}{l}\text { Throws up challenges concerning expansion of } \\
\text { power grid from coasts to main centres of demand. } \\
\text { Limited suitability for base load, requires storage } \\
\text { technologies (storing as } \mathrm{H} 2 \text { or other options; } \\
\text { initiation of renewable } \mathrm{H} 2 \text { economy structurally } \\
\text { possible) }\end{array}$ & $\begin{array}{l}\text { Suitability for base load through use of } \\
\text { heat storage. Without storage: auxiliary } \\
\text { fuelling with natural gas ensures base load } \\
\text { supply. Good coincidence of electricity } \\
\text { supply and demand (load peak caused } \\
\text { by air-conditioning demand in import- } \\
\text { ing countries is especially high when solar } \\
\text { radiation is strong) }\end{array}$ \\
\hline
\end{tabular}




\begin{tabular}{|c|c|c|c|}
\hline Criterion & ccs & Renewables: wind offshore & $\begin{array}{l}\text { Imported renewables: } \\
\text { solar electricity from North Africa }\end{array}$ \\
\hline $\begin{array}{l}\text { Compatibility with } \\
\text { other climate protection } \\
\text { strategies (decentralised } \\
\text { options) }\end{array}$ & $\begin{array}{l}\text { As a centralised generating option only } \\
\text { partly compatible with decentralised } \\
\text { or fluctuating generation. The control- } \\
\text { lability of CCS power stations will be the } \\
\text { determining factor. }\end{array}$ & $\begin{array}{l}\text { As a centralised generating option only partly } \\
\text { compatible with decentralised generation. The } \\
\text { controllability of offshore wind farms will be the } \\
\text { determining factor }\end{array}$ & $\begin{array}{l}\text { As a centralised generating option only } \\
\text { partly compatible with decentralised } \\
\text { generation. The controllability of solar } \\
\text { thermal power facilities will be the deter- } \\
\text { mining factor; local consumers in the } \\
\text { country itself would also have to be taken } \\
\text { into account }\end{array}$ \\
\hline $\begin{array}{l}\text { Effect on import } \\
\text { dependency }\end{array}$ & $\begin{array}{l}\text { Dependency on imported fossil fuels } \\
\text { will increase even more strongly than is } \\
\text { already the case }\end{array}$ & $\begin{array}{l}\text { Reduced import dependency depending on level of } \\
\text { expansion }\end{array}$ & $\begin{array}{l}\text { Rather than reducing import dependency, } \\
\text { shifts it from primary fuels (coal, natural } \\
\text { gas, possibly oil) to electricity. Severity of } \\
\text { dependency will depend on the kinds of } \\
\text { new forms of cooperation that are agreed }\end{array}$ \\
\hline Security implications & $\begin{array}{l}\text { Vulnerability of the energy system as a } \\
\text { whole increases. Pipelines and shipping } \\
\text { lanes are attractive targets for terror- } \\
\text { ist attacks }\end{array}$ & $\begin{array}{l}\text { Electricity system becomes intrinsically more secure } \\
\text { through use of numerous small generators in wind } \\
\text { farms (few MW per generator). Attractiveness as a } \\
\text { target for terrorist attacks low }\end{array}$ & $\begin{array}{l}\text { Vulnerability of the energy system as a } \\
\text { whole may increase. High voltage power } \\
\text { lines could offer attractive targets for } \\
\text { terrorist attacks. } \\
\text { Interruption of supply: acute if solar } \\
\text { thermal generators or power lines affected }\end{array}$ \\
\hline Other aspects & & Risk of failure through shipping accidents & $\begin{array}{l}\text { Case study Germany: Fundamentally } \\
\text { a discussion must be conducted about } \\
\text { whether the high voltage transmission } \\
\text { line would really have to be constructed all } \\
\text { the way through to Germany or whether a } \\
\text { simple meshed infeed at the extremities of } \\
\text { the European grid would be adequate (the } \\
\text { cost of infrastructure would be considerably } \\
\text { less in the latter case) }\end{array}$ \\
\hline
\end{tabular}




\section{Chapter 10 \\ Life Cycle Assessments for Selected CCS Processes}

\subsection{Methodology}

\subsubsection{Goals of Life Cycle Assessment}

For our ecological evaluation of selected systems configurations (from natural gas and coal to low- $\mathrm{CO}_{2}$ electricity and hydrogen) we used the life cycle assessment method (LCA) according to ISO 14.040ff. The first step of a life cycle assessment compares the material and energy flows that enter a system, are converted there and leave it in a different form (input/output balance, inventory analysis). A product LCA thus examines all the material and energy flows caused by a single product, beginning with the extraction and processing of the raw materials and following the process through manufacturing and use to the product's eventual disposal ('cradle-to-grave' approach). The next step is to calculate the environmental impact of the assessed flows. Here it is necessary to 'weigh up, aggregate, or generalise flows of different materials in different environmental media with different environmental impacts' (Schmidt and Häuslein 1997). One of the environmental impact categories is the greenhouse effect, to which atmospheric emissions of $\mathrm{CO}_{2}$, methane and $\mathrm{N}_{2} \mathrm{O}$ contribute to differing degrees. In this chapter we describe LCAs for the different paths of electricity generation and hydrogen production and assess their impact on the environment.

For inventory analysis the individual processes were modelled using Umberto ${ }^{\circledast}$ life cycle software (IFEU and IFU 2005). LCAs were conducted with the following goals:

- First of all, individual analyses were conducted for the different $\mathrm{CO}_{2}$ capture and storage options. This made it possible to identify the plant components and life cycle phases that contribute significantly to the overall result. Also, where some of these technologies are still in the development stage, it was possible to make suggestions as to how the plant could be optimised from the environmental perspective.

- In a second step the different options for $\mathrm{CO}_{2}$ capture and storage were compared with one another in order to identify the advantages and drawbacks of the different technologies.
- Finally, the options for electricity generation and hydrogen production were compared, in order to identify the differences between fossil fuels and renewables regarding climate protection.

The analysis involved several subsequent steps:

- Existing LCAs for parts of the processes under consideration were assessed.

- Specific plant types were described, including the source of the data.

- LCAs were conducted according to ISO 14.040ff (see e.g. Guinée 2002), while the steps of the processes were abridged ('Screening LCA'). In contrast to conventional studies that assess existing systems, we had to consider and assess future plant that have not yet come onto the market: We selected central parameters and modified them to take account of future developments (e.g. modifying power station efficiency from today's level to the probable level of 2020). Of course, such a 'prospective LCA' cannot be regarded as a detailed assessment of a future system, but it does at least reflect a trend.

- The material and energy flows were modelled using the material flow networks methodology implemented in Umberto, forming the basis for the inventory and impact analyses. The impact analyses were conducted using the UBA (German Federal Environment Agency) method of impact categories, which is also implemented in Umberto. The result is 'complete' LCAs (including environmental impact analyses) for CCS-based electricity and hydrogen.

- The results of the impact analysis were split up according to the different life cycle phases and components in order to allow detailed further analyses.

\subsubsection{The Methodology of Material Flow Networks}

When conducting LCAs, Umberto ${ }^{\circledR}$ uses the methodology of material flow networks (MFN) as a particularly flexible and powerful approach. MFN are capable of modelling the material and energy flows between the elements of a particular section of a real system (e.g. within an industrial process or a power station). It is 


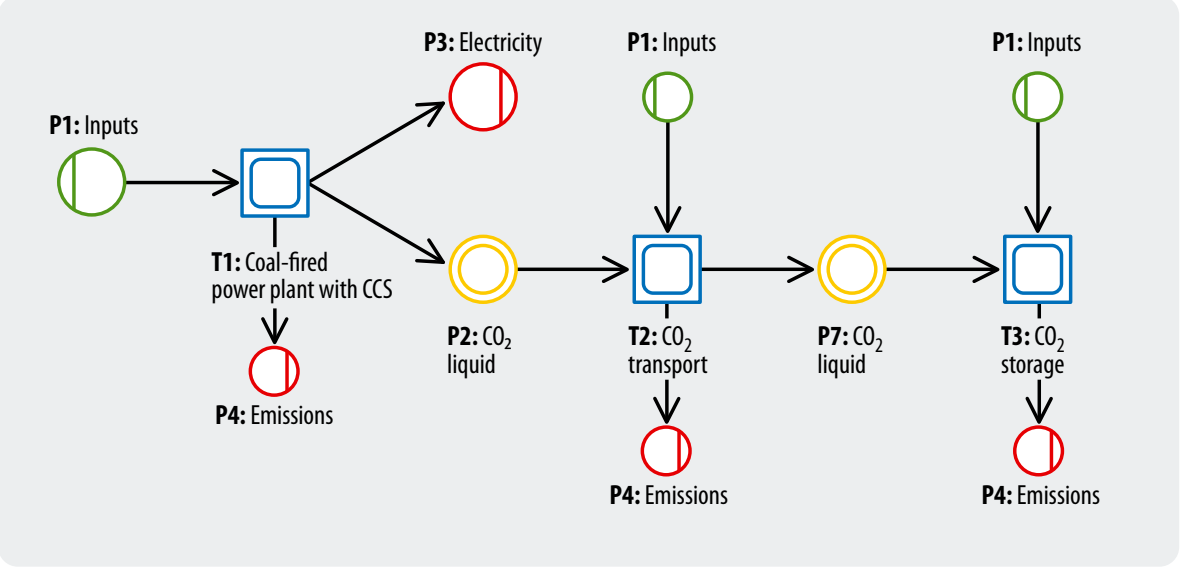

Fig. 10-1:

Model of a 'low- $\mathrm{CO}_{2}$ ' coalfired power station as modelled in Umberto ${ }^{\circledR}$

possible to analyse products (differentiated into supply chains, production, use and disposal) or services (e.g. transport of $\mathrm{CO}_{2}$ ). The corresponding input and output flows then form the basis for creating LCAs. Fig. 10-1 shows the basic model we used for assessing $\mathrm{CO}_{2}$ capture and storage techniques.

Material flow networks consist of three types of element: transitions, places and flows. Transitions (represented by squares) are processes transforming material and energy (e.g. T1: Coal-fired power plant with CCS or T3: $\mathrm{CO}_{2}$ Storage in Fig. 10-1). They play a central role in material flow networks, because all the material and energy flows depend on the transformation processes they represent. The second fundamental element of every material flow network are the places, represented by circles (e.g. P1: Inputs, P3: Electricity). Places separate the transitions from one another and thus make it possible to analyse individual transitions. Finally, flows show the paths taken by material and energy between transitions and places (Möller et al. 2001).
The $\mathrm{CO}_{2}$ sequestration model illustrated above shows the paths of the material flows from the input side to the output side. At transition T1: Coal-fired power plant with CCS, a particular amount of coal produces electricity, and $\mathrm{CO}_{2}$ is emitted. The output flows to places P3: electricity and P2: CO2, liquid. However, coal is not the only input at transition $T 1$. The others represent the 'infrastructure' (manufacture of the power plant and the equipment for $\mathrm{CO}_{2}$ capture and compression) and the consumables used, altogether. The required inputs are taken from place P1: Inputs.

Finally the liquid $\mathrm{CO}_{2}$ is transported via transition $\mathrm{T} 2$ : $\mathrm{CO}_{2}$ transport to a sink where it is stored via $\mathrm{T} 3 \mathrm{:} \mathrm{CO}_{2}$ storage. Additional inputs of material and energy also appear at these transitions (for example for pipeline manufacture and construction) and each of the processes produces emissions.

The transitions with a double border represent another characteristic of material flow networks. Every transi-

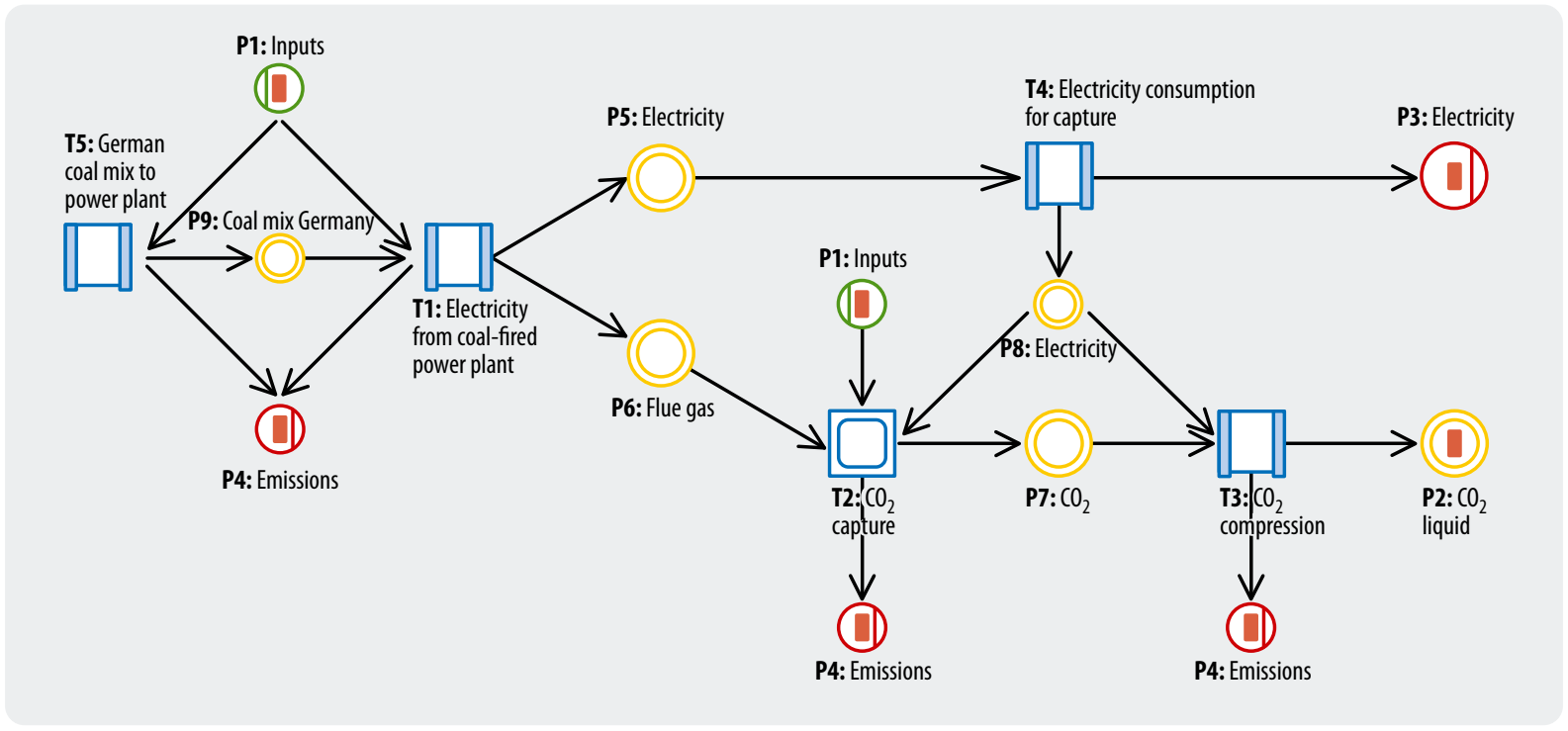

Fig. 10-2: Second-level subnet of T1: Coal-fired power plant with CCS from Fig 10-1 


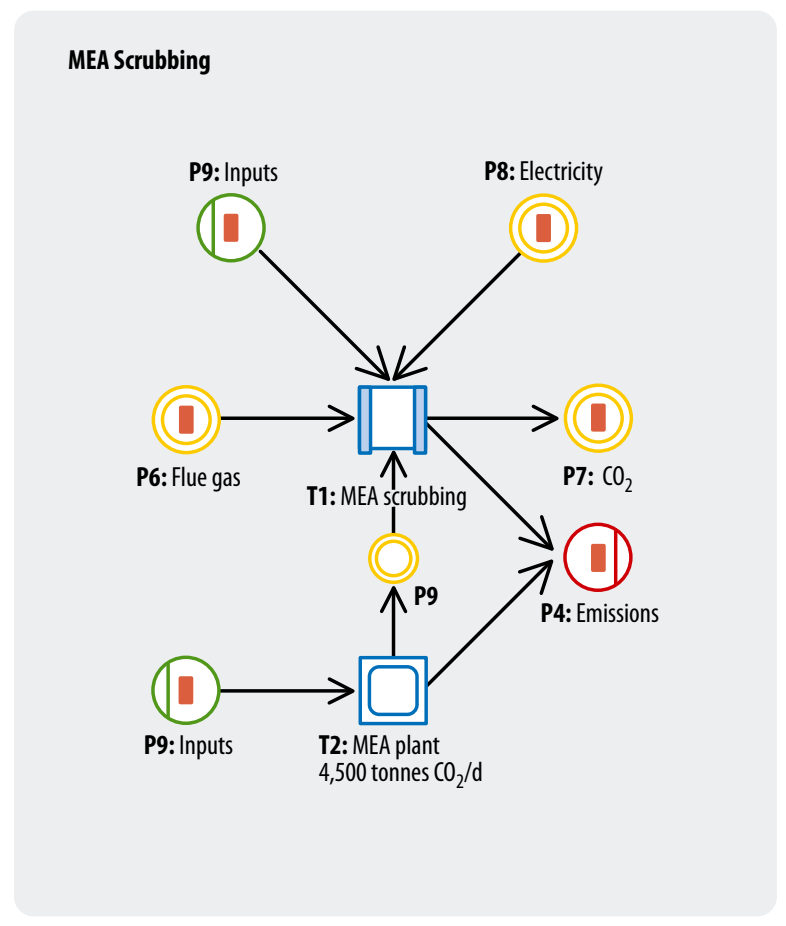

Fig. 10-3: Third-level subnet $\mathrm{T} 2$ ( $\mathrm{CO}_{2}$ capture)

tion represents a generalisation of another more detailed material flow network (known as a subnet). This allows us to create a hierarchical structure with any number of nested networks. Fig. 10-2 shows the refinement of transition T1: CCS-based coal-fired power station from Fig. 10-1.

The detailed process of burning coal to generate electricity (based on the German power mix) is represented within transition T1: Electricity from coal-fired power plant. The flue gas flows to place P6: Flue gas and passes to transition T2: $\mathrm{CO}_{2}$ capture. After transition T3: $\mathrm{CO}_{2}$ compression the liquefied carbon dioxide leaves the subnet and is now analysed further in the material flow network of level 1 . The net electricity output (place P3) ultimately comprises the electricity generated in the power station (place $P 5$ ) minus the electricity required for $\mathrm{CO}_{2}$ capture and compression at place $P 8$.

The detailed post-combustion capture technology itself is modelled in the level-three subnet T2. Fig. 10-3 shows the corresponding subnet for mono ethanol amine (MEA) scrubbing.

Other subnetworks at the same level as this one model the transport and storage of the captured carbon dioxide.

\subsubsection{Scope of LCAs and Underlying Assumptions}

\section{Different Types of Power Plants}

For electricity generation we investigated the environmental impact of various paths (Table 10-1). They included three capture technologies for fossil fuels: post-combustion (with coal- and lignite-fired steam turbine power plant and natural-gas-fired combined cycle NGCC), pre-combustion (coal-fired IGCC) and coal-fired steam turbine power plant with oxyfuel. The Ruhr region (a major industrial region in western Germany) was selected as the location of the power stations and an empty gas field $300 \mathrm{~km}$ away in northern Germany as the sink.

For purposes of comparison with renewables, electricity generated by solar thermal power plants (in Algeria) and by wind power (in the North Sea) was also modelled. In order to have the same reference location as with the fossil-fuelled options, the electricity was transported to the Ruhr region using high-voltage direct current lines. Fig. 10-4 shows the process chains modelled.

For hydrogen production the environmental impacts of the paths listed in Table 10-2 were investigated. On the fossil fuel side they include steam reforming of natural gas and coal gasification, which currently contribute to global industrial hydrogen production with $33 \%$ and $10 \%$ respectively (alongside $53 \%$ from partial oxidation of crude oil and $4 \%$ from electrolysis). The Ruhr region was again selected as the location.

Table 10-1: Selected systems configurations for electricity generation

\begin{tabular}{|c|c|c|c|}
\hline Path name & Plant & $\begin{array}{l}\text { Capture } \\
\text { technology }\end{array}$ & Location \\
\hline \multicolumn{4}{|c|}{ Low- $\mathrm{CO}_{2}$ electricity from fossil-fuelled power stations with $\mathrm{CO}_{2}$ capture and storage } \\
\hline EL_CCS_1_STK & $\begin{array}{l}\text { Coal-fired steam } \\
\text { turbine }\end{array}$ & $\begin{array}{l}\text { Post-combustion } \\
\text { (MEA scrubbing) }\end{array}$ & Ruhr region \\
\hline EL_CCS_2_NG & $\begin{array}{l}\text { Natural gas com- } \\
\text { bined cycle }\end{array}$ & $\begin{array}{l}\text { Post-combustion } \\
\text { (MEA scrubbing) }\end{array}$ & Ruhr region \\
\hline EL_CCS_3_OXY & $\begin{array}{l}\text { Coal-fired steam tur- } \\
\text { bine with oxyfuel }\end{array}$ & Oxyfuel combustion & Ruhr region \\
\hline EL_CCS_4_IGCC & Coal-fired IGCC & $\begin{array}{l}\text { Pre-combustion } \\
\text { (Rectisol scrubbing) }\end{array}$ & Ruhr region \\
\hline EL_CCS_5_BRK & $\begin{array}{l}\text { Lignite-fired steam } \\
\text { turbine }\end{array}$ & $\begin{array}{l}\text { Post-combustion } \\
\text { (MEA scrubbing) }\end{array}$ & Ruhr region \\
\hline \multicolumn{4}{|c|}{$\mathrm{CO}_{2}$-free electricity from renewables } \\
\hline EL_REG_1_SEGS & $\begin{array}{l}\text { Solar thermal type } \\
\text { SEGS }\end{array}$ & - & $\begin{array}{l}\text { Algeria }+ \text { HVDC to } \\
\text { Ruhr region }{ }^{\text {a) }}\end{array}$ \\
\hline $\begin{array}{l}\text { EL_REG_2 } \\
\text { Wind }\end{array}$ & Wind offshore & - & $\begin{array}{l}\text { North Sea + HVDC } \\
\text { to Ruhr region }\end{array}$ \\
\hline
\end{tabular}




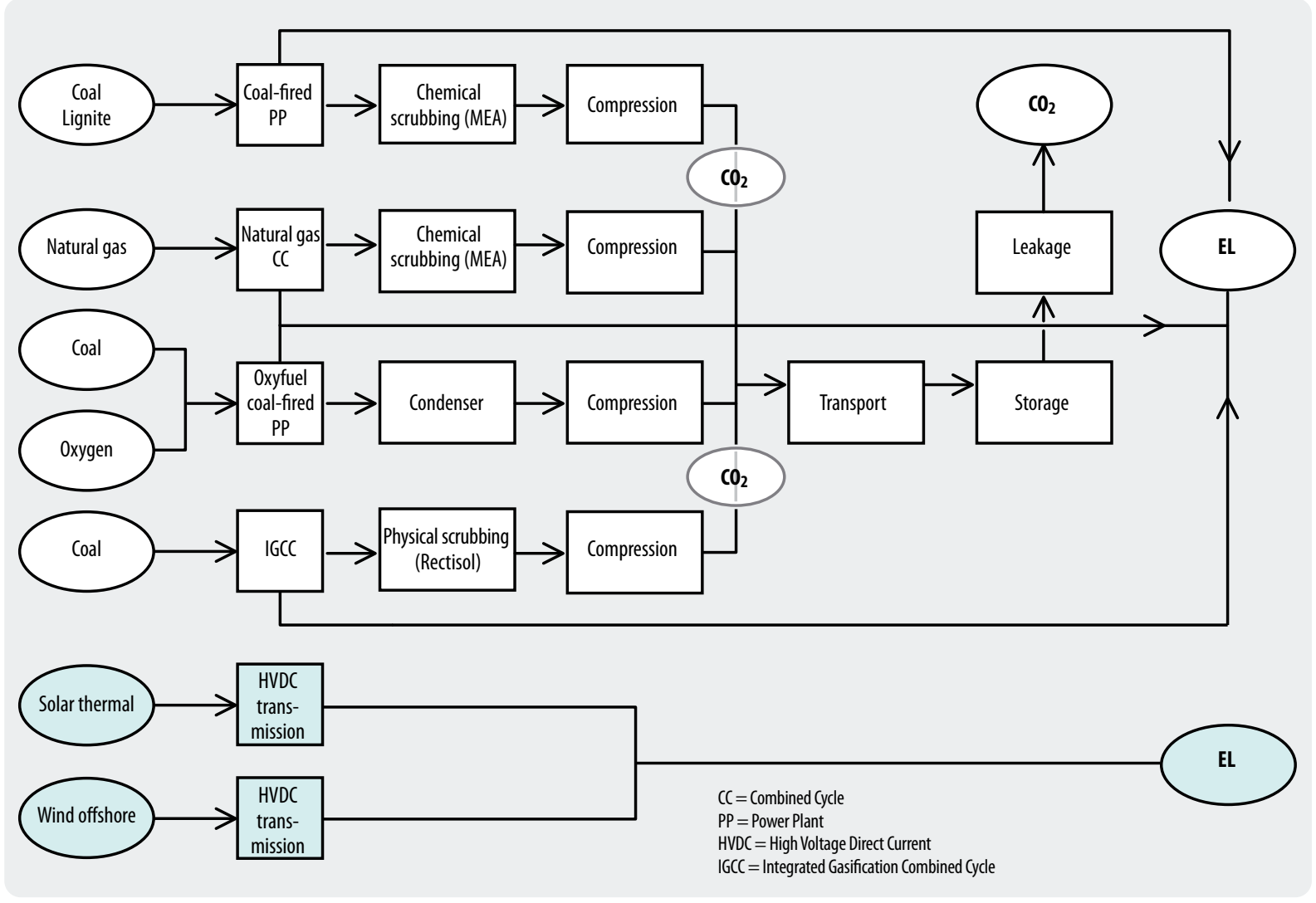

Fig. 10-4: Assessment steps for the electricity generation configurations

Renewable hydrogen production was modelled as electrolysis using electricity from solar thermal power stations in Algeria and offshore wind farms in the North Sea. The location for electrolysis was the Ruhr region; again high-voltage direct-current lines were used for transmission.

Fig. 10-5 shows the process chains modelled.

Table 10-2: Selected systems configurations for hydrogen production

\begin{tabular}{|c|c|c|c|}
\hline Path name & Plant & $\begin{array}{l}\text { Capture } \\
\text { technlology }\end{array}$ & Location \\
\hline \multicolumn{4}{|c|}{ Low- $\mathrm{CO}_{2}$ hydrogen from fossil fuels including $\mathrm{CO}_{2}$ capture and storage } \\
\hline H2_CCS_1_NG & $\begin{array}{l}\text { Steam reforming } \\
\text { (natural gas) }\end{array}$ & $\begin{array}{l}\text { Chemical scrubbing } \\
\text { (MEA) }\end{array}$ & Ruhr region \\
\hline H2_CCS_2_STK & Coal gasification & $\begin{array}{l}\text { Physical scrubbing } \\
\text { (Rectisol) }\end{array}$ & Ruhr region \\
\hline \multicolumn{4}{|c|}{$\mathrm{CO}_{2}$-free hydrogen from renewables } \\
\hline H2_REG_1_SEGS & $\begin{array}{l}\text { Electrolysis (solar } \\
\text { thermal) }\end{array}$ & - & $\begin{array}{l}\text { Algeria + } \\
\text { HVDC to Ruhr } \\
\text { region }^{\text {a) }}\end{array}$ \\
\hline H2_REG_2_Wind & $\begin{array}{l}\text { Electrolysis (wind, } \\
\text { offshore) }\end{array}$ & - & $\begin{array}{l}\text { North Sea + } \\
\text { HVDC to Ruhr } \\
\text { region }\end{array}$ \\
\hline
\end{tabular}

\section{Functional Unit}

The functional unit for electricity generation is chosen to be $1 \mathrm{kWh}_{\mathrm{el}}$, for hydrogen production it is $1 \mathrm{kWh}_{\mathrm{th}}$. In both cases this means $1 \mathrm{kWh}$ leaving the plant. These system boundaries were selected intentionally because electricity distribution is characterised by considerable data uncertainty and there is as yet no infrastructure for hydrogen distribution.

\section{Geographical Scope and Timeframe}

The geographical reference is Germany; i.e. we used LCA modules that cover technologies in Germany or Europe.

Within the project the reference year was 2020 because as yet there are only pilot projects for $\mathrm{CO}_{2}$ sequestration and capture technologies for use in large power stations have still to be developed. 2020 was also selected as the reference year for the LCAs. For the most important processes such as electricity mix, steelmaking and aluminium smelting, LCA modules projected to 2010 exist, making it possible to conduct a 'dynamic' assessment. That means that product manufacture was assessed not according to the current state of the art but instead approximating production conditions in 2010. This applies, for example, to changes in the electricity mix or increased recycling rates in steel and aluminium production. 


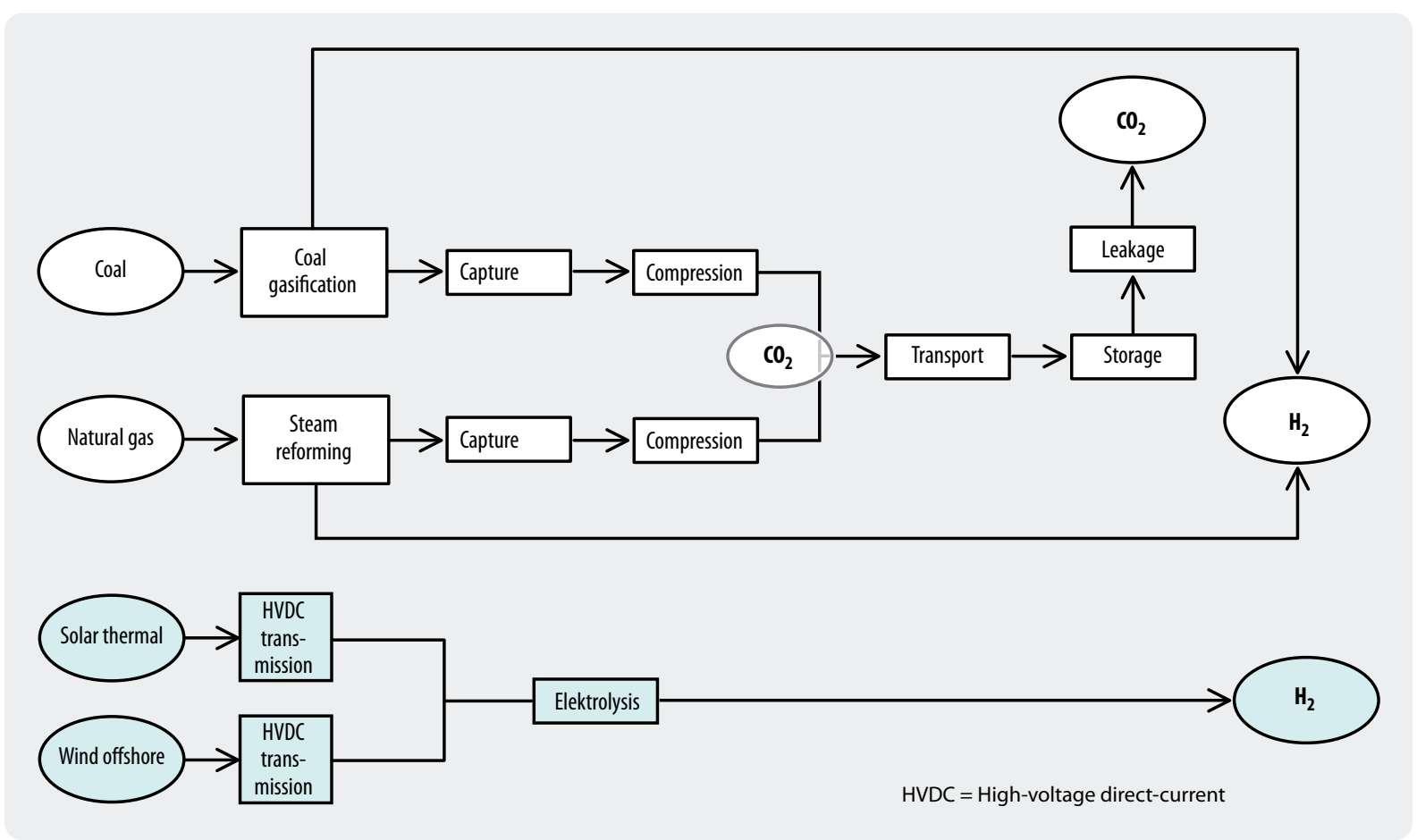

Fig. 10-5: Assessment steps for hydrogen production configurations

Table 10-3: Impact categories and assessment parameters considered in this study

\begin{tabular}{|c|c|c|c|}
\hline $\begin{array}{l}\text { Impact } \\
\text { category }\end{array}$ & $\begin{array}{l}\text { Assessment } \\
\text { parameter }\end{array}$ & $\begin{array}{l}\text { Aggregated } \\
\text { impact } \\
\text { parameter }\end{array}$ & Ratio \\
\hline $\begin{array}{l}\text { Resource } \\
\text { consumption }\end{array}$ & $\begin{array}{l}\text { Cumulative energy } \\
\text { demand }\end{array}$ & $\begin{array}{l}\text { MJ (inventory } \\
\text { parameter) }\end{array}$ & \\
\hline $\begin{array}{l}\text { Global warming } \\
\text { potentiala) }^{\text {a) }}\end{array}$ & $\begin{array}{l}\mathrm{CO}_{2} \\
\mathrm{CH}_{4} \\
\mathrm{~N}_{2} \mathrm{O} \\
\end{array}$ & $\begin{array}{l}\mathrm{gCO}_{2-}^{-} \\
\text {equivalent }\end{array}$ & $\begin{array}{r}1 \\
21 \\
310 \\
\end{array}$ \\
\hline Acidification & $\begin{array}{l}\mathrm{SO}_{2} \\
\mathrm{NO}_{\mathrm{X}} \\
\mathrm{NH}_{3} \\
\mathrm{HCl}\end{array}$ & $\begin{array}{l}\mathrm{mgSO}_{2-}^{-} \\
\text {equivalent }\end{array}$ & $\begin{array}{r}1 \\
0.7 \\
1.88 \\
0.88\end{array}$ \\
\hline Eutrophication & $\begin{array}{l}\mathrm{NO}_{\mathrm{x}} \\
\mathrm{NH}_{3} \\
\end{array}$ & $\begin{array}{l}\mathrm{mg} \mathrm{PO}_{4}^{3-}- \\
\text { equivalent }\end{array}$ & $\begin{array}{l}0.13 \\
0.33 \\
\end{array}$ \\
\hline $\begin{array}{l}\text { Photo-oxidant } \\
\text { formation } \\
\end{array}$ & $\begin{array}{l}\mathrm{NMHC} \\
\mathrm{CH}_{4} \\
\end{array}$ & $\begin{array}{l}\text { mg ethene } \\
\text { equivalent }\end{array}$ & $\begin{array}{l}0.416 \\
0.007 \\
\end{array}$ \\
\hline Particles and dust & $\begin{array}{l}\text { Airborne particles (PM10) } \\
\text { Sekundary aerosol } \mathrm{SO}_{2} \\
\text { Sekundary aerosol } \mathrm{NO}_{\mathrm{x}} \\
\text { as } \mathrm{NO}_{2} \\
\text { Sekundary aerosol } \mathrm{NMVOC} \\
\text { Sekundary aerosol } \mathrm{NH}_{3}\end{array}$ & $\begin{array}{l}\text { kg PM10- } \\
\text { equivalent }\end{array}$ & $\begin{array}{r}1 \\
0.087 \\
\\
0.216 \\
0.012 \\
0.159\end{array}$ \\
\hline
\end{tabular}

\section{Impact Categories and Assessment Parameters}

The impact category method prescribed by ISO 14.042 was used for the inventory analysis, in the specific form of the 'UBA method' developed by the German Federal Environment Agency (UBA) (UBA 1995, 1999) and implemented in Umberto ${ }^{\circledR}$ as the 'UBA method'. The inventory analysis parameters (Table 10-3) were selected to match the impact categories under consideration (Pehnt 2002). 


\section{Standardisation}

In order to evaluate the improvement yielded by using renewables and applying $\mathrm{CO}_{2}$ capture and storage to fossil fuels, the results of the LCAs were compared with competing conventional systems. For each scenario under consideration a reference electricity generating system and a widespread type of hydrogen production were selected and compared using the same impact categories.

\subsubsection{Data Sources and Quality}

In order to conduct an LCA it is necessary to have the invetory data for the individual processes under consideration: material and energy consumption figures for manufacture, operation and disposal of the respective power plant types. Different levels of detail are possible depending on the data available. The data were drawn from various sources. The right-hand column in Table 10-4 shows which LCAs had to be drawn up completely from scratch from literature investigation or our own modelling. Existing LCAs were modified to reflect the $\mathrm{CO}_{2}$ capture situation.

Estimates of environmental data for renewable energy systems always involve uncertainties. The following quality gradients generally apply (Pehnt 2002):

- Energy consumption data and factors for consumption-related emissions (especially $\mathrm{CO}_{2}$ ) are more reliable than factors for emissions unrelated to consumption;

- Factors for emissions from production of infrastructure are less reliable than those for emissions from operation;

- Data for infrastructure of the power stations themselves are more reliable than data for infrastructure of upstream energy supply chains (for example natural gas supply);

- Data for the infrastructure of renewable energy systems are more reliable than those for the infrastructure of fossil-fuelled systems with which they are compared (because in the former case they often represent the only environmental impact);

- Factors for controlled emissions (e.g. $\mathrm{NO}_{\mathrm{x}}, \mathrm{CO}$, hydrocarbons) are more reliable than factors for non-restricted emissions.

Differences that arise within impact categories when comparing different technologies can be regarded as insignificant as long as they remain under $5 \%$ for energy consumption and global warming potential, under $20 \%$ for eutrophication and under $30 \%$ for particles and dust.
Table 10-4: Data sources of processes under consideration

\begin{tabular}{|c|c|c|c|}
\hline Process & Data source & $\begin{array}{l}\text { Existing } \\
\text { LCA }\end{array}$ & $\begin{array}{l}\text { New LCA } \\
\text { prepared }\end{array}$ \\
\hline \multicolumn{4}{|c|}{ Electricity generation and $\mathrm{CO}_{2}$ capture } \\
\hline $\begin{array}{l}\text { Natural gas and coal-fired } \\
\text { power stations }\end{array}$ & Umberto, ecoinvent & $x$ & \\
\hline MEA-scrubbing & $\begin{array}{l}\text { Mariz } 1998 \\
\text { Chapel and Mariz } 1999 \\
\text { Rao and Rubin } 2002 \\
\text { Ecoinvent }\end{array}$ & $x$ & $x$ \\
\hline IGCC power station & Briem et al. 2004 & & $x$ \\
\hline 0xyfuel power station & Göttlicher 1999 & & $x$ \\
\hline $\begin{array}{l}\text { Electricity from renewables } \\
\text { (wind, solar thermal) }\end{array}$ & DLR database & $x$ & \\
\hline HVDC transmission & DLR database & $x$ & \\
\hline \multicolumn{4}{|c|}{ Hydrogen production and $\mathrm{CO}_{2}$ capture } \\
\hline $\begin{array}{l}\text { Coal gasification with/ } \\
\text { without CCS }\end{array}$ & data from IGCC used & & $x$ \\
\hline $\begin{array}{l}\text { Natural gas steam } \\
\text { reforming }\end{array}$ & Pehnt 2002 & & $x$ \\
\hline $\begin{array}{l}\text { Natural gas steam } \\
\text { reforming with CCS }\end{array}$ & ZSW DOE 2002 & & $\begin{array}{l}x \\
x\end{array}$ \\
\hline Electrolysis & DLR database & $x$ & \\
\hline Compression & Göttlicher 1999 & & $x$ \\
\hline \multicolumn{4}{|l|}{ Transport } \\
\hline Pipeline & Ecoinvent & $x$ & \\
\hline Storage & - & & \\
\hline
\end{tabular}

\subsection{Mathematical Methodology - Captured versus Avoided $\mathrm{CO}_{2}$}

Fig. 10-6 shows the derivation of the captured and avoided amounts of $\mathrm{CO}_{2}$ per $\mathrm{kWh}$ for the example of a coal-fired power station (efficiency $49 \%$, gross $\mathrm{CO}_{2}$ emissions $\left.710 \mathrm{~g} / \mathrm{kWh}_{\mathrm{el}}\right)$.

Bar 1 shows the $\mathrm{CO}_{2}$ emissions from the power station without capture, divided into upstream chain (preprocesses) and operation. Capturing $\mathrm{CO}_{2}$ requires additional electricity to be generated - and consequently causes additional emissions. The emissions associated with the additional demand are also shown, divided into upstream chain and power station operation (bar 2). The capture rate is $88 \%$, both from the regular operation emissions (assigned to the final product $1 \mathrm{kWh}$ electricity) and those from emissions that arise through capture (bar 3). In bar 4 the respective captured and remaining emissions are added together. Then the $\mathrm{CO}_{2}$ emissions from transport and storage are added (bar 5). Bar 5 thus brings together all the residual emissions: from the original upstream chain, from original power 


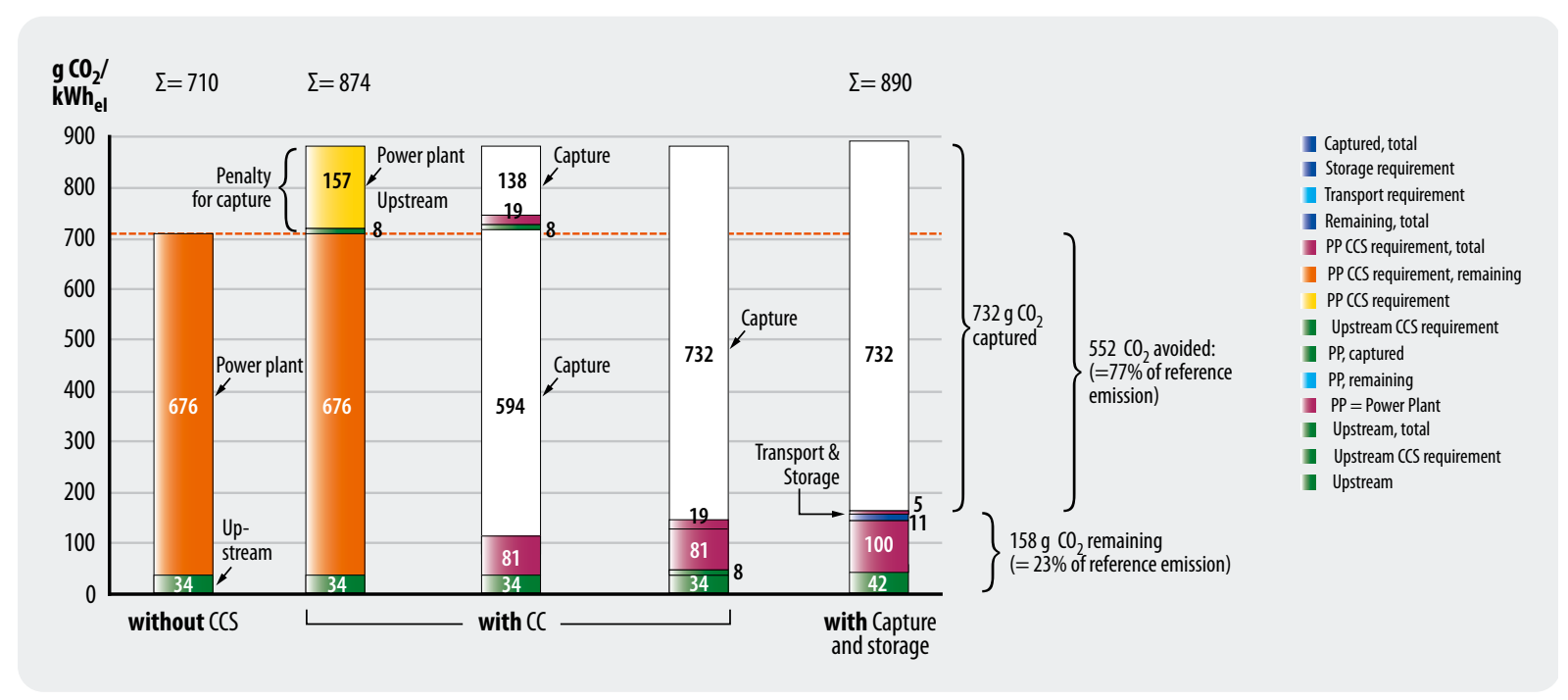

Fig. 10-6: Methodology for calculating captured and avoided $\mathrm{CO}_{2}$ for the example of a coal-fired power station with and without $\mathrm{CCS}(\mathrm{CC}=\mathrm{carbon}$ capture only, without transport and storage). Efficiency without CCS $=49 \%$, with CCS $=40 \%$, capture rate $=88 \%$

station operation without CCS, from the additional demand and its upstream chain, and from transport and storage (small bracket). Altogether owing to the additional energy demand the gross emissions of $710 \mathrm{~g} /$ $\mathrm{kWh}_{\mathrm{el}}$ initially rise considerably to $913 \mathrm{~g} / \mathrm{kWh}_{\mathrm{el}}-$ which means that the real avoided $\mathrm{CO}_{2}$ emissions (mediumsized bracket) are actually a good deal less than the captured $\mathrm{CO}_{2}$ (large bracket).

\subsection{Plant and Processes for Conventional Electricity Generation with CCS}

\subsubsection{Reference Power Stations}

Table 10-5 shows the basic data of the reference power stations without and with $\mathrm{CO}_{2}$ capture. They are compatible with the data used for the economic calculations and refer to 2020 .

In each case the most up-to-date modules for power stations and the supply chain were used to model the LCA. The power station modules are projected through to 2020 by modifying the efficiency according to the values in the table above. The LCA modules came from various sources (see Table 10-6):

- Coal-fired power plant: The module describes a coastal coal-fired power station using imported coal in the early 1990s. A flue gas desulphurisation plant, a $\mathrm{DeNO}_{\mathrm{x}}$ unit and an electric filter are included to reduce emissions. Flue gas desulphurisation operates using the wet process with pulverised limestone sorbent $\left(\mathrm{CaCO}_{3}\right)$ and a stoichio- metric relationship of limestone to $\mathrm{SO}_{2}$. It reduces $\mathrm{SO}_{2}$ emissions by $90 \%$, dust emissions by $90 \%$ and $\mathrm{HCl}$ and $\mathrm{HF}$ emissions by $95 \%$. $^{1}$ The $\mathrm{DeNO}_{\mathrm{x}}$ unit operates using the SCR process (selective catalytic reduction) with ammonia as the sorbent in a stoichiometric relationship, and cuts $\mathrm{NO}_{\mathrm{x}}$ emissions by $85 \%$. The electric filter further reduces dust emissions, resulting in an overall reduction of $99.5 \%$.

- Coal-fired IGCC: The module describes a coalfired IGCC power station modelling the operating conditions of 2010. There are relatively few IGCC pilot plants in operation worldwide, and there were no LCAs for IGCC until Briem et al. (2004) modelled a future $450 \mathrm{MW}$ plant by taking certain components from existing power stations (gas turbine, generator, coaling plant, et al.) and scaling up others from smaller plants. For components where there were no existing materials data from known plants (e.g. air separation facility, Claus plant, gasification system, et al.), estimates based on materials data of other known components were used.

- Natural gas CC: The module describes a combined cycle power plant in Germany in 1994 with low- $\mathrm{NO}_{\mathrm{x}}$ combustor. One third of the power comes from the steam turbine, using wet re-cooling via a cooling tower with a water requirement of $190 \mathrm{t} /$ TJ.

- Lignite-fired power plant: The module describes averaged data for the lignite-fired power stations in the German public electricity supply, based on the situation at the end of the 1990s (largely 1998). It models mill-drying, boiler (dust firing, fluidised bed firing), steam turbine (national mix rather than

$1 \mathrm{SO}_{2}$ content of $222 \mathrm{ppmv}$ calculated from the volume flows and specific $\mathrm{SO}_{2}$ emissions. 
Table 10-5: Basic data for fossil-fired reference power stations without and with $\mathrm{CO}_{2}$ capture

\begin{tabular}{|c|c|c|c|c|c|c|}
\hline & & $\begin{array}{l}\text { Lignite-fired } \\
\text { power plant }\end{array}$ & \multicolumn{2}{|c|}{ Coal-fired power plant } & $\begin{array}{l}\text { Coal-fired } \\
\text { IGCC }\end{array}$ & $\begin{array}{l}\text { Natural gas } \\
\text { CC }^{\text {b) }}\end{array}$ \\
\hline \multicolumn{7}{|c|}{ A) Without $\mathrm{CO}_{2}$ capture } \\
\hline Output & $\mathrm{MW}_{\mathrm{el}}$ & 700 & \multicolumn{2}{|c|}{700} & 700 & 700 \\
\hline Full load hours & $\mathrm{h}$ & 7,000 & \multicolumn{2}{|c|}{7,000} & 7,000 & 7,000 \\
\hline Efficiency & $\%$ & 46 & \multicolumn{2}{|c|}{49} & 50 & 60 \\
\hline $\mathrm{CO}_{2}$-intensity of fuel & $g\left(\mathrm{O}_{2} / \mathrm{MJ} \mathrm{C}\right)$ & 112 & \multicolumn{2}{|c|}{92} & 92 & 56 \\
\hline & $\mathrm{gCO}_{2} / \mathrm{kWh}$ & 403 & \multicolumn{2}{|c|}{331} & 331 & 202 \\
\hline $\mathrm{CO}_{2}$-intensity of electricity & $\mathrm{gCO} / \mathrm{kWh}_{\mathrm{el}}$ & 849 & \multicolumn{2}{|c|}{676} & 662 & 337 \\
\hline \multicolumn{7}{|l|}{ B) With $\mathrm{CO}_{2}$ capture } \\
\hline Capture method & & Post-combustion & Post-combustion & Oxyfuel & Pre-combustion & Post-combustion \\
\hline Scrubbing method & & Chemical (MEA) d) & Chemical (MEA) d) & $\begin{array}{l}\text { Condensation } \\
\text { only }\end{array}$ & Physikal (Rectisol) & Chemical (MEA) d) \\
\hline Output & MW & 517 & 570 & 543 & 590 & 600 \\
\hline Efficiency & $\%$ & 34 & 40 & 38 & 42 & 51 \\
\hline Loss & $\%$ points & 12 & 9 & 11 & 8 & 9 \\
\hline Capture rate & $\%$ & 88 & 88 & 99,5 & 88 & 88 \\
\hline $\mathrm{CO}_{2}$ to store & t/a & $5,113,525$ & $3,570,336$ & $4,249,383$ & $3,400,320$ & $1,704,508$ \\
\hline \multicolumn{7}{|c|}{ a) $I G C C=$ integrated gasification combined cycle (coal gasification) } \\
\hline \multicolumn{7}{|l|}{ b) $C C=$ Combine cycle } \\
\hline \multicolumn{7}{|l|}{ c) Source: UBA 2003} \\
\hline \multicolumn{7}{|c|}{ d) $M E A=$ monoethanolamine } \\
\hline
\end{tabular}

Table 10-6: Sources for the LCA modules for the fossil-fired reference power stations

\begin{tabular}{|c|c|c|c|c|c|c|}
\hline Power station type & $\begin{array}{l}\text { Output } \\
\text { [MW] }\end{array}$ & $\begin{array}{l}\text { Functional } \\
\text { unit }\end{array}$ & $\begin{array}{r}\text { Efficiency } \\
\text { (net) [\%] }\end{array}$ & Source & Modul name & Year \\
\hline Coal-fired power plant & 500 & $1 \mathrm{kWh}_{\mathrm{el}}$ & 43.5 & Umberto & KW SK D (Küste) & Early $1990 \mathrm{~s}$ \\
\hline Coal-fired IGCC & 450 & $1 \mathrm{kWh}_{\mathrm{el}}$ & 51.5 & Briem et al. 2004 & New & 2010 \\
\hline Lignite-fired power plant & 500 & $1 \mathrm{kWh}_{\mathrm{el}}$ & 30.1 & Umberto & BrkKW o.V & Late 1990s \\
\hline Natural gas CC & 450 & $1 \mathrm{kWh}_{\mathrm{el}}$ & 55 & Umberto & $\begin{array}{l}\text { KW Erdgas } \\
\text { (D, GuD, } 450 \mathrm{MW})\end{array}$ & 1994 \\
\hline
\end{tabular}


individual plant) and flue gas scrubbing (as actually implemented in overall capacity). Flue gas scrubbing includes dust filtering (electric filter) and flue gas desulphurisation ( $80 \%$ wet, $15 \%$ quasi-dry, $5 \%$ dry; $70 \%$ with pulverised limestone, $30 \%$ with quicklime; approach derived from ecoinvent). $\mathrm{DeNO}_{\mathrm{x}}$ catalytic converters are not usually fitted in lignite-fired power stations but $\mathrm{NO}_{\mathrm{x}}$ emissions are reduced to $250 \mathrm{mg} / \mathrm{m}^{3}$ by primary measures.

\subsubsection{Supply Chains}

The LCA modules for the supply chains come from the following sources (Table 10-7) and cover all steps from raw material extraction to local distribution:

- Coal: From unmined coal in deposits to delivered coal at power stations and industrial plant in Germany. The mix of coal sources used was: Germany, $62.1 \%$; Poland (and Eastern Europe), $12.5 \%$; South Africa, $10.2 \%$; Columbia/Canada/USA, $7.8 \%$; Australia,: $4.1 \%$; Netherlands (and rest of Western Europe), 3.3 \% (Statistik der Kohlenwirtschaft e.V. 2000).

- Natural gas: Includes exploration and development of reserves, extraction and conditioning, long-distance transport and regional and local distribution. Most of the natural gas used in Germany is imported, so the supply was divided among the most important supplying regions (Germany, Russia, Norway, Netherlands). Pehnt (2002) projects the current situation described in Umberto for a probable import mix in 2010: Germany, $13 \%$; Netherlands, $19 \%$; Norway, $33 \%$; CIS, $35 \%$. Finally, the greenhouse gas emissions for Russian natural gas were modified according to the results of a study where the Wuppertal Institute and the Max Planck Institute of Chemistry investigated and updated the greenhouse gas emissions for the Russian natural gas export pipelines (WI and MPI 2004).

- Lignite: From unmined lignite to delivery at power stations and industrial plants. The lignite used in Germany is mined almost exclusively in Germany. We distinguished between the western, central and

Table 10-7: Sources for LCA modules for fossil fuel supply chains

\begin{tabular}{|l|c|l|l|l|}
\hline Fuel & $\begin{array}{l}\text { Functional } \\
\text { unit }\end{array}$ & Source & Modul name & Year \\
\hline Coal & $1 \mathrm{~kg}$ & Umberto & $\begin{array}{l}\text { Steinkohle-Mix D frei } \\
\text { KW/In }\end{array}$ & 2000 \\
\hline Lignite & $1 \mathrm{~kg}$ & Umberto & $\begin{array}{l}\text { Braunkohle-Mix D frei } \\
\text { KW/In }\end{array}$ & 1998 \\
\hline Natural gas & $1 \mathrm{~kJ}$ & $\begin{array}{l}\text { Umberto, } \\
\text { Pehnt 2002, } \\
\text { Wland PMl } \\
2004\end{array}$ & $\begin{array}{l}\text { Vorkette__ Erdgas_D_2010 } \\
\text { Ear }\end{array}$ & 2010 \\
\hline
\end{tabular}

eastern deposits to reflect the different complaces of the lignite in those areas. The 1998 mix according to Statistik der Kohlenwirtschaft e.V. (2000) was taken as the basis.

\subsection{3 $\mathrm{CO}_{2}$ Capture Methods}

The following methods were used to separate the carbon dioxide:

\section{$\mathrm{CO}_{2}$ Capture after Combustion}

Coal-fired power plants and natural gas CC were combined with flue gas decarbonisation, which is an obvious option for retrofitting existing power stations (chemical scrubbing). A capture rate of $88 \%$ was assumed. The modelled method was the Econamine process developed by FluorDaniel of Canada, which works with a 30 \% MEA (mono ethanol amine) solution (Mariz 1998; Chapel and Mariz 1999). According to Mariz (1998) consumption of cooling water and electricity is proportional to the $\mathrm{CO}_{2}$ content of the flue gas, whereas the the consumption of steam and chemicals depends only on the amount of captured $\mathrm{CO}_{2}$ (and to an extent also on other emissions).

Based on Göttlicher (1999), the following values for $\mathrm{CO}_{2}$ content were used when determining the variables:

- Coal-fired power plant

$11.2 \% \mathrm{CO}_{2}$ in flue gas

- Natural gas CC

$3.2 \% \mathrm{CO}_{2}$ in flue gas

The following values for consumption and emissions were used for modelling capture; unless otherwise indicated they derive from Chapel and Mariz (1999), who modelled a coal-fired power station with MEA capture and a capacity of 1,000 t $\mathrm{CO}_{2}$ /day and assumed that the $\mathrm{SO}_{2}$ content would be reduced from 250 ppmv to a maximum of 10 ppmv.

\section{Energy consumption}

The following energy consumption figures were used for MEA capture: ${ }^{2}$

- Electricity (coal-fired power plant) $177 \mathrm{MJ}_{\mathrm{el}} / \mathrm{t} \mathrm{CO}_{2}$ or $49 \mathrm{kWh}_{\mathrm{el}} / \mathrm{t} \mathrm{CO}_{2}$

- Electricity (natural gas CC) $526 \mathrm{MJ}_{\mathrm{el}} / \mathrm{t} \mathrm{CO}$ or $146 \mathrm{kWh}_{\mathrm{el}} / \mathrm{t} \mathrm{CO}_{2}$

- Steam (both power station types) $4,200 \mathrm{MJ}_{\mathrm{th}} / \mathrm{t} \mathrm{CO}_{2}$ or $1,166 \mathrm{kWh}_{\mathrm{th}} / \mathrm{t} \mathrm{CO}_{2}$

In modelling terms the steam appears in the LCA as a loss of electricity, which could not be generated by the

2 Chapel and Mariz (1999) use the American short ton (te) so all the figures they cite had to be multiplied by 1.1023 to give values in metric tonnes $(\mathrm{t})$. 
Table 10-8: Modelled residual efficiency of the steam turbine process

\begin{tabular}{|l|c|c|l|}
\hline $\begin{array}{l}\text { Power station } \\
\text { type }\end{array}$ & $\begin{array}{l}\text { Residual efficiency } \\
\text { of the steam } \\
\text { turbine process } \\
{[\%]}\end{array}$ & $\begin{array}{l}\text { Lost } \\
\text { turbine output }\end{array}$ & $\begin{array}{l}\text { Direct } \\
\text { electricity } \\
\text { consumption } \\
{\left[\mathrm{kWhhel} / \mathrm{t} \mathrm{CO}_{2}\right]}\end{array}$ \\
\hline $\begin{array}{l}\text { Coal-fired power } \\
\text { plant }\end{array}$ & 13 & 187 & 49 \\
\hline $\begin{array}{l}\text { Lignite-fired } \\
\text { power plant }\end{array}$ & 15.5 & 128 & 49 \\
\hline Natural gas CC & 22.5 & 385 & 146 \\
\hline
\end{tabular}

steam turbine (lost turbine output). However, because the required steam is taken out as saturated steam (i.e. in one of the later steps of the process), we cannot assume that all the relevant steam turbine energy (about $40 \%$ of energy input) is 'lost' for electricity generation. So instead we use a 'residual efficiency' (Table 10-8) that is determined by adding the directly required electricity to the overall efficiency loss of the reference power stations ( 8 to $12 \%$ points, see Table $10-5$ ) and placing the remainder in relation to the required steam. We found the following residual efficiencies of the steam turbine process (column 2), from which we were then able to calculate the amount of electricity lost (column 3). Column 4 shows the directly used electricity.

\section{Chemicals}

- The solvent MEA must be constantly topped up because a proportion of the original volume is lost through degradation, vaporisation and leaks. Here an average consumption of $1.76 \mathrm{~kg} / \mathrm{t} \mathrm{CO}(1.6 \mathrm{~kg} /$ te $\mathrm{CO}_{2}$ ) was assumed. Any residual $\mathrm{SO}_{\mathrm{x}}$ in the flue gas will react with the MEA causing further losses. Additional MEA consumption of $0.49 \mathrm{~kg} / \mathrm{t} \mathrm{CO}_{2}$ $\left(0.446 \mathrm{~kg} /\right.$ te $\left.\mathrm{CO}_{2}\right)$ is factored in to account for the assumed residual content of about 10 ppmv $\mathrm{SO}_{\mathrm{x}}$ (plus additional $\mathrm{SO}_{3}$ ) for a coal-fired steam turbine (see below).

- Owing to lack of data it was impossible to assess the manufacture of the plant for chemical scrubbing, which comprises absorption and desorption columns, three heat exchangers, condensers, pump and fan. However, in comparison with process energy and consumables, manufacturing probably represents a marginal factor.

- Activated carbon and sodium hydroxide $(\mathrm{NaOH})$ are also required for the capture process. The following consumption figures were used: activated carbon $0.0826 \mathrm{~kg} / \mathrm{t} \mathrm{CO} 2\left(0.077 \mathrm{~kg} / \mathrm{te} \mathrm{CO}_{2}\right), \mathrm{NaOH}$ $0.152 \mathrm{~kg} / \mathrm{t} \mathrm{CO}\left(0.137 \mathrm{~kg} / \mathrm{te} \mathrm{CO}_{2}\right)$.
- Neither the Umberto nor the ecoinvent database includes an LCA module for activated carbon, so it has not yet been possible to model its consumption.

\section{Cooling water}

The following values were used for consumption of cooling water for capture:

- Coal-fired power plant $83.2 \mathrm{~m}^{3} / \mathrm{t} \mathrm{CO}_{2}\left(75.5 \mathrm{~m}^{3} /\right.$ te $\left.\mathrm{CO}_{2}\right)$

- Electricity (natural gas $\mathrm{CC}$ ) $121.7 \mathrm{~m}^{3} / \mathrm{t} \mathrm{CO}_{2}\left(110.4 \mathrm{~m}^{3} /\right.$ te $\left.\mathrm{CO}_{2}\right)$

\section{Emissions}

- $\mathrm{SO}_{2}$ in power station flue gas needs to be reduced to a residual content of $10 \mathrm{ppmv}$ in order to minimise the amount of $\mathrm{SO}_{2}$ that can react with the MEA. The coal-fired power station modules we used in Umberto already specify a $90 \%$ reduction in $\mathrm{SO}_{2}$ emissions through flue gas scrubbing, which produces a residual content of $222 \mathrm{ppmv}$. So power station $\mathrm{SO}_{2}$ emissions were reduced further in a ratio of 220:10 but the costs of this additional flue gas desulphurisation could not be modelled.

- The $\mathrm{SO}_{2}$ emissions from natural gas CC plant are low anyway so the values were left unaltered.

Table 10-9: Consumption and emissions data used for modelling the MEA capture process

\begin{tabular}{|c|c|c|c|}
\hline Power station type & & $\begin{array}{l}\text { Coal-fired } \\
\text { power plant }\end{array}$ & $\begin{array}{l}\text { Natural } \\
\text { gas CC }\end{array}$ \\
\hline $\mathrm{CO}_{2}$ content of flue gas & $\%$ & 11.2 & 3.2 \\
\hline \multicolumn{4}{|l|}{ Consumption for MEA capture } \\
\hline $\begin{array}{l}\text { Electricity consumption for } \\
\text { capture }\end{array}$ & $\mathrm{kWh}_{\mathrm{el}} / \mathrm{tCO}_{2}$ & 49 & 146 \\
\hline Steam consumption for capture & $\mathrm{kWh}_{\mathrm{th}} / \mathrm{tCO}_{2}$ & 1,166 & 1,166 \\
\hline MEA consumption & $\mathrm{kg} / \mathrm{tCO}_{2}$ & $1.76+0.49$ & 1.76 \\
\hline Activated carbon & $\mathrm{kg} / \mathrm{tCO}_{2}$ & 0.0826 & 0.0826 \\
\hline Sodium hydroxide ( $\mathrm{NaOH})$ & $\mathrm{kg} / \mathrm{tCO}_{2}$ & 0.152 & 0.152 \\
\hline Cooling water & $\mathrm{m}^{3} / \mathrm{tCO}_{2}$ & 83.2 & 121.7 \\
\hline \multicolumn{4}{|l|}{ Changes in power station emissions } \\
\hline $\mathrm{SO}_{2}$ emissions & $\%$ & -99.5 & - \\
\hline $\mathrm{NO}_{\mathrm{x}}$ emissions & $\%$ & -2.5 & -2.5 \\
\hline Dust emissions & $\%$ & -50 & -50 \\
\hline Hydrogen chloride ( $\mathrm{HCl}$ ) & $\%$ & -95 & -95 \\
\hline
\end{tabular}


- $\mathrm{NO}_{2}$ in flue gas can corrode steel and degrade the solvent so it should also be reduced. Because $\mathrm{NO}_{2}$ represents only $10 \%$ of $\mathrm{NO}_{\mathrm{x}}$ emissions and in turn only $25 \%$ of these emissions can be reduced (Rao und Rubin 2002), power station $\mathrm{NO}_{\mathrm{x}}$ emissions overall are reduced by $2.5 \%$. The costs of this additional cleaning were also impossible to model.

- Dust and hydrogen chloride react with the solvent, allowing dust emissions to be reduced by $50 \%$ and $\mathrm{HCl}$ emissions by 95 \% (Rao and Rubin 2002).

Table 10-9 gives an overview of the figures used.

\section{$\mathrm{CO}_{2}$ Capture before Combustion}

In coal-fired IGCC, the $\mathrm{CO}_{2}$ is captured before combustion (fuel gas decarbonisation) using physical scrubbing to separate the $\mathrm{CO}_{2}$ from a $\mathrm{H}_{2} / \mathrm{CO}_{2}$ mixture. Existing literature specifies only the electricity consumption required for the individual steps of this process (Göttlicher 1999, Fig. 3.45), which meant that it was not possible to model in detail the $\mathrm{CO}$ shift and the physical scrubbing. A capture rate of $88 \%$ was assumed.

\begin{tabular}{lc} 
Electricity consumption CO shift & $125 \mathrm{kWh}_{\mathrm{el}} / \mathrm{t} \mathrm{CO}_{2}$ \\
Electricity consumption physical scrubbing & $48 \mathrm{kWh}_{\mathrm{el}} / \mathrm{t} \mathrm{CO}_{2}$ \\
Lost turbine output & $30 \mathrm{kWh}_{\mathrm{el}} / \mathrm{t} \mathrm{CO}_{2}$ \\
\hline Total & $203 \mathrm{kWh}_{\mathrm{el}} / \mathrm{t} \mathrm{CO}_{2}$
\end{tabular}

\section{Oxyfuel Process}

The oxyfuel process involves burning coal in pure oxygen rather than in air. Here it is applied to the reference coal-fired power station. The advantage of combustion in oxygen is that the volume of waste gas is much smaller, and the flue gases consist largely of $\mathrm{CO}_{2}$ (about $80 \%$ by volume) which means that the $\mathrm{CO}_{2}$ can be captured simply by condensing out the water. No chemical or physical scrubbing is required. The disadvantage is the very large amount of electricity used by the air separation facility to produce the oxygen.

For this project an air separation facility is added to the coal-fired power station, without more detailed modelling of the material flows. The following data were used:

- The air separation facility was taken from the coalfired IGCC model in Briem et al. (2004) which assumes the conditions of application for 2010. A facility dimensioned for a $450 \mathrm{MW}_{\mathrm{el}}$ power station was linearly scaled up for the power station output of $700 \mathrm{MW}_{\mathrm{el}}$ required here.

- The waste gas is condensed in the $\mathrm{SO}_{\mathrm{x}}$ scrubber, meaning that only power stations with wet desulphurisation can be used here (as implemented in the coal-fired power station used in the Umberto module). However, the captured $\mathrm{CO}_{2}$ still has a residual moisture content of approx. $1 \%$. If dry gas is to be generated it must be cooled further to condense out the remaining water. This additional cost is ignored here, making the calculation for capture a conservative one.

- On the other hand, an oyxfuel power station can dispense with the standard denitrification equipment because most of the nitrogen oxides in the standard process originate from the oxidation of atmospheric nitrogen, which is absent here. The lower internal consumption at the oxyfuel power station resulting from the absence of denitrification equipment is also excluded here.

- It has not yet been possible to model the nitrogen oxide emissions, so the old values for the original power station (which are too high) were used.

- Apart from the air separation facility the only extra cost was for liquefying the carbon dioxide.

- $\mathrm{A} \mathrm{CO}_{2}$ capture rate of $99.5 \%$ was assumed according to Göttlicher (1999) who stated that 'considerably more than $99 \%$ ' of the $\mathrm{CO}_{2}$ could be retained.

- Göttlicher (1999) gives $2.7 \mathrm{~kg} \mathrm{O}_{2} / \mathrm{kg}$ fuel as the mean oxygen requirement for a coal-fired oyxfuel power station.

- For the electricity required by the air separation facility, a mean was calculated using the data given by Göttlicher (1999); the figure found was 0.2245 $\mathrm{kWh}_{\mathrm{el}} / \mathrm{kg} \mathrm{O}_{2}$. Here oxygen is produced at a high purity of 96-97\%, which requires more energy. However, this at the same time reduces the work of the compressor because less inert gas has to be liquefied along with the $\mathrm{CO}_{2}$ (Göttlicher 1999).

\subsection{4 $\mathrm{CO}_{2}$ Liquefaction}

For initial compression to 110 bar (and thus liquefaction of the $\mathrm{CO}_{2}$ ) we took a figure of $110 \mathrm{kWh}_{\mathrm{el}} / \mathrm{t} \mathrm{CO}_{2}$ (Göttlicher 1999), for multi-stage compression starting from 1 bar with intermediate cooling to $30^{\circ} \mathrm{C}$.

\subsection{5 $\mathrm{CO}_{2}$ Transport}

The transport and storage of $\mathrm{CO}_{2}$ was modelled for a single power station, taking the Ruhr region as the origin and an exhausted gas field (no further specified) in northern Germany as the destination. An arbitrary transport distance of $300 \mathrm{~km}$ was chosen, and it was assumed that the pipeline would have to be built specially for this power station because only in exceptional circumstances it will be possible to use existing (natural gas) pipelines. This transport and storage scenario was applied to all the reference power stations defined above (see Table 10-10). 
Table 10-10: $\mathrm{CO}_{2}$ transport scenarios for power stations

\begin{tabular}{|c|c|c|c|c|c|c|c|}
\hline 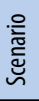 & $\begin{array}{l}\text { Location of } \\
\mathrm{CO}_{2} \text { source }\end{array}$ & $\begin{array}{l}\text { Power station type } \\
\text { and electrical output }\end{array}$ & $\begin{array}{l}\text { Capturec } \\
{[\mathrm{Mt} / \mathrm{a}]^{\mathrm{a})}}\end{array}$ & {$[t / d]^{d)}$} & $\begin{array}{l}\text { Pipeline } \\
\text { land b) + ship } \\
{[\mathrm{km}]}\end{array}$ & \begin{tabular}{|l} 
Pipeline \\
diameterc) \\
{$[\mathrm{mm}]$}
\end{tabular} & Storage location \\
\hline 1 & Ruhr region & Coal $700 \mathrm{MW}$ & 3.57 & 9,781 & $300+0$ & 400 & Gas field onshore \\
\hline 2 & Ruhr region & Lignite $700 \mathrm{MW}$ & 5.11 & 14,010 & $300+0$ & 450 & Gas field onshore \\
\hline 3 & Ruhr region & Natural gas CC $700 \mathrm{MW}$ & 1.70 & 4,670 & $300+0$ & 305 & Gas field onshore \\
\hline 4 & Ruhr region & IGCC $700 \mathrm{MW}$ & 3.4 & 9,316 & $300+0$ & 380 & Gas field onshore \\
\hline 5 & Ruhr region & Coal oxyfuel $700 \mathrm{MW}$ & 4.25 & 11,642 & $300+0$ & 400 & Gas field onshore \\
\hline a) & $\begin{array}{l}\text { culated with } 7,0 \\
\text { oal-fired power } \\
\text { ignite-fired pow } \\
\text { atural gas } \mathrm{CC}: \mathrm{CC} \\
\text { oal IGCC: } \mathrm{CO}_{2} \text { em } \\
\text { oal oxyfuel: } \mathrm{CO}_{2}\end{array}$ & $\begin{array}{l}\text { h/a base load capacity, cap } \\
\text { ation: } \mathrm{CO}_{2} \text { emissions }=676 \\
\text { station: } \mathrm{CO}_{2} \text { emissions }=8 \\
\text { emissions }=337 \mathrm{~g} / \mathrm{kWh}_{\mathrm{el}} \text { e } \\
\text { sions }=662 \mathrm{~g} / \mathrm{kWh}_{\mathrm{el}} \text {, efficie } \\
\text { nissions }=676 \mathrm{~g} / \mathrm{kWh}_{\mathrm{e}} \text {, effi }\end{array}$ & $\begin{array}{l}\text { ure rate } 88 \\
/ \mathrm{kWh}_{\mathrm{el}} \text {, eff } \\
9 \mathrm{~g} / \mathrm{kWh}_{\mathrm{el}} \\
\text { ficiency } 60 \\
\text { cy } 50 \% \rightarrow \\
\text { iency } 49 \%\end{array}$ & $\begin{array}{l}\text { cy } 49 \% \rightarrow \\
\text { iency } 46 \% \\
\rightarrow 51 \% \\
\% \\
38 \%\end{array}$ & $\begin{array}{l}0 \% \\
34 \%\end{array}$ & & \\
\hline \multicolumn{8}{|c|}{ b) Including a gas-turbine-powered turbo-compressor } \\
\hline \multicolumn{8}{|c|}{ c) Estimated after data in Bock et al. (2001) } \\
\hline \multicolumn{8}{|c|}{ d) Calculated with $365 \mathrm{~d} / \mathrm{a}$} \\
\hline
\end{tabular}

Transport was modelled using existing LCA modules for natural gas pipelines from the ecoinvent database (see Table 10-11). Pipelines for $\mathrm{CO}_{2}$ and natural gas are comparable in terms of construction and operation, i.e. data for material, land use, monitoring and dismantling and can be taken from natural gas pipelines. There are marginal differences in operating energy (compressor output for transporting a particular quantity of $\mathrm{CO}_{2}$ over a particular distance) but these can be ignored for the moment. To model larger scale transport scenarios it might be necessary to take into account a port infrastructure (for ship-transport) and/or intermediate storage facilities.

If we compare the transport requirement of the transport scenarios $(300 \mathrm{~km}$ Ruhr region to northern Germany with max. $14,000 \mathrm{t} \mathrm{CO}_{2}$ per day) with the capacities of the long-distance pipeline modules, we find that the 'Onshore, low capacity' type (Table 10-11) is sufficient. With an annual capacity of $5 \mathrm{Mt}$ it might at first seem overdimensioned for the natural gas CC option, but it must be remembered that all costs are calcu- lated in terms of tonne-kilometres transported, so if the quantity of material flowing in the pipeline is smaller the material and energy flows will be smaller too.

\subsection{6 $\mathrm{CO}_{2}$ Storage}

Due to the lack of sources it has not yet been possible to identify data for the required material and energy consumption for storage, but for a similar case Hendriks et al. (2004) give transport costs of $\$ 5 / \mathrm{t} \mathrm{CO}_{2}$ and storage costs of \$1.1-3.6/t $\mathrm{CO}_{2}$ depending on storage depth. So if we take the average figure of $\$ 2.35 / \mathrm{CO}_{2}$, the storage costs amount to about half the transport costs. This relation is also used for the initial storage LCA, where $50 \%$ of the values for transport were used to calculate emissions and cumulative energy demand.

No expert has yet been able to prove that the storage options on offer will be $100 \%$ leak-proof, so an LCA must also address the question of possible leakage rate. The following questions arise here:
Table 10-11: Long-distance natural gas pipeline modules in the ecoinvent database (ecoinvent 2005)

\begin{tabular}{|c|c|c|c|c|c|c|c|}
\hline Type & $\begin{array}{l}\text { Diameter } \\
{[\mathrm{mm}]}\end{array}$ & $\begin{array}{l}\text { Wall } \\
\text { thickness } \\
{[\mathrm{mm}]}\end{array}$ & $\begin{array}{l}\text { Average tran } \\
{\left[\mathrm{Mio} . \mathrm{Nm}^{3} / \mathrm{h}\right]}\end{array}$ & $\begin{array}{l}\text { capacity } \\
{[\mathrm{Mt} / \mathrm{a}]^{\mathrm{a})}}\end{array}$ & {$[\mathrm{t} / \mathrm{d}]$} & $\begin{array}{l}\text { Pressure } \\
\text { [bar] }\end{array}$ & $\begin{array}{l}\text { Service } \\
\text { life } \\
\text { [a] }\end{array}$ \\
\hline $\begin{array}{l}\text { Onshore, } \\
\text { low capacity }\end{array}$ & 950 & 10 & 0.8 & 5 & 13,824 & $65-100$ & 50 \\
\hline $\begin{array}{l}\text { Onshore, } \\
\text { high capacity }\end{array}$ & 1,220 & 12 & 1.1 & 7 & 19,008 & $65-100$ & 50 \\
\hline $\begin{array}{l}\text { Offshore, } \\
\text { high capacity }\end{array}$ & 1,000 & $\begin{array}{r}25+100 \text { for } \\
\text { concrete } \\
\text { casing }\end{array}$ & 1.6 & 10 & 27,648 & $65-100$ & 50 \\
\hline \multicolumn{8}{|c|}{ a) Calculated with $0,72 \mathrm{~kg} \mathrm{CH} / \mathrm{Nm}^{3}$} \\
\hline
\end{tabular}


- Which leakage rate should be modelled?

- Will leakage occur from the outset or only at a later stage?

- Will it be possible to seal leaks or will all the $\mathrm{CO}_{2}$ escape?

- Which period must be considered for leakage?

Given these still unresolved questions, the following models initially take a leakage rate of $0 \%$ in order to determine the 'best case.' Then different leakage rates are applied in a sensitivity analysis (see section 10.7.1).

\subsection{Plant for Generating Electricity from Renewables}

Fossil-fired power stations were compared with those types of power plant using renewables that will be available in 2020. Because the transport scenarios described above took the Ruhr region as the location for the fossil-fuelled power stations, the plant using renewables was also modelled on the basis of delivery of electricity to the Ruhr region. Table 10-20 shows the power plant modelled:

- Solar thermal: It is likely that by 2020 electricity will be generated by solar thermal plant in North Africa and transported to Europe using high-voltage DC transmission lines. Through the use of thermal storage, solar electricity could even be used as base load in the German and European electricity grids (DLR 2006). For purposes of comparison with conventional power stations we took a solar thermal power plant in Algeria with high-voltage transmission to the Ruhr region, using the LCA for a solar thermal plant with $200 \mathrm{MW}$ output designed for solar-only operation. This is possible through thermal storage which stores excess heat during the day and releases it again at night. The SEGS plant was originally modelled by Viebahn (2004) for 80 MW output at a location in Egypt and scaled up to 200 MW by May (2005) for a location in Algeria (with greater solar radiation intensity).

- Wind: By 2020 large offshore wind farms will be operating in the North Sea generating electricity that can also be transported to the Ruhr region using high-voltage lines. The applied LCA uses a 1.5 MW wind generator from Pick (1998). Both Briem et al. (2004) and Chataignere and le Boulch (2003) have demonstrated that the environmental impact of an onshore wind generator is not much different from that of a much larger offshore facility (e.g. 4.5 MW). Wind conditions are considerably better offshore, but much greater amounts of steel and concrete are required for construction. The two effects roughly balance each other out, making it possible to use the existing LCA for the onshore facility.

For the transport of electricity generated in North Africa or the North Sea by high-voltage line to the Ruhr region reference location we used an LCA by May (2005), modelled a $10 \mathrm{GW}$ overhead line $(800 \mathrm{kV}$ double bipole system on two separate lines with aluminium-steel cable) and a $10 \mathrm{GW}$ undersea cable $(800 \mathrm{kV}$ earthing cable with central copper conductor). The following distances were applied in this study:

- Solar thermal, Algeria to Ruhr region: high-voltage transmission via $3,100 \mathrm{~km}$ overhead line and 18 $\mathrm{km}$ undersea cable.

- Wind offshore, North Sea to Ruhr region: highvoltage transmission via $500 \mathrm{~km}$ overhead line and $30 \mathrm{~km}$ undersea cable.

\subsection{Analyses of Individual Electricity Generating Systems}

\subsubsection{Conventional Power Stations}

In the following we use the example of the coal-fired steam power station to show a) which contributions the individual steps of $\mathrm{CO}_{2}$ capture and storage make to the overall result and b) how the emissions and cumulative energy demand change when CCS is used (see Fig. 10-7).

- When power stations are modelled in LCAs we generally distinguish between power station operation itself and the supply chain of the raw materials used, especially fuel. As can be seen in the following figure, the coal upstream chain represents only a small proportion of the $\mathrm{CO}_{2}$ emissions (5\%) but a not inconsiderable share of total greenhouse gas emissions (13\%) (bars 1 and 3).

\begin{tabular}{|l|c|l|l|l|l|}
\hline Plant & $\begin{array}{l}\text { Output } \\
{[\mathrm{MW}]}\end{array}$ & $\begin{array}{l}\text { Fuctional } \\
\text { unit }\end{array}$ & $\begin{array}{l}\text { Efficiency } \\
{[\%]}\end{array}$ & Source & Comments \\
\hline $\begin{array}{l}\text { Solar thermal } \\
\text { (type SEGS) }\end{array}$ & 200 & $1 \mathrm{kWh}$ & 17.6 & $\begin{array}{l}\text { Viebahn 2004, } \\
\text { May 2005 }\end{array}$ & \\
\hline Wind offshore & 5 & $1 \mathrm{kWh}$ & & Pick 1998 & $\begin{array}{l}\text { Onshore plant equated with offshore after } \\
\text { Chataignere and le Boulch (2003) }\end{array}$ \\
\hline
\end{tabular}

Table 10-12: Reference power plant using renewables 
Fig. 10-7:

Comparison of $\mathrm{CO}_{2}$ emissions, total greenhouse gases and cumulative energy demand for the coal-fired power station without and with CCS

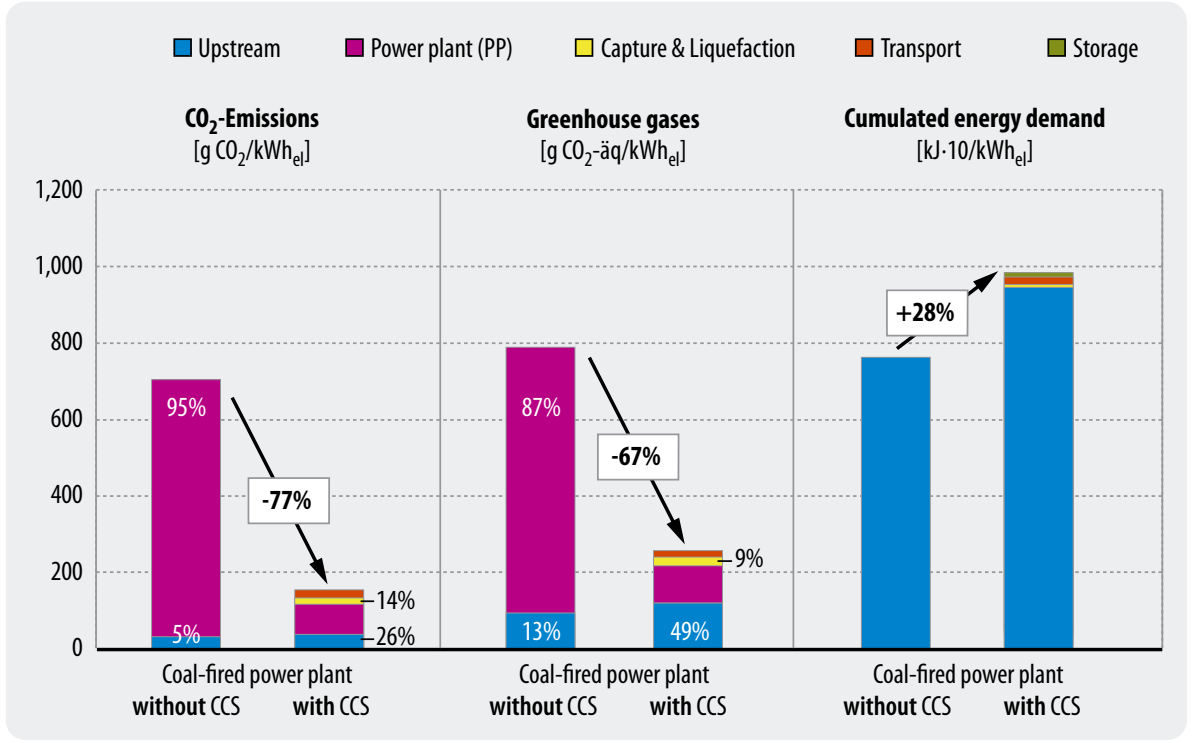

This Screening LCA models emissions of the three greenhouse gases $\mathrm{CO}_{2}$, methane $\left(\mathrm{CH}_{4}\right)$ and $\mathrm{N}_{2} \mathrm{O}$ (nitruous oxide). Methane emissions during mining are a particular issue in the coal supply chain, while in the natural gas supply chain leakages during transport are one of the main causes of emissions (WI and MPI 2004). As well as these impacts from the supply chain, the application of CCS also includes emissions from capture, transport and storage, as can be seen in the second, fourth and sixth bars. While the capture step represents a relevant proportion of emissions ( $9 \%$ of greenhouse gases and $14 \%$ of $\mathrm{CO}_{2}$ emissions), transport and storage each represent only a minimal share of the overall CCS process. Capture also includes liquefaction (compression to 110 bar).
- For the coal-fired power plant, as for the other reference power stations, we took a $\mathrm{CO}_{2}$ capture rate of $88 \%$. But the $\mathrm{CO}_{2}$ emissions of the process as a whole only decrease by $77 \%$ because we have to add the additional (indirect) emissions from the capture process and to a small extent from transport and storage too (compare bars 1 and 2). The impact from the upstream and downsteam chains cannot be reduced by means of $\mathrm{CO}_{2}$ capture. The overall result is significantly worse if we consider greenhouse gas emissions in total, which can only be reduced by $67 \%$ (bars 3 and 4). Here an important role is played in particular by the high level of methane emissions in the supply chain, which cause the supply chain's share to rise to $49 \%$ for the CCS power station (bar 4). Cumulative energy demand ultimately rises to $9,870 \mathrm{~kJ} / \mathrm{kWh}_{\mathrm{el}}$, or $128 \%$ of the original figure of $7,740 \mathrm{~kJ} / \mathrm{kWh}_{\mathrm{el}}$, largely because of the additional energy required for capture (bars 5 and 6).
Fig. 10-8:

Comparison of the shares of power plant and highvoltage DC transmission for emissions and cumulative energy demand

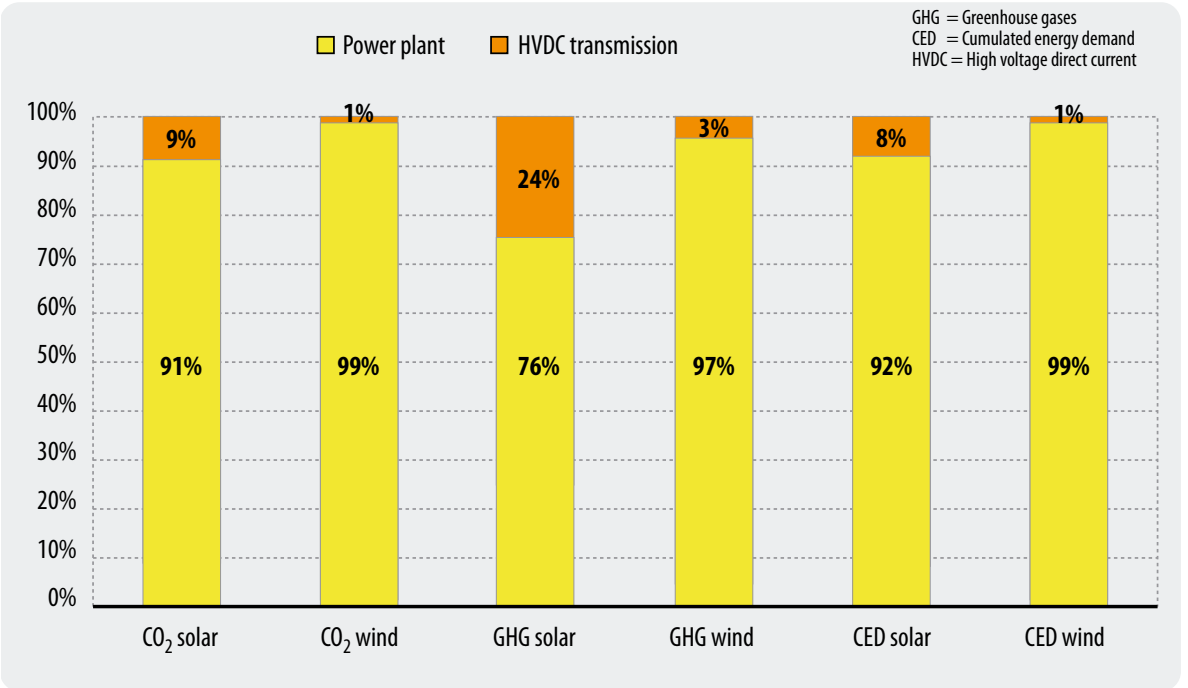




\subsubsection{Power Plant Using Renewables}

With power plant using renewables there is no comparison with an alternative system because in comparison with fossil-fuelled power stations the emissions are very small from the outset (see below). With the wind- and solar-powered plant under consideration here, a distinction between supply chain and power plant is not generally made because there are no fuel supply chains to model.

What is relevant in this study, however, is the distinction between power plant and electricity transport, because as explained above, electricity is transported by high-voltage line from Algeria or the North Sea to the Ruhr region. As Fig. 10-8 clearly shows, with wind the high-voltage line represents only $1-3 \%$ of overall emissions and energy, but for solar thermal the figure is between 8 and $24 \%$. The figures for greenhouse gases are generally somewhat higher because $\mathrm{N}_{2} \mathrm{O}$ emissions occur during operation through ionisation of air molecules on the transmission line (May 2005). The share is generally higher for solar thermal because the transmission line $(3,120 \mathrm{~km})$ is much longer than for wind $(530 \mathrm{~km})$.

\subsection{Comparison of Energy Generation Systems}

\subsubsection{Greenhouse Gases and Cumulative Energy Demand}

The approach described above was applied to all the fossil-fuelled power station types under consideration. The following figures begin by comparing the four fossil-fuelled reference power station types

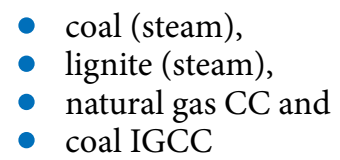

with their respective CCS versions. As well as $\mathrm{CO}_{2}$ emissions (Fig. 10-9) and greenhouse gas emissions (Fig. 10-11), cumulative energy demand is also shown (Fig. 10-13). The climate-relevant emissions of the CCS power stations are also compared with a selection of other options (Fig. 10-10 and Fig. 10-12):

- renewables (solar thermal and wind power) and

- advanced fossil-fuelled combined heat and power (CHP) technologies (natural gas and natural gas $\mathrm{CC})$

Other impact categories are considered in section 10.6.2.

In the comparison with CCS versions it should be noted that a capture rate of $88 \%$ was applied for power stations with pre- and post-combustion $\mathrm{CO}_{2}$ capture, but $99.5 \%$ for the oxyfuel power station.

The following conclusions can be drawn from the comparison of $\mathrm{CO}_{2}$ emissions in Fig. 10-9:

- If we first consider only the power stations with pre- and post-combustion technology, a reduction in $\mathrm{CO}_{2}$ emissions by $72 \%$ to $78 \%$ can be achieved in all four power station types under the given assumptions. Relatively speaking, the natural gas CC power station does worst $(-72 \%)$ because in relative terms the upstream chain emissions are highest in relation to the other emissions (and cannot be reduced by capture technology).

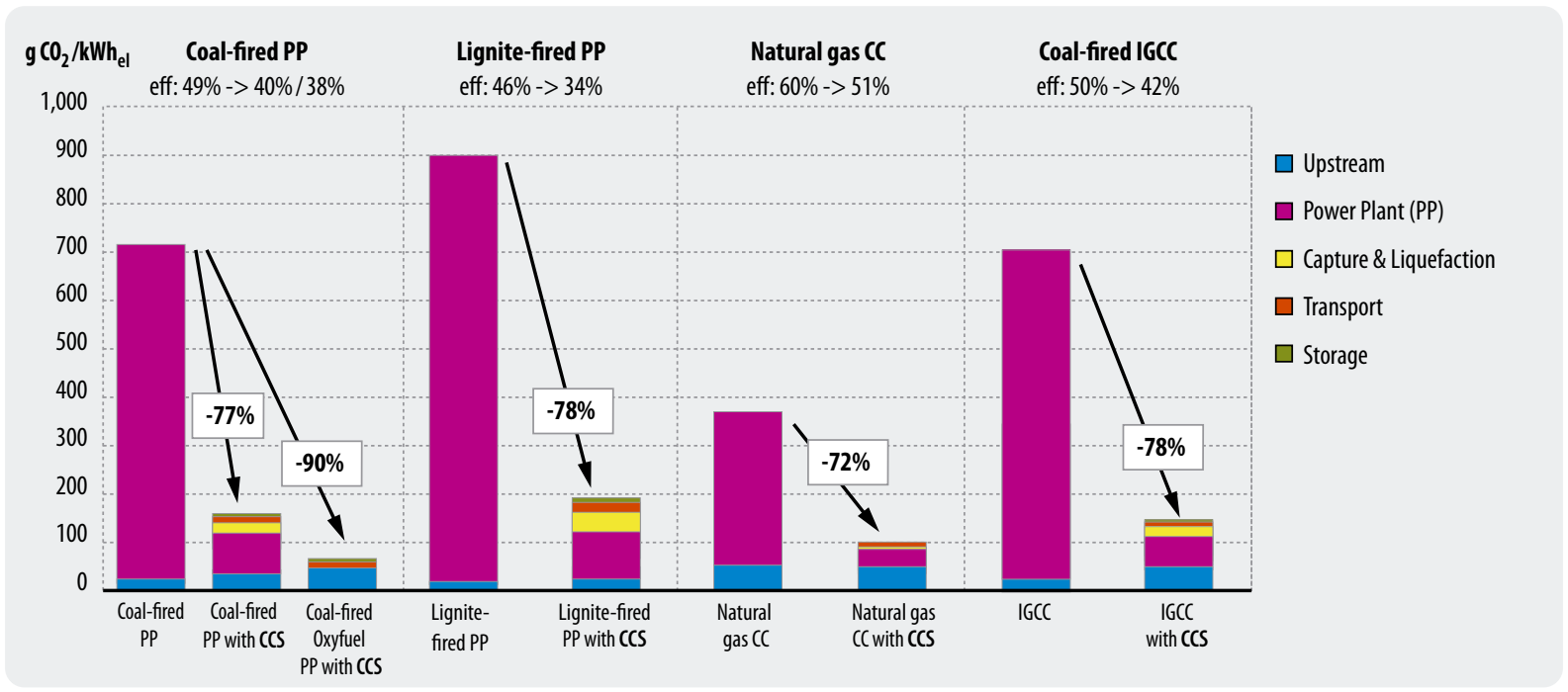

Fig. 10-9: Comparison of $\mathrm{CO}_{2}$ emissions from fossil-fuelled reference power stations without and with $\mathrm{CCS}$ 
Fig. 10-10:

Comparison of $\mathrm{CO}_{2}$ emissions from CCS power stations with selected plant from the fields of renewables and advanced fossil-fuelled CHP technologies

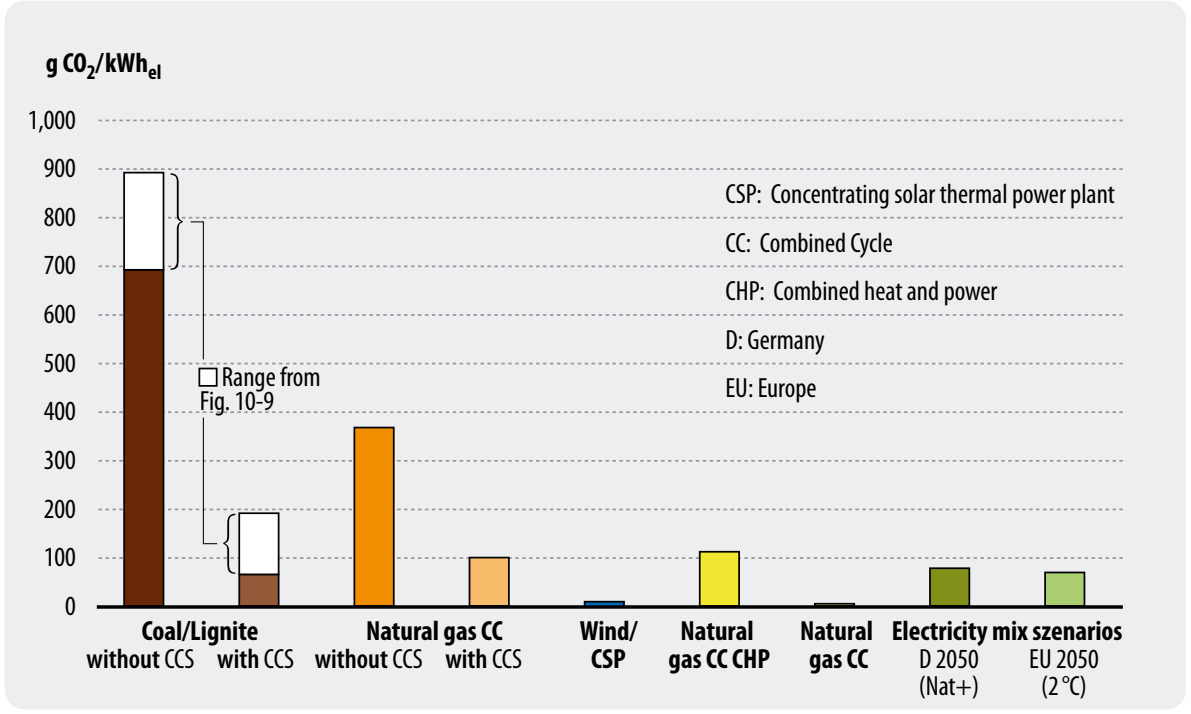

- If we compare the actual reduction (72\% to $78 \%$ ) with the selected capture rate $(88 \%)$, we find a difference of 10 to 16 percentage points. This is caused by the emissions produced in the supply chain and the higher specific energy consumption caused by capture.

The coal-fired power station with oxyfuel technology achieves a $90 \%$ reduction in $\mathrm{CO}_{2}$ emissions. This is 10 percentage points less than the high initial capture rate of $99.5 \%$, and here too the causes are upstream chain emissions and higher energy consumption for both capture and transport (larger quantities to transport).
Fig. 10-10 compares electricity generated in CCS power stations (coal and natural gas) with renewables (offshore wind and solar thermal) and advanced CHP technologies (natural gas, natural gas CC). The comparison also shows possible electricity mixes for Germany and Europe for 2050, whose feasibility has been demonstrated by various studies conducted by DLR. ${ }^{3}$ While the impact of renewables is very small (resulting from the manufacture and construction of plant), the figures for fossil technologies and future electricity mixes (without CCS) are only a little higher than for power stations with CCS.

3 Sources: CHP with natural gas, natural gas CC: Fritsche et al. (2007); electricity mix Germany: Nitsch (2007); electricity mix EU: Greenpeace and EREC (2007)

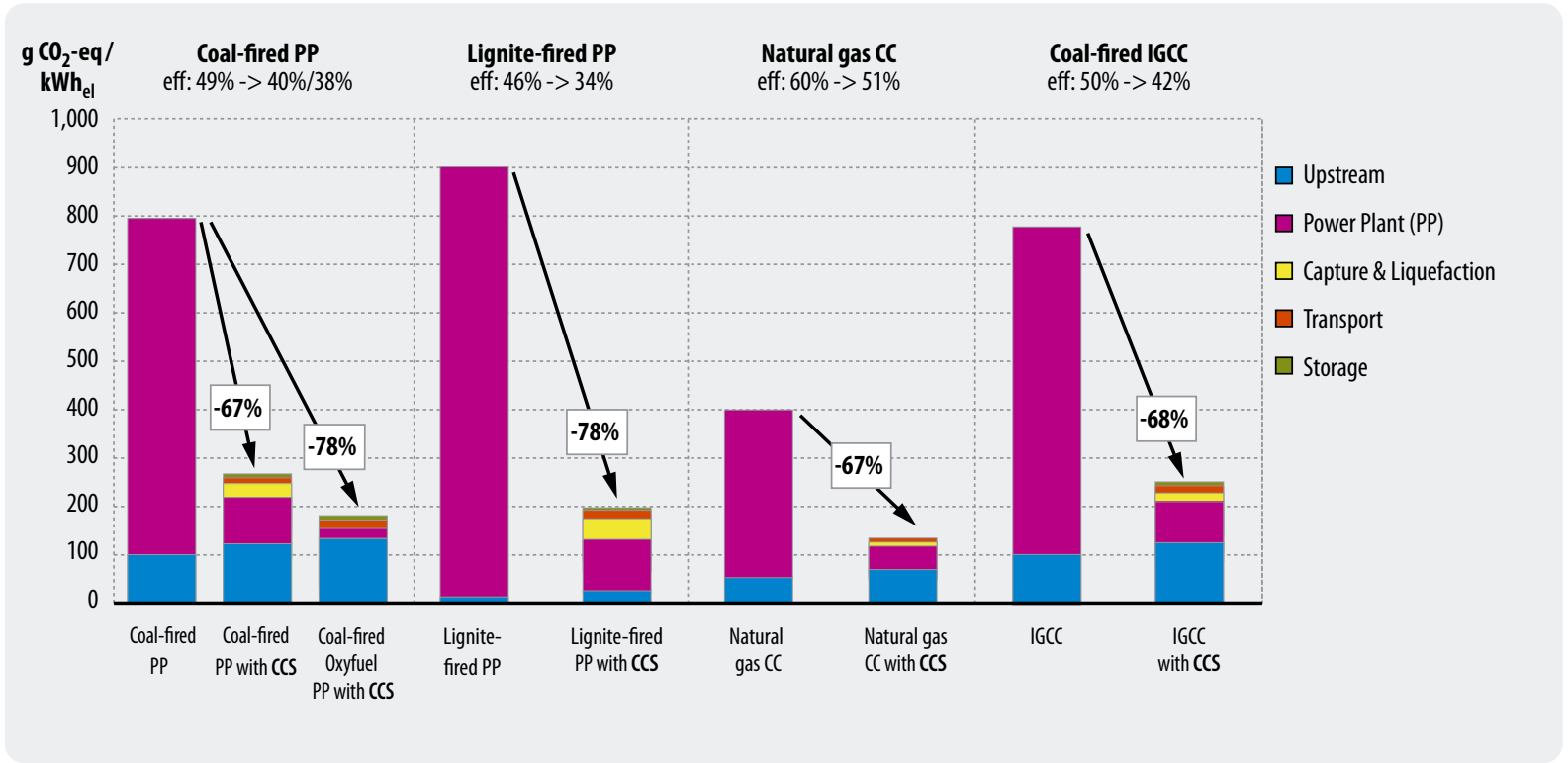

Fig. 10-11: Comparison of greenhouse gas emissions from fossil-fuelled reference power stations without and with CCS 


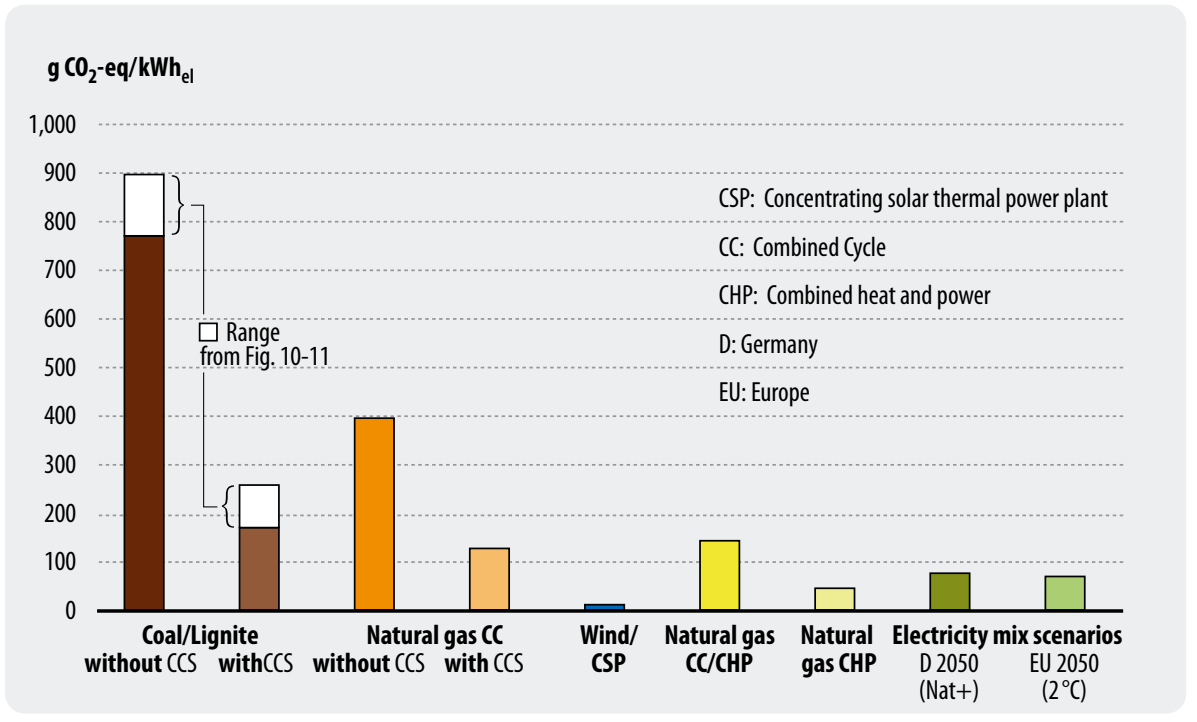

Fig. 10-12:

Comparison of greenhouse gas emissions from CCS power stations with selected plant from the fields of renewables and advanced fossil-fuelled CHP technologies

We find similar conclusions when greenhouse gas emissions are compared (Fig. 10-11). As greenhouse gases we included the $\mathrm{CO}_{2}$ equivalents for $\mathrm{CO}_{2}$ itself, $\mathrm{CH}_{4}$ and $\mathrm{N}_{2} \mathrm{O}$, weighted according to the factors in Table 10-3.

- The relative reductions in greenhouse gas emissions are smaller than just for $\mathrm{CO}_{2}$ emissions, because as well as carbon dioxide, methane and $\mathrm{N}_{2} \mathrm{O}$ also contribute to the global warming potential.

- In power stations with pre- and post-combustion technology a reduction in greenhouse gas emissions of $67 \%$ to $78 \%$ can be achieved. Because of the low level of supply chain emissions the lignite-fired power station does best here (minus $78 \%$ ). With natural gas CC, and especially the coal-fired power station, methane emissions contribute to a higher greenhouse effect (pipeline leakage and release during mining).

- Despite the high $\mathrm{CO}_{2}$ capture rate of $99.5 \%$, the coal-fired power station with oxyfuel technology achieves only a $78 \%$ reduction in greenhouse gas emissions, putting it close to the lignite-fired power station with post-combustion CCS in both relative and absolute terms. The reason for this is again the methane emissions associated with coal mining.

- The best power station without CCS (natural gas CC) has, with $396 \mathrm{~g} \mathrm{CO}_{2}$ equivalent per kWh, only

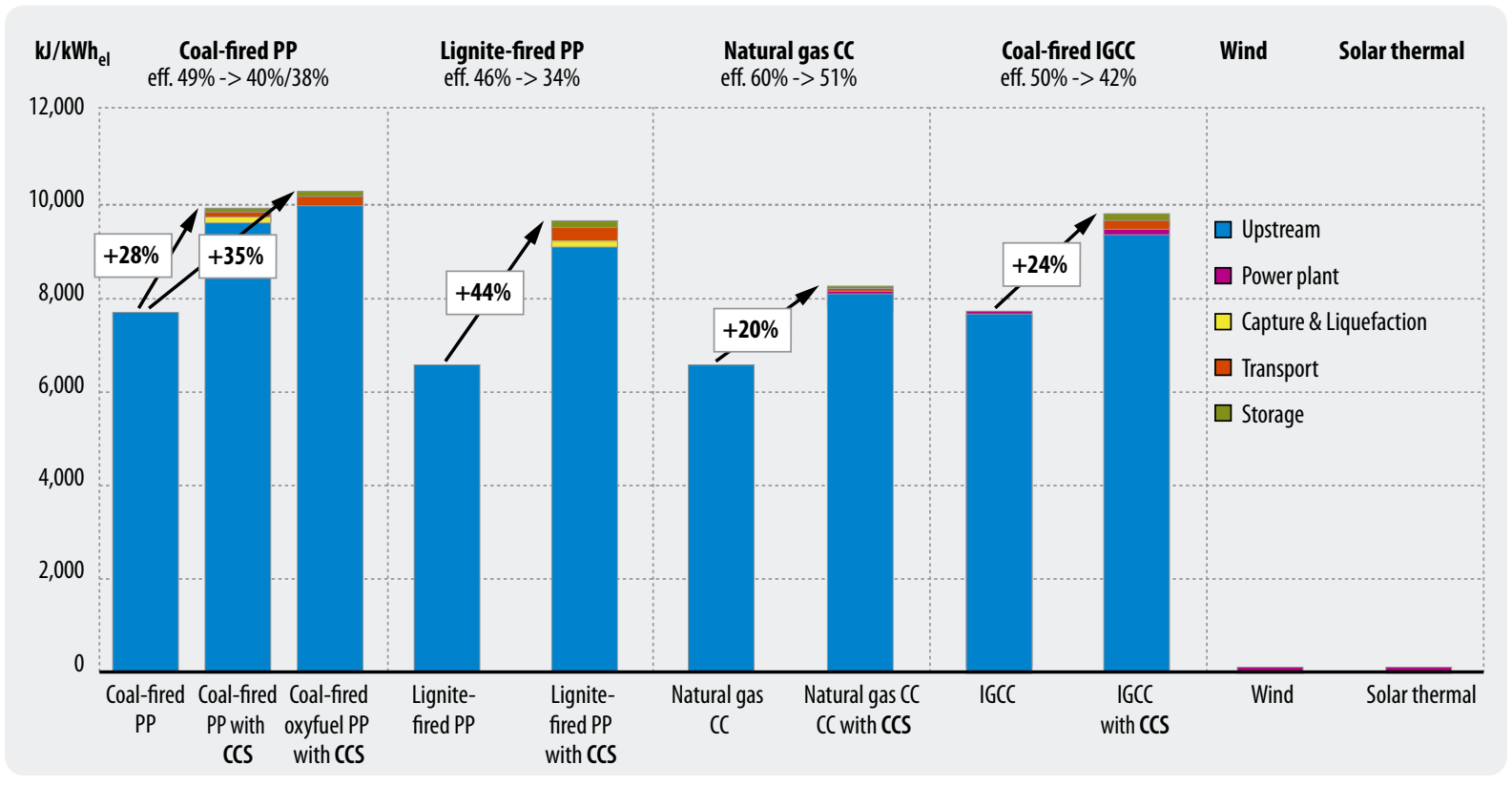

Fig. 10-13: Comparison of cumulative energy demand for reference power plant using fossil fuels and renewables without and with CCS 


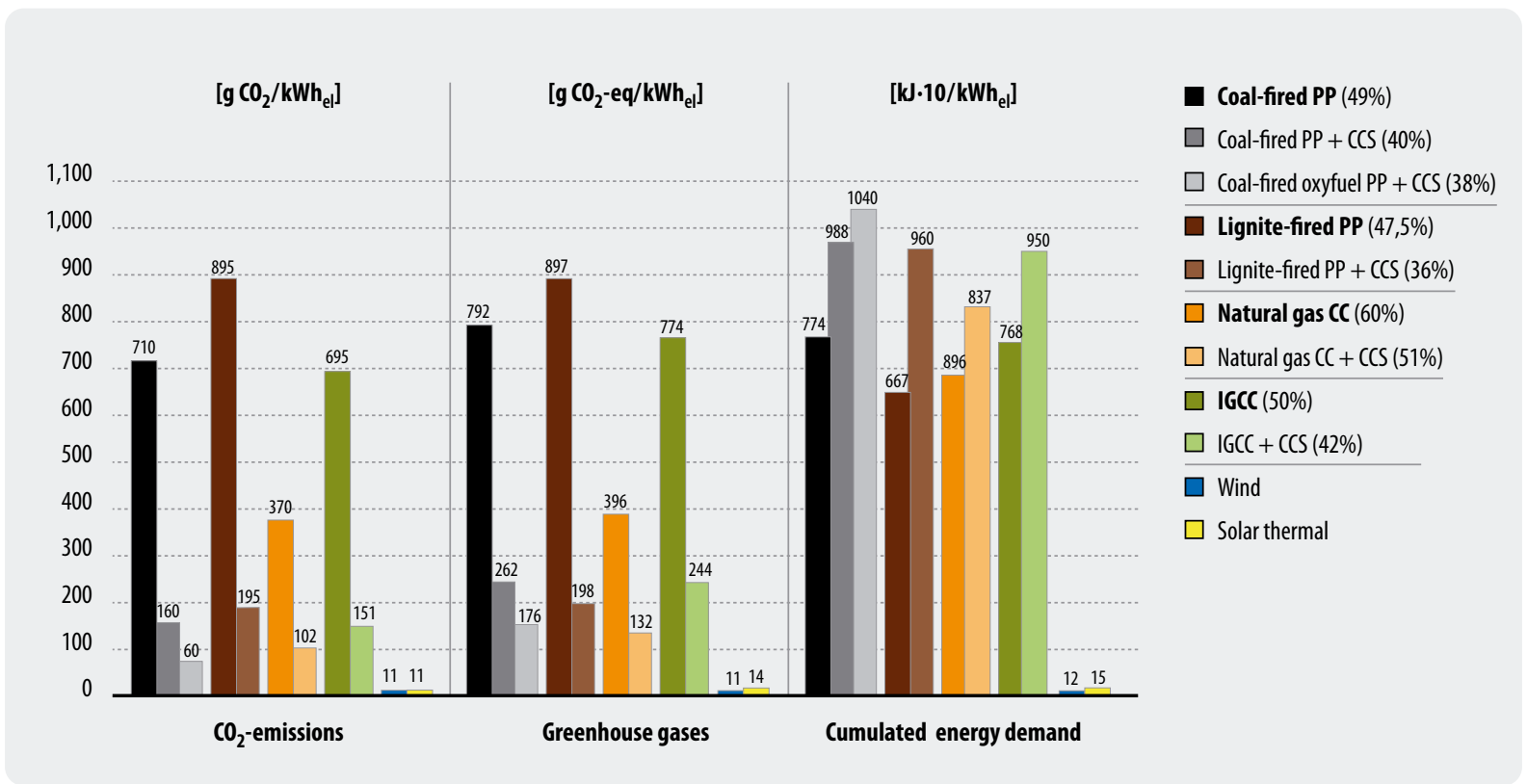

Fig. 10-14: Comparison of absolute $\mathrm{CO}_{2}$ emissions, total greenhouse gases and cumulative energy demand for reference power plant using fossil fuels and renewables without and with CCS

$51 \%$ more emissions than the worst power station with CCS (coal-fired steam power station with postcombustion $\mathrm{CO}_{2}$ capture and $262 \mathrm{~g} \mathrm{CO}_{2}$ equivalent per kWh).

As in the case of the $\mathrm{CO}_{2}$ emissions, the total greenhouse gas emissions from electricity generated from wind or solar thermal plant are negligible (Fig. 10-12). Even more than for $\mathrm{CO}_{2}$ emissions alone, overall greenhouse gas emissions for advanced CHP technologies and future electricity mixes (without CCS) are roughly equivalent to those for power stations using CCS. This means that with CHP using natural gas and natural gas $\mathrm{CC}$, there are technologies on the market today that are already as green as the target for CCS power stations in 2020.

The following conclusions can be drawn for cumulative energy demand (Fig. 10-13):

- The increases in energy demand are between $20 \%$ and $44 \%$. The higher the specific $\mathrm{CO}_{2}$ emissions

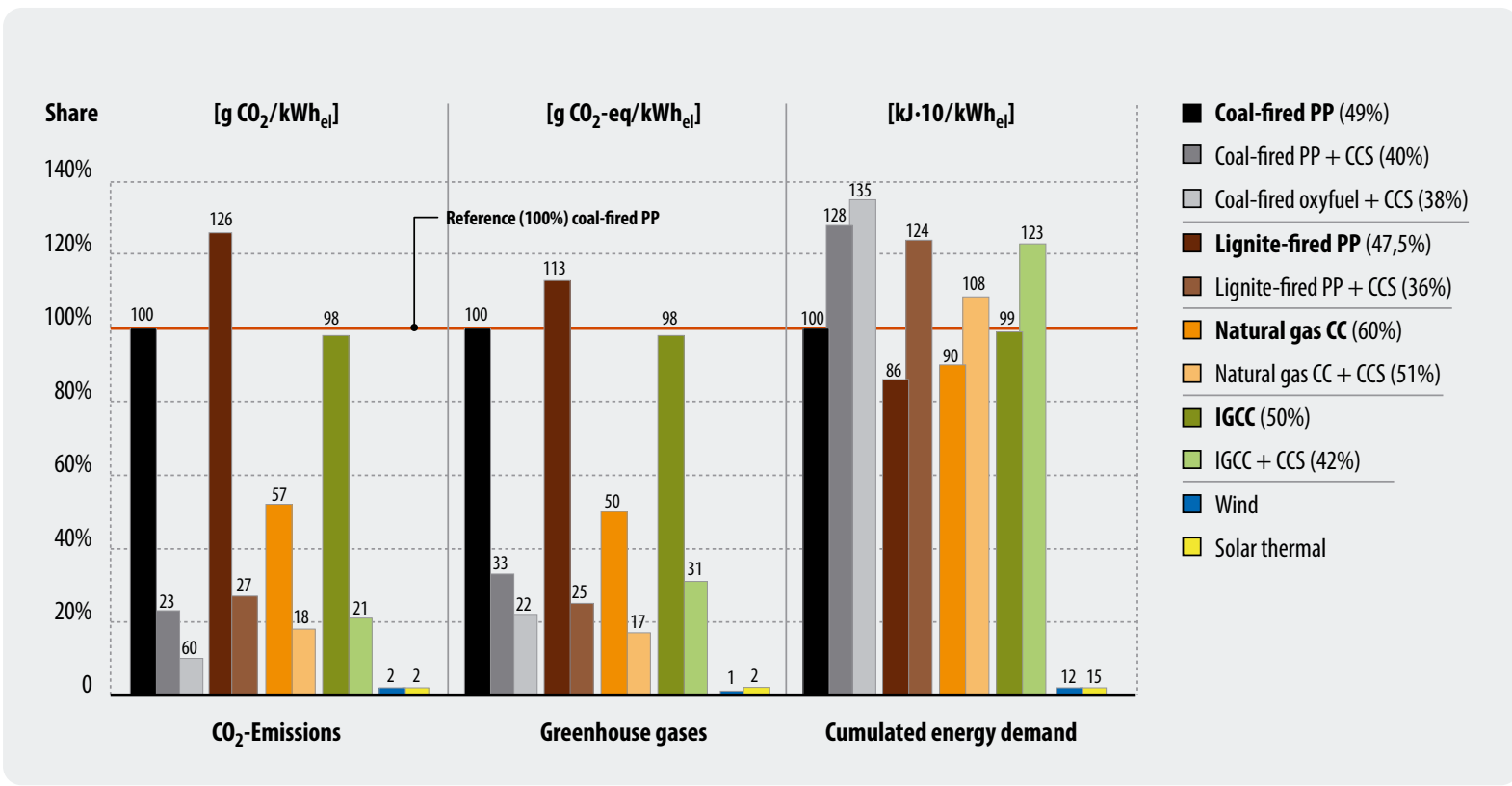

Fig. 10-15: Comparison of relative $\mathrm{CO}_{2}$ emissions, total greenhouse gases and cumulative energy demand for reference power plant using fossil fuels and renewables without and with CCS (relative to coal-fired steam power station) 


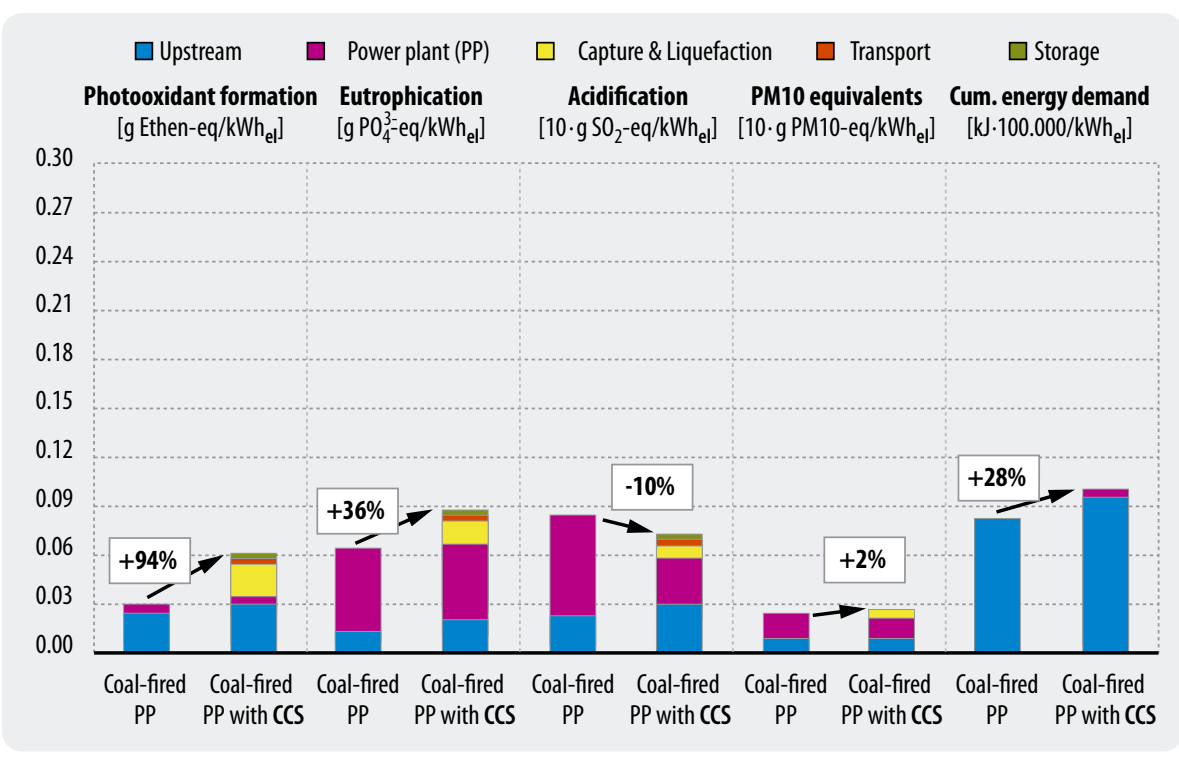

Fig. 10-16:

Comparison of other impact categories for coal-fired steam power station without and with CCS (postcombustion)

of the reference power station (without CCS) the greater the increase, because if emissions are higher more $\mathrm{CO}_{2}$ is captured and consequently more energy is required. Accordingly the lignitefired steam power station has the largest increase in cumulative energy demand, natural gas $\mathrm{CC}$ the smallest.

- The cumulative energy demand for electricity from wind power and solar thermal is again negligible (about $2 \%$ of the cumulative energy demand of the coal-fired reference power station).

The next two figures provide two different illustrations of these relationships. Fig. 10-14 shows the absolute figures, while Fig. 10-15 gives the values relative to the reference coal-fired steam power station $(=100 \%)$.

\subsubsection{Other Impact Categories}

As described in the methodology (section 10.1.3), other impact categories are also analysed in an LCA apart from global warming potential and cumulative energy demand. These are photo-oxidant formation, eutrophication, acidification, and dust and particles. They play a role especially when $\mathrm{CO}_{2}$ capture not only brings about increased energy consumption (in which case they would increase in a linear fashion like $\mathrm{CO}_{2}$ or methane emissions), but other materials and substances are used too, for example the production of monoethanolamine (MEA) for post-combustion capture. Furthermore, as explained above, certain emissions are reduced by reactions with the solvent, which can cause a relative reduction in particular impact categories.

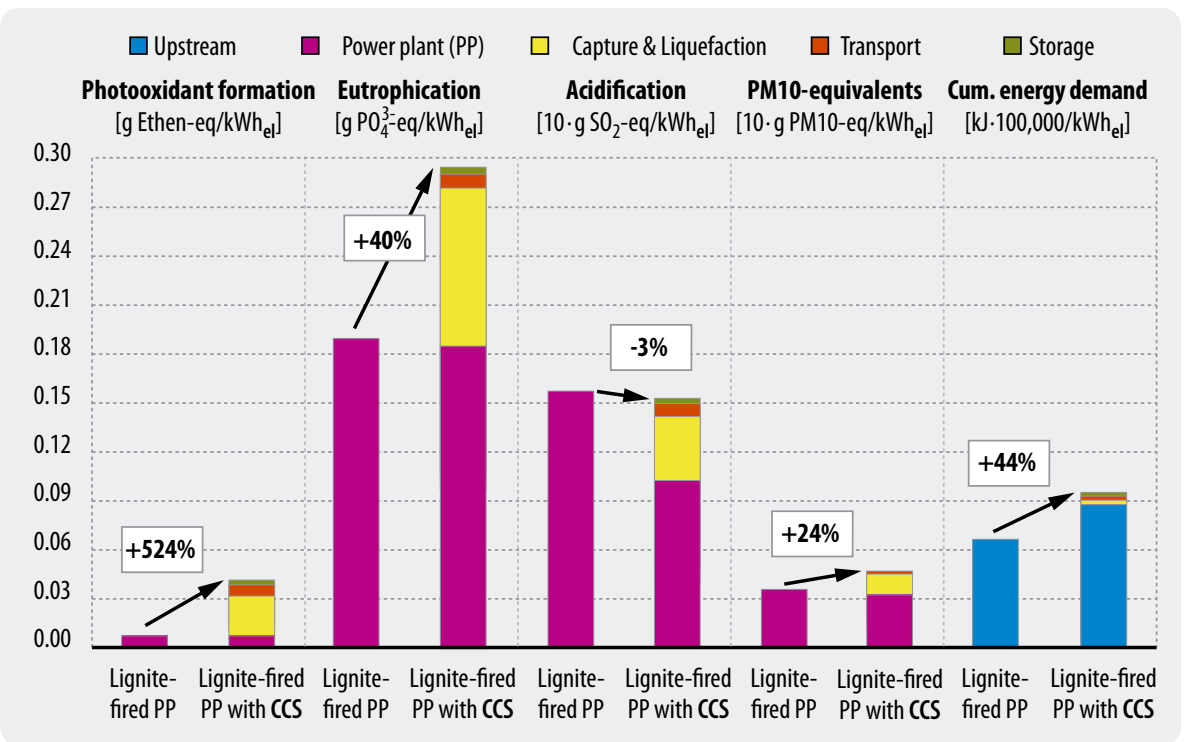

Fig. 10-17:

Comparison of other impact categories for the lignitefired power station without and with CCS (postcombustion) 
Fig. 10-16 shows the change in the impact categories for the example of the coal-fired power station without and with CCS. The $28 \%$ increase in energy consumption for capture, transport and storage initially causes a proportional increase in all the impact categories. But the following influences must also be noted:

- The disproportionate rise in photo-oxidant formation by an additional 66 percentage points (total increase $94 \%)$ is caused by the production of monoethanolamine for the capture process (and to a lesser extent also the required sodium hydroxide).

- The additional increase in eutrophication is also due to production of chemicals, but it is somewhat ameliorated because the $\mathrm{NO}_{\mathrm{x}}$ emissions that contribute to eutrophication are also (slightly) reduced by the $\mathrm{CO}_{2}$ capture process.

- The overall balance of acidification is negative because of the almost complete elimination of $\mathrm{SO}_{2}$ emissions from operation. But because other substances such as $\mathrm{NO}_{\mathrm{x}}$ emissions also contribute to acidification, and the supply chain, transport and storage must also be factored in, the overall reduction is only $10 \%$.

- Similarly, even though particle emissions from operation are halved, there is still a $2 \%$ overall increase in PM10 equivalents.

Overall it must be remembered that it has not yet been possible to fully model the capture process using MEA, so the results should not yet be regarded as conclusive.
Similar effects are found with the lignite-fired power station (Fig. 10-17), except that the values are a good deal higher than for the coal-fired power station (the scales are identical).

- In absolute terms the rise in photo-oxidant formation is slightly larger than for the coal-fired power station (because the greater $\mathrm{CO}_{2}$ emissions mean there is more $\mathrm{CO}_{2}$ to capture and more MEA is used). But in relative terms the effect is much greater $(+524 \%)$ because there are only minimal emissions from the supply chain.

- Because the lignite-fired power station has higher operating emissions, emissions associated with capture are also considerably higher. And the emissions from chemicals production come on top of this too. Because in the power station without CCS the supply chain plays a relatively small role, the overall increase is greater than for the coal-fired power station.

Finally, Fig. 10-18 compares the impact categories of photo-oxidant formation, acidification and eutrophication for all the analysed power stations plus electricity from renewables. All the figures are given in relation to the coal-fired steam power station. The figure shows in particular the great differences in emissions between coal and lignite. It should be noted that detailed modelling of individual emissions has not yet been conducted for the oxyfuel and IGCC (pre-combustion) power stations; instead a proportional increase corresponding to the additional energy demand was assumed.

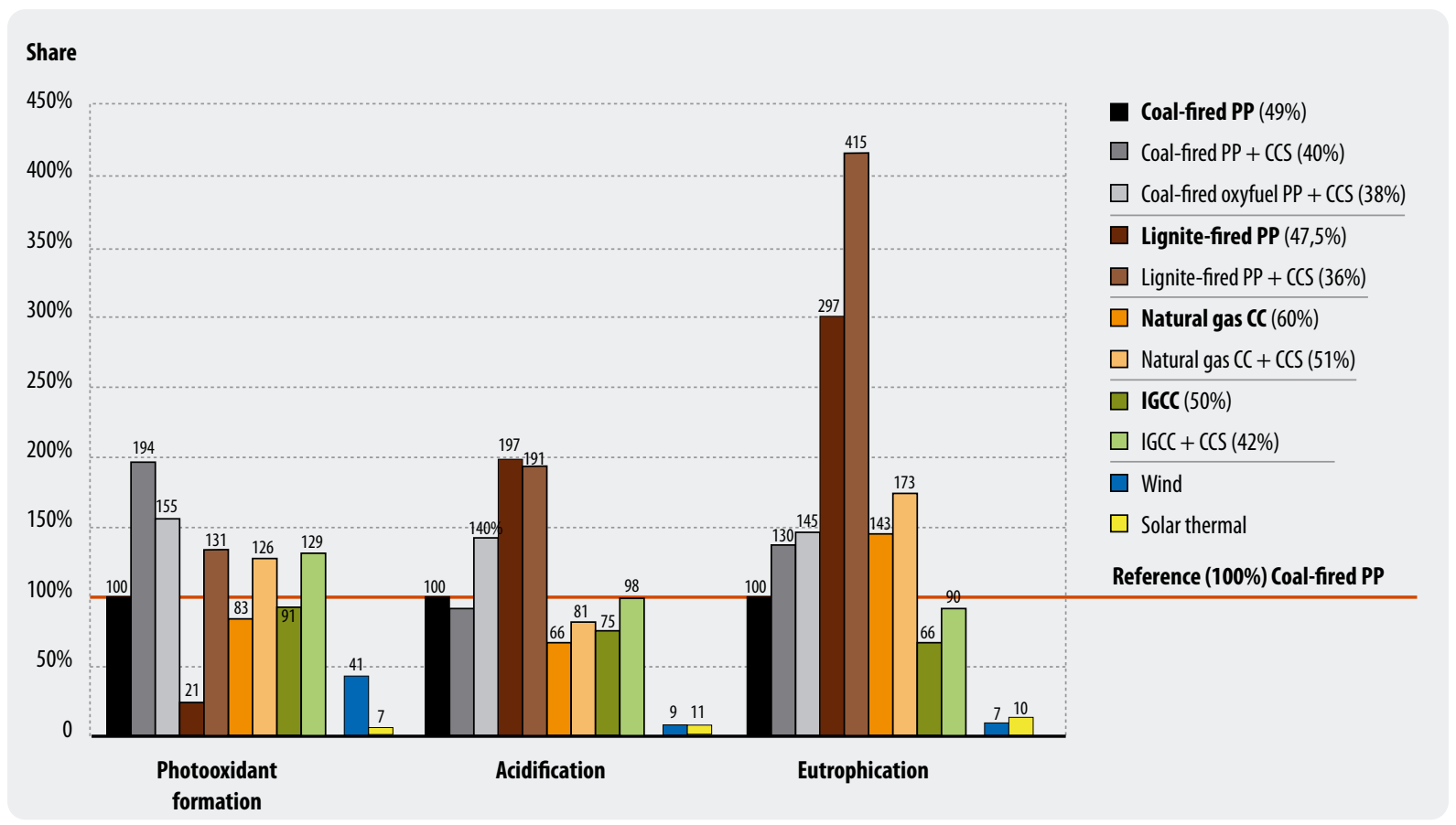

Fig. 10-18: Comparison of impact categories photooxidant formation, acidification and eutrophication in relative form for reference power plant using fossil fuels and renewables without and with CCS (relative to coal-fired steam power station) 
Wind power and solar power plant also score worse here than they do for greenhouse gas emissions and cumulative energy demand, but remain well below the values for fossil-fuelled power stations. These emissions result largely from the manufacture and construction of the power plant. A detailed interpretation of the wind power analyses is found in Bruno (2003) and Chataignere and le Boulch (2003), and of the solar thermal plant data in Viebahn (2004).

\subsection{Sensitivity Analyses of Electricity Generating Systems}

Table 10-13 below shows the sensitivity analyses conducted as part of the LCA.

\subsubsection{Sensitivity Analysis 1: Variation in Leakage Rate}

\section{Basis}

No expert has yet been able to prove that the available sinks will be one hundred percent leak-proof, so any LCA must also include the question of leakage rate. Although there is no reliable information about possible leakage rates, in its special report on CCS the IPCC found that if continuous leakage were to occur this would at least partially negate the benefits for climate protection (IPCC 2005b). So it makes sense to take a look at the effects of possible leakage by means of a sensitivity analysis.

\section{Method}

The following assumptions were made for modelling leakage:

Table 10-13: Sensitivity analyses (electricity generation)

\begin{tabular}{|l|l|l|l|c|l|}
\hline & Unit & Baseline & Variation \\
\hline $\mathbf{1}$ & $1-4$ & $\begin{array}{l}\text { Leakage rate } \\
\text { of sink }\end{array}$ & $\% / \mathrm{a}$ & 0 & $0.0001-0.1$ \\
\hline $\mathbf{2}$ & $6-9$ & $\begin{array}{l}\text { Capture rate, } \\
\text { variable costs }\end{array}$ & $\%$ & 88 & $\begin{array}{l}90-96 \\
\text { with correspond- } \\
\text { ing rise in resource } \\
\text { consumption }\end{array}$ \\
\hline $\mathbf{3}$ & $6 \mathrm{a}-9 \mathrm{a}$ & $\begin{array}{l}\text { Capture rate, } \\
\text { fixed costs }\end{array}$ & $\%$ & 88 & $\begin{array}{l}90-96 \\
\text { with fixed resource } \\
\text { consumption }\end{array}$ \\
\hline $\mathbf{4}$ & $14-17$ & $\begin{array}{l}\text { Methane } \\
\text { emissions } \\
\text { during coal } \\
\text { mining }\end{array}$ & $\mathrm{kg} / \mathrm{TJ}$ & 454 & 363-91 \\
\hline
\end{tabular}

Storage potential and leakage ( $1 \% / a)$

over 100 years

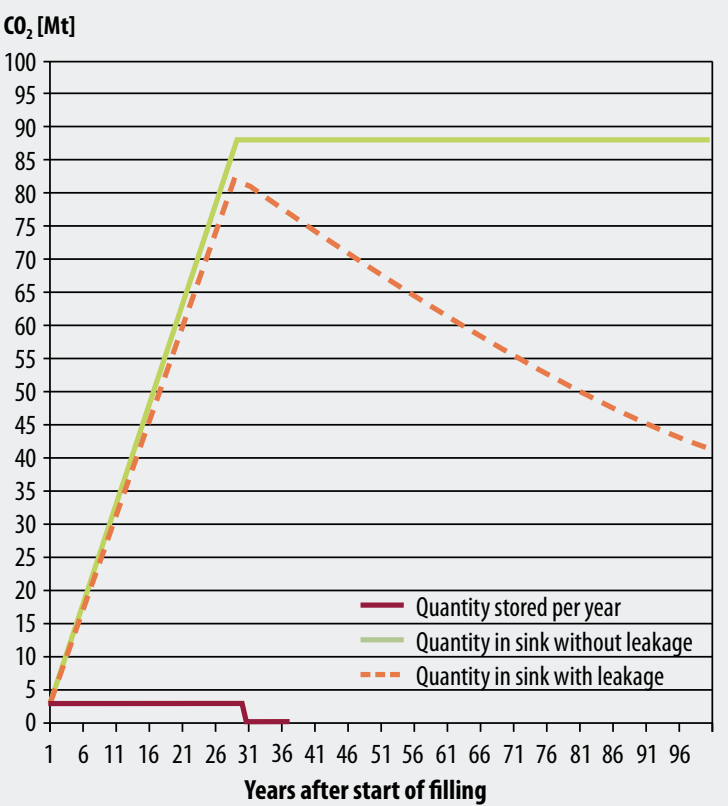

Fig. 10-19: Stored quantity and leakage over the first 100 years with a leakage rate of $1 \% / a$, for the example of a coal-fired power station

- Four different $\mathrm{CO}_{2}$ leakage rates were selected for modelling, in order to cover the range of uncertainty ( $0.1 / 0.01 / 0.001 / 0.0001 \% / a)$. From today's perspective it would appear unlikely that sinks with leakage rates potentially higher than that would be put into operation - and this would in any case be rather pointless in economic terms.

- Leakage begins in the first year of storage, but the actual annual leakage rates are calculated in relation to the level of $\mathrm{CO}_{2}$ in the sink. The less full a sink is, the smaller the actual leakage rate. The full rate is not reached until the point where the sink is full.

- In the model the imaginary sink is full in year 41 , while the service life of the power station is 30 years. During the remaining ten years the sink could be filled from another power station.

- The calculations were conducted using the example of the $700 \mathrm{MW}$ coal-fired power station.

The following two figures show the development of stored quantities. Fig. 10-19 shows the development over the first one hundred years. To illustrate the principle clearly we calculated using a leakage rate of $1 \%$ here, but that figure is not used otherwise. The figure clearly shows how very little $\mathrm{CO}_{2}$ escapes during the first 30 years. The effect of the full leakage rate only begins to be felt after year 41 .

Fig. 10-20 shows the trend over 40,000 years with a leakage rate of $0.01 \% / \mathrm{a}$. During the first 40 years - while 


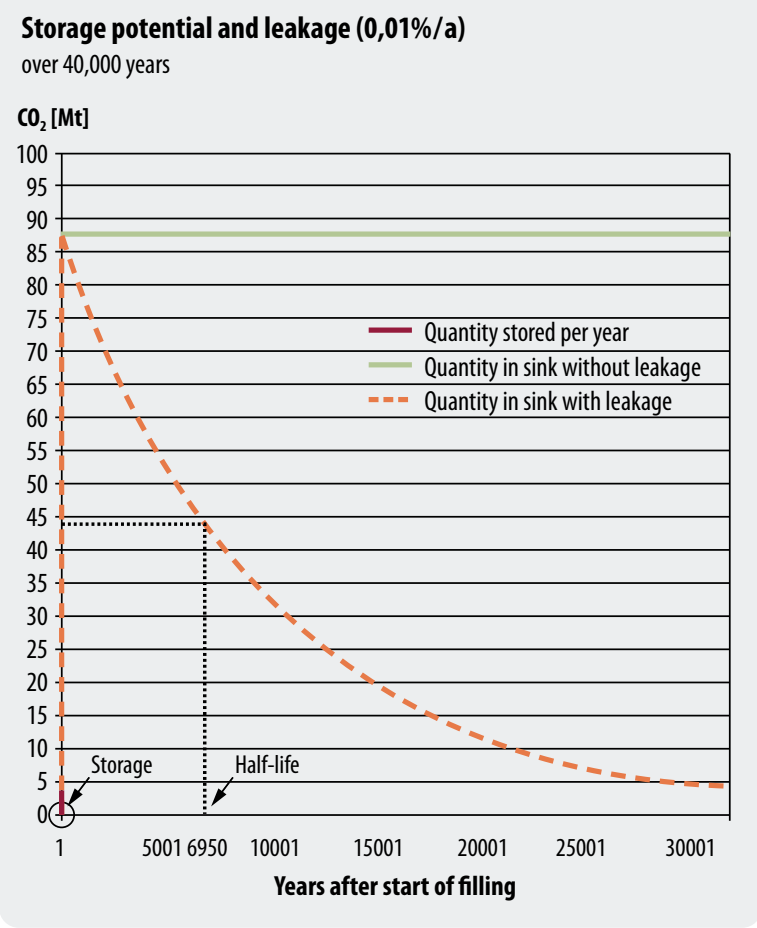

Fig. 10-20: Stored quantity and leakage over the first 100 years with a leakage rate of $0.01 \% / a$, for the example of a coal-fired power station

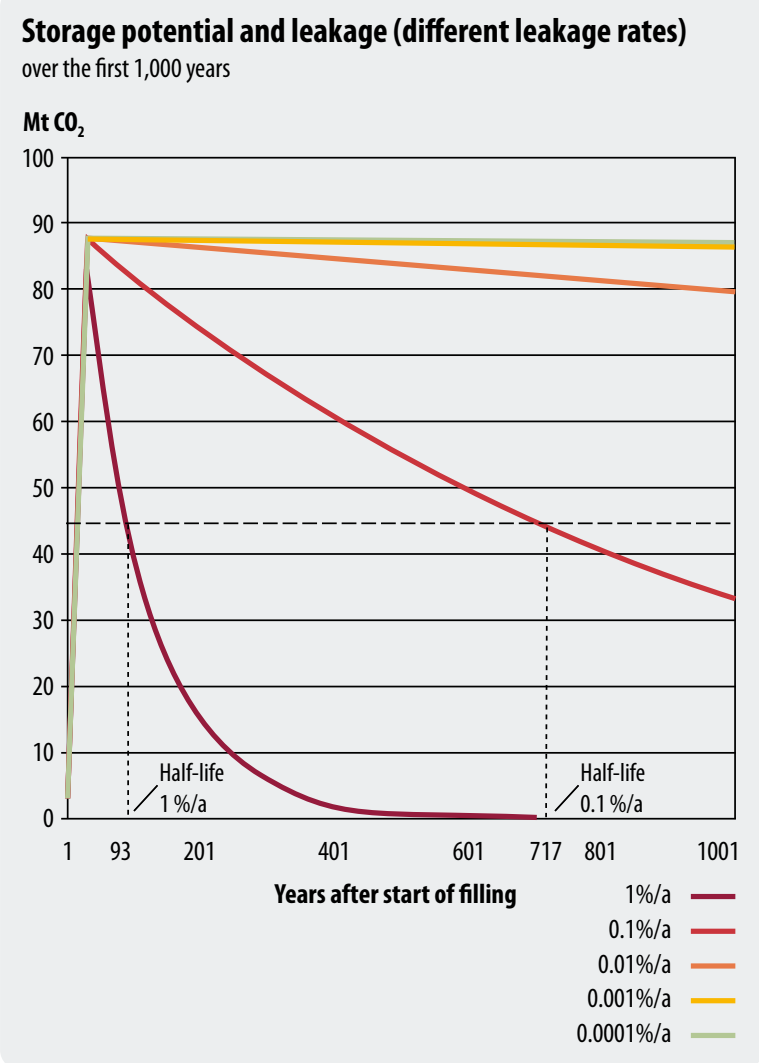

Fig. 10-21: Sink content over the first 1,000 years with leakage rates of $1 \%$ to $0.0001 \% / a$, for the example of a coal-fired power station the sink is filling - almost no $\mathrm{CO}_{2}$ is released. Continuous leakage begins in year 41 and follows an exponential curve until almost all the stored $\mathrm{CO}_{2}$ has escaped again after 40,000 years. ${ }^{4}$ The 'half-life', the time taken for $50 \%$ of the stored $\mathrm{CO}_{2}$ to escape, is 6,950 years in this case.

\section{Mathematical derivation}

If $L_{\text {_rate }}$ is the assumed annual leakage rate and $t_{\text {full }}$ the time when the sink is full, then the actual leakage rate is

actual_Leakage_rate_in_year_i $i=\left[\begin{array}{ccc}L_{-} r a t e * \frac{i}{t_{\text {full }}} & \text { if } & i<t_{\text {full }} \\ L_{-} r a t e & \text { if } & i \geq t_{\text {full }}\end{array}\right.$

Accordingly, for a given sink volume $\mathrm{V}(\mathrm{t})$ the level of leakage $\mathrm{L}(\mathrm{t})$ in year $\mathrm{t}$ is

$$
L(t)=\left[\begin{array}{cll}
V(t) * L_{-} \text {rate } * \frac{i}{t_{\text {full }}} & \text { if } & i<t_{\text {full }} \\
V(t) * L_{-} \text {rate } & \text { if } & i \geq t_{\text {full }}
\end{array}\right.
$$

The volume in the sink in year $t, V(t)$, is the volume in the sink in year $\mathrm{t}-1$, plus the amount added to the sink, $\operatorname{Add}(\mathrm{t})$, minus the leakage $\mathrm{L}(\mathrm{t}-1)$ :

$$
V(t)=\left[\begin{array}{ccc}
V(t-1)+E \text { in }(t)-L(t-1) & \text { falls } & i<t_{\text {voll }} \\
V(t-1)-L(t-1) & \text { falls } & i \geq t_{\text {voll }}
\end{array}\right.
$$

The cumulative leakage $L \_$total in year $t$

$L \_$total $(t)=\sum_{i=0}^{t} L(i)$

is then calculated from (2) and (3)

$L_{-}$total $(t)=\sum_{i=1}^{t_{\text {full }}-1} V(t-1)+A d d(t)-L(t-1)+\sum_{i=t_{\text {full }}}^{t} V(t-1)-L(t-1)$

applied to the quantities before time $t_{\text {full }}$ and after time $\mathrm{t}_{\text {full }}$. The leakage amount at any time $\mathrm{t}$ can be calculated exactly by solving this iterative equation.

\section{Life cycle analysis}

For the purposes of the LCA the released $\mathrm{CO}_{2}$ emissions are divided (rather arbitrarily) into mediumterm and long-term emissions, depending on whether they occur in the next 10,000 years or after that. But this raises the problem of how current and future emissions and impacts are to be weighed up against one another and how events in the future can be discounted. In general LCAs do not distinguish between different times of emission. But this would mean that even the smallest leakage rate would result in all the $\mathrm{CO}_{2}$ escaping into the atmosphere. So unless sinks could be guaranteed $100 \%$ leak-proof the introduction of $\mathrm{CO}_{2}$ capture would automatically lead to a general $25 \%$ increase in $\mathrm{CO}_{2}$ emissions.

4 The last 8,000 years are not shown, because Excel can only show the first 32,000 data points. 


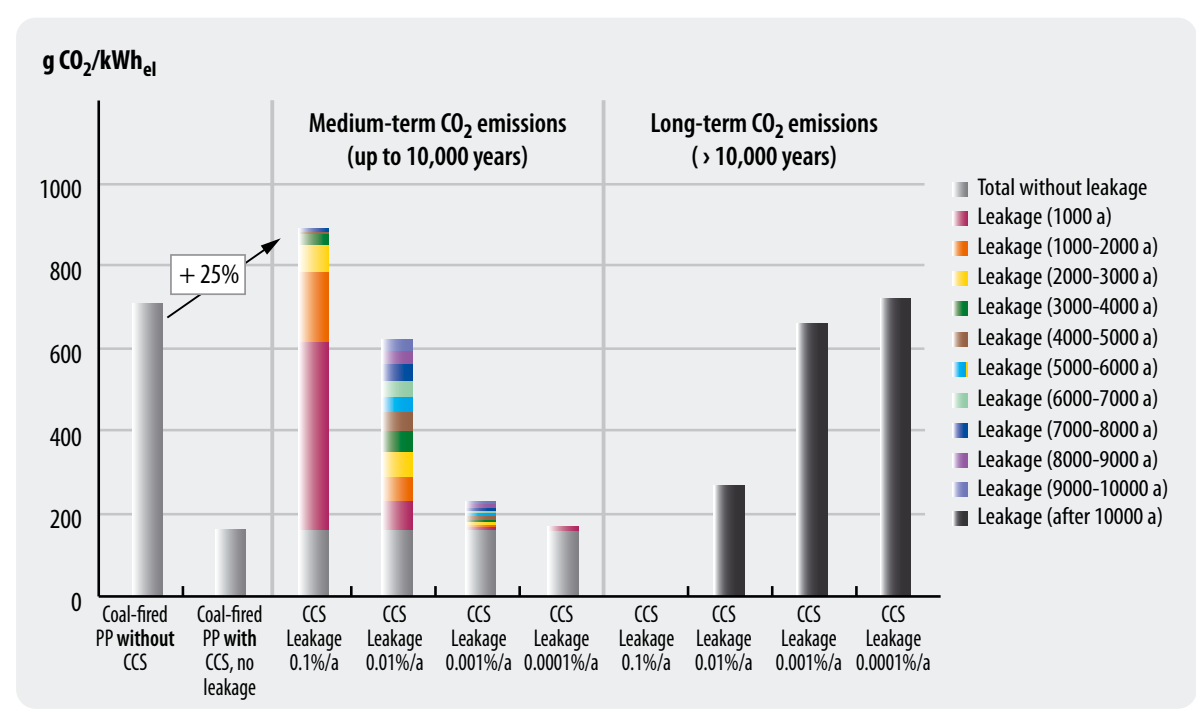

Fig. 10-22:

$\mathrm{CO}_{2}$ emissions for the coalfired power station with different $\mathrm{CO}_{2}$ leakage rates, divided into mediumterm (up to 10,000 years in 1,000-year steps) and long-term emissions $(>10,000$ years)
This means that for LCA research it is necessary to develop a method for discounting the climate effects of future greenhouse gas emissions. So far such work has only been completed for waste disposal, where shortterm emissions from incinerators have been weighed against long-term emissions from dumps (Hellweg et al. 2003).

\section{Results}

The 'best case' is the baseline assumption of a leakage rate of $0 \%$, because all the sensitivity analyses result in higher emissions of $\mathrm{CO}_{2}$. Fig. 10-22 shows how they change. The first bar represents the reference power station without CCS, the second the reference CCS power station (without leakage) and the following bars the four sensitivity cases under consideration. The first group shows medium-term emissions (first 10,000 years), the second the long-term emissions after 10,000 years. In the case of the (relatively high) leakage rate of $0.1 \% / \mathrm{a}$ all the $\mathrm{CO}_{2}$ stored underground would be released into the atmosphere within 6,000 years. The smaller the assumed leakage rate, the more emissions are shifted to the period after 10,000 years.

\subsubsection{Sensitivity Analysis 2: Variation in Capture Rate (Variable Cost)}

\section{Basis}

So far in the study a capture rate of $88 \%$ has been assumed for $\mathrm{CO}_{2}$ emissions directly at the power station, which is generally the state of the art cited in the literature. Post-combustion capture using MEA consumes electricity and steam - in proportion to the amount of $\mathrm{CO}_{2}$ captured - which significantly reduces the net efficiency of the power station. Because the models are based on current state of the art and future values for capture rate and resource consumption with MEA capture are not known, it makes sense to use sensitivity analyses to assess their influence. For example, the effect of increasing $\mathrm{CO}_{2}$ capture through a higher capture rate could be negated if the efficiency were to fall disproportionately through higher consumption of electricity and steam.

\section{Method}

The following assumptions were made for modelling capture rate:

- The $\mathrm{CO}_{2}$ capture rate increases successively from the baseline (88\%) to 90, 92, 94 and $96 \%$ (Sens_6 to Sens_9).

- The consumption of electricity, steam and MEA used in MEA capture is variable, i.e. consumption per $\mathrm{kg}$ of captured carbon dioxide is the same as in the baseline case.

- Calculations were conducted for the example of a $700 \mathrm{MW}$ coal-fired power station (representative for the post-combustion capture power stations).

\section{Results}

As Fig. 10-23 shows, specific $\mathrm{CO}_{2}$ emissions and greenhouse gases (per kilowatt hour) fall continuously as capture rate rises. Again, the first bar represents the reference power station without CCS, the second the reference CCS power station (88\% capture) and bars 3 to 6 the four sensitivity cases under consideration.

The findings result from four partly contradictory developments:

- The specific emissions of the supply chain increase because altogether more energy is consumed.

- The specific emissions of operation fall continuously because of the increased capture rates. 


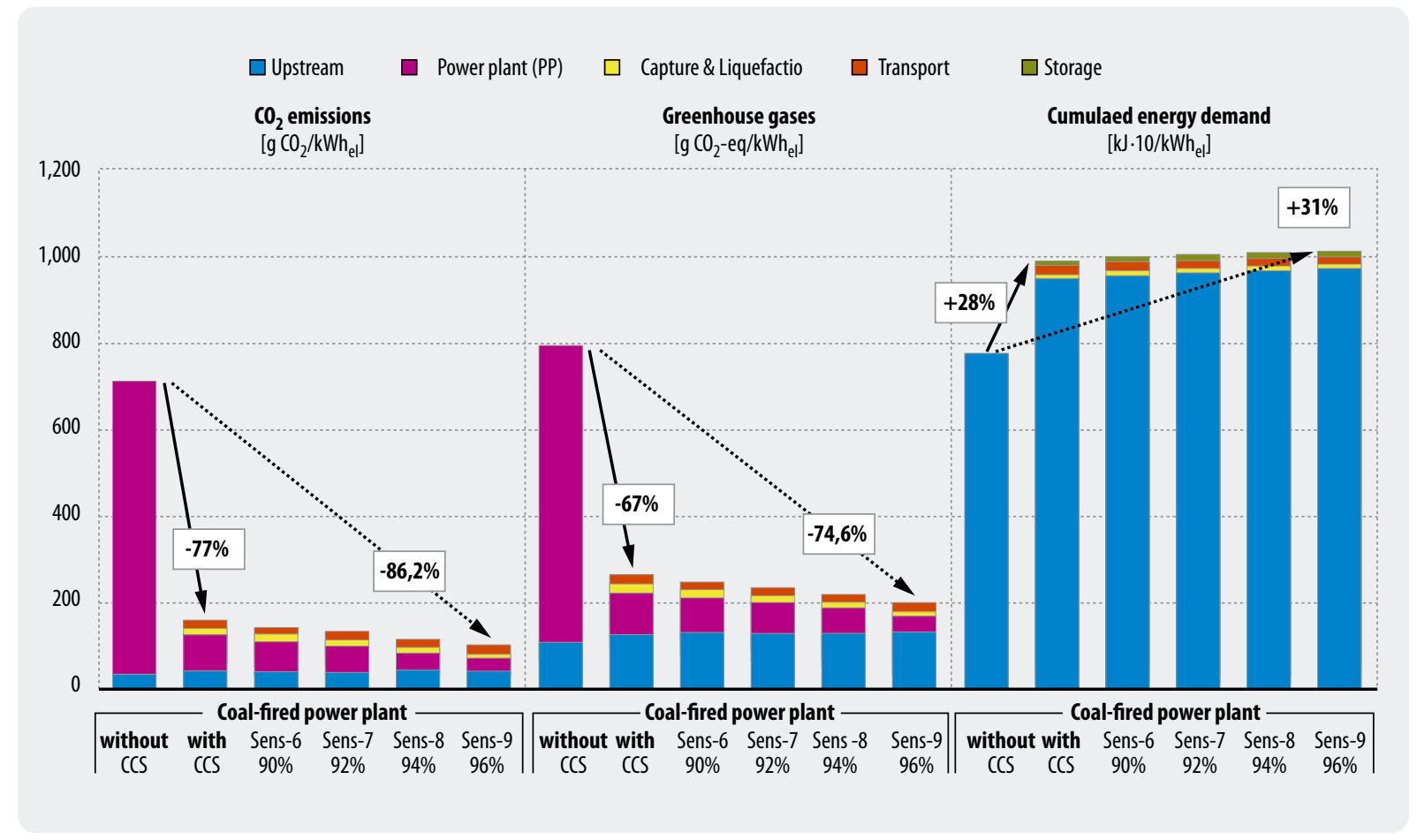

Fig. 10-23: $\mathrm{CO}_{2}$ emissions, total greenhouse gases and cumulative energy demand for the coal-fired power station with various $\mathrm{CO}_{2}$ capture rates (variable capture costs)

- The specific emissions attributable to capture also fall continuously. Because of the higher capture rate more electricity, steam and MEA are used (which increases emissions) but this is more than compensated by the increased quantity of $\mathrm{CO}_{2}$ captured, resulting in a net fall in emissions per $\mathrm{kWh}$.

- Emissions from transport and storage increase continuously because they are directly proportional to the amount of carbon dioxide to be transported and stored.

Energy demand, on the other hand, rises continuously because capture, transport and storage all require more energy.

\subsubsection{Sensitivity Analysis 3: Variation in Capture Rates (Fixed Cost)}

\section{Method}

This time the capture costs were kept constant for the sensitivity analysis (meaning that a capture rate of $96 \%$ requires exactly the same amount of electricity, steam and MEA as a capture rate of $88 \%$ ). This simulates possible technical advances in MEA capture.

- As above, the $\mathrm{CO}_{2}$ capture rate was increased successively from the baseline case (88\%) to 90, 92, 94 and $96 \%$ (Sens_6a to Sens_9a).

- The amounts of electricity, steam and MEA required for MEA capture were kept constant.
- Calculations were again conducted for the example of a $700 \mathrm{MW}$ coal-fired power station (representative for the post-combustion capture power stations).

\section{Results}

As Fig. 10-24 shows, specific $\mathrm{CO}_{2}$ emissions and greenhouse gases (per kilowatt hour) again fall continuously as the capture rate rises. The specific emissions from capture fall even further than in the previous case because no additional cost was modelled, so overall emissions are also slightly lower. At the highest capture rate $\mathrm{CO}_{2}$ emissions fall to $13.6 \%$ (from $13.8 \%$ ) and greenhouse gases fall to $25.0 \%$ (from $25.4 \%$ ). The energy costs are also smaller (increase of $29 \%$ rather than $31 \%$ at highest capture rate). The first bar again represents the reference power station without CCS, the second bar the reference CCS power station $(88 \%$ capture) and bars 3 to 6 the four sensitivity cases under consideration.

From the second and third sensitivity analyses we can conclude that increasing the $\mathrm{CO}_{2}$ capture rate leads to a continuous fall in specific $\mathrm{CO}_{2}$ and greenhouse gas emissions. Although the greater consumption of electricity, steam and MEA initially increases emissions, this is more than compensated by the greater amounts of $\mathrm{CO}_{2}$ captured. If the cost of the capture process is kept constant a further marginal reduction in $\mathrm{CO}_{2}$ and greenhouse gas emissions is possible. 


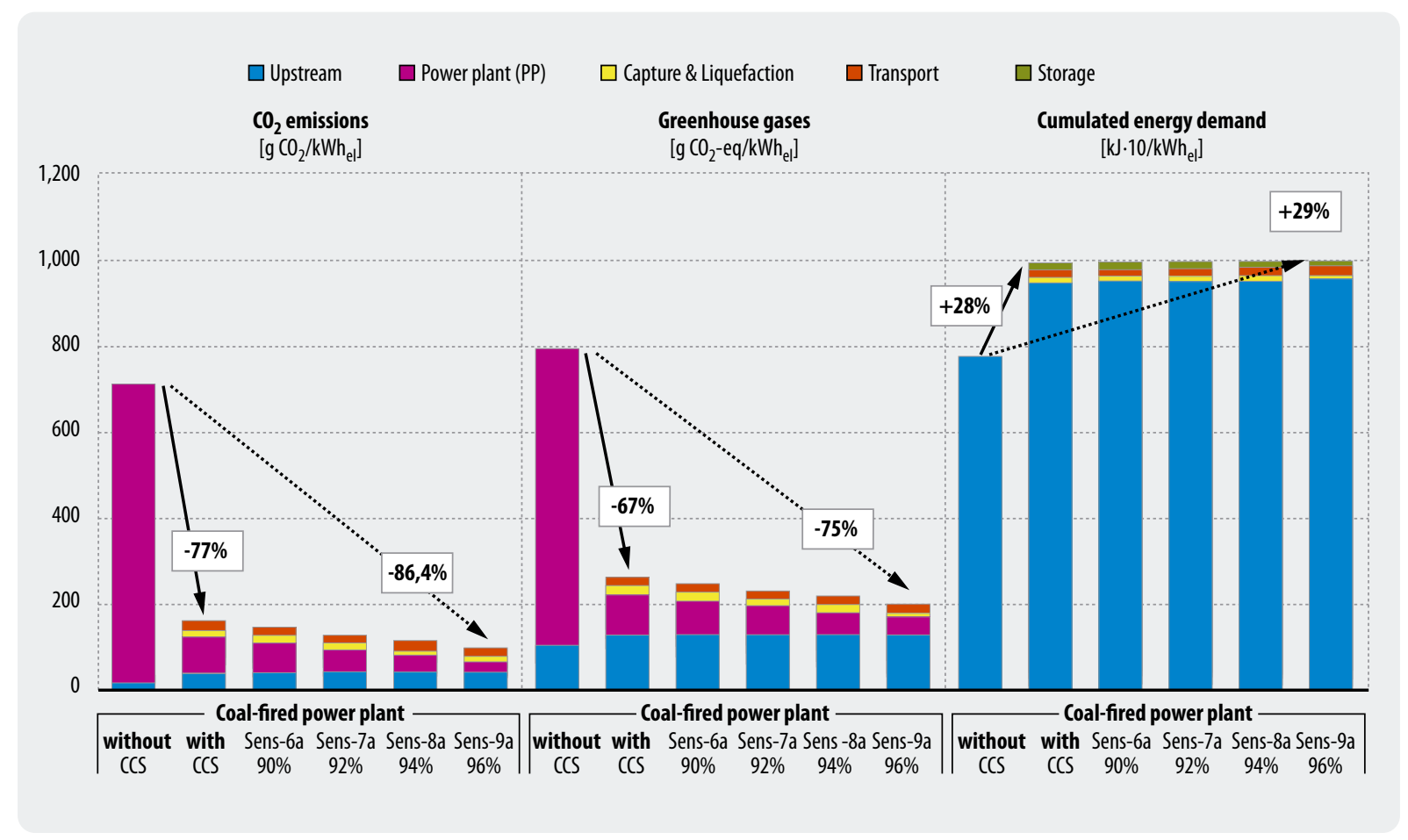

Fig. 10-24: $\mathrm{CO}_{2}$ emissions, total greenhouse gases and cumulative energy demand for the coal-fired power station with various $\mathrm{CO}_{2}$ capture rates and fixed capture costs

\subsubsection{Sensitivity Analysis 4: Variation in Methane Emissions During Coal Mining}

\section{Basis}

In the models so far we have used the coal supply chain 'Steinkohle-Mix D frei KW/In', which models the German coal mix in 2000 (see section 10.3.2). In comparison to lignite and natural gas, methane emissions from coal mining are relatively high, as Table 10-14 shows:

Only for lignite are the upstream emissions negligible, because here the $\mathrm{CO}_{2}$ emissions associated with energy consumption for transport are almost the only factor to play a role. Whereas both energy used to transport the gas and the release of gas through leaks are relevant with natural gas, the major factors in the coal supply chain are energy consumption for transport and above all the release of mine gas (WI and MPI 2004).

Table 10-14: Methane emissions of the primary energy supply chains

\begin{tabular}{|l|l|c|c|}
\hline $\begin{array}{l}\text { Primary } \\
\text { energy }\end{array}$ & Umberto module & Year & $\begin{array}{l}\text { Methane emissions } \\
\text { in kg/TJ }\end{array}$ \\
\hline Coal & Steinkohle-Mix D frei KW/ln & 2000 & 454 \\
\hline Lignite & Braunkohle-Mix D frei KW/In & 2000 & 2 \\
\hline Natural gas & Vorkette_Erdgas_D_2010 & 2010 & 154 \\
\hline
\end{tabular}

Mine gas has been covered by the Renewable Energy Act since 2000, with the result that in Germany it is increasingly being extracted from working and closed mines and used to power CHP units. The installed capacity for using mine gas in the Ruhr coalfield has grown quickly from just $800 \mathrm{~kW}_{\mathrm{el}}$ in 1999 to $90 \mathrm{MW}_{\mathrm{el}}$ in 2003 (Backhaus et al. 2003) and $158 \mathrm{MW}_{\mathrm{el}}$ by the end of 2005 (Landesinitiative 2006). In each of the years 2003 and 2004 about 160 million $\mathrm{m}^{3}$ of methane gas were used to generate $600 \mathrm{GWh}$ of electricity (SteinkohlePortal.de 2006, Geologischer Dienst NRW 2006), and in 2005 the figure rose to 885 GWh (Landesinitiative 2006).

The German coal mix used in Umberto comprises the following sources: Germany (62.1\%); Poland and eastern Europe (12.5\%); South Africa (10.2\%); Colombia, Canada and the United States (7.8\%); Australia (4.1\%); and the Netherlands (and other western Europe) (3.3\%). The high proportion of German coal means that utilising the methane for power also influences the methane emissions of the overall mix. Although detailed data are not yet available, lower emissions than in 2000 should be applied here, especially for the post-2020 period modelled in this case. This sensitivity analysis examines the influence of reduced methane emissions in the coal supply chain on the overall result. 
Fig. 10-25:

Comparison of total greenhouse gases at various levels of methane emissions in the coal supply chain for the fossil-fuelled reference power stations

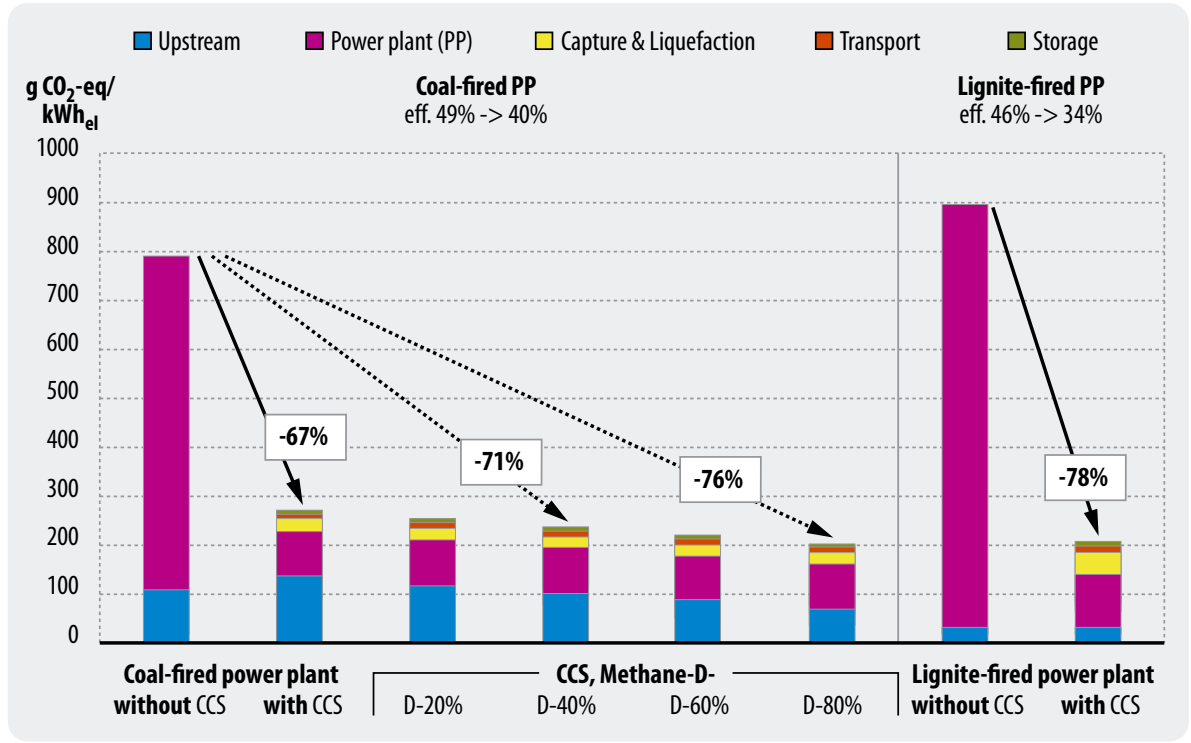

\section{Method}

The following assumptions were made for modelling methane emissions:

- In the Umberto module 'Steinkohle-Mix D frei $\mathrm{KW} / \mathrm{In}$ ' the methane emissions of $454 \mathrm{~kg} / \mathrm{TJ}$ were reduced to $80,60,40$ and $20 \%$ of that value in four sensitivity cases.

- The calculations were again conducted for the example of the $700 \mathrm{MW}$ coal-fired power stations, and the results were compared with those for lignite-fired and natural-gas-fired power stations.

\section{Results}

The first bar in Fig. 10-25 shows the reference power station without CCS, the second bar the reference CCS power station (100\% methane emissions), and bars 3 to 6 show the four sensitivity cases under consideration. Because the coal supply chain causes $\mathrm{CO}_{2}$ emissions as well as methane emissions, the greenhouse gas emissions of the supply chain as a whole only fall by 87 to $46 \%$. In relation to the power station process as a whole (including $\mathrm{CO}_{2}$ capture), we found a reduction in greenhouse gas emissions of $67 \%$ (baseline) to $76 \%$ (sensitivity case 4 with $20 \%$ methane emissions). That brings the coal-fired power station with CCS close to the values for the lignite-fired power station with CCS that is included on the right for comparison.

\subsection{Conclusions for Electricity Generation}

- Although a capture rate of, for example, $88 \%$ would suggest that total $\mathrm{CO}_{2}$ emissions are reduced by $88 \%$, the rate of $\mathrm{CO}_{2}$ capture cited by the industry relates only to the $\mathrm{CO}_{2}$ emissions directly in power station operation. If we take an integrated approach, five percent of the $\mathrm{CO}_{2}$ emissions already occur in the supply chain both with coal-fired steam power stations and with natural gas CC. Reduced efficiency also causes higher consumption of primary energy and thus a 'larger' coal or natural gas supply chain. Taken together, these factors mean that with a capture rate of $88 \%$ actual $\mathrm{CO}_{2}$ emissions can be reduced not by $88 \%$, but only by $72-78 \%$. In view of this fact it would seem unjustified to speak of ' $\mathrm{CO}_{2}$-free' power stations. Even if the capture rate at the power station can be increased still further, the designation 'low- $\mathrm{CO}_{2}$ ' is more pertinent.

- The discussion to date has also neglected to consider that greenhouse gas emissions as a whole and not only $\mathrm{CO}_{2}$ emissions - have to be reduced. The Kyoto Protocol requires Germany to reduce a total of six greenhouse gases (and not just $\mathrm{CO}_{2}$ emissions) by $21 \%$ by 2012 . If we calculate the effects of $\mathrm{CO}_{2}$ capture on greenhouse gas emissions, we find that the potential reduction is less than proportional. For example, with a $\mathrm{CO}_{2}$ capture rate of $88 \%$ greenhouse gases can only be reduced by $67-78 \%$. The reasons for this are the considerably increased primary energy consumption and the methane emissions associated with fuel extraction and transport, which can be relatively high in some cases. These have a disproportionately large effect on the greenhouse effect.

- With $396 \mathrm{~g} \mathrm{CO}_{2}$ equivalent per $\mathrm{kWh}$ the best power station without CCS (natural gas CC) has only $51 \%$ more greenhouse gas emissions than the worst power station with CCS (coal-fired steam power station with $262 \mathrm{~g} \mathrm{CO}_{2}$ equivalent per $\mathrm{kWh}$ ).

- If methane emissions from coal mining were to be reduced by up to $80 \%$ from today's value, this would result in greenhouse gas emissions from the 
coal-fired power station with CCS being reduced by up to $76 \%$, compared with the same power station without CCS. Here the capture rate was kept constant at $88 \%$. This brings the coal-fired power station with CCS close to the values for the lignitefired power station with CCS, but still exceeds the greenhouse gas emissions of natural gas CC by about $50 \%$.

- Of all the fossil-fired power stations considered, oxyfuel combustion was best. Physical capture of almost $100 \%$ of the $\mathrm{CO}_{2}$ allows net rates of reduction of $90 \%$ for $\mathrm{CO}_{2}$ emissions and $78 \%$ for greenhouse gas emissions.

- Overall, $\mathrm{CO}_{2}$ capture requires additional energy consumption of 20 to $44 \%$, depending on the process. Even if the extent of deposits would present no obstacle to increased use of coal, many other aspects must be taken into consideration in connection with coal mining. Fell (2003) names, for example, destruction of landscapes, subsidence, falling water tables, human rights violations in the mining industry and ecological harm caused by burning coal seams in China. These aspects are not registered by an LCA but should not be neglected.

- The considerably higher energy consumption also contributes to a change in the other environmental impact categories. But with the post-combustion approach the MEA solvent also captures other emissions as well as $\mathrm{CO}_{2}$ so the picture is more complex here. In the category of acidification there is a slight reduction in absolute terms; PM10 equivalents (dust emissions) rise slightly, while considerable increases are found for eutrophication and summer smog. For pre-combustion and oxyfuel combustion an overall increase must be expected in the impact categories, but precise modelling was not possible due to lack of data.

- The renewables considered all exhibited better values than the fossil-fuelled power stations with $\mathrm{CO}_{2}$ capture. Even including electricity transport, solar thermal and wind-generated electricity produce only 2 to $3 \%$ of the $\mathrm{CO}_{2}$ emissions, greenhouse gases and cumulative energy demand of fossil-fuelled power stations, and in the other impact categories the values for renewables are also way below those for fossil-fuelled systems.

- If we include advanced power generation concepts based on fossil fuels, we find that with CHP systems (natural gas and natural gas CC) there are already technologies on the market that are as green as the target to be achieved by CCS power stations in 2020.

- While the $\mathrm{CO}_{2}$ capture process itself represents a relevant share of total emissions (about $22 \%$ ), transport and storage play only a secondary role. Further modelling is required for these parts of the process, however, because the basic data are still incomplete.

- The question of discounting future emissions is of more than academic interest. Like in the field of waste disposal, if we assume a leakage rate greater than zero, emissions will occur thousands of years later and have to be discounted if energy systems are to be compared. With the exception of one study, this question has not yet been examined using the LCA methodology, so a simplified approach had to be adopted for the sensitivity analysis.

- From the sensitivity analyses about capture rate and capture cost we can conclude that higher $\mathrm{CO}_{2}$ capture rates contribute to continuous reductions in specific $\mathrm{CO}_{2}$ and greenhouse gas emissions. The greater consumption of electricity, steam and MEA initially increases emissions, but this is more than compensated by increases in the amount of captured $\mathrm{CO}_{2}$. If the cost of the capture process is kept constant, a further marginal reduction in $\mathrm{CO}_{2}$ and greenhouse gas emissions is possible.

\subsection{Plant and Processes for Conventional Hydrogen Production with CCS}

\subsubsection{Reference Plant}

Table 10-15 shows the basic data of the reference hydrogen production processes used in the study with and without $\mathrm{CO}_{2}$ capture. They are compatible with the data used for the economic calculations. All values given relate to lower heating value (LHV).

In each case the most up-to-date available modules for existing technologies and supply chains were used to model the LCA. The modules were projected through to 2020 by modifying the efficiency according to the values in the table above. The LCA modules came from the following sources (Table 10-16).

- Natural gas steam reforming: Pehnt (2002) models the classical natural gas steam reforming process on the basis of a modern production facility built by Lurgi with a relatively small output $\left(8,000 \mathrm{Nm}^{3} / \mathrm{h}\right.$ or $24 \mathrm{MW}_{\mathrm{th}}$ ), using data supplied by the manufacturer. When he compared the data with a literature source for a large-scale Linde plant he found that the values were almost identical. For this reason, here we used the data given by Pehnt and modelled them accordingly in Umberto. The efficiency of the plant under consideration is $72 \%$ if the steam is not used (and $81 \%$ if steam is exported) and was projected to $74 \%$ in 2020 . The plant was modelled with a credit for the steam by offsetting a natural gas condensing boiler, although part of the steam is required to generate the electricity required for the plant itself. Nevertheless, external electricity is 
Table 10-15: Basic data for hydrogen production from fossil fuels without and with $\mathrm{CO}_{2}$ capture

\begin{tabular}{|c|c|c|c|c|}
\hline \multicolumn{5}{|c|}{ A) Without $\mathrm{CO}_{2}$ capture } \\
\hline & & \multicolumn{2}{|c|}{$\begin{array}{l}\text { Natural gas } \\
\text { steam reforming }\end{array}$} & $\begin{array}{l}\text { Coal gasifi- } \\
\text { cation }\end{array}$ \\
\hline Output & MW & \multicolumn{2}{|c|}{350} & 560 \\
\hline Full load hours & h/a & \multicolumn{2}{|c|}{8,000} & 8,000 \\
\hline Efficiencya) & $\%$ & \multicolumn{2}{|c|}{73.6} & 59 \\
\hline \multirow{2}{*}{$\begin{array}{l}\mathrm{CO}_{2} \text { intensity } \\
\text { of fuel }\end{array}$} & $g\left(O_{2} / \mathrm{MJ}\right)$ & \multicolumn{2}{|c|}{56} & 92 \\
\hline & $\mathrm{gCO}_{2} / \mathrm{kWh}$ & \multicolumn{2}{|c|}{202} & 331 \\
\hline $\begin{array}{l}\mathrm{CO}_{2} \text { intensity of } \\
\text { hydrogen (with- } \\
\text { out emissions for } \\
\text { electricity) }\end{array}$ & $\mathrm{gCO} / \mathrm{kWh}_{\mathrm{th}}$ & \multicolumn{2}{|c|}{274} & 561 \\
\hline $\begin{array}{l}\text { External electricity } \\
\text { demand }\end{array}$ & $\mathrm{kWh}_{\mathrm{e}} / \mathrm{kWh}_{\mathrm{th}}$ & \multicolumn{2}{|c|}{0.005} & - \\
\hline Steam export & $\mathrm{kg} / \mathrm{kWh}_{\mathrm{th}}$ & \multicolumn{2}{|c|}{0.158} & - \\
\hline \multicolumn{5}{|c|}{ B) With $\mathrm{CO}_{2}$ capture } \\
\hline & & \multicolumn{2}{|c|}{$\begin{array}{l}\text { Natural gas } \\
\text { steam reforming }\end{array}$} & $\begin{array}{l}\text { Coal gasifi- } \\
\text { cation }\end{array}$ \\
\hline & & $\begin{array}{l}\text { Lurgi/ZsW } \\
\text { model') }\end{array}$ & $\begin{array}{l}\text { DOE } \\
\text { model d) }\end{array}$ & \\
\hline Output & MW & 325 & 329 & 522 \\
\hline Efficiency a) & $\%$ & 68.4 & 69.1 & 55 \\
\hline Reduction & $\%$ points & 5,2 & 4.5 & 4 \\
\hline $\begin{array}{l}\text { External electricity } \\
\text { demand }\end{array}$ & $\mathrm{kWh}_{\mathrm{e} /} / \mathrm{kWh}_{\mathrm{th}}$ & 0.005 & 0.0125 & - \\
\hline Steam export & $\mathrm{kg} / \mathrm{kWh} \mathrm{th}_{\mathrm{th}}$ & 0.079 & 0 & - \\
\hline Capture rate & $\%$ & 53 & 71 & 88 \\
\hline $\mathrm{CO}_{2}$ to dispose of & $t / a$ & 437,389 & 580,001 & $2,374,042$ \\
\hline \multicolumn{5}{|c|}{$\begin{array}{l}\text { a) In terms of calorific value, without export steam } \\
\text { b) Source: UBA } 2003 \\
\text { c) Source: Küppers 2006, d) Source: DOE } 2002\end{array}$} \\
\hline
\end{tabular}

\subsubsection{Supply Chains}

The LCA modules used for the supply chains were taken from the sources given in Table 10-17. In steam reforming they were used both for hydrogen production itself and for the natural gas boiler credit.

- Coal: The same coal supply chain was used as for electricity generation (see section 10.3.2).

- Natural gas: The same natural gas supply chain was used as for electricity generation (see section 10.3.2)

\subsection{3 $\mathrm{CO}_{2}$ Capture}

In contrast to $\mathrm{CO}_{2}$ capture in power stations, for hydrogen production it was not possible to use 'ready-made' plant modules and supplement them with $\mathrm{CO}_{2}$ capture components. Instead the plant had to be remodelled with CCS. When preparing the LCAs the following approach was chosen.

\section{Coal Gasification}

For coal gasification the $\mathrm{CO}_{2}$ is separated from a $\mathrm{H}_{2} /$ $\mathrm{CO}_{2}$ mixture by installing a physical scrubbing facility between the shift reactor and the PSA unit (see e.g. Parsons 2002). For reasons of time it was not possible to model that for this study. Instead, for coal gasification, we used the reference module for IGCC electricity generation and reduced the efficiency according to the figure listed above. The plant's additional consumption was assigned to physical capture. A capture rate of $88 \%$

Table 10-16: Sources for the LCA modules for hydrogen production from fossil fuels

\begin{tabular}{|l|l|l|l|l|l|l|}
\hline Process & $\begin{array}{l}\text { Output } \\
{[\mathrm{MW}]}\end{array}$ & $\begin{array}{l}\text { Functional } \\
\text { unit }\end{array}$ & $\begin{array}{l}\text { Efficiency a) } \\
{[\%]}\end{array}$ & Source & Module name \\
\hline Natural gas steam reforming & 24 & $1 \mathrm{Nm}^{3} \mathrm{H}_{2}$ & 72 & Pehnt 2002 & New \\
\hline Coal gasification (coal IGCC) & 450 & $1 \mathrm{kWh}_{\mathrm{el}}{ }^{\text {b) }}$ & 51.5 & Briem et al. 2004 & New \\
\hline $\begin{array}{l}\text { a) In relation to calorific value } \\
\text { b) The existing IGCC module is only for electricity generation. }\end{array}$
\end{tabular}


Table 10-17: Sources of the LCA modules for the fossil fuel supply chains

\begin{tabular}{|l|c|l|l|c|}
\hline Fuel & Functional unit & Source & Module name & Year \\
\hline Coal & $1 \mathrm{~kg}$ & Umberto & Steinkohle-Mix D frei KW/In & 2000 \\
\hline Natural gas & $1 \mathrm{~kJ}$ & Umberto, Pehnt 2002, WI and PMI 2004 & Vorkette_Erdgas_D_2010 & 2010 \\
\hline
\end{tabular}

was assumed, as for IGCC electricity generation (see also the explanatory notes concerning electricity generation in section 10.3.3).

\section{Natural Gas Steam Reforming}

Natural gas steam reforming with $\mathrm{CO}_{2}$ capture was modelled according to two different sources:
1. In the first case the project partner ZSW simulated natural gas steam reforming on the basis of the Lurgi process as the reference system and integrated $\mathrm{CO}_{2}$ capture by means of chemical scrubbing (MEA process). The reference plant corresponds to the values given by Pehnt (2002) (see section 10.9.1). The plant complete with $\mathrm{CO}_{2}$ capture is illustrated in Fig. 10-26 and exhibits the following differences from the reference case:

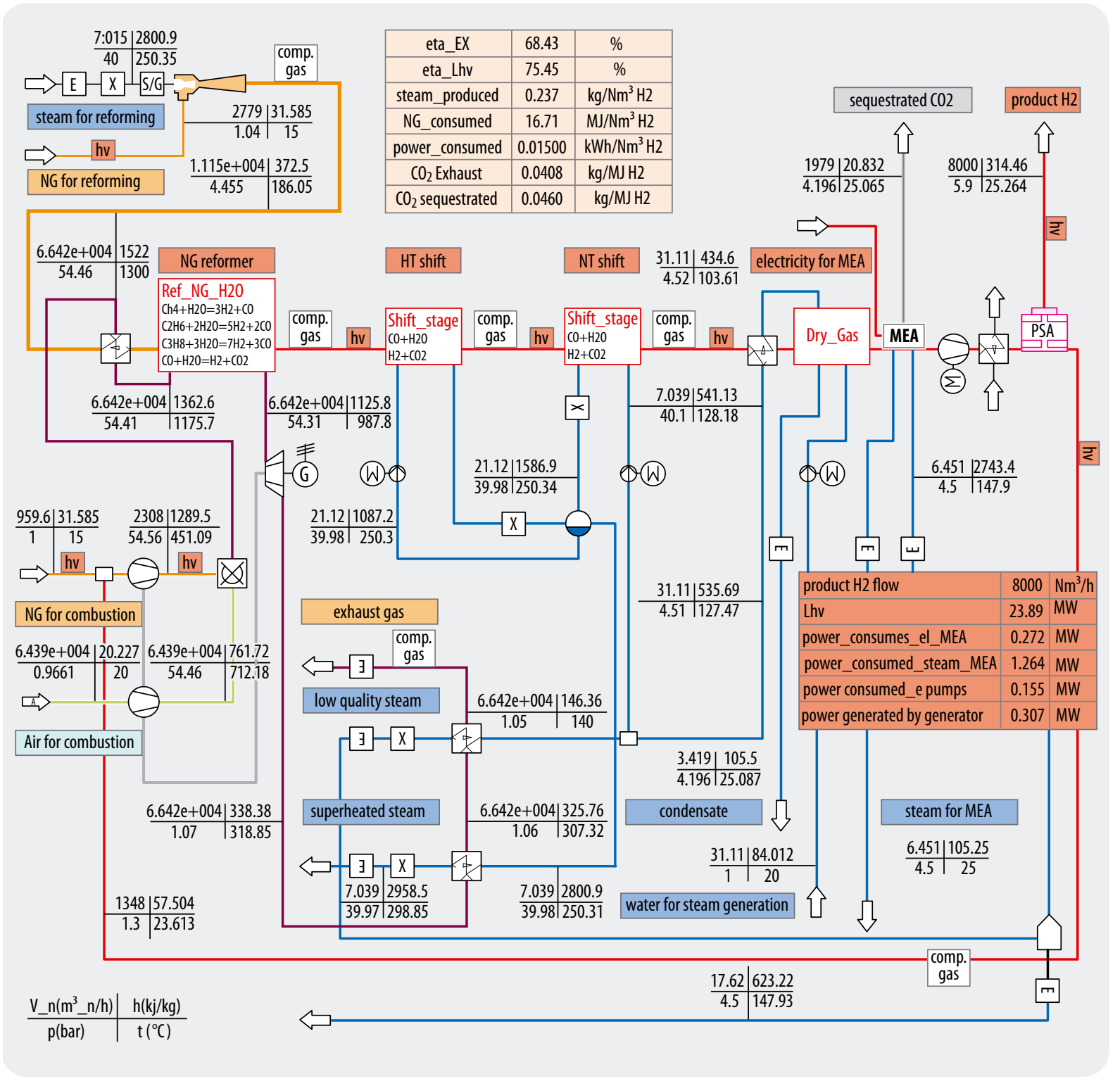

Fig. 10-26: Classical steam reforming plus $\mathrm{CO}_{2}$ capture using chemical scrubbing (MEA solution) (Küppers 2006) 
- Chemical scrubbing using MEA involves consumption of a certain amount of steam and electricity. Part of the excess steam is used for this purpose. In order to avoid increasing the use of external electricity the additional electricity consumption is generated internally, causing the efficiency to fall by 5.2 percentage points. Net export steam falls by about half, so the natural gas boiler credit is correspondingly smaller.

- The net $\mathrm{CO}_{2}$ capture rate is $53 \%$, because capture is carried out in the reformer before the PSA. It would also be technically possible - as in the coal-fired power station - to capture almost all the $\mathrm{CO}_{2}$ from the reformer waste gas, but this would be less favourable in terms of energy.

2. The ZSW model was compared with a similar model described by DOE (2002). It uses all the excess steam so none is available for export and no credit is given. External electricity demand is also $150 \%$ higher. But the plant achieves a net $\mathrm{CO}_{2}$ capture rate of $71 \%$ (with $99 \%$ capture using amines) with a reduction in efficiency amounting to 4.5 percentage points. The assumptions on which this model is based could not be verified because the source cited published only the final results.

In future another process might become available, solar steam reforming. This process - currently under development by the German Aerospace Center - would draw the heat required to produce hydrogen entirely from solar sources (Möller et al. 2006). This would reduce the consumption of natural gas by $40 \%$. The relevant research projects are still in progress so it was not possible to include the process in this study.

\subsection{4 $\mathrm{CO}_{2}$ Liquefaction}

For initial compression to 110 bar (and thus the liquefaction of the $\mathrm{CO}_{2}$ ) we took the same figure as for electricity generation: $110 \mathrm{kWh}_{\mathrm{el}} / \mathrm{t} \mathrm{CO}$ (Göttlicher 1999), for multi-stage compression starting from 1 bar with intermediate cooling to $30^{\circ} \mathrm{C}$.

\subsection{5 $\mathrm{CO}_{2}$ Transport Scenarios}

The transport and storage of $\mathrm{CO}_{2}$ was modelled for a single power station, taking the Ruhr region as the origin and an exhausted gas field (not further spedified) in northern Germany as the destination (Table 10-18). An arbitrary transport distance of $300 \mathrm{~km}$ was chosen, and it was assumed - as for electricity generation - that the pipeline would have to be built specially for this power station because it will not necessarily be possible to use existing (natural gas) pipelines.

As for electricity, transport was modelled using the existing LCA module 'Onshore, low capacity'. With an annual capacity of $5 \mathrm{Mt}$ it might at first seem overdimensioned, but it must be remembered that all costs are calculated in terms of the transported tonne-kilometres, so if the quantity of material flowing in the pipeline is smaller the material and energy flows will be smaller too.

Table 10-18: $\mathrm{CO}_{2}$ transport scenarios for hydrogen technologies

\begin{tabular}{|c|c|c|c|c|c|c|c|}
\hline \multirow{2}{*}{ 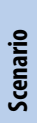 } & \multirow{2}{*}{$\begin{array}{l}\text { Location of } \\
\mathrm{CO}_{2} \text { Source }\end{array}$} & \multirow{2}{*}{$\begin{array}{l}\text { Plant type and } \\
\mathrm{H}_{2} \text { output }\end{array}$} & \multicolumn{2}{|c|}{ Captured $\mathrm{CO}_{2}$} & \multirow{2}{*}{$\begin{array}{l}\text { Pipeline land }{ }^{\mathrm{b})} \\
+ \text { ship } \\
{[\mathrm{km}]}\end{array}$} & \multirow{2}{*}{$\begin{array}{l}\text { Pipeline- } \\
\text { diameter }{ }^{c} \\
{[\mathrm{~mm}]}\end{array}$} & \multirow[t]{2}{*}{ Storage location } \\
\hline & & & {$[\mathrm{Mt} / \mathrm{a}]^{\text {a) }}$} & {$[t / d]^{d)}$} & & & \\
\hline 1 & Ruhr region & $\begin{array}{l}\text { Natural gas steam reforming } \\
350 \mathrm{MW} \text { (ZSW) }\end{array}$ & 0.44 & 1,198 & $300+0$ & 200 & $\begin{array}{l}\text { Gas field } \\
\text { onshore }\end{array}$ \\
\hline 2 & Ruhr region & $\begin{array}{l}\text { Natural gas steam reforming } \\
350 \mathrm{MW} \text { (DOW) }\end{array}$ & 0.58 & 1,589 & $300+0$ & 200 & $\begin{array}{l}\text { Gas field } \\
\text { onshore }\end{array}$ \\
\hline 3 & Ruhr region & Coal gasisfication $560 \mathrm{MW}$ & 2.37 & 6,504 & $300+0$ & 330 & $\begin{array}{l}\text { Gas field } \\
\text { onshore }\end{array}$ \\
\hline \multicolumn{8}{|c|}{ a) Calculated with $8,000 \mathrm{~h} / \mathrm{a}$} \\
\hline \multicolumn{2}{|c|}{ Steam reforming (ZSW): } & \multicolumn{6}{|c|}{ efficiency $74 \% \rightarrow 68 \%$, capture rate $53 \%, \mathrm{CO}_{2}$ emissions (without CCS, without external electricity supply) $=274 \mathrm{~g} / \mathrm{kWh}_{\text {th }}$} \\
\hline \multicolumn{2}{|c|}{ Steam reforming (DOE): } & \multicolumn{6}{|c|}{ efficiency $74 \% \rightarrow 69 \%$, capture rate $71 \%, \mathrm{CO}_{2}$ emissions (without CCS, without external electricity supply) $=274 \mathrm{~g} / \mathrm{kWh}_{\text {th }}$} \\
\hline \multicolumn{2}{|c|}{ Coal gasification: } & \multicolumn{6}{|c|}{ efficiency $59 \% \rightarrow 55 \%$, capture rate $88 \%$, $\mathrm{CO}_{2}$ emissions (without CCS) $=561 \mathrm{~g} / \mathrm{kWh}_{\text {th }}$} \\
\hline \multicolumn{8}{|c|}{ b) Including a gas-turbine-powered tubo-compressor } \\
\hline \multicolumn{8}{|c|}{ c) Estimated according to data in Bock et al. 2001} \\
\hline
\end{tabular}




\subsection{6 $\mathrm{CO}_{2}$ Storage}

As for electricity generation, the costs of storage were initially estimated via the relationship between storage and transport costs, taking a rough approximation of $50 \%$ of the transport values for emissions and cumulative energy demand.

\subsection{Plant for Producing Hydrogen Using Renewables}

\subsubsection{Reference Plant}

As with the power stations, hydrogen production from fossil fuels was compared with plant for producing hydrogen using renewables that will be available in 2020. The technology used is electrolysis powered by electricity generated in solar thermal plant and offshore wind farms. Because the transport scenarios described above took the Ruhr region as the location for the fossil-fired power stations, the plant using renewables was also modelled on the basis of delivery of electricity to the Ruhr region. It was assumed that the electrolysis plant is in the Ruhr region and the required electricity is transported there by high-voltage DC lines from Algeria (solar thermal) and the North Sea (offshore wind power).

To model the LCA we used the latest available module for electrolysis (see Table 10-19):

Pehnt (2002) models hydrogen production by means of alkaline electrolysis (output $200-400 \mathrm{Nm}^{3} / \mathrm{h}$ or $0.6-1.2$ $\mathrm{MW}_{\mathrm{H} 2}$ ), taking account of potential for optimisation compared with state of the art. Data about operational plant were available from the literature and various manufacturers. For the efficiency of energy conversion we took the value of $70 \%$ given by Pehnt, which already takes account of the optimised plant.

In future other methods which promise higher efficiencies will become available (Krewitt and Schmid 2004). These include membrane electrolysers (structured like a PEM fuel cell) and high-pressure electrolysers (like SOFC fuel cells, using high-temperature ceramics at operating temperatures of $900^{\circ} \mathrm{C}$ ). However, in view of the lack of operating data from these new processes we worked on the basis of improved alkaline electrolysis.

\subsubsection{Supply Chains}

The LCA modules for the electricity generation supply chains came from the sources (given in Table 10-20) and are described in section 10.4.

For the transport of electricity generated in North Africa or the North Sea by high-voltage line to the Ruhr region reference location we again used the LCA by May (2005).

\subsection{Individual Analyses of Hydrogen Production Systems}

\subsubsection{Conventional Plant}

\section{Coal Gasification}

Fig. 10-27 shows the impact of $\mathrm{CO}_{2}$ capture on greenhouse gas emissions and energy consumption for hydrogen production by coal gasification.

\begin{tabular}{|l|l|l|l|l|l|l|}
\hline Process & Output & $\begin{array}{l}\text { Functional } \\
\text { unit } \\
{[\mathrm{MW}]}\end{array}$ & $\begin{array}{l}\text { Efficiency a) } \\
{[\%]}\end{array}$ & Source & Module name & Year \\
\hline $\begin{array}{l}\text { (Alkaline) } \\
\text { elektrolysis }\end{array}$ & $0.6-1.2$ & $1 \mathrm{Nm}^{3} \mathrm{H}_{2}$ & 70 & Pehnt 2002 & & 2002 \\
\hline a) In relation of heating value.
\end{tabular}

Table 10-19:

Sources of the LCA modules for production of hydrogen using renewables

\begin{tabular}{|l|c|l|l|l|l|}
\hline Process & $\begin{array}{l}\text { Output } \\
{[\mathrm{MW}]}\end{array}$ & $\begin{array}{l}\text { Functional } \\
\text { unit }\end{array}$ & $\begin{array}{l}\text { Efficiency } \\
{[\%]}\end{array}$ & Source & Comments \\
\hline $\begin{array}{l}\text { Solar thermal } \\
\text { (type SEGS) }\end{array}$ & 200 & $1 \mathrm{kWh}$ & 17.6 & $\begin{array}{l}\text { Viebahn 2004, } \\
\text { May 2005 }\end{array}$ & \\
\hline $\begin{array}{l}\text { Wind } \\
\text { offshore }\end{array}$ & 5 & $1 \mathrm{kWh}$ & Pick 1998 & $\begin{array}{l}\text { Onshore plant equated with offshore } \\
\text { after Chataignere and le Boulch (2003) }\end{array}$ \\
\hline
\end{tabular}

Table 10-20: Reference power plant for renewables 
- $\mathrm{CO}_{2}$ emissions: With gasification by means of IGCC the coal supply chain contributes $5 \%$ to the $\mathrm{CO}_{2}$ emissions while the plant itself is responsible for $95 \%$ of the emissions. With a $\mathrm{CO}_{2}$ capture rate of $88 \%$ total $\mathrm{CO}_{2}$ emissions are only reduced by about $81 \%$. Of the remaining emissions $6 \%$ originate from capture and $25 \%$ from the supply chain.

- Greenhouse gas emissions: As well as $\mathrm{CO}_{2}$ emissions, methane emissions also contribute to the supply chain, with the result that their share of greenhouse gas emissions (13\%) is higher than that of $\mathrm{CO}_{2}$ emissions. $\mathrm{CO}_{2}$ capture reduces overall greenhouse gas emissions by $72 \%$. Of the remaining emissions again $6 \%$ originate from capture and $47 \%$ from the supply chain. This shows again the need to reduce supply chain emissions too if we are to achieve a 'clean coal' solution.

- Cumulative energy demand: $\mathrm{CO}_{2}$ capture causes cumulative energy demand to rise by $11 \%$, most of which is attributable directly to capture.

\section{Natural Gas Steam Reforming}

The situation is somewhat different for the natural gas steam reforming models (see Fig. 10-28).

- $\mathrm{CO}_{2}$ emissions: In natural gas steam reforming the natural gas supply chain contributes $10 \%$ to the $\mathrm{CO}_{2}$ emissions while plant itself is responsible for $90 \%$. Operating emissions comprise the direct emissions from the plant and indirect emissions attributable to use of electricity from the grid. If we consider the models selected for $\mathrm{CO}_{2}$ capture, only those emissions that occur directly in the plant can be captured (and efficiently only those $\mathrm{CO}_{2}$ emissions that are present in the synthesis gas). Emissions caused by increased use of electricity are not captured. So with a net $\mathrm{CO}_{2}$ capture rate of $53 \%$ (ZSW) overall emissions are only reduced by $39 \%$; with a net $\mathrm{CO}_{2}$ capture rate of $71 \%$ (DOE) the figure is $52 \%$. Of the remaining emissions $11 \%$ (ZSW) or $14 \%$ (DOE) are attributable to capture. The share of the supply chain rises to $18 \%$ (ZSW) or $22 \%$ (DOE).

- Greenhouse gas emissions: As well as the $\mathrm{CO}_{2}$ emissions, methane emissions also contribute to the supply chain, so the supply chain share of greenhouse gas emissions (without capture) (15\%) is half as much again as the $\mathrm{CO}_{2}$ emissions (10\%). Overall greenhouse gas emissions are reduced by the $\mathrm{CO}_{2}$ capture process by $36 \%(\mathrm{ZSW})$ or $49 \%$ (DOE). Of the remaining emissions $10 \%$ (ZSW) or $13 \%$ (DOE) are attributable to capture. The share of the supply chain rises to $25 \%$ (ZSW) or $30 \%$ (DOE).

- Cumulative energy demand: $\mathrm{CO}_{2}$ capture causes cumulative energy demand to rise by $22 \%$ (ZSW) or $20 \%$ (DOE), most of which is directly attributable to capture. Contributing factors here are the reduction in efficiency and the additional electricity required.

Overall it was found that the DOE model has a higher external electricity requirement and because all the steam produced is used internally no credit can be given. But through the higher efficiency (or lower loss
Fig. 10-27:

Comparison of $\mathrm{CO}_{2}$ emissions, total greenhouse gases and cumulative energy demand for coal gasification by IGCC without and with CCS

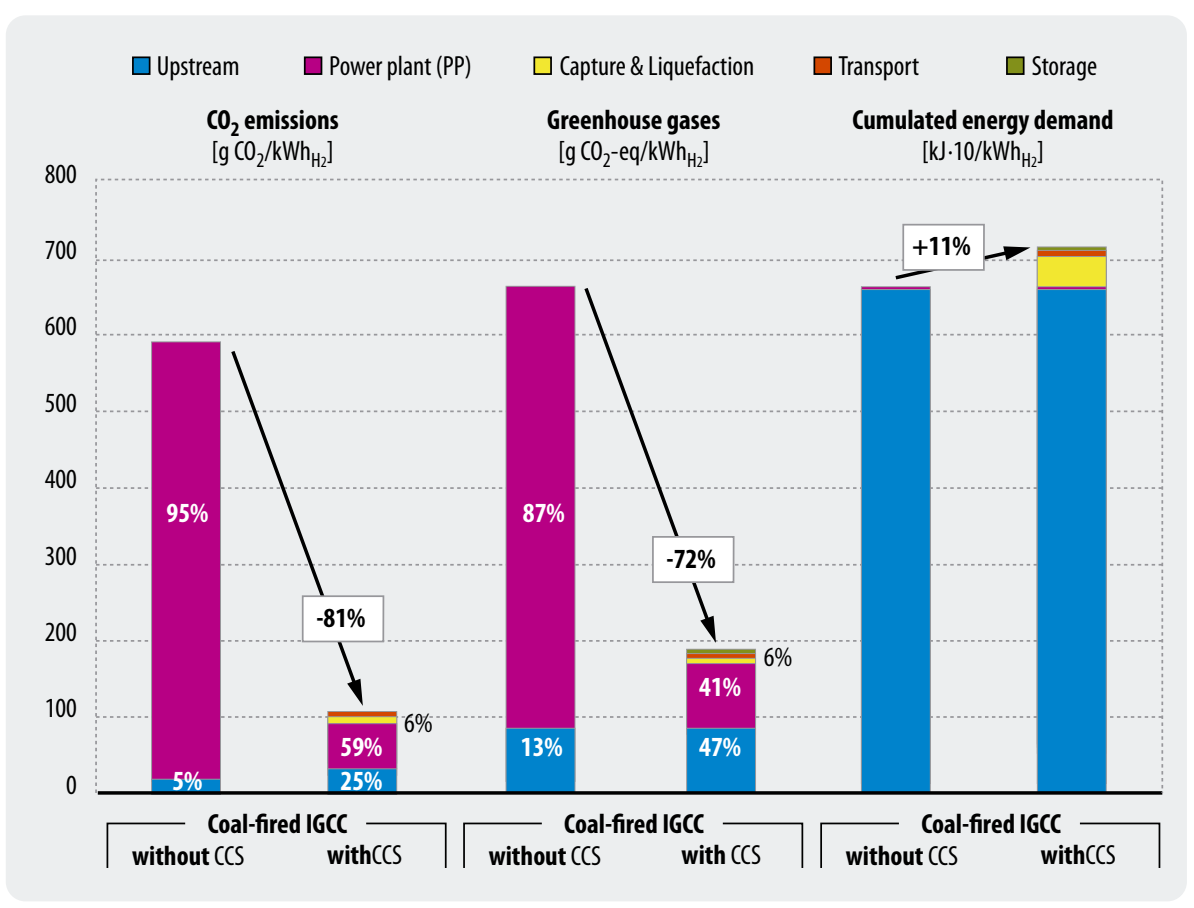




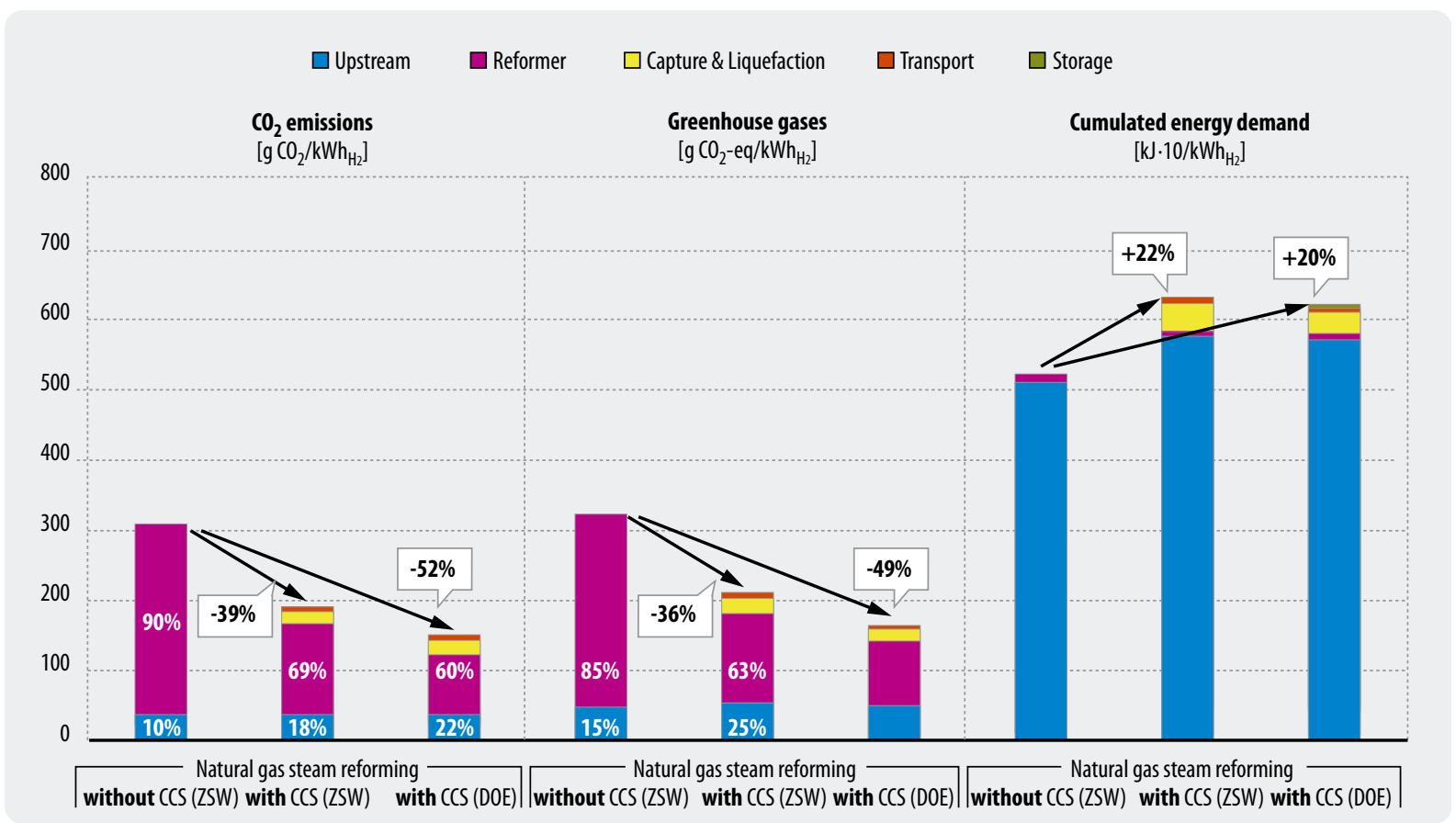

Fig. 10-28: Comparison of $\mathrm{CO}_{2}$ emissions, total greenhouse gases and cumulative energy demand for natural gas steam reforming (ZSW and DOE methods) without and with CCS

of efficiency) that is possible and the higher capture rate, these drawbacks - compared to the ZSW model - are more than balanced out, with the result that overall greater emissions reductions and lower cumulative energy demand are possible.

\subsubsection{Plant Using Renewables}

The processes using renewables (electrolysis with electricity from solar thermal and wind power) are not described in detail here. For details see the direct comparison with hydrogen production from fossil fuels (section 10.10).

\subsection{Comparison of Hydrogen Production}

\section{Systems}

\subsubsection{Greenhouse Gases and Cumulative Energy Demand}

Fig. 10-29 compares the fossil fuel processes with electrolysis using solar thermal and wind power. Although in the reference case hydrogen production from coal produces considerably higher $\mathrm{CO}_{2}$ emissions than natural gas steam reforming, when $\mathrm{CO}_{2}$ capture is applied it achieves (with $114 \mathrm{~g} \mathrm{CO}_{2} / \mathrm{kWh}_{\mathrm{H} 2}$ ) lower values than natural gas (186 or $145 \mathrm{~g} \mathrm{CO}_{2} / \mathrm{kWh}_{\mathrm{H} 2}$ ). The reason for this is the higher $\mathrm{CO}_{2}$ capture rate with coal gasification.

If we consider greenhouse gases in total, the relationship between coal gasification and reforming changes.
Because of the high methane emissions from the supply chain it is only possible to achieve a reduction to $185 \mathrm{~g}$ $\mathrm{CO}_{2}$ equivalent/ $\mathrm{kWh}_{\mathrm{H} 2}$ for coal, whereas the natural gas processes achieve 205 or $164 \mathrm{~g} \mathrm{CO}_{2}$ equivalent $/ \mathrm{kWh}_{\mathrm{H} 2}$. So the figure for coal gasification lies between those for the two natural gas processes. In terms of cumulative energy demand, coal gasification with $7.2 \mathrm{MJ} / \mathrm{kWh}_{\mathrm{H} 2}$ does worse than the two natural gas processes (6.29 and 6.17 $\mathrm{MJ} / \mathrm{kWh}_{\mathrm{H} 2}$ ).

With hydrogen production from renewables both $\mathrm{CO}_{2}$ emissions and overall greenhouse gas emissions are about 3-6 \% of the values for fossil fuel processes. Cumulative energy demand is 3-4\% of the fossil fuel systems.

\subsubsection{Other Impact Categories}

In the other impact categories the renewable processes do not score as well as with greenhouse gas emissions, but still remain far below the values for the fossil fuel systems they are compared with. Fig. 10-30 shows this for the examples of photo-oxidant formation, acidification and eutrophication. The emissions involved are caused largely by the manufacture of the power plant itself, but in the wind power alternative the manufacture of electrolysers also takes a share of about $10 \%$. With the solar version the long transmission distance by high-voltage line also contributes about $10 \%$ to emissions. The relatively high values in the acidification category are caused by the $\mathrm{SO}_{\mathrm{x}}$ emissions in steelmaking, which are significant because of the relatively high consumption of steel in both wind farms and solar thermal plant. 
Fig. 10-29:

Comparison of absolute $\mathrm{CO}_{2}$ emissions, total greenhouse gases and cumulative energy demand for hydrogen production using fossil fuels and renewables

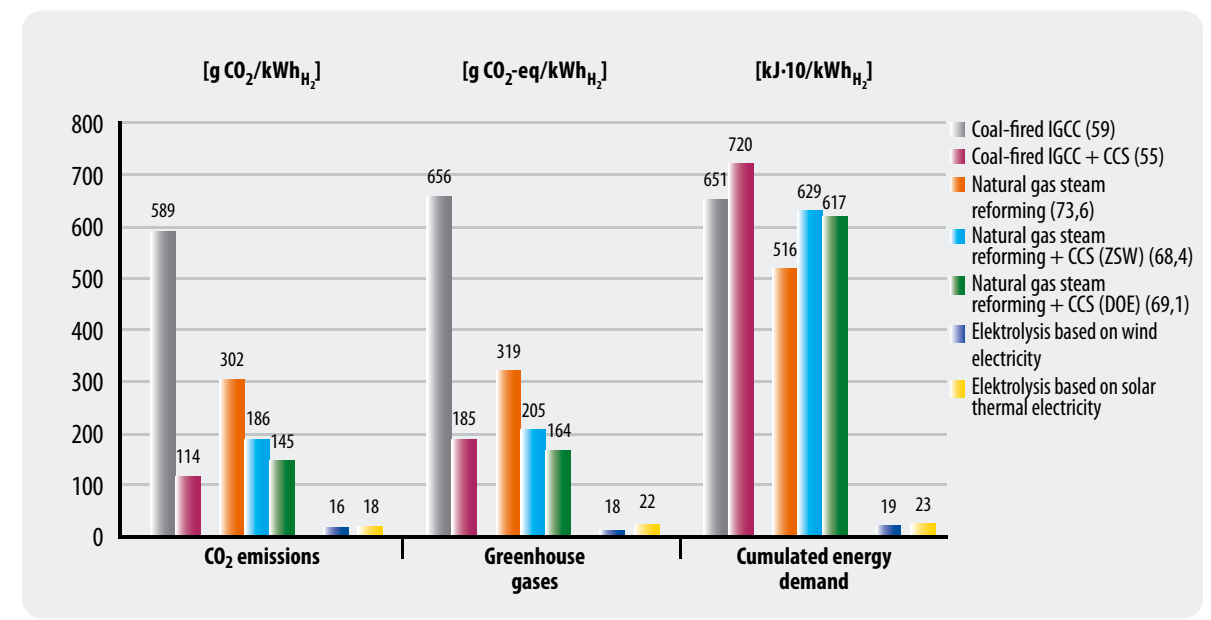

\subsection{Conclusions for Hydrogen Production}

- As with the case of power stations, we cannot speak of ' $\mathrm{CO}_{2}$-free' or 'zero- $\mathrm{CO}_{2}$ ' production. It would be more pertinent to use the term 'low- $\mathrm{CO}_{2}$ ' hydrogen. Even with a capture rate of $88 \%$ (coal gasification) it will only be possible to reduce $\mathrm{CO}_{2}$ emissions by $81 \%$.

- Depending on the different methods of ZSW and DOE, with natural gas steam reforming reduction rates of $\mathrm{CO}_{2}$ emissions of only $39 \%$ and $52 \%$ and of greenhouse gas emissions of 36 and $49 \%$ respectively are possible. This is because only the $\mathrm{CO}_{2}$ emissions from the synthesis gas can be captured at reasonable cost but not those that occur beforehand during natural gas combustion.
- Total greenhouse gas emissions can only be reduced less than proportionally because of the considerably increased primary energy consumption and the relatively high methane emissions associated with raw material extraction (coal mining) and transport (natural gas). These have a disproportionate influence on the greenhouse effect (supply chain share of $47 \%$ for coal gasification with CCS and $25 \%$ or $30 \%$ for natural gas steam reforming with CCS).

- According to the literature the $\mathrm{CO}_{2}$ capture process itself as a whole requires less additional energy than in the case of electricity generation. But the costs of transport and storage remain.
Fig. 10-30:

Comparison of impact categories photooxidant formation, acidification and eutrophication for hydrogen production using fossil fuels and renewables

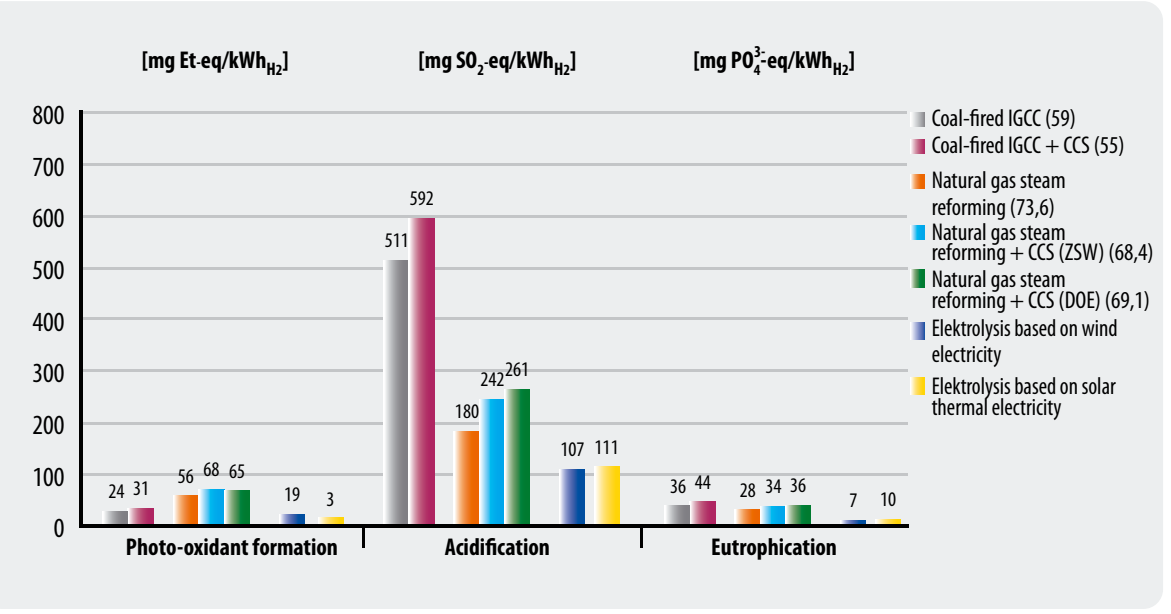




\section{Chapter 11 \\ Other Ecological Assessment Criteria for CCS}

The previous chapter presented LCAs for $\mathrm{CO}_{2}$ capture (using various technologies), liquefaction and transport. As we showed there, environmental problems associated with the other impact categories - such as acidification and eutrophication of soils and water bodies, summer smog and particle emissions - increase too, in particular because of the large amount of energy required for $\mathrm{CO}_{2}$ capture. However, when assessing a field of technology as complex as $\mathrm{CO}_{2}$ capture we need to cover and assess much more than the criteria included in an LCA. That expanded ecological perspective is addressed in the present chapter.

Concern about preserving the natural environment is increasingly reflected in the self-image of many businesses and individuals, as well as politicians and other actors in society. It has also found its way into environmental law, which treats the natural habitats of flora and fauna as goods worth preserving. A broad-based examination of the different $\mathrm{CO}_{2}$ sequestration paths must therefore be conducted in that light. Anyway, given the influence environmental organisations have today, environmentally unacceptable solutions would be difficult to implement at all. Public opinion - partly influenced by the environmental lobby - is a decisive factor here.

The safety aspect should be seen as complementary to the ecological. Whereas ecological risks - as understood here - relate to flora and fauna, safety in general also addresses the hazards for people. One concept of safety applies primarily to specific one-off events; i.e., in connection with direct risks such as accidents caused by sudden pipeline leaks. The second meaning of the term 'safety' is defined in terms of long-term safety and thus poses the question of how 'safe' storage options are; i.e., how efficiently and permanently $\mathrm{CO}_{2}$ will remain in the sink. This aspect was already touched on in the discussion of storage options.

\section{$11.1 \mathrm{CO}_{2}$ Capture}

The ecological problems of the capture phase were largely dealt with in the LCAs. An issue not included there was the significant amount of additional space needed at power station sites - e.g. for installing $\mathrm{CO}_{2}$ flue gas scrubbers.

\section{$11.2 \mathrm{CO}_{2}$ Transport}

The conceivable transport methods for $\mathrm{CO}_{2}$ are: pipeline (liquid or supercritical $\mathrm{CO}_{2}$ ), rail or road tanker, ship (liquid $\mathrm{CO}_{2}$ or the special case of dry ice for deep ocean storage). Another special case is ocean seeding, where the seeding agent (iron sulphate or iron oxide) would be transported to the place of dispersal in the ocean. The possible risks of the different transport options are discussed below.

\section{Transport of liquid or solid $\mathrm{CO}_{2}$ by road, rail or ship}

The extent to which the transport network (road or rail) would have to be expanded for vehicle transport is not yet apparent. But this is the variable on which the direct ecological consequences ultimately depend (in terms of land use, habitat loss, etc.). Increased pollution emissions from the vehicles (diesel combustion in lorries and locomotives or electricity production for locomotives) would affect ecosystems and people directly. Anyway, road or rail transport appears relevant only for the start-up phase of a $\mathrm{CO}_{2}$ infrastructure.

In the case of large-scale marine $\mathrm{CO}_{2}$ storage, increased release of pollutants from ships (which usually run on heavy fuel oil) would probably lead to perceptible harm to ecosystems. But there are not yet any specific calculations on this.

Transport of solid $\mathrm{CO}_{2}$ (dry ice) is fairly safe. For example, after an accident dry ice can be recovered almost without danger and reloaded. However, producing dry ice from captured $\mathrm{CO}_{2}$ (to store in the deep oceans simply by tipping it into the sea) is an extremely energyintensive process (see chapter 6) where all the ecological impact associated with increased use of energy would have to be taken into account. It can be assumed that dry ice will not represent a relevant transport option.

\section{Transport by $\mathrm{CO}_{2}$ pipeline}

Building pipelines disrupts the ecosystems they pass through. During operation leakages or breakages suddenly releasing large amounts of $\mathrm{CO}_{2}$ could have grave local effects on nearby ecosystems because in high concentrations $\mathrm{CO}_{2}$ acts as a respiratory toxin. After completion of construction and following closure it is not always possible to fully restore the original ecosystems. 


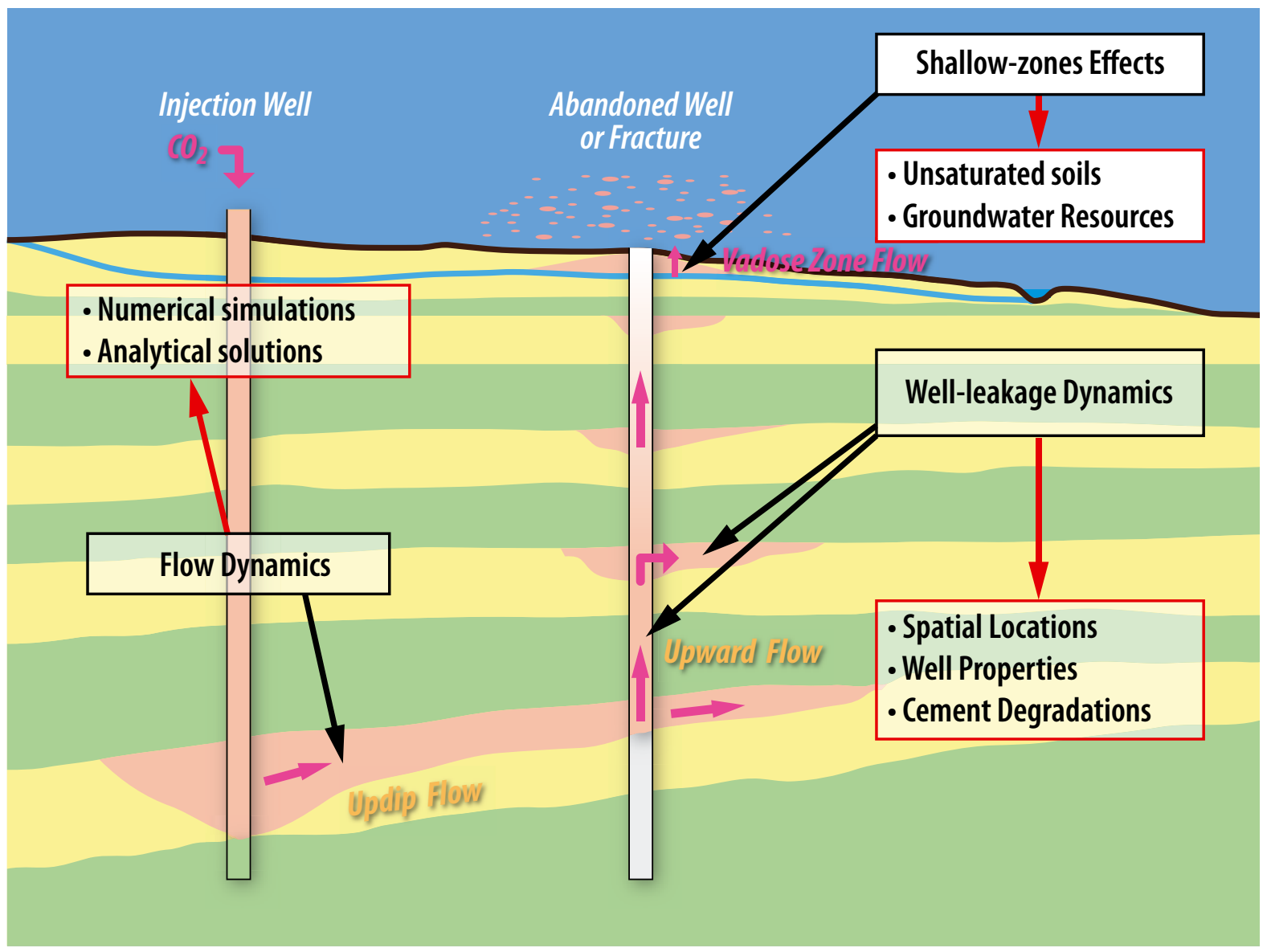

Fig. 11-1: $\mathrm{CO}_{2}$ injection wells and possible leakages (Celia and Scherer 2004)

Pipelines are associated with various risks. Accidents (e.g. breakage) can occur through material fatigue, but can also be caused by external influences such as vehicle collision or deliberate destruction. Both cases would lead to $\mathrm{CO}_{2}$ escaping, but a quantitative assessment of the risks cannot be provided here. However, the damage would probably be small, and current knowledge and experience with natural gas pipelines suggests that such incidents are rather unlikely.

\section{Transport of iron sulphate or iron oxide for ocean seeding}

Iron sulphate and iron oxide occur as by-products in numerous industrial processes. So depending on the scale on which ocean seeding was conducted it might be possible to supply the seeding agent without additional energy use. It is not presently possible to say anything more precise about this option, because the efficiency of ocean seeding has not been sufficiently clarified. If ocean seeding was introduced on a large scale, increased shipping could affect ecosystems (including regions away from the major shipping routes). Transporting iron compounds presents no particular problems in terms of transport safety. Protective clothing would be required when applying the substances.

\subsection{Storing $\mathrm{CO}_{2}$}

\section{Geological options}

All the geological storage options are subject to the risk of leaks through unsealed or inadequately sealed boreholes, tunnels and shafts (oil and gas fields, coal mines), through new or previously unknown faults and fractures in the storage formation, or through seismic activity. All of these can allow the carbon dioxide to escape to the surface or to enter other geological strata, such as strata containing groundwater (see Fig. 11-1). This safety aspect of long-term stability is also important in relation to possible recognition of $\mathrm{CO}_{2}$ storage projects under the clean development mechanism of the Kyoto Protocol (see also chapter 15).

All living creatures (human, animal, plant, microorganism) above and below the earth's surface would be affected by the toxic effects of $\mathrm{CO}_{2}$ in high concentrations.

\section{a. Deep saline aquifers}

Storing $\mathrm{CO}_{2}$ in porous salt-water-bearing strata requires deep sedimentary basins. These structures have so far generally only been explored in the vicinity of hydrocarbon deposits so there is a lack of comprehensive 
data and assessments of their petrophysical properties. This applies, for example, to pore volume (which determines gas saturation), fracture and deformation processes, and chemistry (tightness of overlying layers), all of which are required to estimate the storage capacities of these geological structures and their safety risks in relation to possible leakage (May et al. 2003). Possible effects on microbiological processes in the geological formations are also still unclarified. Furthermore, the introduction of $\mathrm{CO}_{2}$ leads to acidification of the water in the aquifer. Through its corrosive properties the acidic water could cause changes to the surrounding strata (especially carbonates) and to unprotected borehole seals (Ploetz 2002).

\section{b. Exhausted oil and gas fields}

When considering this option it should be noted that carbon dioxide possesses different chemical properties than substances stored to date. Globally, exhausted gas fields offer greater capacity than oil fields (cf. Table 7-2 and Fig. 7-2). As mentioned above, these options are subject to ecological restrictions to the extent that existing boreholes penetrating the covering layers could serve as escape paths for the $\mathrm{CO}_{2}$ if sealing measures fail (May et al. 2003). There is no currently known type of cement that can be continuously exposed to high concentrations of $\mathrm{CO}_{2}$ without corroding (Greenpeace 2004).

c. Deep unmineable coal seams (currently uneconomic)

This option poses the ecological risk of the extracted methane (which has a considerably higher greenhouse gas potential than $\mathrm{CO}_{2}$ ) escaping.

\section{d. Closed coal mines}

The risk of gas escaping through leaks in densely populated areas (e.g. the Ruhr region in Germany) is very high because the covering layers are often thin, there are complex branching tunnel and shaft systems with connections to still operating areas, and sometimes there are also 'forgotten' tunnels and unrecorded subsidence (Ploetz 2002).

\section{Marine options}

For all marine storage options it should be noted that to date scientific investigation of the deep sea regions in general and their ecosystem structures has been very fragmentary, and the effects of $\mathrm{CO}_{2}$ storage in these areas have so far only been studied in small-scale experiments or computer simulations. For these reasons, and because the physical state of the $\mathrm{CO}_{2}$ can change as it sinks, any assessment of consequences can only be provisional.
In particular, the issue of seawater acidification should be noted, with its negative influences on physical/ chemical and metabolic/physiological processes in both the abiotic and biotic spheres (Germanwatch 2004). As acidification increases calcifying organisms add less calcium carbonate to their shells, causing them to become thinner. Eventually acidification can even lead to the dissolution of calcium carbonate structures. This would affect shellfish, corals and many plankton organisms such as Foraminifera; Pteropoda are already affected (Feely et al. 2004; Wolf-Gladrow 2004; WolfGladrow et al. 1999). Because many marine organisms react very sensitively to changes in $\mathrm{pH}$, it is doubtful whether the marine biota would be capable of responding quickly enough to a fast anthropogenic change in living conditions, because adaptation to changing environmental conditions usually occurs over much longer periods (Knutzen 1981; Omori et al. 1998; Yamada and Ikeda 1999). If these organisms were to disappear food chains would be severed (or at least changed), with as yet unforeseeable consequences.

Oceanic storage would not lead to permanent sequestration of the $\mathrm{CO}_{2}$. If $\mathrm{CO}_{2}$ were to be dissolved in the ocean depths it would begin to escape back into the atmosphere after a few hundred years at the latest, when the water masses involved came into contact with the atmosphere again.

An induced algal bloom resulting from large-scale iron seeding would also have unforeseeable effects on marine ecosystems. A large part of the algae would be ingested by krill, for example, and thus pass up the food chain so that in the medium term the $\mathrm{CO}_{2}$ would be released again (e.g. through breathing). The dead remainder would sink to the depths where it would be degraded (consuming oxygen) into gases such as methane and nitrous oxide $\left(\mathrm{N}_{2} \mathrm{O}\right)$ which contribute proportionally much more to the greenhouse effect than does $\mathrm{CO}_{2}$.

An increased photosynthesis rate of phytoplankton would lead to warming of the oceanic surface waters with consequences for oceanic circulation. This would also affect atmospheric chemistry and climate, for example because the phytoplankton produces dimethyl sulphide which forms cloud condensation nuclei (Lawrence 2002).

\section{Other options}

Biomass: Primary forests and wetlands are almost impossible to expand as sinks because many of the areas are limited in extent and threatened. So the foremost goal must be to protect the diversity of existing virgin and primary forests and to manage them sustainably. An end must also be put to clear-felling because the carbon already stored in old trees is quickly released, e.g. via the paper industry, which uses much of such timber (Forum Umwelt und Entwicklung 2001). Mediumterm storage could be achieved by using timber for construction because wooden elements can last 100 to 150 years (Pro REGENWALD 1998). 
Through their fast growth tree plantations quickly bind large quantities of $\mathrm{CO}_{2}$ (between 1.4 and $15 \mathrm{t}$ carbon/ ha, natural forests $7-8 \mathrm{t} / \mathrm{ha}$ ), but after just a few years or decades growth drops considerably and all that is left is depleted soil that is scarcely of any use for further cultivation.

Furthermore, the planting of fast-growing, non-native monocultures leads to the reduction and displacement of the natural species. Monocultures are also very susceptible to pests, and the application of fertilisers and pesticides worsens the greenhouse gas balance (Pro REGENWALD 1998). Plantations often compete for land with food production and in the process displace small-scale agricultural structures, above all in developing countries. They also exacerbate soil erosion and cause groundwater levels to fall through irrigation measures. Planting genetically modified trees has been proposed in connection with $\mathrm{CO}_{2}$ storage. This would risk altering existing ecosystems through gene transfer with as yet unknown effects (Umweltinstitut München 2004). Storing $\mathrm{CO}_{2}$ in trees represents only a temporary storage option.

Absorption in minerals: As things currently stand, binding $\mathrm{CO}_{2}$ to magnesium silicate requires a very large energy input and large quantities of water for the reaction, when the whole process is considered. Capturing and binding the $\mathrm{CO}_{2}$ from a $1 \mathrm{GW}$ power station would require $400 \mathrm{MW}$ of heat energy (Kohlmann 2001). The land used for mining the magnesium silicate and the emissions involved in transporting and disposing of the reaction product are problematic factors (Herzog 2002).

\subsection{A Comparison of Strategies}

Table 11-2 summarises the ecological effects of the CCS processes and compares them with renewables and energy efficiency. Both strategy options - renewables and energy efficiency - bear ecological burdens that have to be taken into account for integrated technology assessment. The examples of wind power and solar thermal power serve to illustrate the point:

Wind farms can alter local biospheres because both their foundations and the required access roads represent interventions in ecosystems. Offshore construction leads to the death of local benthic (bottom-living) fauna during the building phase. Towers create new habitats (artificial reefs), which change the composition of flora and fauna. However, this is often regarded as a positive effect because the area within the wind farm has weaker currents and no fishing and is used by many animals for resting and reproduction (nursing grounds).
The installation of solar thermal power plant, for example in Spain or in desert regions of North Africa, could cause harm to habitats because the great amount of space required would change conditions on the ground. This change is brought about not, however, by soil sealing, but primarily by the shading of the ground.

The broad range of ecological effects is listed in Table 11-1. 
Table 11-1: Overall assessment of various climate protection options (criterion: ecological impact)

\begin{tabular}{|c|c|c|c|}
\hline Technology & $\begin{array}{l}\text { During construction/ } \\
\text { introduction (short-term) }\end{array}$ & $\begin{array}{c}\text { Ecological impact } \\
\text { During use }\end{array}$ & $\begin{array}{l}\text { After use } \\
\text { (long-term) }\end{array}$ \\
\hline \multicolumn{4}{|c|}{$\mathrm{CO}_{2}$ capture and storage } \\
\hline Process chain in general & & $\begin{array}{l}\text { - Energy consumption: seriously increased for all options, } \\
\text { consequent increase in all material flows and associ- } \\
\text { ated strain on ecosystems } \\
\text { - Increased demand for coal: increased ecological stress } \\
\text { through mining and increased shipping } \\
\text { - Increased other emissions: e.g. methane and } \mathrm{N}_{2} \mathrm{O} \text {, } \\
\text { atmospheric pollutants, dust } \\
\text { - Increased demand for natural gas: increased produc- } \\
\text { tion and pipeline transport increases existing safety } \\
\text { risks }\end{array}$ & \\
\hline Capture processes & & $\begin{array}{l}\text { - Considerable increase in fuel use in comparison to } \\
\text { existing processes through longer process chain (flue } \\
\text { gas scrubbing) or introduction of new process lines } \\
\text { (IGCC, oxyfuel) (for consequences see above) }\end{array}$ & \\
\hline Flue gas scrubbing & $\begin{array}{l}\text { - Greater material require- } \\
\text { ment because flue gas } \\
\text { scrubbing requires numer- } \\
\text { ous additional components }\end{array}$ & $\begin{array}{l}\text { - The most energy-intensive method of } \mathrm{CO}_{2} \text { capture, } \\
\text { increases energy required by up to } 40 \% \text {; all associated } \\
\text { environmental impacts increase accordingly } \\
\text { - Possible consequences of release of toxic scrubbing } \\
\text { agent }\end{array}$ & \\
\hline $\begin{array}{l}\text { Integrated gasification } \\
\text { combined cycle (IGCC) }\end{array}$ & $\begin{array}{l}\text { - Additional material } \\
\text { requirement through intro- } \\
\text { duction of IGCC not yet } \\
\text { assessable }\end{array}$ & $\begin{array}{l}\text { - Apart from increased energy requirement and associ- } \\
\text { ated environmental impacts (see above) negative eco- } \\
\text { logical consequences will not be much greater than for } \\
\text { existing conventional power stations }\end{array}$ & \\
\hline Oxyfuel process & $\begin{array}{l}\text { - Additional material } \\
\text { requirement through intro- } \\
\text { duction of the oxyfuel proc- } \\
\text { ess not yet estimable }\end{array}$ & $\begin{array}{l}\text { - Ecological consequences for the oxyfuel process itself } \\
\text { cannot yet be estimated because the process is still } \\
\text { under development. Apart from increased energy } \\
\text { requirement and associated environmental impacts } \\
\text { (see above) negative ecological consequences will not } \\
\text { be much greater than for existing conventional power } \\
\text { stations }\end{array}$ & \\
\hline Transport & & $\begin{array}{l}\text { - Transporting } \mathrm{CO}_{2} \text { in any form is energy-intensive and } \\
\text { therefore increases material flows; especially when } \\
\text { conditioning the } \mathrm{CO}_{2} \text { (compressing, liquefying) }\end{array}$ & \\
\hline Pipeline & $\begin{array}{l}\text { - Intervention in all ecosys- } \\
\text { tems along pipeline route }\end{array}$ & $\begin{array}{l}\text { - Leaks and accidents (breakage etc.) can lead to } \\
\text { elimination of ecosystems }\end{array}$ & $\begin{array}{l}\text { - Restoration of original ecosystems along } \\
\text { closed pipeline route is questionable }\end{array}$ \\
\hline $\begin{array}{l}\text { Dry ice: by ship and/ } \\
\text { or rail }\end{array}$ & & - Producing dry ice is extremely energy-intensive & $\begin{array}{l}\text { - Rail: none, because existing transport routes } \\
\text { used } \\
\text { - Ship: destruction of ecosystems through } \\
\text { increased release of pollutants into water }\end{array}$ \\
\hline $\begin{array}{l}\text { Iron sulphate or oxide, } \\
\text { transport by ship }\end{array}$ & & $\begin{array}{l}\text { - Energy-intensive process, resulting strain on } \\
\text { ecosystems }\end{array}$ & $\begin{array}{l}\text { - Owing to increase in shipping possible } \\
\text { destruction of ecosystems through increased } \\
\text { release of pollutants into water }\end{array}$ \\
\hline
\end{tabular}




\begin{tabular}{|c|c|c|c|}
\hline \multirow[b]{2}{*}{ Technology } & \multicolumn{3}{|c|}{ Ecological impact } \\
\hline & $\begin{array}{l}\text { During construction/ } \\
\text { introduction (short-term) }\end{array}$ & During use & $\begin{array}{l}\text { After use } \\
\text { (long-term) }\end{array}$ \\
\hline \multicolumn{4}{|l|}{ Storage } \\
\hline \multicolumn{4}{|l|}{$\begin{array}{l}\text { Terrestrial } \\
\text { storage option }\end{array}$} \\
\hline Forestation & $\begin{array}{l}\text { - Creation of plantations may } \\
\text { involve clearing of natural } \\
\text { woodland and trees }\end{array}$ & $\begin{array}{l}\text { - Plantations generally store less } \mathrm{C}_{2} \text { than mixed forests } \\
\text { and natural woodland } \\
\text { - Monocultures compete with food production } \\
\text { - Monocultures are susceptible to disease and pests } \\
\text { - Primary forest sinks are practically unexpandable } \\
\text { - Various woodland ecosystems have different levels of } \\
\text { potential storage capacity } \\
\text { - Use of genetically modified (GM) plants could harm } \\
\text { wild species or displace them with monocultures }\end{array}$ & $\begin{array}{l}\text { - Forestation should be seen more as a } \\
\text { temporary storage option with delayed } \mathrm{CO}_{2} \\
\text { release. } \mathrm{CO}_{2} \text { released later contributes to } \\
\text { climate change because it is fixed only for a } \\
\text { few decades during the tree's growth phase } \\
\text { - Biomass/algae: strictly limited potential after } \\
\text { consideration of ethical and ecological aspects }\end{array}$ \\
\hline \multicolumn{4}{|l|}{$\begin{array}{l}\text { Geological } \\
\text { storage options }\end{array}$} \\
\hline Closed coal mines & & $\begin{array}{l}\text { Ecosystems may be strongly endangered through high } \\
\text { leakage risk }\end{array}$ & $\begin{array}{l}\text { - Ecosystems may be strongly endangered } \\
\text { through high leakage risk }\end{array}$ \\
\hline $\begin{array}{l}\text { Deep coal seams } \\
\text { (unmineable) }\end{array}$ & & - Escaping methane may increase the greenhouse effect & - Permanent storage of $\mathrm{CO}_{2}$ not yet proven \\
\hline Saline aquifers & & - If insertion process is safe risks are low & $\begin{array}{l}\text { - Long-term stability of } \mathrm{CO}_{2} \text { in aquifers not yet } \\
\text { adequately clarified }\end{array}$ \\
\hline Salt caverns & & - Danger of sudden emptying if leakage occurs & - None, as long as leaks can be prevented \\
\hline Mineralisation & $\begin{array}{l}\text { Mining of raw materials } \\
\text { (reactants) uses land and } \\
\text { causes destruction of eco- } \\
\text { systems }\end{array}$ & $\begin{array}{l}\text { - High energy consumption for mineralisation processes } \\
\text { and transport } \\
\text { - High transport intensity }\end{array}$ & $\begin{array}{l}\text { - Large land requirement for depositing } \\
\text { minerals displaces ecosystems }\end{array}$ \\
\hline \multicolumn{4}{|l|}{ Marine storage options } \\
\hline Induced algae blooms & & $\begin{array}{l}\text { - Surface waters: possible shifts in ecosystems in favour } \\
\text { of other species } \\
\text { - Warming of surface waters alters stratification, changes } \\
\text { or even eliminates ecosystems } \\
\text { - Seabed: degradation of sinking algae consumes oxygen } \\
\text { creating low- } \mathrm{O}_{2} \text { or } \mathrm{O}_{2} \text {-free zones. Consequence: elimi- } \\
\text { nation of ecosystems }\end{array}$ & $\begin{array}{l}\text { - Long-term effects on ecosystems not yet } \\
\text { predictable }\end{array}$ \\
\hline $\begin{array}{l}\text { Physical dissolution by } \\
\text { pumping into seawater }\end{array}$ & & $\begin{array}{l}\text { - Long-term use would reduce the } \mathrm{pH} \text { of seawater, } \\
\text { harming ecosystems globally; calcifying organisms are } \\
\text { affected first } \\
\text { - Delayed re-release of } \mathrm{CO}_{2}\end{array}$ & $\begin{array}{l}\text { - Long-term application lowers pH of sea water, } \\
\text { harming ecosystems globally }\end{array}$ \\
\hline Sinking dry ice & & $\begin{array}{l}\text { - Organisms die in vicinity of sunk dry ice shipments } \\
\text { - Delayed re-release of } \mathrm{CO}_{2}\end{array}$ & $\begin{array}{l}\text { - Organisms die in vicinity of sunk dry ice } \\
\text { shipments }\end{array}$ \\
\hline $\begin{array}{l}\text { Creation of } \mathrm{CO}_{2} \text { lakes on } \\
\text { ocean floor }\end{array}$ & & $\begin{array}{l}\text { - Organisms die in vicinity of lakes } \\
\text { - Extensive destruction of whole ecosystems through } \\
\text { possible slippage of sediments and subsequent uncon- } \\
\text { trolled spread of liquid } \mathrm{CO}_{2}\end{array}$ & $\begin{array}{l}\text { - Organisms die in vicinity of lakes } \\
\text { - Extensive destruction of whole ecosystems } \\
\text { through possible slippage of sediments and } \\
\text { subsequent uncontrolled spread of liquid } \mathrm{CO}_{2}\end{array}$ \\
\hline
\end{tabular}




\begin{tabular}{|c|c|c|c|}
\hline \multirow[b]{2}{*}{ Technology } & \multicolumn{3}{|c|}{ Ecological impact } \\
\hline & $\begin{array}{l}\text { During construction/ } \\
\text { introduction (short-term) }\end{array}$ & During use & $\begin{array}{l}\text { After use } \\
\text { (long-term) }\end{array}$ \\
\hline \multicolumn{4}{|c|}{ Renewables } \\
\hline Wind power onshore & $\begin{array}{l}\text { Foundations and access } \\
\text { roads alter local abiotic } \\
\text { environment, consequen- } \\
\text { tial alteration of natural } \\
\text { biospheres }\end{array}$ & $\begin{array}{l}\text { - Provokes avoidance behaviour in certain bird species, } \\
\text { which may reduce size of habitat } \\
\text { - Noise emissions } \\
\text { - In some cases still flickering shadow problem, but } \\
\text { largely eliminated by modern control technology }\end{array}$ & - None, complete restoration possible \\
\hline \multirow[t]{2}{*}{ Wind power offshore } & \multicolumn{3}{|c|}{$\begin{array}{l}\text { North Sea and Baltic both intensively used for decades with wide-ranging consequences for ecological systems: intense utilisation as fishing grounds } \\
\text { (overfishing), as shipping route (pollutants), as source of raw materials (gravel) and as dumping ground (waste dumping) }\end{array}$} \\
\hline & $\begin{array}{l}\text { - During construction phase } \\
\text { death of benthic communi- } \\
\text { ties locally } \\
\text { - Foundations alter abiotic } \\
\text { environment, consequen- } \\
\text { tial alteration of natural } \\
\text { biospheres } \\
\text { - Underwater noise during } \\
\text { construction of foundations } \\
\text { could damage hearing of } \\
\text { marine mammals (no limits } \\
\text { for noise exposure set yet) }\end{array}$ & $\begin{array}{l}\text { - Provokes avoidance behaviour in certain bird species } \\
\text { - Noise emissions } \\
\text { - Possible positive effects: } \\
\text { - Sheltered zones in and around wind parks can serve as } \\
\text { nursing grounds for fauna } \\
\text { - Foundations and towers serve as artificial reefs and } \\
\text { offer a habitat for numerous groups of organisms (with } \\
\text { consequences further up food chain ) }\end{array}$ & - None, complete restoration possible \\
\hline $\begin{array}{l}\text { Biomass and Biogas } \\
\text { Cultivation of 'energy } \\
\text { plants'(renewable raw } \\
\text { materials) } \\
\text { Residual forest wood } \\
\text { Loppings } \\
\text { Sewage sludge } \\
\text { Liquid manure }\end{array}$ & & $\begin{array}{l}\text { - Cultivation of monocultures reduces species diversity } \\
\text { and so impairs natural control dynamics (applies only } \\
\text { to energy crops) } \\
\text { - Possible prospective use of genetically modified (GM) } \\
\text { plants with unpredictable consequences (applies only } \\
\text { to energy crops) } \\
\text { - Displacement of natural biotopes (applies only to } \\
\text { energy crops) } \\
\text { - Depending on biofuel and combustion process, } \mathrm{SO}_{2} \text { and } \\
\mathrm{NO}_{x} \text { emissions }\end{array}$ & $\begin{array}{l}\text { - Restoration of original ecosystems normally } \\
\text { impossible (e.g. drained wetlands) } \\
\text { - Possible unpredictable consequences of use of } \\
\text { GM organisms }\end{array}$ \\
\hline $\begin{array}{l}\text { Hydropower } \\
\text { a) Small river-flow } \\
\text { plants } \\
\text { b) Large river-flow } \\
\text { plants } \\
\text { c) Reservoir storage }\end{array}$ & $\begin{array}{l}\text { - Grave intervention in sur- } \\
\text { rounding ecosystems }\end{array}$ & $\begin{array}{l}\text { - River-flow plants have extensive ecological and hydro- } \\
\text { logical consequences: changes in quality, quantity and } \\
\text { dynamic of run-off and sediment regime, diverse expe- } \\
\text { rience in dealing with consequences of damming } \\
\text { - Disruption or prevention of fish migration and migra- } \\
\text { tion of macrozoobenthic organisms } \\
\text { - Reservoirs cause direct loss of land and ecosystems }\end{array}$ & $\begin{array}{l}\text { - Depends on post-closure use of hydroelectric } \\
\text { plant, but restoration of original ecosystems } \\
\text { normally impossible }\end{array}$ \\
\hline $\begin{array}{l}\text { Solar radiation I } \\
\text { Photovoltaik } \\
\text { on buildings } \\
\text { on open spaces }\end{array}$ & $\begin{array}{l}\text { - Minimal intervention } \\
\text { during construction phase } \\
\text { - Significant energy and } \\
\text { material requirement } \\
\text { depending on cell tech- } \\
\text { nology }\end{array}$ & $\begin{array}{l}\text { - Land-use intensity can impair ecological habitats, e.g. } \\
\text { through shading }\end{array}$ & $\begin{array}{l}\text { - None on site because complete restoration } \\
\text { possible } \\
\text { - Depending on materials used complex dis- } \\
\text { posal with possible environmental risks, espe- } \\
\text { cially with cadmium telluride and gallium } \\
\text { arsenide cells (Cd and As are heavy metals) }\end{array}$ \\
\hline $\begin{array}{l}\text { Solar radiation II } \\
\text { Solar thermal power } \\
\text { plant }\end{array}$ & & $\begin{array}{l}\text { - Land-use intensity can impair ecological habitats, e.g. } \\
\text { through shading }\end{array}$ & - None, complete restoration possible \\
\hline
\end{tabular}




\begin{tabular}{|c|c|c|c|}
\hline \multicolumn{4}{|c|}{ Ecological impact } \\
\hline Technology & $\begin{array}{l}\text { During construction/ } \\
\text { introduction (short-term) }\end{array}$ & During use & $\begin{array}{l}\text { After use } \\
\text { (long-term) }\end{array}$ \\
\hline $\begin{array}{l}\text { Geothermall } \\
\text { near surface }\end{array}$ & $\begin{array}{l}\text { - Small-scale harm to eco- } \\
\text { systems through drilling }\end{array}$ & & \\
\hline $\begin{array}{l}\text { Geothermal II } \\
\text { deep }\end{array}$ & $\begin{array}{l}\text { - Small-scale harm to eco- } \\
\text { systems through drilling } \\
\text { and access roads }\end{array}$ & - Rather small & \\
\hline $\begin{array}{l}\text { Ocean energy } \\
\text { Tidal, wave power, } \\
\text { currents, temperature } \\
\text { gradients }\end{array}$ & & $\begin{array}{l}\text { - All systems apart from tidal power are currently in } \\
\text { development stage, conclusive estimate of ecological } \\
\text { consequences not yet possible } \\
\text { - Tidal power station: possible impediment to animal } \\
\text { movements }\end{array}$ & - Not yet sufficiently known \\
\hline \multicolumn{4}{|c|}{ Energy efficiency } \\
\hline $\begin{array}{l}\text { Supply side measures: } \\
\text { increase of generation } \\
\text { efficiency }\end{array}$ & $\begin{array}{l}\text { Normally no increase in } \\
\text { ecological stress in com- } \\
\text { parison to less efficient } \\
\text { technologies }\end{array}$ & $\begin{array}{l}\text { - Normally no increase in ecological stress in comparison } \\
\text { to less efficient technologies }\end{array}$ & $\begin{array}{l}\text { - No increase in ecological stress in comparison } \\
\text { with less efficient technologies }\end{array}$ \\
\hline $\begin{array}{l}\text { Demand side measures: } \\
\text { efficiency of technolo- } \\
\text { gies on consumer level }\end{array}$ & $\begin{array}{l}\text { - In some cases greater } \\
\text { material intensity }\end{array}$ & - None & $\begin{array}{l}\text { - Possible increased disposal costs (e.g. insulat- } \\
\text { ing materials) }\end{array}$ \\
\hline
\end{tabular}




\section{Chapter 12}

\section{Development of Electricity and Hydrogen Generation Costs with CCS}

\author{
12.1 Future Electricity Generation Costs Taking \\ Account of Technological Developments, Fuel Price \\ Rises and Cost of $\mathrm{CO}_{2}$ Emission Certificates
}

\subsubsection{Price Trends for Fuel and $\mathrm{CO}_{2}$ Emission Certificates}

If we are to correctly assess long-term investment decisions such as the construction of power stations that will be in operation for decades, one of the things we require are scenarios about future prices of fossil fuels. Such scenarios must cover a sufficiently broad range of possible developments and in particular take into consideration the fact that - as in the case of CCS plant investment decisions may not have to be made until around 2020 but their effect will then last for thirty years and more. In the light of the recent hefty price rises for crude oil that have put an end to a good decade of very low prices and the medium-term prospect of this resource becoming scarce, it would also make sense to consider price developments that would have been regarded as improbable just a few years ago. In fact, these could now prove to be more likely than many of the low-price scenarios that served as the basis of numerous studies over the past five years. Here we use two price trajectories for fossil fuel prices that roughly cover this spectrum. The 'traditional' price scenario referred to as 'EWI 2005' - is based on the scenarios in Energiereport IV (EWI and Prognos 2005). It is based on the comparatively low level of energy prices that still existed around 2002 and describes a price development through to 2030, which we have projected on to 2050 . The second, referred to as 'DLR 2005', includes the most recent price rises and basically projects them into the future. It is based partly on the BMU's assumptions (2004) and has been updated accordingly.

Figure 12-1 compares the past development of the price of crude oil on the basis of annual averages ( $\$ /$ bbl real 2000 prices) with these two price scenarios. Whereas the average price in 2002 was still $\$_{2000} 24 / \mathrm{bbl}$, it rose to $\$_{2000} 36 / \mathrm{bbl}$ in 2004 and by 2005 (average January to September) had already reached $\$_{2000} 48 /$ bbl. Nominal prices have already exceeded the price peaks of around 1982, although the real price level (annual average) is still lower. In 2006 there were already brief price peaks of around $\$_{2000} 70 / \mathrm{bbl}$.
Starting from the price level of 2002, EWI 2005 reaches a real oil price of $\$_{2000} 37 / \mathrm{bbl}$ in 2030 (nominal $\$ 63 /$ bbl) and $\$_{2000} 50 / \mathrm{bbl}$ in 2050 (nominal $\$ 110 / \mathrm{bbl}$ ), so throughout this whole period it is below the 2005 level. In other words, the current oil price would have to fall again considerably to reach those levels. The DLR 2005 scenario starts from the 2005 price level and assumes that there will be a further price increase, but a moderate one. Here a price of $\$_{2000} 65 / \mathrm{bbl}$ (nominal $\$ 110 /$ bbl) is reached in 2030 and $\$_{2000} 72 / \mathrm{bbl}$ (nominal $\$ 160$ / bbl) in 2050 .

For the further discussion the prices of natural gas and coal in particular are significant for power stations. Power stations in Germany are already subject to emissions trading, so future prices for $\mathrm{CO}_{2}$ certificates are also of interest. They currently cost around $€ 15-20 / t$, even though it was originally thought that the first phase of emissions trading (until 2007) would not see prices rising above $€ 10 / \mathrm{t} \mathrm{CO}_{2}$. In both scenarios $\mathrm{CO}_{2}$ prices rise continuously: in EWI 2005 only very slightly, from $€ 5 / \mathrm{t} \mathrm{CO}_{2}$ in 2010 to $€ 15 / \mathrm{t} \mathrm{CO}_{2}$ in 2030 (and projected on to $€ 22.50 / \mathrm{t} \mathrm{CO}_{2}$ in 2050); in DLR 2005 somewhat more steeply, but still relatively moderately, from $€ 7.50 / \mathrm{t} \mathrm{CO}_{2}$ in 2010 to $€ 22.50 / \mathrm{t} \mathrm{CO}_{2}$ in 2030 and $€ 35 / \mathrm{t}$ $\mathrm{CO}_{2}$ in 2050 . In the calculations for electricity generation costs cited in the following discussion these $\mathrm{CO}_{2}$ prices are added to the fuel price according to the carbon content of the fuel.

The resulting power station fuel prices with and without $\mathrm{CO}_{2}$ penalty are summarised in Fig. 12-2 and Table 12-1. In EWI 2005 the 2005 gas price is not reached again until 2025, the coal price not until 2045. A $\mathrm{CO}_{2}$ penalty brings those dates a long way forward, to 2015 and 2010. In the DLR 2005 scenario fuel prices without $\mathrm{CO}_{2}$ penalty in 2020 (the year when the first commercial CCS systems could come on stream) are about one third higher than in EWI 2005 and in 2050 about $45 \%$ higher for gas and about $30 \%$ higher for coal. The assumed $\mathrm{CO}_{2}$ penalties make coal in particular considerably more expensive. In DLR 2005 the coal price in 2050 (including $\mathrm{CO}_{2}$ penalty) is three times the 2005 price, while the natural gas price is 2.5 times higher. The lignite price is also given for comparison. 


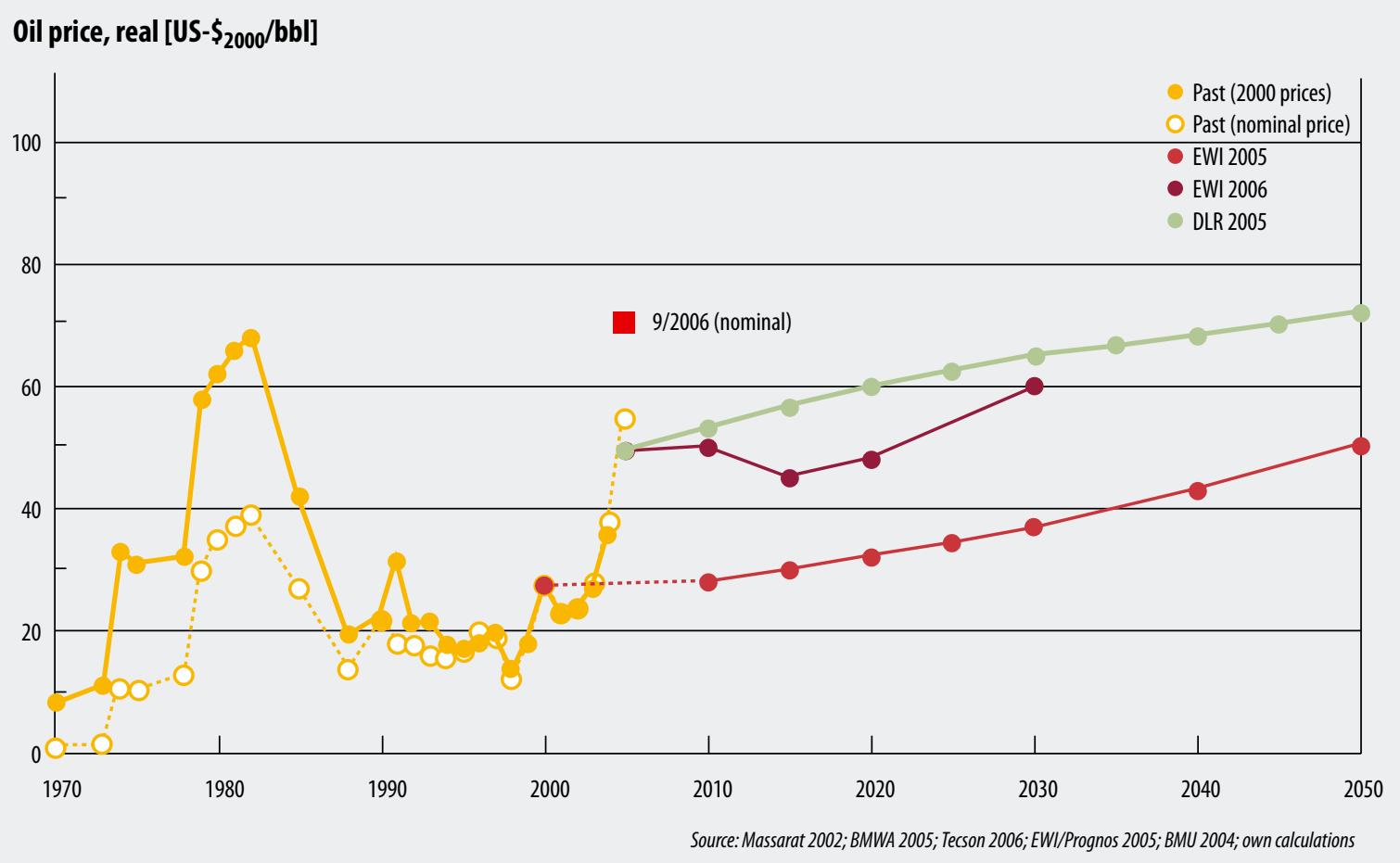

Fig. 12-1: Real $\left(\$_{2000}\right)$ and nominal oil price since 1970; energy price scenarios (EWI 2005 and DLR 2005) in real prices until 2050 and (for comparison) the EWI 2006 scenario until 2030
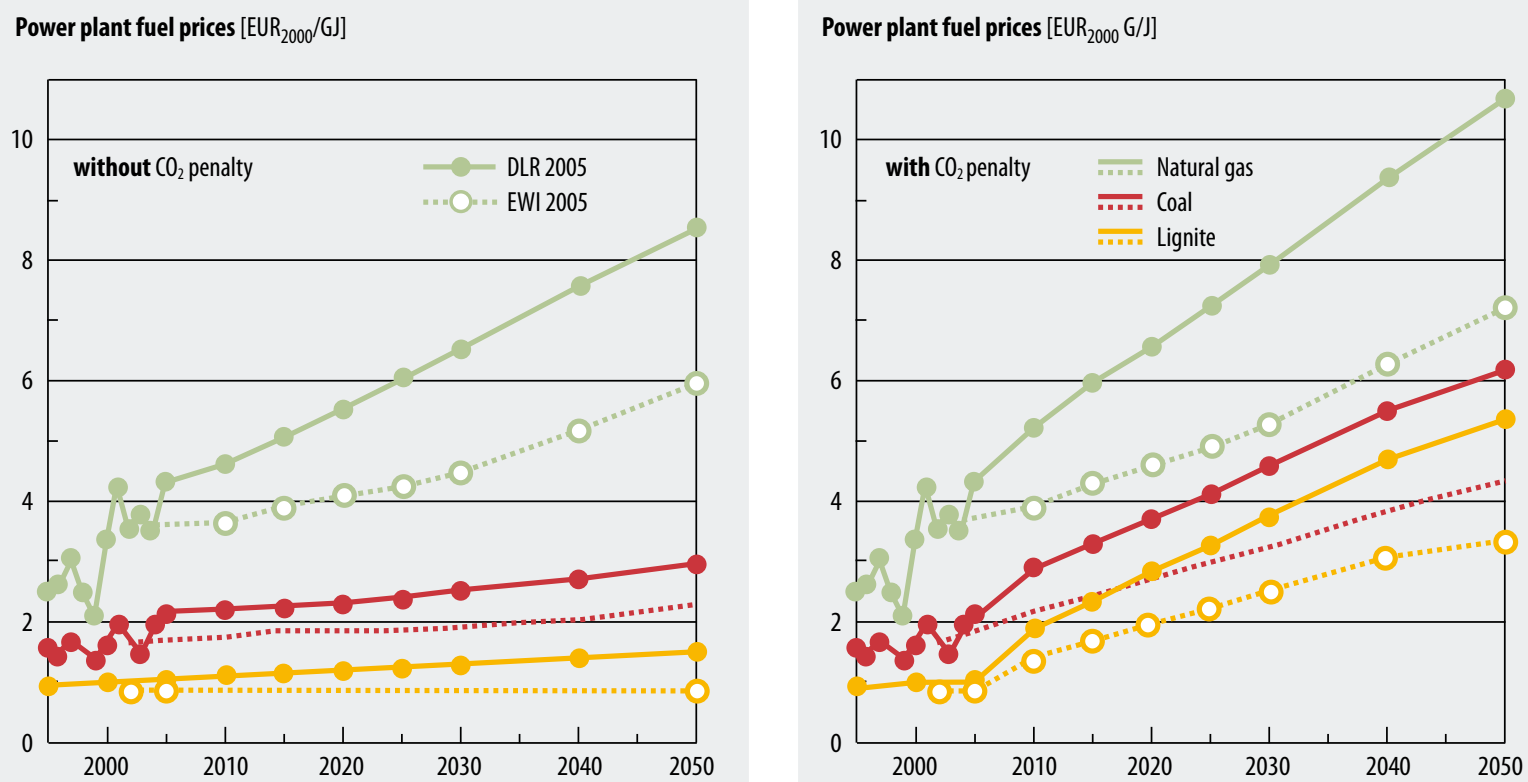

Fig. 12-2: Fuel prices at power station (in $\$ 2000 / \mathrm{GJ}$ ) for natural gas, coal and lignite for price scenarios DLR 2005 (solid lines) and EWI 2005 (broken lines) without (left) and with (right) $\mathrm{CO}_{2}$ penalty 
Table 12-1: Fuel prices for power stations in two price scenarios (EWI 2005 and DLR 2005) without and with $\mathrm{CO}_{2}$ penalty in ct $\epsilon_{\epsilon 2000} / \mathrm{KWh}_{\mathrm{th}}$ and in $\epsilon_{2000} / \mathrm{GJ}$

\begin{tabular}{|c|c|c|c|c|c|c|c|c|c|c|c|c|c|}
\hline & & & \multicolumn{5}{|c|}{ EWI } & \multicolumn{4}{|c|}{ Projection } & \multirow{2}{*}{$\begin{array}{l}\text { Mean } \\
20-50\end{array}$} & \multirow{2}{*}{\begin{tabular}{|c|}
$\begin{array}{c}\text { Inccrease } \\
\text { by } 2050\end{array}$ \\
$\% / a$ \\
\end{tabular}} \\
\hline & 2000 & 2005 & 2010 & 2015 & 2020 & 2025 & 2030 & 2035 & 2040 & 2045 & 2050 & & \\
\hline \multicolumn{14}{|l|}{ EWI 2005} \\
\hline \multicolumn{14}{|l|}{ Natural gas } \\
\hline $\mathrm{ct} / \mathrm{kWh}_{\mathrm{th}}$ & 1.27 & 1.55 & 1.30 & 1.40 & 1.46 & 1.52 & 1.60 & 1.72 & 1.85 & 1.98 & 2.15 & 1.75 & 1.59 \\
\hline EUR/GJ & 3.53 & 4.31 & 3.61 & 3.88 & 4.04 & 4.23 & 4.45 & 4.78 & 5.14 & 5.50 & 5.98 & 4.87 & \\
\hline \multicolumn{14}{|l|}{ Coal } \\
\hline $\mathrm{ct} / \mathrm{kWh} \mathrm{th}_{\mathrm{th}}$ & 0.57 & 0.76 & 0.62 & 0.65 & 0.65 & 0.66 & 0.67 & 0.69 & 0.72 & 0.77 & 0.81 & 0.71 & 0.79 \\
\hline EUR/GJ & 1.59 & 2.12 & 1.72 & 1.82 & 1.82 & 1.84 & 1.86 & 1.93 & 2.00 & 2.13 & 2.25 & 1.98 & \\
\hline \multicolumn{14}{|l|}{ Lignite } \\
\hline $\mathrm{ct} / \mathrm{kWh} \mathrm{th}_{\mathrm{th}}$ & 0.30 & 0.30 & 0.30 & 0.30 & 0.30 & 0.30 & 0.30 & 0.30 & 0.30 & 0.30 & 0.30 & 0.30 & 0.00 \\
\hline EUR/GJ & 0.83 & 0.83 & 0.83 & 0.83 & 0.83 & 0.83 & 0.83 & 0.83 & 0.83 & 0.83 & 0.83 & 0.83 & \\
\hline $\mathrm{EWI} 2005+\mathrm{CO}_{2}$ & & $E U R / t$ & 5.00 & 7.50 & 10.00 & 12.50 & 15.00 & 17.50 & 20.00 & 21.25 & 22.50 & & \\
\hline \multicolumn{14}{|l|}{ Natural gas } \\
\hline $\mathrm{ct} / \mathrm{kWh}_{\mathrm{th}}$ & 1.27 & 1.55 & 1.40 & 1.55 & 1.66 & 1.77 & 1.91 & 2.08 & 2.26 & 2.43 & 2.61 & 2.10 & 1.90 \\
\hline EUR/GJ & 3.53 & 4.31 & 3.89 & 4.30 & 4.61 & 4.92 & 5.30 & 5.79 & 6.28 & 6.76 & 7.24 & 5.84 & \\
\hline \multicolumn{14}{|l|}{ Coal } \\
\hline $\mathrm{ct} / \mathrm{kWh}_{\mathrm{th}}$ & 0.57 & 0.76 & 0.78 & 0.88 & 0.99 & 1.08 & 1.17 & 1.28 & 1.38 & 1.47 & 1.56 & 1.27 & 1.93 \\
\hline EUR/GJ & 1.59 & 2.12 & 2.18 & 2.46 & 2.74 & 2.99 & 3.24 & 3.55 & 3.85 & 4.09 & 4.33 & 3.54 & \\
\hline \multicolumn{14}{|l|}{ Lignite } \\
\hline $\mathrm{ct} / \mathrm{kWh}_{\mathrm{th}}$ & 0.30 & 0.30 & 0.50 & 0.60 & 0.70 & 0.80 & 0.90 & 0.95 & 1.10 & 1.05 & 1.20 & 0.96 & 2.38 \\
\hline \multirow[t]{2}{*}{ EUR/GJ } & 0.83 & 0.83 & 1.39 & 1.67 & 1.95 & 2.22 & 2.50 & 2.64 & 3.06 & 2.92 & 3.34 & 2.66 & \\
\hline & & & \multicolumn{9}{|c|}{ DLR } & & \\
\hline & 2000 & 2005 & 2010 & 2015 & 2020 & 2025 & 2030 & 2035 & 2040 & 2045 & 2050 & $20-50$ & $\% / a$ \\
\hline \multicolumn{14}{|l|}{ DLR } \\
\hline \multicolumn{14}{|l|}{ Natural gas } \\
\hline $\mathrm{ct} / \mathrm{kWh} \mathrm{th}_{\mathrm{th}}$ & 1.21 & 1.55 & 1.73 & 1.90 & 2.06 & 2.23 & 2.40 & 2.58 & 2.76 & 2.96 & 3.15 & 2.59 & 1.76 \\
\hline EUR/GJ & 3.35 & 4.31 & 4.81 & 5.27 & 5.73 & 6.20 & 6.67 & 7.17 & 7.67 & 8.21 & 8.76 & 7.20 & \\
\hline \multicolumn{14}{|l|}{ Coal } \\
\hline $\mathrm{ct} / \mathrm{kWh} \mathrm{th}_{\mathrm{th}}$ & 0.57 & 0.76 & 0.79 & 0.81 & 0.84 & 0.87 & 0.90 & 0.94 & 0.98 & 1.03 & 1.08 & 0.95 & 0.97 \\
\hline EUR/GJ & 1.59 & 2.12 & 2.20 & 2.26 & 2.32 & 2.42 & 2.51 & 2.62 & 2.72 & 2.86 & 3.00 & 2.64 & \\
\hline \multicolumn{14}{|l|}{ Lignite } \\
\hline $\mathrm{ct} / \mathrm{kWh}_{\mathrm{th}}$ & 0.34 & 0.36 & 0.38 & 0.40 & 0.41 & 0.43 & 0.45 & 0.47 & 0.49 & 0.51 & 0.52 & 0.47 & 0.86 \\
\hline EUR/GJ & 0.95 & 1.00 & 1.05 & 1.10 & 1.15 & 1.20 & 1.25 & 1.31 & 1.36 & 1.40 & 1.45 & 1.30 & \\
\hline DLR $2005+\mathrm{CO}_{2}$ & & EUR/t & 7.50 & 11.25 & 15.00 & 18.75 & 22.50 & 26.26 & 30.00 & 32.50 & 35.00 & & \\
\hline \multicolumn{14}{|l|}{ Natural gas } \\
\hline $\mathrm{ct} / \mathrm{kWh}_{\mathrm{th}}$ & 1.21 & 1.55 & 1.82 & 2.05 & 2.29 & 2.54 & 2.80 & 3.07 & 3.33 & 3.57 & 3.80 & 3.06 & 2.20 \\
\hline EUR/GJ & 3.35 & 4.31 & 5.05 & 5.70 & 6.37 & 7.06 & 7.78 & 8.52 & 9.26 & 9.91 & 10.56 & 8.49 & \\
\hline \multicolumn{14}{|l|}{ Coal } \\
\hline $\mathrm{ct} / \mathrm{kWh}_{\mathrm{th}}$ & 0.57 & 0.76 & 1.03 & 1.17 & 1.32 & 1.48 & 1.64 & 1.80 & 1.96 & 2.09 & 2.22 & 1.79 & 2.27 \\
\hline EUR/GJ & 1.59 & 2.12 & 2.86 & 3.25 & 3.67 & 4.11 & 4.55 & 5.00 & 5.45 & 5.81 & 6.17 & 4.97 & \\
\hline \multicolumn{14}{|l|}{ Lignite } \\
\hline $\mathrm{ct} / \mathrm{kWh}_{\mathrm{th}}$ & 0.34 & 0.36 & 0.68 & 0.85 & 1.02 & 1.19 & 1.35 & 1.52 & 1.69 & 1.81 & 1.93 & 1.50 & 2.97 \\
\hline EUR/GJ & 0.95 & 1.00 & 1.89 & 2.36 & 2.84 & 3.29 & 3.75 & 4.23 & 4.70 & 5.03 & 5.37 & 4.17 & \\
\hline
\end{tabular}


Table 12-2:

Data used for calculating electricity generation costs of fossil-fuelled power stations

\begin{tabular}{|c|c|c|c|c|c|c|}
\hline & & $\begin{array}{c}\text { Williams } \\
(2002)\end{array}$ & $\begin{array}{c}\text { IEA } \\
(2003)\end{array}$ & $\begin{array}{l}\text { ECOFYS } \\
(2004)\end{array}$ & $\begin{array}{l}\text { IPCC 2) } \\
(2005)\end{array}$ & Reference \\
\hline Interest rate & $\% / a$ & 12 & 10 & 10 & & 10 \\
\hline Depreciation period & $a$ & 15 & 30 & 25 & & 25 \\
\hline Annuity & $\% / a$ & 15.0 & 10.6 & 11.0 & $11-17$ & 11.0 \\
\hline Load factor & $\mathrm{h} / \mathrm{a}$ & 7,000 & 8,200 & 7,500 & $5,700-7,800$ & 7,000 \\
\hline $\begin{array}{l}\text { Influence on electricity } \\
\text { generation costs in } \\
\text { relation to reference }\end{array}$ & & 1.10 & 0.85 & 0.93 & $0.80-1.20$ & 1.00 \\
\hline Fuel prices & & & & & & \\
\hline Natural gas & $€ / G J$ & 3.93 & 3.20 & 3.00 & $3.0-4.8$ & $4.0-5.7^{1)}$ \\
\hline Coal & $€ / G J$ & 1.24 & 1.60 & 2.00 & $1.8-2.3$ & $1.8^{-2.3^{1)}}$ \\
\hline
\end{tabular}

The scenario price trends for fuel and $\mathrm{CO}_{2}$ emission certificates have effects both on the cost differences between technologies with and without $\mathrm{CO}_{2}$ capture (owing to the different levels of efficiency) and on competitiveness with $\mathrm{CO}_{2}$-free technologies based on renewable energy sources.

\subsubsection{Data Used for Cost Calculations and Electricity Costs in 2020}

In the following we describe the cost information given by various relevant sources for future power stations with and without $\mathrm{CO}_{2}$ capture. However, these costs were calculated on the basis of different economic data such as base year for prices, interest rates and depreciation periods, different plant lifetimes and in some cases very different fuel prices, so they are only partially comparable. The different assumptions about annuity and plant lifetimes alone (Table 12-2) cause differences of up to $\pm 20 \%$ in the cost calculations. Different power station sizes can also lead to different specific investment costs. The differences in fuel prices are also considerable, although in general nothing was said about rates of increase during the plant's lifetime (e.g. between 2020 and 2050). In the following we contrast data from four important sources (Williams 2002, IEA 2003, ECOFYS 2004, IPCC 2005) on the basis of identical data for interest rate, depreciation period, annual full load hours and fuel costs and compare them with the four reference technologies defined here.

Table 12-3 shows the data for three types of power station that are particularly important for early introduction of $\mathrm{CO}_{2}$ capture techniques (around 2020). These are
- efficient coal-fired thermal power stations

- coal-fired combined cycle power stations with integrated coal gasification and

- gas-fired combined cycle power stations.

They are covered by all the relevant sources. Only ECOFYS (2004) additionally investigates gas-fired thermal power stations. But because they have significantly lower efficiency than combined cycle power stations they are not of great interest for $\mathrm{CO}_{2}$ capture. Considerable differences arise in the assessments for coalfired thermal power stations, so the reference power station data take special account of the German situation. Accordingly, the data for the coal-fired thermal power station for 2020 were defined on the basis of the NRW reference power station (VGB 2004). With gasfired combined cycle power stations the differences in the assumptions are smaller. Coal-fired IGCC power stations are in general still found to be considerably more expensive in 2020.

Under these assumptions the resulting electricity generation costs in 2020 for coal-fired thermal power stations are 3.51-3.87 ct/ $\mathrm{kWh}_{\mathrm{el}}$ and for gas-fired combined cycle power stations $3.56-4.44 \mathrm{ct} / \mathrm{kWh}_{\mathrm{el}}$. So with the assumed cost relationships, efficient modern 'conventional' coal-fired power stations are more cost-effective than gas-fired combined cycle power stations. With coal gasification costs can be expected to be about 0.6 $\mathrm{ct} / \mathrm{kWh}_{\mathrm{el}}$ higher. $\mathrm{A} \mathrm{CO}_{2}$ penalty of $€ 15 / \mathrm{t}$ in 2020 (DLR $2005+\mathrm{CO}_{2}$ ) makes electricity generated from coal more expensive by $1 \mathrm{ct} / \mathrm{kWh}_{\mathrm{el}}$ and electricity from gas by 0.5 $\mathrm{ct} / \mathrm{kWh}_{\mathrm{el}}$, which has the effect of inverting the cost relationship between the two options at that point in time.

If the electricity costs are calculated using the average fuel price over the whole period of operation (see Table $12-1$, second-last column), the cost of electricity from coal is $0.3 \mathrm{ct} / \mathrm{kWh}_{\mathrm{el}}$ above those of 2020 and the cost of electricity from natural gas - due to steeper rates of 


\begin{tabular}{|c|c|c|c|c|c|c|}
\hline & & $\begin{array}{c}\text { Williams } \\
\text { (2002) }\end{array}$ & $\begin{array}{c}\text { IEA } \\
\text { (2003) }\end{array}$ & $\begin{array}{l}\text { ECOFYS } \\
(2004)\end{array}$ & $\begin{array}{c}\text { IPCC } \\
(2005)^{1)}\end{array}$ & Reference \\
\hline \multicolumn{7}{|l|}{ Coal-fired thermal power station } \\
\hline Output & MW & 460 & n.a. & 500 & n.a. & 700 \\
\hline Efficiency & $\%$ & 42.7 & 44 & 42 & 45.6 & 49 \\
\hline Investment & $€ / \mathrm{kW}_{\mathrm{el}}$ & 1,425 & 1,086 & 1,085 & 870 & 950 \\
\hline Running and maintenance costs & $€ / k W, a$ & 72.1 & 33.0 & 50.0 & $48.3^{21}$ & 48.3 \\
\hline $\begin{array}{l}\text { Electricity costs } 2020 \\
\text { - DLR 2005, without } \mathrm{CO}_{2} \text { penalty } \\
\text { - DLR 2005, with } \mathrm{CO}_{2} \text { penalty } \\
\text { - EWI } 2005 \text {, without } \mathrm{CO}_{2} \text { penalty }\end{array}$ & $\mathrm{ct} / \mathrm{kWh} \mathrm{el}_{\mathrm{e}}$ & 5.19 & 4.15 & 4.39 & 3.90 & $\begin{array}{l}3.87 \\
4.89 \\
3.51\end{array}$ \\
\hline \multicolumn{7}{|l|}{ Coal-fired IGCC power station } \\
\hline Output & MW & 425 & n.a. & 500 & 365 & 700 \\
\hline Efficiency & $\%$ & 43.1 & 46 & 47 & 49.4 & 50 \\
\hline Investment & $€ / \mathrm{kW}_{\mathrm{el}}$ & 1,557 & 1,335 & 1,685 & 1,100 & 1,300 \\
\hline Running and maintenance costs & $€ / k W, a$ & 59.3 & 37.1 & 57.5 & $53.0^{21}$ & 53.0 \\
\hline $\begin{array}{l}\text { Electricity costs } 2020 \\
\text { - DLR 2005, without } \mathrm{CO}_{2} \text { penalty } \\
\text { - DLR } 2005 \text {, with } \mathrm{CO}_{2} \text { penalty } \\
\text { - EWI } 2005 \text {, without } \mathrm{CO}_{2} \text { penalty }\end{array}$ & $\mathrm{ct} / \mathrm{kWh}_{\mathrm{el}}$ & 5.21 & 4.48 & 5.18 & 4.20 & $\begin{array}{l}4.46 \\
5.46 \\
4.12\end{array}$ \\
\hline \multicolumn{7}{|c|}{ Natural gas combined cycle power station } \\
\hline Output & MW & 385 & n.a. & 500 & 380 & 700 \\
\hline Efficiency & $\%$ & 53.6 & 59 & 58 & 58.6 & 60 \\
\hline Investment & $€ / \mathrm{kW}_{\mathrm{el}}$ & 590 & 424 & 480 & 700 & 400 \\
\hline Running and maintenance costs & $€ / k W, a$ & 23.3 & 14.8 & 37.3 & $34.1^{2}$ & 34.1 \\
\hline $\begin{array}{l}\text { Electricity costs } 2020 \\
\text { - DLR 2005, without } \mathrm{CO}_{2} \text { penalty } \\
\text { - DLR 2005, with } \mathrm{CO}_{2} \text { penalty } \\
\text { - EWI 2005, without } \mathrm{CO}_{2} \text { penalty }\end{array}$ & $\mathrm{ct} / \mathrm{kWh}_{\mathrm{el}}$ & 4.97 & 4.35 & 4.71 & 5.00 & $\begin{array}{l}4.44 \\
4.94 \\
3.56\end{array}$ \\
\hline 1) Average values for'advanced tec & logies' & re taken fr & iference & & & \\
\hline
\end{tabular}

Data for fossil-fuelled power stations in 2020 and their electricity generation costs on the basis of the same data (without capture and final storage of $\left.\mathrm{CO}_{2}\right)$; all costs in $€$ or cents (2000 prices) price increase and the generally greater proportional importance of fuel prices -0.6 to $1.2 \mathrm{ct} / \mathrm{kWh}_{\mathrm{el}}$ above those of 2020.

Table 12-4 shows the same comparison of these power stations but with $\mathrm{CO}_{2}$ capture. With coal-fired thermal power stations and gas-fired combined cycle power stations this is $\mathrm{CO}_{2}$ capture after combustion; with coalfired IGCC power stations it is capture before combustion. The data shown in the 'Reference' column are 'best estimates' on the basis of all consulted sources, the reference power stations as per Table 12-3 and other findings from this study. In all cases it is assumed that the plant in question has completed its pilot and demonstration phase and will be basically commercially available by 2020 .

The resulting electricity generation costs in 2020 (using fuel prices without $\mathrm{CO}_{2}$ penalty) for low- $\mathrm{CO}_{2}$ coal-fired thermal power stations are between 5.52 and $5.95 \mathrm{ct} /$ $\mathrm{kWh}_{\mathrm{el}}$. Low- $\mathrm{CO}_{2}$ coal-fired power stations with IGCC have electricity costs between 5.88 and $6.46 \mathrm{ct} / \mathrm{kWh}_{\mathrm{el}}$. For low- $\mathrm{CO}_{2}$ gas-fired combined cycle power stations the cost is between 5.04 and $6.08 \mathrm{ct} / \mathrm{kWh}_{\mathrm{el}}$ and thus within the cost range for coal-fired power stations at the same time. If we take the $\mathrm{CO}_{2}$ penalties into account, 
Table 12-4:

Data for fossil-fuelled power stations in 2020 and their electricity generation costs on the basis of the same data (with capture, without final storage of $\left.\mathrm{CO}_{2}\right)$; all costs in $€$ or cents (2000 prices)

\begin{tabular}{|c|c|c|c|c|c|c|}
\hline & & $\begin{array}{c}\text { Williams } \\
\text { (2002) }\end{array}$ & $\begin{array}{c}\text { IEA } \\
\text { (2003) }\end{array}$ & $\begin{array}{l}\text { ECOFYS } \\
\text { (2004) }\end{array}$ & $\begin{array}{c}\text { IPCC } \\
(2005)^{1)}\end{array}$ & Reference \\
\hline \multicolumn{7}{|l|}{ Coal-fired thermal power station } \\
\hline Output & MW & 330 & n.a. & 385 & n.a. & 570 \\
\hline Efficiency & $\%$ & 31.0 & 36.0 & 33.7 & 35.4 & 40.0 \\
\hline Investment & $€ / \mathrm{kW}_{\mathrm{el}}$ & 2,385 & 1,823 & 1,880 & 1,470 & 1,750 \\
\hline Running and maintenance costs & $€ / k W, a$ & 129 & 78.0 & 79.7 & $80.0^{2)}$ & 80.0 \\
\hline $\begin{array}{l}\text { Electricity costs } 2020 \\
\text { - DLR 2005, without } \mathrm{CO}_{2} \text { penalty } \\
\text { - DLR 2005, with } \mathrm{CO}_{2} \text { penalty } \\
\text { - } \mathrm{EWI} 2005 \text {, without } \mathrm{CO}_{2} \text { penalty }\end{array}$ & $\mathrm{ct} / \mathrm{kWh} \mathrm{h}_{\mathrm{el}}$ & 8.06 & 6.29 & 6.48 & 5.78 & $\begin{array}{l}5.95 \\
6.13 \\
5.52\end{array}$ \\
\hline \multicolumn{7}{|l|}{ Coal-fired IGCC power station } \\
\hline Output & MW & 365 & n.a. & 385 & 360 & 590 \\
\hline Efficiency & $\%$ & 37.0 & 40.0 & 42.2 & 40.3 & 42.0 \\
\hline Investment & $€ / \mathrm{kW}_{\mathrm{el}}$ & 2,022 & 1,733 & 2,375 & 1,720 & 2,000 \\
\hline Running and maintenance costs & $€ / k W, a$ & 72.0 & 55.0 & 87.5 & $85.0^{2)}$ & 85.0 \\
\hline $\begin{array}{l}\text { Electricity costs } 2020 \\
\text { - DLR 2005, without } \mathrm{CO}_{2} \text { penalty } \\
\text { - DLR 2005, with } \mathrm{CO}_{2} \text { penalty } \\
\text { - EWI 2005, without } \mathrm{CO}_{2} \text { penalty }\end{array}$ & $\mathrm{ct} / \mathrm{kWh} \mathrm{el}_{\mathrm{el}}$ & 6.56 & 5.57 & 6.95 & 6.00 & $\begin{array}{l}6.28 \\
6.46 \\
5.88\end{array}$ \\
\hline \multicolumn{7}{|c|}{ Natural gas combined cycle power station } \\
\hline Output & MW & 310 & n.a. & 440 & 330 & 600 \\
\hline Efficiency & $\%$ & 43.3 & 51.0 & 52.0 & 50.6 & 51.0 \\
\hline Investment & $€ / \mathrm{kW}_{\mathrm{el}}$ & 1,125 & 850 & 890 & 1,170 & 900 \\
\hline Running and maintenance costs & $€ / k W, a$ & 52.8 & 35.0 & 51.7 & $54.0^{2}$ & 54.0 \\
\hline $\begin{array}{l}\text { Electricity costs } 2020 \\
\text { - DLR 2005, without } \mathrm{CO}_{2} \text { penalty } \\
\text { - DLR 2005, with } \mathrm{CO}_{2} \text { penalty } \\
\text { - } \mathrm{EWI} 2005 \text {, without } \mathrm{CO}_{2} \text { penalty }\end{array}$ & $\mathrm{ct} / \mathrm{kWh} \mathrm{el}_{\mathrm{l}}$ & 7.12 & 5.77 & 5.99 & 6.59 & $\begin{array}{l}6.08 \\
6.16 \\
5.04\end{array}$ \\
\hline 1) Average values for'advanced tec & logies' & taken from & erence & & & \\
\hline
\end{tabular}

the electricity costs of these power stations rise too if only slightly - because the remaining $\mathrm{CO}_{2}$ emissions from CCS power stations are only about $15 \%$ of those from power stations without CCS (capture rate $88 \%$ ). Compression, transport and final storage of the $\mathrm{CO}_{2}$ are not yet included in these costs.

Table 12-5 shows the efficiency losses resulting from $\mathrm{CO}_{2}$ capture and the extra expense for market-ready CCS facilities in 2020. In the reference case $\mathrm{CO}_{2}$ cap- ture increases the cost of electricity from coal-fired thermal power stations by approx. $2 \mathrm{ct} / \mathrm{kWh}_{\mathrm{el}}$. The cost increase $\left(1.8 \mathrm{ct} / \mathrm{kWh}_{\mathrm{el}}\right)$ with $\mathrm{CO}_{2}$ capture in IGCC power stations is somewhat smaller because gasification has already occurred in the power station without $\mathrm{CO}_{2}$ capture. In relation to the lower-cost coal-fired thermal power station, however, the cost increase at this point in time rises to $2.6 \mathrm{ct} / \mathrm{kWh}_{\mathrm{el}}$ (values in parentheses in Table 12-5). The cost increases are smallest with gasfired combined cycle power stations with values around 


\begin{tabular}{|c|c|c|c|c|c|c|}
\hline & & $\begin{array}{l}\text { Williams } \\
\text { (2002) }\end{array}$ & $\begin{array}{l}\text { IEA } \\
(2003)\end{array}$ & $\begin{array}{l}\text { ECOFYS } \\
(2004)\end{array}$ & $\begin{array}{l}\text { IPCC } \\
(2005)^{1)}\end{array}$ & $\begin{array}{l}\text { Reference } \\
\text { (2005) }\end{array}$ \\
\hline \multicolumn{7}{|l|}{ Coal-fired thermal power station } \\
\hline Efficiency & $\%$ points & -11.7 & -8.0 & -8.3 & -10.2 & -9.0 \\
\hline $\begin{array}{l}\text { Avoided } \mathrm{C}_{2} \text { emissions/original } \\
\text { emissions }\end{array}$ & $\%$ & 83.5 & 85.3 & 85.0 & 84.4 & 85.3 \\
\hline Additional investment costs & $€ / \mathrm{kW}_{\mathrm{el}}$ & +960 & +737 & +795 & +600 & +800 \\
\hline $\begin{array}{l}\text { Electricity costs } 2020 \\
\text { - DLR 2005, without } \mathrm{CO}_{2} \text { penalty } \\
\text { - DLR } 2005 \text { with } \mathrm{CO}_{2} \text { penalty } \\
\text { - EWI } 2005 \text {, without } \mathrm{CO}_{2} \text { penalty } \\
\text { Range of other studies }{ }^{3)}\end{array}$ & $\mathrm{ct} / \mathrm{kWh}$ el & 2.87 & 2.14 & 2.09 & 1.88 & $\begin{array}{r}2.08 \\
1.24 \\
2.01 \\
2.1-4.2\end{array}$ \\
\hline \multicolumn{7}{|l|}{ Coal-fired IGCC power station } \\
\hline Efficiency & $\%$ points & -6.1 & -6.0 & -4.8 & -9.0 & -8.0 \\
\hline $\begin{array}{l}\text { Avoided } \mathrm{C}_{2} \text { emissions/original } \\
\text { emissions }\end{array}$ & $\%$ & 86.0 & 86.2 & 86.6 & 91.1 & 85.7 \\
\hline Additional investment costs & $€ / \mathrm{kW}_{\mathrm{el}}$ & +465 & +398 & +690 & +620 & +700 \\
\hline $\begin{array}{l}\text { Electricity costs } 2020 \\
\text { - DLR } 2005 \text {, without } \mathrm{CO}_{2} \text { penalty } \\
\text { - DLR } 2005 \text { with } \mathrm{CO}_{2} \text { penalty } \\
\text { - EWI } 2005 \text {, without } \mathrm{CO}_{2} \text { penalty } \\
\text { Range of other studies }{ }^{3)}\end{array}$ & $\mathrm{ct} / \mathrm{kWh} \mathrm{el}_{\mathrm{l}}$ & $\begin{array}{r}1.35 \\
(1.37)\end{array}$ & $\begin{array}{r}1.09 \\
(1.42)\end{array}$ & $\begin{array}{r}1.77 \\
(2.56)\end{array}$ & $\begin{array}{r}1.80 \\
(2.10)\end{array}$ & $\begin{array}{r}1.82(2.41)^{2)} \\
1.00 \\
1.76 \\
1.3-2.7\end{array}$ \\
\hline \multicolumn{7}{|c|}{ Natural gas combined cycle power station } \\
\hline Efficiency & $\%$ points & -10.3 & -8.0 & -6.0 & -8.6 & -9.0 \\
\hline $\begin{array}{l}\text { Avoided } \mathrm{C}_{2} \text { emissions/original } \\
\text { emissions }\end{array}$ & $\%$ & 85.1 & 86.1 & 86.6 & 94.1 & 85.9 \\
\hline Additional investment costs & $€ / \mathrm{kW}_{\mathrm{el}}$ & +535 & +426 & +410 & +470 & +500 \\
\hline $\begin{array}{l}\text { Electricity costs } 2020 \\
\text { - DLR 2005, without } \mathrm{CO}_{2} \text { penalty } \\
\text { - DLR } 2005 \text { with } \mathrm{CO}_{2} \text { penalty } \\
\text { - EWI } 2005 \text {, without } \mathrm{CO}_{2} \text { penalty } \\
\text { Range of other studies }{ }^{3)}\end{array}$ & $\mathrm{ct} / \mathrm{kWh} \mathrm{el}_{\mathrm{e}}$ & 2.15 & 1.42 & 1.72 & 1.59 & $\begin{array}{r}1.64 \\
1.22 \\
1.48 \\
1.1-2.3\end{array}$ \\
\hline
\end{tabular}

Table 12-5:

Difference in data of power stations with and without $\mathrm{CO}_{2}$ capture (without transport and final storage of the $\left.\mathrm{CO}_{2}\right)$, all costs in $€ \mathrm{ct}$ (2000 prices)

$1.6 \mathrm{ct} / \mathrm{kWh}_{\mathrm{el}}$. $\mathrm{CO}_{2}$ penalties of $€ 15 / \mathrm{t}$ - as included in the DLR 2005 plus $\mathrm{CO}_{2}$ penalty price scenario - reduce the cost increase compared with power stations without $\mathrm{CO}_{2}$ capture to about $1.2 \mathrm{ct} / \mathrm{kWh}_{\mathrm{el}}$.

If we compare the above values with the ranges determined by ECOFYS (2004) from ten other studies (the values given there were converted to be compatible with the economic reference data and the respective lowest and highest value was ignored) the refer- ence cost increases described here are at the low ends of the respective ranges. IPCC (2005) gives ranges of $1.7-4.2 \mathrm{ct} / \mathrm{kWh}_{\mathrm{el}}$ for coal-fired thermal power stations and $0.8-2.5 \mathrm{ct} / \mathrm{kWh}_{\mathrm{el}}$ for coal-fired IGCC and gas-fired combined cycle power stations. So the results for the electricity generation costs of the reference technologies selected here form a representative and reliable starting point for cost comparisons. 
Table 12-6:

Comparison of 'marketready' CCS power stations (2020) with 'mature' CCS power stations (2040) and their reference power stations without CCS

\begin{tabular}{|c|c|c|c|c|c|c|c|}
\hline & & \multicolumn{2}{|c|}{ Coal-fired thermal } & \multicolumn{2}{|c|}{ Coal-fired IGCC } & \multicolumn{2}{|c|}{ Natural gas CC } \\
\hline & & 2020 & 2040 & 2020 & 2040 & 2020 & 2040 \\
\hline \multicolumn{8}{|l|}{ A) Without $\mathrm{CO}_{2}$ capture } \\
\hline Efficiency & $\%$ & 49.0 & 52.0 & 50.0 & 54.0 & 60.0 & 62.0 \\
\hline Investment & $€ / \mathrm{kW}_{\mathrm{el}}$ & 950 & 900 & 1,300 & 1,200 & 400 & 400 \\
\hline Running and maintenance & $€ / k W, a$ & 48.3 & 45.0 & 53.0 & 49.0 & 34.1 & 32.0 \\
\hline $\mathrm{CO}_{2}$ emissions, direct & $\mathrm{g} / \mathrm{kWh}_{\mathrm{el}}$ & 673 & 635 & 660 & 611 & 337 & 326 \\
\hline $\begin{array}{l}\text { Electricity costs (with fuel costs } \\
2020, \text { DLR scenario) }\end{array}$ & $\mathrm{ct} / \mathrm{kWh}_{\mathrm{el}}$ & 3.87 & 3.60 & 4.46 & 4.12 & 4.44 & 4.32 \\
\hline \multicolumn{8}{|l|}{ B) With $\mathrm{CO}_{2}$ capture } \\
\hline Efficiency & $\%$ & 40.0 & 44.0 & 42.0 & 46.0 & 51.0 & 55.0 \\
\hline Reduction & $\%$ points & 9 & 8 & 8 & 8 & 9 & 7 \\
\hline Capture rate & $\%$ & 88 & 90 & 88 & 92 & 88 & 92 \\
\hline Investment & $€ / \mathrm{kW}_{\mathrm{el}}$ & 1,750 & 1,600 & 2,000 & 1,800 & 900 & 750 \\
\hline Difference & $€ / \mathrm{kW}_{\mathrm{el}}$ & 800 & 700 & 700 & 600 & 500 & 350 \\
\hline Running and maintenance & $€ / k W, a$ & 80.0 & 74.0 & 85.0 & 78.0 & 54.0 & 50.0 \\
\hline $\mathrm{CO}_{2}$ emissions, direct & $\mathrm{g} / \mathrm{kWh}_{\mathrm{el}}$ & 99 & 75 & 94 & 57 & 48 & 40 \\
\hline $\begin{array}{l}\text { Avoided emissions/original } \\
\text { emissions }\end{array}$ & $\%$ & 85.3 & 88.2 & 85.7 & 90.6 & 85.9 & 91.0 \\
\hline Additional fuel used & $\%$ & 22.5 & 18.2 & 19.0 & 17.4 & 17.6 & 12.7 \\
\hline $\begin{array}{l}\text { Electricity costs (with fuel costs } \\
\text { 2020, DLR scenario) }\end{array}$ & $\mathrm{ct} / \mathrm{kWh}_{\mathrm{el}}$ & 5.95 & 5.43 & 6.28 & 5.74 & 6.08 & 5.50 \\
\hline $\begin{array}{l}\text { Cost difference (CCS minus cost } \\
\text { without CCS) }\end{array}$ & $\mathrm{ct} / \mathrm{kWh}_{\mathrm{el}}$ & 2.08 & 1.83 & $\begin{array}{r}1.82 \\
(2.41)\end{array}$ & $\begin{array}{r}1.62 \\
(2.14)\end{array}$ & 1.64 & 1.18 \\
\hline
\end{tabular}

\subsubsection{Electricity Generation Costs with Changing Technology Parameters and Fuel Prices}

Technologies undergo continuous improvements, which may also be reflected in cost reductions. Introduction on a broad scale also leads to cost reductions. Such cost reductions derived from 'learning curves' are especially suitable for large production runs of similar or identical energy converters, as is the case with renewables and motor cars. These mechanisms can also be applied to CCS power stations and their components (Rubin 2004; Riahi 2004). The reference technologies for power stations with and without CCS are defined as 'market-ready' technologies for the period around 2020, meaning that they have already achieved the cost reductions achievable through $\mathrm{R} \& \mathrm{D}$ and demonstration projects. But if they penetrate the energy market on a larger scale this automatically subjects them to a maturing process. For that reason a second status is defined, that of 'mature' plant for the period around 2040. An approximation of the aforementioned learning effects is included in these data, which are listed in Table 12-6 along with some CCS-specific figures.
Whereas conventional power stations without CCS are already highly developed before 2020 and consequently only relatively small changes are to be expected, the room for improvements in CCS plant could be greater because the CCS-specific components will still be more at the beginning of their learning curve in 2020. We assume that efficiency and $\mathrm{CO}_{2}$ capture rate will increase considerably and that investment costs will also fall noticeably. Rubin (2004) found that doubling cumulative capacity would reduce the costs of typical CCS components (gas scrubbers) by 11-13\%. If we assume that that figure will apply to all CCS components and remember that the CCS-related additional costs make up about 30-40\% of total investment for CCS power stations, we can go on to estimate learning rates for complete CCS power stations. Technical improvements and reduced investment costs resulting from growing market volumes have a positive effect on electricity generation costs. While electricity costs from power stations without CCS (with constant fuel costs) fall by about 0.20 to $0.25 \mathrm{ct} / \mathrm{kWh}_{\mathrm{el}}$, those from CCS plant fall by 0.50 to $0.60 \mathrm{ct} / \mathrm{kWh}_{\mathrm{el}}$. The cost gaps between plant with and without CCS also close correspondingly (last row in Table 12-6). 


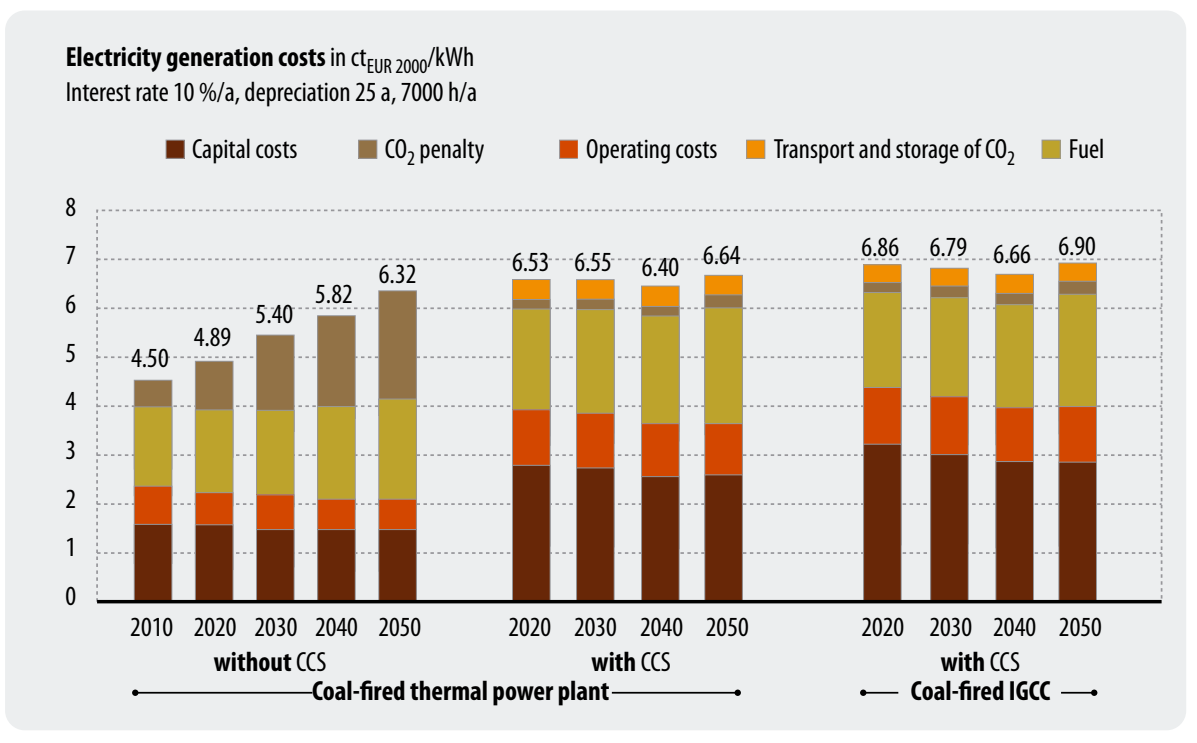

Fig. 12-3:

Electricity costs of new coalfired power stations at the respective start-up time in relation to technological improvements, fuel prices and $\mathrm{CO}_{2}$ penalties (costs for transport and storage of $\mathrm{CO}_{2}$ also listed; price scenario DLR 2005)

Unlike plant using renewable sources of energy, fossilfuelled plant is subject to rising prices of limited energy resources, and for plant with significant $\mathrm{CO}_{2}$ emissions there are additional costs caused by the $\mathrm{CO}_{2}$ emission certificate system. Both effects reduce or even reverse the aforementioned cost reduction potentials, whereby gas-fired power stations (due to their high proportion of fuel-related costs) respond more sensitively than coal-fired power stations. Figs. 12-3 and 12-4 show the results of these interrelationships, whereby the electricity costs are calculated using the fuel costs at the time of start-up.
For coal-fired power stations the electricity generation costs without $\mathrm{CO}_{2}$ penalty remain roughly constant at approx. $4.0 \mathrm{ct} / \mathrm{kWh}$. But a $\mathrm{CO}_{2}$ penalty has a noticeable impact, increasing electricity costs in $2020(€ 15 / \mathrm{t})$ by $1.0 \mathrm{ct} / \mathrm{kWh}$ and in $2050(€ 35 / \mathrm{t})$ by $2.2 \mathrm{ct} / \mathrm{kWh}$ to a total of $6.3 \mathrm{ct} / \mathrm{kWh}$. CCS power stations would then be competitive from around 2040 at about $6 \mathrm{ct} / \mathrm{kWh}$ (without including the cost of transporting and storing the $\mathrm{CO}_{2}$, see below). By then rising fuel prices will be balanced out by falling capital and running costs. Because the additional costs caused by rising $\mathrm{CO}_{2}$ penalties are also small, coal-fired power stations with CCS would be

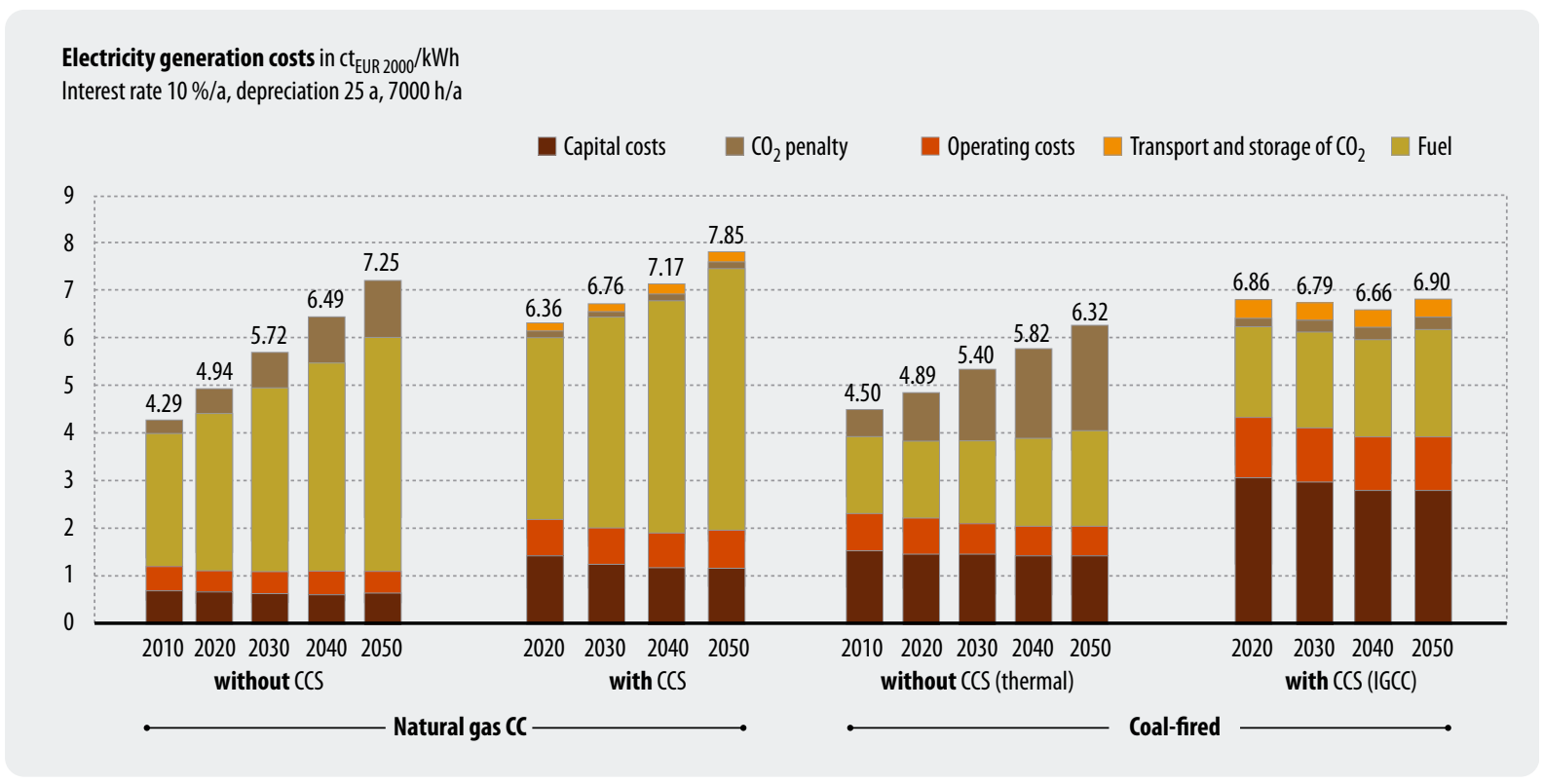

Fig. 12-4: Electricity costs of new gas-fired combined cycle and coal-fired power stations at the respective start-up time in relation to technological improvements, fuel prices and $\mathrm{CO}_{2}$ penalties ( $\mathrm{CS}$ plant including costs for transport and storage of $\mathrm{CO}_{2} ;$ DLR 2005 price scenario) 
Fig. 12-5:

Comparison of $\mathrm{CO}_{2}$ avoidance costs of CCS power stations (without transport and storage of $\left.\mathrm{CO}_{2}\right)$ for status 2020 (as reference also 2040) (DLR 2005 price scenario)

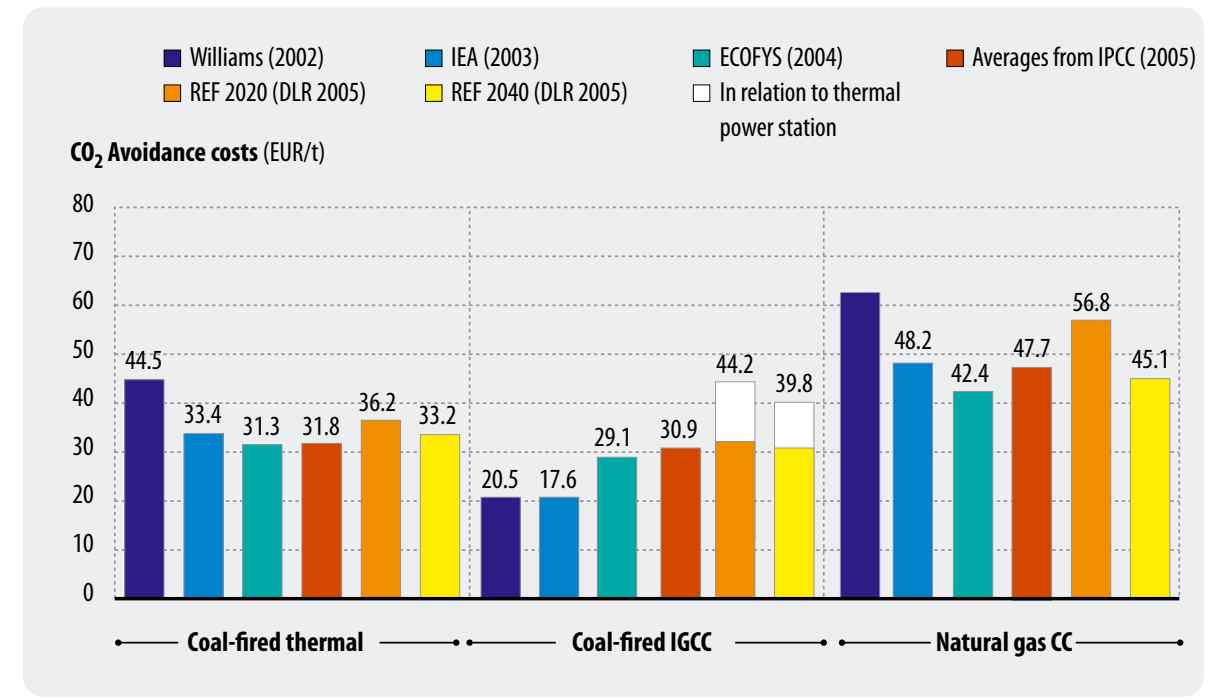

largely immune to possible rises in climate protection costs, see Fig. 12-3.

With gas-fired power stations, on the other hand, fuel price rises as described in Table 12-1 (DLR 2005 price scenario) cause considerable rises in electricity prices, which are amplified yet further by $\mathrm{CO}_{2}$ penalties (Fig. 12-4). On the basis of the price scenarios used here this makes gas-fired combined cycle power stations considerably more expensive than coal-fired power stations as of 2030. Gas-fired CCS plant can, in contrast to coalfired power stations with CCS, only compensate for a small part of the fuel price increase, so if the price of natural gas increases further we can expect a steady increase in electricity generation costs from CCS power stations too.

The above electricity costs were calculated using the fuel prices at the time the plant begins operation. But for a correct comparison with technologies that are little or not at all fuel-dependent (i.e. renewables) we need electricity generation costs calculated with fuel costs and $\mathrm{CO}_{2}$ penalties averaged over the whole plant lifetime. For coal-fired power stations operating between 2020 and 2050 the cost differences are relatively small ( 0.3 to $0.5 \mathrm{ct} / \mathrm{kWh}$ ), while for gas-fired power stations they are significantly higher $(0.6-1.2 \mathrm{ct} / \mathrm{kWh})$.

Finally, Fig. 12-5 shows the $\mathrm{CO}_{2}$ avoidance costs for the CCS power stations considered here in 2020 (without transport and storage). It shows at which levels of $\mathrm{CO}_{2}$ penalties these plants can be operated profitably in comparison with the respective reference power stations without CCS. For coal-fired thermal power stations the figures are around $€ 32-36 / \mathrm{t} \mathrm{CO}_{2}$, for IGCC somewhat lower and for gas-fired combined cycle power stations around $€ 50 / \mathrm{t} \mathrm{CO}_{2}$. For technology status 2040 the avoidance costs are about $10 \%$ lower. If we compare coal-fired power stations using CCS generally with the lower-cost reference thermal power station the avoidance costs for IGCC plant rise to about $€ 40 / \mathrm{CO}_{2}$. If we compare coal-fired power stations with the gas-fired reference power station, the $\mathrm{CO}_{2}$ avoidance costs roughly triple due to the then significantly smaller amount of avoided $\mathrm{CO}_{2}$. So statements about $\mathrm{CO}_{2}$ avoidance costs must always indicate the respective reference power station.

\subsubsection{Including the Costs of Transporting and Storing $\mathrm{CO}_{2}$}

If we are to draw comparisons with other low- $\mathrm{CO}_{2}$ and $\mathrm{CO}_{2}$-free technologies, the costs of compression, transport and final storage must be added to those of capturing the $\mathrm{CO}_{2}$. According to current research these additional costs for the typical transport distances in Germany of around 200 kilometres can be estimated at $0.20 \mathrm{ct} / \mathrm{kWh}_{\mathrm{el}}$ for gas-fired power stations and $0.40 \mathrm{ct} /$ $\mathrm{kWh}_{\mathrm{el}}$ for coal-fired. It is assumed that they too will fall by about $10 \%$ over the course of time.

The resulting overall costs for CCS power stations and the resulting additional costs compared with the respective reference power stations are listed in Table 12-7 for three different fuel price scenarios.

According to these calculations low- $\mathrm{CO}_{2}$ electricity from gas-fired power stations will cost between 5.2 and $6.4 \mathrm{ct} / \mathrm{kWh}$ in 2020 and between 5.5 and $7.2 \mathrm{ct} / \mathrm{kWh}$ in 2040. For low- $\mathrm{CO}_{2}$ electricity from coal-fired plant we find costs between 5.9 and $6.9 \mathrm{ct} / \mathrm{kWh}$ in 2020 and between 5.6 and $6.7 \mathrm{ct} / \mathrm{kWh}$ in 2040. This means that gas-fired CCS power stations are cheaper than coalfired in 2020 and if fuel price rises remain moderate (EWI 2005) this even remains the case in 2040. But if prices rose more steeply (DLR 2005) coal-fired CCS power stations would have the lower costs after 2020 . The resulting additional costs for $\mathrm{CO}_{2}$ capture compared with the same power station type without CCS depend less strongly on the price scenarios. In 2020 they are between 1.7 and $2.5 \mathrm{ct} / \mathrm{kWh}$ and fall to values between 1.4 and $2.3 \mathrm{ct} / \mathrm{kWh}$ by 2040 . 


\begin{tabular}{|c|c|c|c|c|c|c|}
\hline \multirow{2}{*}{$\begin{array}{l}\text { With } \mathrm{CO}_{2} \text { capture } \\
\text { (with transport and storage) }\end{array}$} & \multicolumn{6}{|c|}{ Year of starting operation } \\
\hline & 2005 & 2010 & 2020 & 2030 & 2040 & 2050 \\
\hline \multicolumn{7}{|l|}{ Prices EWI 2005} \\
\hline - Natural gas CC & & & 5.24 & 5.27 & 5.46 & 6.00 \\
\hline - Coal-fired thermal & & & 5.92 & 5.74 & 5.62 & 5.83 \\
\hline - Coal-fired IGCC & & & 6.28 & 6.07 & 5.92 & 6.12 \\
\hline \multicolumn{7}{|l|}{ Prices DLR 2005} \\
\hline - Natural gas CC & & & 6.28 & 6.68 & 7.06 & 7.71 \\
\hline - Coal-fired thermal & & & 6.35 & 6.32 & 6.17 & 6.37 \\
\hline - Coal-fired IGCC & & & 6.68 & 6.57 & 6.44 & 6.64 \\
\hline \multicolumn{7}{|l|}{ Prices DLR $2005+\mathrm{CO}_{2}$} \\
\hline - Natural gas CC & & & 6.36 & 6.77 & 7.17 & 7.84 \\
\hline - Coal-fired thermal & & & 6.53 & 6.55 & 6.39 & 6.64 \\
\hline - Coal-fired IGCC & & & 6.86 & 6.79 & 6.66 & 6.90 \\
\hline \multirow{2}{*}{$\begin{array}{l}\text { Additional cost of } \mathrm{CO}_{2} \text { capture } \\
\text { (with transport and storage) }\end{array}$} & \multicolumn{6}{|c|}{ Year of starting operation } \\
\hline & 2005 & 2010 & 2020 & 2030 & 2040 & 2050 \\
\hline \multicolumn{7}{|l|}{ Prices EWI 2005} \\
\hline - Natural gas CC & & & 1.68 & 1.51 & 1.36 & 1.42 \\
\hline - Coal-fired thermal & & & 2.41 & 2.26 & 2.17 & 2.21 \\
\hline - Coal-fired IGCC & & & 2.16 & 2.05 & 2.00 & 2.03 \\
\hline \multicolumn{7}{|l|}{ Prices DLR 2005} \\
\hline - Natural gas CC & & & 1.84 & 1.71 & 1.54 & 1.61 \\
\hline - Coal-fired thermal & & & 2.48 & 2.41 & 2.26 & 2.28 \\
\hline - Coal-fired IGCC & & & 2.22 & 2.13 & 2.07 & 2.10 \\
\hline \multicolumn{7}{|l|}{ Prices DLR $2005+\mathrm{CO}_{2}$} \\
\hline - Natural gas $C C$ & & & 1.42 & 1.05 & 0.68 & 0.59 \\
\hline - Coal-fired thermal & & & 1.64 & 1.15 & 0.57 & 0.32 \\
\hline - Coal-fired IGCC & & & 1.40 & 0.991 & 0.44 & 0.20 \\
\hline
\end{tabular}

Table 12-7:

Electricity generation costs ( $\left.\mathrm{ct}_{\epsilon 2000} / \mathrm{kWh}_{\mathrm{el}}\right)$ of new CCS power stations at the time of starting operation including transport and storage for three price scenarios and the resulting additional costs compared with the same power station type without $\mathrm{CO}_{2}$ capture

\begin{tabular}{|c|c|c|c|c|c|c|}
\hline \multirow{2}{*}{$\begin{array}{l}\text { With } \mathrm{CO}_{2} \text { capture } \\
\text { (with transport and storage) }\end{array}$} & \multicolumn{6}{|c|}{ Year of starting operation } \\
\hline & 2005 & 2010 & 2020 & 2030 & 2040 & 2050 \\
\hline \multicolumn{7}{|l|}{ Prices EWI 2005} \\
\hline - Natural gas CC & & & 58.2 & 51.5 & 45.8 & 47.8 \\
\hline - Coal-fired thermal & & & 42.0 & 39.8 & 38.8 & 39.5 \\
\hline - Coal-fired IGCC & & & 38.2 & 36.6 & 36.1 & 36.6 \\
\hline - Coal-fired IGCC (in relation to coal-fired thermal) & & & 47.8 & 44.8 & 42.8 & 43.3 \\
\hline \multicolumn{7}{|l|}{ Prices DLR 2005} \\
\hline - Natural gas CC & & & 63.7 & 58.3 & 51.9 & 54.2 \\
\hline - Coal-fired thermal & & & 43.2 & 42.5 & 40.4 & 40.7 \\
\hline - Coal-fired IGCC & & & 39.2 & 38.1 & 37.4 & 37.9 \\
\hline - Coal-fired IGCC (in relation to coal-fired thermal) & & & 48.5 & 46.0 & 43.8 & 44.1 \\
\hline \multicolumn{7}{|l|}{ Prices DLR $2005+\mathrm{CO}_{2}$} \\
\hline $\mathrm{CO}_{2}$ penalty $(\mathrm{EUR} / \mathrm{t})$ & & & 15.0 & 22.5 & 30.0 & 35.0 \\
\hline - Natural gas CC & & & 49.2 & 35.8 & 22.9 & 19.9 \\
\hline - Coal-fired thermal & advoid & e costs & 28.5 & 20.3 & 10.2 & 5.7 \\
\hline - Coal-fired IGCC & & & 24.7 & 16.3 & 7.9 & 3.6 \\
\hline - Coal-fired IGCC (in relation to coal-fired thermal) & & & 34.0 & 24.0 & 14.5 & 10.0 \\
\hline
\end{tabular}

Table 12-8:

$\mathrm{CO}_{2}$ avoidance costs of CCS power stations (including transport and storage) in $\epsilon_{2000} / \mathrm{t} \mathrm{CO}_{2}$ for different fuel price scenarios and times of starting operation 
Table 12-9: Development of the electricity costs of new renewable energy plant according to the NaturschutzPlus-new scenario (BMU 2005) with comparable economic data (interest rate $10 \%$, plant lifetime $20-25$ years)

\begin{tabular}{|c|c|c|c|c|c|c|c|c|c|c|}
\hline \multicolumn{11}{|c|}{$\begin{array}{l}\text { Electricity costs of new renewable energy (ct/kWh); annuity 0.11-0.126 (10\% interest, } 20-25 \text { years) } \\
\text { according to the NaturschutzPlus-new scenario (BMU 2005, new plant) }\end{array}$} \\
\hline New plant: & 2005 & 2010 & 2015 & 2020 & 2025 & 2030 & 2035 & 2040 & 2045 & 2050 \\
\hline Wind offshore & & 10.10 & 6.50 & 5.00 & 4.85 & 4.70 & 4.60 & 4.50 & 4.40 & 4.30 \\
\hline Wind power (mix) & 10.80 & 10.00 & 7.10 & 6.10 & 5.95 & 5.80 & 5.40 & 5.00 & 5.05 & 5.10 \\
\hline Hydropower (mix) & 5.50 & 6.10 & 6.60 & 7.10 & 7.10 & 7.10 & 7.25 & 7.40 & 7.50 & 7.70 \\
\hline Geothermal & 42.00 & 22.00 & 15.40 & 10.20 & 9.60 & 9.20 & 8.80 & 8.40 & 7.90 & 7.50 \\
\hline Solar thermal power stations (at border) & & & 14.00 & 9.00 & 8.40 & 7.60 & 7.20 & 6.70 & 6.50 & 6.30 \\
\hline Photovoltaic (mix) & 72.30 & 46.20 & 27.10 & 19.30 & 17.60 & 15.80 & 13.50 & 14.40 & 14.00 & 13.70 \\
\hline Solid biomass & 10.90 & 12.50 & 14.00 & 12.00 & 11.20 & 10.40 & 9.70 & 9.00 & 8.30 & 7.70 \\
\hline Biogas & 11.90 & 10.90 & 9.70 & 8.10 & 7.80 & 7.50 & 7.20 & 6.90 & 6.65 & 6.40 \\
\hline Typical mix & 13.80 & 12.30 & 10.10 & 8.10 & 7.50 & 7.00 & 6.60 & 6.20 & 6.15 & 6.10 \\
\hline
\end{tabular}

Using the DLR $2005+\mathrm{CO}_{2}$ price scenario the electricity costs of CCS power stations increase only slightly in comparison with those without $\mathrm{CO}_{2}$ capture. The remaining additional costs in 2050 of $0.2-0.6 \mathrm{ct} / \mathrm{kWh}$ show that CCS power stations are almost competitive with their conventional counterparts - if we assume that by then $\mathrm{CO}_{2}$ penalties will have reached $€ 35 / \mathrm{t}$. Table 12-8 shows the complete $\mathrm{CO}_{2}$ avoidance costs of CCS power stations including the costs of transport and storage of the $\mathrm{CO}_{2}$. Compared with those without these costs (cf. Fig. 12-5) they are $€ 10-13 / \mathrm{t}$ higher and amount in 2020 to $€ 40-45 / t$ for coal-fired power stations and $€ 60 / t$ for gas-fired combined cycle power stations.

The current values published by IPCC (2005a) allow us to put these results into context. That publication gives the following values for $\mathrm{CO}_{2}$ avoidance costs for the case of geological storage (Table S4; in relation to reference power station of same type): coal-fired thermal power station between $€_{2000} 31$ and $€_{2000} 73 / \mathrm{t} \mathrm{CO}_{2}$; coal-fired IGCC between $€_{2000} 21$ and $73 €_{2000} / \mathrm{tCO}_{2}$ and gas-fired combined cycle between $€_{2000} 41$ and $€_{2000} 94 / \mathrm{t} \mathrm{CO}$. In other words, the costs calculated in the present study are close to the average values found by the IPCC studies, which confirms the suitability as reference plant of the CCS power stations defined here.

\subsubsection{Cost Comparison with Plant Using Renewables}

On the basis of the costs calculated above, a comparison with plant using renewables can be conducted. Table 12-9 lists their future electricity costs (BMU 2005) (annual interest rate $10 \%$ ). Starting from today's average of $13.8 \mathrm{ct} / \mathrm{kWh}$ the 'NaturschutzPlus-new' scenario finds the cost of a representative mix of new renewables plant in 2020 to be $8.1 \mathrm{ct} / \mathrm{kWh}$ with a range between
$5.0 \mathrm{ct} / \mathrm{kWh}$ (wind offshore) and $19.3 \mathrm{ct} / \mathrm{kWh}$ (photovoltaic). Unlike fossil-fuelled plant, which is subject to fuel price increases, costs for renewable energy can be assumed to remain constant over the whole plant lifetime. By 2050 the cost of electricity from newly installed plant falls to about $6.1 \mathrm{ct} / \mathrm{kWh}$ (if the annual interest rate is assumed to be $6 \%$, as is the case in BMU 2005, the cost is $5.2 \mathrm{ct} / \mathrm{kWh})$.

The learning curves on which the cost trend is based are documented by BMU (2005). The cost development calculated here assumes that the pace of construction of new plant stated in the 'NaturschutzPlus-new' scenario will be maintained over the whole period. In this scenario for Germany the contribution of renewables to the electricity supply in 2050 is about $64 \%$, and the level of new construction of plant capacity which that requires provides the market volumes required for a successful learning process. However, it is also assumed that the momentum of growth in renewables described there for Germany will also extend in the foreseeable future at least to the European markets, and better still to the global ones.

Fig. 12-6 shows the economic prospects of the two options - renewables and CCS - for a representative case, namely, Germany's energy supply. The development trend of electricity generation costs from fossilfuelled power stations without CCS according to the EWI 2005 price scenario (broken lines) illustrates the general necessity of introducing effective climate protection instruments.

If they fail to take effect and at the same time fuel prices remain at a low level - as the EWI 2005 price scenario assumes - neither option would be an economic prospect in the long term. Further technological improvements in conventional power stations largely compensate for the rather small electricity price rises. Steeper 


\section{Electricity generation costs in ct/kWh}

DLR 2005 price forecast with $\mathrm{CO}_{2}$ penalty; interest rate $10 \% / \mathrm{a}$

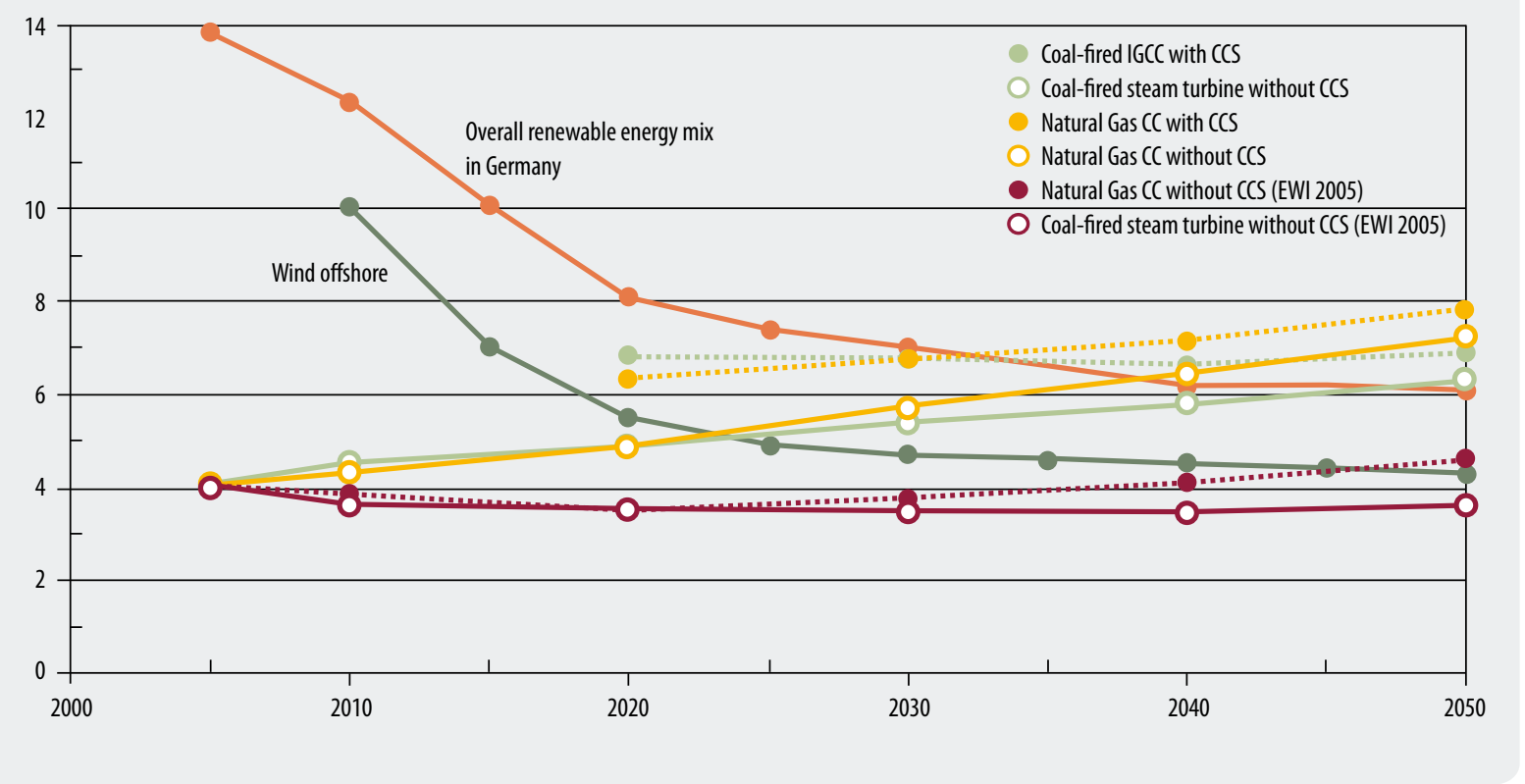

Fig. 12-6: Development of electricity generation costs (for new plant) for renewables, conventional gas- and coal-fired power stations and CCS power stations. Fuel prices after DLR 2005+ $\mathrm{CO}_{2}$ penalty; conventional power stations after EWI 2005 given for comparison.

price rises as per the DLR 2005 price scenario, and even more so a steady price increase for $\mathrm{CO}_{2}$ emission certificates (here rising to $€ 35 / \mathrm{t} \mathrm{CO}_{2}$ in 2050) increase the electricity generation costs of conventional power stations by $50 \%$ by 2030 and by $65 \%$ by 2050 to reach a level of 6.5 to $7.0 \mathrm{ct} / \mathrm{kWh}$. Thus they reach a level of costs close to those of effective climate protection options. The price increase, which will of course probably continue after 2050, is relatively similar for coal-fired and gas-fired power stations. Whereas for the former the steadily increasing $\mathrm{CO}_{2}$ penalty is most decisive, the rising gas price has the biggest effect for gas-fired power stations.

An effective reduction in $\mathrm{CO}_{2}$ emissions from fossilfuelled power stations requires (or causes) a level of electricity generation costs at the power station of between 7 and $8 \mathrm{ct} / \mathrm{kWh}$, if, as assumed here, market-ready CCS power stations are ready for operation by 2020 and are developed further over the following decades. So in the longer term coal-fired power stations in particular are economically interesting. Renewables, which today still have mean electricity generation costs of 12 to $13 \mathrm{ct} / \mathrm{kWh}$ (at annual interest rates of $10 \%$ ), could also achieve that level of costs by 2020 if their expansion continues at a similar pace to now. Since about 1990 their cost reduction has been following learning curves with learning rates between 15 and $20 \%$. These will decrease in the course of time, but will still be sufficient to reduce their level of costs - if introduced on a broad basis according to the NaturschutzPlus scenarios according to BMU (2004) - to values of around $6 \mathrm{ct} / \mathrm{kWh}$. If, as these sce- narios assume, the momentum of expansion of renewables in the electricity sector remains strong then they will be able to compete with CCS power stations as soon as the latter come into operation and will subsequently actually widen the gap still further. If fuel price rises are very small the situation for CCS plant turns out to be a little more favourable (compare the approx. $0.5 \mathrm{ct} / \mathrm{kWh}$ cheaper electricity generation costs of CCS plant according to the EWI 2005 price scenario in Table 12-7). But if CCS is to become competitive at an early stage, significantly higher $\mathrm{CO}_{2}$ certificate prices (of at least $€ 40-50 / t$ ) would have to come into effect by 2020 .

The above calculations are based on an annual interest rate of $10 \%$. If we calculate all the data with an annual interest rate of $6 \%$ instead, the more capital-intensive renewable energy technologies do even better. Renewables would already cost less than CCS power stations by 2025 (overall renewables mix), and offshore wind power would already be clearly cheaper than CCS power stations by 2020 . 


\subsection{Costs of Hydrogen Production from Fossil Resources with $\mathrm{CO}_{2}$ Capture}

\subsubsection{Hydrogen Production with $\mathrm{CO}_{2}$ Capture}

Here we present cost comparisons - analogous to those for electricity in section 12.1.1 - for the production of hydrogen from natural gas (steam reforming) and coal (coal gasification) with identical economic data and uniform fuel prices. Table 12-10 lists the corresponding starting data. As was the case for electricity, data from IEA (2003) and Williams (2002) were used here too. Information from NREL (Padro and Putsche 1999) and ETH Zurich (Fahrni 2002) was also included. The DLR reference data originate largely from the EU research project CASCADE MINTS (Krewitt and Schmid 2004), where the DLR developed the technology database for hydrogen production technologies. The data are identical with those for electricity generation (see also Table 12-11 for the fuel prices). But with $8,000 \mathrm{~h} / \mathrm{a}$ the reference load factor was set higher than that for electricity generation. All hydrogen-related data relate to the high heating value (HHV). In relation to the low heating value for hydrogen the efficiency figures would be lower by a factor of 1.18 , investment and generation costs higher by the same factor.

Table 12-11 shows the available data for plant generating hydrogen from natural gas (steam reforming), coal (gasification) and electricity (electrolysis) without $\mathrm{CO}_{2}$ capture, coming on stream in 2020. These are largescale plants with several hundred MW of hydrogen production capacity. Only the data from Fahrni (2002; provided for comparison) relate to today's status.

The data are relatively uniform for steam reforming of natural gas, which is already practised on a large scale today. According to the data, at natural gas costs of $€ 5.70 / G J$ (2020, DLR 2005 price scenario) hydrogen can be produced at a cost of around $€ 8.50 / \mathrm{GJ}$. Today's generation costs are around $€ 6.50 / \mathrm{GJ}$ (gas price $€ 4.30 /$ GJ). For coal gasification the data are less consistent. The very favourable figures given by Williams (2002) and IEA (2003) (here only for facilities with $\mathrm{CO}_{2}$ capture) contrast with much higher figures cited by Padro and Putsche (1999) and Fahrni (2002). This applies both to investment costs and to running costs, although in Fahrni (2002) the latter can only be derived indirectly. The reference data taken from Krewitt and Schmid (2004) lie roughly in the middle of the range and can therefore from today's perspective be regarded as relatively representative. Thus hydrogen from coal is available in 2020 for approx. $€ 9.50 / \mathrm{GJ}$ (coal price $=€ 2.30 / \mathrm{GJ}$; DLR 2005 price scenario); at today's coal price (€1.80/ GJ) the generation costs would amount to $€ 8.50 / \mathrm{GJ}$. For hydrogen from coal the dependency on the fuel price is considerably smaller than for hydrogen from natural gas, due to the higher capital costs.

The reference technology for electrolysis is medium/ high-pressure alkaline electrolysis in a form that can
Table 12-10: Data for calculating the cost of generating hydrogen from fossil fuels

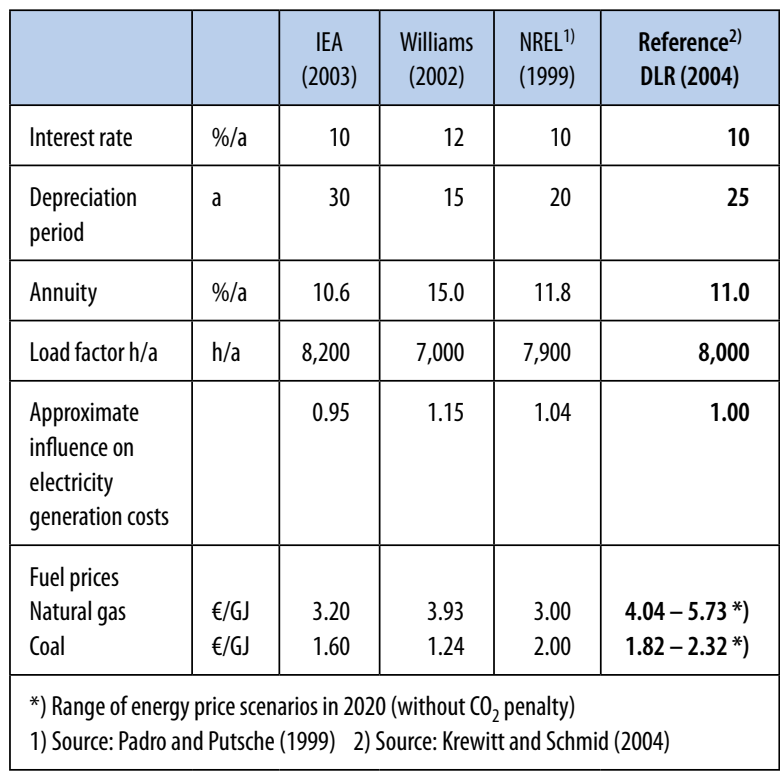

be implemented in 2020. Although the sources used here differ little in their estimates of costs, there are still clear differences in their estimates of possible efficiency rates. But because today electrolysers already exhibit efficiencies of $65-70 \%$ (LHV) or 77-84\% (HHV) (cf. Fahrni 2002), the efficiency figure for future reference technology was set at $77 \%$ (LHV) or $91 \%$ (HHV) following Krewitt and Schmid (2004). At an electricity cost of $4 \mathrm{ct} / \mathrm{kWh}$ and a load factor of $8,000 \mathrm{~h} / \mathrm{a}$ (e.g. with hydropower) it would be possible to achieve hydrogen costs of $€ 14 / \mathrm{GJ}$ (or $5.04 \mathrm{ct} /$ $\mathrm{kWh}_{\mathrm{t}}$ ). Table 12-12 compares in the same way the data for hydrogen production from natural gas and coal with capture of $\mathrm{CO}_{2}$. As in the case of electricity generation, all data assume large-scale plant capable of coming on stream in 2020 after already having undergone a certain learning process. That would mean that pilot plants, whose costs would be higher, would have to be available by about 2010 if the necessary experience is to be gathered and translated into practice in time. By 2020 the cost of hydrogen from low- $\mathrm{CO}_{2}$ natural gas reforming could be between $€ 7 / G J$ and $€ 8 /$ GJ with a natural gas price of $€ 4.10 / G J$ (EWI 2005) or between $€ 9 / \mathrm{GJ}$ and $€ 11 / \mathrm{GJ}$ with a natural gas price of $€ 5.70 / G J$ (DLR 2005). Because the estimates for fixed and variable running costs differ widely, the degree of dependency of hydrogen costs on the natural gas price differs widely in the different sources. For low$\mathrm{CO}_{2}$ hydrogen from coal the range of estimates is relatively broad with $€ 8-11 / \mathrm{GJ}$ (coal price $€ 1.80 / \mathrm{GJ}$; EWI 2005 ) or $€ 9-12 / G J$ (coal price $€ 2.30 / G J$; DLR 2005). The selected reference case after Krewitt and Schmid (2004) lies roughly in the middle of that range. 


\begin{tabular}{|c|c|c|c|c|c|c|}
\hline & & $\begin{array}{c}\text { IEA } \\
(2003)\end{array}$ & $\begin{array}{l}\text { Williams } \\
\text { (2002) }\end{array}$ & $\begin{array}{l}\text { NREL1) } \\
\text { (1999) }\end{array}$ & $\begin{array}{l}\text { ETH Zürich }^{2)} \\
\left.(2002)^{* * *}\right)\end{array}$ & $\begin{array}{l}\text { Reference }^{3)} \\
\text { DLR (2004) }\end{array}$ \\
\hline \multicolumn{7}{|l|}{ Natural gas steam reforming } \\
\hline Output & $\mathrm{MW}_{\mathrm{H} 2}$ & & 810 & 960 & 1100 & 350 \\
\hline Efficiency & $\%$ & & 81 & $87^{*}$ & 90 & 87 \\
\hline Investment & $€ / \mathrm{kW}_{\mathrm{H} 2}$ & & 251 & 377 & & 325 \\
\hline Running and maintenance costs & $\% \operatorname{lnv} . / a$ & & 5 & 5 & & 5 \\
\hline $\begin{array}{l}\mathrm{H}_{2} \text { costs } 2020 \\
\cdot \text { EWI } 2005 \\
\cdot \text { DLR } 2005 \\
\cdot \text { DLR } 2005+\mathrm{CO}_{2}\end{array}$ & $€ / G J$ & & $\begin{array}{l}6.45 \\
8.47\end{array}$ & $\begin{array}{l}6.76 \\
8.68\end{array}$ & $5.3-6.5$ & $\begin{array}{l}6.47 \\
8.39 \\
9.13\end{array}$ \\
\hline \multicolumn{7}{|l|}{ Coal gasification } \\
\hline Output & $\mathrm{MW}_{\mathrm{H} 2}$ & & 560 & 600 & 1,100 & 560 \\
\hline Efficiency & $\%$ & & 70.3 & $\left.70^{*}\right)$ & $68-74$ & 70 \\
\hline Investment & $€ / \mathrm{kW}_{\mathrm{H} 2}$ & & 620 & 897 & & 755 \\
\hline Running and maintenance costs & $\% \operatorname{lnv} . / a$ & & $5^{* * 1}$ & $7^{* *)}$ & & $7^{* * 1}$ \\
\hline $\begin{array}{l}\mathrm{H}_{2} \text { costs } 2020 \\
\text { - EWI } 2005 \\
\text { - DLR } 2005 \\
\text { - DLR } 2005+\mathrm{CO}_{2} \\
\end{array}$ & $€ / G J$ & & $\begin{array}{l}7.09 \\
8.16\end{array}$ & $\begin{array}{r}9.27 \\
10.34\end{array}$ & $13.2-16.3$ & $\begin{array}{r}8.38 \\
9.45 \\
12.15 \\
\end{array}$ \\
\hline \multicolumn{7}{|l|}{ Elektrolyse } \\
\hline Output & $\mathrm{MW}_{\mathrm{H} 2}$ & n.a. & 500 & & $>100$ & 500 \\
\hline Efficiency & $\%$ & 85 & 80 & & $76-88$ & 91 \\
\hline Investment & $\begin{array}{l}€ / \mathrm{kW}_{\mathrm{H} 2} \\
€ / \mathrm{kW}_{\mathrm{el}}\end{array}$ & $\begin{array}{l}420 \\
355 \\
\end{array}$ & $\begin{array}{l}425 \\
340 \\
\end{array}$ & & & $\begin{array}{l}396 \\
360 \\
\end{array}$ \\
\hline Running and maintenance costs & $\% \operatorname{lnv} . / a$ & 3 & 3 & & & 2 \\
\hline $\begin{array}{l}\text { H2 costs } 2020 \text { with electricity cost } \\
4 \mathrm{ct} / \mathrm{kWh}\end{array}$ & $€ / G J$ & 15.10 & 15.97 & & $14-16.5$ & 14.01 \\
\hline \multicolumn{7}{|c|}{$\begin{array}{l}\text { *) Figure taken from DLR reference } \\
\text { **) Plus variable running costs } \\
\text { ***) Data for current technology; conversion to match DLR data only approximately possible }\end{array}$} \\
\hline
\end{tabular}

Table 12-11:

Data for hydrogen

production
Altogether the range of resulting costs is considerably greater than for conventional plant without $\mathrm{CO}_{2}$ capture. Whereas IEA (2003) and Williams (2002) assume relatively favourable conditions for future plants, NREL estimates the costs considerably higher, as can also be seen from the additional costs. Capturing most of the $\mathrm{CO}_{2}$ increases the cost of hydrogen by about $€ 1.5$ to $2 /$ $\mathrm{GJ}$ (or by 20 to $25 \%$ compared with plant without $\mathrm{CO}_{2}$ capture) with no fundamental difference between gasbased and coal-based plants. A comparison with plant without $\mathrm{CO}_{2}$ capture using the DLR $2005+\mathrm{CO}_{2}$ price scenario (in other words taking account of future $\mathrm{CO}_{2}$ penalties) shows that for natural gas reforming, plant without capture is still cheaper (row 'DLR 2005+CO' in Table 12-13). In this case hydrogen from coal gasification with $\mathrm{CO}_{2}$ capture would be cheaper because the $\mathrm{CO}_{2}$ penalty for the conventional plant makes a much bigger difference (the additional costs for CCS hydrogen that arise due to the existence of residual emissions of $\mathrm{CO}_{2}$ were ignored here).

Like in the case of electricity generation, here too the rising prices of fossil fuels must be taken into account for the longer-term perspective (Table 12-14 and Fig. 12-7 without $\mathrm{CO}_{2}$ capture). Plant using natural gas is currently and in the medium term more cost-effective 
Table 12-12:

Data for hydrogen generation plant using fossil feedstock in 2020 and their generation costs on the basis of the DLR data (with $\mathrm{CO}_{2}$, capture, without transport and final storage); figures relate to high heating value $\left(\mathrm{HHV}=3.55 \mathrm{kWh} / \mathrm{Nm}^{3}\right)$
Table 12-13:

Difference in data of

hydrogen generation plant with and without $\mathrm{CO}_{2}$ capture (without transport and final storage of $\mathrm{CO}_{2}$ )

\begin{tabular}{|c|c|c|c|c|c|}
\hline & & $\begin{array}{c}\text { IEA } \\
(2003)\end{array}$ & $\begin{array}{c}\text { Williams } \\
(2002)\end{array}$ & $\begin{array}{l}\text { NREL }{ }^{1)} \\
\text { (1999) }\end{array}$ & $\begin{array}{l}\text { Reference }^{2)} \\
\text { DLR (2004) }\end{array}$ \\
\hline \multicolumn{6}{|l|}{ Natural gas steam reforming } \\
\hline Output & $\mathrm{MW}_{\mathrm{H} 2}$ & n.a. & 780 & n.a. & 335 \\
\hline Efficiency & $\%$ & 79 & 78 & n.a. & 80 \\
\hline Investment & $€ / \mathrm{kW}_{\mathrm{H} 2}$ & 260 & 460 & 660 & 540 \\
\hline Running and maintenance costs & $\%$ Inv./a & $\left.2.5^{*}\right)$ & 5 & 5 & 5 \\
\hline $\mathrm{H}_{2}$ costs 2020 & $€ / G J$ & & & & \\
\hline - EWI 2005 & & 6.36 & 7.76 & 8.81 & 8.08 \\
\hline - DLR 2005 & & 8.47 & 9.90 & 10.92 & 10.16 \\
\hline \multicolumn{6}{|l|}{ Coal gasification } \\
\hline Output & $\mathrm{MW}_{\mathrm{H} 2}$ & n.a. & 540 & n.a. & 520 \\
\hline Efficiency & $\%$ & 75 & 67.7 & n.a. & 65 \\
\hline Investment & $€ / \mathrm{kW}_{\mathrm{H} 2}$ & 880 & 770 & 1220 & 965 \\
\hline Running and maintenance costs & $\% \operatorname{lnv} . / \mathrm{a}$ & $5^{*}$ & 5 & $\left.6^{*}\right)$ & $\left.6^{*}\right)$ \\
\hline $\mathrm{H}_{2}$ costs 2020 & $€ / G J$ & & & & \\
\hline - EWI 2005 & & 8.59 & 7.20 & 13.47 & 9.92 \\
\hline - DLR 2005 & & 9.45 & 7.78 & 14.34 & 10.63 \\
\hline 1) Source: Padro and Putsche (1999) & \multicolumn{5}{|c|}{ 2) Source: Krewitt and Schmid (2004) } \\
\hline
\end{tabular}

\begin{tabular}{|c|c|c|c|c|c|}
\hline & & $\begin{array}{c}\text { IEA } \\
(2003)\end{array}$ & $\begin{array}{c}\text { Williams } \\
\text { (2002) }\end{array}$ & $\begin{array}{l}\text { NREL }{ }^{1)} \\
\text { (1999) }\end{array}$ & $\begin{array}{l}\text { Reference }^{2)} \\
\text { DLR (2004) }\end{array}$ \\
\hline \multicolumn{6}{|l|}{ Natural gas steam reforming } \\
\hline Efficiency & $\%$ & & $-3,0$ & $(-7,0)$ & $-7,0$ \\
\hline Investment & $€ / \mathrm{kW}_{\mathrm{H} 2}$ & & +210 & +283 & +215 \\
\hline $\begin{array}{l}\mathrm{H}_{2} \text { costs } 2020 \\
\text { - EWI } 2005 \\
\cdot \text { DLR } 2005 \\
\text { - DLR } 2005+\mathrm{CO}_{2}\end{array}$ & $€ / G J$ & $\begin{array}{l}\text { No data on plant } \\
\text { without } \mathrm{CO}_{2} \text { capture }\end{array}$ & $\begin{array}{l}+1,31 \\
+1,43\end{array}$ & $\begin{array}{l}+2,05 \\
+2,24\end{array}$ & $\begin{array}{l}+1,61 \\
+1,76 \\
+1,03\end{array}$ \\
\hline \multicolumn{6}{|l|}{ Coal gasification } \\
\hline Efficiency & $\%$ & & $-2,6$ & $(-5,0)$ & $-5,0$ \\
\hline Investment & $€ / \mathrm{kW}_{\mathrm{H} 2}$ & & +150 & +323 & +210 \\
\hline $\begin{array}{l}\mathrm{H}_{2} \text { costs } 2020 \\
\text { - EWI } 2005 \\
\cdot \text { DLR } 2005 \\
\text { - DLR } 2005+\mathrm{CO}_{2}\end{array}$ & $€ / G J$ & $\begin{array}{l}\text { No data on plant } \\
\text { without } \mathrm{CO}_{2} \text { capture }\end{array}$ & $\begin{array}{l}+0,94 \\
+0,96\end{array}$ & $\begin{array}{r}+1,80 \\
+1,85\end{array}$ & $\begin{array}{r}+1,51 \\
+1,57 \\
-1,13\end{array}$ \\
\hline 1) Source: Padro and Putsche (1999) & 2) Sour & vitt and Schmid (2004 & & & \\
\hline
\end{tabular}


Table 12-14: Hydrogen costs of reference plant (start-up 2020) in relation to fuel price; plant without $\mathrm{CO}_{2}$ capture

\begin{tabular}{|c|c|c|c|c|c|}
\hline Without $\mathrm{CO}_{2}$ & 2005 & 2020 & 2030 & 2040 & 2050 \\
\hline & $€ / G J_{H H V}$ & $€ / G J_{H H V}$ & $€ / G J_{H H V}$ & $€ / G J_{H H V}$ & $€ / G J_{H H V}$ \\
\hline EWI 2005 & & & & & \\
\hline $\begin{array}{l}\text { Natural gas- } \\
\text { steam reforming }\end{array}$ & 6.5 & 6.47 & 6.92 & 7.72 & 8.68 \\
\hline Coal gasification & 8.5 & 8.38 & 8.61 & 9.06 & 9.28 \\
\hline DLR 2005 & & & & & \\
\hline $\begin{array}{l}\text { Natural gas- } \\
\text { steam reforming }\end{array}$ & 6.5 & 8.39 & 9.48 & 10.63 & 11.87 \\
\hline Coal gasification & 8.5 & 9.45 & 9.79 & 10.24 & 10.80 \\
\hline DLR $2005+\mathrm{CO}_{2}$ & & & & & \\
\hline $\begin{array}{l}\text { Natural gas- } \\
\text { steam reforming }\end{array}$ & 6.5 & 9.13 & 10.76 & 12.71 & 14.21 \\
\hline Coal gasification & 8.5 & 12.15 & 13.95 & 15.75 & 17.21 \\
\hline
\end{tabular}

than plant using coal. However, the clear sensitivity of steam reforming to rising natural gas prices is discernible as the most likely trend from today's perspective, especially when the DLR 2005 price scenario is used as the basis. Only if fossil fuels are burdened with the costs of their $\mathrm{CO}_{2}$ emissions (DLR 2005 $+\mathrm{CO}_{2}$ price scenario) does steam reforming become the cheaper form of production in the longer term. If we assume that prices will follow the DLR 2005 scenario, today's hydrogen costs will roughly double.

When we turn to the corresponding figures for plant with $\mathrm{CO}_{2}$ capture (Table 12-15) the natural gas and coal options move closer together. Because capital costs are higher, the relative influence of fuel costs is smaller. Assuming that corresponding large-scale commercial plant was to be available by 2020 , low- $\mathrm{CO}_{2}$ hydrogen from fossil sources could be made available at costs between $€ 8.10$ and 11.00/GJ. By 2050 these costs (for plant coming on stream in 2020) would increase to about $€ 10.50$ to $14.00 / \mathrm{GJ}$. If price developments followed DLR 2005 hydrogen from coal - costing around $€ 12.50 / \mathrm{GJ}$ - would then be a good deal cheaper than hydrogen from natural gas.

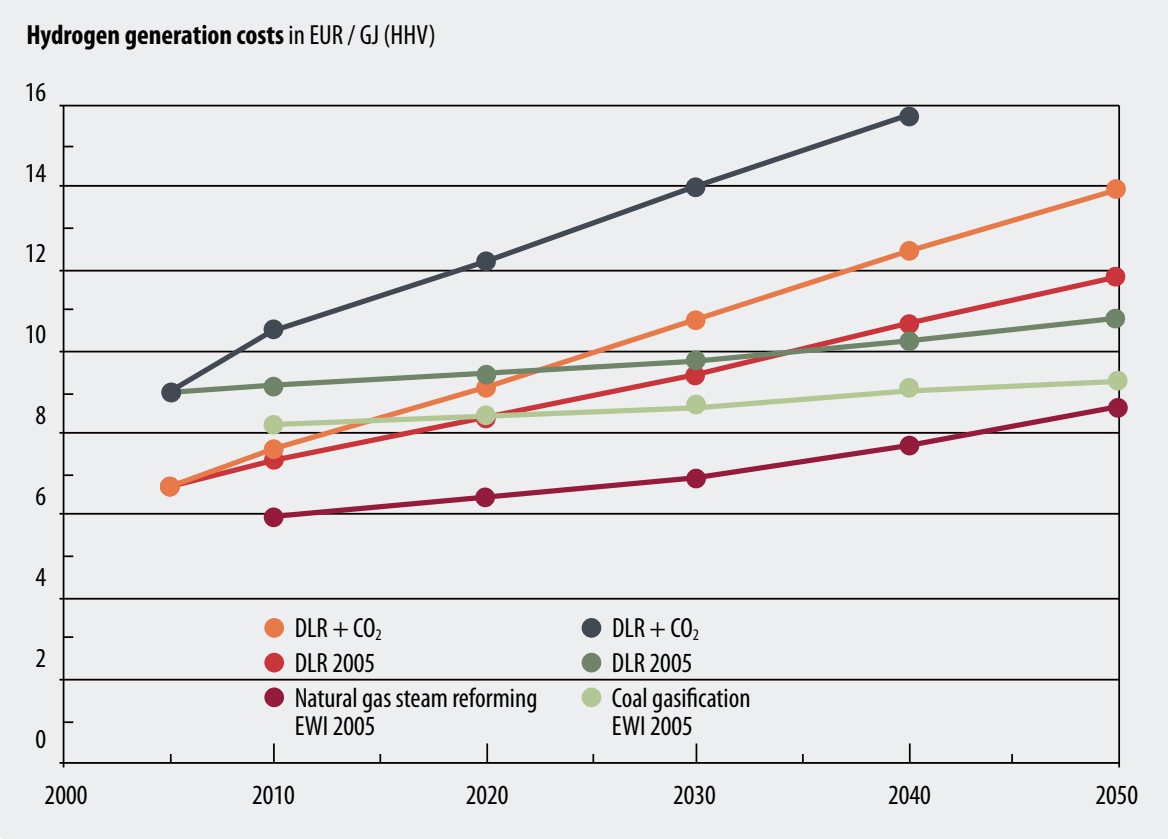

Fig. 12-7:

Hydrogen generation costs in relation to prices for natural gas and coal (three price variants through to 2050) for plant without $\mathrm{CO}_{2}$ capture 
Table 12-15: Hydrogen costs of reference plant (start-up 2020) in relation to fuel price; plant with $\mathrm{CO}_{2}$ capture, without transport and final storage

\begin{tabular}{|c|c|c|c|c|}
\hline With $\mathrm{CO}_{2}$ capture & 2020 & 2030 & 2040 & 2050 \\
\hline & $€ / G J_{H H V}$ & $€ / G J_{H H V}$ & $€ / G J_{H H V}$ & $€ / G J_{H H V}$ \\
\hline \multicolumn{5}{|l|}{ EWI 2005} \\
\hline Natural gas steam reforming & 8.08 & 8.57 & 9.43 & 10.48 \\
\hline Coal gasification & 9.89 & 10.13 & 10.61 & 10.84 \\
\hline \multicolumn{5}{|l|}{ DLR 2005} \\
\hline Natural gas steam reforming & 10.16 & 11.35 & 12.60 & 13.95 \\
\hline Coal gasification & 11.02 & 11.38 & 11.85 & 12.44 \\
\hline
\end{tabular}

\subsubsection{Accounting for the Costs of Transport and Storage of $\mathrm{CO}_{2}$}

The costs of compressing, transporting and storing the captured $\mathrm{CO}_{2}$ have not so far been included in the costs of CCS hydrogen production. Relying on the same data and assumptions as for power stations, we find that these costs will be in the range between $€ 16$ and 34/t $\mathrm{CO}_{2}$. Steam reforming produces about $0.05 \mathrm{t} \mathrm{CO}$ per GJ of hydrogen, while with coal gasification the figure is about $0.1 \mathrm{t} \mathrm{CO}_{2}$ per GJ. In each case about $85 \%$ is captured. So assuming disposal costs are a mid-range $€ 20 / \mathrm{t}$ $\mathrm{CO}_{2}$, the additional costs incurred are $€ 0.85 / \mathrm{GJ} \mathrm{H}_{2}$ for steam reforming and $€ 1.70 / \mathrm{GJ}_{2}$ for coal gasification. Table 12-16 shows the resulting total (ex works) hydrogen costs for steam reforming and coal gasification.

\subsubsection{Cost Comparison with Hydrogen from Renewables}

The costs thus determined can be compared with those for electrolytic hydrogen production using renewable sources of energy. Figure 12-8 first of all shows the cost of the reference electrolysis process for an electricity cost range of 2.5 to $8 \mathrm{ct} / \mathrm{kWh}_{\mathrm{el}}$ and load factors between 2,000 and $8,000 \mathrm{~h} / \mathrm{a}$. The achievable hydrogen costs corresponding to different electricity generation costs from renewables are indicated (see section 12.1.5).

By 2020 hydrogen can be produced using wind energy (e.g. offshore with $4,000 \mathrm{~h} / \mathrm{a}$ ) at about $€ 19 / \mathrm{GJ}$. Only if cheap hydropower is available (on a large scale) the generation costs could be reduced to $€ 13-14 / G J$. In 2020 electricity from solar thermal power stations would still produce considerably more expensive hydrogen. The lower broken line (status 2040) can be regarded as the longer-term achievable limit, showing that renewable hydrogen with $€ 15 / \mathrm{GJ}$ (wind, $4,000 \mathrm{~h} / \mathrm{a}$ ) to $€ 20 / \mathrm{GJ}$
Table 12-16: Hydrogen costs of reference plant (start-up 2020) in relation to fuel price; plant with $\mathrm{CO}_{2}$ capture, with transport and final storage

\begin{tabular}{|l|r|r|r|l|}
\hline $\begin{array}{l}\text { With } \mathrm{CO}_{2} \text { capture, } \\
\text { with transport and } \\
\text { final storage }\end{array}$ & 2020 & 2030 & 2040 & 2050 \\
\hline & $€ / \mathrm{GJ}_{\text {HHV }}$ & $€ / \mathrm{GJ}_{\text {HHV }}$ & $€ / \mathrm{GJ}_{\text {HHV }}$ & $€ / \mathrm{GJ}_{\text {HHV }}$ \\
\hline EWI 2005 & & & & \\
Natural gas steam reforming & 8.93 & 9.42 & 10.28 & 11.33 \\
Coal gasification & 11.59 & 11.83 & 12.31 & 12.54 \\
& & & & \\
DLR 2005 & 10.91 & 12.20 & 13.45 & 14.80 \\
Natural gas steam reforming & 12.72 & 13.08 & 13.55 & 14.14 \\
Coal gasification & & & & \\
\hline
\end{tabular}

(solar electricity, 6,000 h/a) always remains a relatively expensive source of energy. In return it produces practically no $\mathrm{CO}_{2}$ during its production, in contrast to 'low$\mathrm{CO}_{2}{ }^{\prime} \mathrm{CCS}$ hydrogen, which is still burdened with 0.017

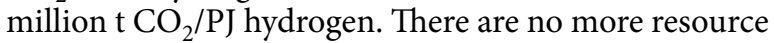
problems either.

'Conventional' electricity (from nuclear power or low$\mathrm{CO}_{2}$ fossil-fuelled power stations) can also be used for electrolytic generation of $\mathrm{CO}_{2}$-free or low- $\mathrm{CO}_{2}$ hydrogen. Fig. 12-8 shows the resulting hydrogen generation costs. According to the calculated electricity generation costs (7-9 ct/kWh), the path of using 'fossil' electricity is considerably more expensive than producing hydrogen directly from coal or natural gas and can therefore be excluded. The option of electricity from nuclear power stations remains. If we follow the IEA's figures, electricity from new nuclear power stations can be produced at a cost of around 3.0 to $3.5 \mathrm{ct} / \mathrm{kWh}$ (load factor about $8,000 \mathrm{~h} / \mathrm{a}$ ). That would make it possible to achieve hydrogen costs of around $€ 12-14 / \mathrm{GJ}$ which would be comparable with those for hydrogen from hydropower in Fig. 12-8 below. If electricity from nuclear power was costed at about $5 \mathrm{ct} / \mathrm{kWh}(8,000 \mathrm{~h} / \mathrm{a})$ that would be comparable with wind power $(4 \mathrm{ct} / \mathrm{kWh}, 4,000 \mathrm{~h} / \mathrm{a})$. So whether nuclear power can be an option for hydrogen production depends in the first place on the political assessment of nuclear power (keywords: risk assessment, external costs).

This is also demonstrated by a comparison of fossil and renewable generation options. Fig. 12-9 compares hydrogen production from natural gas and coal (costs as per Table 12-16) with electrolytic hydrogen production using wind and hydropower. However, the scarcity of the resource means that using hydropower to produce hydrogen will remain at best a market niche. Potential for large-scale renewable hydrogen production exists only via wind - and in the long term especially via 
Hydrogen costs in EUR/GJ (HHV)

Elektrolysis status 2020: Efficiency $91 \%$ (HHV), 400 EUR/kWH ${ }_{2}$ (HHV)

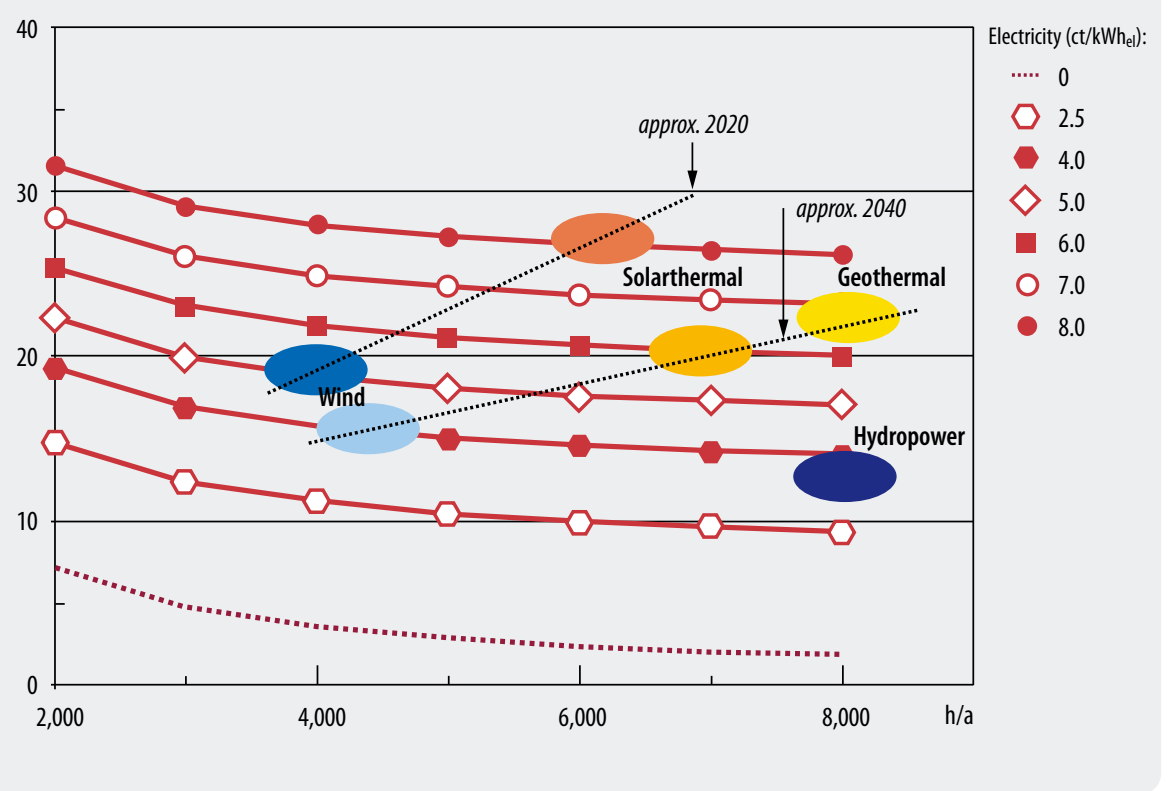

Fig. 12-8:

Cost of reference electrolysis and approximate hydrogen costs given use of windgenerated electricity (3,500-4,500 h/a), solar thermal power stations (6,000-7,000 h/a; electricity costs at border), and geothermal and hydropower $(8,000 \mathrm{~h} / \mathrm{a})$ for 2020 and 2040

Fig. 12-9:

Cost comparison of hydrogen production from low$\mathrm{CO}_{2}$ plant using natural gas and coal $(8,000 \mathrm{~h} / \mathrm{a})$ with electrolytic hydrogen from wind power and hydropower (todayís hydrogen costs are for fossil plant without $\mathrm{CO}_{2}$ capture) 
solar thermal electricity. In 2020 cheap hydrogen from renewable electricity (wind) will still be about twice as expensive. Compared with low- $\mathrm{CO}_{2}$ hydrogen from natural gas the cost gap can close in the longer term. According to the cost assumptions used here, low- $\mathrm{CO}_{2}$ hydrogen from coal remains cheaper in the longer term too because roughly equal costs would require electricity from renewable sources to cost about 3-3.5 ct/kWh. However, if fossil plant is operated for less than 8,000 $\mathrm{h} / \mathrm{a}$ the hydrogen production costs rise accordingly.

It should be pointed out that the cost comparison is not yet complete. In particular a comparison of additional infrastructure costs is still lacking. Production from fossil resources requires very large centralised plants, which requires a fully developed transport and distribution structure for hydrogen. Systems based on renewables could have advantages here, although they may also involve not insignificant additional costs (e.g. wind offshore). The option of producing hydrogen from biomass has not been considered here, but it must be assumed that the potential is very limited.

Overall, a comparison of low- $\mathrm{CO}_{2}$ and $\mathrm{CO}_{2}$-free options for hydrogen turns out quite differently than was the case for electricity generation. In the case of electricity the available data showed no cost advantage for the fossil option (section 12.1), whereas for hydrogen production the fossil option fared better. Before making a final assessment in this matter, however, it must be remembered that electricity is an established medium and that decisions about expanding climate-friendly technologies will have to be made relatively quickly. Hydrogen on the other hand will not be required as a fuel in relevant quantities before 2030 (probably not until 2050) (UBA 2006) so it will not be able to contribute to climate protection until then. That will probably be too late for the substantial climate protection efforts that are required by 2050 . This also clearly reduces the potential economic advantage of low- $\mathrm{CO}_{2}$ hydrogen from fossil sources and its importance for climate protection. The scenario analyses in chapter 14 go into this question in greater detail. 


\section{Chapter 13}

\section{Other Energy Sector Criteria}

As well as considering the purely economic aspects of the costs of generating electricity and hydrogen, other aspects relating to the energy sector are also relevant for the implementation of CCS. Selected factors (listed in Table 9-1) are discussed in the following.

\subsection{Social Acceptance}

Numerous surveys and studies have examined the social acceptance of technologies for exploiting renewable sources of energy. Although there are now several hundred local campaigns against wind power in Germany as well as certain reservations against the use of biomass, a large majority of the German population nonetheless has a positive attitude towards the use of renewables. Comparable studies for CCS have not yet been conducted in Germany, and it must also be noted that public knowledge about CCS is still threadbare. To that extent the introduction of CCS does not encounter a preconceived public opinion. The general strategy and wording of argumentation could therefore be decisive in influencing public opinion for or against CCS. The extent to which, for example, the basic choice of vocabulary (for example ' $\mathrm{CO}_{2}$-free'/'zero-carbon' versus 'low- $\mathrm{CO}_{2}$ ' and ' $\mathrm{CO}_{2}$ storage' versus ' $\mathrm{CO}_{2}$ dumping') could have the effect of increasing or reducing acceptance has yet to be properly investigated.

\subsection{Transferability of Technology to Developing Countries}

Increasingly the criterion of transferability to developing countries is being used to measure the suitability of technologies for responding to climate change. Although the industrialised countries still have the highest share in total energy consumption - and produce the most $\mathrm{CO}_{2}$ - it is expected that the situation will be reversed in the coming decades and that the developing countries will come to be the biggest energy consumers and biggest producers of $\mathrm{CO}_{2}$ emissions (IEA 2004). That means that for a global emissions reduction strategy, technologies that can only be applied in the mature energy infrastructures of industrialised countries are automatically inferior to those that can be applied in developing countries. The level of complexity of a technology is measured not only by the controllability of the technology itself but also - especially - by whether it can be integrated into the existing energy system. Criteria for this are:

- Controllability of the technology in the power station,

- Controllability of the technology in the overall system

Relevant criteria for controllability in the power station include the level of training of engineers and the availability of spare parts. In many developing countries these two factors are simply not available, and thus represent limiting factors. ${ }^{1}$

Where technical or economic circumstances represent limiting factors, technologies have to be as robust as possible; i.e. they must be designed to be as uncomplicated as possible in order not to themselves become a limiting factor within the system as a whole. The application of post-combustion technology - as an addition to conventional power station technology - represents an increase in the degree of complexity. In developing countries it would be necessary to test whether these additions can be reliably controlled by the local engineers and whether the low flexibility of such a system can be reconciled with the existing energy infrastructure. Partially or completely new technologies such as IGCC and oxyfuel may require even higher standards of knowledge and training than post-combustion technologies.

On the other hand, controlling offshore wind generators could possibly place lower requirements on training of skilled personnel even though the turbines are also high-technology products, and servicing in particular is a complex matter. The aspect of whether offshore wind farms are compatible with existing power grid infrastructures in developing countries - and whether they are controllable - appears problematic. New challenges would arise here, especially for generation and power grid planning.

Solar thermal power stations are comparable with conventional power stations; the difference is simply that the heat for operating the turbines is gained from solar radiation. To that extent solar thermal power stations do not fundamentally require any higher standards of training for skilled personnel than those required for normal operation of conventional power stations.

1 At the same time, it must be emphasised that great progress has been made in some areas of technical training in developing countries. 


\subsection{Technology Leadership and Export Opportunities}

In the field of CCS German and US-American companies and research institutes are important leaders. Relatively speaking, the United States already provides considerably more R\&D funding than other countries. That means that promoting CCS in developing countries could benefit primarily American companies.

\subsection{Import Dependency}

Increasing dependency on energy imports is a general trend in very many countries. Here we describe the situation for Germany and the European Union, which is symptomatic for other countries. Germany is more than $70 \%$ dependent on energy imports; for individual fuels the figures are: oil, approx. $97 \%$; natural gas, approx. $80 \%$; nuclear fuel, $100 \%$ and coal more than $50 \%$ (the latter determined not by the volume of domestic reserves but by the high cost of extraction). Only lignite is available domestically in sufficient quantities for electricity generation. Decreasing domestic production will cause import dependency to increase significantly in the coming years. This tendency can be observed in many industrialised countries, and import dependency is increasing at the EU level too. This is especially significant in relation to CCS because capturing $\mathrm{CO}_{2}$ significantly reduces conversion efficiency.

The supply structure for coal is characterised by two main features:

- The number of suppliers is relatively large, and

- The exporting countries are generally politically stable.

Coal is available in sufficient quantities so we can assume that structural supply shortages will probably not occur in the coming decades. For the aforementioned reasons, import dependency can be treated as primarily a problem of market economics.

The situation for natural gas is more problematic than for coal. For natural gas the supplier structure - especially the distribution of economically exploitable resources - is less diverse than for coal. Germany's main suppliers are Russia, Norway and the Netherlands (see Fig. 13-1). Because the infrastructure is capital-intensive and requires long-term planning, in Germany in recent decades there has been a kind of 'natural monopoly' of various suppliers and of the various companies positioned between supplier and consumer (e.g. gas distributors). The capital intensity of the gas pipelines - which represent the biggest share of overall costs - was also the factor that has to date prevented suppliers from further afield from entering the market. For example, neither Germany nor the European Union imports natural gas from the Persian Gulf (except for small amounts of

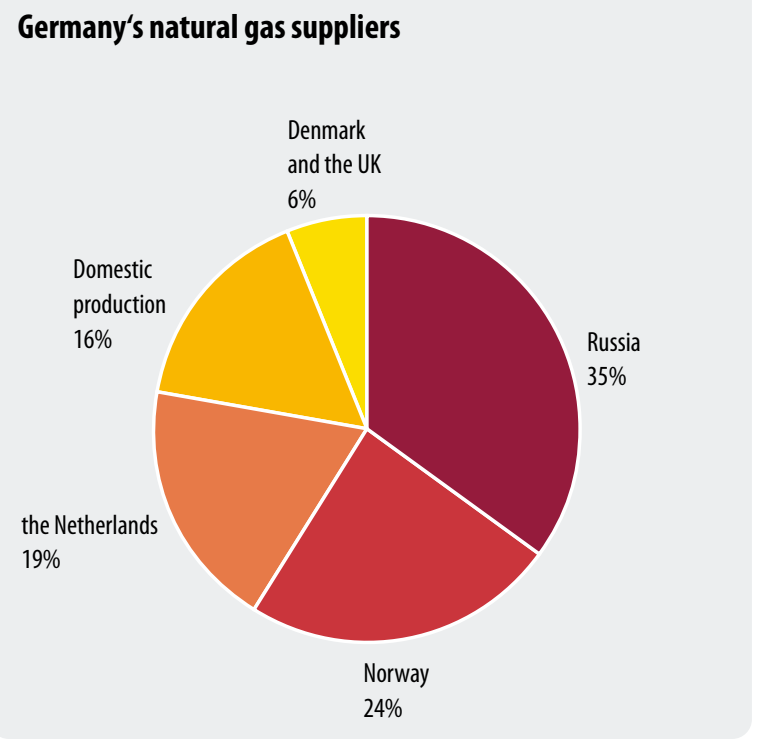

Fig. 13-1: Germany's natural gas suppliers (Ruhrgas 2005)

LNG/LPG). However, this could change in the coming years for two reasons:

- Gas prices have risen steeply, which would make it potentially profitable to build and operate longer pipelines,

- Rising prices make the use of liquefied natural gas (LNG) competitive, meaning that gas can also be transported by ship and taken flexibly to the markets.

Because of the restricted number of exporters, increasing import dependency, e.g. in the case of natural gas, is not only an economic problem but increasingly also a political one. By contrast, the use of domestic renewables can help to reduce dependency on fossil fuel imports and thus maintain political leverage.

Large-scale import of renewable electricity by contrast, would create new dependencies through the fixed transmission structures for international electricity transport. In the case of solar thermal electricity generation in North Africa the transmission lines would pass through several countries and could easily be disrupted (e.g. by terrorism).

\subsection{Security Policy Implications}

The influence of import dependencies on political leverage is closely tied to the ensuing security policy consequences. The greater the dependency on politically unstable states and hence the vulnerability to interruptions of supply, the more important the international dimension of security policy becomes. Vulnerability 
to interruptions of supply arises when supply routes become extended and more difficult to protect. The EU Commission's green paper on 'Security of Energy Supply' addresses the security importance of energy supply and proposes possible first steps towards a comprehensive European response. These include developing a coherent European energy foreign policy (including setting up long-term energy cooperation arrangements with producers and transit countries), developing a political concept for safeguarding and diversifying energy supply, and other approaches (EU 2006).

At this point we can note that an increase in natural gas imports through the introduction of large-scale CCS would exacerbate security problems. Changes in dependency relationships through large-scale renewable electricity imports, on the other hand, would present new security challenges, because dependency on other states would arise (e.g. transit countries).

\subsection{Vulnerability and Complexity of the System}

In general terms, the vulnerability of technical systems to failure increases with increasing complexity, because the probability of failure of the system as a whole is the product of the individual failure probabilities of the system's components. Hence each additional vertical component (i. e. introducing more technological processes) increases the probability of failure of the system as a whole. In the case of CCS this applies in particular to the additional components for flue gas scrubbing (postcombustion), coal gasification (pre-combustion) and air separation (oxyfuel), because in each of these cases an additional step is added to the conventional power station process.

The lack of commercial readiness has been the reason why IGCC power stations have not become more widespread to date despite their higher efficiency. No relevant experience has yet been gathered with oxyfuel. But in general terms it can be said that in comparison with proven technologies newly launched and more complex technologies have initially demonstrated lower availability, because operating experience has yet to be gathered and new components often demonstrate their actual reliability only under everyday conditions - and are then subjected to ongoing optimisation efforts.

But in terms of the availability and thus also the reliability of the plant, the power station process itself is not the only relevant factor. Transporting $\mathrm{CO}_{2}$ away from the power station further increases the level of complexity given the associated transport infrastructure. For example, if a pipeline were to fail, it would be necessary either to have corresponding buffer storage capacity on hand or to purchase $\mathrm{CO}_{2}$ emission certificates. But experience from other network-based infrastructures (e.g. gas pipelines) shows that the risk of that eventuality is relatively low.

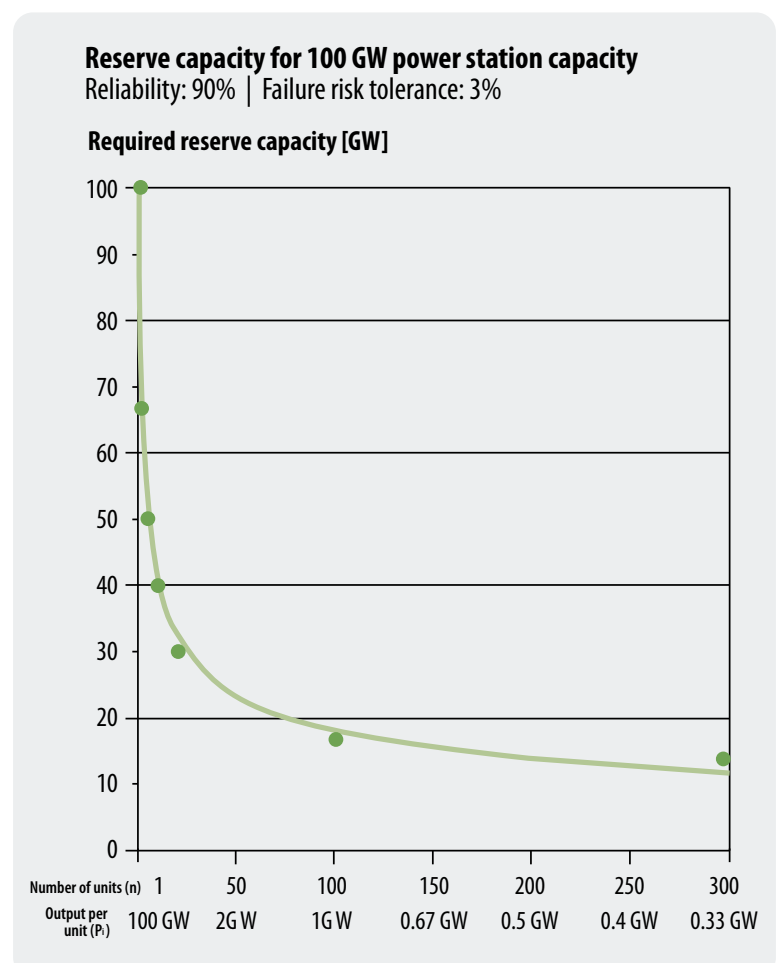

Fig. 13-2: Required reserve capacity as a function of unit output $P_{i}$ (assuming identically sized units) for $100 \mathrm{GW}$ generating capacity (Schüwer 1997)

For reasons of cost the large-scale introduction of the CCS option would only make sense for large power station units. This would lead to the preservation or expansion of centralised structures and thus further increase the probability of failure and the costs of maintaining reserve capacity. The reason for this is that if the reliability of individual systems remains constant, the probability of failure of the system as a whole (and thus the required reserve capacity) of a few large systems is always greater than that of many small ones (see Fig. 13-2). So more centralised structures tend to increase reserve capacity costs - for example in the form of dedicated reserve power stations or contracted reserve capacity.

The terrorism argument that has entered the debate in recent years (especially in connection with nuclear power stations) is probably less relevant for the case of $\mathrm{CO}_{2}$ pipelines. However, because it is based on largescale power stations, CCS automatically implies greater vulnerability and less flexibility than is the case with decentralised systems. 


\subsection{Conflicting Alternative Uses}

In many decisions opportunity costs play an important role; in other words, the question of what has to be given up in order to obtain a particular thing. Opportunity costs are reflected in use conflicts: how should particular resources be treated - storage capacity, land use, etc.? There are two dimensions here. Firstly the horizontal dimension examining current use conflicts (spatial competition). Secondly the vertical dimension of future restrictions imposed by today's decisions. The latter especially is difficult to assess because the future is always difficult to predict. People today cannot precisely picture what future generations will regard as desirable or worthy of preservation.

For example storing $\mathrm{CO}_{2}$ in salt caverns would make future use of the caverns - for the salt or as storage facilities for other substances - impossible for all time (in human terms). The same may apply to future geothermal applications for generating heat and electricity and to heat and cold storage, which could collide with the use of aquifers as $\mathrm{CO}_{2}$ sinks. Use conflicts have already been addressed in the discussion of the different types of sink (Chapter 7). 


\section{Chapter 14 \\ Systems Analysis of CCS Scenarios}

The previous chapters discussed the technological basis of CCS and presented ecological and economic comparisons with renewable energy options; we now move on to analyse the significance of CCS for energy supply and climate policy in the overall context. After reviewing the general factors influencing the implementation of CCS we analyse a range of scenarios to show which of the future perspectives for CCS are plausible and sensible. The analysis is based on the German energy system, but some aspects are also in principle applicable to other countries, especially those planning similarly large power station replacement programmes.

\subsection{CCS in the Energy Economy}

The role of CCS in the energy economy as a whole is influenced by many factors. This chapter begins with an overview of these, starting by taking a more fundamental look at the compatibility of CCS with other climate protection measures.

\subsubsection{General Factors Affecting CCS}

Alongside technical, ecological and economic considerations, the availability of alternatives and social acceptance, the future role of CCS will be determined above all by the potential demand for power generation capacity over the period under consideration. From the energy economy perspective, the relationship between power station replacement demand and technological availability of CCS is the decisive factor that determines the limits of general applicability of CCS.

Initial rough estimates of the theoretical (demand-side) limits of CCS are found in Fig. 14-1. The starting point for the analyses here is a scenario where - under conditions otherwise identical to the reference scenario - all new fossil-fuelled power stations built after 2020 are fitted with $\mathrm{CO}_{2}$ capture and storage. ${ }^{1}$

1 Reference scenario from Energiereport IV in EWI and Prognos (2005).

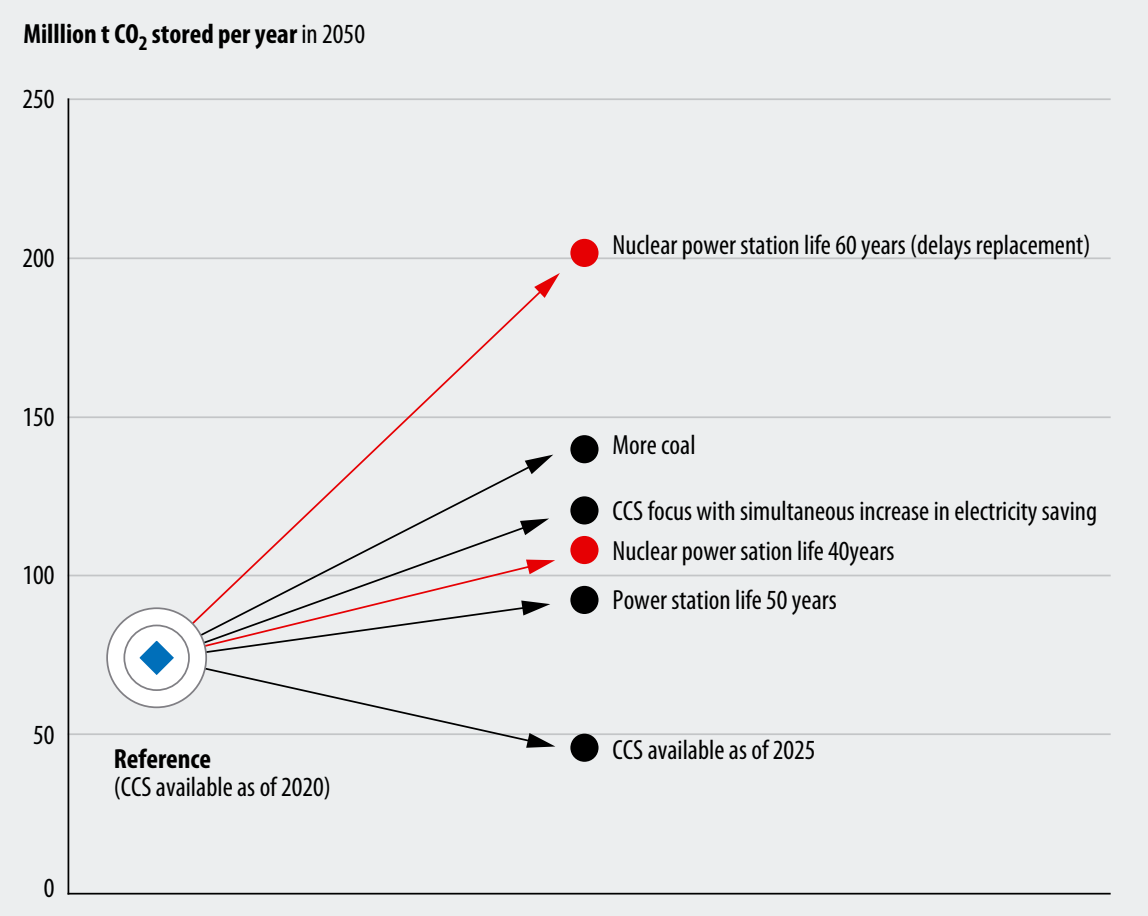

Fig. 14-1:

The main factors influencing future $\mathrm{CO}_{2}$ capture and storage in Germany (analysis for 2050) 


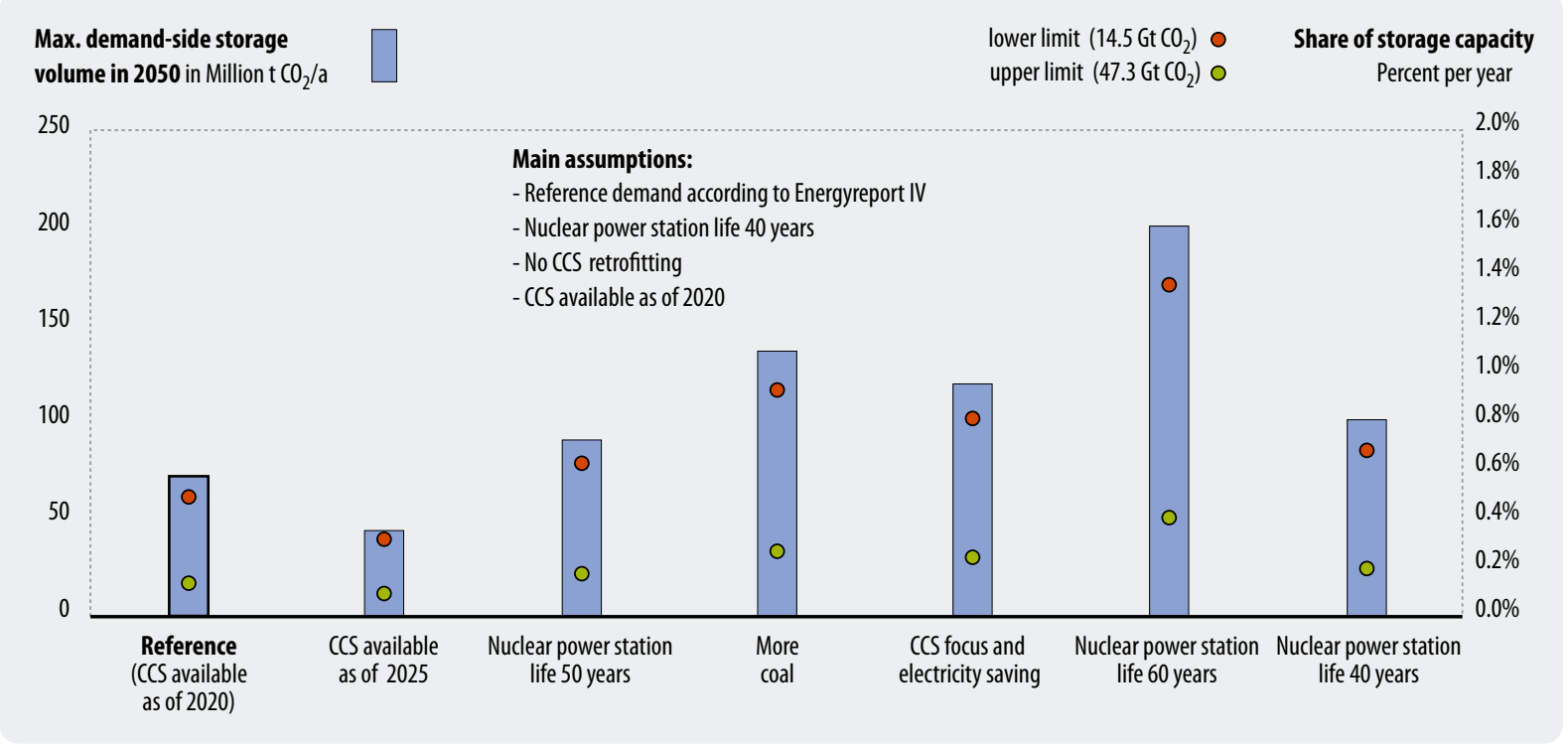

Fig. 14-2: Relationship between possible storage demand and available capacity

Taking this approach we find an annual storage demand of 73.1 million $\mathrm{C} \mathrm{CO}_{2}$ for the reference case. Various factors could influence this theoretical figure. A considerable proportion of power generation capacity will have to be replaced by 2025, so a five-year delay in getting CCS ready for implementation would (if we for the moment exclude the question of retrofitting) reduce the storage demand to 47.8 million $\mathrm{CO}_{2}$. Increases of the amount of $\mathrm{CO}_{2}$ to be stored could result in particular from a change in the power station mix (larger share of coal compared to the reference case) but also from any change in the assumptions about nuclear power plant operating life that would delay the need to replace capacity. Increasing the operating lives of the fossilfuelled power stations themselves (from 40 to 50 years) would have a comparable effect because it would also delay the need to replace capacity.

If we compare the resulting annual storage quantities

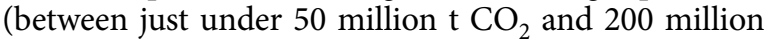
$\mathrm{t} \mathrm{CO}_{2}$ ) with the minimum and maximum figures for available storage capacity in Germany (see chapter 7), we find that capacity problems are not to be expected, at least where CCS is used as part of a transitional strategy. ${ }^{2}$ This applies under the provison that the identified storage capacities also turn out to be viable - i.e., sufficient long-term stability, ecologically compatible, exploitable at acceptable cost. It also assumes that power stations can be connected to suitable sinks (through new $\mathrm{CO}_{2}$ infrastructure) with enough capacity to allow storage during each power station's whole operating life.

2 For the calculations here we set the lower limit of national storage potential at $14.5 \mathrm{Gt} \mathrm{CO}_{2}$ (sum of minimum capacity estimates for exhausted oil and gas fields and saline aquifers). For the upper limit we added together the maximum capacity estimates for oil and gas fields and saline aquifers, and also included deep coal seams (ECBM, enhanced coal bed methane recovery) to arrive at a total capacity of $\mathbf{4 7 . 3} \mathrm{Gt} \mathrm{CO}_{2}$ (cf. Table 7-5).
Fig. 14-2 shows the respective shares of available storage capacity represented by annual storage demand, while Fig. 14-3 shows the corresponding static ranges for the storage capacity.

If we take the lower capacity figure as our measure, by 2050 the projected annual storage volume will have filled only between $0.3 \%$ (best case) and $1.4 \%$ (worst case) (Fig. 14-2).

The situation becomes even clearer when we consider the resulting static ranges. If we calculate the static range for the lower storage capacity figure we find depending on the scenario - a possible storage period of 72 to 305 years (Fig. 14-3). As the figures show, the possible implementation of CCS in power stations will be largely determined by the need to replace increasingly ageing power stations, which is already enormous today. In this context the question of retrofitting CCS in existing power stations is highly significant and will be addressed in the next section (14.1.2). Equally significant is the potential expansion of $\mathrm{CO}_{2}$ capture to include hydrogen production. Section addresses this aspect in greater detail in quantitative scenario analyses.

\subsubsection{Power Station Retrofitting}

There are two possibilities for retrofitting $\mathrm{CO}_{2}$ capture in existing coal-fired power stations. Firstly, post-combustion $\mathrm{CO}_{2}$ capture from the flue gas, e.g. by means of monoethanolamine scrubbing (MEA), and secondly, converting the combustion process to function with pure oxygen (oxyfuel). Both involve considerable infrastructure changes within the power station. In the case of MEA scrubbing the main factors are the considerable additional space required for the flue gas scrubbers and the column for regenerating the scrubbing solution 


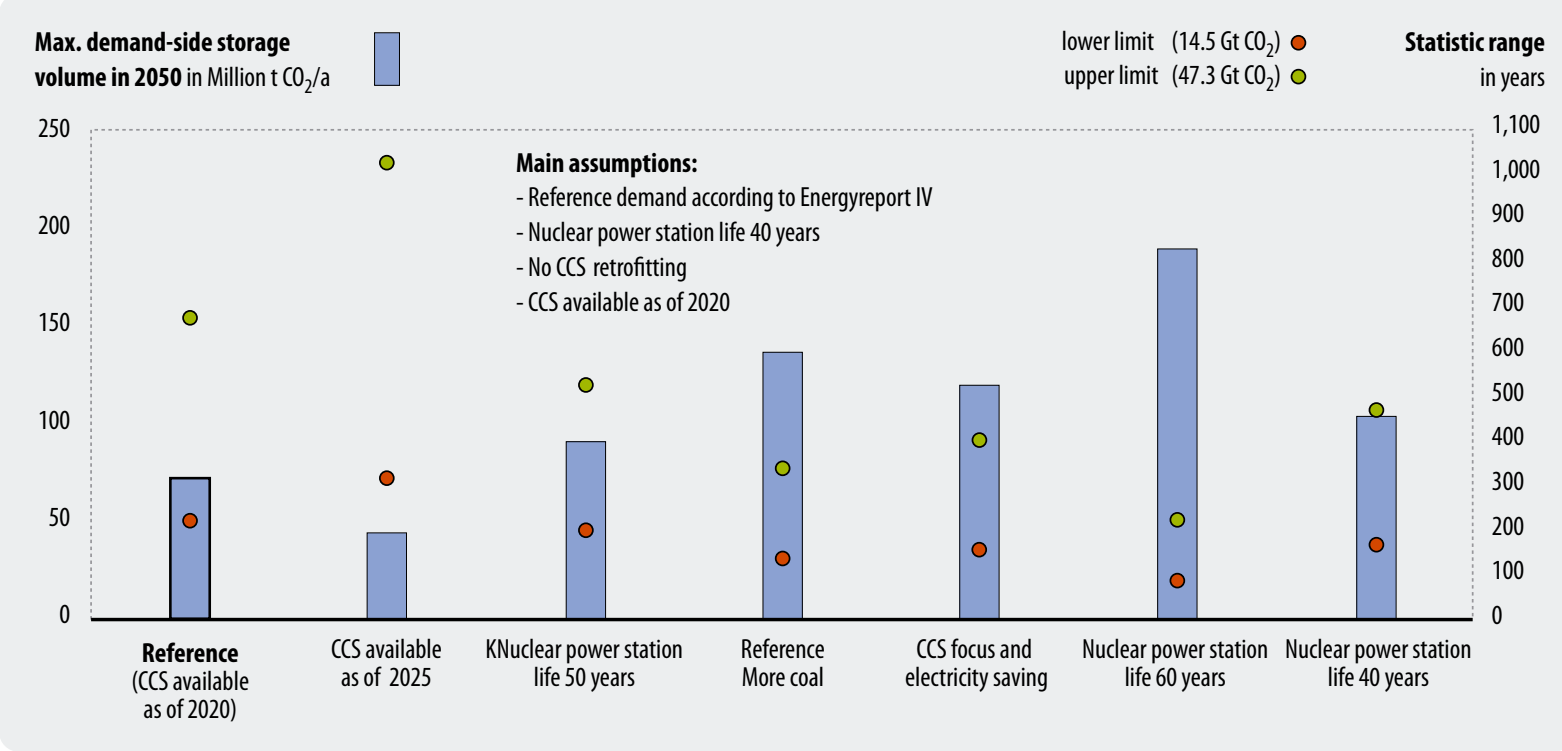

Fig. 14-3: Static ranges of storage capacity for different power generation scenarios

(plus space for storage facilities required for the MEA). Additionally, it is still unclear how much further purification of the flue gas will be required for the process to function properly. For example, if amine scrubbing is used for $\mathrm{CO}_{2}$ capture, the $\mathrm{SO}_{2}$ and $\mathrm{NO}_{\mathrm{x}}$ concentrations must be reduced further than required by the legal emission limits. Surplus oxygen after combustion also has a disruptive effect, but developing more stable solvents to replace conventional MEA could permit higher residual $\mathrm{O}_{2}$ concentrations.

In the case of retrofitting as an oxyfuel power station an air separation facility is needed to supply pure oxygen. Such a conversion would also involve major rebuilding of the furnace, for example to allow the possibility to recirculate $\mathrm{CO}_{2}$ from the waste gas (as required to control the temperature of combustion).

During the retrofit procedure power stations can only operate at limited or zero outputwith corresponding financial losses. Because of the large losses in efficiency involved, retrofitting only makes sense in power stations that have a high level of efficiency to start with. So from today's perspective (especially if we consider the residual operating life required to amortise the additional investment) retrofitting is probably only conceivable for power station new builds that are part of the forthcoming capacity replacement programme (Fischedick et al. 2006). For coal these include power stations operating comparable to the reference power station (with an electrical efficiency of $46 \%$ ) and potentially also power stations using new $700^{\circ} \mathrm{C}$ steam technology with conversion efficiency of possibly more than $50 \%$.

Retrofitting must also take account of possible effects on plant operation performance. In the case of post-combustion $\mathrm{CO}_{2}$ capture in a conventional power station probably no negative effects on dynamics and control are to be expected, because the effects of MEA scrubbing will be comparable to the flue gas desulphurisation scrubbers that are normally already fitted. In the case of pre-combustion capture in an IGCC process, $\mathrm{CO}_{2}$ capture represents a major process between gasification and gas turbine, which requires closely regulated interconnection of the different steps of the process. Because the steps cannot be operated independently of one another, $\mathrm{CO}_{2}$ capture can be expected to have a system-relevant impact that does not fundamentally exclude retrofitting but does at least place restrictions on it. In comparison to pre- and post-combustion concepts for $\mathrm{CO}_{2}$ capture, dynamics and control in an oxyfuel power station are influenced little or not at all by $\mathrm{CO}_{2}$ capture. After combustion in pure oxygen the waste gas consists largely of $\mathrm{CO}_{2}$ and $\mathrm{H}_{2} \mathrm{O}$, and rather than separating the $\mathrm{CO}_{2}$ from the gas mixture the steam is separated out by condensation. The combustion and steam processes are largely separate.

There is growing research into the question of retrofitting power stations and the possibilities of implementing preparatory measures (capture-ready plant). Work is already under way, for example in the Dutch CATO programme, and studies for a capture-ready concept are currently also being prepared by the Canadian Clean Power Coalition and Sask Power for a 350 to $450 \mathrm{MW}$ coal-fired power station. In Germany RWE Power is planning to build an IGCC plant with $\mathrm{CO}_{2}$ capture by 2014 and also intends to work on retrofitting concepts (in cooperation with BASF and Linde). In the Netherlands there is already discussion about making captureready design obligatory for new power stations.

In terms of energy and climate policy retrofitting could be of great importance if current power station construction plans (without carbon capture) are implemented in full, and sooner or later a clear conflict with ambitious climate protection goals arises. 


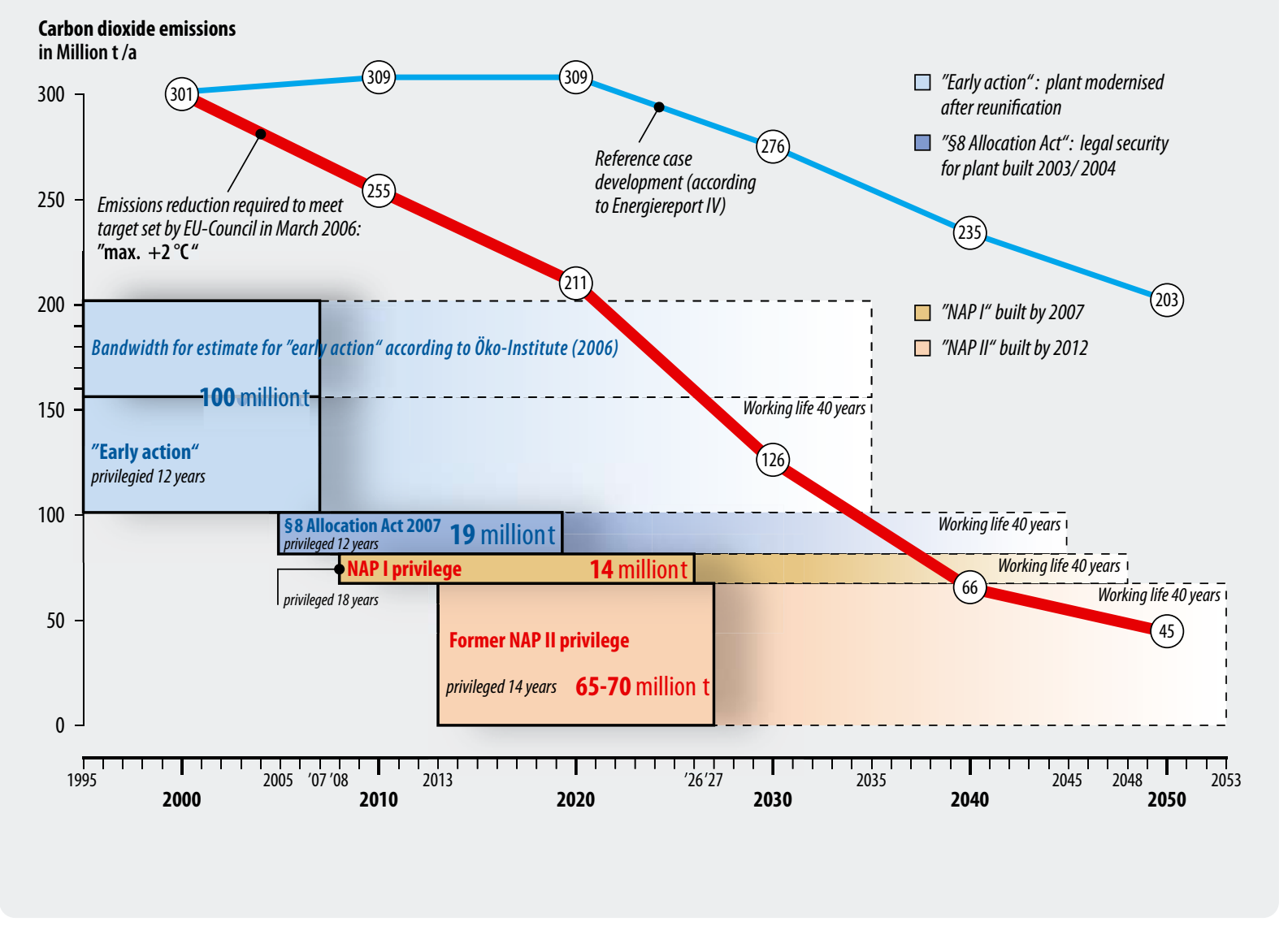

Fig. 14-4: Emissions from existing and planned power stations in relation to two emissions reduction trajectories in Germany (WI calculations)

The forthcoming investment programme doubtlessly contains many opportunities. It offers good prospects for economic and employment policy, represents sensible industrial policy, and will boost the German economy with respect to export markets. But it also represents a great opportunity for ecological modernisation. If we start from the existing plans for up to thirty-two power stations with an installed capacity of about 18 GW, and assume initially that these will merely replace existing power stations (with the same fuel but considerably worse fuel efficiency) we find a considerable theoretical $\mathrm{CO}_{2}$ saving of $24 \%{ }^{3}$

On the other hand, the announced new builds represent structural decisions with implications that extend far into the future and must therefore be examined for conflicts with future developments. This applies in particular to long-term responses to the climate policy challenge. The sum of all construction projects could thus prove incompatible with such goals, and even if new power stations are considerably more efficient than the existing ones they replace, the problem will remain. In times of climate change even 'much better' may prove to be 'not good enough'. Or put another way, for climate

$318 \mathrm{GW}$ is a rather conservative figure. Various sources cite plans involving up to $40 \mathrm{GW}$. protection not only the 'class of plant' but also the simple 'mass of plant' is relevant.

If we compare the new build plans with specific goals for $\mathrm{CO}_{2}$ emissions (see Fig. 14-4) the potential conflict is obvious.

The figure shows that by the third decade of this century the new power stations already planned today will be coming into conflict with climate protection goals. Put another way, if all the power stations were to be built as planned, we would already have decided today that it will not be possible to apply a restrictive (but necessary) climate protection target to the power station sector that is proportionate to other sectors' targets. Consequently other sectors would have to be treated more strictly than the electricity generating sector if the overall target is to be met, and it is doubtful whether that could be sustained politically.

The general situation changed recently. In former years the NAP II privilege allowed more plans for new builds. After cancellation of the privilege the number of new builds will strongly depend on the developments of the European emissions trading scheme.

As already mentioned, the conflict stems in the first 
place from the volume of planned new capacity. But this could be reduced considerably by targeted electricity saving measures (which are generally also very attractive in broader economic terms) and a further diversification of the range of renewables (see section 14.2). Assuming the power stations are built, it may prove necessary to retrofit them with $\mathrm{CO}_{2}$ capture in the medium term. It would therefore be logical to equip today's new power stations with the possibility of retrofitting for $\mathrm{CO}_{2}$ capture and storage (capture-ready). Corresponding incentive regimes are not yet in place, but they would be conceivable and are currently under discussion especially at the European level.

\subsubsection{Compatibility of CCS with Other Climate Protection Measures}

From the perspective of energy economics it is also relevant to know which fields of application CCS technologies relate to today and in the future and how they stand in relation to other climate protection strategies regarding compatibility with them and whether conflicts will arise.

\section{Applications for CCS}

Because of the high costs and infrastructure investment involved, $\mathrm{CO}_{2}$ capture and storage is most obviously an option for the centralised structure of large power stations. It is not yet clear to what extent $\mathrm{CO}_{2}$ capture and storage will remain restricted only to these central point sources or whether in future the many small-scale sources (e.g. fuel cells for stationary domestic supply, vehicles) could be included directly or indirectly (e.g. gasification prior to capture, $\mathrm{CO}_{2}$ capture from the atmosphere). ${ }^{4}$

CCS for decentralised structures is possible at least indirectly through the introduction of a hydrogen economy where hydrogen would be produced centrally, distributed through new or existing pipeline systems (e.g. the natural gas pipeline network) and used locally, for example to generate electricity or heat or to power vehicles. On the one hand this would expand the length of the process and thus imply additional energy losses but on the other hand (pure) hydrogen applications in particular would allow high conversion efficiency rates. To what extent and in what applications and timeframes introducing a hydrogen economy makes sense and would lead to a rational energy balance remains to be investigated.

\section{Compatibility or conflict}

A further question that arises in any analysis of energy economics is the compatibility of CCS with other climate protection options. Table 14-1 provides an overview of compatibility testing of CCS with the climate protection strategies that play a decisive role in the NaturschutzPlus scenario (BMU 2004). The matrix identifies the possible negative interactions and (potential) positive synergies; it thus represents one of the main starting points for the process of defining scenarios described in section 14.2, and begins to address whether CCS stands in conflict with the expansion of renewables or represents a bridge to reaching that goal.

According to Table 14-1 the greatest competition is with the expansion of centralised renewable electricity generation (wind offshore, import of renewables). Compatibility problems arise above all with respect to decentralised combined heat and power. Synergy possibilities and combined solutions appear possible with respect to hydrogen production. For geothermal there are still open questions to resolve. Here there would seem to be both the possibility of competition and the potential to exploit synergy effects because both cases involve the use of underground structures. However, the number of potential $\mathrm{CO}_{2}$ sinks is limited. Other conflicting interests could arise if compressed air storage gains in importance, for example to balance out fluctuations in electricity generated from renewables. Conflicting interests with natural gas storage are obvious, because in some cases deep aquifers are already used today.

4 Given that the $\mathrm{CO}_{2}$ produced by combustion weighs more than three times as much as the carbon in the mineral oil, capture in the vehicle is a problematic option and would automatically impact negatively on the energy balance. 
Table 14-1: Interaction matrix for CCS (basic assumption: available from 2020/2025) and other relevant climate protection strategies (focus on electricity generation and fuel production, geographical scope: Germany)

\begin{tabular}{|c|c|c|c|c|c|}
\hline \multicolumn{6}{|c|}{ Assumption CCS availability from 2020/2025 } \\
\hline $\begin{array}{l}\text { Technology/ } \\
\text { strategy }\end{array}$ & Availability & Synergy potential with CCS & Conflict potential with CCS & Potentials & $\begin{array}{l}\text { Conclusion: conflict- } \\
\text { ing development? }\end{array}$ \\
\hline \multicolumn{6}{|c|}{ Fossil and nuclear electricity generation } \\
\hline $\begin{array}{l}\text { Efficient central- } \\
\text { ised electricity } \\
\text { generation }\end{array}$ & $\begin{array}{l}\text { Immediately } \\
\left(700^{\circ} \mathrm{C} \text { plant from }\right. \\
2015)\end{array}$ & $\begin{array}{l}\text { Efficiency increases create lee- } \\
\text { way for CCS }\end{array}$ & $\begin{array}{l}\text { Efficiency reduction; in combi- } \\
\text { nation with renewables high } \\
\text { flexibility required, probably } \\
\text { not provided by CCS power } \\
\text { stations (due to additional } \\
\text { components) }\end{array}$ & $\begin{array}{l}\text { Significantly reducing over } \\
\text { time }\end{array}$ & \\
\hline $\begin{array}{l}\text { Centralised public } \\
\text { and independ- } \\
\text { ent CHP }\end{array}$ & Immediately & & $\begin{array}{l}\text { Normally gas-fired power sta- } \\
\text { tions due to high electricity- } \\
\text { to-heat-ratio (smaller CCS } \\
\text { incentive), high equipment } \\
\text { investment for independent } \\
\text { operators (space requirement } \\
\text { critical) }\end{array}$ & $\begin{array}{l}\text { Replacement of existing } \\
\text { power } \\
\text { stations }\end{array}$ & \\
\hline Decentralised CHP & Immediately & $\begin{array}{l}\text { Via hydrogen fuel supply (best } \\
\text { prospects with use of fuel cells) }\end{array}$ & $\begin{array}{l}\text { CCS not practicable for decen- } \\
\text { tralised applications (high } \\
\text { costs }\end{array}$ & $\begin{array}{l}\text { Significant expansion ( } 16 \% \\
\text { share of electricity gen- } \\
\text { eration in 2050), later with } \\
\text { fuel cells }\end{array}$ & (Yes) \\
\hline Nuclear power & Immediately & & & No new builds - phase-out & $\begin{array}{l}\text { Yes - but public accept- } \\
\text { ance more important }\end{array}$ \\
\hline \multicolumn{6}{|c|}{ Electricity generation from renewables } \\
\hline Hydropower & Immediately & & & Maximum capacity installed & No \\
\hline $\begin{array}{l}\text { Wind energy } \\
\text { (onshore) }\end{array}$ & Immediately & & $\begin{array}{l}\text { Intermittent renewables } \\
\text { require high flexibility which is } \\
\text { probably not provided by CCS } \\
\text { power stations }\end{array}$ & $\begin{array}{l}\text { Maximum capacity installed } \\
\text { (but onshore repowering) }\end{array}$ & No \\
\hline $\begin{array}{l}\text { Wind energy } \\
\text { (offshore) }\end{array}$ & 2010 & & see above & $\begin{array}{l}\text { Large contribution long- } \\
\text { term, contribution of wind } \\
\text { to total renewable electriticy } \\
\text { generation } 33 \% \text { (of which > } \\
2 / 3 \text { offshore) }\end{array}$ & Yes \\
\hline $\begin{array}{l}\text { Imported } \\
\text { renewables }\end{array}$ & From 2025 & & & $\begin{array}{l}\text { Share rising long-term } \\
(65 \text { TWh in 2050, } 13 \% \text { share } \\
\text { of electricity generation } \\
\text { by 2050) }\end{array}$ & $\begin{array}{l}\text { Yes - strong conflict } \\
\text { with CCS regarding date } \\
\text { of deployment }\end{array}$ \\
\hline Photovoltaics & Immediately & & $\begin{array}{l}\text { Intermittent renewables } \\
\text { require high flexibility which is } \\
\text { probably not provided by CCS } \\
\text { power stations }\end{array}$ & $\begin{array}{l}\text { Limited mid-termimpor- } \\
\text { tance in Germany }\end{array}$ & (No) \\
\hline Biomass & $\begin{array}{l}\text { Gasification } \\
\text { from } 2015\end{array}$ & $\begin{array}{l}\text { Double dividend with CCS } \\
\text { (negative emissions), multi- } \\
\text { fuel use possible e.g. with } \\
\text { co-combustion of biomass in } \\
\text { power stations or combined } \\
\text { gasification }\end{array}$ & $\begin{array}{l}\text { Due to fuel logistics usually } \\
\text { smaller plants, especially with } \\
\text { CHP }(<20 \mathrm{MW})\end{array}$ & High importance of biomass & $\begin{array}{l}\text { Consider combined } \\
\text { concepts }\end{array}$ \\
\hline $\begin{array}{l}\text { Geothermal } \\
\text { (heat, electricity) }\end{array}$ & From 2015 & 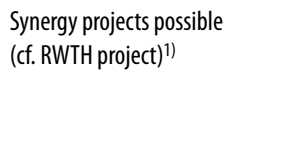 & $\begin{array}{l}\text { Conflicts conceivable, espe- } \\
\text { cially with heat supply, CCS at } \\
800 \mathrm{~m} \text { and deeper } \\
\text { open question }\end{array}$ & $\begin{array}{l}\text { Cautious estimate: } 14.5 \mathrm{TWh} \\
\text { in } 2050 \text { corresponds to just } \\
\text { over } 3 \%\end{array}$ & \\
\hline
\end{tabular}




\begin{tabular}{|c|c|c|c|c|c|}
\hline $\begin{array}{l}\text { Technology/ } \\
\text { strategy }\end{array}$ & Availability & Synergy potential with CCS & Conflict potential with CCS & Potentials & $\begin{array}{l}\text { Conclusion: conflict- } \\
\text { ing development? }\end{array}$ \\
\hline \multicolumn{6}{|c|}{ Electricity generation from renewables } \\
\hline Electricity saving & Immediately & & & $\begin{array}{l}\text { High, saving in } 2050 \text { about } \\
20 \% \text { compared with refer- } \\
\text { ence development }\end{array}$ & $\begin{array}{l}\text { Yes - but efficiency tech- } \\
\text { nologies available earlier }\end{array}$ \\
\hline Wärmeeinsparung & Immediately & & & $\begin{array}{l}\text { In buildings very high (e.g. } \\
\text { passive house standard com- } \\
\text { pared to current German } \\
\text { buildings standard ("EnEV") }\end{array}$ & $\begin{array}{l}\text { (Yes - compared to } \\
\text { CCS-H2, but efficient } \\
\text { technologies are avail- } \\
\text { able earlier) }\end{array}$ \\
\hline \multicolumn{6}{|c|}{ Fuel supply } \\
\hline Biofuels & & & & $\begin{array}{l}\text { Limited use of biofuels (111 } \\
\text { PJ in 20502) }\end{array}$ & No \\
\hline $\begin{array}{l}\text { Hydrogen } \\
\text { (fuel, feed into } \\
\text { natural gas net- } \\
\text { work) }\end{array}$ & & $\begin{array}{l}\text { Low-C02 hydrogen can be } \\
\text { imported (CO2 separation at } \\
\text { borehole), hydrogen produc- } \\
\text { tion in IGCC plants, (combined } \\
\text { cycle multi-purpose concepts) }\end{array}$ & & $\begin{array}{l}\text { Limited quantities of hydro- } \\
\text { gen in scenario ( } 189 \mathrm{PJ} \text { in } \\
2050 \text { ) on basis of electricity } \\
\text { from renewables }\end{array}$ & $\begin{array}{l}\text { Think about combined } \\
\text { concepts }\end{array}$ \\
\hline Mineral oil & & $\begin{array}{l}\text { Enhanced oil recovery creates } \\
\text { favourable economic frame- } \\
\text { work }\end{array}$ & & & $\begin{array}{l}\text { International first step } \\
\text { for cCSS }\end{array}$ \\
\hline Natural gas & & $\begin{array}{l}\text { Capture of } \mathrm{CO} \text { as natural gas } \\
\text { impurity }\end{array}$ & & & $\begin{array}{l}\text { International first step } \\
\text { for CCS }\end{array}$ \\
\hline \multicolumn{6}{|c|}{ Storage systems } \\
\hline $\begin{array}{l}\text { Compressed air } \\
\text { stores }\end{array}$ & $\begin{array}{l}\text { In principle } \\
\text { immediately, } \\
\text { intense research } \\
\text { under way }\end{array}$ & & $\begin{array}{l}\text { Competition for suitable geo- } \\
\text { logical storage formations, } \\
\text { which are also of fundamen- } \\
\text { tal interest for compensating } \\
\text { intermittent renewable con- } \\
\text { tributions }\end{array}$ & & (Yes) \\
\hline $\begin{array}{l}\text { Thermal energy } \\
\text { stores (seasonal) }\end{array}$ & $\begin{array}{l}\text { In principle } \\
\text { immediately, } \\
\text { intense research } \\
\text { under way }\end{array}$ & & $\begin{array}{l}\text { Competition for suitable geo- } \\
\text { logical storage formations, } \\
\text { seasonal stores are fundamen- } \\
\text { tally of great importance for } \\
\text { renewable heat storage }\end{array}$ & & (Yes) \\
\hline \multicolumn{6}{|c|}{1 Integrating $\mathrm{C}_{2}$ in reflux water in geothermal projects (deep geothermal at depth of e.g. $1,500 \mathrm{~m}$ ) - calcite formation } \\
\hline \multicolumn{6}{|l|}{$\begin{array}{l}2 \text { Very rest } \\
\text { found in }\end{array}$} \\
\hline
\end{tabular}

\subsection{Scenario Analyses: Assessment of the Strategic Importance of CCS}

The results of calculations in models are highly dependent on the assumptions on which the models are based. This applies in particular to the fundamental economic data of the available alternatives and the development of fuel prices. In the following we examine scenarios for Germany in order to elucidate - without the distractions of optimisation models - the strategic importance of CCS for reaching ambitious climate protection goals.

\subsubsection{Storylines for Political Relevant CCS Scenarios}

In the light of the interaction matrix described above (Table 14-1) and earlier studies dealing with ways to meet ambitious climate protection targets - as already presented in scenario studies conducted for the Federal Environment Ministry and the Federal Environment Agency (UBA 2006b, BMU 2004, WI/DLR 2002) - this study identifies three different scenarios ${ }^{5}$ (name of scenario in brackets):

5 Target: $80 \%$ reduction in $\mathrm{CO}_{2}$ emissions by 2050 compared to reference year 1990 . 
- CCS as the main element of a climate protection strategy with maximum application of CCS technologies, whereas development of renewables is derived from the reference trend (CCSMAX)

- Avoidance of CCS as a result of great success in increasing efficiency and through the ambitious expansion of technologies for using renewable energy as described for example in the NaturschutzPlus scenarios (BMU 2004, 2005) (NATP)

- CCS as a bridge to renewable energies in a scenario where increases in efficiency and expansion of renewables cannot be sufficiently mobilised to achieve the climate protection goal on their own in the envisaged time frame (BRIDGE)

Rather than developing completely new scenarios we based our work on the NaturschutzPlus scenario (modified and adapted to current conditions) (BMU 2004; UBA 2006b) and the reference forecast from the EWI/ Prognos Energiereport IV. ${ }^{6}$ All three scenarios either state a climate protection goal to be achieved by 2050 or else examine whether such a goal is achievable. The goal is specified by the NaturschutzPlus scenario: 242 million t $\mathrm{CO}_{2}$ emissions in 2050. The scenarios are also shaped by specific storylines, which are described below. The principal results of the scenarios are described in the following.

\section{CCS as the main climate protection strategy (CCSMAX scenario)}

If CCS is chosen as the main strategic pillar of climate protection this can function on two different levels:

- Central electricity generation (largely condensation power plant). The driving forces here are that existing structures could be maintained (including operator structures), that coal (as the fossil fuel with the greatest reserves) could continue to be used, and that this option could represent an industrial policy model for other countries with significant coal reserves.

- Central hydrogen production (on the basis of coal gasification). Low-emission electricity generation alone will not be enough to achieve the required reduction in $\mathrm{CO}_{2}$, and in the transport sector biofuels - alongside improving efficiency - can make only a limited contribution to climate protection. So here the driving force for expanding the CCS option would be to diversify the range of different fuels to include hydrogen for reasons of security of supply.

6 In the course of an investigation of fuel strategies for the Environment Agency (UBA 2006b) the climate protection strategies developed for the Federal Environment Ministry (BMU 2004) were modified to account for changes in conditions (e.g. population trends) in accordance with the EWI/Prognos Energiereport IV.
Because of the structural preconditions (strong focus on large-scale power station technology) it is logical to develop the scenario on the basis of the existing Energiereport IV (i.e. a 'business-as-usual' approach) with the goal of meeting comparable climate protection targets ( $80 \%$ emissions reduction goal).

When expanding CCS, the existing age structure of the power stations initially has a restrictive effect, but it must also be taken into account that a hydrogen system cannot be established at the drop of a hat. Conceivable steps would be first to launch the system with a centralised supply for major consumers (e.g. airports), establishing 'stand-alone systems' and starting to feed into the natural gas network to certain shares. Then the successive creation of the first mixed gas structures could follow (including necessary modifications of application technology for mixed gas), and finally a gradual move (in both the temporal and geographical sense) to full-blown hydrogen systems.

\section{CCS as a bridge to expanding renewables (BRIDGE scenario)}

In this scenario CCS is understood as a complementary technology for a climate protection strategy that ultimately aims to further expand renewables and increase energy efficiency, but cannot implement these in the required intensity due to conflicts of interests and insurmountable obstacles.

In contrast to the idea of using CCS exclusively as a back-stop technology (a technology that is only applied when other measures fail to have sufficient effect), this development strategy integrates CCS as a strategic element from the outset and regards it as necessary for meeting the climate protection target in time. The foremost questions to be analysed here are firstly the extent to which the necessary expansion of renewables and the implementation of energy efficiency measures (including the expansion of decentralised CHP) can be spread over a longer period and secondly whether CCS can turn out to be a longer-term complementary and transitional option (compatible with the expansion of renewables) for the technologies that are strongly expanded in the NATP scenario.

\subsubsection{Definitions and Parameters for the Scenarios}

The required demographic and economic data for all the scenarios are taken from EWI and Prognos (2005), with modifications only with respect to the development of transport volume, where figures from UBA (2006) were used (Table 14-2). However, the reference development used here was determined on the basis of the 2005 situation. This means that for the near future (based on 2010) a number of deviations from the energy data in Energiereport IV arise. In all the scenarios the agreed phase-out of nuclear power is completed on schedule. 
Table 14-2: Demographic and economic data for the scenarios

\begin{tabular}{|c|c|c|c|c|c|c|c|c|c|c|}
\hline Data & 1996 & 1998 & 2000 & 2002 & 2005 & 2010 & 2020 & 2030 & 2040 & 2050 \\
\hline Population (million) & 81.94 & 82.11 & 82.21 & 82.41 & 82.41 & 82.41 & 81.39 & 79.42 & 77.30 & 75.12 \\
\hline Employment (million) & 37.27 & 37.62 & 38.75 & 38.67 & 38.76 & 38.92 & 38.95 & 37.50 & 37.00 & 35.80 \\
\hline Households (million) & 37.30 & 37.60 & 38.15 & 38.76 & 39.15 & 39.67 & 40.02 & 39.72 & 39.20 & 38.50 \\
\hline Housing units (million) & 36.10 & 36.80 & 37.06 & 37.27 & 37.60 & 38.20 & 39.80 & 40.85 & 39.50 & 38.50 \\
\hline Housing space (million m²) & 3,080 & 3200 & 3,281 & 3,347 & 3,450 & 3,615 & 4,010 & 4,406 & 4,560 & 4,510 \\
\hline Heated industrial space (million m²) & 1,310 & 1,385 & 1,458 & 1,465 & 1,485 & 1,514 & 1,539 & 1,500 & 1,480 & 1,432 \\
\hline $\operatorname{GDP}(€ 1,000$ million. 2000) & 1,870 & 1,934 & 2,030 & 2,050 & 2,110 & 2,306 & 2,691 & 3,050 & 3,355 & 3,600 \\
\hline Cars (million) & 41.00 & 41.70 & 42.84 & 44.52 & 44.83 & 46.96 & 50.60 & 51.90 & 52.38 & 52.09 \\
\hline $\begin{array}{l}\text { Passenger transport } \\
(1,000 \text { million passenger-km) }\end{array}$ & & & 1,169 & 1,186 & 1,220 & 1,285 & 1,433 & 1,511 & 1,560 & 1,536 \\
\hline Goods transport (1,000 million t-km) & & & 490 & 496 & 535 & 607 & 748 & 843 & 918 & 980 \\
\hline \multicolumn{11}{|l|}{ Ratios } \\
\hline Household size & 2.20 & 2.18 & 2.15 & 2.13 & 2.11 & 2.08 & 2.03 & 2.00 & 1.97 & 1.95 \\
\hline Living space/head (m²) & 37.6 & 39.0 & 39.9 & 40.6 & 41.9 & 43.9 & 49.3 & 55.5 & 59.0 & 60.0 \\
\hline Size of housing unit $\left(\mathrm{m}^{2}\right)$ & 85.3 & 87.0 & 88.5 & 89.8 & 91.8 & 94.6 & 100.7 & 107.9 & 115.4 & 117.1 \\
\hline Cars/household & 1.10 & 1.11 & 1.12 & 1.15 & 1.15 & 1.18 & 1.26 & 1.31 & 1.34 & 1.35 \\
\hline Useful area/employee $\left(\mathrm{m}^{2}\right)$ & 35.1 & 36.8 & 37.6 & 37.9 & 38.3 & 38.9 & 39.5 & 40.0 & 40.0 & 40.0 \\
\hline GDP/head (€2000) & 22,822 & 23,554 & 24,692 & 24,875 & 25,603 & 27,982 & 33,062 & 38,403 & 43,402 & 47,923 \\
\hline Passenger transport/head (km) & & & 14,219 & 14,391 & 14,804 & 15,593 & 17,606 & 19,025 & 20,181 & 20,447 \\
\hline Goods transport/head (km) & & & 5,960 & 6,018 & 6,492 & 7,366 & 9,190 & 10,614 & 11,876 & 13,046 \\
\hline \multicolumn{11}{|l|}{ Index $(2000=100)$} \\
\hline Population & 99.7 & 99.9 & 100.0 & 100.2 & 100.2 & 100.2 & 99.0 & 96.6 & 94.0 & 91.4 \\
\hline Employment & 96.2 & 97.1 & 100.0 & 99.8 & 100.0 & 100.4 & 100.5 & 96.8 & 95.5 & 92.4 \\
\hline Households & 97.8 & 98.6 & 100.0 & 101.6 & 102.6 & 104.0 & 104.9 & 104.1 & 102.8 & 100.9 \\
\hline Housing units & 97.4 & 99.3 & 100.0 & 100.6 & 101.5 & 103.1 & 107.4 & 110.2 & 106.6 & 103.9 \\
\hline Housing space & 93.9 & 97.5 & 100.0 & 102.0 & 105.2 & 110.2 & 122.2 & 134.3 & 139.0 & 137.5 \\
\hline Heated useful area & 89.8 & 95.0 & 100.0 & 100.5 & 101.9 & 103.8 & 105.6 & 102.9 & 101.5 & 98.2 \\
\hline GDP & 92.1 & 95.3 & 100.0 & 101.0 & 103.9 & 113.6 & 132.6 & 150.2 & 165.3 & 177.3 \\
\hline Cars & 95.7 & 97.3 & 100.0 & 103.9 & 104.6 & 109.6 & 118.1 & 121.1 & 122.3 & 121.6 \\
\hline Passenger transport & 0.0 & 0.0 & 100.0 & 101.5 & 104.4 & 109.9 & 122.6 & 129.3 & 133.4 & 131.4 \\
\hline Goods transport & 0.0 & 0.0 & 100.0 & 101.2 & 109.2 & 123.9 & 152.7 & 172.0 & 187.3 & 200.0 \\
\hline GDP growth (\%/a) & & 1.68 & 2.42 & 0.49 & 0.96 & 1.78 & 1.54 & 1.25 & 0.95 & 0.70 \\
\hline
\end{tabular}

The overall economic and energy data in the NaturschutzPlus I and II scenarios developed by BMU (2004) - which serve as the basis for our NATP scenario - are largely based on the year 2000. In the meantime considerable changes have occurred both in the energy market and in the development of renewables. Compared with the reference development presented by the Enquete Commission (expert commission of the German Bundestag) in 2002 (Enquete 2002), the energy market reference forecast for 2030 ('Energiewirtschaftliche
Referenzprognose 2030') in Energiereport IV (EWI and Prognos 2005) already reaches quite different conclusions regarding probable trends. But even this relatively new study, based largely on data from 2002, does not include the latest energy price rises and the sharp increase in recent years in the contribution of renewables to electricity generation and liquid fuels. Upcoming power station new builds are included as per known planning of the electricity companies. 
Table 14-3: Primary and final energy consumption and gross electricity generation in the three scenarios, itemised by energy source

\begin{tabular}{|c|c|c|c|c|c|c|c|c|c|c|c|c|c|c|}
\hline \multirow[b]{3}{*}{$\begin{array}{l}\text { Year/ } \\
\text { scenario }\end{array}$} & \multicolumn{6}{|c|}{ Total energy supply (PJ/a) } & \multicolumn{8}{|c|}{ Electricity generation } \\
\hline & \multicolumn{2}{|c|}{ Primary energy } & \multicolumn{2}{|c|}{ Final energy } & \multicolumn{2}{|c|}{$\begin{array}{l}\text { Renewables pri- } \\
\text { mary }\end{array}$} & \multicolumn{4}{|c|}{ Gross generation (TWh/a) } & \multicolumn{4}{|c|}{ Installed capacity (GW) } \\
\hline & Total & $\begin{array}{l}\text { of which } \\
\text { fossil }\end{array}$ & Total & $\begin{array}{l}\text { of which } \\
\text { electricity }\end{array}$ & (PEV) & (END) & Total & $\begin{array}{l}\text { Renew- } \\
\text { ables }\end{array}$ & Nuclear & Fossil & Total & $\begin{array}{l}\text { Renew- } \\
\text { ables }\end{array}$ & Nuclear & Fossil \\
\hline 2005 & 14,238 & 11,833 & 9,118 & 1,836 & 658 & 572 & 613 & 62 & 163 & 387 & 131.2 & 26.9 & 21.3 & 83.0 \\
\hline \multicolumn{15}{|l|}{2020} \\
\hline CCSMAX & 12,980 & 11,556 & 8,800 & 1,886 & 1,097 & 892 & 591 & 112 & 30 & 449 & 139.4 & 40.9 & 4.3 & 94.2 \\
\hline BRIDGE & 12,565 & 10,861 & 8,531 & 1,796 & 1,377 & 1,072 & 575 & 127 & 30 & 418 & 144.3 & 51.3 & 4.3 & 88.7 \\
\hline NATP & 12,071 & 10,174 & 8,291 & 1,710 & 1,570 & 1,230 & 551 & 159 & 30 & 362 & 147.7 & 61.1 & 4.3 & 82.3 \\
\hline \multicolumn{15}{|l|}{2030} \\
\hline CCSMAX & 12,375 & 11,068 & 8,403 & 1,853 & 1,300 & 1,084 & 581 & 145 & 0 & 436 & 142.5 & 49.1 & 0.0 & 93.4 \\
\hline BRIDGE & 11,699 & 9,957 & 7,977 & 1,746 & 1,742 & 1,392 & 559 & 168 & 0 & 391 & 147.5 & 61.2 & 0.0 & 86.3 \\
\hline NATP & 10,534 & 8,237 & 7,689 & 1,638 & 2,297 & 1,886 & 529 & 265 & 0 & 264 & 158.4 & 87.1 & 0.0 & 71.3 \\
\hline \multicolumn{15}{|l|}{2050} \\
\hline CCSMAX & 12,483 & 10,837 & 7,309 & 1,782 & 1,646 & 1,392 & 569 & 197 & 0 & 372 & 146.2 & 63.8 & 0.0 & 82.4 \\
\hline BRIDGE & 10,419 & 8,010 & 6,523 & 1,598 & 2,409 & 2,002 & 542 & 245 & 0 & 297 & 148.3 & 74.2 & 0.0 & 74.1 \\
\hline NATP & 8,122 & 4,696 & 6,025 & 1,512 & 3,426 & 2,881 & 534 & 384 & 0 & 150 & 158.3 & 111.5 & 0.0 & 46.8 \\
\hline
\end{tabular}

The NATP scenario describes a development that gradually continues the expansion of renewables already initiated through energy policy and increasingly links it with growing contributions from more efficient energy conversion (CHP) and use (efficiency measures). It describes the short- to medium-term effects of the German government's current energy policy and projects this favourable framework into the future. It abides by the German government's climate protection goals and the agreed targets for expanding renewables. The required instruments remain effective in their current state (e.g. Renewable Energies Act, CHP Act, tax breaks, obligation to blend biofuels) or are strengthened (energy efficiency promotion in the heat market). Earlier and current studies (BMU 2004, 2006) have shown that the growth dynamic initiated in renewables must be maintained at least at the current extent for the foreseeable future if energy policy in this field is to successfully meet its goal of making renewables competitive in the energy market without further subsidies.

By consistently continuing to expand renewables until 2050 - and assuming a successful mobilisation of potential efficiency improvements in energy conversion and use - the NATP scenario leads to a clear reduction in use of fossil fuels and thus to a considerable reduction in $\mathrm{CO}_{2}$ emissions. It largely follows the lower reduction path shown in Fig. 14-4. In 2050 about 240 million $t$ $\mathrm{CO}_{2}$ /a will still be emitted, which represents a reduction of $76 \%$ from the figure for the reference year 1990 . Here the application of CCS technologies is not necessary for climate protection. This scenario is the archetype of an ambitious climate protection policy based on the strategies of efficiency and expanding renewa- bles and thus serves as a yardstick for assessing the $\mathrm{CO}_{2}$ emissions that have to be avoided by means of CCS in other scenarios.

We updated the original NaturschutzPlus scenario on this basis with 2005 as the baseline for all energy data. ${ }^{7}$ The potential for improving efficiency in the electricity, heat and transport sectors and the combined heat and power subsegment was reassessed using the latest data. The most important alterations in these areas relate to expected short-term electricity consumption, and to the amount of electricity and heat currently actually produced by CHP and the perspectives for short-term expansion there. The figure for gross electricity generation taken as the starting point here - $613 \mathrm{TWh} / \mathrm{a}$ in 2005 (comparison 2000: $571 \mathrm{TWh} / \mathrm{a}$ ) - is considerably higher than that used by BMU (2004). Electricity generated from fossil fuels in CHP has remained stagnant for about ten years at about 50-53 TWh/a. Recently, however - stimulated by rising electricity prices and trading in $\mathrm{CO}_{2}$ certificates - a slight increase has been noted again. For 2005 we take $53 \mathrm{TWh} / \mathrm{a}$ as a staring point. Thanks to the favourable framework offered by the Renewable Energy Sources Act there is also about $10 \mathrm{TWh} / \mathrm{a}$ CHP electricity from biomass (including biogas).

The CCSMAX scenario continues current energy policy - on the basis of the energy market reference forecast by EWI and Prognos (2005) - and leads to a certain

7 When the work was conducted some of the data for overall energy supply in 2005 were still provisional. 


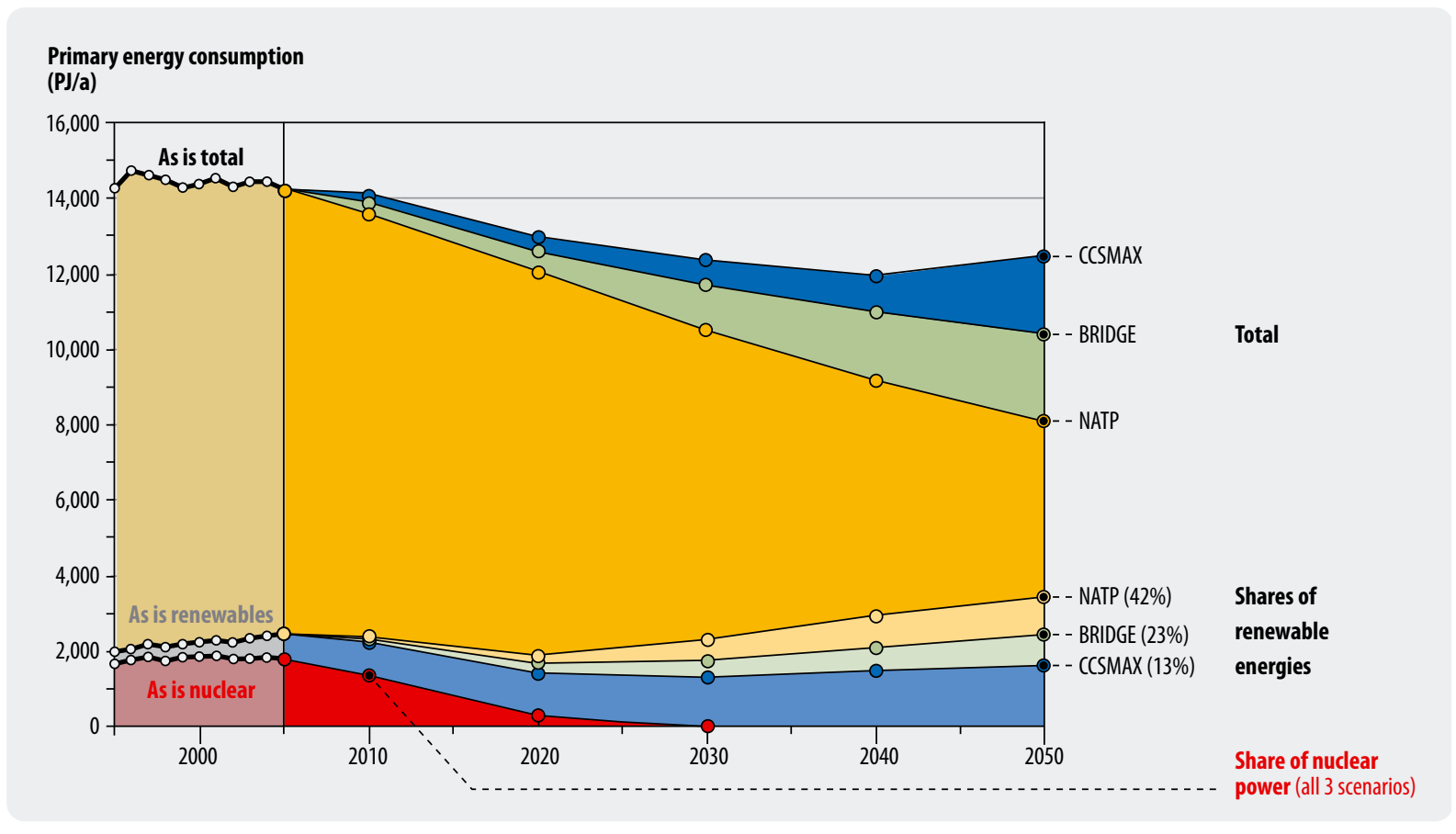

Fig. 14-5: Primary energy trends in the three scenarios showing the shares of nuclear and renewables

degree of progress in trends to increase dissemination of efficiency and renewable energy technologies. But the progress is far from being sufficient to meet existing climate protection goals. The scenario thus models a climate protection policy that will be inadequate in the medium term; one that would necessitate the use of CCS technologies from about 2020 if the 2050 climate protection target is to be met in time after all. It models from the demand side the maximum CCS contribution that the German energy supply system could require by 2050. It was assumed that development of efficiency and renewable energy technologies would not fall behind the levels assumed in the reference development.

Compared to the reference development, the BRIDGE scenario defines an accelerated climate protection policy that boosts efficiency and renewable energy strategies in comparison to the reference case. But because from the outset major players in energy policy and the energy business do not expect these two strategy elements to be enough to meet the $80 \%$ emissions reduction target, CCS technologies are included here from about 2020 as part of an overall strategy for meeting climate protection targets.

Table 14-3 summarises the main data for overall energy supply - and in particular for electricity generation based on the above assumptions. Fig. 14-5 shows structural differences in primary energy supply between the scenarios and the shares of different energy sources.

Even in the reference case, primary energy consumption shows a slight downward trend, (which is replicated in CCSMAX) because it is assumed that the trend for continuous improvements in energy productivity can more than compensate the growth in energy services (expressed by growth in GDP). In the longer term falling population in Germany also has an effect. But only the NATP scenario exploits the great potential of structural technical efficiency improvements. Here only the economically viable options are considered at any particular time. Both the other scenarios assume that structural and institutional impediments will to differing degrees impede effective exploitation of these potentials.

In both scenarios with CCS the reduction in primary energy consumption slows after 2020 because of the increasing use of primary energy for low- $\mathrm{CO}_{2}$ production of electricity and hydrogen. In the CCSMAX scenario this actually causes use of primary energy to rise again after 2040 . So in this scenario the use of fossil energy in $2050(10,837 \mathrm{PJ} / \mathrm{a})$ is only $9 \%$ less than today $(11,830 \mathrm{PJ} / \mathrm{a})$. In the BRIDGE scenario use of fossil primary energy falls considerably (by $33 \%$ ) and in the NATP scenario even further (by $60 \%$ ). Given that GDP grows by $75 \%$ between 2005 and 2050, primary energy intensity falls in the NATP scenario to $34 \%$ of today's value by 2050 . That does not yet, however, reach the structural technical limits, which the Enquete Commission puts at a mean value of approx. $25 \%$ ('Factor Four') (Enquete 2002). So there is still further potential for reduction especially in the transport sector and in utilisation of electricity.

The contribution from renewables increases in all scenarios. But measured against the speed of growth of the past five to seven years future growth slows significantly 


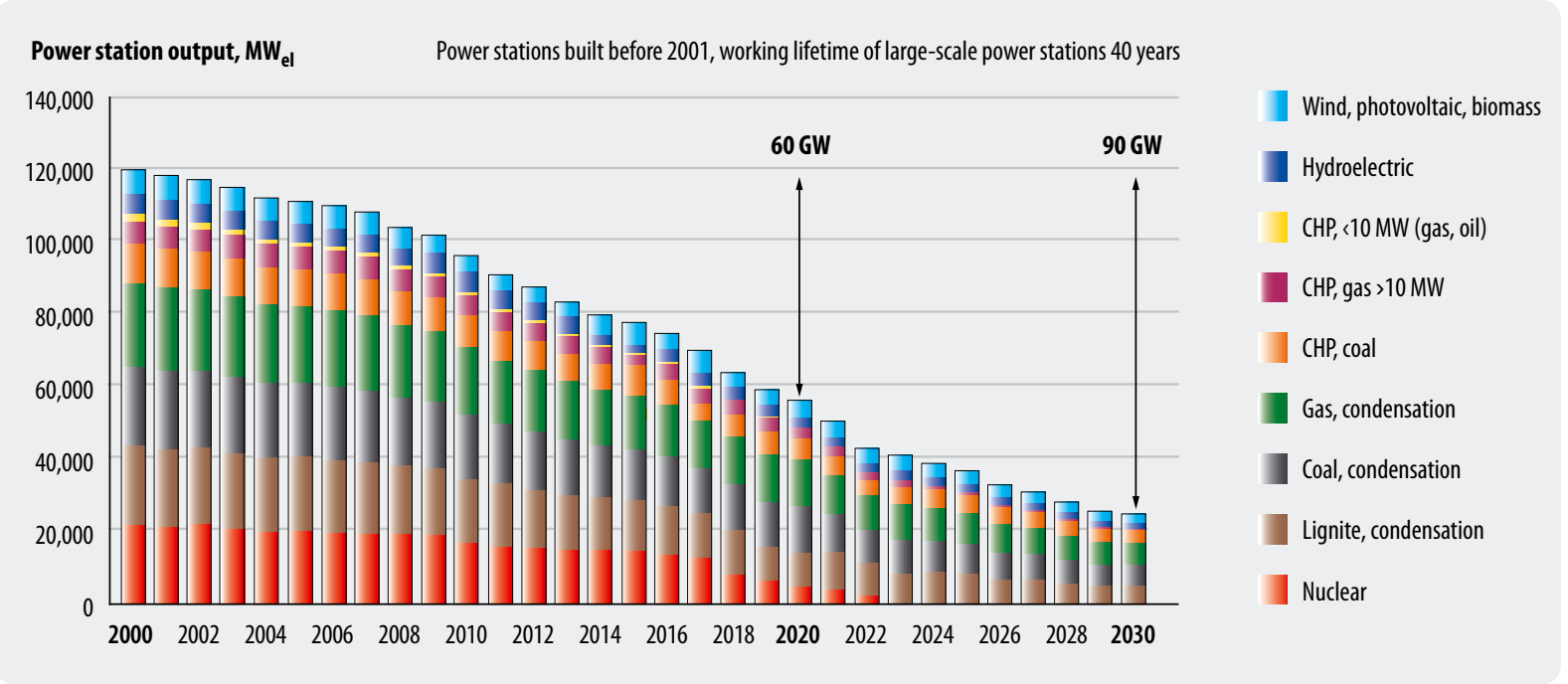

Fig. 14-6: Remaining output of power stations built before 2001 in Germany, itemised by type

in the CCSMAX scenario, reaching only 2.5 times today's value in 2050. That corresponds with a policy that allows existing funding instruments to expire in the foreseeable future and neglects to establish them in the first place in some fields (e.g. heat supply). In the other extreme case, the NATP scenario, the current speed of growth of renewables is maintained over the coming decades. How quickly the relative shares of renewables grow, will depend strongly on the development of primary energy consumption. In the NATP scenario in 2050 their contribution in absolute terms (3,426 PJ/a) is double that of the CCSMAX scenario, but their share $(42 \%)$ is more than three times higher.

\subsubsection{Scenarios for Developing CCS Technologies in the Electricity Sector}

The intensity of structural change in electricity generation is largely defined by the necessity of replacing ageing fossil-fuelled power stations. The decision to phase out nuclear power, the continuing growth in renewables and the development of electricity consumption also influence this transformation.

Fig. 14-6 shows the capacity retirement line for German power stations in the twenty-first century. If we assume that a large-scale power station has a working lifetime of forty years we can calculate the consequential replacement demand from the capacity retirement line. Of the power stations built before 2000, a total of $60 \mathrm{GW}$ will have to be replaced by 2020: approx. $35 \mathrm{GW}$ fossil-fuelled power stations (including approx. $8 \mathrm{GW}$ in CHP plant), $8 \mathrm{GW}$ plant using renewables and 18 GW nuclear power. By 2030 altogether $90 \mathrm{GW}$ or $75 \%$ of installed capacity in 2000 will have to be replaced.

In conjunction with the expansion of renewables and the expansion of CHP (especially decentralised), both of which are aims of energy policy, the potential 'market' for CCS power stations is defined. However, whereas renewables and CHP already profit from the pre-2020 structural changes, which affect more than half of existing power station capacity, CCS plant will not be ready for this market (that being the assumption in the scenarios under consideration). The potential market volume for CCS plant could expand if it is possible to retrofit CCS technologies in fossil-fuelled power stations built between 2005 and 2020 .

In electricity consumption too, a small reduction already occurs in the reference case (see Table 14-3). ${ }^{8}$ But in the CCSMAX scenario for 2050 final demand for electricity is only $3 \%$ less than the value for 2005 (and thus as high as consumption in 2000). Partial exploitation of potential for electricity savings in the NATP scenario increases the savings to $18 \%$. In all the scenarios production and supply of hydrogen using renewable energy begins in 2030, which requires in the CCSMAX scenario in 2050 an additional $22 \mathrm{TWh} / \mathrm{a}$ of electricity (in BRIDGE: 31 TWh/a; in NATP: 47 TWh/a).

In the electricity sector the interdependence with renewables is especially great because they already have a share of more than $10 \%$ and current growth is most dynamic of all in that sector. But in the CCSMAX scenario electricity from fossil fuels still dominates in 2050 with a share of $65 \%$. In the BRIDGE scenario both energy sources are almost equally involved (fossil $56 \%)$, while in the NATP scenario renewables (72\%) clearly outweigh fossil fuels.

The following assumptions were made when determining installable CCS capacity in the electricity sector:

- Commercial application begins in 2020, all largescale power stations have a working lifetime of 40 years.

8 However, the reference case is based on data from 2000 when gross electricity generation was $571 \mathrm{TWh} / \mathrm{a}$ (without pumped storage), and doesn't include the relatively steep increase to 2005 . 


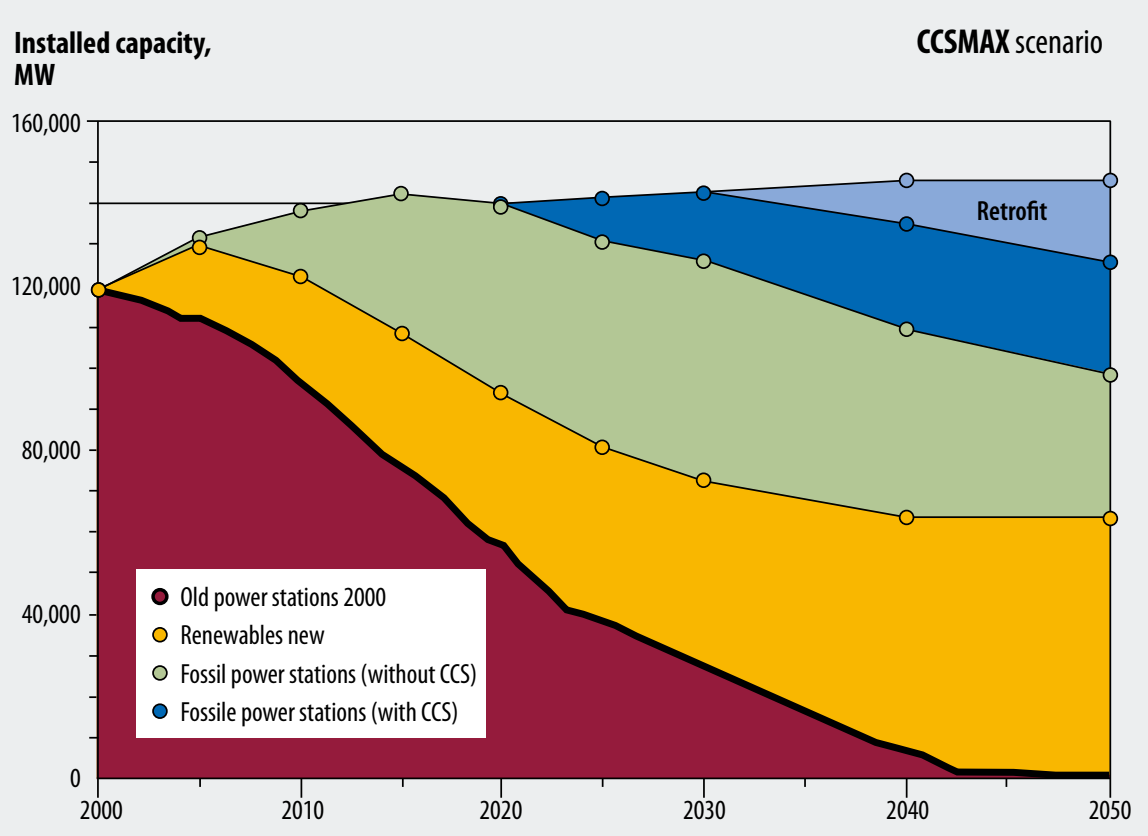

Fig. 14-7:

Installed output in the CCSMAX scenario: old power stations, new renewable energy plant and new fossilfuelled power stations with and without CCS

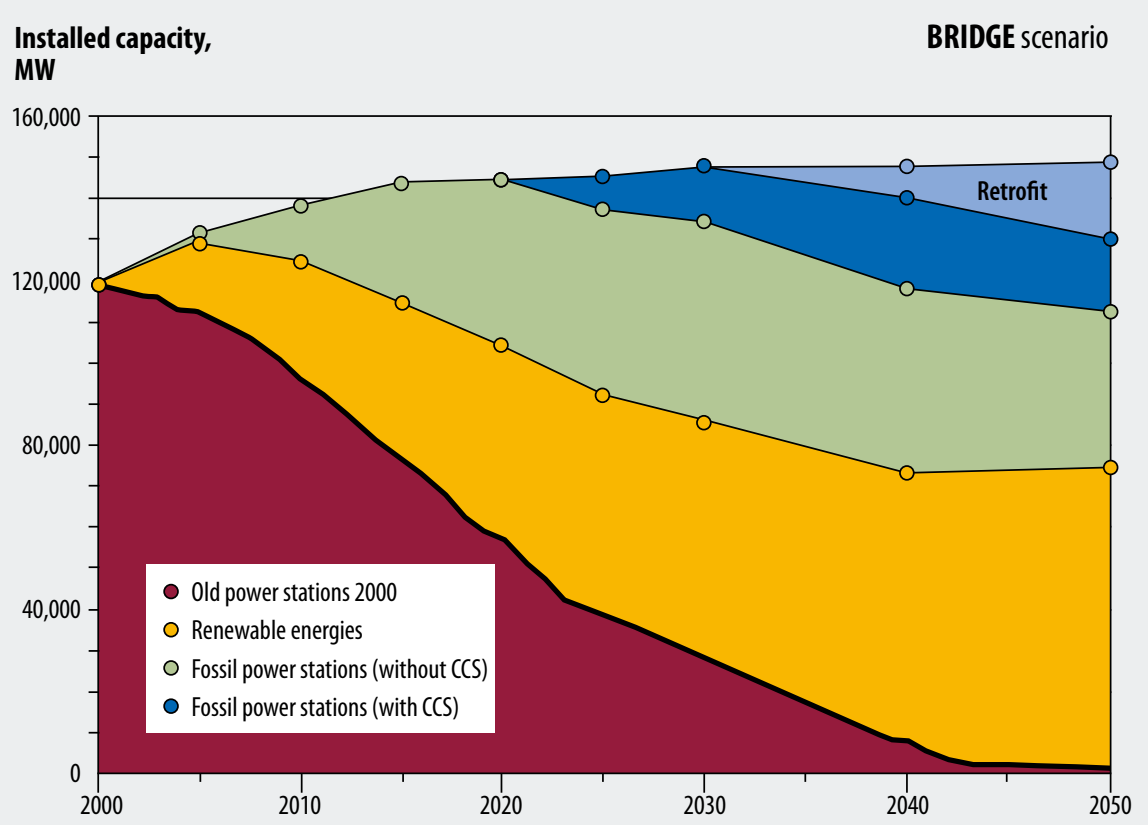

Fig. 14-8:

Installed output in the BRIDGE scenario: old power stations, new renewable energy plant and new fossilfuelled power stations with and without CCS
- From then on $90 \%$ of new condensation power stations and $50 \%$ of large cogeneration plants (CHP) will be equipped with CCS technologkies.

- New power stations built between 2005 and 2010 will be replaced by new CCS plant between 2045 and 2050.

- New power stations built between 2011 and 2020 (large condensation power stations, large cogeneration plants) will be retrofitted with CCS technology after 2030, in the same proportions as new builds.
- The parameters of power stations without and with CCS are taken from chapter 12; only the direct $\mathrm{CO}_{2}$ issions are considered; ${ }^{9}$ in all scenarios fossilfuelled power stations without CCS have the same parameters.

9 So indirect $\mathrm{CO}_{2}$ emissions (from upstream processes) and other greenhouse gases (e.g. methane) are not included here. The LCAs in chapter 10 show, however, that these emissions assume significant dimensions. 
Fig. 14-9:

Installed output in the NATP scenario: old power stations, new renewable energy plant and new fossil-fuelled power stations without CCS

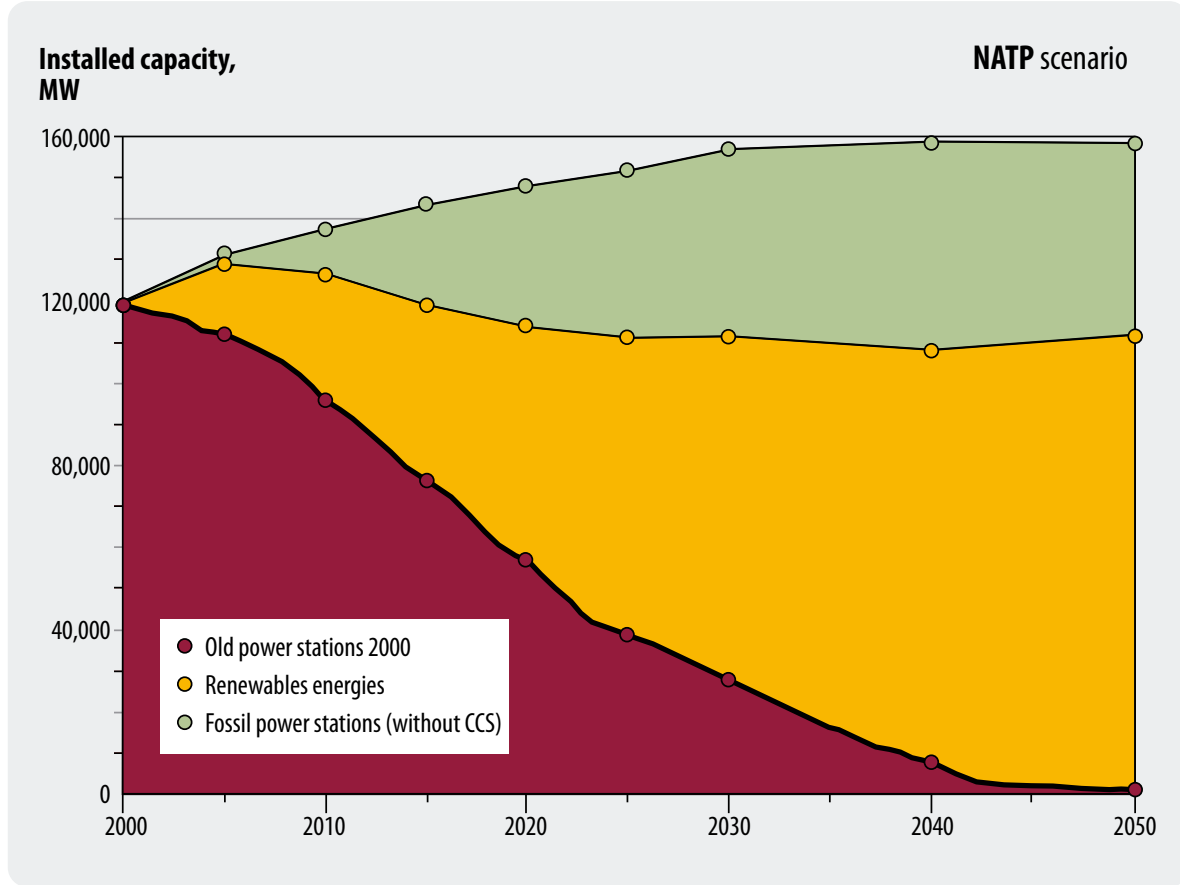

- Renewables and cogeneration plants will be expanded in the dimensions described above.

Fig. 14-7 to Fig. 14-9 show the output curves of the different power station types in the three scenarios (see also Table 14-3). In Fig. 14-7 and Fig. 14-8 the upper segment represents installed CCS capacity divided into new and retrofitted plant. By 202042 GW (CCSMAX), $36 \mathrm{GW}$ (BRIDGE) or $30 \mathrm{GW}$ (NATP) of new fossilfuelled large scale power station capacity - which cannot initially be equipped with CCS technology - will already have to have been installed. On the basis of the assumed conditions the following maximum CCS capacities can be installed by 2050 :

- CCSMAX: 47 GW (of which 7 GW coal, 14 GW lignite, $27 \mathrm{GW}$ natural gas; power station structure until 2030 taken from Energiereport IV [EWI and Prognos 2005])

- BRIDGE: $36 \mathrm{GW}$ (14 GW coal, $8 \mathrm{GW}$ lignite, $14 \mathrm{GW}$ natural gas)

The installed capacity of all renewables - currently 27 GW - rises through expansion measures to between 64 GW (CCSMAX) and 112 GW (NATP). Apart from biomass and thermal storage in conjunction with solar thermal and geothermal power, their capacity utilisation may fluctuate depending on conditions. The fossil-fuelled power station capacity required in the CCSMAX scenario rises slightly until 2020 before returning to about today's level with a figure of about $83 \mathrm{GW}$. It falls slightly until 2050 in BRIDGE to reach 74 GW and falls strongly in NATP to $47 \mathrm{GW}$. These figures also include a growing trend towards fossil-fuelled CHP capacity (currently $18 \mathrm{GW}$, in 2050 in CCSMAX 31 GW, in BRIDGE and NATP $36 \mathrm{GW}$ ).
To reflect the different power station structures the scenarios model a broad range of possible investment strategies. As a consequence the power station load factors are different too. In 2050 in the CCSMAX scenario 228 TWh/a of electricity are generated from CCS power stations (40\%) and in the BRIDGE scenario $146 \mathrm{TWh} / \mathrm{a}$ (27\%).

Fig. 14-10 and Fig. 14-11 show how these data fit into the overall generation structure. The CCSMAX scenario demands extremely fast growth of CCS technologies if the opportunities offered by power station replacement

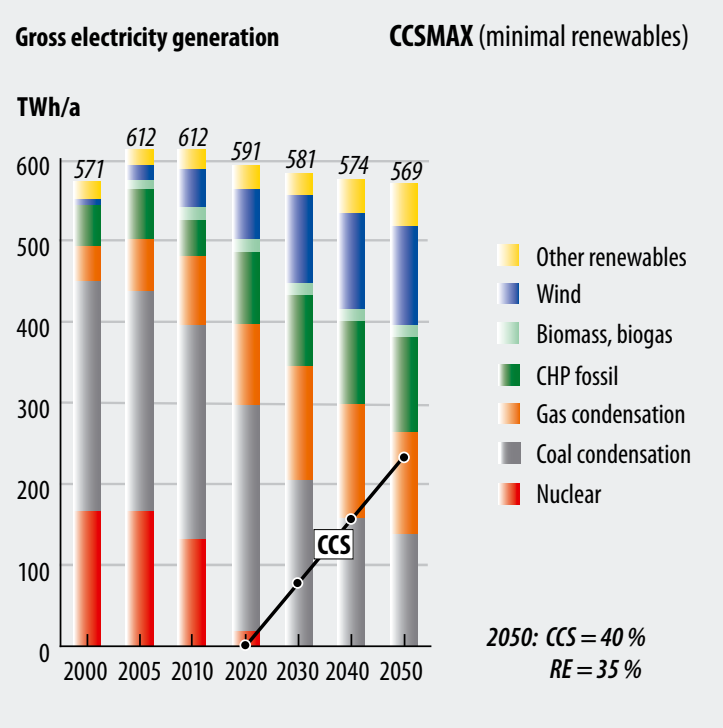

Fig. 14-10: Structure of gross electricity generation of CCSMAX scenario $\mathrm{RE}=$ renewable energies 


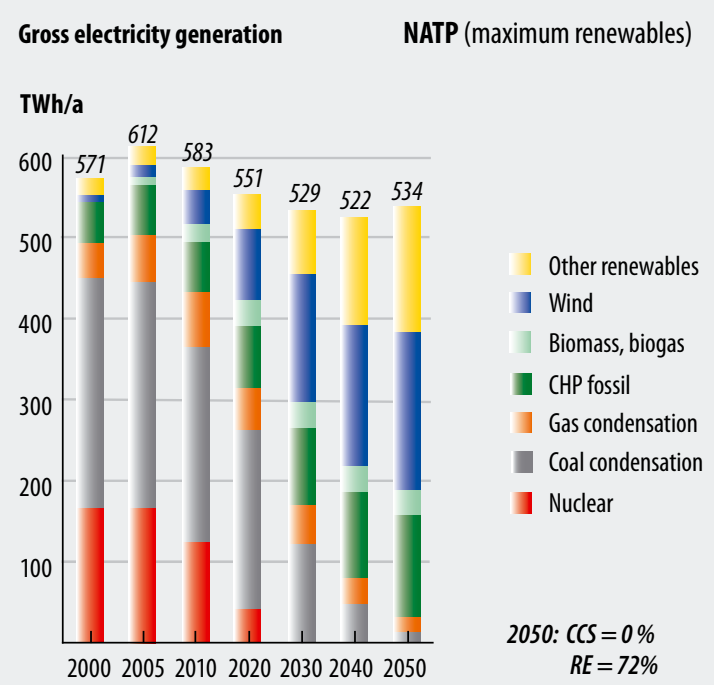

Fig. 14-11: Gross electricity generation in the NATP scenario

demand are to be used to the full. Between 2020 and 2050 an average of 1,600 MW CCS power station capacity would have to come on stream every year (or after 2030 to be retrofitted). In BRIDGE it would be less at 1,200 MW/a, but still considerable.

In all three scenarios between $72 \%$ and $75 \%$ of electricity in 2050 is generated with low or no emissions with different shares in the two technology categories (Fig. 14-10 to 14-12). Because of the differences in total amount generated, the respective absolute amounts vary between $384 \mathrm{TWh} / \mathrm{a}$ (NATP: $72 \%$ renewables + $0 \%$ CCS

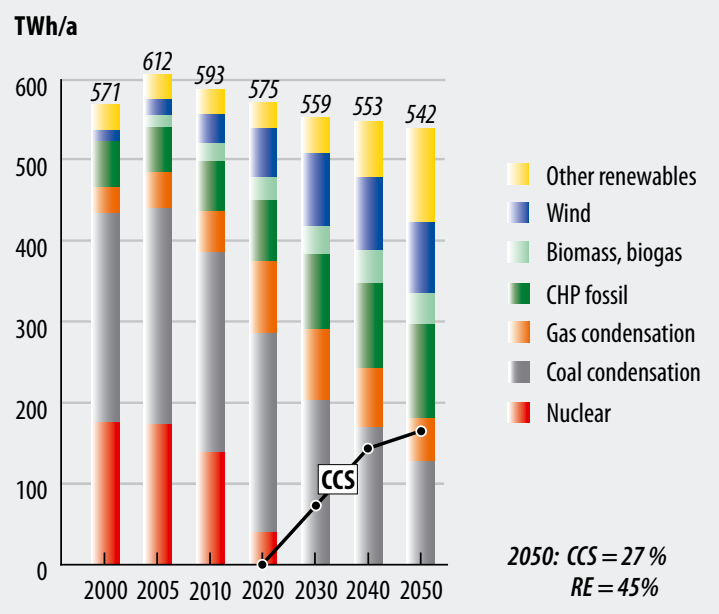

Fig. 14-12: Gross electricity generation in the BRIDGE scenario

out of total $534 \mathrm{TWh} / \mathrm{a}$ ) and $425 \mathrm{TWh} / \mathrm{a}$ (CCSMAX: 35 $\%$ renewables $+40 \%$ CCS out of total $569 \mathrm{TWh} / \mathrm{a})$.

Fig. 14-11 clearly shows the effects of the investment strategies on $\mathrm{CO}_{2}$ emissions from electricity generation. By 2020 the combination of ambitious efficiency measures and continuing expansion of renewables in the NATP scenario leads to a clear fall in $\mathrm{CO}_{2}$ emissions that more than compensates for the phasing out of nuclear power. The assumed smaller contribution of the efficiency and renewables strategy in the BRIDGE scenario leads to a fairly stable level of emissions between

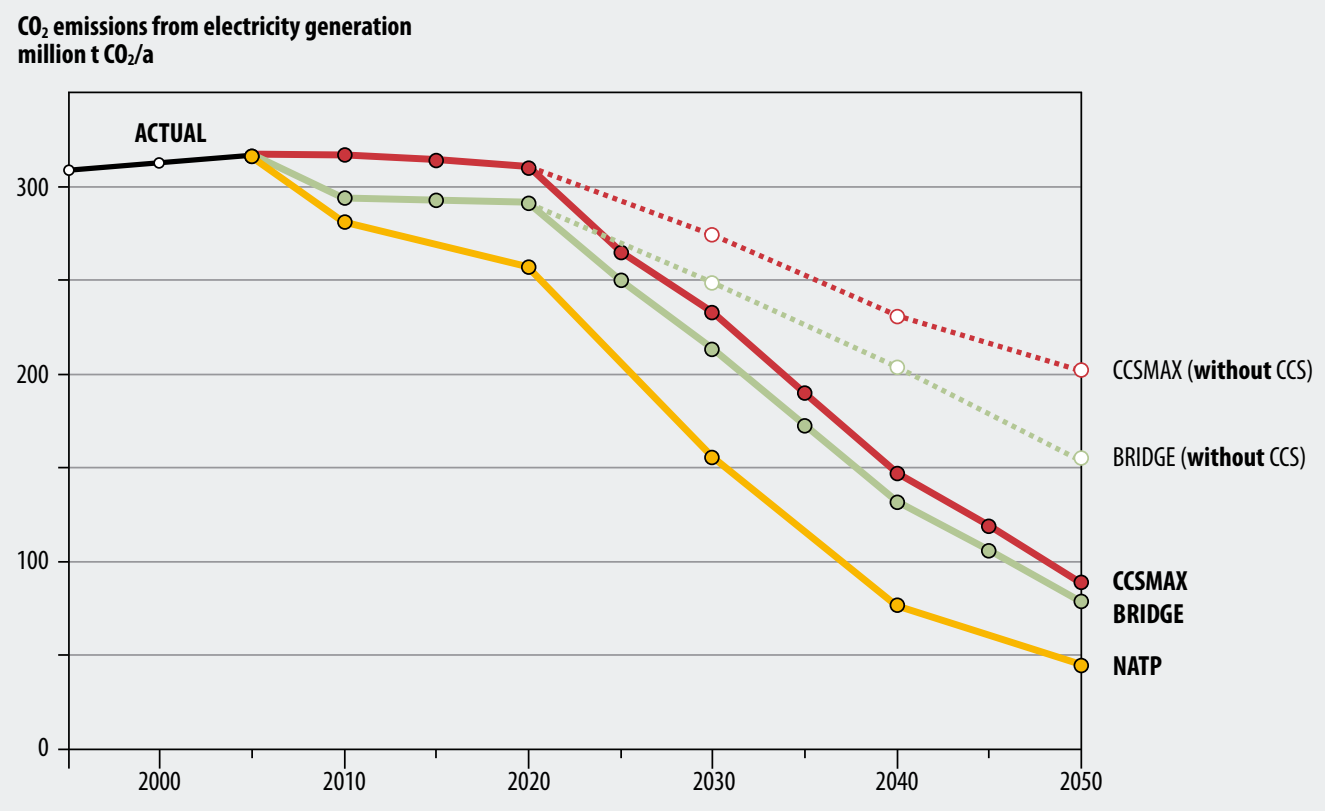

Fig. 14-13: $\mathrm{CO}_{2}$ emissions from electricity generation in the scenarios (broken line = without introdution of CCS technologies; (HP electricity generation with credit for heat supply) 
2010 and 2020 when the impact of phasing out nuclear power is greatest. In the CCSMAX scenario today's level of emissions is maintained until 2020. In comparison to the efficiency and renewables strategy in the NATP scenario, the CCS deployment scenarios achieve comparable gradients of $\mathrm{CO}_{2}$ reduction after 2020, but are unable to make good the deficit that has accumulated before 2020. The NATP scenario achieves the lowest emissions figure for the electricity sector, with just 45 million $\mathrm{t} \mathrm{CO}_{2} / \mathrm{a}$. By contrast, the CCSMAX scenario has 90 million $\mathrm{t} \mathrm{CO}_{2} / \mathrm{a}$ and the BRIDGE scenario $80 \mathrm{mil}$ lion $\mathrm{t} \mathrm{CO}_{2} / \mathrm{a}$. In the BRIDGE scenario the $\mathrm{CO}_{2}$ emissions avoided through application of CCS in electricity generation are 76 million $\mathrm{t} / \mathrm{a}$; in the CCSMAX scenario the figure is 113 million $\mathrm{t} / \mathrm{a}$.

Theoretically the NATP scenario could also be combined with a CCS strategy after 2020 to achieve similarly low emission values in 2050 . But to do that the expansion of renewables would first have to be accelerated hard until 2020 and then drastically reduced again to free capacity for increased construction of CCS power stations. Under the conditions of these scenarios there would be no reason to do that because by that point - especially through their dynamic expansion - renewables (apart from photovoltaic) would have become almost completely competitive on the electricity market. So it is then unlikely that in this scenario CCS technologies would be able to gain any worthwhile foothold in electricity supply. If the expansion dynamic of renewables continued as in NATP it would at least in theory be possible to install about another $15 \mathrm{GW}$ of CCS capacity by 2050 . But this would have to occur primarily in cogeneration plants and in power stations with low load factors, so that only $40 \mathrm{TWh} / \mathrm{a}$ of CCS electricity could be generated. That would be an absolutely unattractive market niche.

If renewables are expanded more slowly from the outset - as proposed in the BRIDGE scenario - and at the same time progress on efficiency is slow, CCS technologies would have greater chances of establishing themselves in the German electricity market after 2020. In this scenario the market volume for CCS technologies is around $47 \mathrm{GW}$. For 2050 this results in a relatively balanced mix of electricity from renewables (245 TWh/a), CCS electricity (146 TWh/a) and conventionally generated electricity from fossil fuels (150 TWh/a). In this case CCS technologies could compensate for less than ideal development of renewables and efficiency technologies and thus ensure a tolerably low level of emissions from electricity generation (80 million t/a in 2050). Table 14-4 shows the situation in 2050 after introducing CCS for electricity generation.

\subsubsection{Scenarios for Developing CCS Technologies in the Hydrogen Sector}

Even with great success, emission-reducing measures in the electricity sector alone will not be sufficient to reduce total emissions far enough to meet the $80 \%$ cli-
Table 14-4: Effects of applying CCS in electricity generation in the CCSMAX and BRIDGE scenarios in 2050

\begin{tabular}{|l|c|c|c|}
\cline { 2 - 4 } \multicolumn{1}{c|}{} & Avoided $\mathrm{CO}_{2}$ & Captured $\mathrm{CO}_{2}$ & $\begin{array}{c}\text { Extra primary } \\
\text { energy required }\end{array}$ \\
\cline { 2 - 4 } & million t/a & million t/a & PJ/a \\
\hline CCSMAX & $\mathbf{1 1 2 . 8}$ & $\mathbf{1 5 6 . 9}$ & $\mathbf{3 8 2}$ \\
\hline from coal & 16.7 & 21.9 & 44 \\
\hline from lignite & 65.9 & 96.4 & 225 \\
\hline from natural gas & 30.3 & 38.6 & 112 \\
\hline BRIDGE & $\mathbf{7 5 . 5}$ & $\mathbf{1 0 3 . 6}$ & $\mathbf{2 4 1}$ \\
\hline from coal & 27.8 & 36.5 & 74 \\
\hline from lignite & 33.4 & 48.8 & 114 \\
\hline from natural gas & 14.4 & 18.3 & 53 \\
\hline
\end{tabular}

mate protection target. Similarly comprehensive measures are also required in the heat and vehicle fuels sectors. If we wish to apply CCS technologies here too, one obvious option is generating hydrogen from fossil primary energy while retaining the $\mathrm{CO}_{2}$. Questions of resources and cost mean that only coal gasification comes into consideration.

The quantities of hydrogen to be produced in the scenarios were selected so as to ensure that the overall climate protection goal for 2050 was achieved for the German energy system (i. e. NATP emissions level, 240 million t $\left.\mathrm{CO}_{2} / \mathrm{a}\right)$. The following assumptions were made:

- The overall efficiency of coal gasification with $\mathrm{CO}_{2}$ capture is $65 \%$, the plant load factor is $7,800 \mathrm{~h} / \mathrm{a}$. The $\mathrm{CO}_{2}$ capture rate is $88 \%$, so CCS hydrogen is thus still burdened with $\mathrm{CO}_{2}$ emissions of 0.017 million $\mathrm{tCO}_{2} / \mathrm{PJ}_{\mathrm{H} 2}$ (in relation to the coal used that means 0.011 million $\mathrm{tCO}_{2} / \mathrm{PJ}_{\mathrm{th}}$ ).

- CCS hydrogen only substitutes oil products (heating oil, petrol and diesel). So 0.055 million $\mathrm{t} \mathrm{CO}_{2}$ can be avoided for every PJ of hydrogen used (if natural gas is replaced the substitution effect sinks accordingly and amounts to just 0.039 million $\mathrm{t}$ $\mathrm{CO}_{2} / \mathrm{PJ}_{\mathrm{H} 2}$ ).

- In all the scenarios a baseline of $300 \mathrm{PJ} / \mathrm{a}$ is reached in 2030; this requires $16.5 \mathrm{GW}_{\text {th }}$ gasification output and $460 \mathrm{PJ} / \mathrm{a}$ of coal, with which $310 \mathrm{PJ} / \mathrm{a}$ of crude oil can be substituted.

The quantity of $\mathrm{H}_{2}$ required in 2050 in the CCS scenarios varies depending on the assumed reduction in final energy demand through increases in user efficiency and the assumed expansion of renewables. Table 14-5 summarises the main data. 


\begin{tabular}{|c|c|c|c|c|c|c|}
\hline & Hydrogen & $\begin{array}{l}\text { Coal } \\
\text { required }\end{array}$ & $\begin{array}{l}\text { Gasification } \\
\text { output }\end{array}$ & $\begin{array}{c}\mathrm{CO}_{2} \\
\text { reduction*) }\end{array}$ & $\begin{array}{c}\mathrm{CO}_{2} \\
\text { captured }\end{array}$ & $\begin{array}{c}\text { Extra primary } \\
\text { energy required }{ }^{*} \text { ) }\end{array}$ \\
\hline & $\mathrm{PJ} / \mathrm{a}$ & $\mathrm{PJ} / \mathrm{a}$ & $\mathrm{GW}_{\text {th }}$ & million t/a & million $\mathrm{t} / \mathrm{a}$ & $\mathrm{PJ} / \mathrm{a}$ \\
\hline \multicolumn{7}{|l|}{2030} \\
\hline Both & 300 & 462 & 16,5 & 17 & 37 & 152 \\
\hline \multicolumn{7}{|l|}{2040} \\
\hline CCSMAX & 1,000 & 1,538 & 55 & 55 & 125 & 502 \\
\hline BRIDGE & 700 & 1,077 & 38 & 38 & 87 & 351 \\
\hline \multicolumn{7}{|l|}{2050} \\
\hline CCSMAX & 3,440 & 5,290 & 188 & 189 & 429 & 1,725 \\
\hline BRIDGE & 1,800 & 2,770 & 99 & 99 & 224 & 904 \\
\hline *) Sub & ineral oil & & & & & \\
\hline
\end{tabular}

Table 14-5:

Application of CCS in hydrogen production in the CCSMAX and BRIDGE scenarios in 2030, 2040 and 2050
In order to achieve the set goal of reducing $\mathrm{CO}_{2}$ emissions to 242 million $\mathrm{CCO}_{2} / \mathrm{a}$ in the BRIDGE scenario, about $60 \%$ of the oil demand in 2050 would have to be replaced with 1,800 PJ/a hydrogen; in the CCSMAX scenario it would have to be $95 \%(3,440 \mathrm{PJ} / \mathrm{a}$ hydrogen). The contribution made by hydrogen in this scenario would also influence the use of fossil feedstock in the chemicals industry, which would then have to partially switch to natural gas or synthesis gas produced by coal gasification. But these interactions cannot be investigated in any greater detail here. A move to substitution of natural gas is not sensible because of the small substitution effect, or would cause relatively high $\mathrm{CO}_{2}$ avoidance costs. The additional quantities of coal required amount to $27 \%$ (BRIDGE) to $42 \%$ (CCSMAX) of total primary energy demand in 2050.

The expansion of gasification capacity would have to occur exceptionally quickly, with $1,650 \mathrm{MW}_{\mathrm{th}} / \mathrm{a}$ having to be constructed between 2020 and 2030. In the period 2040 to 2050 this construction rate would have to rise to $6,100 \mathrm{MW}_{\text {th }} / \mathrm{a}$ in the BRIDGE scenario and to the very considerable figure of $15,000 \mathrm{MW}_{\mathrm{th}} / \mathrm{a}$ in the CCSMAX scenario. So one minimum precondition for implementing this strategy would be for commercial coal gasification plant to be set up on a large scale from 2020 without major teething or acceptance problems and for hydrogen production and $\mathrm{CO}_{2}$ capture and storage to operate at high load factor.

A second significant criterion is that a hydrogen infrastructure would need to follow this growth. Although the share of hydrogen in final energy demand in 2040 is relatively small in CCSMAX (14 \%) and BRIDGE (10 $\%)$, by 2050 in the CCSMAX scenario hydrogen would already be the predominant final energy type (with 47 $\%)$. From today's perspective that appears to be a great obstacle (UBA 2006). But a share of $29 \%(=1,900 \mathrm{PJ} /$, including $100 \mathrm{PJ} / \mathrm{a}$ renewable hydrogen), as required in the BRIDGE scenario to meet the climate protection target, appears achievable by 2050 in terms of infrastructure.

\subsection{Conclusions of the Scenario Analysis for Germany}

In our overall analysis we found very different structures for primary energy supply in Germany in 2050. The CCSMAX scenario represents an energy future strongly shaped by coal, indeed to speak of a 'renaissance of coal' would not be exaggerated. Here coal represents $47 \%$ of primary energy, plus another $10 \%$ lignite. Together with natural gas (whose quantities in this scenario are about the same as today) the share of fossil primary energy is $87 \%$ - which is higher than today's $83 \%$ (Fig. 14-14).

In the BRIDGE scenario, too, fossil fuels still predominate with a total of $77 \%$. Here coal with $35 \%$ is no longer the predominant energy source, but it still represents the main fossil fuel. However, efficiency successes are already notable here ( $17 \%$ less primary energy than in CCSMAX) as well as a noticeable contribution from renewables. In the NATP scenario effective implementation of major efficiency measures allows the absolute contribution of fossil fuels to be reduced considerably, to represent only $58 \%$ of energy needs by 2050 .

Fig. 14-15 compares the changes in primary energy structure in the CCSMAX and NATP scenarios. Put simply, NATP's avoidance of energy demand and greater contribution from renewables is replaced in the CCSMAX scenario by fossil primary energy whose $\mathrm{CO}_{2}$ emissions are considerably reduced through the use of CCS technology. But in order to meet the 2050 
Fig. 14-14:

Primary energy structures in 2000 and 2005 and in the scenarios for 2050, showing the amounts of coal required for production of CCS hydrogen

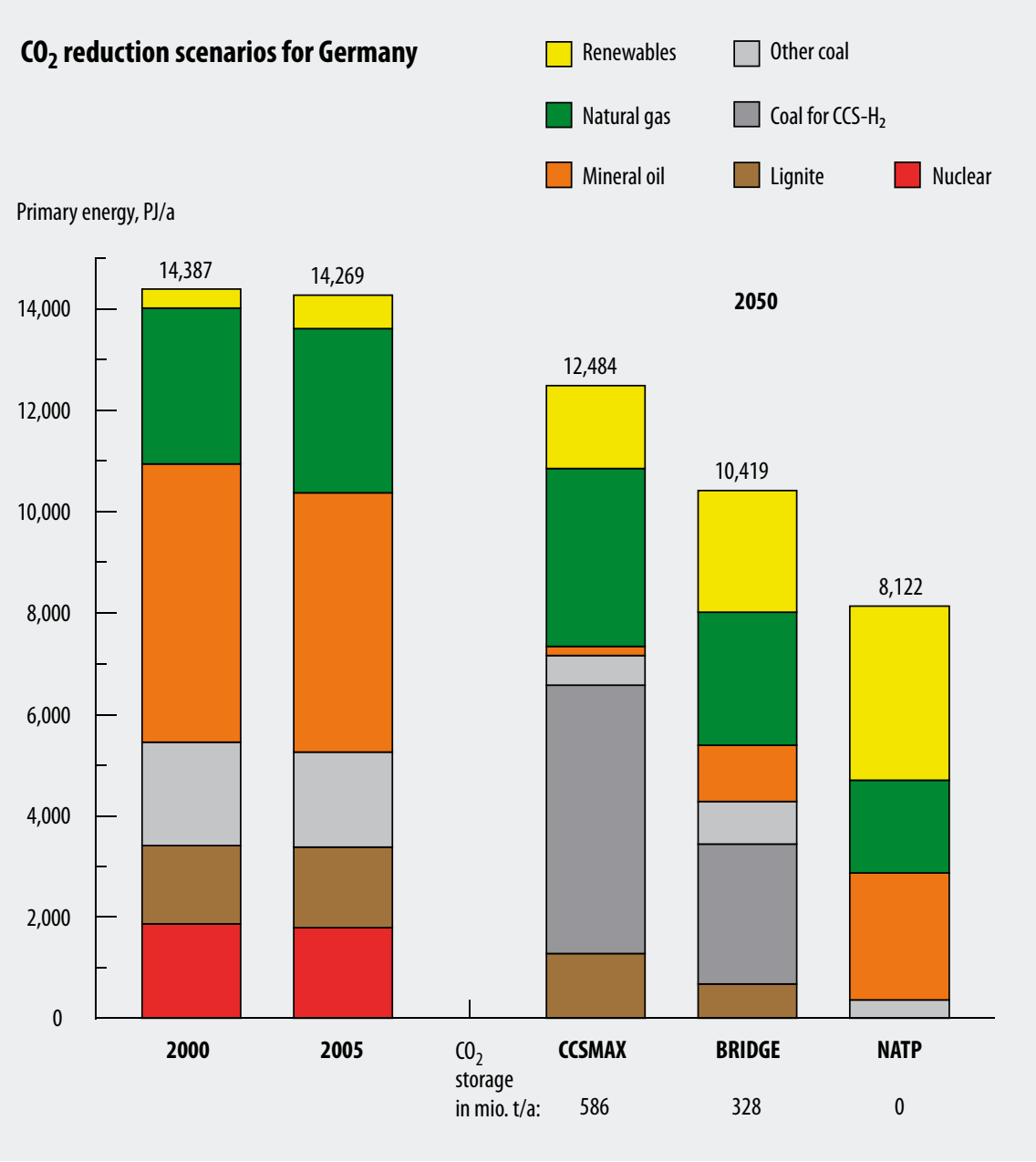

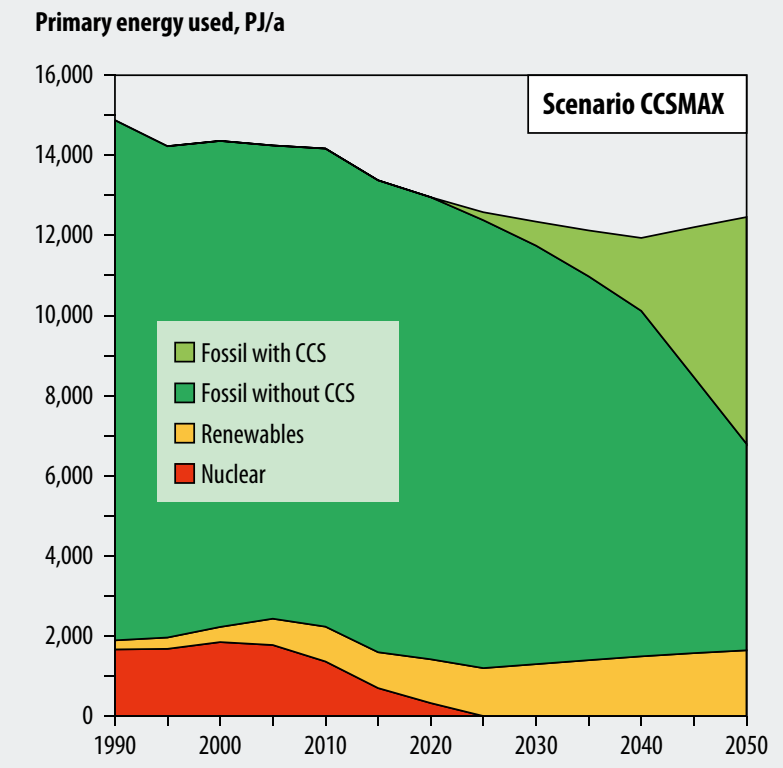

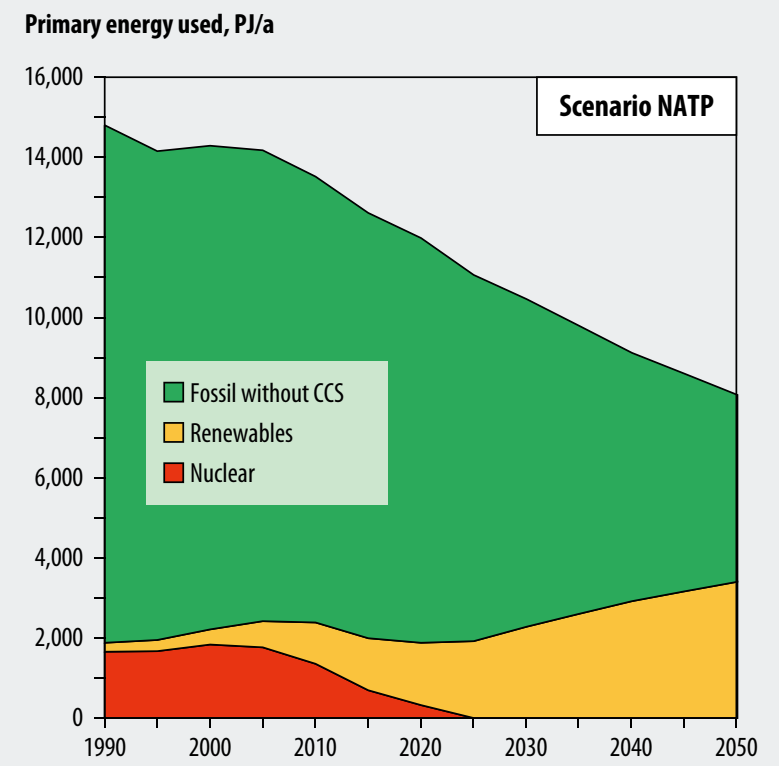

Fig. 14-15: Primary energy sources in the CCSMAX and NATP scenarios 


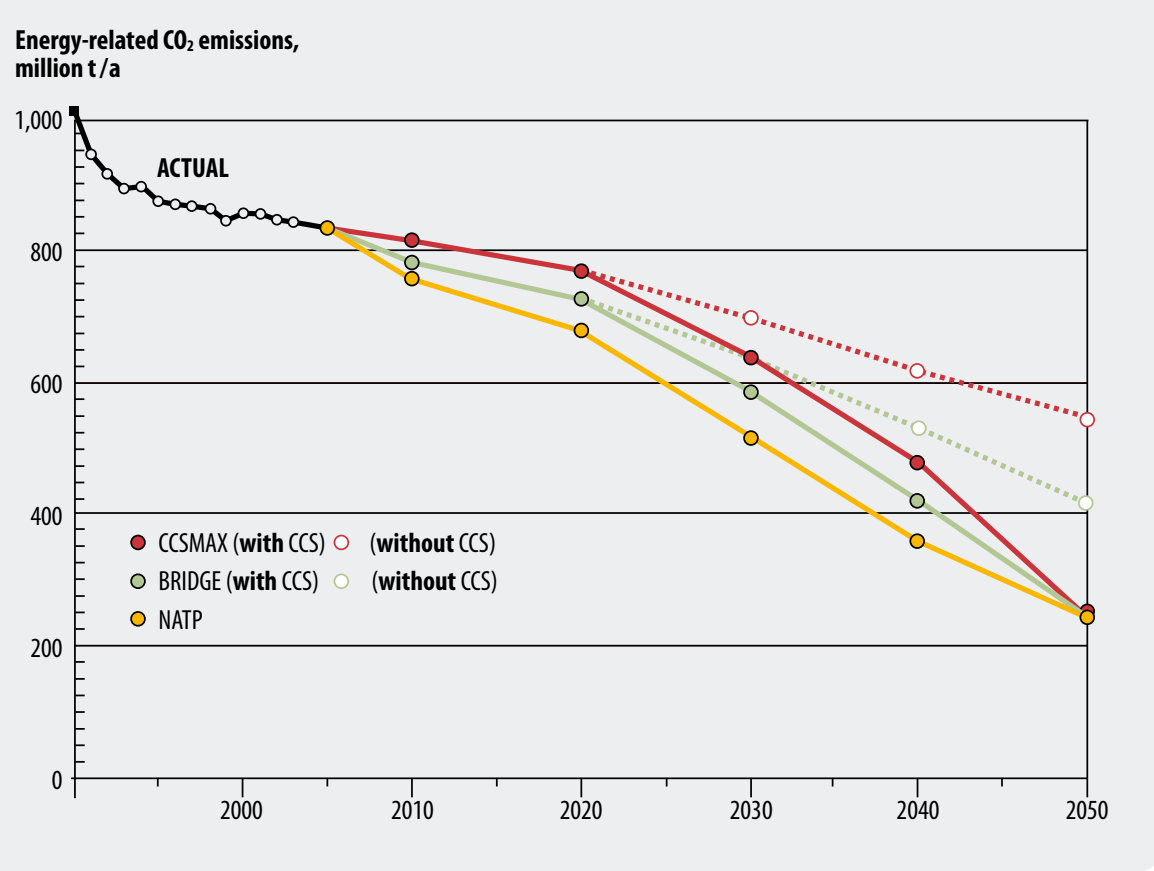

Fig. 14-16:

Energy-related $\mathrm{CO}_{2}$ emissions in the CCSMAX, BRIDGE and NATP scenarios until 2050 (broken line $=$ CCSMAX/ BRIDGE without CCS technologies) climate protection target extremely fast growth rates in that technology would be required after 2020 - a good deal faster even than the current rates of expansion in renewables.

All the scenarios meet the defined climate protection target in 2050 (Fig. 14-16). ${ }^{10}$ In CCSMAX the climate protection measures progress too slowly until 2020 and have to 'catch up' later in order to meet the target by 2050. Altogether CCS can be used to avoid between 175 million $\mathrm{CCO}_{2} / \mathrm{a}$ (BRIDGE) and 300 million $\mathrm{C} \mathrm{CO}_{2} / \mathrm{a}$ (CCSMAX) in 2050, compared to the reference case. In 2030 and 2040 the contribution from the electricity sector still predominates, but by 2050 the contribution from hydrogen production is foremost (Table 14-6). In the CCS scenarios considerable amounts of $\mathrm{CO}_{2}$ have to be captured and stored. In particular substituting mineral oil with hydrogen from coal (including CCS) requires capturing 2.26 million $\mathrm{CO}_{2}$ per avoided tonne of $\mathrm{CO}_{2}$. This puts the amount of $\mathrm{CO}_{2}$ to be captured and stored in 2050 at between 586 million t/a (CCSMAX) and 328 million t/a (BRIDGE). Under these conditions the available storage volume in Germany would be exhausted within 25 to 80 years in the CCSMAX scenario ( 44 to 145 years in the BRIDGE scenario).

\section{The main points are the following:}

- As the main pillar of a climate protection strategy, CCS as modelled in the CCSMAX scenario runs

10 Here the climate protection target is defined solely in terms of the greenhouse gas $\mathrm{CO}_{2}$. However, the large amounts of coal required for BRIDGE and especially for CCSMAX are associated with emissions of methane during coal mining, with considerable negative climatic impact (see chapter 10). into structural limits if the climate protection target of reducing $\mathrm{CO}_{2}$ emissions by $80 \%$ by 2050 is to be met with efficiency and renewables merely following a 'business as usual' trajectory. The assumption that CCS technologies will not be commercially viable before 2020 necessitates accelerated construction of CCS plant and hydrogen infrastructure during the remainder of the period until 2050. The high demand for coal (in CCSMAX approx. 5,900 PJ/a or 3.1 times today's figure) leads to extensive purchases on the world market which would lead to corresponding price reactions. Cost advantages for the forms of energy produced using CCS (electricity and hydrogen) compared to renewables cannot be identified (electricity) or are small (hydrogen) so from the economic perspective there is no decisive incentive for such a one-sided prioritisation of CCS. Furthermore such a strong expansion of CCS would necessitate starting straight away with great investment in R\&D and pilot plants for this technology option on a scale incompatible with the current energy policy of promoting efficiency strategies and expanding renewables. Also a very high degree of clarity would have to be achieved very quickly regarding the ecological compatibility and safety of $\mathrm{CO}_{2}$ storage. To pursue both strategies 'at full steam' until 2020 (efficiency and expansion of renewables following NATP until 2020; CCS development as in CCSMAX), but then to largely drop one of the options would not be a sensible way to proceed. Also the potential storage capacity for $\mathrm{CO}_{2}$ is insufficient for the required massive expansion of CCS. 
Table 14-6:

$\mathrm{CO}_{2}$ emissions in the scenarios with and without CCS technologies, captured $\mathrm{CO}_{2}$ quantities and resulting additional primary energy demand

\begin{tabular}{|c|c|c|c|c|c|c|c|c|c|c|c|}
\hline \multicolumn{6}{|c|}{$\mathrm{CO}_{2}$ emissions (million t/a) } & \multicolumn{3}{|c|}{ captured (million t/a) } & \multicolumn{3}{|c|}{$\begin{array}{l}\text { Additional primary energy } \\
\text { demand ( } \mathrm{PJ} / \mathrm{a})\end{array}$} \\
\hline \multirow{2}{*}{$\begin{array}{l}\text { Year/ } \\
\text { scenario }\end{array}$} & \multirow{2}{*}{$\begin{array}{l}\text { Total } \\
\text { without } \\
\text { CCS }\end{array}$} & \multicolumn{3}{|c|}{ reduction } & \multirow{2}{*}{$\begin{array}{l}\text { Total } \\
\text { with } \\
\text { CCS }\end{array}$} & \multirow[t]{2}{*}{$\mathrm{H}_{2}$} & \multirow{2}{*}{$\begin{array}{l}\text { Electric- } \\
\text { ity }\end{array}$} & \multirow[t]{2}{*}{ Total } & \multirow{2}{*}{$\begin{array}{l}\mathrm{CCS} \\
\mathrm{H}_{2}\end{array}$} & \multirow{2}{*}{$\begin{array}{l}\text { CCS- } \\
\text { electric- } \\
\text { ity }\end{array}$} & \multirow[t]{2}{*}{ Total } \\
\hline & & $\begin{array}{l}\text { through } \\
\text { electric- } \\
\text { ity }\end{array}$ & $\begin{array}{l}\text { through } \\
\mathrm{H}_{2}\end{array}$ & Total & & & & & & & \\
\hline 2005 & $824 *)$ & - & - & - & - & - & - & - & - & - & - \\
\hline \multicolumn{12}{|l|}{2020} \\
\hline CCSMAX & 696 & 41 & 17 & 58 & 638 & 37 & 67 & 94 & 152 & 139 & 291 \\
\hline BRIDGE & 638 & 35 & 17 & 52 & 586 & 37 & 48 & 85 & 152 & 110 & 262 \\
\hline NATP & 517 & 0 & 0 & 0 & 517 & 0 & 0 & 0 & 0 & 0 & 0 \\
\hline \multicolumn{12}{|l|}{2030} \\
\hline CCSMAX & 616 & 84 & 55 & 139 & 477 & 125 & 117 & 242 & 502 & 286 & 788 \\
\hline BRIDGE & 530 & 72 & 38 & 110 & 420 & 87 & 100 & 187 & 351 & 228 & 579 \\
\hline NATP & 357 & 0 & 0 & 0 & 357 & 0 & 0 & 0 & 0 & 0 & 0 \\
\hline \multicolumn{12}{|l|}{2050} \\
\hline CCSMAX & 544 & 113 & 189 & 302 & 242 & 429 & 157 & 586 & 1,725 & 382 & 2,107 \\
\hline BRIDGE & 417 & 76 & 99 & 175 & 242 & 224 & 104 & 328 & 904 & 241 & 1,145 \\
\hline NATP & 242 & 0 & 0 & 0 & 242 & 0 & 0 & 0 & 0 & 0 & 0 \\
\hline
\end{tabular}

- A climate protection strategy following the NATP scenario, which manages without CCS, would not yet develop of its own accord. As well as maintaining the current dynamic rate of expansion of renewables in the electricity sector and extending their use to the heat sector on a significant scale, considerable additional support measures to encourage much greater efficiency in use and conversion of energy would be required if the 2050 climate protection target is to be met on time by this strategy. Expanding renewables and increasing efficiency are measures that take effect relatively quickly so as long as the necessary support measures impact quickly - they allow the restructuring process to run more harmoniously than in the CCSMAX case described above. Major transformation of energy infrastructures would be required, but this could be realised in stages. A strategy concentrating especially on energy productivity also makes sense in broader economic terms because many of the efficiency measures to be taken represent the most economic option for climate protection regardless what measures are taken on the supply side. If external costs were included the overall economic situation would be even more favourable. To that extent this scenario represents an 'ideal strategy' but one which demands that very effective energy policy decisions be taken quickly, especially a clear target oriented and expansion of energy efficiency policy (including combined heat and power). In the longer term this scenario necessitates considerable structural changes, increasing network and system integration on the electricity side, integrat- ing energy import structures (e.g. electricity from solar thermal power plant in North Africa) and greatly expanding district heating systems.

- From today's perspective a development in line with the BRIDGE scenario would also definitely require additional stimuli for further increases in efficiency and further expansion of renewables that would have to exceed the current reference development. However, the necessary changes would probably be easier to implement than in the case of the NATP scenario. They are also easier to justify to other countries that have made less progress than Germany in the direction of an 'ideal' NATP strategy or have a greater interest in using coal. The pressure to introduce CCS technologies and a hydrogen infrastructure is less than in CCSMAX because until 2030 the required contributions from these options can remain relatively small. Nor - in the event that CCS technologies turn out to be a sensible energy policy option - does the level that needs to be reached by 2050 come up against any fundamental limits concerning required plant capacity, infrastructure changes or storage capacity.

In view of the real interests involved and the different assessments of technology options in the field of energy (especially in the global context), an energy policy following the BRIDGE strategy can be characterised as a 'pragmatic' strategy. It demands a general intensification of energy policy efforts on a broad front (CCS, energy efficiency, renewables) if long-term climate protection goals are to be tackled 
seriously. At the same time this strategy offers the possibility - in the interval until 2020 - of exploring the development and cost potentials of CCS technologies thoroughly and without enormous pressure of time and demonstrating their feasibility in initial pilot plants.

Analyses of the costs of renewables and CCS technologies for producing electricity and hydrogen show no obvious economic advantages for the CCS option. If the learning curves for renewable energy technologies continue and our assumptions about price developments for fossil fuels are correct, electricity generation from most renewable energy technologies around 2020 will tend to be cheaper than electricity generation with CCS. The latter will definitely require $\mathrm{CO}_{2}$ prices between 30 and $50 € / \mathrm{t} \mathrm{CO}$ if it is to be attractive to private investors compared with conventional electricity generation from fossil fuels. After 2020 the costs of renewable energy technologies fall still further, while the real cost of generating electricity from coal with CCS will probably remain roughly constant if technical developments are taken into account. If we include the external costs we find further advantages for energy efficiency and renewables.

There are many uncertainties concerning the relative profitability of CCS and renewables. The assessments presented above for renewables are based on a dynamic global market where very considerable cost-reduction effects can be exploited via mass production and learning curve effects.

One factor that could impede a comprehensive CCS strategy is that the broad introduction of generally expensive low- $\mathrm{CO}_{2}$ or $\mathrm{CO}_{2}$-free hydrogen has to come earlier than in a strategy based on the NATP scenario.

The aspects discussed above show that a consistent strategy following the NATP scenario make more economic sense in the medium to long term and should therefore be the goal of energy policy. At the same time it is advisable to subject the CCS option to continued thorough scrutiny and in particular a realistic practical demonstration, in order to have - after about a decade - more precise knowledge of the potential and limits of these technologies. If it then turns out that in the global restructuring of the energy supply the expansion of energy efficiency and renewables is 'only' running at the intensity laid out in the BRIDGE scenario, CCS would offer an additional climate protection option.

\subsection{Applicability of Results to Other Countries}

The analyses described above were conducted for Germany taking particular account of the situation there. This means they cannot be applied to other countries one-to-one. At the same time certain underlying tendencies do also apply elsewhere and in some cases similar starting conditions are also present (e.g. large demand for short-term power station replacement). The scope of this study precludes us from going into the role of CCS in other countries in detail, but in the following we bring together findings from the scenario analyses for Germany that can be regarded as being more broadly applicable. The concluding chapter of this report (chapter 15) also examines the discussion of the role of CCS from a global perspective.

The following aspects are of a more general nature:

- The future role of CCS is affected by various factors. These include the structure and age of power station capacity and especially the domestic availability of fossil fuels. Countries with large coal reserves of their own (e.g. China, Australia) will be keen to use them as intensively as possible even if conditions (especially climate protection rules) change significantly.

- Large-scale CCS technologies will probably not come on stream until 2020, but the international trend for massive expansion of power station capacity continues apace (especially new coal-fired power stations). Just in China a new power station starts operation every week. This means it is necessary not only to consider new builds but also to direct increasing attention to the retrofitting option. Between 2006 and 2020 China will build about six to eight times more new power station capacity than the current installed total in Germany. Development efforts in this connection are required in particular to reduce the extra fuel required after CCS retrofitting (e.g. through more efficient scrubbing processes). But the question of how power stations can be prepared for later retrofitting (captureready status) when they are still at the planning stage (i.e. before they are even built) also needs to be answered.

- A climate protection strategy based largely on CCS appears conceivable neither for Germany nor for most other countries. Structural limits (e.g. storage capacity, infrastructure aspects) mitigate against it as does the necessity, according to climatologists, to take action well before 2020 not only to initiate climate protection measures but to implement them too.

- For Germany the analyses show that ambitious climate protection targets can be met without using CCS at all. For other countries with an even stronger focus on coal or faster growth rates for energy demand this might be more difficult or require deeper structural changes. But for these countries too, further expansion of renewables and improvements in energy efficiency will be the climate protection strategy of choice.

- The extent to which renewables and energy efficiency improvement meet with resistance that hinders their implementation and increases demand for supplementary climate protection measures will 
be a decisive question. This may differ from country to country and increase the necessity for CCS as a bridge technology.

- The decisive factor for introducing CCS need not necessarily be the field of electricity generation. It is also conceivable that the greatest impetus will come from the production of hydrogen from fossil fuels. Rising oil prices in recent years (to more than $\$ 90$ per barrel) and the almost complete dependence of the transport sector on fossil fuels (especially petroleum products) have increased the incentives to turn to alternative options for supplying fuels. Alongside first- and second-generation biofuels these also include producing liquid fuel from coal. Processes for turning coal into synthetic fuels (coal-to-liquid) are being pursued in various countries, especially China, the United States and South Africa. But they suffer the great disadvantage that (considering the whole process from extraction to combustion) they have $90 \%$ higher $\mathrm{CO}_{2}$ emissions than conventional petrol or diesel. Even if the $\mathrm{CO}_{2}$ produced during the conventional coal liquefaction process is captured and stored, the emissions over the process as a whole are higher than for the reference fuels. If coal is to replace conventional fuels while observing climate protection restrictions the only current option is producing hydrogen from coal and capturing the $\mathrm{CO}_{2}$. This would require infrastructure investment as described above for the $\mathrm{CO}_{2}$ logistics and for a completely new hydrogen infrastructure.

- Polygeneration projects of the kind currently planned or being implemented by RWE in Germany (and other actors elsewhere in the world) represent door-openers for such developments. These plants, based on gasification technology, possess great flexibility both in terms of the fuel they use and the product they produce. Possible products are electricity, synthesis gas, synthetic liquid fuels (via Fischer-Tropsch synthesis) and hydrogen.

- Finally it must be supposed that countries with potential for EOR or EGR (and consequently with a commercial interest in using $\mathrm{CO}_{2}$ ) will be among the leaders. Companies from these countries may also be interested in expanding the capture of $\mathrm{CO}_{2}$ during natural gas extraction (e.g. in LNG and $\mathrm{H}_{2}$ ).

- Decisive impetus is also expected from countries with a strong gas industry (e.g. Norway, United Kingdom). They possess know-how that can be put to profitable use and depleted gas fields with storage potential.

- As well as the aspect of climate protection, implementation of CCS will also be determined by other, sometimes very pragmatic aspects. In particular tangible economic advantages will also make certain countries (or more precisely certain actors from these countries) into pioneers. This applies above all to countries such as Norway and the United Kingdom, which possess considerable storage potential underneath the seabed in hydrocarbon deposits and saline aquifers deep below the North Sea. 


\section{Chapter 15 \\ CCS in the International Context}

Is CCS a necessity if an ambitious climate protection goal is to be achieved, for example the European Union's $2^{\circ} \mathrm{C}$ target? And what requirements must then be met for international implementation? This chapter examines those two questions in the light of economic scenarios and thoughts about a possible institutional framework for CCS. The focus is on a global perspective for CCS.

\subsection{The Significance of CCS as a Climate Protection Option}

The importance of CCS in the context of climate protection lies primarily in the possibility of stabilising the level of $\mathrm{CO}_{2}$ in the atmosphere at a lower level. If the increase in global average temperature is to be restricted to $2^{\circ} \mathrm{C}$ above the pre-industrial level it will very probably be necessary to stabilise the $\mathrm{CO}_{2}$ concentration in the atmosphere at below $450 \mathrm{ppm}$ (Meinshausen 2006). This is the climate protection goal of both the European Union and the German government. ${ }^{1}$ There is good reason to believe that it will only be possible to achieve this low stabilisation level at low overall economic cost if CCS can be used as an additional option for reducing $\mathrm{CO}_{2}$ (alongside renewables and enhanced energy efficiency).

In fact, the lower the stabilisation level of $\mathrm{CO}_{2}$ concentration is to be, the greater the importance of CCS. Fig. 15-1 shows that the contribution of CCS is evaluated differently in different models. The reason for this is that the models make different assumptions about the growth in emissions and the technical and economic potential of renewables.

The discussion about the relevance of CCS for global climate protection has gained in importance in recent years as doubts have grown that today's strategies will suffice to achieve a global climate protection goal. In particular, international controversy has blown up about whether the European Commission's $2^{\circ} \mathrm{C}$ target (Tol, in press) is achievable or sensible. Here interest focuses on the costs and strategies of climate protection.

1 Cf. Sixth Community Environment Action Programme (2002), http://eur-lex.europa.eu/LexUriServ/site/en/oj/2002/1_242/ 1_24220020910en00010015.pdf.

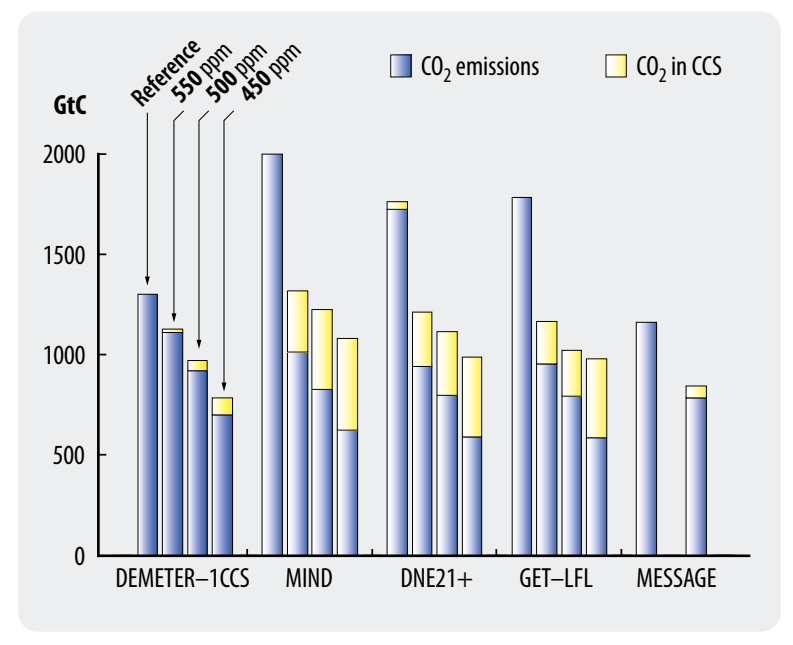

Fig. 15-1: Cumulative quantity of anthropogenic $\mathrm{CO}_{2}$ emissions and $\mathrm{CO}_{2}$ captured through $\mathrm{C} C \mathrm{~S}$ in relation to the stabilisation level of atmospheric $\mathrm{CO}_{2}$ concentration (reference case $=$ no stabilisation target) in various models (Edenhofer et al. 2006)

However, until recently assessments of climate protection costs have largely neglected the potential of technological progress for achieving reductions. Only recently have economists attempted to clarify the question of whether and to what extent technical progress can be fostered to reduce climate protection costs. The Innovation Modelling Comparison Project (IMCP) shows that technical progress really can reduce climate protection costs. The results of modelling presented in Fig 15-2 show that discounted economic costs increase clearly if a concentration target of $450 \mathrm{ppm}$ or less is to be achieved, but in the overwhelming majority of the models they could be kept to figures below $1 \%$ of global GDP.

In the case of climate protection, the economic costs quantify how many units of GDP would have to be sacrificed for the sake of climate protection. ${ }^{2}$ Because these losses occur at different times they have to be normed to one particular point in time. This is done by discounting the GDP losses to a base year using a discount rate. Here the GDP growth in the case with climate protection is compared with growth without climate

2 This approach relates exclusively to the costs of reducing climate change (mitigation). The costs of adapting to climate change (adaptation) are not included. 


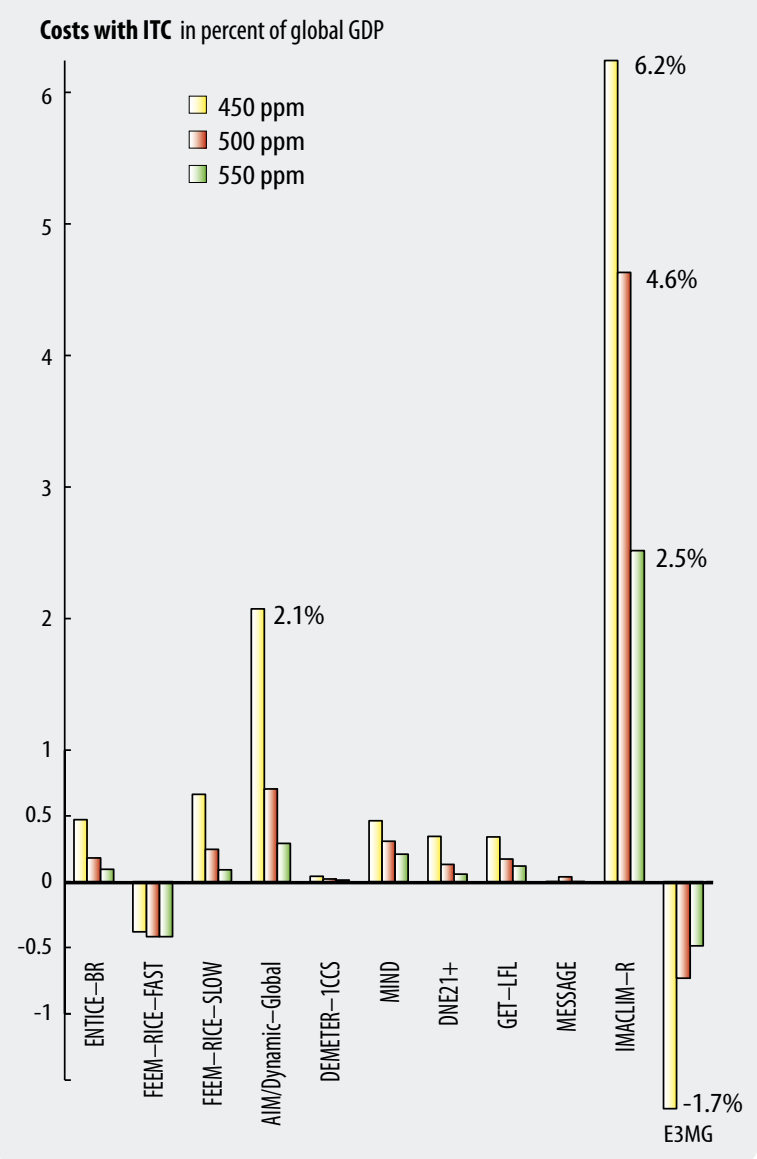

Fig. 15-2: Discounted economic costs in percent of global GDP, taking technological progress into account, in various models that account endogenously for technological learning effects. ITC: Induced Technological Change (Edenhofer et al. 2006)

protection. Discounted losses of one percent for the next hundred years mean that growth in the case with climate protection will be delayed by three months. ${ }^{3}$

In this context there is reason to hope that CCS can - especially at the global level - reduce the economic costs of climate protection, possibly by more than $30 \%$ (IPCC 2005), if technical progress allows further refinement of the technologies.

The following main uncertainty factors affect the influence of CCS on the economic costs of climate protection, and are analysed in greater detail in section 15.2:

3 The following example explains where this estimate comes from: If we assume that global GDP grows by $2 \%$ per annum in the business-as-usual case (i.e. without climate protection) and by $1.97 \%$ per annum if climate protection measures are introduced, the losses over the century as a whole (measured as a reduction in global GDP discounted at $5 \%$ per annum) would add up to $1 \%$. Thus global GDP would reach the absolute value in 2101 that it would otherwise (in the business-as-usual case) have reached in 2100 (cf. Azar and Schneider 2002 for a similar argumentation)
- Learning rates in using CCS,

- Learning rates for renewables,

- Leakage rates of geological formations,

- Discount rates,

- Costs of exploitation and extraction of fossil resources,

- Time of availability of CCS,

- Costs and speed of implementation of increased energy efficiency (supply and demand sides).

The term "uncertainty factors" should be understood as meaning that the listed factors have a decisive influence on the results of models of the use of CCS. At the same time the factors can be understood as risks that have to be discussed in connection with CCS.

The importance of CCS and the relevance of these uncertainty factors is reflected in a series of scientific studies where the outcomes of several different models of the application of CCS are compared (e.g. IPCC 2005, Edenhofer et al. 2006). ${ }^{4}$

In the public discussion about the implementation of CCS the debate about acceptable leakage rates takes a prominent place. If the part of the stored $\mathrm{CO}_{2}$ quantified by the leakage rate escapes from the sink over a given period then the climate protection effect is reduced accordingly. The lower the rate the more effectively can CCS be implemented; therefore leakage is an important uncertainty factor in the economic analysis too. How these aspects could be dealt with institutionally and technically is discussed in section 15.3.

Alongside the question of the conditions under which CCS can make a contribution to climate protection, the possible impact of this technology on ecosystems and human health must also be discussed if we are to reach a comprehensive assessment. That approach of embedding climate protection in a more general understanding of sustainable development is ultimately also prescribed by the United Nations Framework Convention on Climate Change of 1997. In this context it must also be assumed that the perception of the risks associated with CCS could influence public acceptance of specific CCS projects at the local level (cf. e.g. Huijts 2003; overview in Flachsland 2005, 94 ff.). This question has already been discussed extensively earlier in this study.
4 The discussion about CCS and the associated uncertainty factors has also been conducted by pressure groups (especially environmental groups) and by the German government's Advisory Council on Global Change (WBGU) (cf. WBGU 2003, WBGU 2006). 


\subsection{CCS in a Portfolio of Climate Protection Strategies: Analysis of Uncertainty Factors}

Here we explore the role of CCS for climate protection using the tools of social cost-benefit analysis. The MIND model employs CCS as a technological option - alongside the use of renewables and measures to improve energy efficiency - with the goal of maximising social welfare and setting a limit to emissions or temperature rise. ${ }^{5}$

Here we discuss outcomes from the models in order to assess the global risks described above. In various scenarios we identify the critical variables for the introduction of CCS in the electricity sector by evaluating the effects of parameter modifications on the model results (total amount of $\mathrm{CO}_{2}$ sequestrated or costs incurred). In the graphics showing the results of the simulations (Figs. 15-3 ff.) each tile represents the result of the particular combination of parameters. The gradient represents the sensitivity: in areas of high sensitivity (steep gradient) small changes in the parameters cause large changes in the amount of sequestrated $\mathrm{CO}_{2}$ or the costs. ${ }^{6}$

Altogether, the application of CCS demonstrates a broad range of outcomes. Depending on the assumptions used in the models, between 0 and $700 \mathrm{Gt}$ carbon are sent for storage between 2000 and 2100. Using Monte Carlo simulations it was possible to show that under plausible assumptions the median and mean would amount to about $100 \mathrm{GtC}$ by 2050 (Bauer 2005). That order of magnitude also corresponds with other estimates for the technical potential of CCS.?

\subsubsection{The Cost Reduction Potentials of CCS and Renewables and the Discount Rate}

The results of the simulation are conspicuously dependent on learning rates and leakage rates. Learning rates designate the cost reduction per unit that results when the cumulative capacity is expanded. Here the learning rates for CCS and for alternative technologies play the decisive role. CCS plant can come into play as an option above all where it becomes profitable more quickly than

5 The MIND model is an integrated assessment model that couples a model of the global economy based on the concept of endogenous growth (and focused on the energy sector) with a climate model. It calculates timelines of investment and consumption decisions which combine a prescribed limitation of the rise in global mean temperature with maximising the social good on the basis of per capita consumption over the whole period (Bauer 2005, Edenhofer et al. 2005)

6 The figures for the sequestrated amount are given in the graphics in gigatonnes of carbon ( $\mathrm{GtC})$. The corresponding amount of $\mathrm{CO}_{2}$ is greater by a factor of $44 / 12 \approx 3.67$.

7 On the basis of technological solutions whose fundamental applicability has already been demonstrated, the IPCC concludes that it is almost certain that up to $200 \mathrm{Gt} \mathrm{CO}_{2}$ could be sequestrated (at least $99 \%$ probability) and probable that up to 2,000 Gt CO could be sequestrated (66-90\% probability) (IPCC 2005). For a detailed discussion of storage potential see chapter 7 .

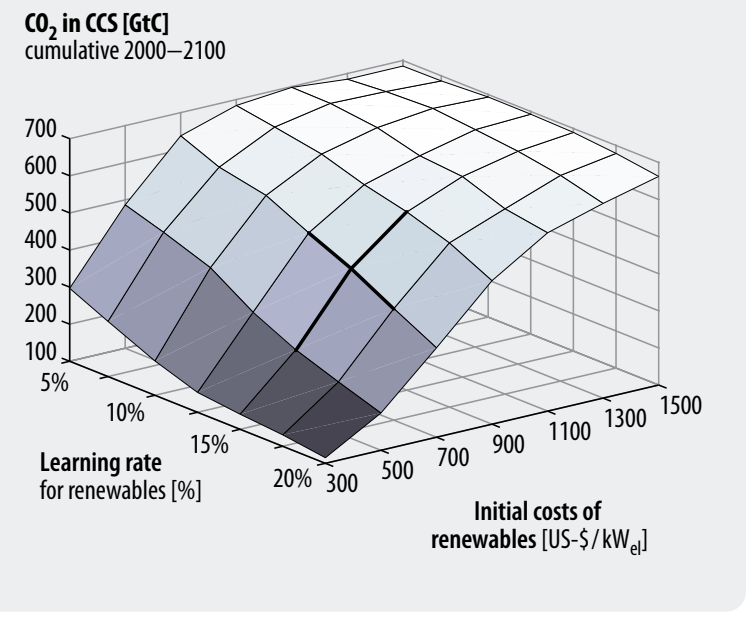

Fig. 15-3: Optimum cumulative amount of sequestrated carbon between 2000 and 2100 in relation to learning rate and the initial investment costs of renewables

renewables. This assumes that the current learning rates and market developments for renewables will not continue over the next 20 years, in particular that there are no so-called technology leaps where as yet unforeseeable developments become usable for renewables. The more slowly the cost-cutting potential of renewables is realised and the more robust the technical possibilities and cost-cutting potential of CCS technologies become, the greater the cumulative amount of captured and stored $\mathrm{CO}_{2}$ will be and the longer the timeframe for using CCS as a climate protection option. The less energy is saved and the higher the global primary energy consumption, the greater will be the importance of developing climate-friendly energy sources.

The MIND model investigates a direct connection between the development of the two learning rates in relation to implementation of the CCS option. Fig. 15-3 shows the amount of stored carbon in gigatonnes calculated by MIND in relation to the learning rate for renewable electricity generation options and the initial costs for new generation capacity for renewables. ${ }^{8} \mathrm{~A}$ low learning rate and/or high initial costs characterise a development trajectory for renewables that takes effect relatively late compared with CCS. Therefore in this case the amount of sequestrated $\mathrm{CO}_{2}$ increases significantly. An area of particularly high sensitivity is found for comparatively low initial costs for renewables with simultaneously high learning rates.

Alongside learning rates and initial investment costs, the level of floor costs also determines the rate of techno-

8 In this model costs are given as specific investment costs $(€ /$ $\mathrm{kWel})$, but this value allows no direct conclusions to be made about the level of electricity generating costs $(\mathrm{Ct} / \mathrm{kWh})$. 


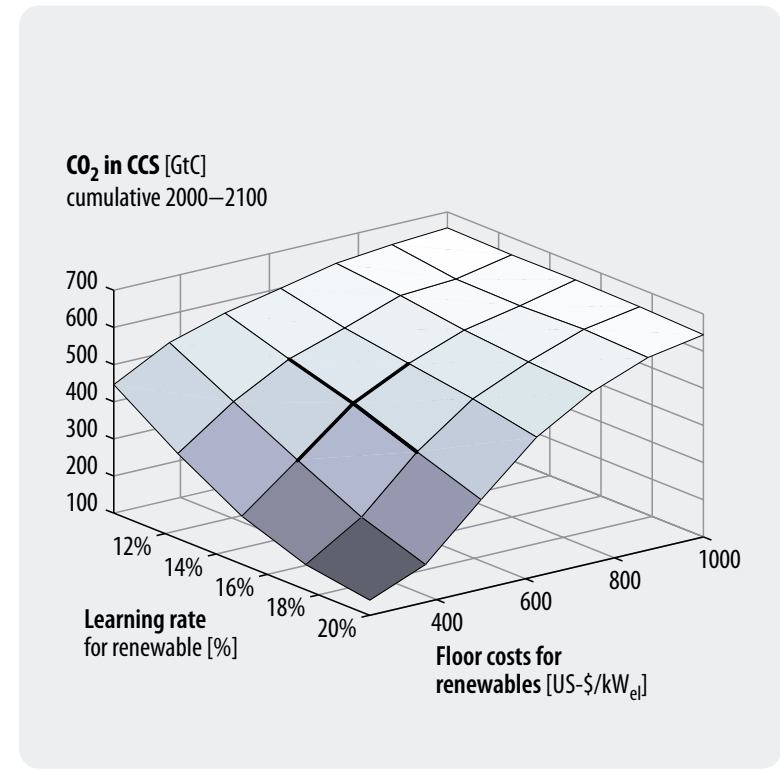

Fig. 15-4: Optimum cumulative amount of sequestrated carbon between 2000 and 2100 in relation to learning rate and floor costs

logical progress. ${ }^{9}$ The higher the floor costs for renewables, the more slowly the capacity of the renewables can be expanded, assuming a given volume of investment, and consequentially the greater the amount of sequestrated $\mathrm{CO}_{2}$ for a given climate protection goal (see Fig. 15-4). With very high floor costs the potential for technological progress also falls. The contribution from CCS then ceases to be sensitive to the learning rate.

CCS can be applied economically efficiently only on condition that the forecast leakage rates of well under $1 \%$ per annum are actually adhered to. ${ }^{10}$ According to current estimates this condition is fulfillable. The IPCC's hypothesis is that for the global proven potential of 2,000 Gt $\mathrm{CO}_{2}$ more than $99 \%$ of the sequestrated $\mathrm{CO}_{2}$ would "probably" remain in the sink after a storage period of 1,000 years (IPCC 2005). ${ }^{11}$ Where $\mathrm{CO}_{2}$ is stored in closed geological formations it should take several thousand years for significant amounts of $\mathrm{CO}_{2}$ to come to the surface through diffusion processes, but measurable leaks could occur sooner too, for example through unexpected faults. ${ }^{12}$ The sensitivity study presented here makes no claims as to the probability of leakage rates, but merely shows how the assumed leakage rates influence the overall result.

9 Floor costs are those costs that cannot be reduced through learning processes, for example specific material consumption.

10 With an annual leakage rate of $1 \%$ only about $60 \%$ of the stored quantity would remain in the sink after 50 years, while after 100 years about two thirds of the original stored quantity would have escaped.

11 According to the IPCC "probably" means a probability in the range 66-90\%.

12 As well as geological strata other sinks, such as the oceans, are also under discussion. But in the general discussion geological formations play the dominating role.

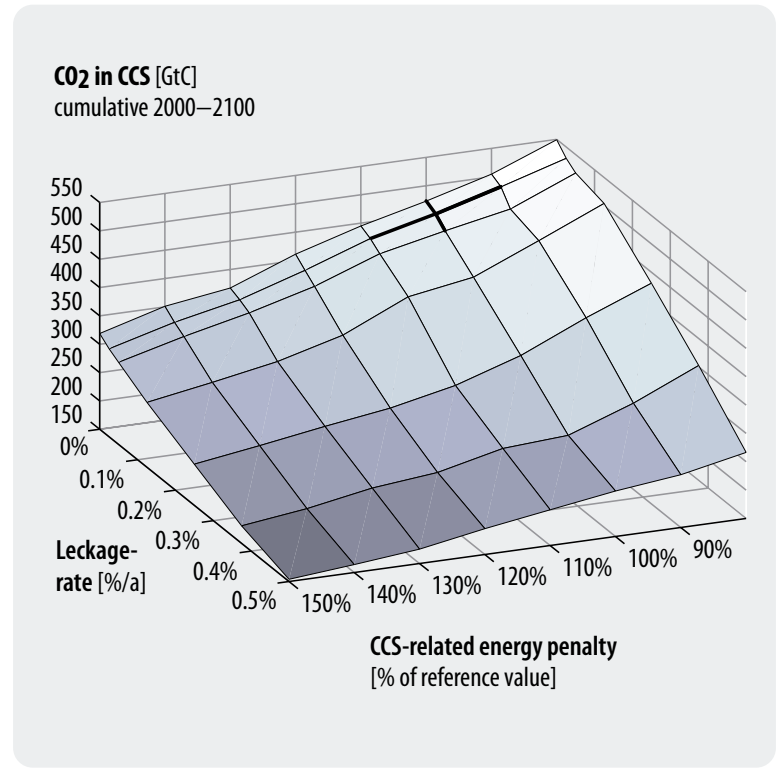

Fig. 15-5: Optimum cumulative amount of sequestrated carbon between 2000 and 2100 in relation to leakage rate and the energy penalty on the optimum amount of sequestrated $\mathrm{CO}_{2}$

Fig. 15-5 documents how the overall amount of injected $\mathrm{CO}_{2}$ depends on the leakage rate and the energy penalty. ${ }^{13}$ It describes the effect whereby, because of the energy required for the CCS technology itself, the technical efficiency of the power station falls when additional components for capturing (and sequestrating) $\mathrm{CO}_{2}$ are added. The smaller the amount of $\mathrm{CO}_{2}$ escaping from the geological formations and the more favourable the energy penalty, the more cost-effective and efficient is the application of CCS. The figure also shows that the leakage rate definitely has a noticeable influence on the use of CCS, especially in connection with a low energy penalty.

For the cost-cutting potential the result is the following. If we assume an average learning rate of $15 \%$ for renewables and an annual leakage rate of $0.05 \%$ of the stored $\mathrm{CO}_{2}$, it turns out that limiting atmospheric $\mathrm{CO}_{2}$ to below $450 \mathrm{ppm}$ would involve a relative loss of only $0.6 \%$ of global GDP compared with the businessas-usual option, and the capture and sequestration of approx. $456 \mathrm{GtC}$.

With increasing use the relative costs of CCS sink. In comparison to versions with lower learning rates considerably more $\mathrm{CO}_{2}$ is stored. Increasing efficiency of the investments in CCS (caused by learning curve effects and a decreasing energy penalty) allows the cumulative amount of CCS to increase until the technical progress is exhausted and no significant further reductions in the economic costs of climate protection can be achieved.

13 The energy penalty is the additional energy required for the CCS technology. One hundred percent represents a default value, values $<100$ represent a lower energy penalty, in other words a smaller loss of efficiency. 
The discount rate also plays an important role in models for calculating climate protection strategies because it is decisive in determining the emission reduction goals. The higher the discount rate, the more is consumed in the present and the less invested, which means that more of the costs of climate protection are displaced into the future - and with them the emission reductions.

The level of the discount rate has considerable influence on the selection of avoidance options. With a high discount rate CCS plays a bigger role and at the same time greater use of renewables is delayed. The reason is that in this case the investment that must be made in renewables today - and thus the costs of restructuring the energy system - is postponed, because a high discount rate makes it more profitable in the future. The extended use of fossil fuels implied by this constellation can only be reconciled with climate protection targets if the use of CCS is expanded.

The introduction and promotion of renewables (and an increase in energy efficiency, which is not explicitly addressed in this study) remain unavoidable, especially if we assume that geological storage potential is limited and relevant leakage rates will occur. Investment in CCS could ease the transition to an emissions-free energy supply if the current speed of market development and cost reduction for renewables were to slow considerably and at the same time CCS technologies were to realise their cost-cutting potential very quickly. If both options are roughly equally successful economically, the relative demand will depend largely on the level of successful efficiency increases.

\subsubsection{The Costs of Exploration and Extraction of Fossil Fuels}

The role of the availability of fossil resources has to date played little part in calculations of the opportunity costs of climate protection in general and CCS in particular. The more fossil resources (coal, oil, natural gas) are available when an effective climate protection policy is introduced, the greater the opportunity costs of climate protection. This is because climate protection devalues the reserves of fossil resources and the whole stock of capital that is tied up in the fossil resource sector. With climate protection a large part of the reserves that were economically usable in the business-as-usual scenario would no longer be viable.

The faster technical progress in the exploration and extraction sector opens up new fossil resources, the stronger this effect becomes. If technical progress in the exploration and extraction sector is very dynamic CCS will find relatively broad application in order to allow the fossil resources to be used even under the conditions of relatively ambitious climate protection. The following scenario analyses investigate the effects of uncertainties about the current status of progress in exploration and extraction and the associated costs the detail of which is currently controversial.

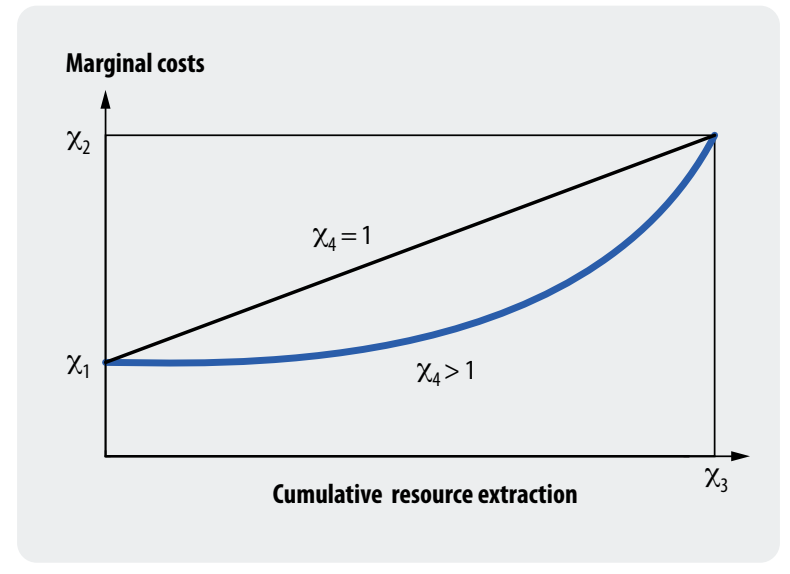

Fig. 15-6: Rogner curve, showing in a simplified form the marginal costs of resource extraction in relation to cumulative resource extraction (based on Nordhaus and Boyer 2000)

But first we have to clarify what we mean by resources: "resources" are the physical totality of existing raw materials, while "reserves" are the deposits that can be exploited with today's technology at today's prices (Rogner 1997). If the technical possibilities and associated costs change, resources become reserves. Rising prices lead to increasing efforts to open up new resources and turn them into exploitable reserves.

The Rogner curve abandons the distinction between resources and reserves. It describes the extraction costs in relation to the quantity extracted to date. The trajectory of the cost increase depends on three aspects. Firstly, the extraction costs themselves, secondly the possibilities of substitution between the different fossil fuels and thirdly technical progress (Rogner 1997, Leggett 2005).

The Rogner curve can be understood as follows: opening up new resources counteracts the exhaustion of the existing ones, and the more units of a resource have already been extracted the more exhaustion leads to increasing extraction costs. In the ideal case the cost increase is constant (see Fig. 15-6, Rogner 1997). Uncertainties about the shape of the curve are described by parameters: $\chi_{3}$ represents the resource base; $\chi_{4}$ describes whether the cost increase takes effect early (small value) or only begins later (high value). ${ }^{14}$

Fig. 15-7 shows that the costs of climate protection increase, if more fossil resources become available, for example through intensified exploration efforts. Fig. 15-7 shows the costs of climate protection in relation to the available resource base $\chi_{3}$ and the parameter

14 For example if $\chi_{4}=1$ is selected the Rogner curve is a linear function, i.e. a straight line, while $\chi_{4}=2$ produces a quadratic Rogner curve. In the quadratic case the costs remain lower than in the linear case until quantity $\chi_{3}$ has been extracted. Beyond that point the quadratic function describes higher costs. This effect is amplified further by selecting larger values for $\chi_{4}$ (e.g. $\chi_{4}=3$, cubic). 


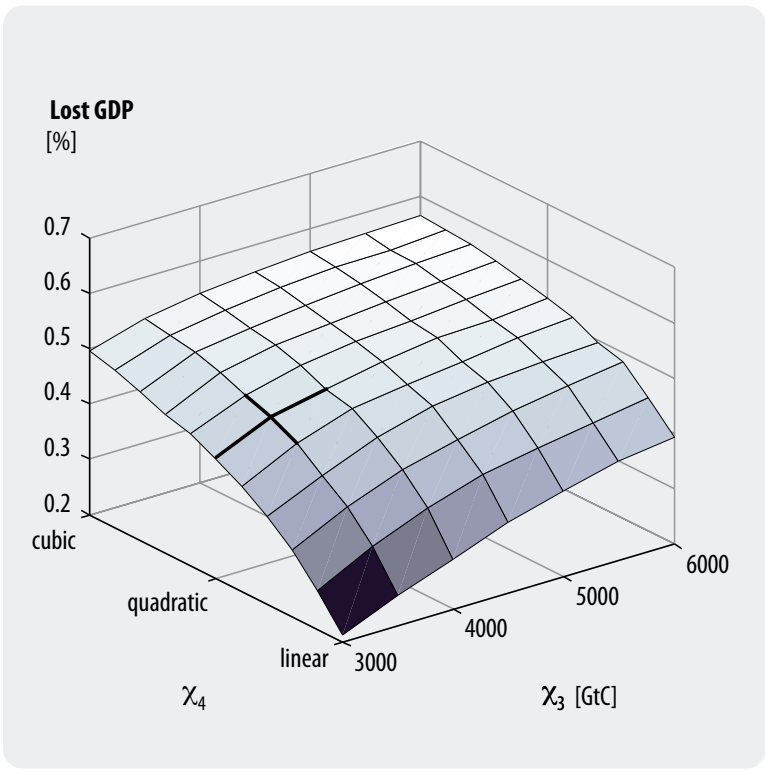

Fig. 15-7: Cost of climate protection as percentage loss of global GDP in relation to the resource base $\left(\chi_{3}\right)$ and the parameter characterising the development of extraction costs $\left(\chi_{4}\right)$

for $\chi_{4}$. Even if the costs of extraction only increase relatively late, the economic costs of CCS also increase for the whole period. The reason is that if extraction costs rise late (in the business-as-usual case) relatively large quantities of cheap fossil fuels would be available and would be used - which would then no longer be possible in the climate protection case. This would result in higher opportunity costs for climate protection. Assuming strong technical progress in the extraction sector the gap between the business-as-usual and climate protection cases in terms of the emissions to be reduced is relatively large due to the extensive use of fossil resources. Consequently CCS is used particularly intensively in order to achieve the climate target at all (Fig. 15-9).

The resource base for fossil fuels is currently estimated at 3,500 to $6,500 \mathrm{GtC}$ (WEC 2000). If all of that were to be converted into $\mathrm{CO}_{2}$ it would be impossible to limit climate change. The limiting factor for use of fossil energy would be the climate system rather than the fossil resources. Because the extraction costs for coal will rise more slowly than those for oil, a partial substitution of oil by coal is to be expected. For this reason too, the importance of CCS will probably increase.

In economic terms, the debate about peak oil scenarios is primarily about the costs of replacing oil by coal and gas rather than the question of when extraction peaks. Because the uncertainties are enormous here, four additional scenarios were calculated using different assumptions about the shape of the Rogner curve

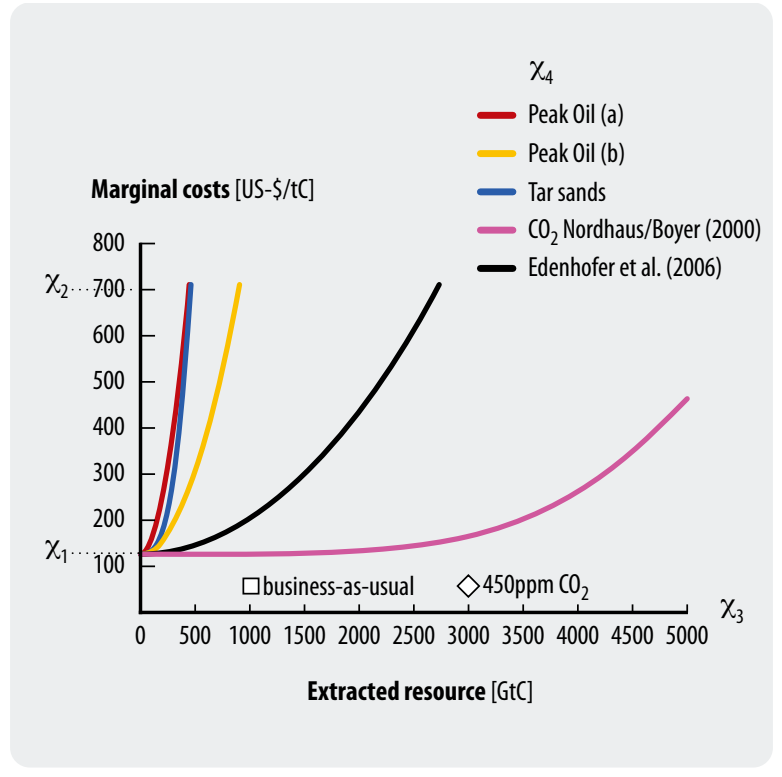

Fig. 15-8: Marginal costs of resource extraction in relation to cumulative resource extraction for the scenarios described in the text

(see Figs. 15-8 and 15-9). ${ }^{15}$ The three peak oil scenarios (Peak Oil (a) and (b), Tar Sands) assume that coal and gas can replace oil only at enormous cost. In the fourth scenario, which also enjoys a claim to plausibility and is used by Nordhaus as the basis of his forecasts (Nordhaus and Boyer 2000), the long-term costs of substitution are relatively low. The process of analysing the different Rogner curves described here - especially using bottom-up models - can be regarded as an important research task because it is on this that the economic benefit of CCS in the climate protection context will decisively depend.

If the costs of fossil extraction now fall through learning curve effects, the share of available reserves in the resource base expands. The lower the costs of exploration and extraction, the more $\mathrm{CO}_{2}$ will be sequestrated over the course of the next century (Fig. 15-9). However, these learning curve effects and falling costs do not mean falling prices for fossil fuels, but rather a flattening out of the general price rise (in Fig. 15-8 this can be pictured as a transition to a curve with a less steep gradient).

The results of the simulations show that technical progress in exploration and extraction of fossil resources makes climate protection more expensive (cf. Fig. 15-7). Paradoxically, rising prices for fossil fuels do not lead the energy markets to invest exclusively in renewables. Instead, rising prices offer an incentive to invest in the exploration and extraction of high-emis-

15 Nordhaus and Boyer (2000): $\chi_{3}=6,000 \mathrm{GtC}, \chi_{4}=4$. Edenhofer et al. (2006): $\chi_{3}=3,000 \mathrm{GtC}, \chi_{4}=2$. Peak Oil (a) $: \chi_{3}=500 \mathrm{GtC}, \chi_{4}=$ 2. Peak Oil (b): $\chi_{3}=1,000 \mathrm{GtC}, \chi_{4}=2$. Tar Sands: $\chi_{3}=500 \mathrm{GtC}$, $\chi_{4}=3$. In all scenarios: $\chi_{1}=113$ US $\$ / \mathrm{tC}$ and $\chi_{2}=700 \mathrm{US} \$ / \mathrm{tC}$. 


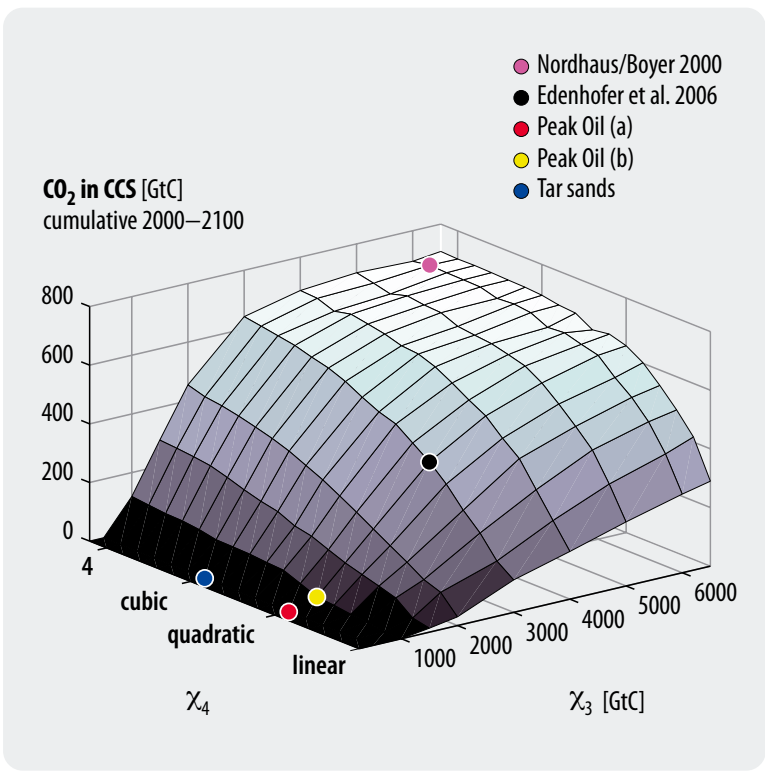

Fig. 15-9: Optimum cumulative quantity of sequestered carbon between 2000 and 2100 in relation to the resource base $\left(\chi_{3}\right)$ and the parameter characterising the development of extraction costs $\left(\chi_{4}\right)$. Coloured dots indicate the scenarios discussed in the text. Peak Oil (a) and (b) and Tar Sands are peak oil scenarios with relatively small differences in their parameters. As the name suggests, the Tar Sands scenario assumes that tar sands will be mined (see below).

sion fossil resources that had previously been largely ignored ("unconventional resources"). ${ }^{16}$ This effect can be observed at present: the high oil price has stimulated the extraction of tar sands and oil shales in Alberta, where they can be mined economically on a large scale at a price of approx. $\$ 80$ per barrel (Economist 2006). So high oil and gas prices greatly increase the economic value of the fossil resources to the extent to which new deposits are discovered. The ensuing technical progress causes fossil fuels to continue to be competitive until their costs catch up with those of renewables.

Without climate protection policy, i.e. without internalising the social costs of a destabilised climate (and in particular with a resource-led increase in the focus on coal) the necessary restructuring of energy systems would come much too late to be able to meet relevant climate protection goals.

However, in recent years a partial rethinking on the part of the energy business has been observed. As well as stimulating increased efforts to exploit unconventional resources, higher oil and gas prices have also given a clear boost to technologies for using renewables (Leggett 2005). The rising costs of climate protection caused

16 There are, however, limiting factors for the use of unconventional resources. For example social acceptance, which in the case of tar sands in Canada and oil shales in the United States could be a decisive factor, because of the severe environmental impact. Other limits are set by the scale that can be achieved over time. Large-scale provision of fuels gained from unconventional sources takes years and cannot be increased in any order (Economist 2006).

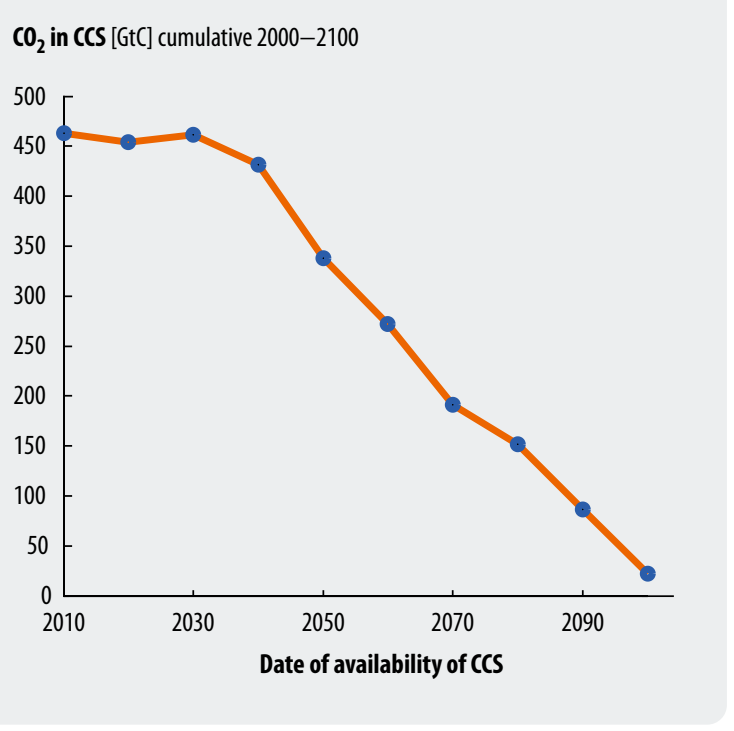

Fig. 15-10: Optimum cumulative quantity of sequestered carbon between 2000 and 2100 in relation to the time when the technology becomes available

by technical progress in exploration and extraction of fossil resources can be moderated if CCS is introduced on a relatively large scale. Time is working for CCS: the longer it takes to agree a treaty regime for international climate protection, and the longer fossil fuels are used on a massive scale and can in some way benefit from learning effects, the more probable it becomes that CCS will be introduced on a large scale.

If a structural restriction on the extractability of conventional fossil fuels - and thus a lasting price rise occurs within the coming years or decades different substitution effects will occur. But these types of substitution over time and their overall outcome have not yet been sufficiently investigated. Overall the analysis shows clearly that the development over time of the use of different fuels is still subject to uncertainties. In the following section the effects of CCS becoming available at different times are examined.

\subsubsection{Timeframes of CCS Availability}

In the discussion about the benefits of CCS the time when it becomes available plays a central role. Some critics claim that if the CCS option does not become available on a large scale within the coming decade then it will not be an economic proposition. This argument deserves closer examination.

The simulations show that CCS can still be worth using even if its introduction is delayed by decades - although the cumulative quantity of CCS for the twenty-first century decreases considerable if it turns out that the technology will only become available after 2050 (Fig. 15-10). The discounted consumption losses caused by the costs of climate protection rise accordingly (Fig. 


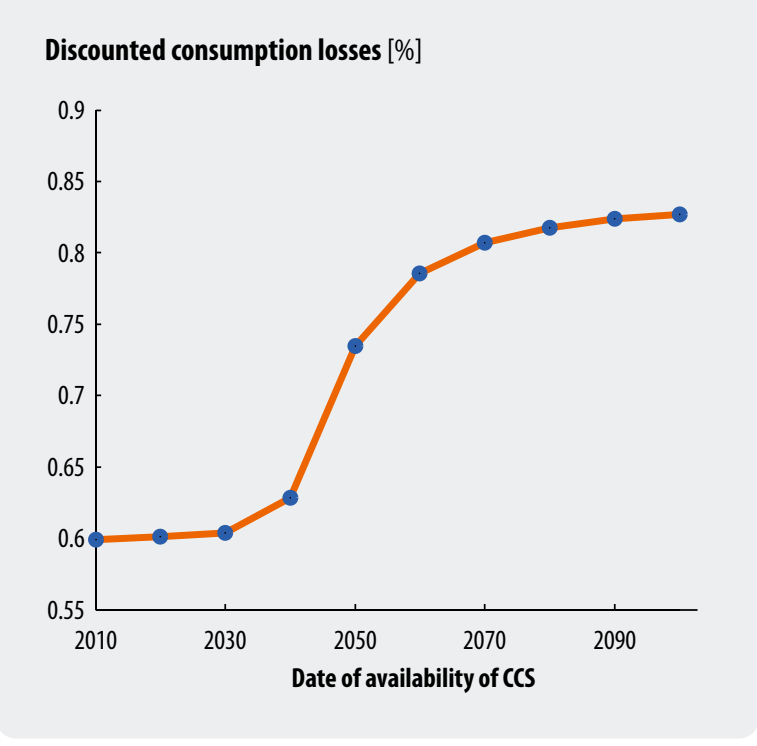

Fig. 15-11: Discounted consumption losses in percent caused by cost of climate protection, in relation to the time when the technology becomes available

15-11), because the cost reduction potential of CCS for climate protection is greatest in the next four decades. However, if the CCS option becomes available later this does not decisively alter either the cumulative amount of reduced emissions or the timeline of reductions (Fig. 15-12).

Fig. 15-11: Discounted consumption losses in percent The results can be explained as follows. If there is a delay in the introduction of CCS it is more worthwhile from today's perspective to force the promotion of renewables from the outset, because after 2050 the costs of extraction of fossil fuels will increase steeply, which makes large-scale use of CCS after 2050 less attractive. With the assumption that learning curves for renewables remain constant, the rising costs of fossil fuels cause the opportunity costs of climate protection to rise most strongly in the first four decades when the CCS option is not available.

Overall the contribution of CCS to the implementation of an ambitious climate policy consists in reducing the costs regardless of when it is introduced on a large scale. These cost reductions turn out differently depending on whether CCS is implemented sooner or later.

\subsection{Requirements for an Institutional Framework for CCS}

The introduction of a climate protection option is associated with far-reaching consequences of an institutional nature. The specific costs and risks for CCS must be noted, but also the possibility of integrating CCS as an additional climate protection option in a portfolio of existing policy instruments.

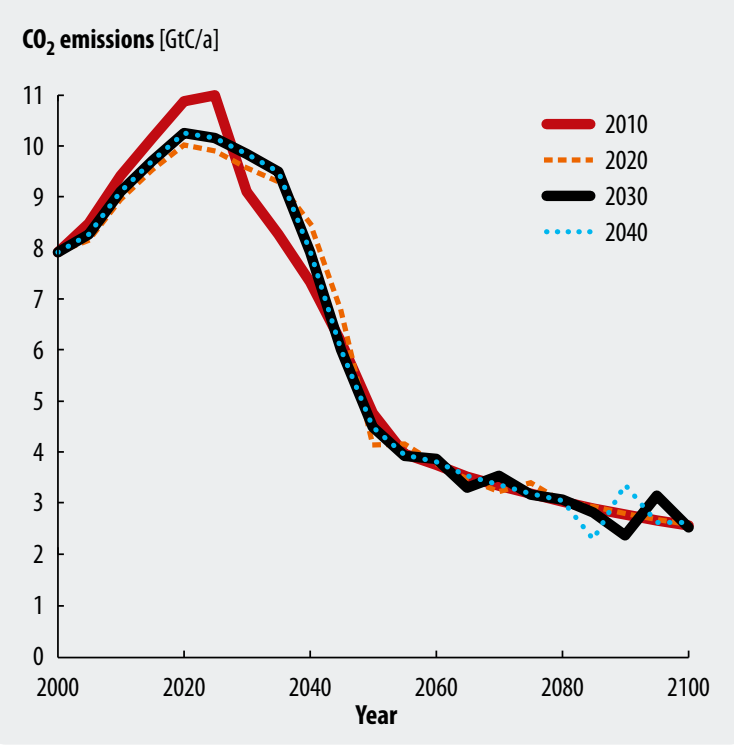

Fig. 15-12: $\mathrm{CO}_{2}$ emissions paths with different availability dates of $\mathrm{CCS}$

In the following, various aspects are identified that will have to be taken into consideration when drawing up a regulatory framework for CCS. The starting point here is the question of what consequences can be drawn from the results of the modelling in the previous section for the debate about whether the "cap and trade" system or a technology protocol should be the governing approach in climate protection agreements. Then we move on to examine crucial legal aspects of a regulatory framework for CCS, supplemented by an overview of examples of existing arrangements in the United States, Japan, the EU and Germany. Lastly, the international challenges are outlined for an institutional framework that would accommodate the economic analysis from section 15.2 and aim to integrate it appropriately in the international climate regime.

The work of developing a suitable institutional framework involves challenges on several levels:

- Time: The long timeframe for CCS demands particular attention; the consequences of leakages must be dealt with over much more than a few decades.

- Space: Local risks (for example for ecosystems near a sink) and global impacts (i.e. the possible risk to climate protection goals through leakages from sinks).

- Content: New concepts are required if CCS is to be integrated in the global climate protection regime. Local risks have to be covered by existing legal frameworks as well.

The implementation of an institutional framework depends on the approval of democratic sovereign bodies, so the public perception of CCS must not be neglected. Currently CCS is regarded with scepticism by the pub- 
lic, especially in direct comparison with other climate protection options, but there is also a great information deficit (IPCC 2005), so it would seem advisable to improve the supply of information to the public and intensify public discussion of the CCS option.

\subsubsection{The Basis for an Institutional Framework: "Cap and Trade" versus Technology Protocol}

The modelling results point to a central dilemma of current climate protection policy. Renewables are the central option for creating a sustainable low-emission energy supply, while CCS is seen as an option for reducing the costs of the transition (see also Bauer 2005). In both cases, the cost-cutting potential is only realised if sufficient investment occurs. But this investment will not be made unless the prices for emission certificates rise and the certificate prices cannot rise unless further emissions agreements are achieved. Such agreements are being held up because the treaty states regard climate protection as being expensive, but costs cannot be reduced unless there is investment.

If the oil price also rises - even if only temporarily - this will divert investment to the resource extraction sector where it can increase the size of available reserves which in turn further increases the economic cost of climate protection.

These are the arguments that are behind the debate between the technology protocol idea and a "cap and trade" system. On the one side the proponents of technology protocols do not expect that multilateral agreements will come soon enough to allow low-emission energy technologies to be developed sufficiently quickly. But the development of these technologies is necessary if the costs of climate protection are to be kept within acceptable limits. On the other side the supporters of "cap and trade" approaches argue that unless emissions reductions are specified there is no incentive to introduce CCS and renewables on a large scale. So in the long term a technology protocol alone cannot guarantee effective climate protection.

A combination of technology protocol and "cap and trade" certainly could offer an opportunity to bring movement into the international climate negotiations. And through its cost-cutting potential CCS could contribute to the success of this approach. At the same time, targeted support for CCS technologies makes sense then because the greatest economic benefit will be gained if CCS is introduced in the coming decades. Therefore political support for pilot projects is of great importance - not only for CCS but also for renewables and efficiency increases. Section 15.3.6 takes a closer look at the importance of pilot projects.

\subsubsection{Critical Legal Aspects}

\section{Consequences of the precautionary and polluter pays principles in environmental law}

Environmental law is based on fundamental principles that can serve as a normative guide for regulating CCS. They are applied at the German, European and international levels - sometimes with differing formulations and emphases (Kloepfer 2004). ${ }^{17}$ Among these, the precautionary principle, the polluter pays principle and the principle of public responsibility are the most relevant for CCS.

The precautionary principle requires legislators to take preventive action even against possible future dangers. In view of the long-term nature of $\mathrm{CO}_{2}$ storage and the ensuing consequences any institutional framework will have to define suitable arrangements for dealing with future risks. Specifically, the legal framework for CCS must therefore be in a position to ensure responsibility and liability for future risks - especially leakage of $\mathrm{CO}_{2}$ - over very long periods of time. By the time a problem is discovered in the storage formation the company responsible for sequestration there may no longer even exist. Incentives to shift legal and financial responsibility to future generations must be avoided, but suitable global frameworks for that do not yet exist (IPCC 2005).

In this connection the polluter pays principle is also relevant: the cost of environmental harm is always borne by the polluter. But if the polluter cannot be identified or if application of the principle would lead to serious economic disruption, the principle of public responsibility dictates that the public has to bear the costs. For possible harm resulting from sequestration, that means arrangements have to be avoided that shift responsibility for risks from CCS from the responsible companies to the state. But the state will bear an ultimate responsibility, especially in the event that the company no longer exists when harm occurs (see also WBGU 2006).

\section{Defining an acceptable leakage rate}

As well as the unavoidable slow leakage from $\mathrm{CO}_{2}$ sinks, accidents while capturing, transporting and storing $\mathrm{CO}_{2}$ can also cause the sudden release of larger quantities of $\mathrm{CO}_{2}$. Because of the risk of grave local damage to ecosystems and human health, safety thresholds must not be exceeded. However, arrangements for this can be based on existing regulations for plant failure (IPCC 2005). Low leakage rates have a great effect in the long term and are acceptable only up to a particular maximum level because they counteract the global climate protection effect and possible emission reduction obligations. The associated problems and proposals for solutions are discussed in more detail in section 15.3.5.

17 For European Union law see Art. 174, para. 2, item 2 of the EC Treaty, introduced by the Single European Act of 1986. This provision was explicitly included in German law by Art. 34 of the Unification Treaty of 1990 


\section{Selection and approval of sinks}

The selected sinks must simultaneously satisfy the criteria of safety against accidents, low long-term leakage and good cost efficiency. Companies will attempt to externalise the costs of selecting safe sinks while also passing the risk of leakage to third parties, such as the state. Following the polluter pays principle, the crucial point will be to create incentives for companies to find safe sinks and accept liability for possible leakage. Here the liability rules should at the same time promote technical progress in the direction of enhancing safety (see for example Perrings 1989). On the other hand, the principle of public responsibility requires suitable arrangements to be found for the eventuality that the operating company ceases to exist.

\section{Supervision and monitoring of sinks}

Sinks have to be supervised in order to monitor the amount of $\mathrm{CO}_{2}$ stored and the rate of leakage and to impose penalties if necessary. Apart from the issue of whether it is even technically possible to measure leakage rates in ranges under 0.1 percent per year, for example, it is also necessary to define the period of time over which sinks are to be supervised.

There are proposals to give this task to private-sector companies for a period of about 30 years (Wilson 2004). Given that reliable $\mathrm{CO}_{2}$ storage must in principle be guaranteed over millennia, the precautionary and polluter pays principles throw up the question of how long-term supervision of storage can be guaranteed, and by whom. The argument against the idea of giving sole responsibility to the public sector would be that this might distort competition to the disadvantage of other climate protection options (Dietrich and Bode 2005).

\section{Attributing responsibility and liability}

The issues of responsibility and liability that arise in connection with CCS can be divided into three areas: ${ }^{18}$

- Operational responsibility and liability in connection with the processes involved,

- In-situ liability for harm to human health or to local ecosystems caused by an accident,

- Responsibility for leakages in terms of the consequences for climate protection, also in order to generate incentives even at the planning and sequestration stages for ensuring the best possible storage conditions.

Ways of dealing with the first two areas can be derived from existing arrangements (for example safety in manufacturing, transporting and storing chemical prod-

18 For a more detailed discussion see de Figueiredo et al. (2006). ucts), although it is difficult to achieve agreement with respect to balancing the polluter pays and public responsibility principles and thus the distribution of risks between operating companies and the state. But responsibility for consequences for the climate cannot easily be dealt with within the scope of existing arrangements. The potentially long interval between sequestration and the harm it could cause makes it more difficult to apply existing liability rules. Additionally, the violation of individual legal interests as a result of the negative effect on climate caused by the leakage is difficult to prove (Dietrich and Bode 2005).

A further challenge for regulations dealing with responsibility is the issue of sinks that extend across national borders. Sequestered $\mathrm{CO}_{2}$ can cross borders intentionally or - via leakage between geological formations unintentionally (IPCC 2005). This is another reason why CCS must be subject to an international regulatory system. The controversial proposal to inject $\mathrm{CO}_{2}$ into international waters complicates the problem even further. International conventions, in particular the London Convention on the Prevention of Marine Pollution by Dumping of Wastes and Other Matter of 1972, must be taken into account here as considerable legal obstacles (IPCC 2005).

\subsubsection{Statutory Regulations in Selected States and the EU}

Here we briefly summarise the existing legal situation in the European Union and Germany, in Japan and the United States to the extent that is relevant for CCS (cf. description in Flachsland 2005, 165 ff. and references there). ${ }^{19}$ For the legal position it is relevant that sequestration of $\mathrm{CO}_{2}$ - apart from the first CCS pilot projects - has to date always been conducted as part of an industrial process rather than for reasons of climate protection. For example in the oil industry $\mathrm{CO}_{2}$ can be injected into a deposit to improve the recovery rate (enhanced oil recovery). For this reason - and because the quantities and storage periods involved with CCS are many times greater and longer than for operations to date - the current legal situation cannot be applied to future CCS projects. ${ }^{20}$ So the legal position is still rather unclear and requires further investigation.

\section{European Union and Germany}

CCS would probably be regulated at the level of European law, because the EU holds partial responsibility for the community's environmental policy (according to Art. 174 of the EC Treaty), and also because of the possibility of transfrontier storage. Directive 96/61/EC

19 As well as the legal situation, the treatment of CCS in the scope of EU emissions trading must also be considered. For more detail, please refer to the literature (Dietrich and Bode 2005).

20 The amounts of $\mathrm{CO}_{2}$ sequestrated in current CCS pilot projects (e.g. Weyburn, Sleipner, Ketzin) are many times smaller than would be the case with large-scale CCS projects pursuing ambitious climate protection goals. 
lists industrial facilities - principally large-scale point sources of emissions - that require official permits. Although the facilities required for CCS are not to be found in this list - and there would be certain problems involved in including them - it at least becomes clear that facilities of this kind do in principle require official approval under EU law.

With respect to possible contamination or pollution of drinking water, the European Water Framework Directive specifies that freshwater reservoirs must not be contaminated in any way. Here too the question arises how risks associated with CCS can be integrated in this framework.

In current EU law captured $\mathrm{CO}_{2}$ is defined as waste (as of December 2007). Currently underground storage of substances that are subject to physical, chemical or biological change after disposal is explicitly forbidden in the EU.21 However, the European Commission has announced that it intends to exclude $\mathrm{CO}_{2}$ captured forCCS purposes from waste law. In January 2008 it published a proposal for a "directive of the european parliament and of the council on the geological storage of carbon dioxide". Its main scope is the regulation of $\mathrm{CO}_{2}$ storage and the removal of barriers in existing legislation to $\mathrm{CO}_{2}$ storage.

In addition to EU environmental law, national legislation must also be considered. In Germany this includes the Federal Mining Act (Bundesberggesetz) on underground storage of natural gases, the Closed Substance Cycle and Waste Management Act (Kreislaufwirtschafts- und Abfallgesetz), the Federal Water Act (Wasserhaushaltsgesetz) and the Federal Immission Control Act (Bundesimmissionsschutzgesetz).

All the listed laws include points where official permits would be required for CCS, so integrating CCS in existing regulatory frameworks would bring with it a number of difficulties. Consequently, CCS would probably be regulated in a specially designed framework of its own.

\section{Japan}

Japan plays a special role among the states leading the development of CCS, because the geographical and geological situation there means that storage would probably take place largely in the oceans rather than in geological formations. ${ }^{22}$

One special problem that arises here is the possibility of harming the "biological pump" of the oceans, where

21 In the case of $\mathrm{CO}_{2}$ that could mean chemical reactions with other substances or phase changes caused by expected underground migration processes.

22 However, the London Convention (mentioned in section 15.3.2) presents legal obstacles to implementation. Furthermore, the lack of public acceptance could hamper or completely prevent the realisation of marine $\mathrm{CO}_{2}$ storage (see also the analysis of actors in chapter 3). phytoplankton in surface waters bind atmospheric $\mathrm{CO}_{2}$ and subsequently transport it to greater depths. If injected $\mathrm{CO}_{2}$ returns to the surface it will reduce the $\mathrm{pH}$ value there, which would in turn reduce the performance of the pump. Furthermore, the ecological consequences of increased $\mathrm{CO}_{2}$ concentrations in marine systems are largely unknown (see also section 11.3).

\section{United States}

In the United States geological formations have been used to sequester waste since the 1930s. After problems arose, especially with contamination of drinking water, the federal authority, the Environmental Protection Agency (EPA) in the 1980s instituted the UIC programme (Underground Injection Control). Thirty-four states have expanded the scope of this federal regulatory programme by adding regulations of their own.

The central element of UIC is its classification of boreholes used for sequestration into different categories. The first category covers the storage of household and hazardous waste in sealed geological formations that are separated from drinking water reservoirs by impermeable strata. They must satisfy the strictest safety standards and they cause the highest regulatory costs. The second category comprises the extraction and sequestration of substances during energy production (enhanced oil recovery). Comparable standards apply here too, although authorisation is handled less strictly. The other regulatory categories are unlikely to be relevant for regular CCS operations.

The regulations for pipeline construction basically stipulate that a right of way (ROW) is required. In deciding whether to grant a ROW, the Federal Energy Regulatory Commission (FERC) considers possible ecological impact and the existing public interest in the respective pipeline.

\subsubsection{CCS in the Kyoto Protocol}

Multilateral agreements represent the main thrust of global regulation efforts. The most relevant for CCS are the United Nations Framework Convention on Climate Change and its expression in the Kyoto Protocol, where flexible market mechanisms (certificate trading, joint implementation and clean development mechanism) play a key role for achieving the agreed emissions reductions cost-efficiently. CCS could be included in the flexible mechanisms as an emissionreducing measure.

CCS is not yet mentioned explicitly in the United Nations Framework Convention on Climate Change (UNFCCC). But the revised version of the "IPCC 2006 Guidelines on National Greenhouse Gas Emission Inventories" (corrected April 2007) for the first time provides guidelines for defining and measuring emissions sequestered through CCS (and their possible re- 
emission). ${ }^{23}$ CCS is categorised as a set of technologies that allows emissions savings that are to be included in the national greenhouse gas inventories (Eggleston 2006).

The possibility of stored $\mathrm{CO}_{2}$ migrating across state frontiers is a challenge, especially when a flow of $\mathrm{CO}_{2}$ occurs from an Annex B country to a non-Annex B country (IPCC 2005). In the aforementioned regulatory frameworks leakage from sinks is assigned to the emissions inventory of the state on whose territory sequestration was carried out (Eggleston 2006). Finally, technical uncertainties involved in the monitoring of sinks and the measurement of leakage rates still result in uncertainties in the calculation of emission reductions (IPCC 2005). The guidelines for this provide for a combination of measurement and modelling approaches to be specified on a case-by-case basis (Eggleston 2006).

In view of the uncertainties about leakage rates, the WGBU calls for sequestered $\mathrm{CO}_{2}$ not to be counted in full as avoided emissions. Alongside regulatory agreements such as a fixed deduction from the emissions volume the WGBU proposes market-based liability mechanisms, in particular the instrument of Carbon Sequestration Bonds, which are described in the next section (WBGU 2006).

If CCS is included as an avoidance measure in the Kyoto Protocol, CCS projects could also be handled via flexible instruments such as the Clean Development Mechanism (CDM) and in principle also Joint Implementation (JI). The UNFCCC treaty states conference in November 2006 decided to instigate an SBSTA process with the aim of reaching a decision at the 2008 treaty states conference (CoP 14). ${ }^{24}$ Beforehand there was also discussion in the responsible bodies about the economic incentive effect of the flexible instruments in connection with CCS and the question of how long-term liability could be shared by the participating states (Wuppertal Institut 2006). ${ }^{25}$

\subsubsection{Carbon Sequestration Bonds: A Proposal for Regulating Responsibility for $\mathrm{CO}_{2}$ Storage}

The central question in regulating CCS is to systematically include critical uncertainty parameters in the institutional framework and to create incentives that would encourage the CCS and renewables options to develop in a complementary way (see section 15.2.1). In this context the specific case with CCS is that it is not a backstop option that can be applied as a permanent

23 Here only CCS with geological storage is considered.

24 SBSTA is the Subsidiary Body for Scientific and Technological Advice

25 Certain energy corporations (e.g. Shell, BP) are currently already lobbying for CCS to be integrated in the CDM (Point-Carbon 2006). But because there is still great uncertainty concerning the risks of CCS, environmental groups such as Greenpeace criticise the idea of integrating CCS in the CDM system because this would export the risks to the developing countries (Greenpeace 2005). long-term solution to the climate problem, because the storage capacities and fossil resources are limited. Instead, this option is a set of technologies that could fulfil an important bridging function for the transition to an energy system characterised by renewables and energy efficiency. The later or more slowly the cost-cutting potential of renewables can be mobilised, the more important this function would potentially be.

The long-term stability of sinks (i.e. the leakage rate) represents an uncertainty factor that demands risk management of its own over and above the emissions trading of the Kyoto Protocol. The instrument of Carbon Sequestration Bonds (CSBs) is the only proposal to date for this (the following description follows Edenhofer et al. 2004, see also WBGU 2006). It presupposes a modified system of $\mathrm{CO}_{2}$ emissions trading and is to that extent compatible with the market approach of the existing Kyoto Protocol. The CSB instrument attempts to solve the key problems of how the use of sinks with low leakage rates can be encouraged and how residual leakage and its climate impact can be dealt with.

In the following we describe the two versions and their respective impact on safety of storage. They are not mutually exclusive, and indeed could be combined. In both cases politically supported CCS pilot projects could improve the effectiveness of the CSB system and thus of global regulation. By improving the reliability of information about CCS, pilot projects would resolve market distortions that could otherwise reduce the chances of success of the CSB instrument.

\section{Version 1: CSB as an instrument supplementing emission rights}

The maximum level of harm caused by leakage of stored $\mathrm{CO}_{2}$ is easy to calculate in financial terms. It is the amount of $\mathrm{CO}_{2}$ that escapes from the geological formation multiplied by the certificate price of the emissions at the time leakage occurs. If $\mathrm{CO}_{2}$ escapes from a geological formation, the atmosphere is used as the "sink" for the $\mathrm{CO}_{2}$, but no price has been paid for this use. So in the event of leakage the company would have to purchase a certificate for this use of the atmosphere.

Because the volume of certificates doesn't rise, their price increases. This signals to investors, consumers and businesses that utilisation rights for the atmosphere are scarcer than they originally assumed.

However, with this solution alone it will not be possible to prevent companies from acting speculatively when they store $\mathrm{CO}_{2}$ in geological formations. The management of a company could speculate that the $\mathrm{CO}_{2}$ will not escape until the company has ceased to exist, that the certificate price will fall in the long term or simply that a different management team will have to cope with the problem. If the timeframe of investors and managers is shorter than the suspected timeframe of $\mathrm{CO}_{2}$ leakage and the willingness to take risks is high, storage in geological formations with less long-term stability can represent a business opportunity for investors to pass the 
risk on to future generations. So it is crucial to create an incentive in advance for companies to store $\mathrm{CO}_{2}$ in the safest possible formations in their own interests.

The introduction of Carbon Sequestration Bonds opens up the possibility of rational risk management. Any business that wished to store $\mathrm{CO}_{2}$ in geological formations would have to purchase a bond corresponding to the value of the stored quantity of $\mathrm{CO}_{2}$. From the company's point of view, this bond is an asset that appears on the assets side on its balance sheet. The company guarantees for the term of the bond that the $\mathrm{CO}_{2}$ will remain in the geological formation. If this actually happens the bond will be repaid to the company with interest (at the level of a long-term security). But the bond is also depreciated every three years by an as yet unspecified environmental agency, unless the company can demonstrate beyond doubt that the $\mathrm{CO}_{2}$ has remained in the geological formation. If $\mathrm{CO}_{2}$ escapes, the bond will be partially devalued and the company is forced to partially write off its claim against the environmental agency.

The sum that passes to the environmental agency can be used to subsidise renewables. This earmarking is designed to keep the transition to a climate-friendly energy system as short as possible. Subsidisation can also be understood as compensation for the competitive disadvantage suffered by renewables. But if stored $\mathrm{CO}_{2}$ escapes from the geological formations in the intervening period, valuable time that would have been needed for a cost-effective restructuring of the energy system will have been wasted. As such, the bond represents a kind of insurance premium against risky and insecure $\mathrm{CO}_{2}$ reduction activities.

Carbon Sequestration Bonds must be tradable on markets. Then a company can sell its bonds to obtain liquid funds. But companies will only be able to sell their bonds if they are able to offer buyers a better rate of interest than a security without risks. How high this risk premium is will depend on how great buyers perceive the risks to be that the bond will be devalued. So the company will only be able to achieve a high price for its bonds if it can convince buyers that the sink is safe.

The whole sector therefore has an incentive not to undermine confidence in the bonds. The threat of devaluation turns the safety standard of the geological formation into a tradable commodity, because companies then have an incentive to develop powerful monitoring techniques to demonstrate that the $\mathrm{CO}_{2}$ has remained in the geological formation. ${ }^{26}$ The better the proof the greater the value of the bonds. Because CSBs are tradable, investors can express their confidence in CCS by buying bonds. The greater public confidence is, the higher the price. Moreover, this would give the public the opportunity to participate via investment decisions in the general decision on whether or not to implement CCS.

26 This proof would have to be verified by an independent body.

\section{Version 2: CSBs as special emission rights}

In the second version CSBs are issued to ensure that a maximum emissions limit is observed. Here the CSB is no longer a separate instrument, but is fully integrated in the certificate trading system. So preconditions would be the implementation of such a trading system and the definition of a corresponding upper limit for emissions.

As in the first version, companies involved in CCS are required to purchase a certain number of bonds, again before sequestration. A bond represents an asset that can be traded immediately on the markets. But the purchaser of the bond then himself bears the risk that this bond will lose value if later emissions are subsequently charged to it. Only then would the bond have mutated into an emissions right. But the bond should not contain an emission right until it has been possible to demonstrate clearly what proportion of the $\mathrm{CO}_{2}$ can be stored permanently.

After a certain latency period an independent environmental agency will verify how high the proportion of permanently stored $\mathrm{CO}_{2}$ actually is. If a company can prove that the $\mathrm{CO}_{2}$ is stored safely it is free to sell the bonds. This ensures that the emissions limit is not exceeded, and furthermore ensures that it is profitable for companies to store $\mathrm{CO}_{2}$ as securely as possible.

In comparison with the first version, the security of storage is given a higher priority. A higher than expected level of leakage would not only cause a monetary devaluation of the bonds, but also the loss of real emission rights.

\subsubsection{The Role of Pilot Projects: Levelling the Playing Field}

Successful control of leakage risks through CSB is subject to two processes of market distortion: a) liquidity restrictions, b) social herd effects and time inconsistencies. Pilot projects initiated by the state and publicly funded could avoid these processes (Held et al. 2006).

\section{Liquidity restrictions}

Both versions implicitly presuppose smoothly functioning financial markets. But in reality liquidity problems can arise: Banks could overprice credit, and potential purchasers of CSBs could offer prices that were too low if they falsely overestimated the risks of different forms of storage because the financial markets lacked information about the future leakage rates of the alternatives. In other words there is an asymmetrical information structure. Pilot projects could provide the financial markets with the required information. Then the financial markets would be in a position to promote the further refinement of CCS efficiently and without further state control mechanisms. 


\section{Social herd effects and time-inconsistency}

When CSBs are transferred, expectations about risk are exchanged. Where there is great uncertainty about future leakage rates market participants might tend to copy the buying behaviour of other participants rather than making risk assessments of their own. At the beginning the risk might be underestimated (because leakage is more likely to be a problem in the distant future). If it turns out later that the confidence in CCS was too great, the prices for CSBs will sink. This forces other sectors to reduce their emissions more strongly or might even persuade the state to relax the upper limit for emissions. Conversely, in the long term overestimation of risk may discourage others from implementing potential emission reductions. The market horizon for CSB is consequently too short to allow a rational estimation of the risks. In this situation the state has to promote pilot projects to rectify the timeinconsistency by signalling to the market that it is pursuing a long-term interest in maintaining its emissions limit and having CCS with low leakage rates. At the international level this strengthens the confidence of other states that climate protection obligations will be observed.

The ultimate responsibility of the state arising from the principle of public responsibility that was underlined earlier as one of the crucial legal aspects (see section 15.3.2) also means that the state should emphasise its lasting responsibility for successful climate protection at an early stage by initiating lighthouse projects. In this sense ultimate responsibility would not be a matter only for the distant future.

Altogether Carbon Sequestration Bonds represent an innovative instrument to minimise the risk of leakage endangering climate protection goals while at the same time achieving a plausible distribution of responsibility between companies, investors and the state (WBGU 2006). With respect to the increasing involvement of re-insurers and "green funds" in climate protection, the introduction of a market instrument for regulating liability and safety could prove to be a sensible choice.

\subsubsection{CCS in the Kyoto Architecture after 2012: A Possible Strategy for the EU}

The challenge for a climate policy for the period after 2012 is to set the right price incentives for investment in emission-reducing technologies by means of effective international agreements (see sections 15.2.2 and 15.3.1). The European Union has set itself the climate protection goal of restricting the rise in global mean temperature by 2100 to a maximum of $2^{\circ} \mathrm{C}$. This goal cannot be achieved by Europe acting alone, even though Europe's emissions goals are much more ambitious than the commitments made by other coun- tries. ${ }^{27}$ But the question is whether these goals signal credibly to the other main emitters that the EU is actually pursuing - and will implement - a policy that will both meet the agreed European reduction targets and also offer an international incentive for the other main emitters to aim for ambitious emissions targets themselves.

Convincing incentive systems are required to prevent countries from becoming successful "free riders" in climate protection. This will be all the more the case the quicker the involved parties learn that climate protection is associated with relatively modest costs and might even produce an additional dividend through growth potential (triggered for example by exports of innovative technology).

Currently one of the greatest challenges in international climate policy is persuading states that currently do not make such commitments - either because they are sceptical about the Kyoto regime (e.g. the United States) or because as newly industrialising or developing countries they are not covered by the firm obligations of Annex B (e.g. China) - to agree to adopt and observe emissions reductions. The introduction of CCS as an instrument could improve the chances of this. At the same time, from the EU's perspective the chances would improve of achieving its own ambitious climate protection goals. The idea that the CCS option would improve the willingness to adopt emission reductions can be backed up as follows for the cases of the United States and China.

The US Department of Energy (DoE) regards CCS as the central climate protection element for pursuing what the US-American administration regards as ambitious climate protection goals (e.g. stabilisation at today's level). And CCS is also an important issue in the Asia Pacific Partnership.

Over the coming decades China will undertake a great expansion of its power station capacity. The number of coal-fired power stations is expected to triple by 2030 (IEA 2002). So a potential market for CCS is already emerging today. The current Kyoto Protocol signatories could now grant countries like China and India generous emission rights that largely correspond with their business-as-usual emissions trend. At the same time an international fund could buy up these emission rights and take them out of circulation at least until the price of $\mathrm{CO}_{2}$ rises to a point where CCS becomes profitable (von Weizsäcker 2004).

However it must be feared that the price of taking certificates out of circulation would be high. Europe would have to take on a disproportionate share of funding for climate protection. Europe can only reduce this funding burden if it succeeds at the same time in launching a credible technology policy that has the goal of bring-

27 The EU aims to reduce $\mathrm{CO}_{2}$ emissions by at least $20 \%$ by 2020

(under certain conditions by $30 \%$ ) and by $60-80 \%$ by 2050

(compared with 1990). 
ing CCS technologies - and also renewable energy and efficiency technologies - quickly to the point where they are ready for large-scale commercial application. Europe could then hope to export CCS technologies. And the costs of buying up the certificates might possibly then be redeemed. ${ }^{28}$

The potential of the CCS option for globalising the market in emission certificates and thus enabling fast emission reductions should, however, not be overestimated. CCS can act as a bridge between today's energy system and a future energy system whose contours are only just becoming apparent. Most energy analyses show that renewables, alongside efficiency increases, will play a decisive role in the energy mix of the future. But they will be part of a portfolio of technologies where - especially from the global perspective - CCS could be able to make a decisive contribution to lowering costs and thus act as an incentive in international climate negotiations 



\section{Appendix}

Contents

$\begin{array}{ll}\text { A.1 Physical Properties of } \mathrm{CO}_{2} & 199\end{array}$

A.2 $\mathrm{CO}_{2}$ Capture Methods (to Chapter 5) 199

$\begin{array}{ll}\text { A.2.1 Chemical/Physical Absorption } & 200\end{array}$

$\begin{array}{ll}\text { A.2.2 Adsorption on Solids } & 201\end{array}$

A.2.3 Cryogenic Distillation $\quad 201$

A.2.4 Membrane Method $\quad 202$

A.2.5 High-temperature Method $\quad 202$

$\begin{array}{ll}\text { A.2.6 Conclusions } & 203\end{array}$

A.3 Worldwide Overview of CCS Projects (to Chapter 7) 203

$\begin{array}{ll}\text { A.3.1 Projects within the EU } & 206\end{array}$

A.3.2 International Activities and Political Strategies $\quad 210$

A.3.3 CCS Projects in Germany 213

A.4 Central Issues for Planning a $\mathrm{CO}_{2}$ Transport Infrastructure

(to Chapter 8)

A.5 Data Used for Analysing Mass Flows of Fuel and $\mathrm{CO}_{2}$

(to Chapter 10)

Tables

Table A-1: Chemical and thermodynamic properties of carbon dioxide $\left(\mathrm{CO}_{2}\right) \quad 199$

Table A-2: Global distribution of projects and main research areas (as of 10/06) 203

Table A-3: Analysis of additional fuel quantities required for CCS and quantities of $\mathrm{CO}_{2}$ to be stored for different power station types (electricity production)

Table A-4: Analysis of additional fuel quantities required and quantities of $\mathrm{CO}_{2}$ to be stored for different synthesis gas plants ( $\mathrm{H}_{2}$ production) 


\section{Figures}

Figure A-1: $\quad$ Phase diagrams for carbon dioxide 199

Figure A-2: Global $\mathrm{CO}_{2}$ capture projects (selection) 204

Figure A-3: Global $\mathrm{CO}_{2}$ storage projects (selection) 204

Figure A-4: Overview of the global distribution of CCS projects in relation to the major sources of $\mathrm{CO}_{2}$ emissions 205

Figure A-5: Selection of European field trials and demonstration projects 205

Figure A-6: Electricity generation using hydrogen at Peterhead, Scotland

Figure A-7: Organisational structure and members of the European Technology Platform for Zero Emission Fossil Fuel Power Plants (ZEFFPP)

Figure A-8: CSLF project categories and research areas $\quad 210$

Figure A-9: CCS demonstration projects in the United States 211 


\section{A.1 Physical Properties of $\mathrm{CO}_{2}$}

Carbon dioxide $\left(\mathrm{CO}_{2}\right)$ is a colourless, odourless, tasteless gas, which is not flammable and - at the normal atmospheric concentration of approx. $0.04 \mathrm{vol} \%$ - not toxic. With a specific gravity density of $1.85 \mathrm{~kg} / \mathrm{m}^{3}$ (at 15 ${ }^{\circ} \mathrm{C}$ and 1 bar) it is about 1.5 times heavier than air and consequently accumulates in low areas when present at high concentrations. The highest permissible workplace concentration is $0.5 \%$ or 5,000 ppm (parts per million). Because carbon dioxide displaces atmospheric oxygen, breathing air with concentrations greater than 7-8\% will lead to death by suffocation within 30 to $60 \mathrm{~min}$ utes.

As the phase diagram shows (Fig. A-1), $\mathrm{CO}_{2}$ is a gas (g) under normal conditions $\left(1.0 \mathrm{bar} / 15^{\circ} \mathrm{C}\right)$ and freezes at a temperature of $-78,5^{\circ} \mathrm{C}$ (Table A-1). Frozen $\mathrm{CO}_{2}$ is referred to as dry ice. Below 5.8 bar heating causes it to pass directly from the solid state (s) to the gaseous state (sublimation). The liquid phase (l) exists only above the triple point (TP) of 5.8 bar and $-57^{\circ} \mathrm{C}$. The triple point is the point where all three phases coexist in equilibrium. So at ambient temperatures $\mathrm{CO}_{2}$ can be compressed for example to 100 bar for transport purposes. In the liquid state the density increases (e.g. to $824 \mathrm{~kg}$ / $\mathrm{m}^{3}$ at $15^{\circ} \mathrm{C}$ and 51 bar), meaning that in the liquid state the volume to be dealt with is much smaller than in the gaseous state. In the supercritical range (supercr.) above the critical point (CP) of 74 bar and $31^{\circ} \mathrm{C} \mathrm{CO}_{2}$ occurs in a uniform phase with a constant density $\left(464 \mathrm{~kg} / \mathrm{m}^{3}\right)$.

\section{A.2 $\mathrm{CO}_{2}$ Capture Methods (to Chapter 5)}

Several fundamentally different methods are available for decarbonising combustible gases and flue gases. In the following we describe the methods and their characteristic features and assess their suitability for possible use in $\mathrm{CO}_{2}$ sequestration systems.
Table A-1: Chemical and thermodynamic properties of carbon dioxide $\left(\mathrm{CO}_{2}\right)$

\begin{tabular}{|c|c|c|}
\hline Molecular weight & 44.01 & $\mathrm{~kg} / \mathrm{kmol}$ \\
\hline Relative density of gas (air $=1$ ) & 1.53 & - \\
\hline Density of gas & 1.85 & $\mathrm{~kg} / \mathrm{m}^{3}$ \\
\hline $\begin{array}{l}\left.\text { Density of liquid }{ }^{*}\right) \quad\left(-50^{\circ} \mathrm{C} / 6.84 \mathrm{bar}\right) \\
\qquad \begin{array}{l}\left(0^{\circ} \mathrm{C} / 34.86 \mathrm{bar}\right) \\
\left(15^{\circ} \mathrm{C} / 50.85 \mathrm{bar}\right) \\
\left(31.06^{\circ} \mathrm{C} / 73.84 \mathrm{bar}\right)\end{array}\end{array}$ & $\begin{array}{l}1,156 \\
928.8 \\
823.8 \\
463.7\end{array}$ & $\begin{array}{l}\mathrm{kg} / \mathrm{m}^{3} \\
\mathrm{~kg} / \mathrm{m}^{3} \\
\mathrm{~kg} / \mathrm{m}^{3} \\
\mathrm{~kg} / \mathrm{m}^{3}\end{array}$ \\
\hline Density of solid & $\approx 1,550$ & $\mathrm{~kg} / \mathrm{m}^{3}$ \\
\hline Boiling/freezing point (at 1 bar) & -78.5 & ${ }^{\circ} \mathrm{C}$ \\
\hline Triple point & $\begin{array}{r}5.81 \\
-56.6\end{array}$ & $\begin{array}{l}\text { bar } \\
{ }^{\circ} \mathrm{C}\end{array}$ \\
\hline Critical point & $\begin{array}{l}73.84 \\
31.06\end{array}$ & $\begin{array}{l}\text { bar } \\
{ }^{\circ} \mathrm{C}\end{array}$ \\
\hline $\begin{array}{l}\text { *) Saturated } \\
\text { Source: Dubbel (1990), Reiniger and Schubert ( }\end{array}$ & $\operatorname{ter}(2003$ & \\
\hline
\end{tabular}

$\mathrm{CO}_{2}$ capture methods can be placed in two basic categories:

- low-temperature methods and

- high-temperature methods.

With low-temperature $\mathrm{CO}_{2}$ capture methods the gases generally have to be cooled and the water condensed out before the actual capture process begins. The lowtemperature methods are:

- Chemical absorption in organic and inorganic solutions (alcohol-amine, alkali carbonate, etc.),

- Physical absorption in organic and inorganic solutions (methanol, propylene carbonate, water),

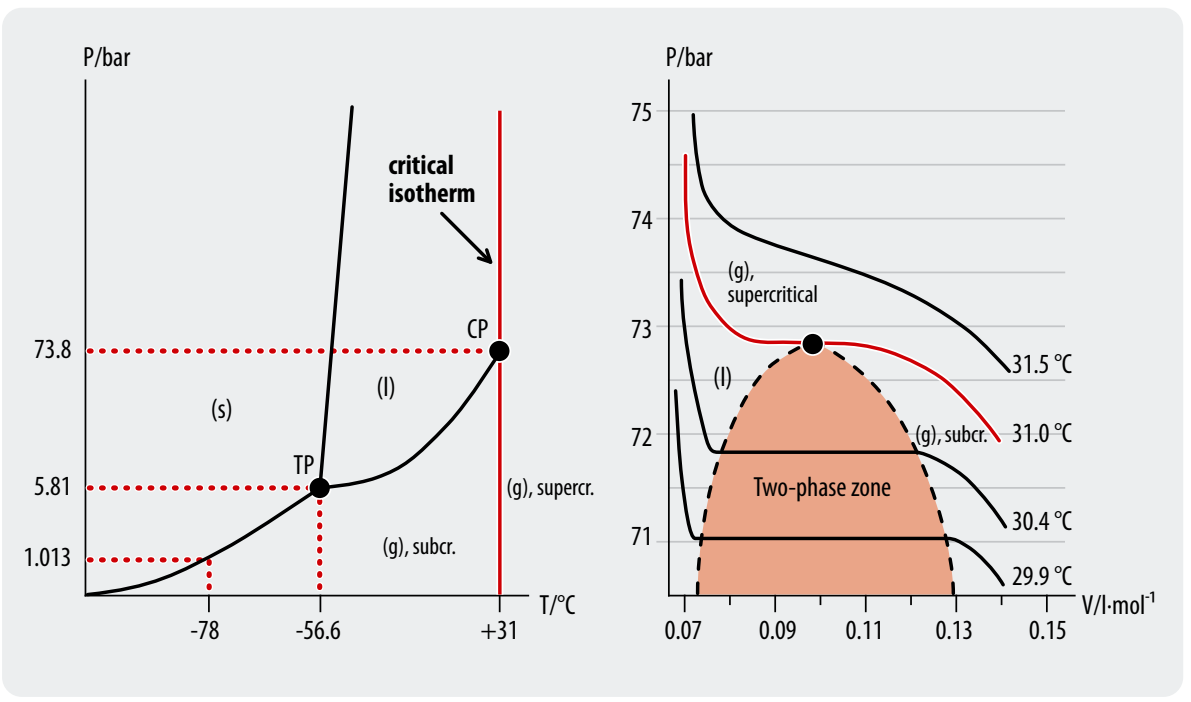

Fig. A-1:

Phase diagrams for carbon dioxide ( $\mathrm{p} / \mathrm{T}$ diagram on left, $\mathrm{p} / \mathrm{V}$ diagram on right) (Reininger and Schubert 1999) 
- Adsorption on solids (molecular sieves, activated carbon, etc.)

- Cryogenic distillation

- Membrane methods

Methods using chemical and physical absorption in solutions are current state of the art. Their suitability for $\mathrm{CO}_{2}$ capture has been extensively demonstrated in gas scrubbing processes and enrichment. The most commonly used solutions are: ethanol amine (monoethanol, diethanol, triethanol amine), potassium carbonate, propylene carbonate, methanol (Rectisol), polyethylene glycol dimethyl ether (Selexol), and others. The most extensively tested process is capturing $\mathrm{CO}_{2}$ from flue gases with monoethanolamine (MEA). For example, a $\mathrm{CO}_{2}$ scrubber using a $20 \%$ MEA solution has been operating since 1991 at a $300-\mathrm{MW} \mathrm{CHP}$ plant at Shady Point (Oklahoma). The daily production of $200 \mathrm{t}$ of $\mathrm{CO}_{2}$ is used in the food industry. Because amine is degraded by impurities such as dust, $\mathrm{SO}_{2}, \mathrm{NO}$ and $\mathrm{O}_{2}$, these must be removed from the flue gas before amine capture (Hendricks 1994).

Zeolite molecular sieves, activated carbon, aluminium oxide, silica gel, etc. can be used to capture $\mathrm{CO}_{2}$ in adsorption systems. This technology is state of the art, but has not yet been used in the power station sector. The most commonly used process is pressure swing adsorption (PSA) with molecular sieves. One major drawback of molecular sieves is their affinity for water. Consequently any water must be condensed out before $\mathrm{CO}_{2}$ capture.

$\mathrm{CO}_{2}$ can be condensed out of gas mixtures through cooling at pressures as low as 4-5 bar (cryogenic distillation). Exxon has developed and industrially tested the controlled freezing zone process. The process is energyintensive, especially when the $\mathrm{CO}_{2}$ concentration is low. However, its advantage is that capture and compression for transport are accomplished in a single step. Today it is already used for conditioning biogas, but no experience has yet been gathered in the power station sector.

Membrane methods separate gases by making use of differences in their ability to pass through thin membranes. Efficient separation demands high selectivity, a large membrane surface and high permeability for the desired gas components. This method is currently under development and is not yet state of the art. Today membranes are used for gas separation on a small scale. They are especially efficient for separating gases with very different-sized molecules. Membrane separation of $\mathrm{H}_{2}$ is today close to becoming competitive with other methods. By contrast, given the still very poor membrane selectivity, $\mathrm{CO}_{2}$ capture from flue gases (largely $\mathrm{N}_{2} / \mathrm{CO}_{2}$ mixtures) is still a long way from commercial application, and no breakthrough can be expected in the next ten to fifteen years.

High-temperature methods for $\mathrm{CO}_{2}$ capture are based on binding $\mathrm{CO}_{2}$ to oxides or silicates, e.g. $\mathrm{CaO}$. This method is still at the development stage. Its attraction is that $\mathrm{CO}_{2}$ capture occurs at high temperatures, so (tar- laden) combustible gases from a gasification process can pass to a turbine without having to be cooled first. This allows efficiency to be increased in comparison with conventional $\mathrm{CO}_{2}$ capture methods (e.g. scrubbing). It makes sense to implement these systems in IGCC power stations (coal-fired integrated gasification combined cycle) and gas-fired combined cycle power stations before combustion or directly in the combustion chamber. $\mathrm{CO}_{2}$ bonding occurs at temperatures below the equilibrium temperature. The absorbent has to be regenerated after the absorption phase. The regeneration temperature is approx. $50-100{ }^{\circ} \mathrm{C}$ above the equilibrium temperature.

In the following section the aforementioned methods are briefly outlined and assessed. The theoretical specific energy requirement for the capture methods listed below relates to capture of $\mathrm{CO}_{2}$ from flue gases ( $\mathrm{ZSW}$ 1996). A distinction must be made between thermal and electrical energy. In practice the values are (sometimes) much higher so they should be treated with caution. The decisive factor is the achieved power station efficiency.

\section{A.2.1 Chemical/Physical Absorption}

Description of process: Chemical and physical absorption of $\mathrm{CO}_{2}$ in solutions is an industrially tested capture method. In chemical absorption $\mathrm{CO}_{2}$ is bonded chemically to organic or inorganic molecules. In physical absorption the amount of $\mathrm{CO}_{2}$ the solvent will accept stands in an approximately linear relationship to the partial pressure of the $\mathrm{CO}_{2}$. The levels of bonding energy involved are much weaker than with chemical absorption, which is advantageous when it comes to regeneration. After the $\mathrm{CO}_{2}$ has been scrubbed from the raw gas the saturated solution must be regenerated and the $\mathrm{CO}_{2}$ extracted. With chemical absorption the solutions are regenerated by heating, with physical absorption by a drop in pressure.

Theoretical specific energy requirement after ZSW (1996)

Chemical absorption:

$1.08 \mathrm{MJ} / \mathrm{kg} \mathrm{CO}_{2}$ (MEA with $50 \%$ capture rate)

$1.95 \mathrm{MJ} / \mathrm{kg} \mathrm{CO}$ (MEA with $90 \%$ capture rate)

Physical absorption: $0.1 \mathrm{MJ} / \mathrm{kg} \mathrm{CO}$

Achievable capture rate:

Chemical absorption: $90 \%$

Physical absorption: $60-80 \%$

Applications and experience: The technology is state of the art. Whether physical or chemical scrubbing is used depends on the partial pressure of the $\mathrm{CO}_{2}$. Below 10 bar chemical absorption is used, above 10 bar physical absorption.

Possible uses: $\mathrm{CO}_{2}$ capture from flue gases (coal-fired thermal power stations, CC, coal-fired IGCC), e.g. at 
Shady Point, Oklahoma $\left(200 \mathrm{t} \mathrm{CO}_{2} /\right.$ day for the food industry, $\mathrm{ABB}$ technology).

Advantages and disadvantages, $\mathrm{CO}_{2}$ avoidance costs, power station efficiency: The operating temperature for chemical absorption is around $50-60^{\circ} \mathrm{C}$ (for physical absorption less) so the gas being treated must be cooled and cleaned (of $\mathrm{SO}_{\mathrm{x}}, \mathrm{NO}_{\mathrm{x}}$, dust, etc.). This leads to loss of energy in the form of sensible heat. The power station technology must be adapted for absorption with solvents (e.g. gas scrubbing, $\mathrm{O}_{2}$ concentration). Specific investment costs, e.g. for a CC power station, rise by about $87-93 \%$ and the overall efficiency of the arrangement is - at about $48-55 \%$ - significantly lower than without $\mathrm{CO}_{2}$ capture. The $\mathrm{CO}_{2}$ avoidance costs lie in the range of $\$ 32-49 / \mathrm{tCO}_{2}$. For a coal-fired power station the overall efficiency of $33-37 \%$ is significantly lower than with a conventional generating process without flue gas decarbonisation. The specific investment costs rise by about $80 \%$. Specific $\mathrm{CO}_{2}$ avoidance costs in the range of \$47-49 per avoided tonne of $\mathrm{CO}_{2}$ are cited in the literature. One advantage of this method is that power stations can be retrofitted.

Technical limits and required R\&D: Most solvents (especially amines) are subject to degradation over time, leading to losses and consequent environmental impacts (amines are toxic!). Degradation of the solvent depends strongly on the concentrations of impurities in the flue gases (e.g. $\mathrm{SO}_{\mathrm{x}}$ and $\mathrm{NO}_{\mathrm{x}}$ ). Many solvents are also corrosive and consequently cause material problems. Research is still required into the development of corrosion-resistant materials. The system as a whole (power station plus $\mathrm{CO}_{2}$ capture) has yet to be demonstrated in the long term.

Timeframe for large-scale application: The technology is available and is already used in the oil industry and for extracting $\mathrm{CO}_{2}$ from power station waste gases for use in the food industry. Long-term experience in large-scale commercial power stations is still lacking.

\section{A.2.2 Adsorption on Solids}

Description of process: Zeolite molecular sieves, activated carbon, aluminium oxide, etc. can be used to capture $\mathrm{CO}_{2}$ in adsorption systems. The most commonly used process is pressure swing adsorption (PSA) with molecular sieves. Adsorption is accomplished through physical forces (van der Waals forces). The adsorption phase is followed by regeneration by means of pressure reduction. The adsorbent can also be regenerated thermally (temperature swing adsorption) or in a combined process of pressure and temperature swing adsorption (PTSA). Molecular sieves have the highest $\mathrm{CO}_{2}$ adsorption capacity per $\mathrm{kg}$ in comparison with other materials.

Specific energy requirement after ZSW (1996): 2.9 MJ/ $\mathrm{kg} \mathrm{CO}_{2}$ (molecular sieves, PSA, TSA)

Achievable capture rate: $90 \%$
Applications and experience: The method is state of the art. So far it has only been used for small gas flows. No experience has yet been gathered in the use of this method with large gas flows (e.g. power stations).

Advantages and disadvantages, $\mathrm{CO}_{2}$ avoidance costs, power station efficiency: Adsorption is a relatively simple, well-tested method, but it has not yet been used for large gas flows. The large energy requirement reduces the attractiveness of this method for $\mathrm{CO}_{2}$ capture in power stations. Additional investment costs are not especially high. Energy consumption is lowest with PSA (approx. 1/3 compared with TSA). One important drawback is the affinity of molecular sieves for water. For this reason the water must be condensed out before $\mathrm{CO}_{2}$ capture. Calculations show that in almost all types of power station, implementing $\mathrm{CO}_{2}$ capture with PSA would double electricity generating costs.

Technical limits and required R\&D: The process is mature, but not relevant for $\mathrm{CO}_{2}$ capture in power stations. However, new methods such as metal oxide gels could make the process more viable.

Timeframe for large-scale application: The technology is already available, but unattractive for power stations. New advances could be ready for implementation in about twenty years.

\section{A.2.3 Cryogenic Distillation}

Description of process: $\mathrm{CO}_{2}$ can be condensed out of gas mixtures by cooling at pressures as low as $4-5$ bar. The gas mixture being treated must be dried first.

Specific energy requirement after ZSW (1996): 4.35 $\mathrm{MJ} / \mathrm{kg} \mathrm{CO}$

\section{Achievable capture rate: $90 \%$}

Applications and experience: The method is very energy-intensive, especially where the $\mathrm{CO}_{2}$ concentration in the gas is low. In the past it was used to extract $\mathrm{CO}_{2}$ from gases with $\mathrm{CO}_{2}$ concentrations $>90$ vol.\%. Today cryogenic distillation is already used for conditioning biogas $\left(\mathrm{CO}_{2}+\mathrm{CH}_{4}\right)$, but no experience has yet been gathered in the generation sector. Future implementation of the process would be conceivable with IGCC $\left(\mathrm{O}_{2}\right)$ and oxyfuel processes. However, from the energy (and consequently ecological) perspective application is very questionable.

Advantages and disadvantages, $\mathrm{CO}_{2}$ avoidance costs, power station efficiency: The gas being treated must be free of water (big disadvantage). The method is only feasible for gas flows with high $\mathrm{CO}_{2}$ concentrations. However, the advantage of this process is that capture and compression for transport are accomplished in a single step, with a single-stage process producing solid or liquid $\mathrm{CO}_{2}$. Large-scale industrial application is not on the horizon. Calculations for IGCC and oxyfuel power stations show that cryogenic $\mathrm{CO}_{2}$ capture would reduce 
power station efficiency by 14 and 18 percentage points respectively. Investment costs increase by approx. $80 \%$. Another possibly more attractive application could arise with fuel-cell power stations, where $\mathrm{CO}_{2}$ occurs in a very concentrated form.

Technical limits and required R\&D: There is still a great need for research to optimise the process with the goal of significantly reducing the energy requirement.

Timeframe for large-scale application: The technology is in principle already available. Oxyfuel power stations and SOFC are regarded as the best opportunities for implementation. But commercial viability is not expected for another fifteen to twenty years.

\section{A.2.4 Membrane Method}

Description of process: Membrane methods make use of the different rates at which gases pass through thin membranes. Efficient separation demands high selectivity, a large membrane surface and high permeability for the required gas components in comparison with the other gases in the mixture. Polymers, metals or ceramics can be used as the membrane material.

\section{Specific energy requirement after ZSW (1996): 1.15} $\mathrm{MJ} / \mathrm{kg} \mathrm{CO}{ }_{2}$

\section{Achievable capture rate: $60 \%$}

Applications and experience: $\mathrm{CO}_{2}$ capture using membranes could be implemented with CC (reforming or combustion in $\mathrm{O}_{2}$ ) and coal-fired IGCC power stations before or after combustion. However, membrane technology is not yet state of the art.

Advantages and disadvantages, $\mathrm{CO}_{2}$ avoidance costs, power station efficiency: When used for $\mathrm{CO}_{2}$ capture with CC or IGCC oxyfuel power stations (in situ $\mathrm{CO}_{2}$ capture before combustion) the efficiency of the CC power station is $48-50 \%$, or $8-10$ percentage points less than that of a conventional power station. The efficiency of a coal-fired IGCC power station with membrane capture is $35-39 \%$, or $6-10$ percentage points less than IGCC without $\mathrm{CO}_{2}$ capture. The specific investment costs are 33-54\% higher than for IGCC without $\mathrm{CO}_{2}$ capture. The $\mathrm{CO}_{2}$ avoidance costs are in the range $\$ 18-40 / \mathrm{t}$.

Technical limits and required R\&D:

Development work is still required on the following components and processes:

- efficient membranes for separating $\mathrm{CO}_{2}$

- reactor concepts for in situ $\mathrm{CO}_{2}$ capture with hightemperature membranes

- high-temperature membranes for separating off $\mathrm{O}_{2}$

- reactors for the separation process

- turbines for $\mathrm{H}_{2}$-rich gases
Timeframe for large-scale application: The method is not state of the art but in the development stages. It will be available in ten to fifteen years at the earliest. Improvements are needed above all in selectivity, permeability and stability (at high temperatures). A combination of membrane and absorption solution would be an interesting prospect. This development is at the laboratory stage.

\section{A.2.5 High-temperature Methods}

Description of process: The high-temperature methods for capturing $\mathrm{CO}_{2}$ are based on in-situ bonding of $\mathrm{CO}_{2}$ (combustion, gasification, reforming) with oxides (quick lime, dolomite, etc.), silicates, etc. This method is still at the development stage. The attraction of the method is that $\mathrm{CO}_{2}$ capture is accomplished at high temperatures so the combustion gases can pass to the turbine without cooling. This makes it possible to achieve higher levels of efficiency than with conventional $\mathrm{CO}_{2}$ capture methods (e.g. absorption solutions). The $\mathrm{CO}_{2}$ absorbent is located either directly in the conversion reactor (combustion, reforming, gasification, etc.) or downstream (e.g. in a shift reactor).

\section{Specific energy requirement: $0.8 \mathrm{MJ} / \mathrm{kg} \mathrm{CO} 2$}

\section{Achievable capture rate: $>90 \%$}

Applications and experience: High-temperature $\mathrm{O}_{2}$ capture could be implemented in the pre-combustion phase in CC (steam reforming) and IGCC processes and in the combustion phase in coal-fired power stations. High-temperature absorbers for $\mathrm{CO}_{2}$ are in the development stages. The promising options include natural carbonates (e.g. limestone and dolomite) and natural and synthetic silicates and zirconates. The most important property of the high-temperature absorber is its cyclic stability. For industrial application the absorbers must be able to withstand as many $\mathrm{CO}_{2}$ absorption/ regeneration cycles as possible without significant loss of capacity. Toshiba has developed a lithium orthosilicate that is claimed to maintain its stability over more than five hundred cycles.

Advantages and disadvantages, $\mathrm{CO}_{2}$ avoidance costs, power station efficiency: The attraction of $\mathrm{CO}_{2}$ capture at high temperatures is that the combustion gases do not need to be cooled, and can be used directly. In this case even tars in the product gas can be utilised without problems. $\mathrm{CO}_{2}$ absorption is exothermic and the heat of reaction can be integrated in the process. One disadvantage of the process is the regeneration of the saturated absorbent, for which temperature change is the principal option. Repeated absorption/regeneration destroys the structure of the absorber, which gradually loses its capacity to absorb $\mathrm{CO}_{2}$. The presence of water accelerates this process.

These materials have not to date been used industrially for $\mathrm{CO}_{2}$ capture. 
Technical limits and required R\&D: Development work is still required on the following materials and process design:

- cyclically stable materials that withstand as many absorption/desorption cycles as possible without significant changes in absorption capacity

- reactor and process concepts for in situ $\mathrm{CO}_{2}$ capture

- efficient regeneration.

Timeframe for large-scale application: The method is not yet available. Possible industrial application in approximately fifteen to twenty years.

\section{A.2.6 Conclusions}

As things stand today, the most efficient processes for $\mathrm{CO}_{2}$ capture in power stations causes efficiency losses of 6-14 percentage points. In order to maintain the same nominal output the power stations consume approx. 15-35\% more fuel, and investment costs rise by $30-120 \%$. Capturing $\mathrm{CO}_{2}$ from flue gases by absorption in solutions is state of the art and can be implemented in all (existing and future) power station types. Of all the $\mathrm{CO}_{2}$ capture options, flue gas decarbonisation in conventional coal-fired power stations using absorption solutions is the least favourable.

There is believed to be great potential in pre-combustion $\mathrm{CO}_{2}$ capture methods when combined with new power station types such as:

- CC with steam reforming

- IGCC

- Power stations using the oxyfuel process (combustion in $\mathrm{O}_{2} / \mathrm{CO}_{2}$ ).

This would require $\mathrm{R} \& \mathrm{D}$ in the fields of membranes for $\mathrm{CO}_{2}$ and $\mathrm{O}_{2}$, hydrogen turbines, power station engineering and high-temperature absorbers. Large-scale industrial application can be expected in approx. fifteen to twenty years.

Cryogenic distillation can be implemented where $\mathrm{CO}_{2}$ occurs in concentrations upwards of $90 \%$, for example in oxyfuel power stations, high-temperature fuel cells (SOFC), chemical looping, etc. This would require development work in power station design. Large-scale industrial application can be expected in approx. fifteen to twenty years.

An economically advantageous solution is offered by pre-combustion capture of $\mathrm{CO}_{2}$ in IGCC power stations. Commercial availability can be expected in fifteen to twenty years.

It should be noted that efficient methods of $\mathrm{CO}_{2}$ capture are tied to power station technologies that are not yet state of the art. In the long term membrane technologies will play an important role in reducing the energy requirements and investment costs of $\mathrm{CO}_{2}$ capture. A combination of oxygen-permeable membranes and the oxyfuel process could in future lead to a major reduction in the energy required for $\mathrm{CO}_{2}$ capture.

\section{A.3 Worldwide Overview of CCS Projects (to Chapter 7)}

Globally there are more than one hundred projects relating to CCS. A good overview and introduction is provided by the Intergovernmental Panel on Climate Change (IPCC):

www.ipcc.ch

and by two websites maintained by the International Energy Agency (IEA):

www.ieagreen.org.uk/ccs.html www.co2captureandstorage.info.

The websites are organised by region and topic, making it easy to access the large amount of information. The world maps below show a selection of global activities in the fields of capture (Fig. A-2) and storage (Fig. A-3).

In international comparison North America has the most studies and projects relating to CCS (71), followed by Europe (36) and Asia (13) (as of October 2006). Japan plays an important role, running or participating in six of the Asian projects (see Table A-2, left-hand side).

If we look at the types of issue investigated (see Table A-2, right-hand side), $\mathrm{CO}_{2}$ storage comes first with 44 studies addressing geological storage (30 of them in North America) and 8 (in the United States and Japan) examining marine storage options. In second place come 41 studies focusing on new technologies (especially in relation to the process of capture at the power

Table A-2: Global distribution of projects and main research areas (as of 10/06)

\begin{tabular}{|c|c|c|c|}
\hline \multicolumn{2}{|c|}{ Number of projects by region } & \multicolumn{2}{|c|}{ Number of projects by research area } \\
\hline United States and Canada & 71 & Geological storage & 44 \\
\hline Europe & 37 & New technologies & 41 \\
\hline Asia (Japan) & $13(6)$ & Uses for $\mathrm{CO}_{2}$ & 12 \\
\hline Australia & 6 & Modelling and databases & 13 \\
\hline New Zeeland & 1 & Marine storage options & 8 \\
\hline Brazil & 1 & $\operatorname{ccs}$ costs & 4 \\
\hline United Arab Emirates & 1 & $\mathrm{CO}_{2}$ monitoring projects & 6 \\
\hline Algeria & 1 & Hydration & 2 \\
\hline Total & 131 & $\mathrm{CO}_{2}$ transport & 1 \\
\hline & & Total & 131 \\
\hline
\end{tabular}




\section{Global $\mathrm{CO}_{2}$ capture projects}

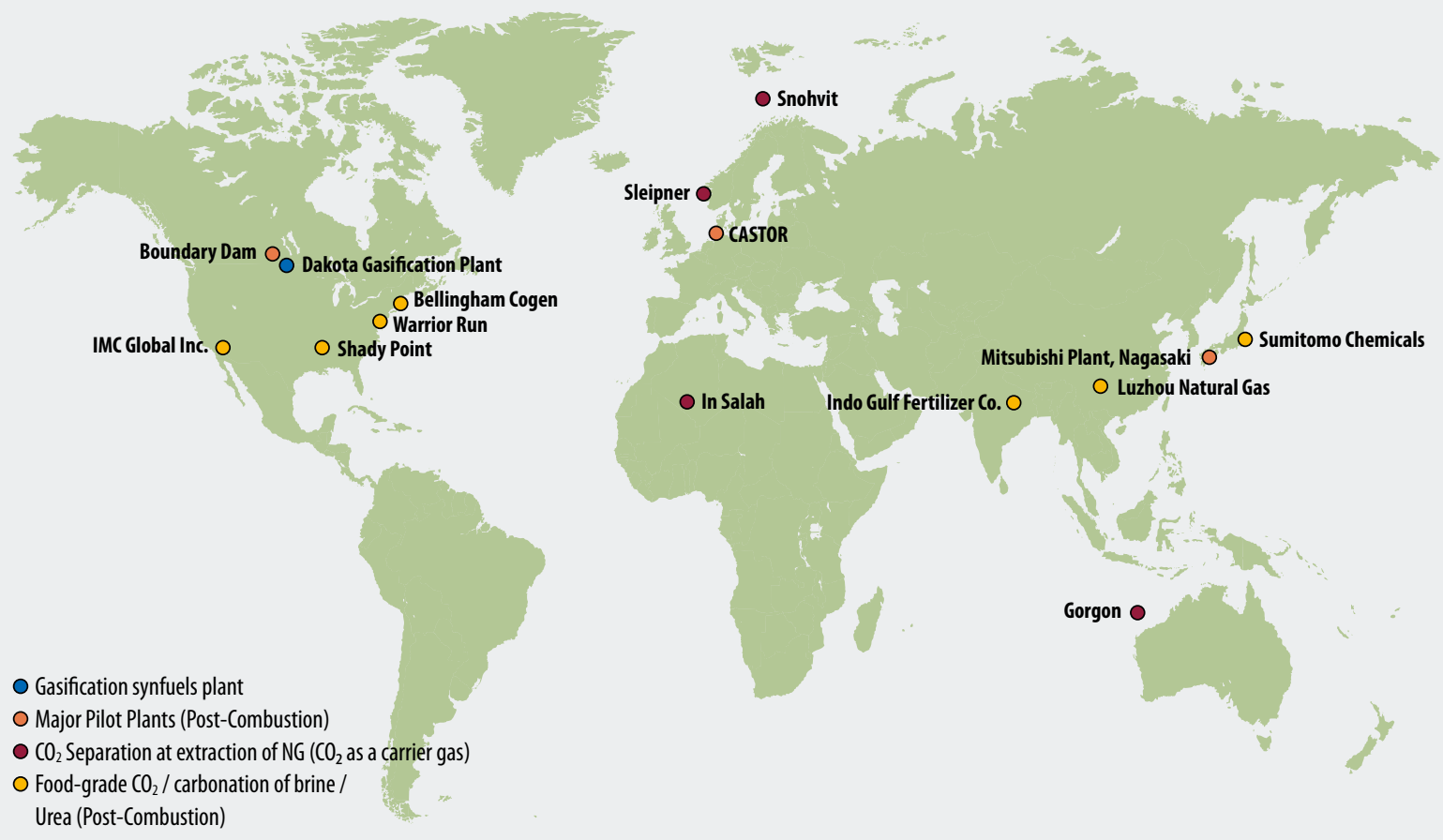

Fig. A-2: Global $\mathrm{CO}_{2}$ capture projects (selection)

\section{$\mathrm{CO}_{2}$ storage projects operating worldwide}

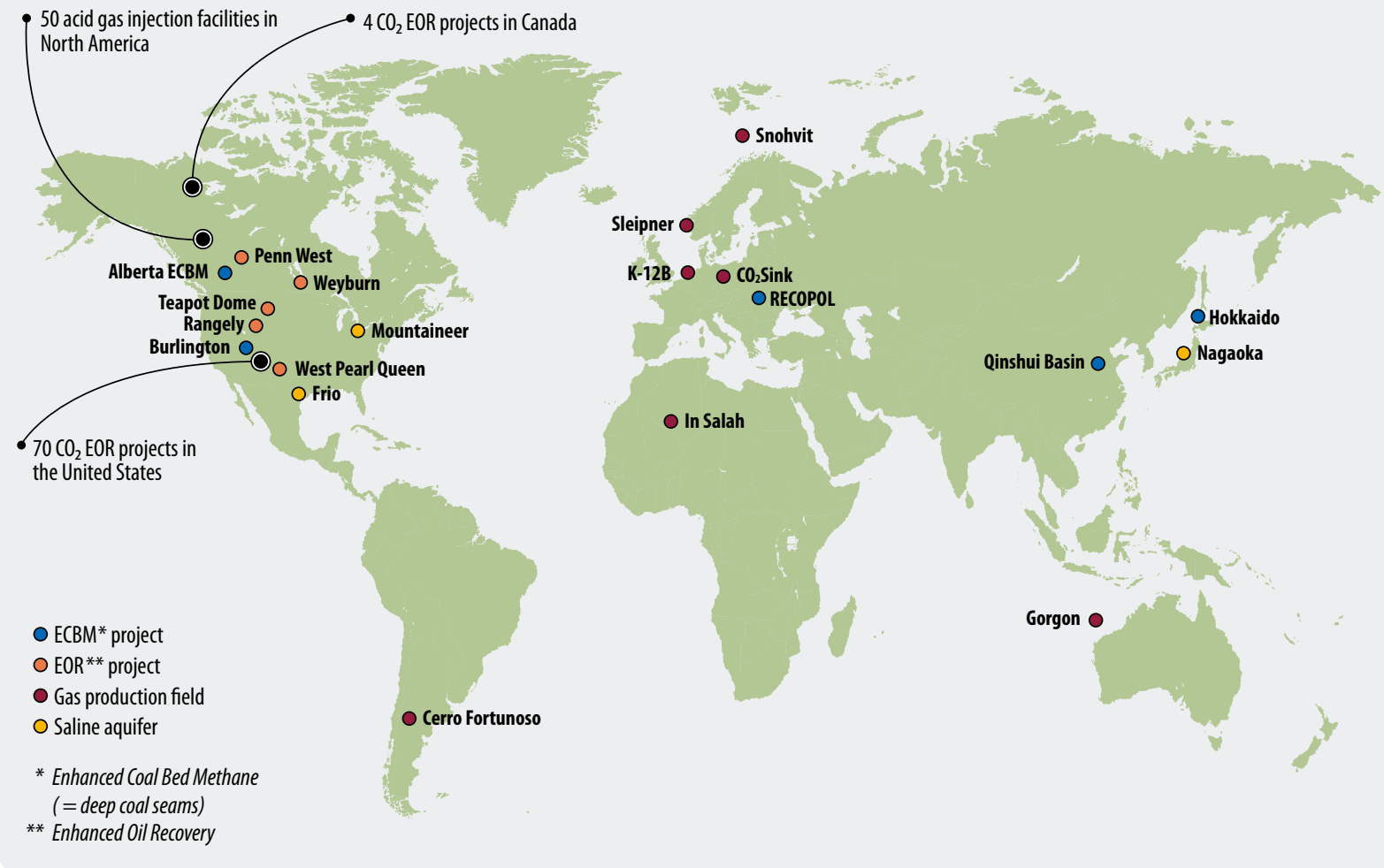

Fig. A-3: Selection of global $\mathrm{CO}_{2}$ storage projects (http://www.co2captureandstorage.info/docs/IEAGHGccsworldmap.pdf) 


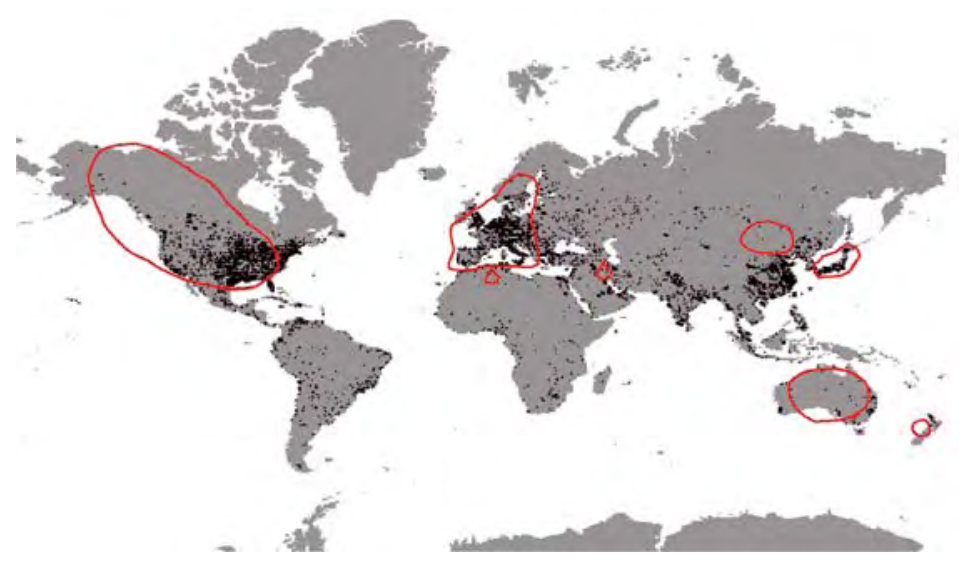

Fig. A-4: Overview of the global distribution of $\mathrm{CCS}$ projects (encircled in red) in relation to the major sources of $\mathrm{CO}_{2}$ emissions (dots)

\section{Selection of European field trials and demonstration projects (not exhaustive)}
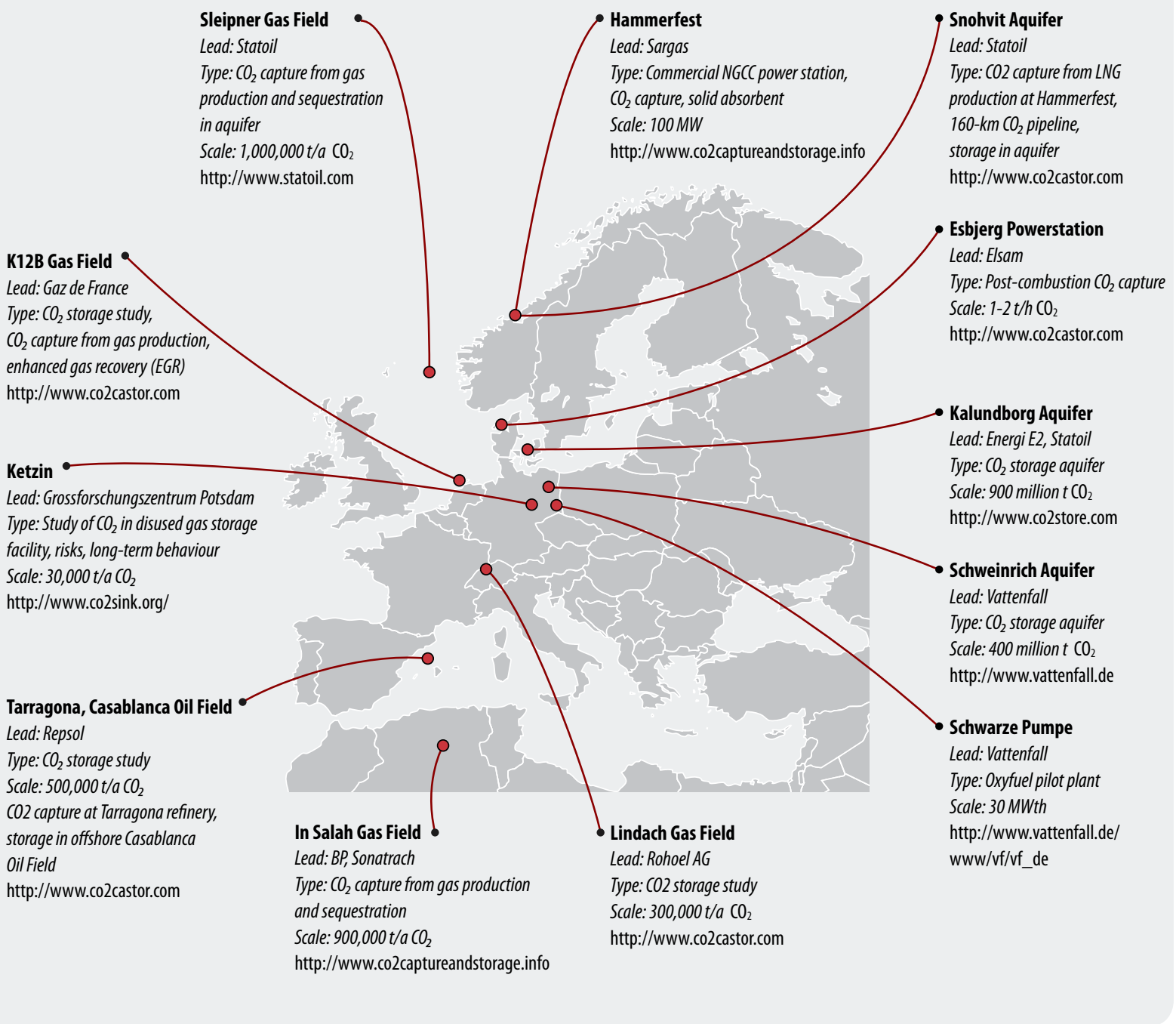

Fig. A-5: Selection of European field trials and demonstration projects (not exhaustive) 
station) followed by 13 projects preparing models and databases and 12 on possibilities for using $\mathrm{CO}_{2}$. One project analyses $\mathrm{CO}_{2}$ transport and two involve hydration of $\mathrm{CO}_{2},{ }^{1}$ while four projects focus on the costs of CCS and six investigate $\mathrm{CO}_{2}$ monitoring.

\section{A.3.1 Projects within the EU}

The European approach to $\mathrm{CO}_{2}$ reduction in the field of electricity generation from fossil fuels does not differ fundamentally from the activities worldwide. Generally priority is given to increasing power station efficiency, which reduces specific $\mathrm{CO}_{2}$ emissions and in general also makes economic sense. Beyond this there are also numerous possibilities for $\mathrm{CO}_{2}$ capture, as discussed below. The measures differ in terms of technology, cost of capture (e.g. energy consumption and financial cost), development status and thus availability timeframe. The development perspectives in different countries also differ according to the respective political and economic framework. As well as increasing efficiency, reducing the cost of capture processes is also another leading goal.

Fig. A-5 shows the distribution of field trials in Europe by way of illustrating the technological development perspectives. Most field trials already in existence or in advanced stages of planning tend to follow economic frameworks. As can be seen from the map (Fig. A-5) there is a concentration of field trials among the numerous oil and gas fields of the North Sea. On the one hand, locations are found where the $\mathrm{CO}_{2}$ contained in raw natural gas has to be separated off when the gas is conditioned following extraction. On the other hand, project locations are also associated with the exploitation of oil fields, where $\mathrm{CO}_{2}$ is injected to boost falling recovery rates (enhanced oil recovery or EOR). It is not yet clear to what extent the use of compressed $\mathrm{CO}_{2}$ for EOR or EGR (enhanced gas recovery) can be regarded as a storage option.

There are considerably fewer field trials for $\mathrm{CO}_{2}$ capture from power station flue gases or for developing new power station concepts with subsequent $\mathrm{CO}_{2}$ transport and sequestration, because in these fields economic frameworks are not yet in sight. For one thing, $\mathrm{CO}_{2}$ capture at the power station requires a great deal of energy (reduced efficiency, increased fuel consumption), while for another there is still a great shortage of information concerning long-term behaviour (leakage, environmental impact).

Through its research programmes the European Union promotes the development and demonstration of technologies and measures for reducing and storing $\mathrm{CO}_{2}$. Activities concerning the field of energy are summarised at: http://europa.eu.int/comm/research/energy/ $\mathrm{nn} / \mathrm{nn}$ _rt/nn_rt_co/article_1150_en.htm.

1 Process whereby water molecules become attached to dissolved ions through electrostatic forces between the charged ions and the water dipoles.
There are national and international programmes for promoting CCS projects. In April 2005 the European Commission published the first draft of its seventh Research Framework Programme proposing a total of nine current research areas with a funding volume of $€ 2,951$ million for the period 2007-13. In the seventh Research Framework Programme -as was already the case in its predecessor - $\mathrm{CO}_{2}$ capture and storage ('near zero emission power generation') plays an important role in the field of energy research, and in absolute terms has actually increased considerably in importance (see also http://europa.eu.int/comm/index_de.htm).

Furthermore, as part of its initiative to create a European Research Area (ERA) the European Commission supports the EU-level coordination of corresponding national programmes, for example in the field of lowemissions power stations the ERA Net FENCO (Fossil Energy Coalition). In December 2005 the EU also started a new technology platform on ' $\mathrm{CO}_{2}$-free' power stations for fossil fuels.

The text box below outlines selected CCS research projects (in particular EU-funded projects) with information about their aims, timeframes and participating German research partners.

As well as the aforementioned research projects, Sleipner (Norway) and CRUST (Netherlands) represent two major European $\mathrm{CO}_{2}$ storage projects that are already operating commercially.

In the field of research into $\mathrm{CO}_{2}$ sequestration the following networks exist at the EU level:

$\mathrm{CO}_{2}$ GeoNet - This network focuses on geological $\mathrm{CO}_{2}$ storage. The members come from the spheres of science and industry.

$\mathrm{CO}_{2} \mathrm{NET}$ - The European networking development programme for geological $\mathrm{CO}_{2}$ storage, $\mathrm{CO}_{2}$ capture and zero-emissions technology has given rise to the European Carbon Dioxide Thematic Network $\left(\mathrm{CO}_{2} \mathrm{NET}\right)$, which networks the geological agencies of EU member states and other research institutes.

EuroGeoSurveys - Network supporting the EU by collecting the entirety of technical know-how of the geological agencies of EU member states and membership candidates.

Eurogif - Represents the European oil and gas service and supply industry. 'EUROGIF brings an industry perspective to the EU in terms of their formulation of both energy policy and Framework Programmes for sponsored research.' 
CASTOR: $\mathrm{CO}_{2}$ from capture to storage

$\mathrm{CO}_{2}$ storage in aquifers $/ \mathrm{CO}_{2}$ storage in hydrocarbon reservoirs / membranes / modelling and mapping / monitoring and verification / physical absorption / safety and environmental questions

Period: February 2004 - January 2008

Participants: BGR

$\mathrm{CO}_{2}$ SINK: Storage of $\mathrm{CO}_{2}$ from a biomass power station in aquifers (near Ketzin)

Modelling and mapping / monitoring and verification / safety and environmental questions

Period: April 2004-March 2009

Participants: GFZ, G.E.O.S, Stuttgart University, RWE Power AG

$\mathrm{CO}_{2}$ STORE: $\mathrm{CO}_{2}$ storage project in aquifers

Monitoring and verification

Period: 02/03-02/06

Participants: BGR

GESTCO: Assessment of European storage potential for $\mathrm{CO}_{2}$ from combustion of fossil fuels

Period: June 1999-December 2001

Participants: BGR

\section{ICBM: Investigation of a series of technical challenges in} sequestration of $\mathrm{CO}_{2}$ by the ECBM method (Enhanced Coal Bed Methane Recovery)

Period: 0ctober 2003-0ctober 2006

Participants: Deutsche Steinkohle AG

Dynamis: Towards Hydrogen and Electricity Production with Carbon Dioxide Capture and Storage

Goal of this project is to investigate possible ways of low-cost industrial hydrogen production with integrated $\mathrm{CO}_{2}$ capture and storage. Funding from the $\mathrm{EU}$ and a consortium of industrial partners

Period: 36 months starting March 2006

Participants: BGR
$\mathrm{CO}_{2}$-Geonet: European Network of Excellence on Geological Storage of $\mathrm{CO}_{2}$ Building on the findings of previous EU research projects, the partners in this network together coordinate development of $R \& D$ work in order to consolidate Europe's leading position in this field.

Period: April 2004-March 2009

Participants: BGR

ENCAP CO $\mathrm{O}_{2}$ : ENhanced CAPture of $\mathrm{CO}_{2}$ Development of low- $\mathrm{CO}_{2}$ power station concepts with $\mathrm{CO}_{2}$ capture before or integrated in combustion (low- $\mathrm{CO}_{2} \mathrm{IGCC}$, oxyfuel, membranes)

Period: March 2004-March 2009

Participants: RWE, Siemens

OxyCoal-AC: Programme to develop components (phase 1) and bring them together in a pilot plant (phase 2) for the oxyfuel process (combustion in oxygen), with development of high-temperature membrane methods

Funding from BMWA and BMWF

Period: September 2004-2007 (phase 1)

Participants: six departments at RWTH Aachen, RWE Power, E.ON, Siemens, Linde, WS-Wärmeprozesstechnik

RECOPOL: Trial $\mathrm{CO}_{2}$ storage (near Katowice) in uneconomic deep coal seams

Period: November 2001-November 2004

Participants: RWTH Aachen

ISCC: Innovative in $\mathrm{Situ} \mathrm{CO}_{2}$ Capture technology for solid fuel gasification The project has the aim of process-integrated capture of storable $\mathrm{CO}_{2}$ during lignite gasification $\left(\mathrm{C}_{2}>90 \%\right)$

Period January 2004-December 2006

Participants: Stuttgart University, IVD

GeoCapacity: Assessing European Capacity for Geological Storage of Carbon Dioxide

The goal of this project is to create a European information system on the distribution of $\mathrm{CO}_{2}$ sources and storage possibilities. The project integrates and builds on the results of preceding GESTCO and CASTOR projects, and adds in particular data for the new EU member states in eastern Europe. The research project is funded by the European Union and a consortium of industrial partners.

Period: January 2006-January 2009

Participants: BGR

\section{Research programmes of selected european states}

The UK government's CATS initiative (Carbon Abatement Technology Strategy) is a research and demonstration programme for furthering the development of 'zero-emission technologies' and increasing efficiency in the field of coal-fired power stations. This is a tenyear programme also focusing on international cooperation in this field.

Also in the UK the Carbon Capture and Storage Association (CCSA) has been founded. This is an alliance of companies - largely from the energy supply and plant engineering sectors - that are interested in working to develop geological storage and representing their interests in this field.
Also worth mentioning is the Dutch CCS research programme CATO $\left(\mathrm{CO}_{2}\right.$ Capture, Transport and Storage in the Netherlands), led by the Utrecht Centre for Energy Research (UCE) and supported by Dutch industry, research institutes, universities and environmental organisations. The goal of this programme is to demonstrate under what conditions CCS can be integrated in a sustainable energy system, taking into consideration economic, technical, social and ecological aspects. The programme has total funding of $€ 25.4$ million for the period from 2004 to 2008 .

In Norway offshore natural gas extraction is subject to a $\mathrm{CO}_{2}$ tax. In 1996 this led Statoil to begin storing $\mathrm{CO}_{2}$ coming out of the Sleipner gas field (where the extracted gas mixture contains $9 \% \mathrm{CO}_{2}$ ) in a saline aquifer located 
Fig. A-6:

Electricity generation using hydrogen at Peterhead, Scotland (BP Sustainability Report 2005)

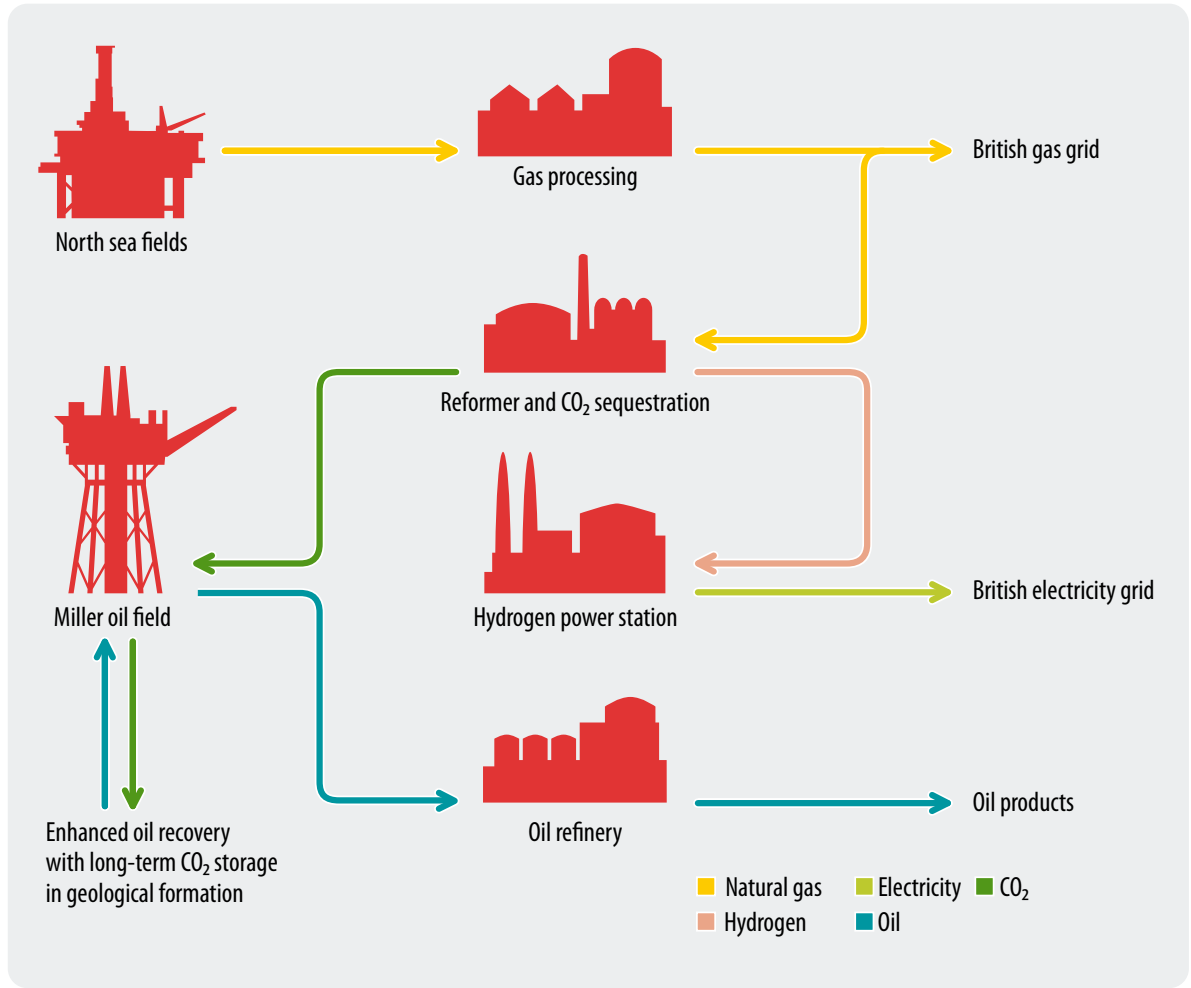

above the gas field (the Utsira Formation) (1 Mt/a). Furthermore Statoil and the Anglo-Dutch Shell company drew up plans to build a combined cycle power station at Tjeldbergodden in Norway by 2012 at the latest and transport the carbon dioxide emissions to the Draugen and Heidrun oil and gas fields where the captured $\mathrm{CO}_{2}$ was to be used for EOR/EGR, with the outcome of storing 2-2.5 $\mathrm{Mt} \mathrm{CO}_{2}$ annually. This project has, however, since been abandoned for reasons of cost.

The CRUST project, which has been operating since March 2005, represents the first attempt to inject $\mathrm{CO}_{2}$ into a gas field that is still producing. This pilot project has begun by storing 20,000 tonnes of $\mathrm{CO}_{2}$ annually; it is planned to increase that figure later to 480,000 tonnes per year. In terms of its approach the project can be designated as enhanced gas recovery (EGR), but its prime concern is in fact to research the migration behaviour of $\mathrm{CO}_{2}$ rather than actually to increase the gas recovery rate. The gas produced has a high $\mathrm{CO}_{2}$ share of approx. $13 \%$ (IEA 2005). The project is $90 \%$ funded by the Dutch Economics Ministry, so it has to date required little funding from the private sector (the remaining $10 \%$ are provided by Gaz de France).

CRUST involves capturing $\mathrm{CO}_{2}$ from the produced gas and then returning it into the reservoir. The Netherlands, incidentally, has a pricing regime for $\mathrm{CO}_{2}$-free electricity which in principle would also include electricity generated from fossil fuels, presuming the $\mathrm{CO}_{2}$ involved is withdrawn from the atmosphere.

An integrated project reforming natural gas to hydrogen and $\mathrm{CO}_{2}$ was planned by $\mathrm{BP}$ in conjunction with Cono-
coPhillips, Shell and Scottish and Southern Energy at Peterhead in Scotland (see Fig. A-6). The hydrogen was to be used to fuel a CC power station capable of generating electricity to supply more than 700,000 households. Per year 1.8 million tonnes of $\mathrm{CO}_{2}$ were planned to be transported offshore and injected into the Miller oil field at a depth of more than three kilometres below the seabed, which would extend the productive life of the oil field by fifteen to twenty years and increase the yield (BP 2005). Actually this plant is now to be built in the United Arab Emirates in Abu Dhabi. According to $\mathrm{BP}$, the UK government delayed its financial contribution (The Scotsman 2008).

\section{Development perspectives in Europe}

As well as the international and US-American information platforms and networks, the European Union offers information platforms and networks as part of its research programmes.

The establishment of the European Technology Platform for Zero Emission Fossil Fuel Power Plants (ETP ZEFFPP 2005) created a body to coordinate the measures required for reducing $\mathrm{CO}_{2}$ emissions from electricity generation. Fig. A-7 shows the organisational structure. The Strategic Research Agenda and Strategic Deployment Document produced by working parties define strategies for market introduction and for Europe to achieve the $\mathrm{CO}_{2}$ reduction goals, divided into immediate measures, measures to be taken by 2030 and beyond then. 


\section{Technology Platform ZEFFPP}

Organisational Structure

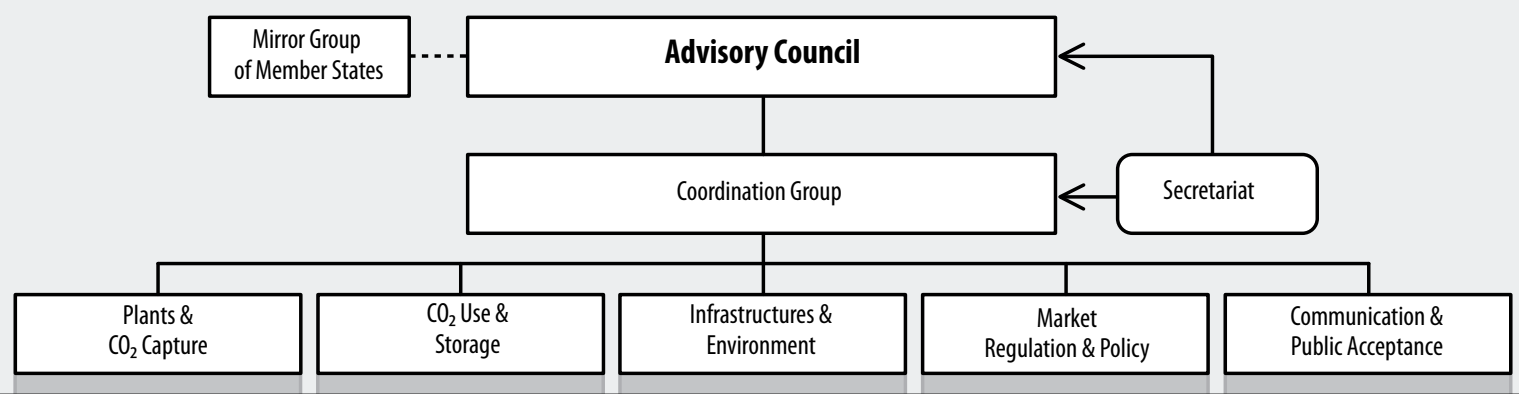

Strategic Research Agenda (SRA)

\section{Deployment Strategy (DS)}

\section{Technology Platform ZEFFPP}

Members of Advisory Council

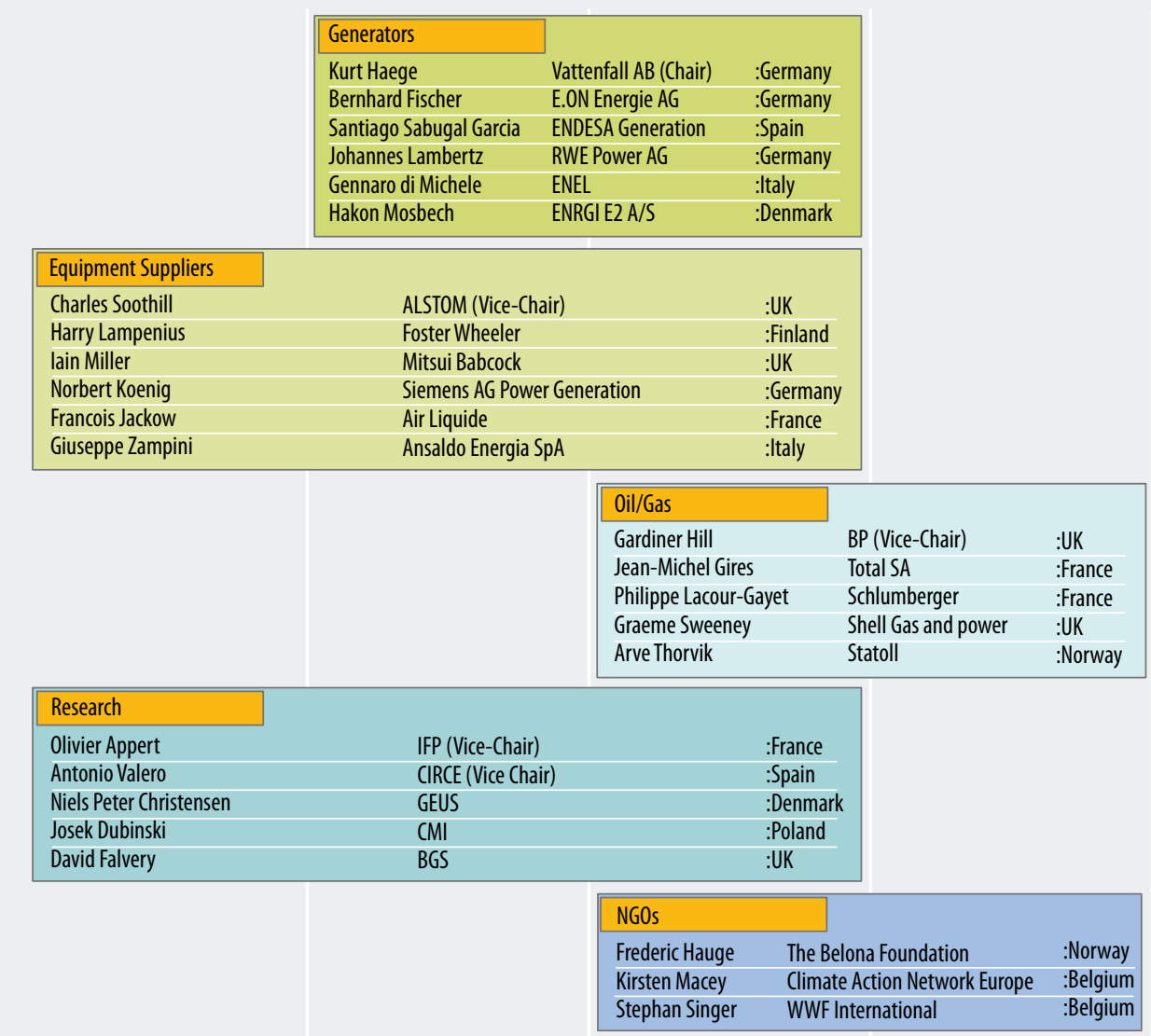

Fig. A-7: Organisational structure and members of the European Technology Platform for Zero Emission Fossil Fuel Power Plants (ZEFFPP) (http://ec.europa.eu/research/energy/pdf/zeffpp_power_plant_en.pdf) 
Fig. A-8:

CSLF project categories and research areas (Hake 2005)
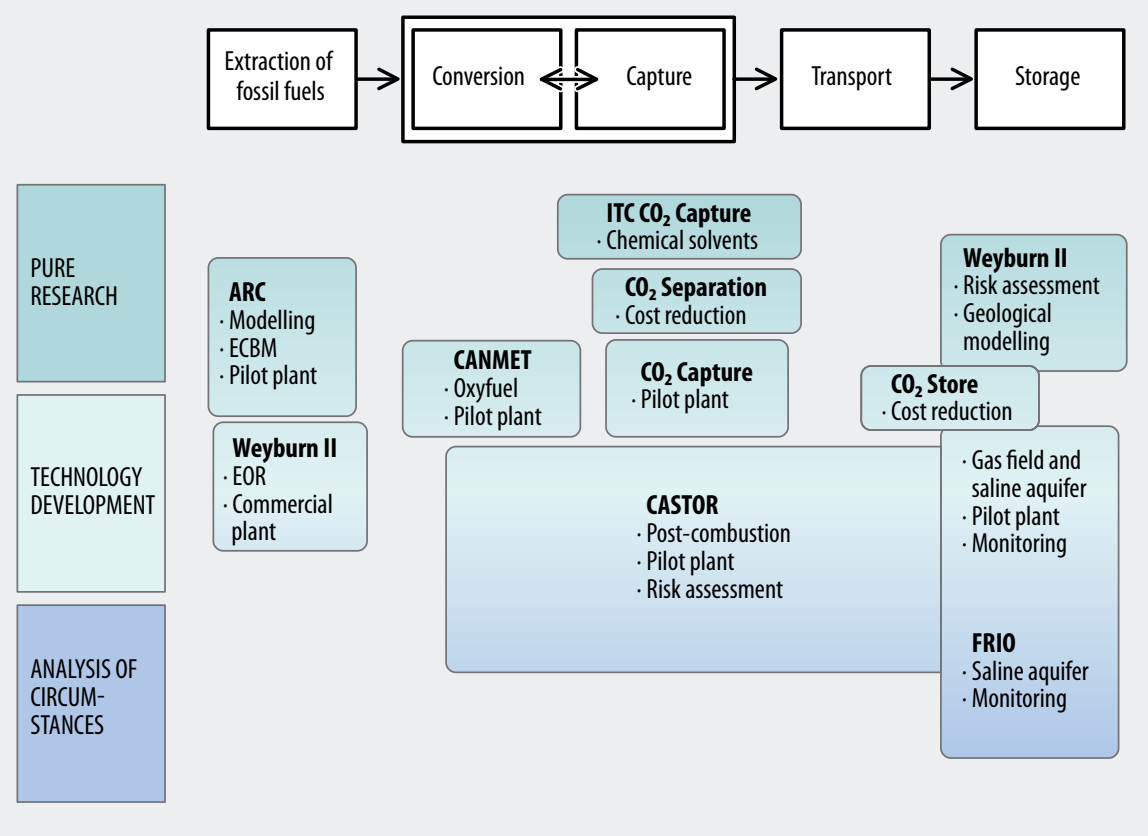

\section{A.3.2 International Activities and Political Strategies}

The Carbon Sequestration Leadership Forum (CSLF) is an internationally important climate protection alliance that was set up in 2003 on the initiative of the United States. The CSLF works for the development of cost-effective capture and storage technologies, lowcost $\mathrm{CO}_{2}$ transport and long-term stability of storage, and promotes the exchange of information about CCS activities in the field of climate protection. As well as the EU, twenty other states are also members of this initiative (www.cslforum.org). Currently about seventeen projects supported by the CSLF are under way across the world. Fig. A-8 shows the research priorities.

One of these projects is the Enhanced Coalbed Methane Recovery Project of the Alberta Research Council (ARC) in Canada, which is running a trial to investigate whether $\mathrm{CO}_{2}$ can be injected into a deep coal seam and how the methane released in the process can be used (ECBM). The results will be used as the basis for the development of China's Coalbed Methane Technology/ Carbon Dioxide Sequestration Project.

The International Energy Agency (IEA) is conducting the following work in the field of CCS: the Working Party on Fossil Fuels promotes the development of 'zero emissions technologies' and coordinates international cooperation and exchange in this field. The Clean Coal Centre stimulates the innovation and use of coal as a 'clean fuel' by identifying the potential of apparently suitable technologies, identifying open questions and jointly publishing the results of cooperative projects. The Greenhouse Gas R\&D Programme analyses and assesses various technical options for their potential for climate protection, and publishes the results.
Certain countries have set up their own CCS programmes; these are briefly outlined below. The Australian COAL 21 programme aims to reduce greenhouse gas emissions from electricity generation using coal through a joint initiative supported by the government, industry and research bodies.

The EU-China Partnership on Climate Change established in autumn 2005 includes an EU-China Action Plan on Clean Coal which seeks to promote joint development and implementation of 'near zero emission coal projects'. The first concrete agreement in this context was concluded in January 2006 between the UK and China: a three-year feasibility study will begin by examining the practicality of various concepts and investigating the options for geological storage of $\mathrm{CO}_{2}$. This shows that research efforts and also first practical steps in the field of CCS are beginning to extend beyond the EU and the United States.

The United States has published an internationally significant policy strategy in the form of the Carbon Sequestration Technology Roadmap and Program Plan (DoE 2003/2005), which covers the following three fields of research:

A. Core R\&D The goal of this programme is to advance sequestration research and develop new sequestration technologies through to the market launch phase. The core programme has five areas:

- $\mathrm{CO}_{2}$ capture,

- $\mathrm{CO}_{2}$ storage,

- Monitoring, mitigation and verification,

- Control of other greenhouse gases,

- New concepts. 


\section{$\mathrm{CO}_{2}$ sequestration projects in North America}

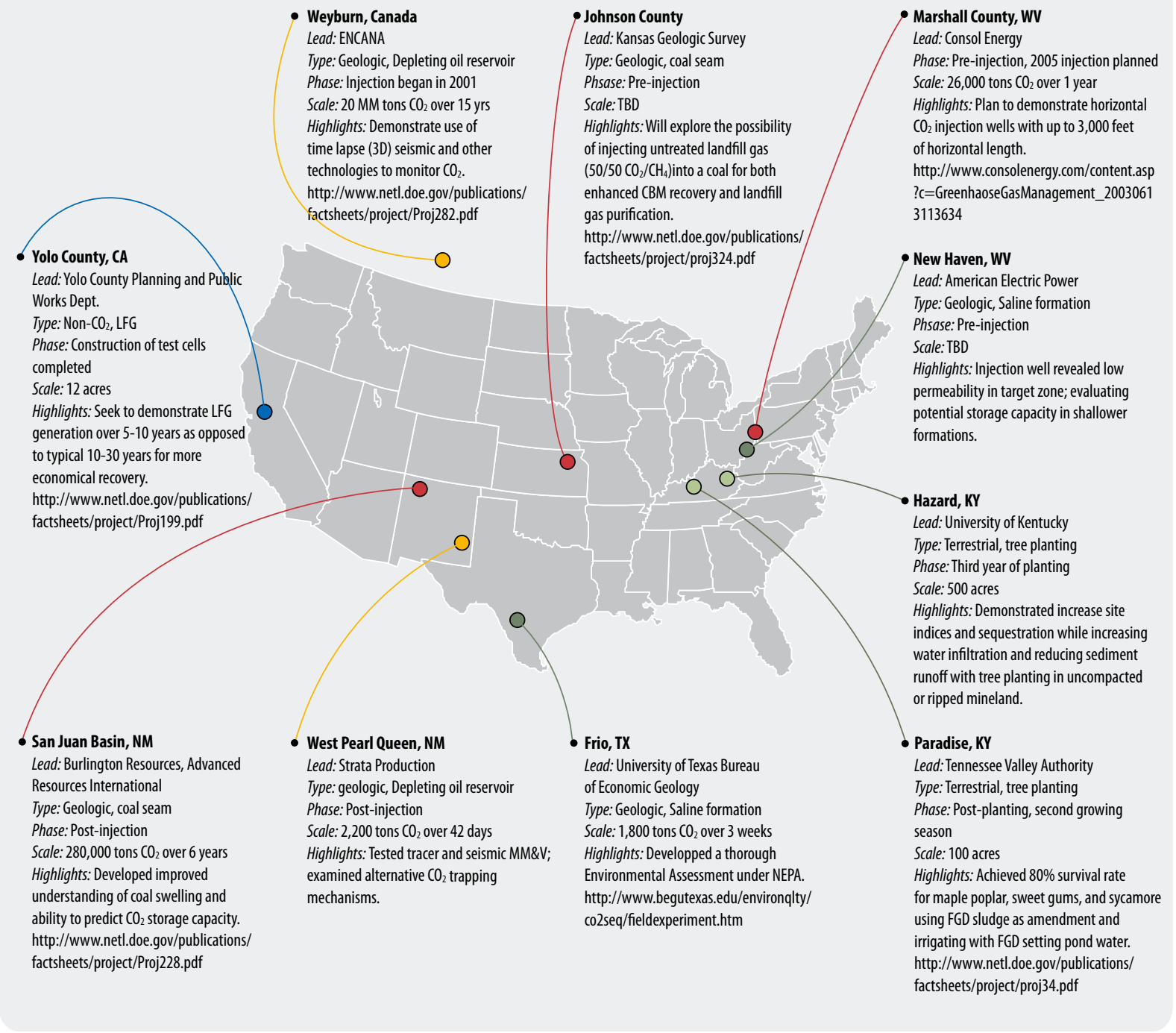

Fig. A-9: CCS demonstration projects in the United States (DoE 2005, Department of Energy)

These research areas are complemented by demonstration projects focusing on different aspects, see Fig. A-9.

B. Infrastructure development The US Department of Energy (DoE) in 2003 initiated seven regional $\mathrm{CO}_{2}$ sequestration partnerships with the goal of developing an infrastructure for future CCS pilot projects. This partnership has given rise to a national network of firms and experts aiming to advance the use of CCS, and to a Carbon Sequestration Atlas of the United States that identifies priority regions for CCS pilot projects.

C. Program management This is the R\&D management programme. In a bid to deploy its budget and pursue its research goals as effectively as possible, the DoE has set up public-private partnerships, and engaged in national and international cooperation, analyses and project evaluation, and proactive public relations work.

As part of the broad-based Clean Energy Programme, which has funding of almost $\$ 2,000$ million of which $80 \%$ is provided by the state, the DoE has launched the FutureGen venture with the aim of producing the prototype for a new commercial coal-fired power station technology. It involves the biggest electricity generating and coal mining corporations in the United States, including RAG AmericanCoal and Eon. The technology is to be based on coal gasification, aiming for efficiency of $60 \%$ and a $\mathrm{CO}_{2}$ capture rate of $90 \%$. As well as electricity, hydrogen is also to be generated for other applications, for example for fuel cells for road transport. The aim is to generate electricity at a cost no more than $10 \%$ higher than with current technologies. 
RAG Coal International is also involved in another research project in the United States, the Zero Emission Coal to Hydrogen Alliance (ZECA), which also tackles the issue of generating electricity from coal without $\mathrm{CO}_{2}$ emissions. The goal of this project is to safeguard coal's long-term future as a fuel. The starting point for the research is a process where the $\mathrm{CO}_{2}$ emissions produced when coal is burned to generate electricity are not released but fixed in mineral form. Initial experience is to be gathered from an industrial-scale power station based on fuel cell technology, which is to begin operating in the second half of this decade. Further details on the ZECA project can be found at www. zeca.org.

One commercially run storage project in the United States and Canada is found at the Weyburn oil field (Canada), where $\mathrm{CO}_{2}$ is used for enhanced oil recovery (EOR). ${ }^{2}$ The $\mathrm{CO}_{2}$ is supplied by a pipeline system from a gasification plant in North Dakota (USA). After injection it remains underground.

One place where $\mathrm{CO}_{2}$ is also already being used industrially is the Shady Point CHP plant in the state of Oklahoma, where 200 tonnes of $\mathrm{CO}_{2}$ daily are captured from a part of the flue gas and supplied to the food industry.

At Carson, California, there are plans to build a hydrogen power plant using oil coke. This would demonstrate that low- $\mathrm{CO}_{2}$ energy can be generated from coal, of which the United States has abundant reserves. After starting operation the Carson project would generate $500 \mathrm{MW}$ of low- $\mathrm{CO}_{2}$ electricity, enough to supply about 325,000 households in southern California. The plant is also to be used to sequester and permanently store about 4 million tonnes of $\mathrm{CO}_{2}$ annually. $\mathrm{BP}$ and the Edison Mission Group intend to make the final investment decisions in 2008 after preparation of detailed technical and commercial studies. If they go ahead the new power station could come on stream in 2011 (BP 2005).

The Greater Gorgon Gas Development in Australia is a project for gas extraction and subsequent LNG production operated by ChevronTexaco. For LNG production (planned annual volume 10 million tonnes) the $\mathrm{CO}_{2}$ present in the extracted gas must be removed. ${ }^{3}$ The rest of the extracted gas is transported on in gaseous form to the compressor. The $\mathrm{CO}_{2}$ to be injected arises largely from LNG production and in other energyintensive processes, while a smaller part is contributed by the $\mathrm{CO}_{2}$ in the extracted gas. The storage formation is a saline aquifer underneath Barrow Island, where the LNG plant will also be located. The storage project will cost at least AUS $\$ 300$ million (approx. $€ 180$ million). According to ChevronTexaco there is no obligation under Australian law to avoid $\mathrm{CO}_{2}$ emissions. The stated motivation is concern about climate change and the company's responsible attitude to greenhouse gas management (Gorgon 2005).

2 Process whereby water or $\mathrm{CO}_{2}$ is injected into boreholes to increase the oil recovery rate.

3 The $\mathrm{CO}_{2}$ would otherwise freeze and damage the equipment.
In Japan and Australia, too - as in most of the road maps - immediate measures to increase efficiency in new power stations are at the top of the agenda. Since 1995 there has been a continuous increase in the steam parameters of new power stations (pressure and temperature) (Santos and Davison 2006). Whereas shortto medium-term attention in Europe and the United States is focused on pre- and post-combustion measures, Japan has made an early choice to prioritise the introduction of fuel cell technologies in combination with coal gasification. Japan and Australia also cooperate in the fields of oxyfuel combustion and integrated drying gasification combined cycle (IDGCC), which is mainly being pursued in Australia. In the joint Hypercoal Project coal is to be demineralised in Australia and used in Japan for low-emissions energy generation.

Also worthy of note are projects initiated by BP/Sonatrach and ChevronTexaco that have already reached the planning stage. In a joint venture between $\mathrm{BP}$ and Sonatrach in Algeria, the In Salah $\mathrm{CO}_{2}$ Geological Storage Demonstration Project, the accompanying $\mathrm{CO}_{2}$ is separated out as the gas is produced in order to stay within the export specifications $\left(\mathrm{CO}_{2}\right.$ content $\left.<0.3 \%\right)$. The removed $\mathrm{CO}_{2}$ is not released into the atmosphere as usual but instead injected into a geological formation. All in all, 900,000 to 1,000,000 tonnes of $\mathrm{CO}_{2}$ annually are to be stored underground in this way. BP says it is motivated by the company's promise to reduce its climate-relevant emissions. BP has an internal emissions trading system where the stored $\mathrm{CO}_{2}$ can then be converted into certificates. It should be emphasised that most of the $\mathrm{CO}_{2}$ emissions originate from energy-consuming processes, and the $\mathrm{CO}_{2}$ from the extracted gas represents only a small proportion (IEA 2005).

Research into $\mathrm{CO}_{2}$ sequestration also includes the following networks:

Monitoring Network - Founded on 8 November 2004 at a meeting at the University of California Santa Cruz organised by the IEA GHG and BP with the support of EPRI and the American Department of Energy (DoE/ NETL).

International Network for $\mathbf{C O}_{2}$-Capture - The IEA GHG set up the $\mathrm{CO}_{2}$ Capture Network to serve as a forum and to support research projects in the field of capture. All the members are industrial companies.

International Network on Biofixation of $\mathrm{CO}_{2}$ and Greenhouse Gas Abatement with Microalgae - The purpose of the Microalgae Biofixation Network is to offer a platform for organisations interested or involved in $\mathrm{R} \& \mathrm{D}$ work aiming to reduce greenhouse gases using microalgae. Members come from the spheres of science and industry and from the American Department of Energy.

ZECA Zero Emission Coal Alliance - A consortium from the United States and Canada composed of eighteen members from government, research organisations and the coal industry. Its purpose is to advance the 

German projects in the geotechnologies R\&D programme of the Federal Ministry of Education and Research Focusing on
'Exploration, Use and Protection of Underground Resources'

$\mathrm{CO}_{2}$-TRAP: Development and evaluation of innovative strategies for permanent storage of $\mathrm{CO}_{2}$ in geological formations

RWTH Aachen, Bayreuth University, Stuttgart University, RWE-DEA AG (Hamburg), RWE Power AG (Cologne), Saar Energie GmbH (Saarbrücken), Deutsche Steinkohle AG (Herne), Deutsche Montan Technologie (Essen)

Enhanced Gas Recovery (EGR): Storage of $\mathrm{CO}_{2}$ in deep natural gas deposits with the possibility of enhanced gas recovery - a feasibility study Clausthal Technical University, BGR (Hannover), Vattenfall Europe, EEG (Gommern), E.ON-Ruhrgas, Wintershall (Kassel)

COSMOS: $\mathrm{CO}_{2}$ storage and development of monitoring and safety technologies

GeoForschungsZentrum Potsdam, Deutsches Brennstoff Institut - Gastechnologisches Institut GmbH (dbi-gti), Vattenfall Europe Mining AG (Cottbus), Karlsruhe University, RWE Power AG (Essen)

RECOBI0: Recycling of $\mathrm{C}_{2}$ through microbial biochemical conversion into methane $\left(\mathrm{CH}_{4}\right)$ deep underground

GEOS-Freiberg Ingenieurgesellschaft mbH, Dresdner Grundwasserforschungszentrum e.V. (DGFZ)

CDEAL: Fixing $\mathrm{CO}_{2}$ through mineral reactions in acid pit water and flooded disused pits in an open-cast lignite mining area

Freiberg University of Mining and Technology
$\mathrm{CO}_{2} \mathrm{CRS}$ : High-resolution underground imaging for $\mathrm{CO}_{2}$ storage using the CRS method

Trappe Erdöl Erdgas Consultant (Isernhagen), Karlsruhe University, Free University of Berlin

Development of the SPIN instruments system for exploration and monitoring for underground $\mathrm{CO}_{2}$ storage using nuclear magnetic resonance Geohydraulik Data, TU Berlin, FH Gelsenkirchen

CHEMKIN: Real-time monitoring of the chemical and kinetic behaviour of carbon dioxide during geological sequestration

GeoForschungsZentrum (Potsdam), Umwelt- und Ingenieurtechnik GmbH (Dresden), Potsdam University, Clausthal Technical University, Optimare $\mathrm{GmbH}$ (Wilhelmshaven).

Numerical investigations of $\mathrm{CO}_{2}$ sequestration in geological formations problem-based benchmarks

Stuttgart University, Deutsche Montan Technologie (Essen)

$\mathrm{CO}_{2}$-UGS-Risks: Integrated safety and risk analysis of $\mathrm{CO}_{2}$ storage in Germany

Gesellschaft für Anlagen- und Reaktorsicherheit (GRS) mbH (Braunschweig) development of new and highly efficient technologies for electricity generation and/or hydrogen production from coal 'with zero atmospheric emissions'.

EnergyNet - A national Canadian network covering the spheres of science and industry and government ministries for developing future perspectives and new technologies to open up a broad supply of affordable and environmentally sound energy.

\section{A.3.3 CCS Projects in Germany}

In Germany too, projects in the field of $\mathrm{CO}_{2}$ capture and storage are already being conducted or are under development. In addition German institutions are also involved in various EU-wide research projects (see chapter 17.3.1).

One particularly important project is the EU-funded $\mathrm{CO}_{2}$ Sink led by the Potsdam-based Geoforschungsinstitut, where $\mathrm{CO}_{2}$ is injected into a geological formation under real conditions. Seventeen different partners are now involved in this project, including power companies. Storage is in a porous geological formation underneath an underground storage facility for natural gas at Ketzin near Berlin. One of the aims is to use different monitoring methods to track the behaviour of the stored gas and thus gain knowledge about long-term stability.
In its research and development programme GEOTECHNOLOGIEN the Federal Ministry of Education and Research has since March 2005 been funding ten interdisciplinary research groups from scientific institutes and private industry with almost $€ 7.5$ million. The goal of this research programme, which is initially to run for three years, is to examine the technological, ecological and economic perspectives of underground storage of the greenhouse gas $\mathrm{CO}_{2}$ (see the overview in the text box).

The Federal Ministry of Economics initiated the COORETEC research concept, which is designed to lead to the realisation of low-emissions fossil-fuelled power stations through an alliance of partners from the spheres of science and industry. The programme aims to show how the technologies required for highly efficient, largely emissions-free and economic coal- and gas-fired power stations could be developed by 2020. One offshoot of this programme is the COORIVA research project $\left(\mathrm{CO}_{2}\right.$ reduction through integrated gasification and capture), whose aim is to develop an IGCC concept making use of experience already gathered in industrial-scale projects and integrating $\mathrm{CO}_{2}$ capture. In parallel investigations are already under way into the potential of gasification of lignite and coal, the creation of modelling tools and upscaleable studies.

Among the power companies, RWE has announced the construction of an IGCC plant with $\mathrm{CO}_{2}$ capture by 
2014, and in May 2006 Vattenfall began building a demonstration oxyfuel power station at Schwarze Pumpe, which is due to begin operations in 2008.

\section{A.4 Central Issues for Planning a $\mathrm{CO}_{2}$ Transport Infrastructure (to Chapter 8)}

Central questions that could guide the process of designing and setting up a $\mathrm{CO}_{2}$ transport infrastructure are listed below:

1. What are the similarities and differences in the handling of natural gas and $\mathrm{CO}_{2}$ ?

- physical and thermodynamic properties,

- risk management,

- corrosion,

- pipeline transport (pressure, cross-section, volume and mass flows, compressor capacity).

2. Where is experience with handling and transporting $\mathrm{CO}_{2}$ or with transporting gases with similar properties (e.g. LPG) located already?

3. Who is likely to be operating $\mathrm{CO}_{2}$ pipelines?

4. What combinations of onshore/offshore transport systems are conceivable (e.g. onshore pipelines + main pipeline + intermediate storage + ship loading $+\ldots)$ and which of these make sense?

5. What infrastructure questions arise (loading/ unloading systems, competition with existing shipping, etc.)?

6. What selection of route makes sense (in economic and ecological terms and in relation to questions of risk and acceptance)?

7. How many compressor stations (electrical/gaspowered) must be constructed, and where?

8. What questions are relevant for cost analysis?

- $€$ per kilometre of pipeline (as function of diameter, pressure, volume/mass flows, topography...).

- € per tonne-kilometre of transported $\mathrm{CO}_{2}$ (as function of phase, capacity, maturity of technology ...).

- Cost of additional equipment (liquefiers, compressors, collectors, measuring stations...).

9. What might the learning curves for $\mathrm{CO}_{2}$ pipelines look like (individual pipelines, networks, etc.)?

10. What questions are relevant when analysing the timeframe?

- When could which power stations and $\mathrm{CO}_{2}$ sinks come into operation?

- When will which sinks be full?
- How long would it take to set up a $\mathrm{CO}_{2}$ pipeline infrastructure (time for planning, approval and construction)?

- When will which $\mathrm{CO}_{2}$ intermediate storage facilities be required, and when will they be available (for offshore ship transport and onshore road and rail transport)?

11. What approval procedures and planning periods are generally required for building new pipelines or expanding existing ones?

12. What problems can arise if $\mathrm{CO}_{2}$ pipelines are constructed parallel to existing natural gas pipelines (e.g. space requirement where route is narrow, acceptance if additional forest clearance necessary)?

13. What $\mathrm{CO}_{2}$-specific requirements are the pipeline network and components such as compressors, measuring stations subject to in terms of safety, corrosion, etc.?

14. Where $\mathrm{CO}_{2}$ is transported in the supercritical state: is it sufficient to compress once at the beginning (at the power station) or are additional compressor stations required? If so, after what distances or pressure losses?

15. Might disused town gas pipelines be suitable for $\mathrm{CO}_{2}$ transport (following conversion)? If so, what is their geographical distribution (transport from where to where) and what transport capacities do they provide?

\section{A.5 Data Used for Analysing Mass Flows of Fuel and $\mathrm{CO}_{2}$ (to Chapter 10)}

See Tables A-3 and A-4. 

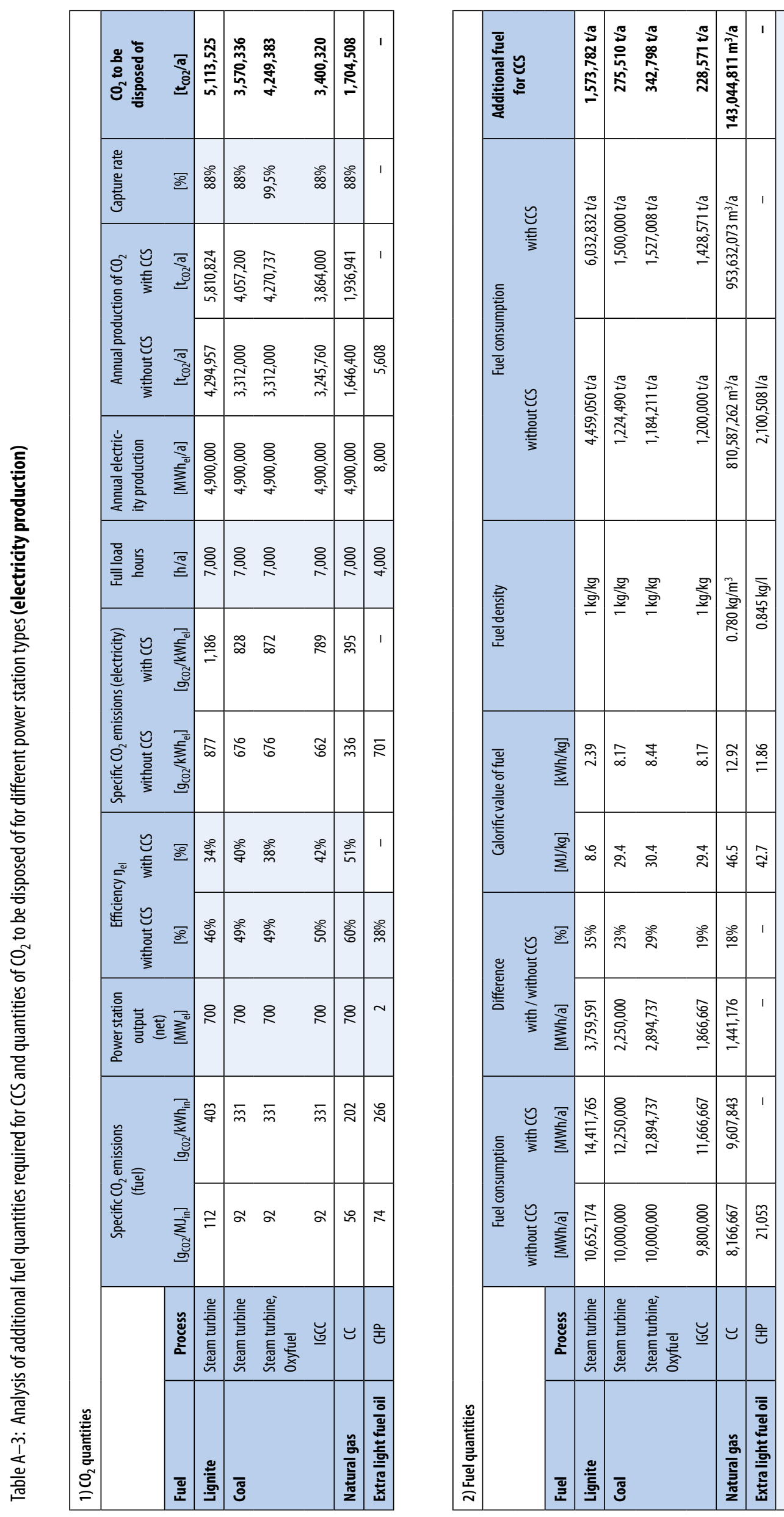

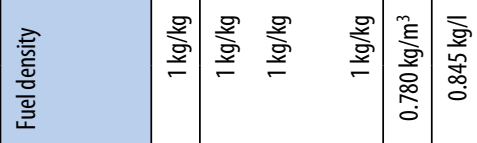

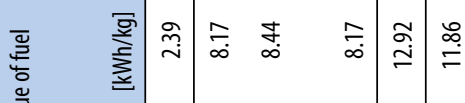

产

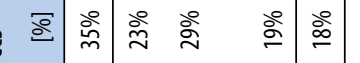

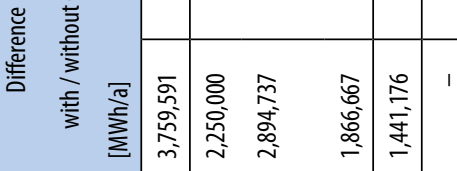

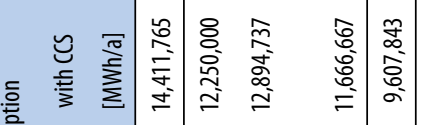

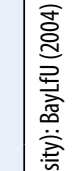

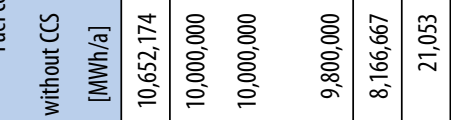

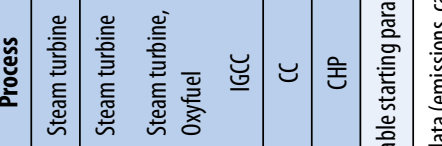

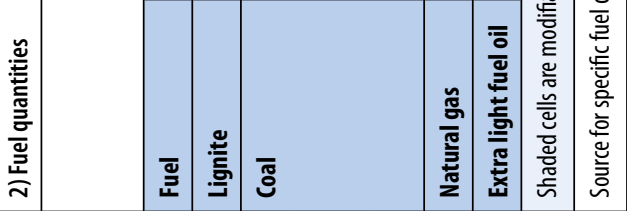




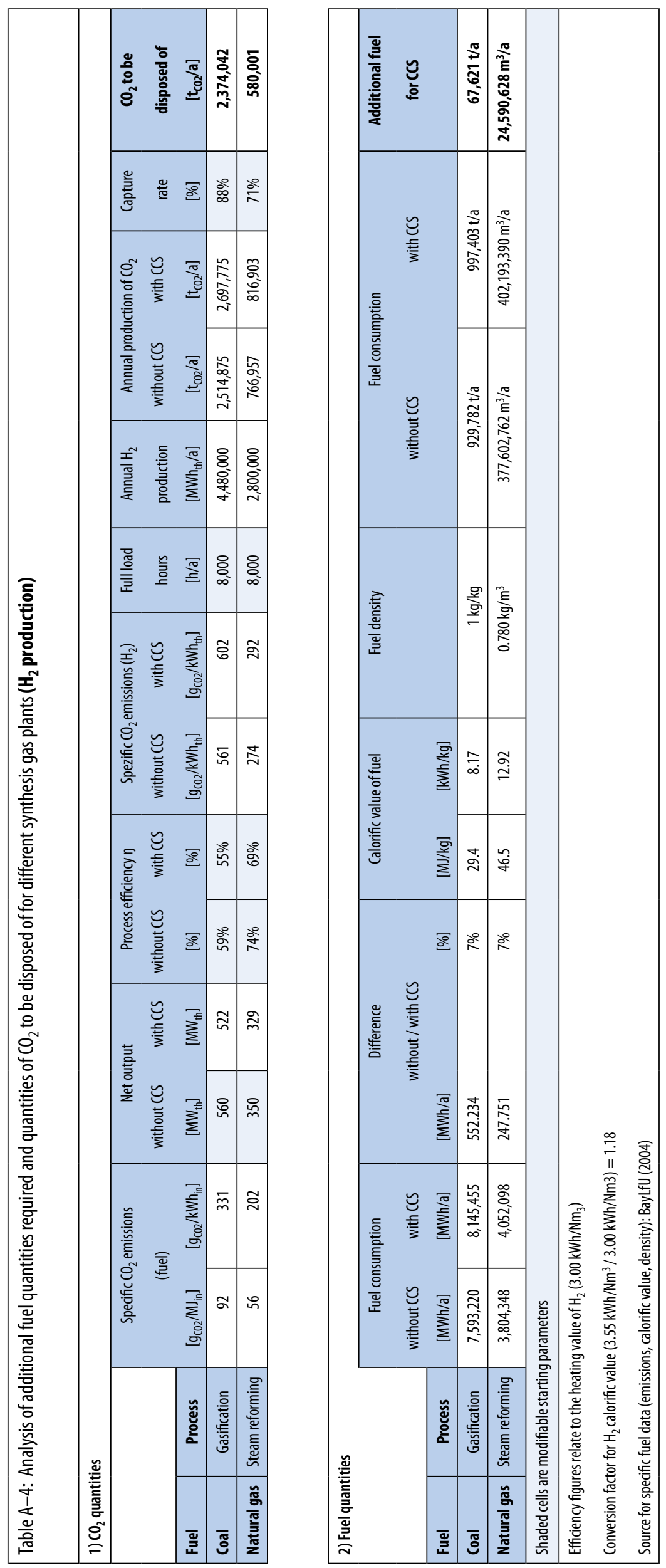




\section{References}

Air Liquide (2005): Personal communication

Arbeitsgruppe Schiffe der Zukunft (2002): Schlussbericht an die Zentralkommission für die Rheinschifffahrt, Straßburg: Zentralkommission für die Rheinschifffahrt

Azar, C.; Schneider, S. (2002): Are the economic costs of stabilizing the atmosphere prohibitive? Ecological Economics 42, 1-2: 73-80

BMVBW (2004): Verkehr in Zahlen 2004/2005, Hamburg

Bündnis 90/Die Grünen (2001): Vom atomaren zum solaren Zeitalter. Das Zukunftsenergieprogramm Bundestagsfraktion Bündnis90/Die Grünen. Dated 12/2001. Berlin

Bündnis 90/Die Grünen (2003): Grüne Eckpunkte für ein Reformprogramm in der Energiepolitik. Resolution passed on 11 Nov 2003. Berlin

Bündnis 90/Die Grünen (2006): Für einen radikalen Realismus in der Ökologiepolitik. 26. Ordentliche Bundesdelegiertenkonferenz, 1-3 Dec 2006, Cologne

Backhaus, C.; Meyer, J.; Spangardt, G. (2002): Energetische Nutzung von Grubengas. Fraunhofer UMSICHT. Vortrag. www.wupperinst.org/download/TerraTec-2003/Meyer.pdf (17 Feb 2006)

Bauer, N.; Edenhofer, O.; Held, H.; Kriegler, E. (2004): Uncertainty of the Role of Carbon Capturing and Sequestration within Climate Change Mitigation Strategies. Accepted for publication in: Rubin, E. S.; Keith, D. W.; Gilboy, C. F. (eds.): Proceedings of the 7th International Conference on Greenhouse Gas Control Technologies. Volume 1: Peer-reviewed Paper and Plenary Presentations, IEA Greenhouse Gas Programme, Cheltenham, UK

Bauer, N. (2005): Carbon Capturing and Sequestration - An Option to Buy Time? Ph.D. Thesis. University of Potsdam

Bundesministerium für Wirtschaft und Arbeit (BMWA, now BMWi) (2003): Forschungs- und Entwicklungskonzept für emissionsarme fossil befeuerte Kraftwerke. Bericht der COORETECArbeitsgruppen. BMWA-Dokumentation No. 527. Berlin

Bundesministerium für Wirtschaft und Technologie (BMWi), Bundesministerium für Umwelt, Naturschutz und Reaktorsicherheit (BMU), Bundesministerium für Bildung und Forschung (BMBF): Entwicklungsstand und Perspektiven von CCS-Technologien in Deutschland. Gemeinsamer Bericht des BMWi, BMU und BMBF für die Bundesregierung. Berlin, September 2007

BMWi 2007: Sozioökonomische Begleitforschung zur gesellschaftlichen Akzeptanz von Carbon Capture and Storage (CCS) auf nationaler und internationaler Ebene. Studie des Wuppertal Instituts für Klima, Umwelt, Energie (WI) in Kooperation mit dem Forschungszentrum Jülich (STE) und dem Fraunhofer ISI im Auftrag des Bundesministerium für Wirtschaft und Technologie (BMWi) 2007

BMU (2004): Nitsch, J.; Reinhardt, G.; Fischedick, M. et al. (2004): Ökologisch optimierter Ausbau der Nutzung erneuerbarer Energien in Deutschland. Untersuchung im Auftrag des BMU, Arbeitsgemeinschaft DLR/IFEU/WI, Berlin, March 2004

BMU 2005: Nitsch, J.; Fischedick, M.; Staiß, F. (2005): Aktualisierung und Detaillierung des Ausbaus erneuerbarer Energien im Stromsektor mit differenzierter Ermittlung der Vergütungszahlungen und der Differenzkosten durch das EEG. Untersuchung im Auftrag des BMU, Stuttgart, Wuppertal, August 2005

BMU (2006): Staiss, F.; Nitsch, J.; Lutz, C.; Edler C. et al. (2006): Wirkungen des Ausbaus erneuerbarer Energien auf den deutschen Arbeitsmarkt unter besonderer Berücksichtigung des Außenhandels. Studie von ZSW, DLR, DIW, GWS; im Auftrag des BMU, Berlin, August 2006

Bock, B.; Rhudy, R.; Nichols, D. (2001): Economic Evaluation of $\mathrm{CO}_{2}$ Sequestration Technologies. Semi-annual Technology Progress Report. DE-FC26-00NT40937. Tennessee Valley Authority. Muscle Shoals

BP (2005): Making Energy More, Sustainability Report 2005. London 
Briem, S.; Blesl, M.; Corradini, R.; Eltrop, L.; Fahl, U.; Gürzenich, D.; Krewitt, W.; Ohl, M.; Mörschner, J.; Richter, S.; Tryfonidou, R.; Viebahn, P.; Voß, A.; Wagner, H.-J. (2004): Lebenszyklusanalysen ausgewählter zukünftiger Stromerzeugungstechniken. Informationsschrift der VDI-Gesellschaft Energietechnik. VDI-Verlag, Düsseldorf. ISBN 3-931384-50-0

Bruno, I. (2003): Ecobalance of a Wind Turbine: LCA Approach. Thesis submitted at Università degli studi di Roma. Rome

BUND (2005): Presentation by Thorben Becker, BUND: BMU expert meeting „Vergleichende Analyse von Maßnahmen zur $\mathrm{CO}_{2}$-Minderung bei modernen Kraftwerkstechnologien und der Nutzung regenerativer Energien im Kontext einer klimaverträglichen Energieversorgung“. 31 March 2005, Berlin

BUND (2006): Bund für Umwelt und Naturschutz Deutschland: BUND Position. $\mathrm{CO}_{2}$-Abscheidung in fossilen Kraftwerken. Berlin

Bundesregierung (2004): Perspektiven für Deutschland. Unsere Perspektiven für eine nachhaltige Entwicklung. Berlin

CAN Europe (2006): CAN Europe Principles on $\mathrm{CO}_{2}$ Capture and Storage (CCS), Brussels, May 2006

CDU (2004): Christlich Demokratische Union, telephone interview with Ms Bendig, CDU spokesperson on energy policy, on 21 Oct 2004

Celia, M. A.; Scherer, G. (2004): Leakage Through Existing Wells: Models, Data Analysis and Lab Experiments, Presentation from the Third CMI (Carbon Mitigation Initiative) Annual Meeting 2004, Princeton Environmental Institute, January 2004

Chapel, D. G.; Mariz C. L. (1999): Recovery of CO from Flue Gases: Commercial Trends. Aliso Viejo

Chataignere, A.; Boulch, D. L. (2003): Wind Turbine (WT) Systems. In: ECLIPSE - Environmental and Ecological Life Cycle Inventories for Present and Future Power Systems in Europe. Final Report. www.eclipse-eu.org/pubres_guide.html (29 Sept 2006)

Christensen, N.; Holloway, S. (2004): GESTCO - Geological Storage of $\mathrm{CO}_{2}$ from Combustion of Fossil Fuel. Summary Report of the GESTCO-Project to the European Commission, Brussels

Chomenko, B. (2005): Eisenbahnkarte von Deutschland, http://www.bueker.net/trainspotting/index. php (05.09.2005)

de Figueiredo, M.; Reiner, D.; Herzog, H.; Oye, K. (2006): The Liability of Carbon Dioxide Storage. Eighth International Conference on Greenhouse Gas Technologies, Trondheim, Norwegen

Dietrich, L.; Bode, S. (2005): $\mathrm{CO}_{2}$-Abscheidung und Ablagerung (CAA): Ordnungsrechtliche Aspekte und ökonomische Implikationen im Rahmen des EU-Emissionshandels. HWWA Discussion Paper 327. Hamburg, Hamburgisches Welt-Wirtschafts-Archiv

Dijkstra J. W., Jansen D. (2002): Novel Concepts for $\mathrm{CO}_{2}$ Capture with SOFC, 6th International Conference on Greenhouse Gas Control Technologies (GHGT-6), 30 Sept - 4 Oct 2002, Kyoto, Japan

DIW (2006): DIW Wochenbericht No. 35/2006, Berlin

DLR (2006): Deutsches Zentrum für Luft- und Raumfahrt: Trans-Mediterranean Interconnection for Concentrating Solar Power (TRANS-CSP). Final Report. http://www.dlr.de/tt/trans-csp (21.07.2006). Stuttgart

DoE (2003): United States Department of Energy: Carbon Sequestration, Technology Roadmap and Program Plan. www.netl.doe.gov/coalpower/sequestration (07.06.2004)

DoE (2005a): U.S. Department of Energy, Office of Fossil Energy, National Energy Technology Laboratory: Carbon Sequestration - Technology Roadmap and Program Plan 2005 http://www. netl.doe.gov/publications/carbon_seq/2005_roadmap_for_web.pdf

DoE (2005b): U.S. Department of Energy, Office of Fossil Energy, National Energy Technology Laboratory: Life-Cycle Analysis of Greenhouse Gas Emissions for Hydrogen Fuel Production in the United States from LNG and Coal. Prepared by J. Ruether, M. Ramezan, E. Grol. http://www. netl.doe.gov/energy-analyses/pubs/H2_from_Coal_LNG_Final.pdf (15.09.2006)

Dubbel (1990): In : Beitz, W.; Küttner, K.-H. (eds.): Dubbel - Taschenbuch für den Maschinenbau. 17th edition; Springer Verlag, Berlin 1990 
ECOFYS (2004): Hendriks, C., Graus, W., van Bergen, F.: Global Carbon Dioxide Storage Potential and Costs. Ecofys, commissioned by the Rijksinstituut voor Volksgezondheit en Milieu, EEP-02001, Utrecht 2004. http://www.ecofys.com/com/publications/documents/GlobalCarbonDioxide Storage.pdf (27 Aug 2004)

ecoinvent (2005): ecoinvent data v1.01. CD-ROM des Schweizer Zentrums für Lebenszyklusdaten. www.ecoinvent.ch. Dübendorf

Economist (2006): The Economist, 22 Apr 2006, 67.

Edenhofer, O.; Held, H.; Bauer, N. (2004): A Regulatory Framework for Carbon Capturing and Sequestration within the post-Kyoto Process. In: E.S. Rubin, D.W. Keith and C.F. Gilboy (eds.), Proceedings of 7th International Conference on Greenhouse Gas Control Technologies. Volume 1: Peerreviewed Papers and Plenary Presentations. Cheltenham, UK: IEA Greenhouse Gas Programme

Edenhofer, O.; Bauer, N.; Kriegler, E. (2005): The Impact of Technological Change and Welfare: Insights from the Model MIND. Ecological Economics 54: 227-292

Edenhofer, O.; Lessmann, K.; Kemfert, C.; Grubb, M.; Köhler, J. (2006): Induced Technological Change: Exploring Its Implications for the Economics of Atmospheric Stabilization: Synthesis Report from the Innovation Modeling Comparison Project. The Energy Journal Special Issue Endogenous Technological Change and the Economics of Atmospheric Stabilization. Pp. 57-107

Eggleston (2006): Estimation of Emissions from $\mathrm{CO}_{2}$ Capture and Storage: the 2006 IPCC Guidelines for National Greenhouse Gas Inventories. http://unfccc.int/files/meetings/workshops/other_ meetings/2006/application/pdf/ccs_20060723.pdf

Enquete-Kommission (2002): „Nachhaltige Energieversorgung“ des deutschen Bundestages: Nachhaltige Energieversorgung unter den Bedingungen der Globalisierung und der Liberalisierung, Abschlussbericht, Deutscher Bundestag, Drucksache 14/9400

EPPSA (2006): European Power Plant Suppliers Association: EPPSA's $\mathrm{CO}_{2}$ Capture Ready Recommendations. Brussels, 7 Dec 2006 (living document)

ETP ZEFFPP (2005): http://europa.eu.int/comm/research/energy/pdf/zeffpp_power_plant_en.pdf

EU (2001): Directorate-General Energie und Transport der Europäischen Union: Green Paper. Towards a European Strategy for the Security of Energy Supply. Office for Official Publications of the European Communities, Luxembourg

EU (2006): Europäische Kommission: Grünbuch. Eine europäische Strategie für nachhaltige, wettbewerbsfähige und sichere Energie. Brussels, 8 March 2006

EWI/Prognos (2005): in: Bartels, M.; Hofer, P. et al.: Energiereport IV - Die Entwicklung der Energiemärkte bis zum Jahr 2030. Energiewirtschaftliche Referenzprognose 2030. Untersuchung im Auftrag des BMWT, Cologne, Basel, April 2005.

EWI/Prognos (2006): in: Lindenberger, D.; Bartels, M. et al.: Auswirkungen höherer Ölpreise auf Energieangebot und -nachfrage. Ölpreisvariante der Energiewirtschaftlichen Referenzprognose 2030. Prognos/EWI, Untersuchung im Auftrag des BMWT, Cologne, Basel, August 2006

Fahrni, R. (2002): An Overview of Hydrogen Production Methods and Costs Today. ETH Zurich, Institut für Energietechnologien, Zurich, April 2002

Fell, Hans-Josef (2003): „Clean Coal“: Die Renaissance des Klimakillers Kohle! In: Solarzeitalter. $2 / 2003$

FDP (2003): Freie Demokratische Partei: Antrag von FDP-Abgeordneten des Deutschen Bundestags, Drucksache 15/2194, 15. Wahlperiode, 10 Dec 2003

Feely, Richard A.; Christopher, Sabine; Kitack, Lee; Berelson, Will; Kleypas, Joanie; Fabry, Victoria J.; Millero, Frank J. (2004): Impact of Anthropogenic $\mathrm{CO}_{2}$ on the $\mathrm{CaCO}_{3}$ System in the Oceans. Science, Vol. 305, 16 July 2004

Fischedick, M.; Günster, W.; Fahlenkamp, H.; Meier, H-J.; Neumann, F.; Oeljeklaus, G.; Rode, H.; Schimkat, A.; Beigel, J.; Schüwer, D. (2006): $\mathrm{CO}_{2}$-Abtrennung im Kraftwerk. Ist eine Nachrüstung sinnvoll? VGB PowerTech 4/2006, pp. 1-10

Fleisch, T.; Quigley, T. (2000): Technologies for the Gas Economy. Paper presented at Energy Frontiers International Members Conference „Gas to Market Options", San Francisco, C.A.

Forum Umwelt und Entwicklung (2001): Der Wald allein wird das Klima nicht retten, AG Wälder position paper, 20 July 2001 
Fritsche, Uwe R.; Rausch, Lothar; Schmidt, Klaus (2007): Treibhausgasemissionen und Vermeidungskosten der nuklearen, fossilen und erneuerbaren Strombereitstellung. Arbeitspapier. Darmstadt. www.oeko.de/publikationen/forschungsberichte/studien/dok/657.php

FZ Jülich (2006): in: Linßen, J.; Markewitz, P.; Martinsen, D.; Walbeck, M.: Zukünftige Energieversorgung unter den Randbedingungen einer großtechnischen $\mathrm{CO}_{2}$-Abscheidung und Speicherung. Abschlussbericht des Forschungsvorhabens FKZ 0326889 im Auftrag des Bundesministeriums für Wirtschaft und Technologie

Gale, J. (2002): IPCC Workshop for Carbon Capture and Storage 18.-21.11.2002 in Regina, Canada: Overview of $\mathrm{CO}_{2}$ emission sources, potential, transport and geographical distribution of storage possibilities

Geologischer Dienst NRW (2006): Geo-Know-how macht Grubengas nutzbar. www.gd.nrw.de/ w_schr01.htm (17.02.2006)

Gerling, J. P. (2004): COORETEC - CO -Speicherung, in: Dokumentation des Fachkongresses „Innovative Technologien zur Stromerzeugung - auf dem Weg zu CO -freien Kohle- und Gaskraftwerken“ vom 10.-12. Mai 2004. Berlin. http://www.kraftwerkskongress.de/deu/index.htm

Gerling, P.; May, F. (2001): Anhörung der Enquete-Kommission „Nachhaltige Energieversorgung“ zum Thema Innovative Energietechnologien und -systeme am 20.11.2001, Kommissionsdrucksache $14 / 111-2$

Germanwatch (ed.) (2004): In: Duckat, R.; Treber, M.; Bals, C.; Kier, G.: CO -Abscheidung und -Lagerung als Beitrag zum Klimaschutz, Ergebnisse des „IPCC Workshop on Carbon Dioxide Capture and Storage" vom November 2002 und Bewertung durch Germanwatch, Bonn, http:// www.germanwatch.org/rio/ccs04.htm

Gesellschaft Deutscher Chemiker e.V. (2004): Press release dated 28April 2004: Kohlendioxidausstoß aus Kraftwerken -Wege zur Verringerung des Treibhausgases, www.gdch.de/oearbeit/press/2004. htm

GESTCO (2004): see Christensen + Holloway

Gibbins, J. R.; Crane, R. I.; Lambropoulos, D.; Booth, C.; Roberts, C. A.; Lord, M. (2004): Maximising the Effectiveness of Post Combustion $\mathrm{CO}_{2}$ Capture Systems. International Conference on Greenhouse Gas Control Technologies, Vancouver 2-9 Sept. 2004, Canada, http://uregina.ca/ghgt7

Gielen, D. (2003): The Future Role of $\mathrm{CO}_{2}$ Capture and Storage: Results of the IEA-ETP Model. IEA/ EET Working Paper. Paris

Göttlicher, G. (1999): Energetik der Kohlendioxidrückhaltung in Kraftwerken. Fortschritt-Berichte VDI, Series 6, No. 421. Düsseldorf. ISBN 3-18-342106-2. Out of print

Göttlicher, G. (2003): State of the Art of $\mathrm{CO}_{2}$-Capture Technologies for Power Plants, Summer School Finland

Göttlicher, G. (2003a): „CO -Emissionsminderung durch Carbon Management“. ew (Fachmagazin der VDEW für Energiewirtschaft) Issue 21, pp. 42-45

Greenhouse Issues (2004): No. 73, http://www.ieagreen.org.uk/july73.html

Greenpeace (2004): Kohlendioxid in den Untergrund? Hokus Pokus $\mathrm{CO}_{2}$-Verpressung, Stellungnahme

Greenpeace (2005): Presentation by Gabriela von Goerne: BMU expert meeting „Vergleichende Analyse von Maßnahmen zur $\mathrm{CO}_{2}$-Minderung bei modernen Kraftwerkstechnologien und der Nutzung regenerativer Energien im Kontext einer klimaverträglichen Energieversorgung“. 31 March 2005, Berlin

Greenpeace (2005a): Greenpeace Memo: EU Submission to the UNFCCC on the Inclusion of Carbon Capture and Storage in the Clean Development Mechanism

Greenpeace (2007): Personal communication, 15 Feb 2007, Gabriela von Goerne, Greenpeace, Hamburg

Greenpeace; EREC (2007): Energy (R)evolution. A Sustainable World Energy Outlook. Amsterdam. http://www.energyblueprint.info/ (26 Jan 2007)

Grimston, M. C.; Karakoussis, V.; Fouquet, R.; van der Vorst, R.; Pearson, P.; Leach, M. (2001): The European and Global Potential of Carbon Dioxide Sequestration in Tackling Climate Change. Climate Policy 1 (2001): 155-171 
Guinée, J. (ed.) (2002): Handbook on Life Cycle Assessment. Operational Guide to the ISO Standards. Kluwer Academic Publishers, Dordrecht, Boston, London

Held, H.; Edenhofer, O.; Bauer, N. (2006): How to Deal with Risks of Carbon Sequestration Within an International Emission Trading Scheme. Paper presented at GHGT8

Hellweg, S.; Hofstetter, Th. B.; Hungerbühler, K. (2003): Discounting and the Environment. Should Current Impacts Be Weighted Differently than Impacts Harming Future Generations? Int J LCA 8 (1): 8-18. ecomed. Landsberg

Hendricks, C. A.; Turkenburg, W. C. (1997): Towards Meeting CO Emission Targets: The Role of Carbon Dioxide Removal. IPTS Report 16, 13-21

Hendricks, C. (1994): “Carbon Dioxide Removal from Coal-fired Power Plants", Kluwer Academic Publishers, Dordrecht, Boston, London

Hendriks, C., Graus, W., van Bergen, F. (2004): Global Carbon Dioxide Storage Potential and Costs. Ecofys, commissioned by the Rijksinstituut voor Volksgezondheit en Milieu, EEP-02001, Utrecht. http://www.ecofys.com/com/publications/documents/GlobalCarbonDioxideStorage.pdf (21 July 2006)

Herzog, H.; Drake, E.; Adams, E. (1997): CO Capture, Reuse and Storage Technologies for Mitigating Global Climate Change, a White Paper, DOE Order No. DE AF22-96PC1257

Herzog, H. (2000): Carbon Sequestration via Mineral Carbonation: Overview and Assessment, 14 March 2004

Hey, C. (2006): Personal communication. Berlin

Huijts, N. (2003): Public Perception of Carbon Dioxide Storage. The Role of Trust and Affect in Attitude Formation. Master's thesis, Eindhoven University of Technology

IEA (2002): International Energy Agency: World Energy Outlook 2002. International Energy Agency. Paris

IEA (2003): World Energy Outlook 2003. Paris

IEA (2004): CO Capture and Storage. IEA Greenhouse Gas R\&D Programme. www.co2sequestration. info (27 July 2004)

IFEU und IFU (2005): Institut für Energie- und Umweltforschung; Institut für Umweltinformatik: Umberto 5.0. Heidelberg/Hamburg

IPCC (2000): Intergovernmental Panel on Climate Change „Climate Change 2000: Emission Scenarios, A Special Report of Working Group III of the Intergovernmental Panel on Climate Change, Cambridge University Press, Cambridge

IPCC (2001): Intergovernmental Panel on Climate Change „Climate Change 2001: Impacts, Adaptation, and Vulnerability”. Contribution of Working Group II to the Third Assessment Report of the Intergovernmental Panel on Climate Change, Cambridge University Press, Cambridge

IPCC (2001a): Intergovernmental Panel on Climate Change (ed.): Climate Change 2001: Mitigation. Contribution of Working Group III to the Third Assessment Report of the IPCC, Cambridge, New York: Cambridge University Press

IPCC (2002): Intergovernmental Panel on Climate Change: Workshop on Carbon Dioxide Capture and Storage. Proceedings. Regina, Canada, 18-21 November 2002. Published by ECN. www.rivm. nl/mnp/ieweb/ipcc/pages_media/ccs-report.html (27 July 2004)

IPCC (2005): Intergovernmental Panel on Climate Change: Special Report on Carbon Dioxide Capture and Storage. Preliminary Version, January 2005

IPCC (2005a): IPCC Special Report on Carbon dioxide Capture and Storage. Summary for Policymakers. Montreal, 25 September

Kloepfer, M. (2004): Umweltrecht. 3rd edition. C. H. Beck, Munich

Kohlmann, J.; Zevenhoven, R. (2001): The Removal of CO from Flue Gases Using Magnesium Silicates in Finland. Presentation at the 22nd Int. Conf. on Coal Science, San Francisco (CA), 19 Sept -5 Oct

Knutzen J. (1981): Effects of Decreased pH on Marine Organisms. Marine Pollution Bulletin, 12: 25-29 
Krewitt, W.; Schmid, S. (2004): EU-Projekt CASCADE MINTS. WP 1.5, D1.1. Fuel Cell Technologies and Hydrogen Production/Distribution Options. Final Draft. 28 July 2004. Stuttgart

Küppers, Laszlo (2006): Personal communication. ZSW. Stuttgart

Lackner, K.S.; Ziock, H.-J. (2001): The Zero Emission Coal Alliance Technology, VGB PowerTech $12 / 2001$, p. 57, Essen

Landesinitiative Zukunftsenergien NRW (2006): Fakten und Zahlen aus NRW: Top - Die Energie quillt! http://www.energieland.nrw.de/about_us/zahlen.htm (31.07.2006)

Lawrence, M. (2002): Side Effects of Oceanic Iron Fertilization, Science Letters vol. 207, 30 Sept 2002, p. 1993

Leggett, J. (2005): Half Gone: Oil, Gas, Hot Air and the Global Energy Crisis. Porto Bello Bux Ltd., London

Lyngfelt, A.; Leckner, N.; Mattisson T. (2001): A Fluidised Bed Combustion Process with Inherent $\mathrm{CO}_{2}$ Separation; Application of Chemical Looping Combustion, Chem. Eng. Sci., 56, 3101

Makino E. (2003): Fischer-Tropsch-Synthesis. In: Ullmann's Encyclopedia of Industrial Chemistry, 6th edition (2003), Vol. 8, pp. 651-664

Marato-Valer, M. M. (2004): Penn State >Live - Recent Headlines: Researchers Study Natural Mineral that Locks Up Carbon Dioxide, 7 Sept 2004, http://live.psu.edu/story/7907

Mariz, C.L. (1998): Carbon Dioxide Recovery: Large Scale Design Trends. Journal of Canadian Petroleum Technology. 1998, 37, 7, 42-47

Maurstad, O.; Bredesen, R.; Bolland, O.; Kvamsdal, H.; Schell, M. (2005): SOFC AND GAS TURBINE POWER SYSTEMS - EVALUATION OF CONFIGURATIONS FOR CO CAPTURE. Proceedings of the 7th International Conference on Greenhouse Gas Control Technologies: Elsevier 2005. ISBN 0-080-44881-X. S. 273-281, presented as peer-reviewed paper at GHGT-7, Vancouver, Sept 2004

May, F.; Brune, S.; Gerling, P.; Krull, P. (2003): Möglichkeiten zur CO -Speicherung in Deutschland eine Bestandsaufnahme im Jahre 2003. geotechnik 26 (2003) No. S: 162-172, VGE; Essen

May, F.; Müller, Chr.; Bernstone, C. (2005): How Much CO Can Be Stored in Deep Saline Aquifers in Germany? In: VGB PowerTech 6/2005, pp. 32-37

May, N. (2005): Ökobilanz eines Solarstromtransfers von Nordafrika nach Europa. Thesis submitted at TU Braunschweig/DLR Stuttgart

Meinshausen, M. (2006): What Does a $2{ }^{\circ} \mathrm{C}$ Target Mean for Greenhouse Gas Concentrations? A Brief Analysis Based on Multi-Gas Emission Pathways and Several Climate Sensitivity Uncertainty Estimates. In: Schellnhuber, H. J.; Cramer, W.; Nakicenovic, N.; Wigley, T.; Yohe, G. (eds.): Avoiding Dangerous Climate Change. Cambridge University Press. Cambridge. Pp. 265-279

Möller, A.; Page, B.; Rolf, A.; Wohlgemuth, V. (2001): Foundations and Applications of Computerbased Material Flow Networks for Environmental Management. In: Rautenstrauch et al.: Environmental Information Systems in Industry and Public Administration. Magdeburg

Möller, S.; Kaucic, D.; Sattler, C. (2006): Hydrogen Production by Solar Reforming of Natural Gas: A Comparison Study of Two Possible Process Configurations. Journal of Solar Energy Engineering. Vol. 128, 16-23

NABU (2005): Presentation by R. Musiol, NABU: BMU expert meeting „Vergleichende Analyse von Maßnahmen zur $\mathrm{CO}_{2}$-Minderung bei modernen Kraftwerkstechnologien und der Nutzung regenerativer Energien im Kontext einer klimaverträglichen Energieversorgung“. 31 March 2005, Berlin

Nitsch, Joachim (2007): Leitstudie 2007 „Ausbaustrategie Erneuerbare Energien“. Aktualisierung und Neubewertung bis zu den Jahren 2020 und 2030 mit Ausblick bis 2050. http://www. erneuerbareenergien.de/inhalt/38787/20049/ (5 Nov 2007)

Nordhaus, W. D.; Boyer, J. (2000): Warming the World. Cambridge University Press. Cambridge

Omori, M.; Norman, C. P.; Ikeda, T. (1998): Oceanic Disposal of CO : Potential Effects on Deep-sea Plankton and Micronekton - A Review. Plankton Biol. Ecol. 45, 87-99

Padro, C. E.; Putsche, V. (1999): Survey of the Economics of Hydrogen Technologies. Nat. Renewable Energy Lab. Golden, Colorado; NREL/TP-570-27079, Sept 1999 
Parsons (2002): Parsons Infrastructure and Technology Group Inc.: Hydrogen Production Facilities. Plant Performance and Cost Comparisons. Final report prepared for DOE. Reading, Pennsylvania. http://www.netl.doe.gov/energy-analyses/pubs/FinalCompReport.pdf (15 Sept 2006)

Pastowski, A. (1997): Decoupling Economic Development and Freight for Reducing Its Negative Impacts (Wuppertal Institute for Climate, Environment and Energy, Wuppertal Paper No. 79), Wuppertal: Wuppertal Institute for Climate, Environment and Energy

Pastowski, A. (2005): Impacts of Energy Use on Demand for Freight Transport: Past Development and Future Perspectives, eceee 2005 Summer Study Proceedings Volume 2, eceee, Stockholm, pp. 697-708

Perrings, C. (1989): Environmental Bonds and Environmental Research in Innovative Activities. Ecological Economics, Volume 1, pp. 95-110

PDS (2004): Partei des Demokratischen Sozialismus: Stellungnahme der BAG Umwelt - Energie Verkehr zur Kohlendioxid-Abtrennung und Deponierung beim Betrieb von Kraftwerken mit fossilen Brennstoffen. Marburg, 2 Sept 2004

Pehnt, M. (2002): Ökobilanzen. In: Ökologisch optimierter Ausbau der Nutzung regenerativer Energien in Deutschland. 2. Zwischenbericht Juli 2002. Stuttgart, Heidelberg, Wuppertal

Pehnt, M. (2002a): Ganzheitliche Bilanzierung von Brennstoffzellen in der Energie- und Verkehrstechnik. Fortschritt-Berichte VDI. Series 6. No. 476. VDI Verlag. Düsseldorf. ISBN 3-18-347606-1

Petersen, R.; Pastowski, A.; Lelowski, P. (1993): Entwicklungsperspektiven der Binnenschifffahrt vor dem Hintergrund einer klimagerechten Verkehrspolitik, in: ISA Consult (ed.): Umweltgerechter Transport und innovative Schiffskonzepte (ISA Schriftenreihe Nr. 9), Bochum: ISA Consult, Part I, pp. 1-37

Pick, E. (1998): Beitrag zum kumulierten Energieaufwand ausgewählter Windenergiekonverter. Universität-GH Essen

Plass, L. (2002): Präsentation zum BMWA-Workshop $\mathrm{CO}_{2}$-Abtrennung/Nutzung/Deponierung, Sachstand in ARGE 2

Ploetz, C. (2003): Sequestrierung von CO: Technologien, Potenziale, Kosten und Umweltauswirkungen. Expertise im Auftrag des WGBU 2003

PointCarbon (2006): CDM \& JI Monitor, 24 Jan 2006

Pro Regenwald (1998): Klima, Bäume und das Geld - Klimaveränderung schafft neue Wälder, Dokumentation No. 2 - Autumn 1998

Prognos (2004): Bohnenschäfer, W. et al. (Prognos AG): Perspektiven für elektrischen Strom in einer nachhaltigen Entwicklung, Untersuchung im Auftrag des Umweltbundesamtes, Berlin

Rao, Anand B.; Rubin, Edward S. (2002): A Technical, Economic, and Environmental Assessment of Amine-based CO Capture Technology for Power Plant Greenhouse Gas Control. Environ. Sci. Technol. 2002, 36, 4467-4475.

Reininger, G.; Schubert, V. (1999): http://ac16.uni-paderborn.de/lehrveranstaltungen/_aac/vorles/ skript/kap_7/kap7_2.html

Riahi, K.; Rubin, E. S.; Taylor, M. R.; Schrattenholzer, L.; Hounshell, D. (2004): Technological learning for carbon capture and sequestration technologies. Energy Economics 26 (2004) 539-564.

Riahi, K.; Rao, S.; Keppo, I. (2006): "Importance of Technological Change and Spillovers in Long-term Climate Policy." The Energy Journal Special Issue, Endogenous Technological Change and the Economics of Atmospheric Stabilization

Richter, I. (2003): $\mathrm{CO}_{2}$-Versenkung im Ozean. Thesis submitted at Universität Oldenburg

Roehrl, R. A.; Riahi, K. (2000): Technology dynamics and greenhouse gas emission mitigation: a cost assessment, Technological Forecasting and Social Change 63, 2000, pp. 231-261

Rogner, H.-H. (1997): An Assessment of World Hydrocarbon Resources. Annual Review of Energy and Environment 22: 217-262

RNE (2004): Rat für Nachhaltige Entwicklung: Perspektiven der Kohle in einer nachhaltigen Energiewirtschaft. Texte, No. 4, October 2004

Rüggeberg, T. (2004): Das deutsche COORETC-Konzept: Wege zum emissionsfreien Kraftwerk auf Basis Kohle und Gas. In: energy, 3/2004, Zeitschrift der Energieverwertungsagentur Österreich, Wien 
Rubin, S.; Yeh, S.; Hounshell, D. (2004): Experience Curves for Power Emission Control Technologies. Int. J. Energy Technology and Policy, Vol. 2, Nos. 1/2

Rubin, E.; Antes M.; Yeh, S.; Berkenpas M. (2006): Estimating the Future Trends in the Cost of $\mathrm{CO}_{2}$ Capture Technologies. Technical Study, Report Number: 2006/6, IEA Greenhouse Gas R\&D Programme 2006

Ruhrgas (2005): E.ON Ruhrgas: downloaded at www.ruhrgas.de

RWE Rheinbraun/Vattenfall Europe (2003): Argumentationspapier zur Entwicklung der Kohlenkraftwerkstechnik unter Berücksichtigung der Klimavorsorge

Santos, S.; Davison, J. (2006): Review of $\mathrm{CO}_{2}$ Capture Technology Roadmap for Power Gerneration Industry. IEA Greenhouse Gas R\&D Programme, 18th January 2006, Cheltenham, UK

Schlattmann, C. (2006): Anforderungen an den Aufbau einer $\mathrm{CO}_{2}$-Infrastruktur in Deutschland, Master's thesis submitted at Fern-Universität Hagen

Schmidt, M.; Häuslein, A. (eds.) (1997): Ökobilanzierung mit Computerunterstützung. Produktbilanzen und betriebliche Bilanzen mit dem Programm Umberto. Berlin: Springer. ISBN 3-89518-163-3

Schüwer, D. (1997): Abgrenzung der Einsatzmöglichkeiten von Brennstoffzellen mit protonenleitender Membran im stationären Einsatz. Research paper submitted at Lehrstuhl für Nukleare und Neue Energiesysteme der Ruhr-Universität-Bochum, August 1997

Sekar, R.; Parsons, J. E.; Herzog, H. J.; Jacoby, H. D. (2005): Future Carbon Regulations and Current Investment in Alternative Coal-fired Power Plant Designs. MIT Joint Program on the Science and Policy of Global Change. Report No. 129

SPD Bundestagsfraktion (2003): Energiepolitische Agenda 2010. Innovativ, sicher und nachhaltig. Resolution passed by the SPD parliamentary group on 16 Oct 2003. Berlin. Downloadable at http://www. spdfraktion.de/cnt/rs/rs_dok/0,31922,00.html

Smetacek, V. (2004): Eisendüngung im Ozean mindert Kohlendioxid-Menge nur minimal, dpa press notice from 7 April 2004 at: www.pro-physik.de/Phy/External/PhyH/1,2-10-0-0-1-display_in_ frame-0-0-,00.html? recordId=4237\&table=NEWS

SRU - Rat der Sachverständigen für Umweltfragen (2000): Umweltgutachten 2000, Berlin

SRU - Rat der Sachverständigen für Umweltfragen (2004): Umweltgutachten 2004: Umweltpolitische Handlungsfähigkeit sichern, Berlin, May 2004

Statistik der Kohlenwirtschaft e.V. (2000): Der Kohlenbergbau in der Energiewirtschaft der Bundesrepublik Deutschland im Jahr 1999. Essen and Cologne

Statoil (2004): Carbon dioxide storage prized. Press release, 18 Dec 2000, updated 26 Jan 2004: http:// www.statoil.com/ STATOILCOM\SVG00990.nsf/ UNID/01A5A730136900A3412569B9006 9E947?opendocument, and further Statoil press releases and annual reports

SteinkohlePortal.de (2006): Grubengas: Energiequelle mit eingebautem Klimaschutz. www. steinkohle-portal.de/content.php?id=276\&lang=de (17.02.2006)

TAB (2006): Büro für Technikfolgenabschätzung des Deutschen Bundestages: Informationen zur Vergabe von Gutachten im Rahmen des Monitoring „Nachhaltige Energieversorgung“. Berlin

Thackeray, F. (2000): Fischer-Tropsch Gas-to-Liquids, Prospects and Implications, SMI Publ. Ltd. London

The Scotsman (2008): Peterhead's doomed BP plant to be built in Abu Dhabi. http://news.scotsman. com

Tol, R.S.J.: Europe’s Long-term Climate Target: A critical Evaluation. Energy Policy, in press

Transpetrol GmbH (2005): Personal communication

Thyssen-Nordseewerke (2005): Gastanker http://www.thyssen-nordseewerke.de/d/prod/gastanker. html (24.10.2005)

Ullmann (2002): Ullmann's Encyclopedia of Industrial Chemistry, Gas Treatment, article online posting:http://www.mrw.interscience.wiley.com/ueic/articles/a12_169/sect5-fs.html

Umweltbundesamt - UBA (1995): Ökobilanz für Getränkeverpackungen. UBA-Texte 52/95. Berlin 
Umweltbundesamt - UBA (1999): Bewertung in Ökobilanzen. UBA-Texte 92/99. Berlin

Umweltbundesamt - UBA (2003): Emissionsfaktoren für $\mathrm{CO}_{2}$ in Deutschland. Berlin

Umweltbundesamt - UBA (2006): Potenzial und Anforderungen an die technische $\mathrm{CO}_{2}$-Abscheidung und Speicherung - Welchen Beitrag könnte die $\mathrm{CO}_{2}$-Abscheidung und Speicherung auf dem Weg zu einem nachhaltigeren Energiesystem leisten? German Environmental Agency position paper. Dessau. http://www.umweltdaten.de/publikationen/fpdf-1/3074.pdf (26 Sept 2006)

Umweltbundesamt - UBA (2006a) (ed.): In: Radgen, P.; Cremer, C.; Warkentin, S.; Gerling, P.; May, F.; Knopf, S.: Bewertung von Verfahren zur $\mathrm{CO}_{2}$-Abscheidung und -Deponierung. Final Report, Dessau

Umweltbundesamt - UBA (2006b) (ed.): In: Ramesohl, S.; Fischedick, M.; Pehnt, M.; Nitsch, J.; Viebahn, P.; Knörr W. et al.: Entwicklung einer Gesamtstrategie zur Einführung alternativer Kraftstoffe. WI Wuppertal, IFEU Heidelberg, DLR Stuttgart. Study commissioned by the German Environmental Agency (FKZ 20345 118), Berlin, March 2006. Unpublished

Umweltinstitut München e.V. (2004): Gentechnik-Bäume gegen den Klimakollaps?, www. umweltinstitut.org/frames/gen/gentechwald.htm

Union (2002): CDU und CSU in einem gemeinsamen Papier: Lebenswerte Umwelt und gesunde Ernährung - für uns und unsere Kinder. Berlin

Vagnetti, R. (2005): Life-Cycle Analysis of Greenhouse Gas Emissions for Hydrogen Fuel Production in the United States from LNG and Coal. DOE/NETL-2006/1227, www.netl. doe.gov/ technologies/ hydrogen_clean_fuels/r $>$ refshelf/pubs/H2_from_Coal_LNG_Final.pdf

VGB-PowerTech (2002): Abscheidung und Speicherung von $\mathrm{CO}_{2}$ aus Kraftwerken - eine Literaturstudie. Sachstandsbericht der VGB-Projektgruppe „ $\mathrm{CO}_{2}$-Abscheidung und -Speicherung“, Essen, August 2002

VGB PowerTech e.V. (2004): CO Capture and Storage - VGB Report on the State of the Art. Essen, 2004

Viebahn, P. (2004): SOKRATES-Projekt, AP 2.2 Technologievergleich: Ökobilanzen von SEGS-, FRESNEL- und DSG-Kollektoren. Stuttgart

von Weizsäcker, C. C. (2004): Was kommt nach „Kyoto“? Konturen eines zukünftigen „echten“ Klima-Abkommens. Energiewirtschaftliche Tagesfragen, Issue 12, December 2004

VTG Aktiengesellschaft (2004): 62 m3 - Druckgas-Kesselwagen, 2nd edition 25 April 2004, VTG AG, Hamburg

VTG Aktiengesellschaft (2005): Block Train, http://www.vtg-rail.de/ accessed on 30 Aug 2005

WBGU (2003): (Wissenschaftlicher Beirat der Bundesregierung für Globale Umweltveränderungen): Welt im Wandel. Energiewende zur Nachhaltigkeit. Hauptgutachten. Berlin, Heidelberg, New York: Springer-Verlag. ISBN 3-540-40160-1. www.wbgu.de/wbgu_jg2003.html

WBGU (2006): Wissenschaftlicher Beirat der Bundesregierung Globale Umweltveränderungen: Die Zukunft der Meere - zu warm, zu hoch, zu sauer. WBGU. Berlin

WEC (2000): World Energy Council, UNDP: World Energy Assessment: Energy and the Challenge of Sustainability. UNDP

Williams, R. H. (2002): Decarbonised Fossil Energy Carriers and Their Energy Technology Competitors. In: IPCC 2002

Williams, R. H. (2003): Progress in IOR Technology, Economics Deemed Critical to Staving Off Worlds' Oil Production Peak. Oil \& Gas Journal, No. 101/30, 4 Aug 2003, pp. 18-25

Wilson, E.; Keith, D.; Wilson, M. (2004): Considerations for a Regulatory Framework for Large-scale Geological Sequestration of Carbon Dioxide: a North American Perspective. In: E. S. Rubin; D. W. Keith; C. F. Gilboy (eds.): Proceedings of 7th International Conference on Greenhouse Gas Control Technologies. Volume 1: Peer-reviewed Papers and Plenary Presentations. Cheltenham, UK: IEA Greenhouse Gas Programme.

Wolf-Gladrow, D.; Riebesell, U.; Burkhardt, S.; Bijma, J. (1999): Direct Effects of CO Concentration on Growth and Isotopic Composition of Marine Plankton. Tellus, Bd. 51B, 1999, S. 461-476.

Wolf-Gladrow, D. (2004): Personal communication, 27 Oct 2004 
WI/DLR (2002): Wuppertal Institut für Klima Umwelt Energie, DLR Institut für Thermodynamik: Langfristszenarien für eine nachhaltige Energienutzung in Deutschland, Forschungsvorhaben für das Umweltbundesamt, Wuppertal, Stuttgart, June 2002

WI, MPI (2004): Wuppertal Institut für Klima, Umwelt, Energie und Max-Planck-Institut für Chemie: Treibhausgasemissionen des russischen Erdgas-Exportpipeline-Systems. Ergebnisse und Hochrechnungen empirischer Untersuchungen in Russland. Projekt im Auftrag der E.ON Ruhrgas AG. Wuppertal, Mainz. http://www.wupperinst.org/download/1203-report-de.pdf (26 Sept 2006)

WI (2006): Wuppertal Institut für Klima Umwelt Energie: UN Workshop on Carbon Capture and Storage as a CDM Project Activity. In: Wuppertal Institut für Klima, Umwelt und Energie (ed.): JIKO Info 3/06, pp. 1-3

WWF (2004): World Wide Fund Position Paper: Carbon Capture and Storage from Fossil Fuels. www.wwf.de

WWF (2005): Präsentation von R. Günther, WWF: BMU-Fachgespräch „Vergleichende Analyse von Maßnahmen zur $\mathrm{CO}_{2}$-Minderung bei modernen Kraftwerkstechnologien und der Nutzung regenerativer Energien im Kontext einer klimaverträglichen Energieversorgung“. 31 March 2005, Berlin

Yamada, Y.; Ikeda, T. (1999): Acute Toxicity of Lowered pH to Some Oceanic Zooplankton. Plankton Biol. Ecol. 46, 62-67

ZSW (1996): ZSW-Studie: „ $\mathrm{CO}_{2}$-Rückhaltesysteme für Fahrzeuge“, industry commission

\section{Background Reading}

Enquete-Kommission (2002): Abschlussbericht der Enquete-Kommission „Nachhaltige Energieversorgung unter den Bedingungen der Globalisierung und der Liberalisierung“ des Deutschen Bundestages. Berlin

Freund, P.; Kaya, Y.; Lior, N. (eds.) (2004): 6th International Conference on Greenhouse Gas Control Technologies. Kyoto, Japan, 1-4 October 2002. In: Energy 29 (9-10) 1237-1657. Elsevier

Hendriks, Chris (1994): Carbon Dioxide Removal from Coal-fired Power Plants. Dordrecht/Boston/ London: Kluwer Academics Publishers. ISBN 0-7923-3269-5

Hendriks, Chris; Turkenburg, Wim C. (1997): Auf dem Weg zur Erfüllung der $\mathrm{CO}_{2}$-Emissionsziele: Die Rolle der CDR-Technologie. The IPTS Report No. 16, July 1997. Sevilla

May, Franz; Gerling, Johannes Peter; Krull, Paul (2002): Untertagespeicherung von $\mathrm{CO}_{2}$. In: PowerTech 8/2002, pp. 45-50

Riemer, H. Audus; Smith, A.: IEA Greenhouse Gas R\&D Programme Report, Carbon Dioxide Capture from Power Stations 
This publication is based on the German research project

"Ökologische Einordnung und strukturell-ökonomischer Vergleich regenerativer Energietechnologien mit anderen Optionen zum Klimaschutz, speziell der Rückhaltung und Speicherung von Kohlendioxid bei der Nutzung fossiler Primärenergien"

on behalf of the Federal Ministry for the Environment, Nature Conservation and Nuclear Safety.

Contact:

Federal Ministry for the Environment,

Nature Conservation and Nuclear Safety (BMU)

Dep. Public Relations

11055 Berlin - Germany

Telefax: +49 30 18305-2044

Homepage: www.bmu.de

This brochure is part of the public relations work of the

Federal Ministry for the Environment, Nature Conservation and Nuclear

Safety. It is distributed free of charge and is not intended for sale.

The brochure is printed on $100 \%$ recycled paper. 